s.

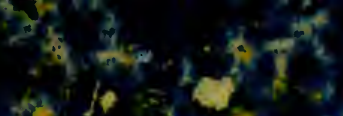

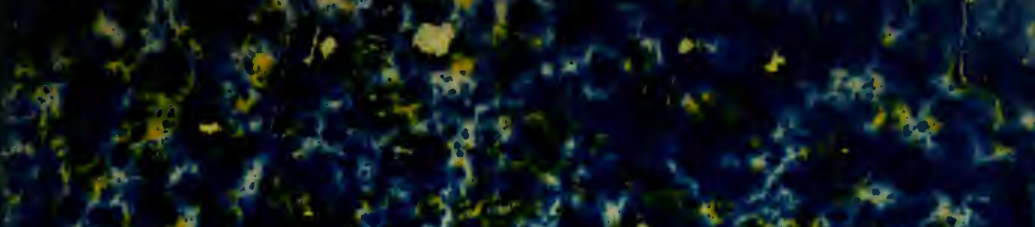

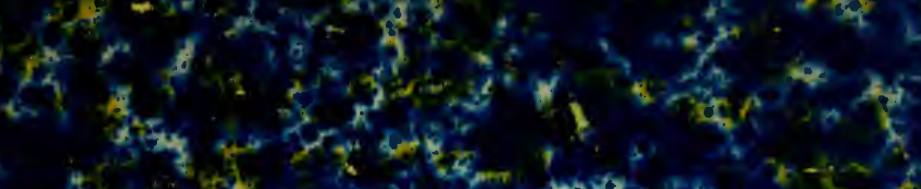

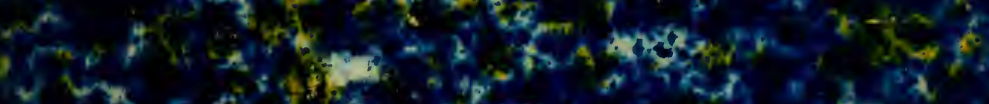

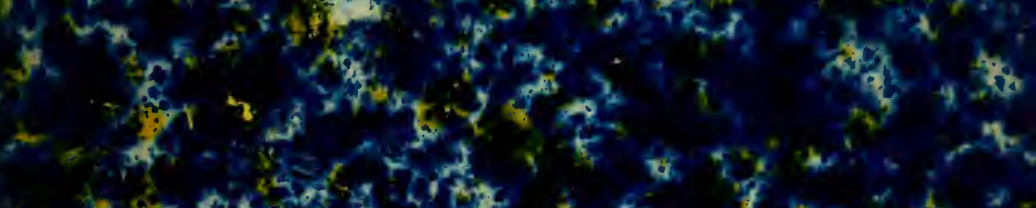

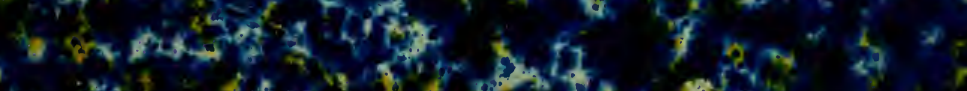

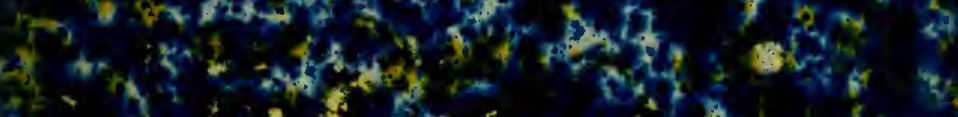

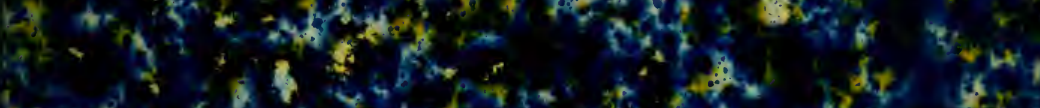

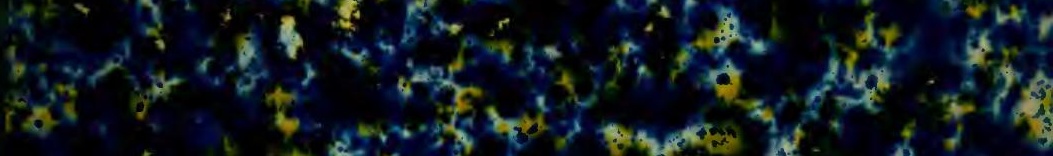
s.t.

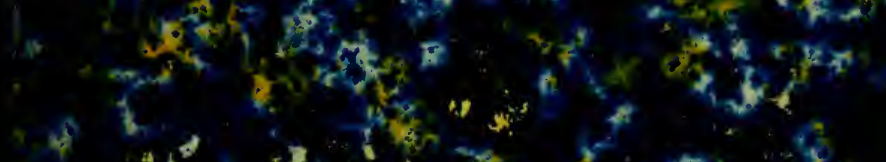

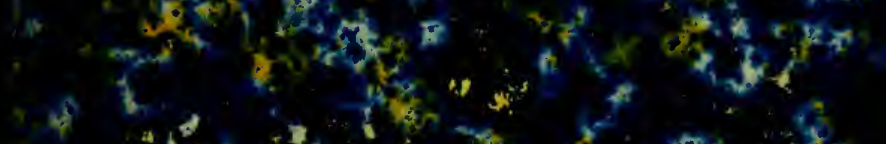

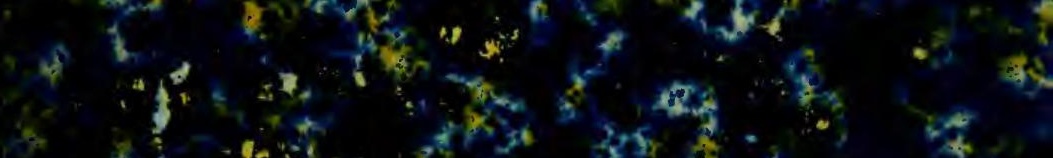

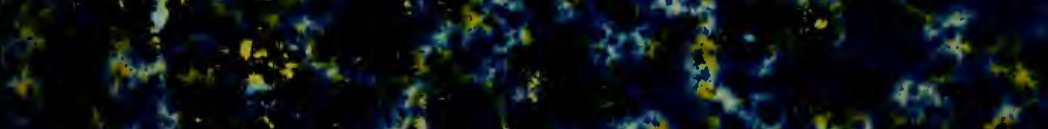

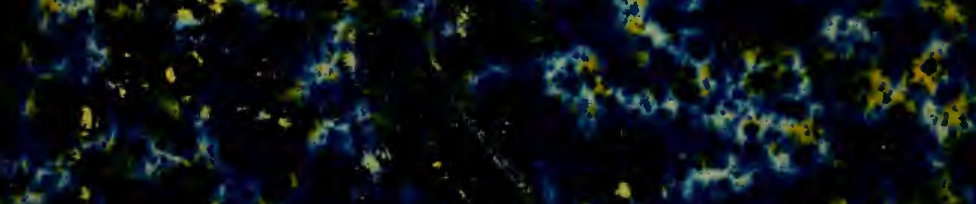

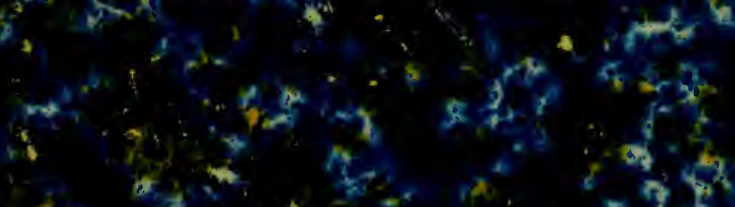

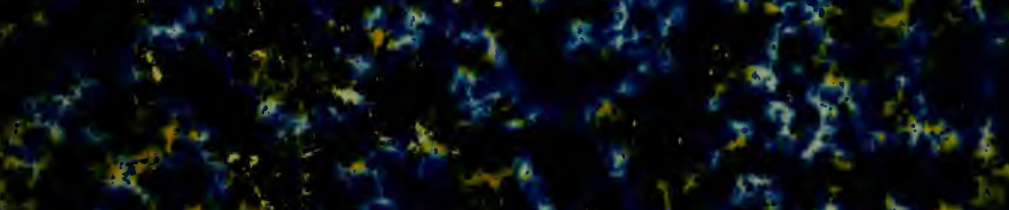

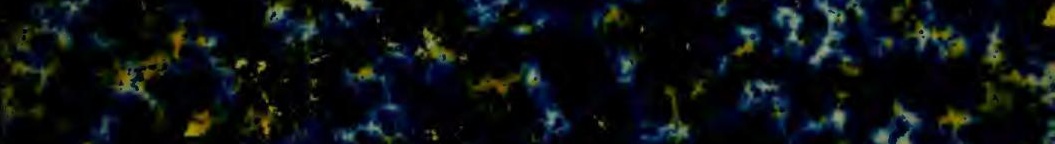

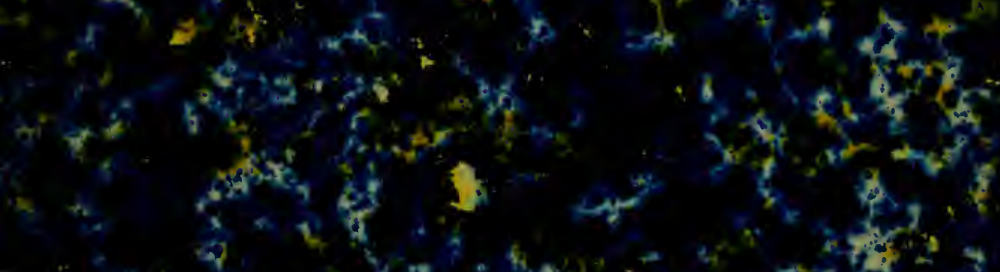

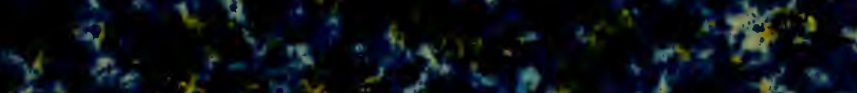

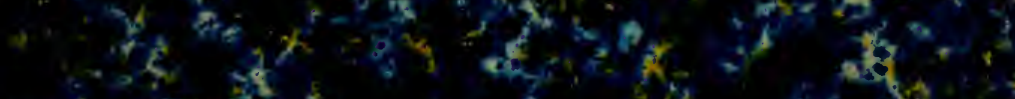

$\therefore$, 


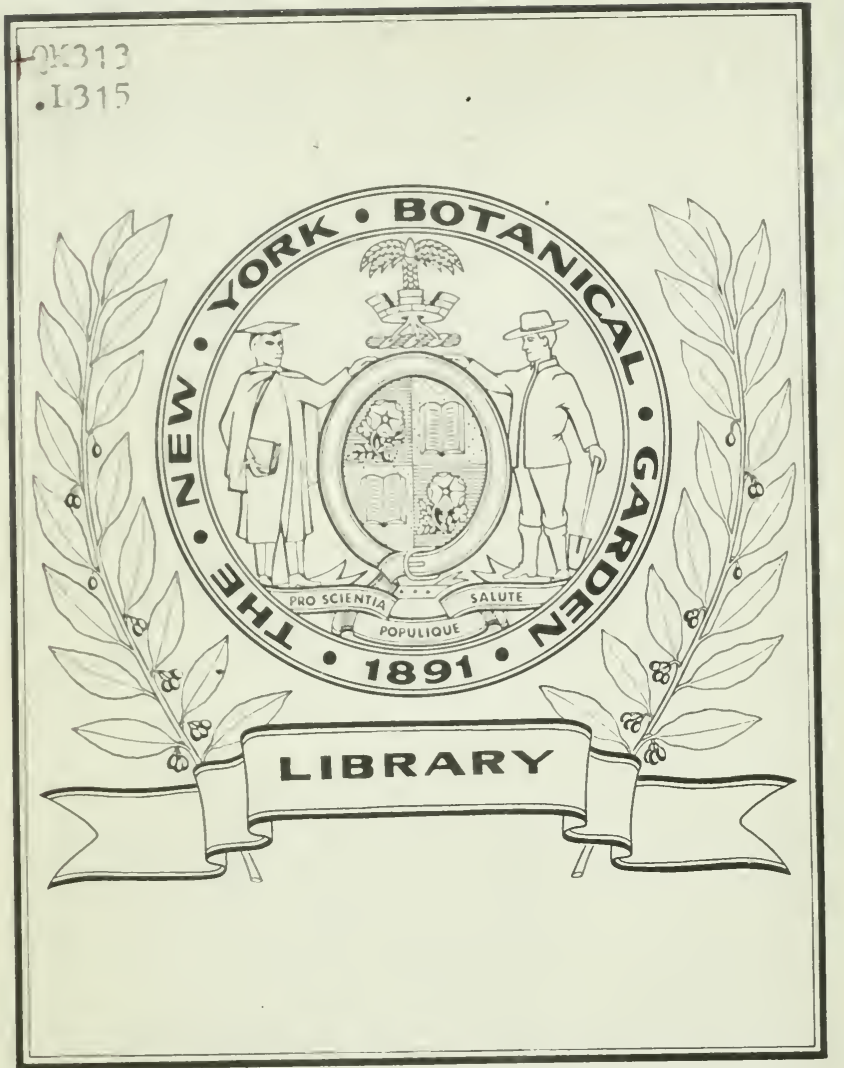

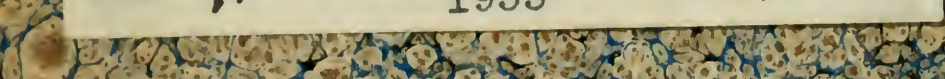
J2. 1. 15.

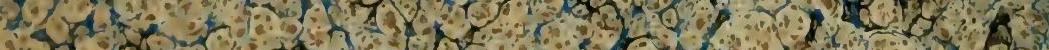

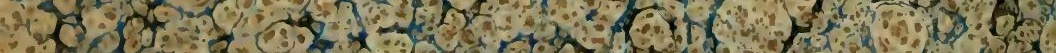

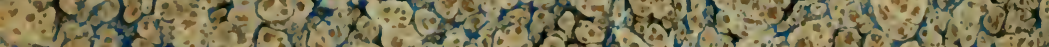

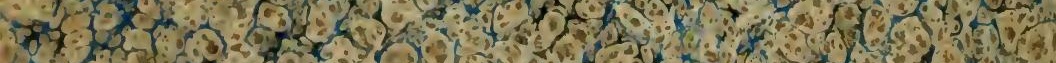

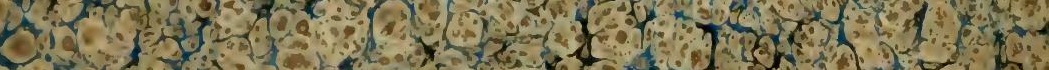

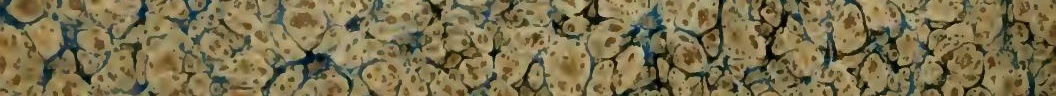




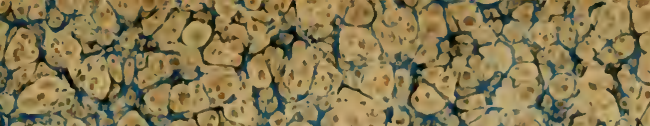

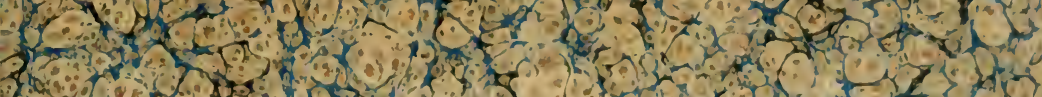

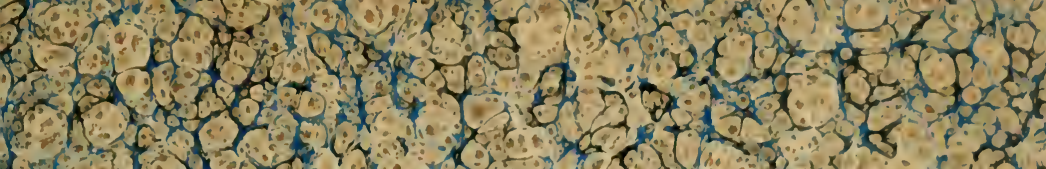

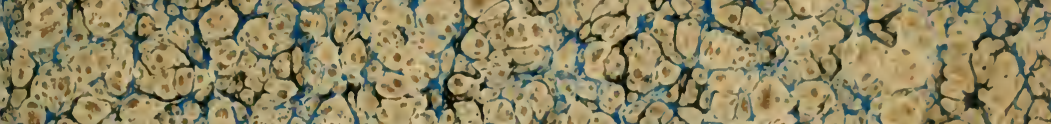
(13)

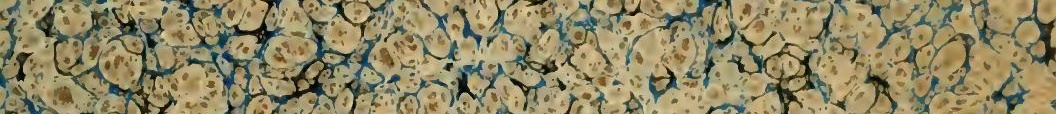

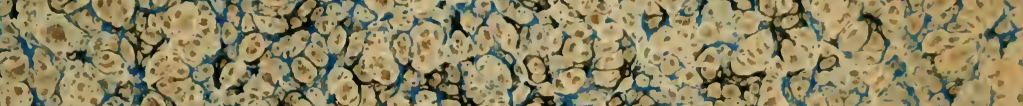

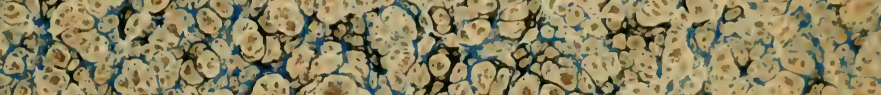

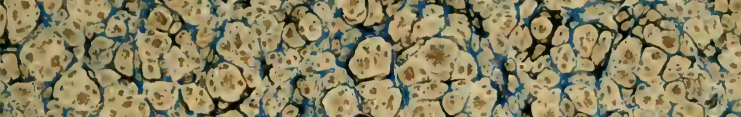

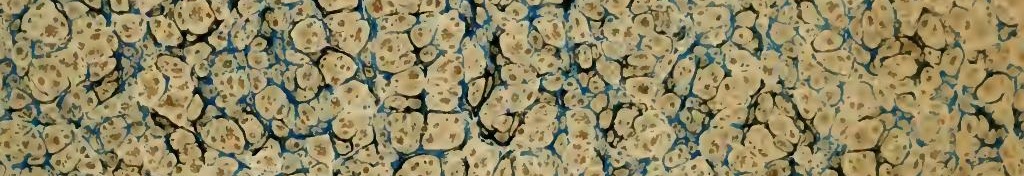
1.

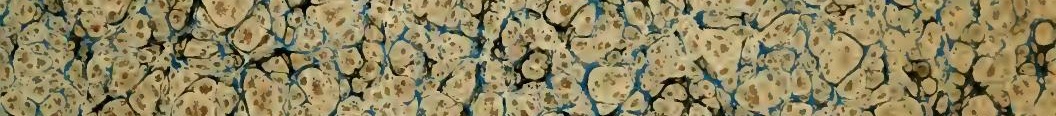

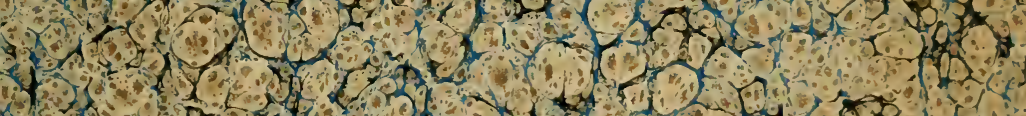

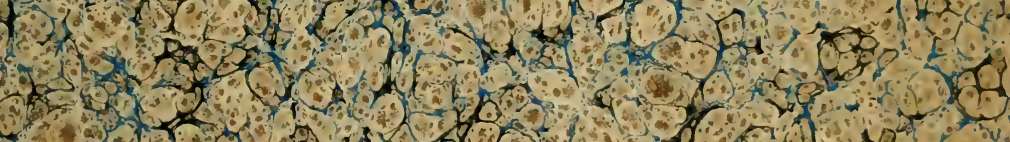

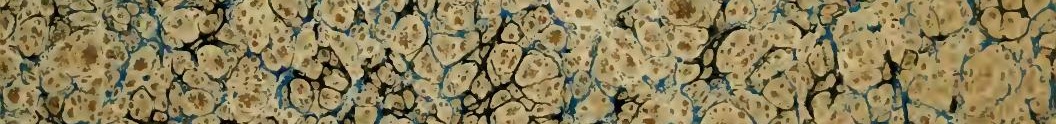

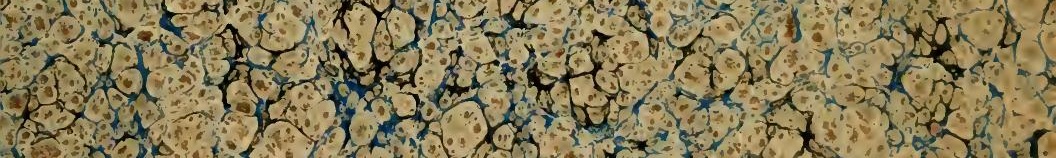
(1) 7.7. 2.

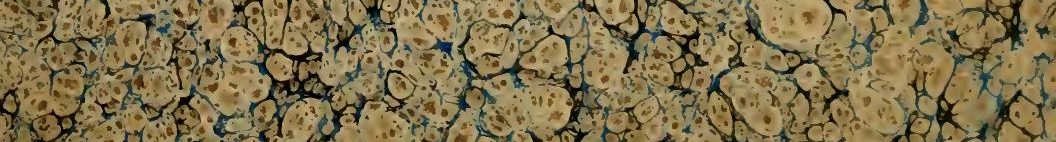





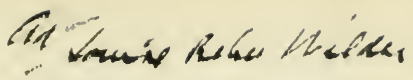

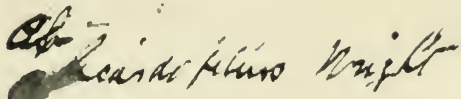

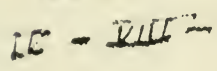





\section{S Y NOPS I S}

\section{PLANTARUM}

IN FLORA GAILICA

DESCR $1 \mathrm{P} T A R U M$;

AUCTORIBUS

J. B. D E $\mathrm{L}_{10} \mathrm{AM} \Lambda \mathrm{R} \mathrm{C}$,

Ex Instituto Scientiarum et Artiun, etc.

$\mathbf{E} \mathbf{T}$

A. P. DE CANDOLLE,

Profess. in Academià Generensi, etc.

\section{$P A I I S I I S$,}

A pud H. Acasse, viâ Pictonum (ruecles Poitevins), n ${ }^{\circ} \cdot 6$.

Ex Typis J. G. A. Stoupe, viâ Cy thareà (rue de la IIcirpe).

$$
\text { I } 8 \circ 6
$$





\section{E C T O R I.}

Cum Flora Gallica, Botanicae et Gallixe ipsius incrementis, evaderit in molem nimiam ut secum hanc in deambulationibus ferre possent Botanici, istis et pracipuè Tironibus opportunum et gratum fore judicavimus, Enchiridium è Florâ extractum, ordine naturali digestum, ad caracteres essentiales redactum, habitationes stationesque Plantarum cautè indicans et brevitatis causâ latinà linguà conscriptum ; quem libellum hodiè in lucem edimus; nonnullas stirpes in Flora omissas, à nobis observatas vel ab amicis communicatas addidimus, sed ut in ipsa Flora Callica, nullam fecimus mentionèm Plantarum nobis ignotarum aut incertarum. Quoad synonymiam, descriptionem et historiam ad Floram Gallicam refugiat Botanicus. Ergo vale, Lector amice; sylvas ruraque laetè peragra, et Scientiam amabilem auge. 



\title{
ORDINUM GENERUMQUE
}

\author{
A NOM A L O R U M
}

\section{CLAVIS ANALYTICA.}

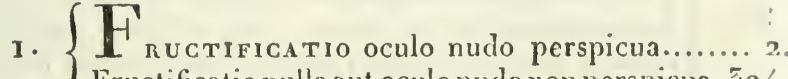
Fructificatio nulla aut oculo nudo non perspicua. 524.

2. $\{$ Flores in involucro communi aggregati......... 3. Flores in involucro communi non aggregati.... 4.

3. $\int$ Antherx coalita.............. composite pag. 255 .

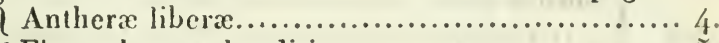

4. Flores hernaphroditi...................... 5 .

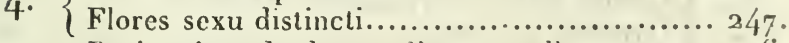

5. $\{$ Perigonium duplex, calix et corolla............6.

5. $\{$ Perigonium simplex aut nullum............. 169 .

6. $\{$ Corolla monopetala........................ 7 .

$\{$ Corolla polypetala......................... 94.

M O N O P E T A L E.

7. $\{$ Ovarium liberum seu supcrum.............. 8.

7. $\{$ Ovarium calici adharens seu inferum......... 86.

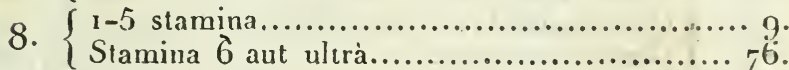

9. $\{$ Corolla regularis..............................

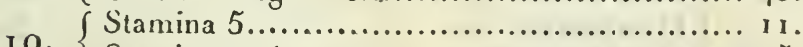

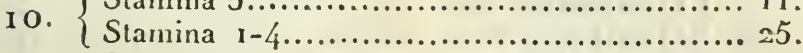

I I. $\{$ Stamina corollie lobis alterna.................. I2. Stamina corollæ lobis opposita. P R I MU L A C E 死 P. 204.

12. $\{$ Folia nulla, radicalia aut alterna............. 15.

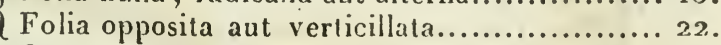

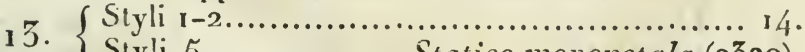
Styli $5 \ldots . . \ldots \ldots \ldots .$. Statice monopetala $(2329)$.

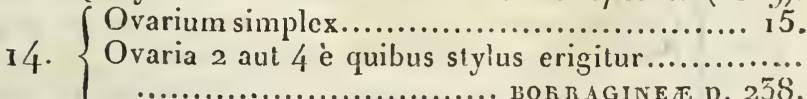
.......................... BonR AGINE P. 238.

I5. $\{$ Stamina corollæ inserta .................... 6 . Stamina corollæ non inserta.... Plumbago p. 205.

I $6 . \quad$ Plantæ foliosæ............................ 7 . $\{$ Plantx aphyllæ................... Cuscuta p. 2úz 
I 7 Stylus $x$; sligmata $1-2 \ldots \ldots . . . . . . . . . . . . . .18$.

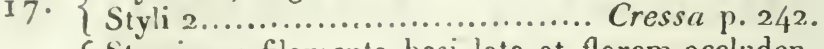

I $8 .\left\{\begin{array}{c}\text { Staminum filamenta basi lata et florem occluden- } \\ \text { tia...................... poLEMONIACE } \text { p. } 242 .\end{array}\right.$ Staminum filamenta basi non dilatata.......... 19.

I. $\{$ Corolla limbus ciliatus aut setoso-echinatus... 20 .

1. $\{$ Corollæ limbus nudus......................... $2 \mathbf{I}$.

$\{$ Limbus supernè echinatus... Menyanthes p. 245 .

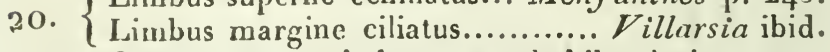
Semina numerosissima ; capsula bilocularis..........

2I. $\quad$............................. Solane p. 244. Semina pauca; capsula 3-/4-locularis..............

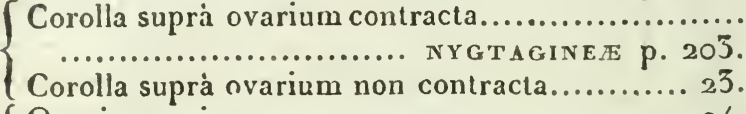

23. Ovarium unicum.............................. 24.

23. Ovaria duo; stylus r........... A POCY NE $p .246$.

24. $\{$ Caulis herbaceus............... GENTIANE正 p. 245.

5. $\{$ Stamina 4 .

25. Stamina 4 .................. 26.

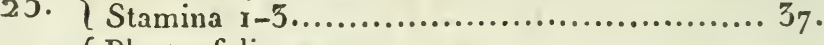

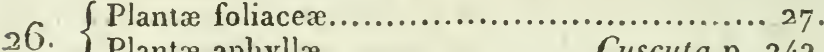

\{ Plantæ aphyllæ..................... Cuscuta p. 242.

\{ Corolla membranaceo-scariosa... Plantago p. 200.

27. $\{$ Corolla non scariosa............................. 28 .

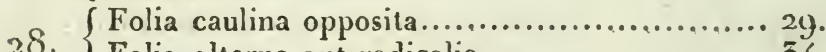

28. $\{$ Folia alterna aut radicalia.................... 54.

\{ Ovarium unicum............................. 30.

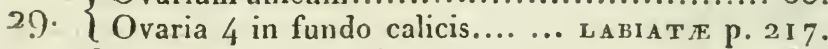

50. $\{$ Stamina 4,2 longiora...................... $3 \mathrm{I}$,

30. $\{$ Stamina equalia.............................. 35.

3. $\{$ Flores lutei....................... Tozzia p. 214.

31. \{ Flores corulei, purpurascentes aut albi........ 32.

52. $\{$ Folia digitata....................... Vitex p. 217. Folia simplicia incisa.............. Verbena ibid.

Corolla rotata................. Centunculus p. 204.

33. $\{$ Corolla tubulosa aut infundibuliformis.............. ................................ Exactem p. 246.

3 个. $\{$ Flores in capitulum aggregati. GLOBULA I I $p .204$.

31. Flores non capitati........................... 35.

55. $\{$ Frutex foliis spinosis................. Ilex p. 336.

55. Herba foliis ineruibus....................... 56 . 
36. $\{$ Caulis erectus nec repens................... 59.

$\{$ Caulis prostratus aut repens...................62.

37. $\{$ Ovarium unicum.............................. 38.

37. Ovaria 4 in fundo calicis......... Lycopus p. 217.

38. $\{$ Stylus r.................................... 39.

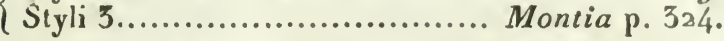

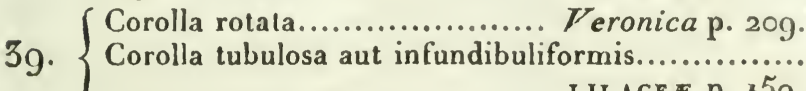

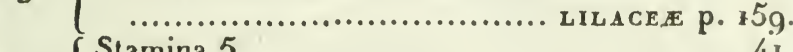

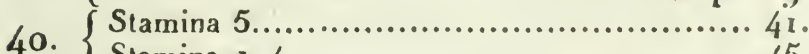

$\left\{\begin{array}{l}\text { Stamina } 1-4 \ldots \ldots \ldots \ldots \ldots \ldots \ldots \ldots \ldots \ldots \ldots \ldots \ldots \ldots \ldots \ldots \ldots \ldots \ldots \ldots \ldots \ldots \ldots \ldots \ldots \ldots \ldots \ldots \ldots \ldots \ldots \ldots \ldots \\ \text { Ovarium } 1 \ldots \ldots \ldots \ldots \ldots \ldots \ldots\end{array}\right.$

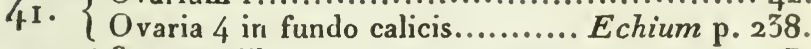

42. $\{$ Stamina libera.............................. 43 .

42. Stamina plurima aut omnia coalita............ 46.

43. $\{$ Calix dentibus 5 spinosis.............. Coris p. 205.

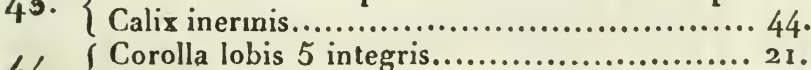

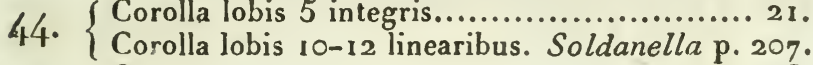

45. $\{$ Ovarium r.................................. 46.

46. $\{$ Folia simplicia..................... Polygala p. 208.

Folia ternata..................... Trifolium p. 346 .

$\int$ Stamina antherifera $2 \ldots \ldots \ldots \ldots \ldots \ldots \ldots \ldots \ldots .48$.

47. $\{$ Stamina antherifera 3............ Montia p. 324.

Stamina antherifera $4 \ldots \ldots . . . \ldots . . . \ldots . . . . . . .552$.

48. $\{$ Corolla calcarata............................. 49.

49. $\{$ Calix 5-lobus.................... Pinguicula p. 230.

49. $\{$ Calix 2-lobus...................... Utricularia ibid.

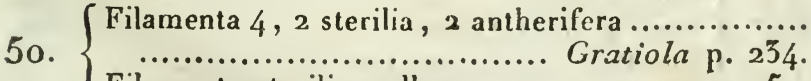

Filamenta sterilia nulla......................... 51.

5 I. $\left\{\begin{array}{l}\text { Corolla rotata; stamina exserta.. Veronica p. } 209 . \\ \text { Corolla campanulata; stamina inclusa.............. }\end{array}\right.$ Limosella p. 250.

52. $\{$ Flores in capitulum aggregati... Globularia p. 204.

Flores liberi..................................... 53.

53. $\{$ Folia radicalia alterna aut nulla.............. 54.

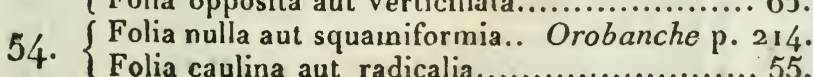
Folia caulina aut radicalia...................... 55 . 
55. $\{$ Calix 5-fidus................................ 56 . Calix 4-fidus................. ACantmaCe

56. $\{$ Corolla bilabiata............................. 57 .

50. Conrolla rotata tubulosa aut campanulata....... 58 .

57. $\{$ Corolla calcarata................. Linaria p. 23 I.

58. $\{$ Caulis erectus foliosus...................... 59.

58. Caulis procumbens aut collo tantum foliosus... 62 .

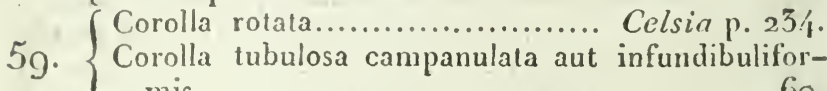
mis...................................... 6.

6o. $\{$ Corollac lobi obcordati emarginati. Erinus p. 230. Coroll $x$ lobi integri........................6r.

61. $\{$ Corolla magnæ ecalcaralæ...... Digitalis p. 23/1. Corollæ parvæ calcaratæ...... Anarrhinum p. 253.

62. $\{$ Flores albi..................... Limosella p. 250. Flores lutei aut rubri........... Sibthorpia p. 2 I I.

63. $\{$ Folia simplicia, integra aut laciniata..........64. 64 . Folia digitata...................... Vitex p. 217.

64. $\{$ Calix 4-dentatus aut 4-lobus..................65. 65.

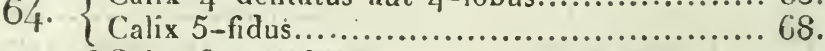

65. $\left\{\begin{array}{r}\text { Spica florum bracteis coloratis imbricata............. } \\ \text {.......................... Melampyrum p. } 2.13 .\end{array}\right.$

Bractex nullæ aut laxæ et foliaceæ............. 66.

66. $\{$ Artheræ tomentosæ................ Bartsia p. 212. Antheræ non tomentos $x . . . . . . . . . . . . . . . .6 .67$. $\int$ Calix inflatus; antherx non spinosa.................. $6_{7} \cdot\left\{\begin{array}{l}\text {.............................. Rhinanthus p. } 212 . \\ \text { Calix non inflatus; antheræ basi spinosa........... }\end{array}\right.$

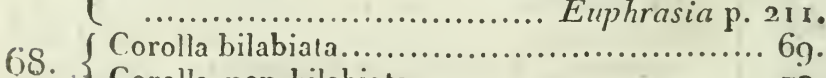

Corolla non bilabiata...................... 72 .

60. $\{$ Corolla basis calcarata aut gibba............. 57

\{ Corolla basis nec gibba nec calcarata......... 70.

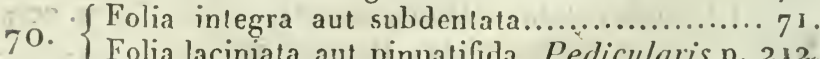

70. Folia laciniata aut pinnatifida. Pedicularis p. 212.

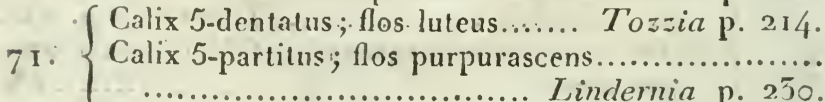
........... Lindernia p. 250

72. $\{$ Corolla subglobosa.......... Scrophularia p. 251.

73. $\{$ Flos purpurascens, cœrulescens aut albus..... 74 . 


\section{A N A L Y T I C A.}

Giraliola p. $2 \% 4$.

$7 \%$ Flores in spicas graciles subnudas dispositi...........

75 Folia integra aut dentata......... T erbena p. 217.

75. \{ Folia pimmalilida aut incisa......... п пв А т

76. $\{$ Ovarium unicum..........................

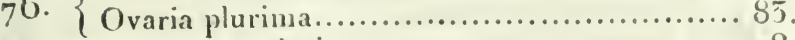

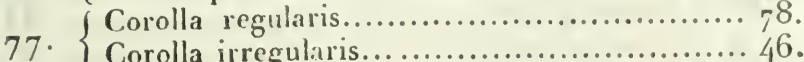

78 $\{$ Caulis lignosus........................... 79.

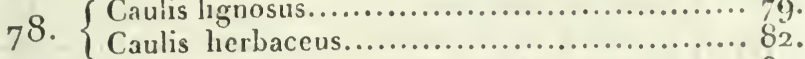

Stigma I simplex.......................... So.

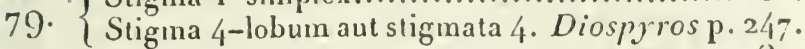

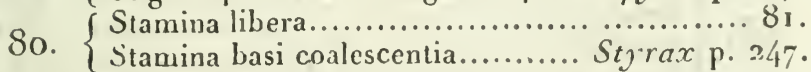

Fructus baccatus, aut capsula valvis septiferis.....

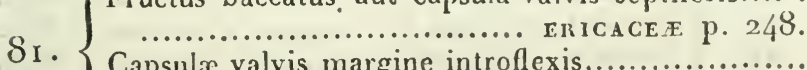

Capsula valvis margine introflexis................

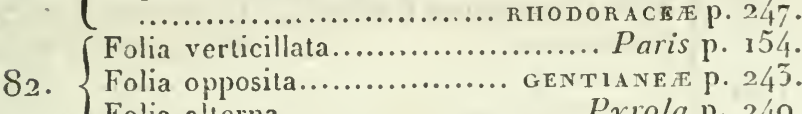

Folia alterng..................... Pyrola p. 249.

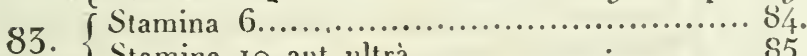

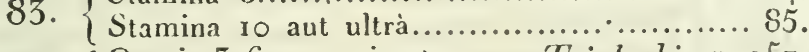

84. $\{$ Ovaria 3-6 approximata...... Triglochin p. 157.

4. $\{$ Ovaria 6-25......................... Alisma p. 156.

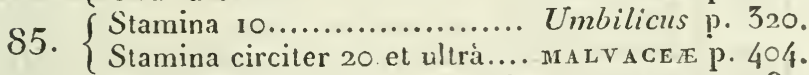

86. $\{$ Folia nulla alterna aut opposita.............. 87 .

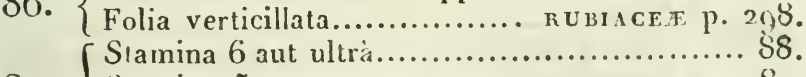

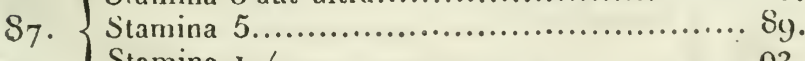

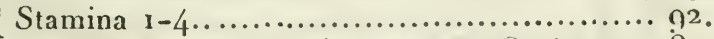

88. $\{$ Herba squamis carnosis onusta... C 3 tinus p. 189 .

8 $\{$ Frutex folia gerens............. Vaccinium p. 250.

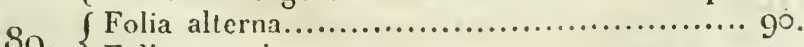

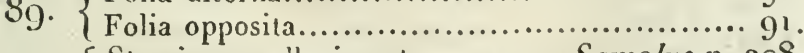

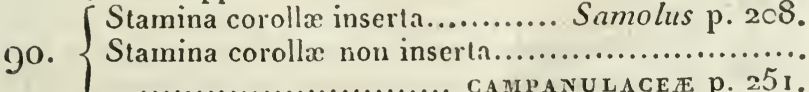
........................ CAMPANULCE P. 251 .

91. $\{$ Fructus baccatus......... CAPRIFOLIACEE P. 502.

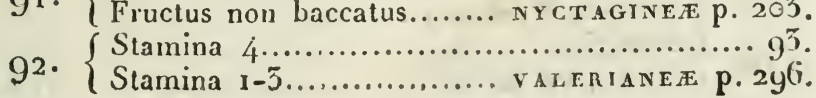


93. $\{$ Flores densè capilati.......... DIPSACE p. 294. 93. $\{$ Flores geminati axillares......... Linnara p. 302. P O L Y P E T A L

94. $\left\{\right.$ Ovarium liberum vel superum ................ $9^{5}$.

9. $\{$ Ovarium calici adnatum vel inferum ........ 157.

95. $\{$ Ovarium unicum .............................. 96.

95. $\{$ Ovaria plura ............................... 154.

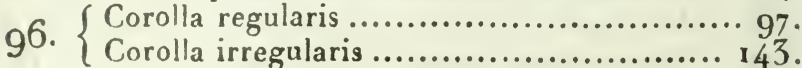

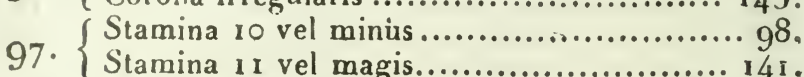

97. Stamina in vel magis.................... 14i

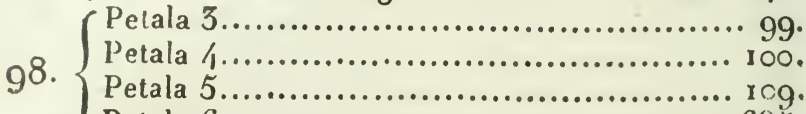

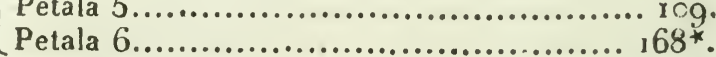

99. $\left\{\begin{array}{l}\text { Stylus } 1 ; \text { stigmata } 3 \ldots \ldots . \ldots . . . \text { Cneorum p. } 364 . \\ \text { Stylus o; stigmata } 3 \ldots \ldots \ldots . . . \text { Elatine p. } 393 . \\ \text { Stylus o; stigmata } 6 \text { vel } 9 \ldots . . \text { Empetrum p. } 250 .\end{array}\right.$

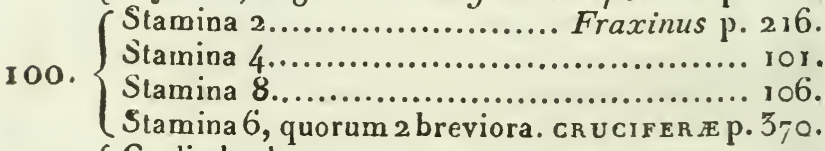

101. $\{$ Caulis herbaceus........................... 102,

Caulis lignosus....................... Ilex p. 366.

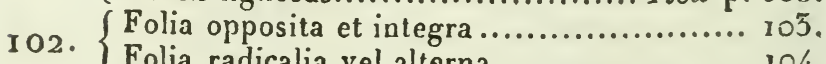

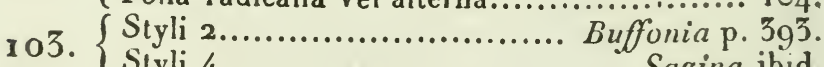
Styli 4 .............................. Sagina ibid.

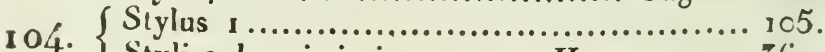

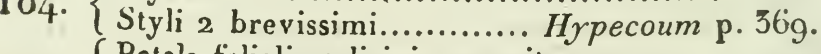

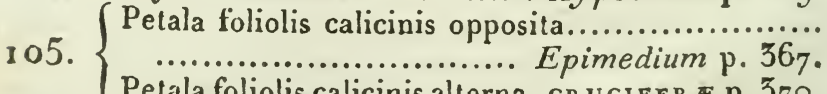
Petala foliolis calicinis alterna. CRUCIFER Æ p. 370. 106. $\{$ Caulis foliosus............................ 10 7 . Caulis aphyllus vel squamosus. Monotropa p. 422.

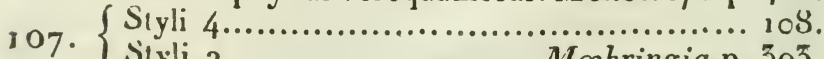

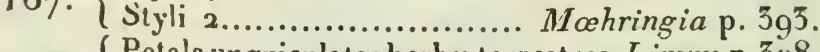

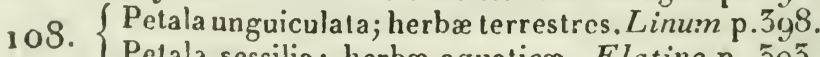
Petala sessilia; herbæ aquaticæ. Elatine p. 595 .

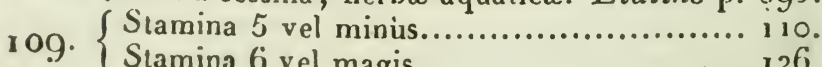

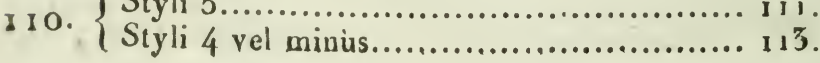




\section{A N A L Y T I C A}

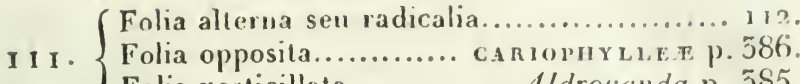
Folia verticillata ............ Aldrovanda p. 385.

Folia pilis glandulosis donata; capsula polysper-

12. ma..................... I)rosera p. 584 . Folia pilis glandulosis destituta; semen $\mathbf{1} . . . . . .$.

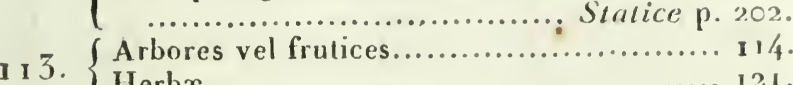

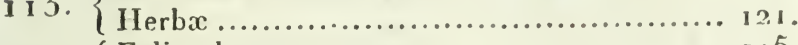

I $4 .\{$ Folia alterna ..........................

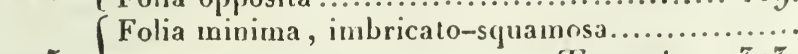

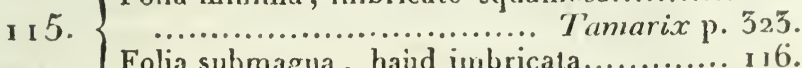

Folia submagna, haud imbricata.......... I 6.

I 6 . $\{$ Flores ierminales....................... I 17 .

Flores axillares vel foliis oppositi........... I 18.

$\{$ Stylus I; stigma I................ Hedera p. 504 .

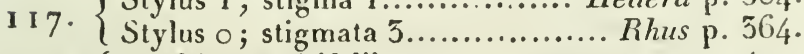

I 8 Cirrhi opposilifolii........ SARMENTACE压 P. 4 I C.

Cirrhi nulli............... FranguLaCE无 p. 365.

I r. $\{$ Stylus I f folia simplicia................. 1 20.

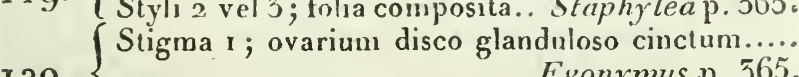

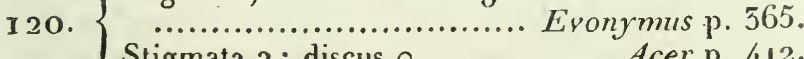

Stigmata 2 ; discus $0 . . . . . . . . .$. Acer p. 412

I 2 I. Folia alterna........................... 1 2:

Folia opposita ........................... I 25.

Glandulæ pedicellatæ intrà florem...............

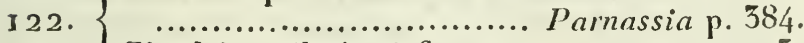

Glandulæ nullæ intrá florem............... $12 \%$.

123. \{ Calix tubulosus... rythrum hyssopifolia (5648).

Calix campanulatus..................... 124 .

Caulis ramosus; semen nudum.................

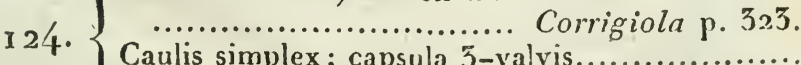

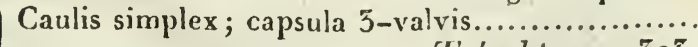

1 25. $\left\{\right.$ Stylus r..................... Frankenia p. $5 q_{2}$

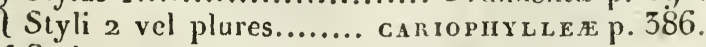
1 26 Stylus I ............................ 1 27.

Styli plures vel nulli; stigmata plura........ 155.

I 27 . $\{$ Folia alterna seu nulla.................... 128.

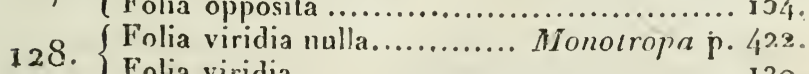

Folia viridia.. ......................... 129 . 
f Frutices............................. I 30.

1 29. $\{$ Herbæ................................ 15

150. $\{$ Folia integra....................... Ledon p. 248.

5 f Flores lutei...................... Ruta p. 385.

$151 \cdot\{$ Flores albidi vel rubescentes............... I 52.

I 32. $\{$ Folia integra vel dentata.................. 153.

Folia composita vel laciniata. Dictanmus p. 386.

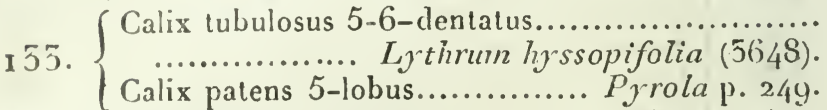

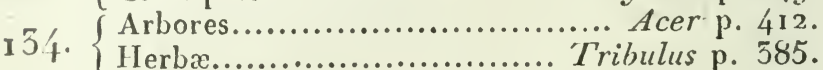

155. $\{$ Arbores aut frutices....................... 156.

35. $\{$ Caulis herbaceus sublignosus............... 157.

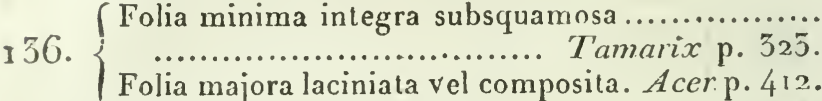

Folia majora laciniata vel composita. Acer p. 4 i2.

I $37 .\{$ Folia alterna vel radicalia................ I 58.

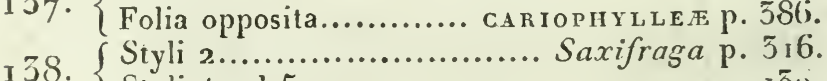

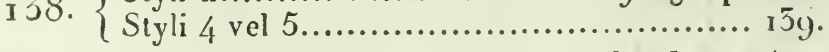

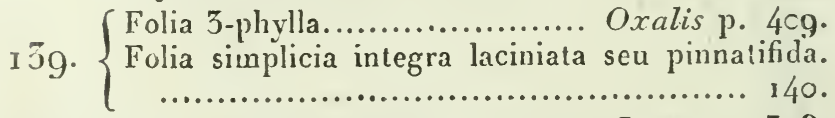

I $40 .\{$ Folia integra exstipulata........... Linum p. 5 g 8.

I LI. $\{$ Petala 5 ; calix persistens..... Portulaca p. 524.

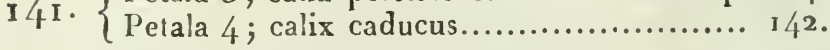

Stigmata 5-10; ovarium globosum vel ovatmm..

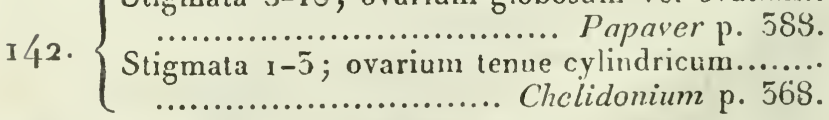

I3. $\{$ Filamenta staminum libera non coalita..... 144.

Filamenta staminum omnia vel plura coalita. 149.

f Calcar I calicis vel corolla basi............ 1 45 .

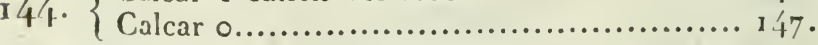

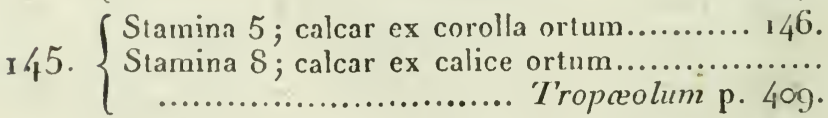

I 46. $\{$ Calix 5-phyllus.................. Violn p. 399.

\{ Calix 2-phyllus.............. Impatiens p. $40 \mathrm{q}$. 
- Stamina 4 ..................... Hypecoum p. 36.

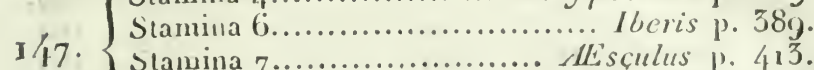

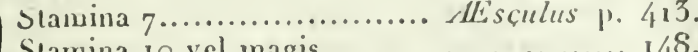
Stamina $10 \mathrm{vel}$ magis...................... 148 . 48. $\{$ Petala laciniata.................... Reseda p. 384.

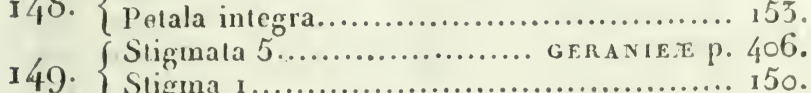
f Slamina 8 vel minus...................... $15 \mathrm{I}$.

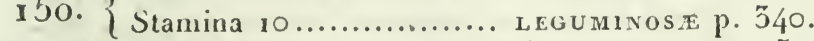

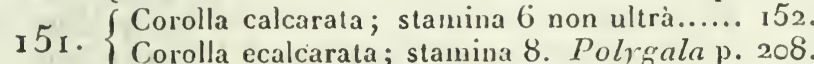
Capsula 1-sperma, sponte haud dehiscens.................. 152. $\{$............................ Fumaria p. $36 \mathrm{~g}$. Capsula 2-valvis, polysperma.... Corydalis ibid. 153. $\{$ Flores rosei vel albi................. Cercis p. 34 1 . $\int$ Petala calici non inserta; stamina monadelpha... 155. Petala calici inserta....... MALVACEÆ.p. 404. Petala calici inserta; stamina libera...............

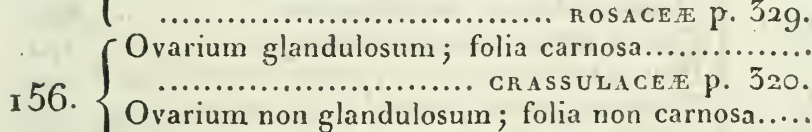
Ovarium non glandulosum; folia non carnosa.... ..................... RANUNCULACE龙 P. 415.

I $57\{$ Stamina 10 vel minus....................... 158.

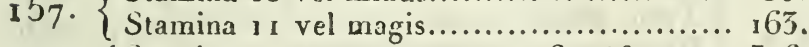
Slamina $10 . . . . . . . . . . . . . .$. Saxifraga p. 516. Stamina $3 \ldots \ldots \ldots \ldots \ldots \ldots \ldots \ldots \ldots \ldots \ldots \ldots . . .159$.

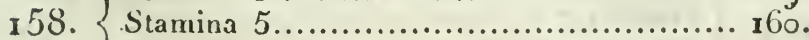

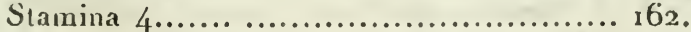

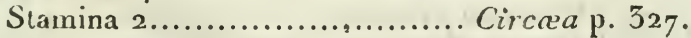
159. $\{$ Flores rubri; semina pilosa. Epilobium p. 328. Frutices; fructus carnosus................... 161 . I6o. Herbæ vel suffrutices; fructus non carnosus bipartibilis............... UMBELLIFER E p. $50 /$. I6. Stigma 1 ; folia sempervirentia.... Hedera ibid. I6I. $\{$ Stigmata 2 ; folia caduca. grossulariæ p. 525. i62. $\left\{\begin{array}{l}\text { Frutex; fiuclus carnosus.......... Cornus p. } 504 . \\ \text { Herba aquatica; fructus non carnosus ............. }\end{array}\right.$ Trapa p. 32\%. 

165. $\left\{\begin{array}{l}\text { Calix bivalvis.................. Portulaca p. } 324 . \\ \text { Calix multivalvis aut multilobus............. } 164 .\end{array}\right.$

64 Folia opposita vel verticillata.............. 165.

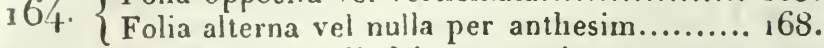
(Herba ; calix cylindricus; stamina $12 \ldots . . \ldots \ldots . .$.

165. $\left\{\begin{array}{l}\text { Frutices; calix campanulatus vel turbinatus; sta- } \\ \text {. }\end{array}\right.$ mina $20 \ldots . . . . . . . . . . . . . . . . . . . . . . . . .166$.

Folia persistentia; fructus carnosus........ 167.

166. Folia caduca; fructus non carnosus; stylus profunde divisus............ Philadelphus p. 32.9 .

167. $\{$ Calix inembranaceus vix coloratus. Myrtus p. 329.

- Calix coriaceus coloratus............ Punica ibid.

I 68 . Stylus 1; stigmata plurima...... Cactus p. 32.4.

\{ Siylus o; stigmata plurima....... Ficorde. $168^{*} .\{$ Herba foliis oppositis.............. Peplis p. 326. \{ Frutex fol. alternis vel fasciculatis. Berberis p. 36-.

I N C O M P L E T E.

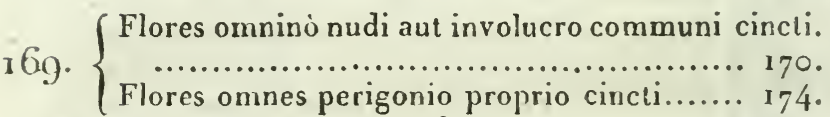

170. $\{$ Planta natantes aut submersæ.............. I 7 I.

Plantæ super terram crescentes............. 172.

171. $\{$ Plantæ marinæ; flores spathacei. Zostera p. 149. Plantæ aquatiles; flores nudi.. NAYADES P. I 18.

172. $\{$ Succus proprius lacteus..................... 173. $\{$ Plantæ non lactescentes......... A ROIDEÆ P. 1/49. Arbor foliis lobatis................ Ficus p. $185^{\circ}$.

373. Herbx aut suffrutices, foliis integris..............

(............................. Euphorbia p. 185.

174. $\{$ Stamina 7 aut ultrà......................... 175.

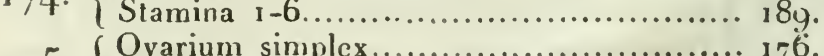

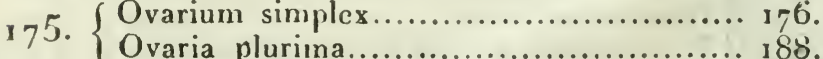

176. $\{$ Ovarium liberum seu superum............. 177

170. \{ Ovarium perigonio adnalum............... I 83.

177. $\{$ Folia alterma............................... 1 7 .

Folia opposita aut verticillata............... 182.

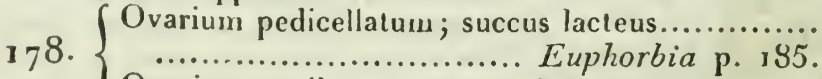

Ovarium sessile; succus non lacteus.......... 179.

179. $\{$ Stylus 1 ; stigma r......... THУ MELEE P. I 9O.

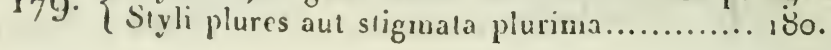


180. $\{$ Arbor............................. U'lmus p. $1 \$ 3$. 180. $\{$ Herba ..................................... 181.

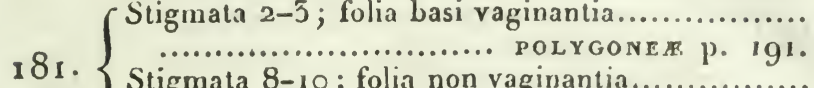
Stigmata 8-10; folia non vaginantia............... Phylolacca p. 194.

82. $\{$ Arbor foliis oppositis................ Acer p. 412. 182. $\{$ Herba foliis verticillatis............. Paris p. 154 . 83. $\{$ Plantæ foliosæ............................ 184. Plantæ aphyllæ squammatæ...... C. 184. $\{$ Stamina 10 aut minus ....................... 185. 85. $\left\{\begin{array}{l}\text { Styli } 2 \ldots \ldots \ldots \ldots \ldots \ldots \ldots \ldots \ldots \ldots \ldots \ldots \ldots \ldots \ldots \ldots \ldots \ldots \ldots \ldots \\ \text { Styli }\end{array}\right.$ 185. $\{$ Styli $4-5 \ldots . . \ldots \ldots \ldots \ldots \ldots \ldots \ldots$. Adoxa p. 320. 186. $\{$ Folia linearia integra........ Scleranthus p. 324. Folia orbiculata crenata.. Chrysosplenium p. 320. $\int$ Stamina 12 ; folia petiolata orbiculata............

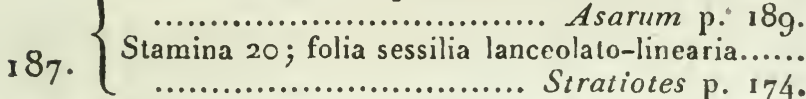

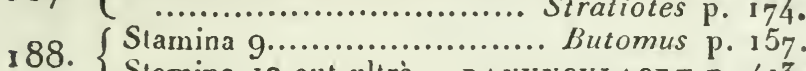
Stama 12 aut ultra... RANUNCUI,ACEE p. 413. 18g. $\{$ Perigonium coloratum petaloideum........... 39. Perigonium glumaceum aut calicinum ....... 207.

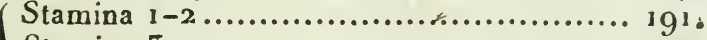

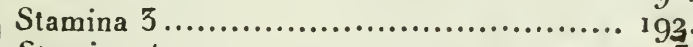

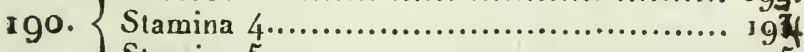

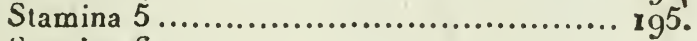
Stamina 6 ............................. 199.

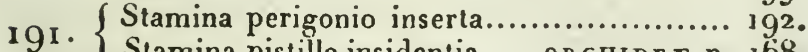
Stamina pistillo insidentia.... or OHIDEÆ p. 168. S Ovarium liberum............... Suffrenia p. 326. 192. Ovarium adnatum seu inferum.................. 193. $\{$ Folia radicalia aut alterna....... IRIDEE p. 166. 93. Folia caulina opposita....... vALER IANEA p. 296. I94. $\{$ Ovarium liberum......... Mayanthemum p. 154. Ovarium perigonio adhærens.. ELEAGNEÆ p. 189 . 195. $\{$ Folia opposita ............................... 196.

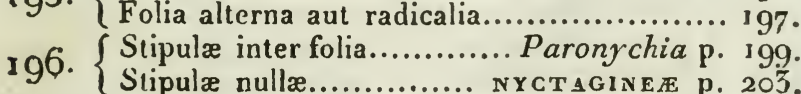
197. $\{$ Ovarium liberum seu superum.............. 198 197. \{ Ovarium perigonio adbærens.. Thesium p. 189. 


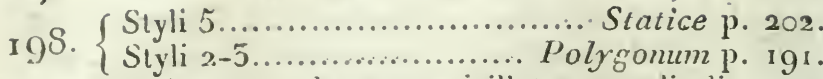

99. Folia sparsa alterna verticillata aut radicalia. 200.

Folia opposita.

200. $\left\{\right.$ Stigmata 2................. Poly gonum p. $19^{\mathbf{r}}$.

$\mathrm{OII}_{\mathrm{I}}$ Fruclus baccatus............................. 206.

202 Ovaria plurima............... ALISMACEE p. 155.

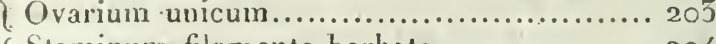

205. \{taminum filamenta barbata................ 204.

Staminum filamenta glabra................. 205.

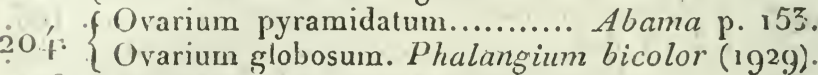
Capsulx valvis medio septiferis.................. Capsulx valvis margine introflexis................ COLCHICACEE P. 157. 206 ( Bacca unica; folia integra... ASPARAGE

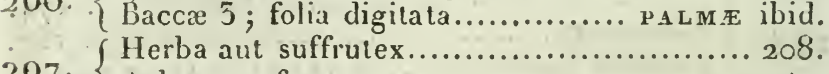

207. $\{$ Arbor aut frutex........................... 241. Staniell 1.................................. 209.

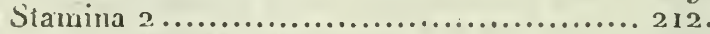

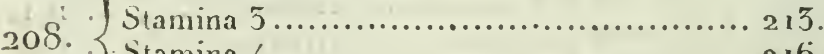

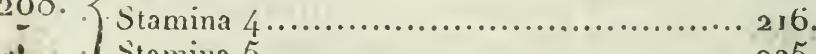

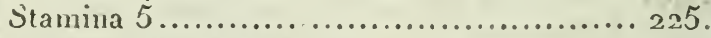

Stamina 6 .............................. 229.

Folia nulla; rami carnosi.... Salicornia p. 197. Folia alterna............................... 2 10.

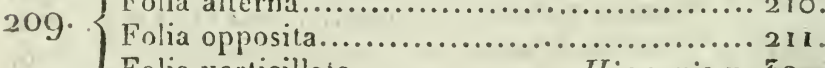

Folia verticillata............... Itippuris p. 52 . Perigonium 3-partitum; fructus carnosus........ 210. ….......................... Blilum p. Ig Perigonium 2-partitum; fructus siccus........... Corispermum p. 198.

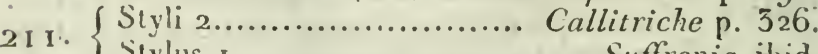

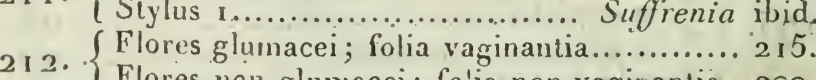
213 . Flores glumacei; folia vaginantia........... 215. Flores non glumacei; folia non vaginantia.. 214. 
214. Perigonium 5-partitum.... Polycnemum p. 198.

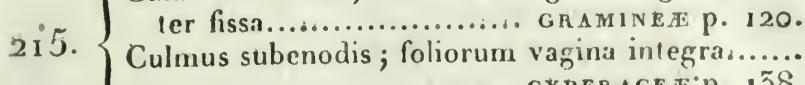

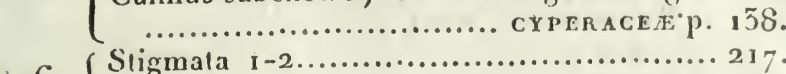

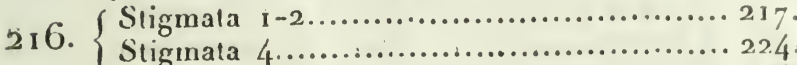

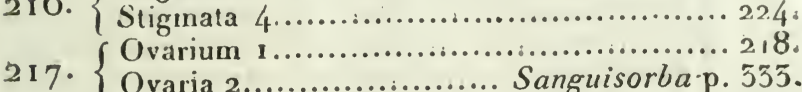

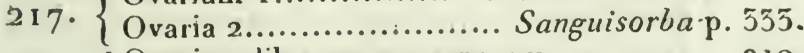

2 I 8. $\{$ Ovarium liberum seu superum ............... 219.

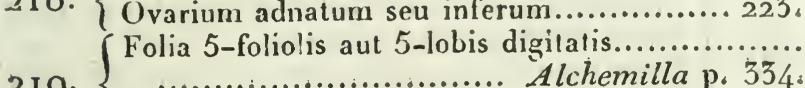
$219 .\{\ldots . . . . . . . . . . . . . . . . . . . . .$. Alchemilla p. 334. Folia integra aut pinnatifida.................. 2.20. Flores axillares; fructus wonospermi.......221. 220. Flores spicati aut capitati; fructus polyspermi.... ............................... Plantago p. 200.

22 I. Folia linearia; flores onnes hermaphroditi. 222. olia ovalia; flores polygami. Parietaria p. 184. 222. Perigonium 4-partitum... Canphorosma p. 198. 233. Folia opposita.................... Isnardia $\mathrm{p}_{\mathrm{i}} 327$ Folia alterna...................... Thesium p. I8g. Perigonium 4-valve; capsulæ sessiles...............

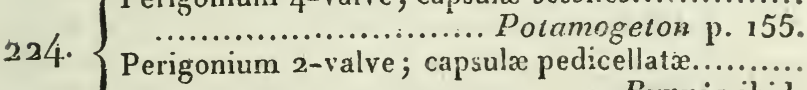
225. Folia alterna ............................... 226 , Folia opposita................. 226. \{ Pei ígonium tubulosum........... Thesium p. 189. \{ Perigonium non tubulosum. CHENO PिODEE. p. 194. 227. Folia basi stipulata..... AMARANTHACEE. p. 198.

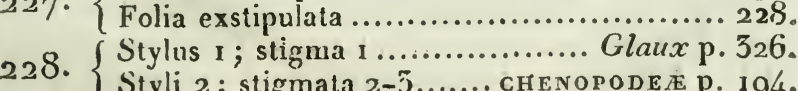
Styli 2 ; stigmata $2-3 \ldots . . .$. CHENOPODE p. 194. 229. $\{$ Stamina pistillo sessilia..... Aristolochia p. 188. 30. $\{$ Perigonium glumaceum bivalve... Oryza p. 122. Ponium 4-phyllum....... СRUCIFER E p. 370. Perigonium 5-6-12-partitum.................231.

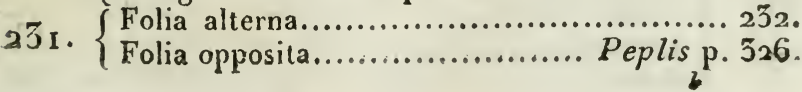


Folia inutabili forma, dentata, inciso-angulosa. 240 .

33. Ovarium 1; stylus I ........................ 25.

Ovaria plura; styli plures................. 259.

234. $\{$ Planla soli vel ayux dulcis incola.......... 255.

Planta marina..................... Caulinia p. 150.

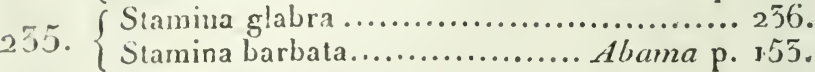

56. Lacinix perigonii rotaiæ vel campanulatx... 237.

Lacinix perigonii in tubum basi coalitæ, apice patentes.................... Aphyllanthes p. 152. Flores densè spicati I-laterales... Acorus p. 150.

257. $\{$ Flores capitati, racemosi, paniculati, solitarii. $25 \mathrm{~S}$.

238. \{ Folia terctia; capsula 5-locularis. Juncus p. 151. Folia plana; capsula 1-locularis.. Luzula p. 150. Involucellum 3.dentatum sub singulo flore........ 59. $\left\{\begin{array}{c}\text {............................... Tofieldia p. } 157 . \\ \text { Involucrum sub singulo flore nulium .............. }\end{array}\right.$ Veratrum p. $155^{\circ}$ $2 / 4 .\{$ Folia integra vel dentata.................. 242 . 242. $\left\{\begin{array}{c}\text { Ovarium globosum; fructus carnosus rotundatus. } \\ \ldots \ldots \ldots \ldots \ldots \ldots \ldots \ldots \ldots \ldots \ldots \ldots \ldots \ldots \ldots \ldots \ldots \ldots \ldots \ldots \ldots \ldots \ldots \ldots \ldots \ldots \ldots \ldots\end{array}\right.$ Ovarium compressum; fructus meinbranaceus complanatus..................... Ulmus p. 185.

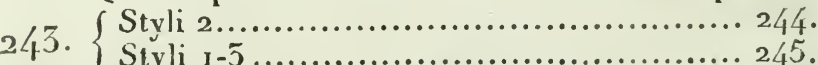

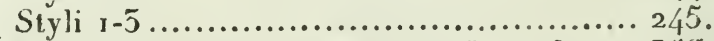
Spinæ in axillis foliorum....... Zizyplus p. $366^{\circ}$. 244. $\{$ Axillæ nudæ, vel stipulis membranaccis donatæ.. 25. Stylus 1....................... Rhammus p. 566.

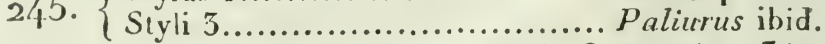
246. $\{$ Folia alala cum impare; stam.5. Ceratonia p. $34 \mathrm{I}$. Folia digitata; stamina 6.... Chamcerops p. 153.

U N I S E X U A L E S.

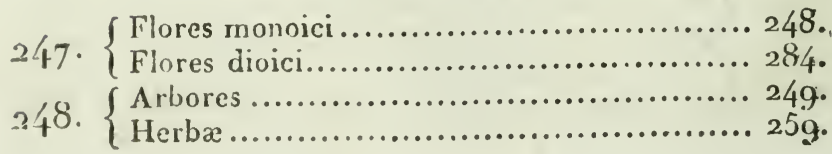




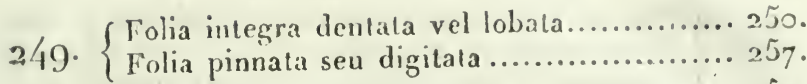

550. $\{$ Folia alterna vel fasciculata ................. $25 \mathrm{r}$

$251 .\left\{\begin{array}{l}\text { Folia integra denticulata vel pinnatifida..... } 252 . \\ \text { Folia }\end{array}\right.$

Filament lobata, nervis palmatis............... 255 quàm dentata sæpiùs linearia persistentia nun-

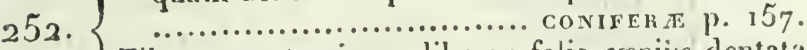

Filamenta staminum libera; folia sapius dentatia sæpius caduca............. AMENTACR. P. 177 .

Succus proprius lacteus; flores involucro carnoso inclusi ........................... Ficus p. 185.

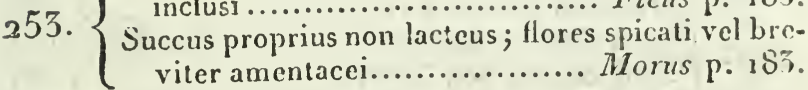

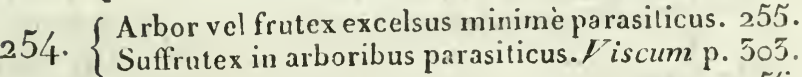
55. Folia integra

Folia 3-5-lobata..........................Acer p. 412.

257. $\{$ Folia (vel gemmæ) opposita.... Fraxinus p. 216. Folia alterna.............................. 258.

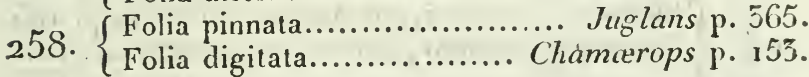

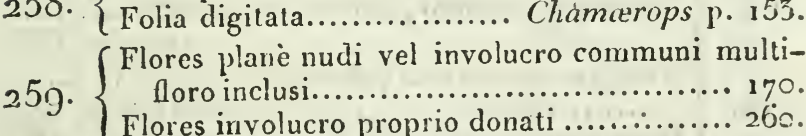
Flores involucro proprio donati ............. 260.

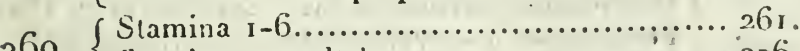

260. $\{$ Stamina 7 et ultrà........................ 2,76 .

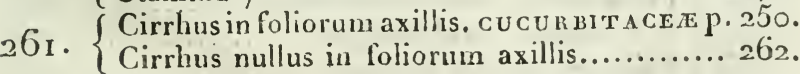

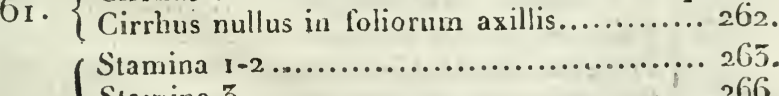

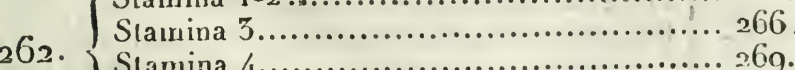

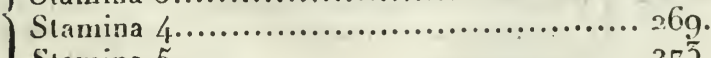

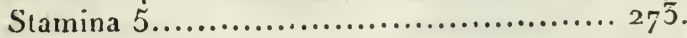
265. $\left\{\begin{array}{l}\text { Ovarium r................................... 264. } \\ \text { Ovaria 2-6 in quoque flore... Zanichellia p. } 155 .\end{array}\right.$

26. $\left\{\begin{array}{c}\text { Caulis erectus, rigidus ; rami carnosi.............. } \\ \text {............................ Salicornia p. } 197 . \\ \text { Caulis debilis vel nullus minime carnosus.... } 265 .\end{array}\right.$ 
655. $\{$ Styli 2 ; folia opposita......... Callitriche p. 326.

265. Stylus nullus vel solitarius; folia alterna vel verticillata ....................... NAYADES p. II 3 .

266. Folia linearia, nervis simplicibus et parallelis. 267. Folia ovata, nervis ramosis. Amaranthus p. 198. $267:\left\{\begin{array}{l}\text { Stylus } 1 \text {; stigmata } 2-3 \text {; vaginæ foliorum integræ. } \\ \text { Stylus } 0 \text {; stigmata } 2 \text {; vagina foliorum longitudi- }\end{array}\right.$ naliter fissa................ GRAMINEE p. 120,

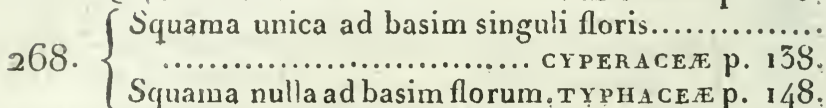

269. $\{$ Ovarium liberum vel superum............... 270,

Ovarium adnatum vel inferum.............272.

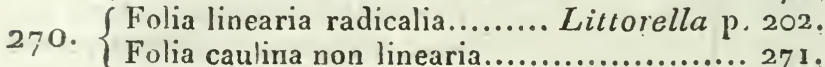
Folia caulina non linearia.................. 27 1 ,

Flores omnes masculi vel feminini; pili urentes..

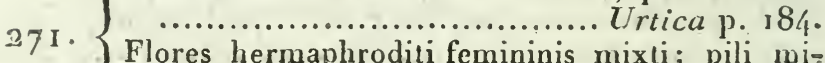

Flores hermaphroditi femininis mixti; pili minimè urentes............... Parietaria p. 184.

272. $\{$ Folia verticillata................. Galium p. 299.

2. \{ Folia opposita.................... Viscum p. 503 .

273. $\{$ Flores aggregati sed non involucrati........ 274 .

Flores in involucro communi congesti...... 275 ,

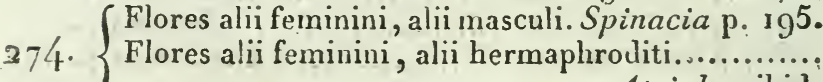

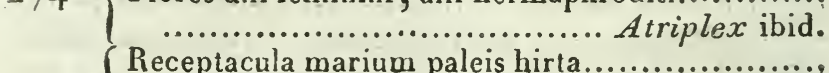

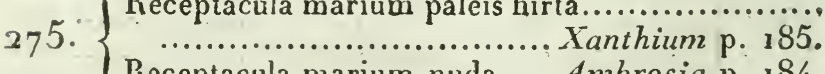

Receptacula marium nuda.... Ambrosia p. 184.

276. $\{$ Folia opposita vel verticillata ...............27. 27.

\{ Folia nulla, radicalia vel alterua............ 280.

277 . $\{$ Folia opposita subintegra .................. 278.

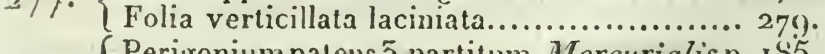

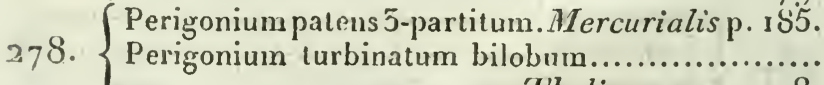

(.......................... Theligonum p. 198.

279. $\{$ Stamina $8 . . . . . . . . . . . . .$. Myriophyllum p. 527.

Stamina circiter 20..... Ceratophyllum p. 326.

280. $\{$ Squamx foliorum loco........... Cytinus p. 189.

$\{$ Folia vera radicalia vel caulina............... 281 .

$2 S_{1} . \quad\{$ Ovarium unicum ......................... 282.

$\{$ Ovaria plura................... Sagittaria p. 157 . 
282. $\left\{\begin{array}{c}\text { Ovarium pedicellatum; succus proprius lacteus... } \\ \text {........................... Euphorbic p. } 1 \$ 5 . \\ \text { Ovarium sessile; succus proprius non lacteus. } 283 .\end{array}\right.$

85. $\begin{aligned} & \text { Perigonium 2-lobum; stigma .' Theligunump. 1 } 8 . \\ & \text { Perigonium 5-lobum; stigmata } 3 \text {, lifida. }\end{aligned}$

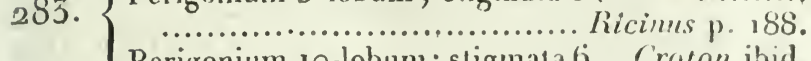
Perigonium ı-lobum; stigmata 6... Croton ibid. 284. $\{$ Arbores aut frutices.......................... 285. Herba............................. $50 \mathrm{x}$. 285. \{ Folia ant gemmæ oppositæ seu verticilla!æ.. 286. Folia aut gemmx alternx................. 289 .

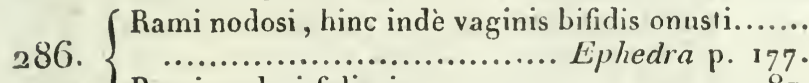
Rami nodosi foliosi........................... 287.

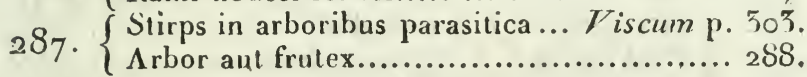

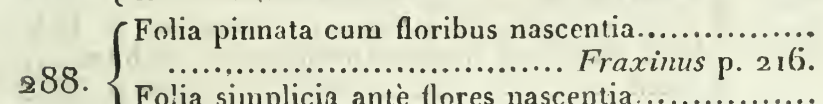
Folia simplicia antè flores nascentia.............. Coriaria p. 422.

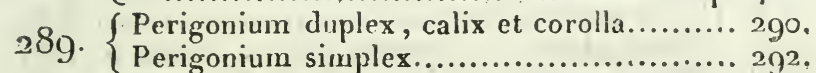
290. $\{$ Petala 5...................... Empetrum p. 250 , $\{$ Petala disco ovarium cingente inserta

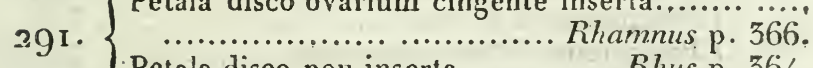
Petala disco non inserta............. Rhus p. 364. 292. Folia pinnata ternata aut digitata............ 293. 292. Folia simplicia aut antheseos tenıpore nulla. 501. 293. $\left\{\begin{array}{l}\text { Folia digitata } 5-7-\text { partita.... Chamcerops p. } 153 . \\ \text { Folia impari-pinnata.......... Ceratonia p. } 3 / 1 . \\ \text { Folia ternata aut pinnata cum impari............... }\end{array}\right.$ Pistacia p. 364.

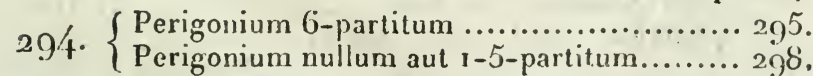

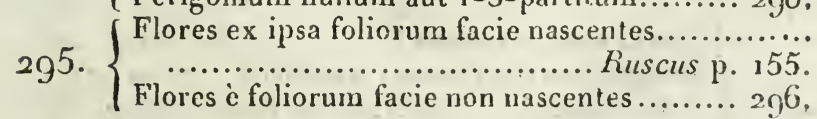
296. \{ Folia linearia fasciculata...... Asparagus p. 153.

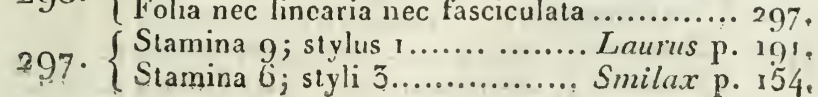


xxij C L $\Lambda$ V I S

2.98. $\{$ Frutex ramis spinosis........ IIippophae p. 189.

\{ Frutex vel arbor incrmis.................. 299.

S Perigonium tubulosum 3-4-5-lobum....... 300.

299. Perigonium nullum vel non tubulosum vel squamiforme vel bipartitum.................. 252 .

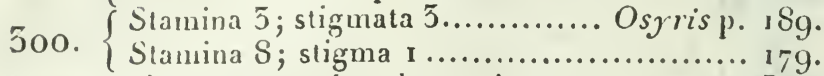

3o . $\{$ Planla terrestris vel parasita................ 302 .

$301 .\{$ Planta aquis vel innatans vel immersa...... 322.

30. $\{$ Folia alterna .............................. 305.

302. $\{$ Folia opposita ............................ $3,6$.

503. \{ Folia pinnala, digitata vel decomposita..... $30 / 4$.

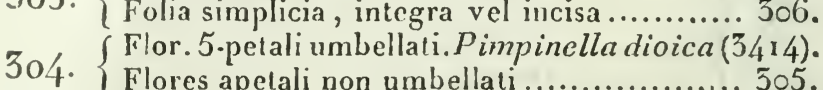

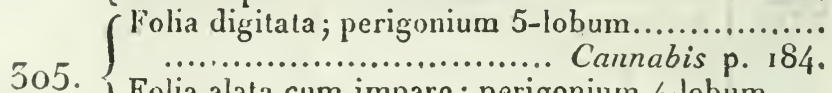
Folia alata cum imparc; perigonium 4-lobum....

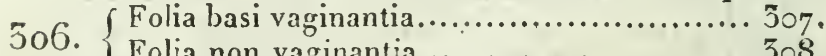

(Folia non vaginantia........................ 308.

307 . Flores glumacei; stamina 2-5..... Carex p. 138.

Flores non glumacei; stamina 6.. Kumex p. 195.

508. Calix et corolla ........... Sedum rhodiola (5605),

\{ Tegumentum florale unicum............... 3c9.

509. $\{$ Perigonium 6-lobum......................... 510.

Perigonium 5-lobum et minus.............. 3 г 2.
$\{$ Folia linearia fasciculata..... Asparagus p. 153.

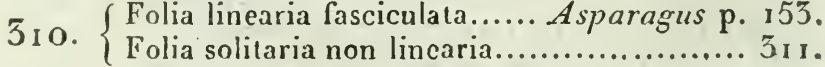

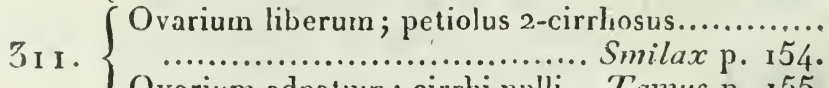

Ovarium adnatun; cirrhi nulli... Tamus p. 155.

512. $\{$ Perigonium 5-lobum........................ 513.

312. \{ Perigonium 2-4-lobuin................... 51/4.

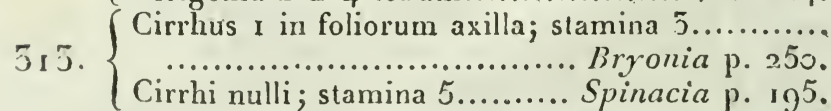

514. $\left\{\begin{array}{r}\text { Perigonium tubulosum; stamina } 8 \text {; stylus latera- } \\ \text { lis........................... Passerina } p .190 .\end{array}\right.$

l'erigonium nou tubulosum; stamina 4-5; stvlus terminalis ............................... 315 .

315. $\{$ Stamina 5 ; styli $4 \ldots \ldots \ldots . . . \ldots . .$. Spinacia $p .1,5$. $\{$ Stamina 4 ; stigma $1 . . . . . . . . . . . .$. Urtica p. 184. 
5I6. $\{$ Caulis scandens................... IIumulus p. $18 /\}$. 517 Planta parasita................... V iscum p. 50 j. 5 Folia digitata.................... Cannabis p.

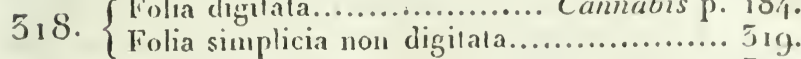
5 f Corolla el calix .......................... 320. 5 I9. \{ Perigonium simplex ...................... 52 I. 520. $\{$ Corolla monopetala......... valERIANFE p. 296.

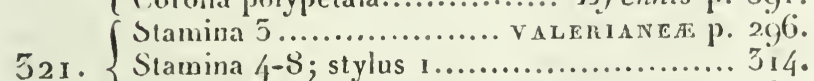

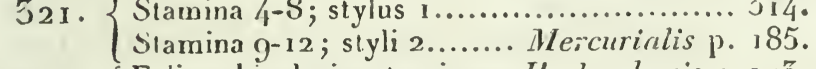
322. $\{$ Folia orbicularia; stamina 9. Iydrocharis p. 175.

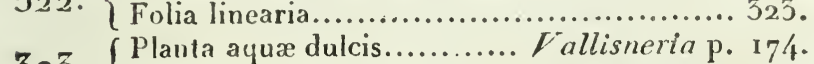

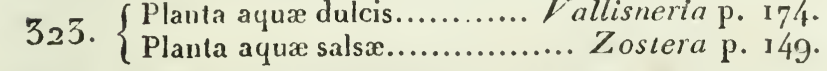

\section{R Y P T O G A M E.}

5.4. $\{$ Plantæ radicibus caulibus foliisque donatx.. 325. 325. \{ructus vel foliis vel intrà folia enascens.... 526. Fructus subpulverulentus; folia juniora apice ad

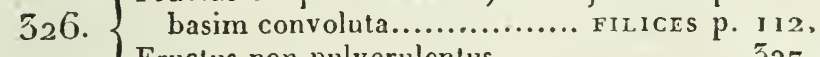
Fructus non pulverulentus................. 327 . 57. $\{$ Capsulæ subglobosæ distinclæ. HePA TICE p. 89.

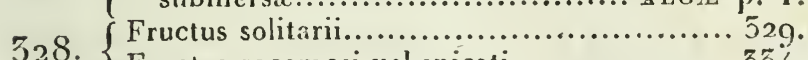
Fructus racemosi vel spicati.................. 334 .

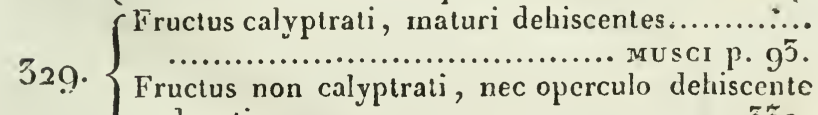

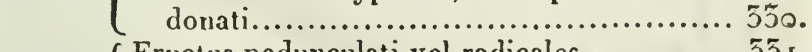
330. $\{$ Fructus pedunculati vel radicales.............. $53 \mathrm{r}$.

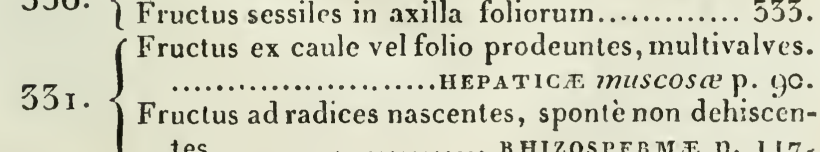
tes...................... к ніzosperma p. 117 . 332. \{ Plantæ terrestres............ Lycopodium p. 116.

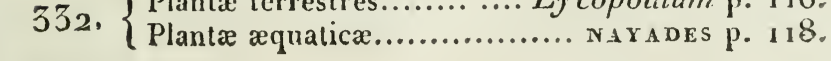


353. Plantaarticulisbasi mutuò commissis constans. 354 .

353. Planta nec articulata nec vaginata.......... 356.

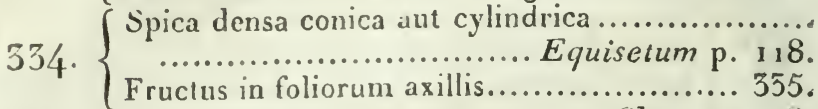

335. $\{$ Folia integra........................ Chara p. 18.

$\{$ Fructus ex radice prodeuntes.......................

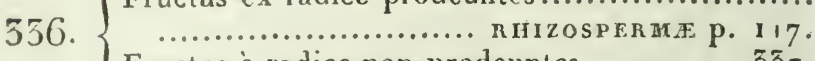

Fruclus è radice non prodeuntes............ 337.

$557 .\{$ Folia minima, numerosa, approximata, imbri-

Folia rara, submagna, sparsa... rilices p. 112.

358. \{ Plantæ virides sæyiüs foliace æ............... 539.

358. Plantæ nec virides nec foliaceæ............... 341.

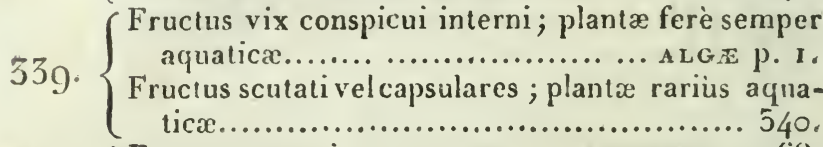

340. \{ Fruclus scutati................... LICHENes p. 68.

3द_O. \{ Fructus capsuliformes vel pileati. HEPА TXCE P. 89 .

3/41. \{lantæ aquaticæ .............................. 342.

Plantæ terrestres .............................. 343.

542. Plantæ filamentosæ vel membranaceæ. ALGE P. I. Plania disco carnoso...... Peziza aquatica (192.).

343. $\left\{\begin{array}{l}\text { Plantæ fungosæ, carnosæ, coriaceæ detritæ nun- } \\ \text { quam virescentes........................... } 344 . \\ \text { Plantæ lichenoideæ, pulverulenæx seu coriaceæ de- }\end{array}\right.$ Plantæ lichenoideæ, pulverulentæ seu coriaceæ detritæ virescentes......................... 345 . 344. $\left\{\begin{array}{c}\text { Semina in pulpa muscosa vel semi-liquida nidu- } \\ \text { lantia.................................... } 345 .\end{array}\right.$

344. $\left\{\begin{array}{l}\text { Semina in pulpa muscosa vel semi-liquida haud } \\ \text { ind }\end{array}\right.$ immixta........................ FUNGI p. 1 $\tilde{3}$.

Receptaculum disci-vel-scuti-forme; semine ad

345. $\left\{\begin{array}{r}\text { Recriciem posita............. LICHENES p. } 68 . \\ \text { superaculum urceolato-rotundatum vel elo }\end{array}\right.$ tum; semina interna........ HурохуLA p. 58. 


\section{S Y N O P S I S}

\section{P L A N T A R U M}

IN FLORA GALLICA

\section{E S C R I P T A R U M.}

\section{L A S S I S P R I M A.}

\section{A C O T Y L E D O N E S.}

$P$

L a N x f contextu celluloso variis modis configurato constantes, poris corticalibus vasis lymphaticis spiralibus et propriis carentes; organa sexualia in plerisque ignota; semina (aut gongyli) absqué cotyledonibus germinantia.

\section{$O \mathrm{R} \mathrm{DO}$ I. $\Lambda \mathrm{L} G \mathrm{AE}$.}

Plantæ sæpissimè aquaticæé, filamentosæ ant membranaccæ, in omnibus partibus similares, liquidum ambientem per solam partem immersam absorbentes ncc ad reliquas transvehentes, nunc rubentes, nunc virides et gazim oxygenium sub aqua soli expositx emittentes.

$$
\text { G E N U S I. N O S T O C H. }
$$

Integumentum virescens membranaceum intùs farctum gelatina mucosa filamentis mouiliformibus intertexta.

1. Commune. Plicatum undulatum membranaceum, filamentorum. articulo ultimo majori. - Habitat ad terraın post plıvias.

2. Coriaceum. Difforme crispum coriaceum solidum, filamentis recurvatis vix moliniformilus.-Ad terram paludosam. Genevæ.

3. Iichenoides. Expansum crispum membranaceum, filamentis annulatis. - Ad arbores et lapides, imprimis post pluvias.

4. Vesicarium. Vesicarium vix rugosum cartilagineum radicula laterali terra adnatum. - Ad terram madidam.

5. Laciniatum. Tenue crispum cartilagineum laciniatum cæspitosum. - Ad terram madidam et super muscos.

6. Sphrericum. Granulatum sphæricum, filamentis moniliformibus. - Ad terram madidam.

7. Verrucosum. Aquaticum, subrotundum tuberculatum solidum, filamentis vix mouiliformibus. - In rivulis. 


\section{2. $R$ I $V$ U L $A$ Ii I $A$.}

Membranæ subcartilaģinex, lobatx aut ramosæ, muco gelatinoso obtectie.

8. Tibulosa. Tubulosa simplex apice crispa. - In rivulis.

$8^{*}$. Lubrica, Fhitans cespitosa convoluta undulata tenuissima gelatinoso-lubrica. - Ulva Jubrica, Reth. Cat. 1. p. 204. t. 5. f. 7. - In fossis aquæ stagnantis.

9. Fretirla. 'Tenuis ramosa foetida atro-viridis. - In rivulis lapidibus allharens.

10. Hallevi. Elongata, apice ramosa, pallidè viridis. - In rivo dicto Seyon propic Neocomum.

$$
\text { 3. U L V A. }
$$

Frondes membranaccæ. Ścmina sıb epidermide latitantia, sæpiùs aggregata, fronlis ipsitus destructione exeuntia.

\section{I. Intius gelatinosa.}

1. Diaphana. Intùs gelatinoso-arnosa, lutescens, pellucida, nunc cyliodrica, nunc compressa, irregulariter ramosa. - Engl. bot. t. 263. Alcyonium gelatiaosnm, Linn. - In Oceano.

12. Tomentosa. Fronde tereti intìs fungoso pluriès dichotoma, angulis apicibusque obtusis. - In Oceano et mari E-Iediterraneo

13. Ariculata. Fronde articulata intùs gelatinosa, articulis ovatis utrinquè attenuatis, ramis oppositis aut rerticillatis. - In rupibus submarinis.

\section{II. Tubulosie.}

1'. Compressa. Tubo compresso basi attenuato, simplici aut ramoso, ramis hasi attenuatis et clausis. - In mari vulgaris.

5. Intestinalis. Tubo longissimo cylindrico subsinuoso simplici. - In fossis aquæ stagnantis dulcis aut subsalsa.

$15^{*}$. Fistulosa. Tubo tereti basi attenuato simplicissimo subolivaceo. - Engl. bot. t. 6-f 2. - In mari Mediterranco.

16. Rugosa. 'Tubo tereti basi attenuato tuberculis manmillosis extus obsito. - In mari Merliterraneo.

§. III. Mrembranacea nervis zonis pedunculisque destituta.

7. Minima. Membranacea diaphana subglobosa parvula. - In rivulis vere lapidibus adhærens.t

$x z^{*}$. Terrestris. Frondibus ronfertis tenuissimis expansis decumbentibus plicato-crispis. - Roth. cat. 1. 1. 211. - Ad terram in ambulacris vix adhærens.

18. Imbilicalis. Fronde orbiculatim dilatata subsinuata centro adharente nembranaceo-subcotiacea. - In rupibus submarinis.

19. Purpurea. Frondihus purpurascentibus tenuibus solitariis oblongo-lanceolatis planis, margine integris undulatis. - In mari. 
20. Lactuca. Frondibus ex una basi plurilus distinctis ol,longis planis subundulatis, inferne attenuatis, sursum dilatatis laciniatis. - In mati frequens.

21. Lanceolata. Frondilus planis integerrimis lanceolatis elongatis utringuè attenuatis. - In mari.

22. Linza. Frondibus oblongis integris solitariis bnllatis, longitudinaliter plicatis. - In Oceano.

23. Comtorta. Frondibus lincaribus ramosis bullatis subgelatinosis acutis. - In Uceano.

2\{. Serrata. Frondibus planis dilatato-palmatis, segmentis margine ciliato-serratis sajè irregularibus, punctis fructifieationis sparsis usque ad narginem frondis. - Ulya atomaria. Engl. bot. 1. 419. - In Oceano.

25. Dichotoma. Frondibus planis dichotomis, segmentis ohtusis margine integris, punctis fructificationis sparsis nunquam ad margines frondis extantibus. - Fucus zosteroides, L'Amou. Diss. t. 22. f. 3. ct t. 23. . 1. - In Occano.

26. Ocellata. Frondibns planis dichotomis, segmentis ohtusis margine integris, punctis fructificationis annulatim dispositis. - Fucus ocellatus, L'Amou. Diss. t. 32. f. 1-4. - In Oceano et mari Mediterraneo.

27. Palmata. Fronclibus membranaceo-pellucidis dilatatis palmatis planis, segmentis oblongis margine integris. - Enyl. Bot. t. 1306. - In Oceano.

28. Eidulis. Frondihus cartilagineis planis dilatatis snbpalmatis, segmentis ohlongis obtusis margine integris. - Eugl. Bot. t. 1307, - In Oceano.

29. Ligulata. Frondibus membranaccis planis ramosis, interdim subdichotonis, sæpius in ligulas lineares margine apiceque productis. - Engl. Bot. t. $420 .-$ In Oceano.

3o. Crispa. Frondibus cartilagineis apice dichotomis, tuberculis fruetiferis intrà frondem nidulantibus ovatis. - In Oceano frequens.

\section{IV. Membranaceie nervo longitudinali donata.}

31. Lingulata. Frondibus novellis è nervo antiquorum ortis, puncta fructificationis aggregata in centro gerentibus. - In Oceano.

32. Polypodioides. Fronde dichotoma, segnentis margine integris obtusis, punctis fructificationis sparsis. - L'Amon. Diss. t. 2\}. f. 2. - In Oceano et mari Mediterraneo.

\section{V. Membranacea pedunculate.}

33. Phyllitis. Fronde tenuissima lanceolata simplici integra, pedunculo brevi compresso. - In Oceano.

34. Saccharina. Fronde coriacea oblongo-lanceolata longissima integra, pedunculo tereti. - In Oceano.

35. Digitata. Fronde palnato-digitata, segmentis ensiformibus, stipite tereti, radice fibrosa. - In Oceano. 
36. Bullonsa. Fronde palmato-digitata, segmentis ensiformibus, stipite plano, radice inflato-bulbosa. - In Uceano rarius.

\section{VI. Membranacea zonis transversalibus notatce.}

37. Pavonin Frondibus planis coriaceis flabelliformibus decnssatinı striatis, simplicibus aut incisis. - Trattinickia pavonia, TVeb. Mohr. ind. mns. - In Oceano et mari Mediterraneo.

38. Squammaria. Horizontalis coriacea, lobis inæqualibus rotundatis , supernè levissimè striatis.-In lapidibus unaris Mediterranei.

$$
\text { 4. F U C U s. }
$$

Algæ marinæ membranaceæ aut filamentosæ. Capsulæ aut semina aggretata in tubcrculos nunc lateralcs, nunc terminales, apice poro debiscentes.

\section{§. I. Tuberculis fructiferis intrà frondem nidulantibus.}

39. Vesirulosus. Fronde nervo medio donata, plana dichotoma integerrima, vesiculis innatis axillaribusque, apicibus ovalibus $\mathbf{t n -}$ midis tuberculatis. - In rupibus submarinis frequens.

4o. Spiralis. Fronde nervo medio donata, plana dichotoma integra vesiculis destituta, apicibus ovalibus tumidis tuberculatis. - In rupibus submarinis.

4r. Ceranoides. Fronde nervo medio donata, plana dichotoma integra vesiculis destituta, apicibus lanceolatis tumidiusculis tuberculatis. - In rupibus Occani rariùs.

42. Longifructus. Fronde nervo medio donata, plana dichotoma integra vesiculis destituta, apicibus oblongis tunidiusculis tuberculatis. - In Oceano rariùs.

43. Serratus. Fronde nervo medio donata, plana dichotona serrato-dentata, apicibus planis tuberculatis obtusis. - In maribus frequens.

44. Volubilis. Fronde avenia spiraliter torta ramosa dentata, interdim in appendices ramosissimas latere producta. - In Mediterraneo mari.

45. Canaliculatus. Fronde arenia hine canaliculata dichotoma lineari, apicibus oblongis obtusis tuberculatis. - In Oceano.

46. Siliquosus. Fronde .compressa ranıosa, ramis distichis alternis oblongis, vesicnlis pedunculatis oblongis articulato-nodosis mucronatis. - In Oceano.

47. Nodosus. Fronde compressa subdichotoma, ramis distichis obnvatis integerrimis, vesiculis innatis solitariis fronde latioribus. - In Occauo.

48. Cespilnsus. Fronde filiformi subenmpressa ramosa, apicibus clavatis fructiferis. - Fucus clavatus, L'Amou. t. 22. f. 1. 2. Cornferva dilatatia, Roth. cat. 2. p. 194.-Ad rupes et muros in Oceano.

49. Limbricalis. Fronde filiforni dichotoma ramosa, ramis subrqualibus acuminatis, angulis ramificationum acutis.-in Oceano. 
5o. Bifurcatus. Fronde filiformi dichotoma, ramis inargualibas obtusis apice tuberculatis, angulis ramificationum obtusis. - In Oceano propè hirivatem (Brest).

5r. Loreus. Fronde compressa dichotoma integerrima acuta lavi, versis apicem utrinque tuberculata. - ln Oceano.

52. Fiúrosus. Frende filiformi ramosissima, ramis compressis dentatis, vesiculis ovoideis innatis quasi catenatis. - In Uceano.

53. Erionides. Fronde filiforni ramosissima, ramis subulatis terminalibus confertis arctè imbricatis basi uberculiferis. - In Oceano et mari Mediterraneo.

54. Sedoides. Fronde filiformi ramosissima, ramis geminatis subulatis, Lasi interua biglandulosis. - In mari Mediterraneo.

55. Barbatus. Fronde filiformi ramosissima, ramulis extremis apice tuberculatis, tuberculis congestis foliolo subulato terminatis. In Oceano.

56. Abmtunifnlius. Fronde filiformi compressa pinnata, ramulis extremis vesiculosis, vesicnlis in foliola nultipartita abeuntibus. In Oceano et mari Mediterraneo.

57. Discors. Fronde subcompressa pinnato-ramosissima, ramis infer is foliaceis lineari-lancerlatis dentatis, superis multipartitis, laciniis filiformibus sæè tuberculatis. - In nari Monspeliensi.

58. Natnns. Caule tereti ramosissimo, foliis lanceolatis serratis, vesiculis globosis pedunculatis. - In Uceano et mari Nediterraneo.

59. Uvarins. Cauls filiformi ramoso, foliis confertis ovatis fornicatis. - In mari Mediterraneo.

$59^{*}$. Pygmoeus. Fronde compressa dichotoma ramosa., ramis apice dilatatis, tuberculis globosis termialibas. - Lightf. t. 3 ?. Engl. Bot. t. 1332. Fucus lichenoides, Trüs. Lian. 3. p. 192.non Desf. - In Oceano.

\section{II. Tuberculis fructiferis lateralibus.}

6o. Hypoglossum. Caule alato ramoso, foliis lineari-lanceolatis planis integerrimis proliferis. - In Oceano.

61. Sanguineus. Cauld tereti ramoso, foliis simplicibus ovato-oblongis obtusis undulatis integerrimis. - In Oceano:

62. Vermicularis. Canle tereti ramoso tenero, ramis dichotomis, foljis cylindricis utrinquè attenuatis, superioribus confertis. - In Oceano et mari Meditcrianeo.

63. Laceratus. Fronde membranacea tenuissima avenia varic ramosa, integra aut ciliato-elentata, tuberculis seminiferis marginalibus aut innatis. - Ulva crispa, Thor. Chl. 4 f 6 . Fusus granateus, L'Anıou. Diss. t. 33. f. 3.4. - Jn Oceano.

$63^{*}$. Ciliatus. Fronde submembranacea avenia ramosa basi attcnuata, ramis lanccolatis acutis ciliatis, ciliis tuberculos globosos laterales gerentibus. - Ulva ciliata, Fl. fr. n. 29. Observationes nuperrima in Engl. Bot.t. 1069 . edita edoeent hanc stirpem fucis non ulvis adnumerandam. - In Occano.

$63^{* *}$. Torvegicus. Fronde subcoriacea avenia plana dichotoma 
ohtusa, tuberculis semiglobosis exsertis in disco sparsis. - Engl. Bot. t. 1080. - In Oceano Armuracia.

6.1. Alatus. Fionde nerro medio donata plana membranacea tenerrima ramosa subdichotoma. - In Oceano.

65. Nervosus. Fronde nervo medio donata plana subcoriacea ramosa, ramis elongatis linearibus margine undulatis. - In mari Nediterranco.

66. Prolifer. Fronde plana avenia submembranacea dichotoma, ramis proliferis lincaribus, ramulis apice dilatatis bifidis, laciniis acutiusculis. - In Oceano.

67. Hybridus. Fronde tereti ramosa ramis teretibus sparsis ramosis, tuberculis in caule ramisve precipuis sparsis, sporangiis pyriformibus. - In Oceano ad rupem Calvados.

65. Pinnatifulus. Fronde compressa cartilaginea ramosa, ramis patentibus subduplicato-pinnatifidis, ramulis obtusis callosis tuberculos gerentibus, sporangiis pyriformibus. - In Oceano.

69. Osnutuda. Fronde compressa carnosa ramosa, ramis patentibus subduplicato-pinnatifidis, ramulis obtusissimis callosis. - In mari Mediterraneo.

7o. Plocamium. Fronde compressa subcarlilaginea ramosissima, ramulis subulatis secundis, tuherculis globosis subscssilibus. - In Oceano et mari Mediterraneo.

7x. Plumosus. Fronde compressa subcartilaginea ramosissima, ramis suprà-decomposito-pinnatis, ramulis oppositis, tuberculis globosis pedunculatis. - In Oceano.

72. Obcusus. Fronde compressa cartilaginea ramósissima, ramis ramulisque subeppositis erectiusculis obtusissimis truncatis. - In Oceano et mari Mediterraneo.

73. Hypnoiles. Fronde compressa cartilaginea bipinnata, pinnulis capillaribus pectinatim dispositis obtusinseulis. - In mari Nlediterraneo.

7 - Corneus. Fronde compressa cartilaginca ramosissima, ramis latioribus alternis, ramulis oppositis divaricato-adscendentibus olstnsis. - In Oceano et mari Mlediterraneo.

75. Comnopifolius. Fronde compressa cartilaginca ramosissima, ramulis obtusis multificlis subconfertis, tuberculis globosis pedunculatis sessilibusque. - In Oceano.

56. Gigariinus. Fronde conıpressa cartilaginea dichotoma ramosa, ramis requalibus acutis spinoso-dentatis, tuberculis globosis latcralibus. - In Oceano.

7.. Fimbrintus. Fronde compressa cartilaginea ramosissima, raunulis a pice multifidis, extrenis tereti-subulatis, punetis fructificationis per totam frondis superficiem inniersis. - In mari Mediterranco prope Cette. $t$.

78. Aculealus. Fronde subcompressa cartilaginea, ramis elongatis compressis acntis, ramulis subulatis brevibus distantibus erectise - In Oceano. 
F $U \subset \boldsymbol{U} \boldsymbol{S}$.

79. Ligulalus. Fronde plana avenia lerbacea snhtriplieain-pinnata, ramis ramulisque distichis, xamulis lineari-lanceolatis spiunsodentutis. - In Uceano.

So. Implexus. Fronde compressa cartilaginea pluries diclıotoma, ramis numerosis implexis acutis rigidulis. - In mari Mediceramen.

$80^{*}$. Amplhibius. Frbule filiformi ramosissima, ramis alternis, ramulis capillaribus apice involntis tuberculatis. - ' 'ians. Linu. 3. p. $22 \%$. Slackh. Ner. t. 14. -In Oceano Armoraciæ.

8r. Virilis. Fronde filiformi ramosissima confervoirle, ramis ramulisque iunumeris capillaribus inordinatis. - In Oceano super fucos majores, propè Dieppan.

82. Arlurscula. Fronde tereti albilla ereeta tenera, ramis nnmerosis simplicilus licrbace is teretibus, inferioribus longioribus. - In Oceano ad rupem. Calvalos.

$\mathrm{S}_{2}{ }^{*}$. Asparagniries. Fronde filiformi ramosissima, tuberculis globosis perlunenlatis, ramulis subulato-setaceis alternatinn opunsitis. - Trans. Linn. 2. p. 29. t 6. Engl. Bot. t. 57 x. - In Occano propi Legionem (Saint-Pol de Léon).

$8_{2}^{* *}$. Wisghii. Fronile filiforni tenera ramosissima , ranulis numerosis confretis brevissimis, aliis sterilibus, aliis tuberculo lanceolato terminatis. - Turn. Trans. Linn. 6. 1. 135. t. 10. Engl. Bot. t. $1165 .-11$ ab. cun priori.

83. Frstigialus. Fronde filiformi dichntoma ramosiosima, ramis fastigiatis aqualibus obtusis, angulis ramificationum subectis. In Occano.

8f. Purpuroscens. Fronde filiformi ramosissima, ramulis setaccis sparsis, tuberculis subrotundis innatis. - Incus capillaceus, Esp. fuc. t. 35. - In Occano.

$84^{*}$. Kaliformis. Fronde fliformi subgelatinosa tuhulosa ramosissima, ramis sparsis, ramulis subrerticillatis obtusinsculis. - Trans. Limn. 3. p. 206: t. 18. Engl. Bot. t. 6ío. L'Amou. Diss. t. 29. In Occano Armosacixe propè Legioncm.

8 f $^{* *}$. Dasyphyllus. Canle tereti ramoso, ranis fliformihns subsimplicibus, ramulis cylindricis nbtusis basi attenuatis sparsis. - Trans. Linn. 2. p. 239 . 1. 23. f. 1-3. Engl. Bot. t. 847. - In Uccant et mari Mediterraineo.

85. Verrucosus. Frnnde filiformi carnosa ramosa, ramis sparsis acutis, tuberculis lateralibus hemisplæreicis. - In Oceano et mari Mediterraneo.

$85^{*}$. Tenuissimus. Fronde fliformi ramnsissima, ramis omnibus capillaribus alternis, ramulis acutis tuberenlatis.-Trans. Linn. 3. p.215. t. 19. - In Occano Ai moracix:

86. Confervoides. Fronde filiformi ramosa, ramis snbdistichis subsimplicibus setaccis, tuberculis lateralibus semi - globosis. - In Oceano.

82. Plicatus. Fronde filiformi dichotoma ramosissima impiexa, 
ranulis subsecundis, tuberculis sparsis lateralibus sessilibus. In Oceano et mari Mediterraneo.

88. Helminthocortos. Fronde filiformi ramosa cæspitosa cornea, ramis acutis ad apicen subarticulatis. - Latourr. Journ. Plıys, 20. t. I. Jaum. Pl. fr. t. 4. f. 1. 2. - In mari Mediterraneo ad littora Corsicæ.

$$
\text { 5. C } \mathbf{E} \mathbb{R} \text { A } \mathbf{I} U \mathbf{M} \text {. }
$$

Stirpes filamentosæ marinæ simplices aut ramosæ, dissepimentis transversalibus nodoso-articulatx; tubercula polysperma subglobosa lateralia aut terminalia.

\section{I. Ranuulis circà caulem verticillatis aut confertissimis.}

S9. Spnngiosum. Ramulis confertissimis imbricatis simplicibus fuscoviridibus. - In Occano.

9o. Verticillatum. Ramulis verticillatis confertis internodio longioribus subramosis fusco-virescentibus. - In Oceano et mari Mediterraneo.

91. Equisetifolium. Ramulis verticillatis dichotomis internodio longioribus purpureis. - In Oceano.

92. Simplicifilum. Ramulis verticillatis simplicibus confertis internodio longioribus purpureis. - In Oceano propè rupem Calvados.

93. Casuarince. Ramulis verticillatis simplicibus distantibus patulis purpurcis. - In Oceano cum priori.

94. Cancellatum. Ramulis alternis confertis imbricatis multipartitodigitatis purpurascentibns. - In mari Mediterraneo.

\section{פ. II. Stirpilus ramosis aut dichotomis.}

95. Coccineum. Caule ramoso tereti setulis numerosis hirsuto, ranis alternis compressis dupliciter pinnatis, ramulis oppositis altcrnatim simplicibus et ramosis, tuberculis ovatis subpedicellatis. - In Occano.

$9^{5}$. Roseum. Caulibus ramosissimis tenerrimis cæspitosis, ramulis flocculosis alternis acutissimis, articulis utrinque compressis, tuberculis lateralibus secundis obovatis subsessilibus. - Roth. Cat. 2 . p. 182. Conferva rosea. Engl. Bot. t. 966. - In Oceano propè rupem Calvados.

$9^{5^{* *}}$. Byssnides. Purpurascens, caule subquadripinnata tenerrima vix articulata, ramis alternis elongatis, ramulis floccosis, tuberculis globosis sessilibus. - Fucus byssoides, Trans. Linn. 3. p. 229. Conferva byssoides, Engl. Bot. 1. 5 \% . - In Oceano.

96. Scoptrium. Fusco-olivaceum cartilagineum ramosissimum, ramis pinnatis, ramulis capillaribns strictis, tuberculis ovatis terminalibus. - In Oceano et mari Mecliterranco.

97. Agagropilum. Atrovirens, filanentis ad genicula contractis dichotomo-ramosis è centru eonfertis globum constituentibus. - In mari Mediterranco.

38. Catenatum. E viridi rufescens, cæspitosum, ramosum, articulis 
oblongo-cylindricis utrinqué contractis, siccitate alternatim contraetis et filiformibus. - In mari Mediterraneo.

99. Sericeum. Pallidè-virescens sericeum, filamentis virgatis ramnsissimis, articulis elongatis utrinque contractis medio tumidis. - In Oceano et mari Mediterraneo.

100. Rupestre. Virescens, filamentis exspitosis pluriès dichotonis, articulis cylindricis, siceitate alternatim conıpressis. - In Oceano.

1от. Incurvum. Nigrescens cartilagineum rauosum, ramis ultimis (filicum juniormu more) involutis vix articulatis. - In Oceano.

102. Penicillatum. Purpureum tenue ramosum, ramulis terminalibus aut lateralibus loco tubereuli filorum fasciculum gerentibus. - In Oceano.

103. Pediccllatum. Purpureum elongatnm ramosum, tuberculis globosis lateralibus pedicellatis. - In Occano.

so ́. Elongatum. Purpureum ramosum, ramis elongatis subsimplicibus distantibus acutis, genienlis subobscuris, articulis cylindricis, tuberculis lateralibus sessilibus. - In Oceano.

105. Fucoides. Fusco-purpureum cartilagineum ramosissimun, articulis vix latitudine longioribus, ramis nltimis capillaribus, tuberculis sessilibus lateralibus. - In Oceano.

10G. Polymorphum. Fusco-nigrescens cartilagineum ramosissimum, ramis bifurcatis divergentibus, geniculis obscuris, tuberculis lateralibus sessilibus. - In Oceano, super fucum nodosum súpiìs parasiticum.

107. Nodulosun. Purpureum ranosum tenue, ramis apice bifurcatis acutis divergentibus, tuberculis globosis ad axillas dichotoniæ sessilibus. - In Oceano.

108. Axillare. Purpureum ramosum pumilum teme, ramis apice bifurcatis acutis divergentibus siccitate albo et fusco annulatis, tuberculis globosis ad axillas dichotomix sessilibus. - In mari Meditcraneo.

109. Gracile. Fusco-purpurcum tenue subrigidulnm pluriès dichotomum, ramis acutis divergentibus, articulis obscuris. - In Oceano. $t$

110. Forcipatum. Purpurascens tenue pluriès dichotomum, ramis ultimis apice forcipatis seu introrsìm involutis. - In Oceano et mari Mediterraneo.

\section{III. Filamentis simplicibus.}

111. Filume. Filamento olivaceo-nigrescente cartilagineo longissimo vix articulato. - In Oceano.

112. Linum. Filis viridibus elongatis geniculatis subrigidis, articnlis cylindricis. - In Oceani et maris Mediterranei oris subpaludosis.

113. Capillare. Filis viridibus tenuissimis elongatis geniculatis subrectis, articulis oblongis. - In Oceano et mari Mcditerraneo.

114. Gromeratum. Filis viridibus tennissimis clongatis geniculatis crispato-implexis, articulis oblongis. - In Occano.: 


\section{D I $N$ T O M A.}

Plantre psendo-parasitic neulo nudo vix conspicure, filamentis. simplicibus articulatis, articulis in arlulta plantat transversin sectis.

15. Rigidum. Tilanentis brevibus, rigidis. - In Oceano.

16. Flocculosum. Filamentis ienuissimis, mollibus. - In Occano.

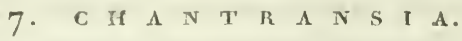

Filamenta ramosa, dissepimentis instructa; semina minutissima, intrà filamenta recondita, in quoque articulo numerosa.

117. Torulosa. E vireseente-nigrescens, filamentis subsimplicibus, articulis ovatis medio umidis. - In fluviis.

18. Fluviatilis. Viridi-nigrescens, filamentis subdirisis cartilagineis, articulis teretibus, geniculis tumiclis. - In aquæ ductibus molinorum.

110. Dichotoma. Viridi-nigrescens, filamentis dichotomis, articulis obennicis. - Conferva nodulosa. Thor. Chor. 4if. - In rivis, lapidibus adharens.

120. Alra. Nigrescens, filamentis ramosis tennissimis, articulis longis teretibus, genicnlis subtnmidis ciliolatis. - In rivis.

12r. Glomerata. Virescens, filamentis multoties ramosis, articulis oblongis medio tmmidulis. - In aquis puris, lapidibus adiærens.

122. Rivularis. Virescens, filamentis longissimis hinc atque hine incrassatis, loculb longitudine latitudinem pluriès exceriente. In rivis.

12.3. Crispata. Virescens, filamentis intricatis, surculis hamatis. Cum priori.

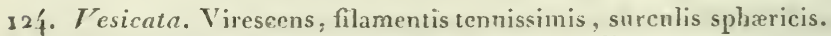
- Foliis caulibusque plantarum aquaticarum adhærens.

$$
\text { 8. } \mathrm{C} \text { O } \mathrm{I} \text { F E } \mathrm{R} \text { V A. }
$$

Filamenta simplicia, dissepimentis instructa, interdum ope tubuli inter se conjuncta, materia viridi, munc spiraliter, nunc bistellatim, nunc sparsiun disposita intra loculos farcta. Semina in quoque loculo solitaria.

\section{S. I. Materia viridis spiraliter disposita.}

125. Jugalis. Spiris pluribus intricatis, loculi longitudine latitudinem parum excerlente, filamentis longioribus. - In aquis stagnantibus, tempore vernali.

126. Porticalis. Spira triplici porticali, loculi longitudine bis latiturlinesn xquante. - In ayis frequens.

127. Condensata. Spira duplici, loculi longitudine latitudinem bis aquante, seminibus sphæricis. - In Rhodano lapidibus inherens.

128. Inflata. Spiris laxis inflatis, loculi longiturline latitudineır ter ircuante, seminibus ovatis. - In fossis.

129. Adnata. Spiris intricatis, lnculi longitudine latitndínem bis :quante, seminibus ovatis. - In oris lacûs Lemani. 
330. Finngata. Spiris clongatis, gramulis interstinctis, Ioculi Jongitudine latitudinem sexies xquante. - In aquis circì Gencvam.

5. II. Materia viridis in Iuplicem stcllam in quoque loculos disposilı.

31. Gracilis. Stellis vix distinctis, filamentis strictis, loculi longitudine latitudinem quater xpante, seminibus sphxricis miuntis. - In fossis.

132. Lutescens. Stella obliterata duplici, locnli Jongitudine latitndinem bis xeruante, labitu pingui nitente. - In fossis frequentissime.

133. Decussata. Stellis vix distinctis, loculi longitudine latitudinen quater equante, filamentis frequenter decussatis. - In paIndibus.

13i. Stellina. Stella dnplici sexradiata, Ineuli Iongitudine latitudinem bis aequante, seninibus ovatis. - In aquis stagnantibus.

135. Cruriata. Stella duplici distincta quadriradiata, loculi longitudine latitudinem bis sequante, seminibus splıricis. - In fossis.

136. Pectinata. Pectine duplici tridentato, loculi longitudine latitudinem parùm excedente, seminibus sphrericis subhispidis. - In fossis circì Genevam.

\section{〕. III. Tubn intùs materia viridi repleto.}

137. Genuflexa. E viridi lutescens lævis, filamentis angulatis, loculi longitudine latitudinem ter aquante. - In fossis, admodum frequens.

135. Serpentina. Filamentis revolutis, loculi longitudine latitudinem bis xquante. - In aquis stagnantilous.

\section{§. IV. Haud planè notre.}

139. Parasitica. Filamentis tenuissimis, hinc indè prolifero-ramosis, granulis in quoque loculo solitariis. - Parasitica in cliantransia glomerata.

14o. Floccosa. Filamentis longissimis tenuissimis, loculi longitudinc latitudinem vix excedente. - In aquis viris et tranquillis.

$$
\text { 9. B A T R A C H O S P E R M U M. }
$$

Filamenta muco gelatinoso obtecta, ramosa, ramis filo hyalino plus nainusve clongato terminatis; annulis ovatis, solidis, ad extremùm progrediendo decrescentibus. Corpusculis hirtis (plantularum rudimentis) inter ramos sparsis.

1. o $^{*}$. Hemispharicum. Subglohosum, lentis magnitudine, atroviride, contextu carnoso denso. - In lapidibus ()ceani.

I fo $^{* *}$. Hrematites. Subghobosum, atro-viride, contextu carnoso intùs zonato. - Conf. hæmatites, Ram. ined. - Ad rupes graniticas madidis Pyræneorum.

1 í. Intricatum. Subglolonsum, filis implexis ramosis. $-\Lambda \mathrm{d}$ fontes. 
1. 2. Fascicalalum. Filis approximatis, simplicibas, summitate ramosis. - In aquis, lapidibus inhærens.

143. Plumosum. Truncis elongatis, ramulis cauli approximatis. In aquis vivis et fontibus.

słfi. Glomeratum. Ramosum, ramulis brevibus, fasciculatis, divergentibus. - In lapidibns rivorum.

145. Woniliforne. Ramosum, ramulis verticillato-fasciculatis. Ubiquè, rivorum lapidibus adlıærens.

146. Ilispidum. Ramosum, ramis magnitudine truncum aquantibus, ramulis pilifornibus undiquè obtectis. - In lapidibus fluviornm.

$146^{*}$. Myurus. 'Trunco elongato simplici, ramulis pilifornibus obtecto. - B. myosurus, Ducl. Essai. p. -6. - In aquis montium Gebenuensium.

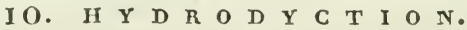

Habitus saceatus, ferè clansus, xetiformis, interstitiis seu areolis polygonis.

147. Pentagonum. Areolis pentagonis. - In aquis stagnantibus liberè natans.

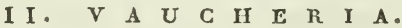

Filamenta herbacea, dissepimentis planè destituta. Semina externa, primò tubo adfixa, tandem caducá.

\section{I. Seminibus pedunculatis.}

1.18. Multicornis. Pedunculis ramosis, vanis alternatim sterilibus et seminiferis. - In aquis.

149. Racemesa. Pedunculis ramosis, ramis omıribus seminiferis, supremo exceptn. - In fossis vernali tempore.

15n. Cruciata. Pedunenlis ramosis, ramis duobus inferis seminiferis tribus superis sterilibus. - In aquis stagnantibus.

15ı. Geminata. Pedunculis tricornibus, ramo medio sterili. - In aquis stagnantibus.

352. Terrestris. Pednnculis simplicibus, seminibus solitariis complanatis. - Ar terram locis humidis.

153. Haneata. Pedunculis simplicibus, seminibus solitariis ovatis.In fossis praludosis.

\section{II. Seminibus sessilibus.}

15\%. Sessilis. Seminibus sparsis binis aut solitariis oblongis. - In aquis stagnantibus.

155. Cespitosa. Seminibus terminalibus duobus. - In aquis puris fontitum.

156. Ovata. Seminibus subterminjubus solitariis. - In rivis tempore liyemali.

S. III. Species nondìn ritè cognita.

157. Clavata. Filamentis apice tumidis. - In aquis puris. 
158. ATammiformis. Filaneutis ex centro communi radiantibus. In saxis humidis.

55). Appendiculata. Filamentis solidis, hine inde appendiculatis.

- In eratcribus aqux salsà circà Ledonem Salinarium ( Lons-leSaulnier ).

160. Infusionum. Filamentis floceosis, ocnlo armato vix conspicnis, materia gelatinosa immixtis. - In aqua pura aeri libero exposita.

\section{O R D O I I. I U N G I.}

Plantx ferè nunquam aquaticx, nee virides, carnosx suberosst aut mucida, forma et colore varix, gazim oxygenimn murquam emittentes. Ciupsule (ant seminis) nunc externie, munc iu ipsa flanta (peridio) inclusa, in licuido pulposo rariter immerse.

\section{T R I B U S I. G Y M N O C A R P I I. \\ + Fungifilamentosi.}

\section{2. B I S S U S.}

Fungifilamentosi, simplices aut sæpiùs ramosi, nunc laxi, nunc intertexti ei fere pannum xunulantes. Scmina ignota.

161. Parietina. Flavescens ant alba, tenera, parietibus adpressa,

filamentis è centro radiantibus, in ramos tennissimos innumeros divisis. - In domis ad parictes.

162. Candida. Candida, tenera, apice subplumoso dilatato. In foliis et ramis deciduis.

163. Flavescens. Flavescens, tenera, adpressa, ramis pelliculam tenuem ferè constituentibus. - In foliis et ramis decidnis.

16.. Elongata. Alba, filamentis tenuissimis in fasciculos subcylindricos ramosos contextis. - In cryptis.

165. Gigantea. Albida, filamentis tennissimis in immensum pannum fomitis æmulum contextis. - In arbornm fissuris internis.

165*. Pinastri. Nigrescens, filamentis intertextis lanam floccosam referentibus. - Ad ramulos abietinos diu nive tectos. Schleicher.

166. Cmptarum. Latè expansa mollissima nigra, filis intertextis pannum referentibus. - Ad dolia in cryptis.

$166^{*}$. Rupestris. Nigrescens, filamentis subgelatinosis intertextis pannum referentibus. - Ad rupes.

167. Intertexla. Rubiginosa, filamentis intricatis hinc inde tuherculis rotundatis inspersis. - In subterraneis Observatorii Parisiensis.

68. Aurantiaca. Flavo-aurantia cespitosa nitida, filis subriginis divergentibus. - Byssus barbata. Engl. Bot.t. zor. - In locis obs curis et humiclis.

3 9. Aurea. Primò aurea, demìm incana, cespitosa subconfluens pulverulenta. - Ad lapides presertim calcarios.

yo. liubra. Cinnabarina filamentis laxis. - In ligno semi putrido. 


\section{3. M O $\mathrm{N}$ I $\mathrm{L}$ I A.}

Stipitata aut effusa, byssoidea moniliformia seu articulata cæspitosa. Stipites apice filamenta gerentes.

17\%. Glauca. Stipite simplici, filimentis innumeris radiato-capi-

tatis. - In fructibus putridis frequens, cespitulos efformans.

172. Digitala. Stipite simplici, filamentis paucis digitatis. - In variis substantiis putrescentibus.

I 3. Racemosa. Stipite ramoso. - Junio mense in viridariis occurrit.

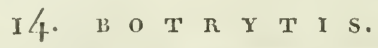

Stipites erecti, fruticnlosi, gracillini, dichotomi seminibus inter se non coalitis, in raccmum conglomeratis.

\section{j. I. Stipitibus erectis ramosis.}

I活. Dendroides. Ex albo fucescens cespitosa, stipitibus ramosissimis, arborcis; seminibus subovato-elongatis. - In fungis et substantiis semi-putridis.

175. Racemosa. Cinerca congesta latè effusa ramosa. - In oleribus putrescentibus.

176. Lignifraga. Ex albo viridis, stipitibus tenuissimis," seminibuz minntissimis, subrotundis. - In cortice betulæ albæ.

\section{G. II. Fibrillis prostratis stipites erectos emittentibus.}

57\%. Umbellata. Ex albo nigricans, stipitibus ad apicem umbellatim livisis. - In fructibns saccharo concoctis.

т 7 . Rosea. Ex albo miniacea, sipitil,ns simplicibus, scminibus ovatis paucissiuis in capitulum confertis. - In arborum corticibus, presertim alni.

I79. Glomerulosa. Ex cinereo rufescens, seminibus numerosis subrotunlo-ovatis glomeratim confertis. - In variis corporibus, præscrim charta madida.

$$
\text { I5. I I G E R I T A. }
$$

Funguli acaules, granuliformes, capsulis sphæricis, sparsis, subfarinaceis. Differt à botrytibus moniliisque habitu glabro et carnoso.

18o. Punctiformis. Minima, hernisphærica, cœruleo-nigrescens. In radicibus immersis hyacinthi oricutalis.

I8r. Aurantia. Crustacea, aurantiaco-flavescens, seminibns minutissimis. - In cortice ligni mortui.

382. Crustacea. Crustaceo-subcoriacea, ex albo sulphurca, demùm rubra, stipitibus vix perspicuis. - Ad superficien casei.

183. Fpixylon. Pulvinata, ex cinereo nigricans, intùs filamentosa.

- In ligno putrido.

$$
\text { I6. C }
$$

Filamenta ramosa byssoidea, hinc indè semina pulveracea fer⿳亠 globulosa gerentia. 
184. Purcinioides. Gregaria nigra, filanentis ramosis, scminibus angulatis,

$$
\text { 17. E I: I IN E U IK. }
$$

Tubi epiphylli sapiins cylindrici alias turbinati, apice truncati, grmmosi, in cespitulum conghtomerati.

15i. Acerinum. Hy poplyhinm depressum latiuscuhum rufo-fuscum (prim) grumosum pallidun ). - In foliis aceris delapsis.

3 S6. Vilis. Hypophyllum maculosum irregulare albo-roseum dein rubiginosun. - In foliis vitis viniferd.

I $86^{*}$. Faginenm. Hypophyllum, subimmersum compactum subellipticun rufescens vel puipureum. - In foliis figincis.

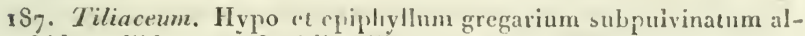
bido-pallitum. - In folis tilic enropea.

$187^{+}$. Alneum. Hypophylinm pulvinatum grumosun fulvo-ferrugineum. - In foliis alni glatinosæ.

$187^{* *}$. Aureum. Hypo et epiphyllum subimmersum latiusculum sericcum aureum. - In folis adhuc viridibus populi nigræereseit.

з $87^{* * *}$. Populinum. Hypopliyllum cupulare immersum subgrumnsum spadiceum (primò subpurpurascens). - In fol. pop. tremulx. $187^{* * *}$. Belula. Epi et hypophyllum grumosum, emersum, roseum vel vinosum. - In fol. betul. albz.

$187^{* * * * *}$. Ilicinum. Hypophyllum agglomeratum, tomentosum, aurantiacum. - In fol. quercûs ilicis.

18S. Articulatum. Minutum nigrescens fasciculatum, setulis divergentibus subarticulatis. - In caulibus lerbarum exsiccatis.

$$
17^{*} \text {. S T T I L }
$$

Fungillimucoriformes, stipitati. Capitulum subrotundum solidum, primò subaquosum, aut subgelatinosum, maturescens ut plurimum opacum turbidum.

${ }_{1} S^{*}$. Rigidum. Stipite rigido persistente nigro, capitulo primìm aquoso lacteo, demúm compacto grisco deciduo. - Ad truncos putrescentes rere.

$188^{* *}$. Nigrum. Totum nigrnm durum, capitulo etiam maturo persistente. - In cortice juniperi.

\section{† F Fungi hymenio lavi nec in pulpam abcunte.}

I 8. II $\quad$ E

Receptaculum stipitatum capiluliforme convexo-hemisphæricum urinquè læve suprà seminiferum.

189. Agariciformis. Albirlun , stipite pleno aciculari, pileo tenui convexo orbiculato. - In ligno putrido.

19o. Fimetarium. Amone rubum, stipite gracillimo, capitulo planinsculo subaugulato. - In fino raccino exsiecato. 


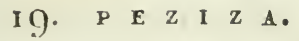

Receptaculum hemisplıxricum concavum vel tumidulum, supernè in diseo lavi semina sub pulreris forma abeuntia gerens.

๑. I. Pezizce coriacea.

rgr. Coriacea. Cinerea, infundibuliformis, stipite tortuoso. - In fimo cervino equino et asinino.

๑. II. Peziza carnosce.

* Sessiles.

392. Aquatica. Coccinea, sessilis, plana vel subconvexa, margine nullo. - In trabibus inundatis.

193. Cinerea. Gregaria parva cinerea pallidare subtremellosa : margine suberecto albidiore. - Ad truncos putrescentes.

э9ł. Patellaria. Gregaria niggra applanata subcoriacea distinctè marginata. - In ligno decorticato.

195. Lenticularis. Subeonvexa adpressa lævis læte flava, stipite vix ullo papillæformi nigrescente. - In fagetis ad truncos.

195 $5^{*}$. Citrina. Conferta tota citrina, stipitc crasso brevi obconico.Peziza citrina. Pers. Syn. 663. Octospora citrina. Hedw. Si. cr. 2. t. 8. f. B. - In ligno mortuo.

I9f. Callosa. Corulescens scutellata subvillosa intùs lævis, margine calloso. - In ligno putrido fructibusque coriaceis.

197. Aranensa. Exigna tenuis fragilis aurantio-miniacea turbinata, subtus fibrillis intricatis operta, cratera complanato-concava. In sylvis umbrosis et in hortis.

$137^{*}$. Nigrella. Hemisplırica concava sessilis atra, extùs byssina tomentosa, intis lævis. - Peziza nigrella. Pers. Syn.6 6 8. - In ligno putrido.

I95. Omphalndes. Gregaria sessilis fragilis glabra aurantiaca, facie inferua subhirsuta, suprema subdepressa umbilicata. - Ad terram.

r99. Scutellata. Plana rubescens, margine convexo pilosn. - In candicibus ad terram.

200. Ciliata. Fulva concava externè lævis, margine ciliato. - In fimo lumano et bovino.

20r. Crinita. Exigua tenuis firma sessilis, subtùs cinerea ciliata, cupula subglobosa concava, intùs purpureo-rubra. - In liguo semi-putrido.

202. Carnosa. Urceolata sanguinca, tomento cano extùs et intùs obtecta. - In ligno semi-putridn.

203. Chrysocoma. Sessilis glahra utrinquè lævis, primò urccolata dein crateriformis. - Gregatin in ligno putrido.

20\%. Stercoraria. Gregaria subconcava fusca aut virescens, externé furfuracea. - In fino.

205. Granulosa. Exigua gregariæ anrantio-rubra planiuscula, subtùs granuloso-rugosa. - In fimo vaccino. 
206. Bicolor. Sparsa subsessilis, extits villosa candida, disco aurantio-coccineo. - In ranis exsicciatis.

207. Corticulis. Gregaria sessilis subrotunda cineren-alloida, extus strigoso-hirta. - Licequens ad contices trunconnu cásorum.

208. Papillaris. Sessilis, eera an instar translucilla, superficis: infera papilis lanata, superiore urecolata dein cratesilormi. Is: lignu purido.

209. Solenia. Temnissima tululiformis glabra candida. - In ligno puriclo.

210. Imberbis. Omninò glabra, alba aut cincrea, sessilis dein turbinatil, receptaculo lijpocraterilormi demim plano. - In ligno autiquo.

211. Lacten. Minutissima alba turbinata, facie infera imprimis margine hirsuta, supenuc concava. - In ligno ioliisque mortuis.

212. Calicirides. Śtipite tenui, disco rotundato plano vel subconvexo, facie superiore levi glabra, stipite facieque infera tuberculoso-scabris. - In trunco arborum cavarmu. - An hujus gencris?

213. Cyuthoidea. Gregaria parva albida aut pallida, cupula cyathilormi itnerusi subtenui, stipite longo deorsum subcrassiore. - In caulibus horbarum semi-putridis.

2rf́. Fructigena. Sparsa aut gregaria, cupula subinfundibuliformi prims pallente dein rnfescente, stipite longo subflexwoso deorsum attenuato. - In ramulis deciduis et ad glandes quereinos.

215. Curnata. Parva stipitata ex allido pallescens, margine dentibus setaceis crectis. - In caulibus plantarum.

216. Clandestina. Stipitata turbinata tomentosa obscurè cinerea, ore connivente. - In ramis aridis.

$216^{*}$. Poriceformis. Crustuceo-efiusa conferta subtomentosa cinerea. Pers. Syn. 656.-Peculiaris hæc species, novum polius geuus format. - In ligno humido.

$216^{* *}$. Sanguinea. Cupulis minutissimis nigris glabris, tomento sangnineo iusidentibus. Pers. Syn. 65̃. - In truneis et assulis Jigneis.

217. Subularis. Fragilis lateritia, stipite tenui elongato, receptaculo hypocrateriforni. - In senumibus semi-putridis helianti annui.

2I8. Echinopllila. Magna crassiusenla firma glabra subfuliginea, in stipitem erassum desinens, cratera scutellato-cupulari ferruginea. - Iu involucris castanex vulgaris.

\section{f. III. Peziza consiülentiam cerce referentes.}

219. Acetabu!um. Fusco-terrea cyathiformis stipitata, cupula extùs angulata venis ramosis. - Ad terram in umbrosis.

$219^{*}$. Badia. Snbacaulis integra, margine subinvoluta obscurè fusca, externè subolivacea. - In sylvis frondosis ad terrani.

220. Tuberosa. Cupula subparra infundibuliformi spadicea aut 
balia, stipite longissimo, radicis tubere difiormi. - Crescit ad terram in nemorosis.

321. Rupulum. Tenuis fragilis glabra pallida dein subsparlicea, in stipitem longum radiculis instructum desinens, cratera cupulari. - Humo profundè infixa occurrit.

222. Stipitata. Maxima multiformis subtus tomentosa, supernè hypocrateritormis, stipite longo pleno nune lævi, nunc sulcato. Ad territil.

223. Epilendra. Stipitata submagna turbinata ant infundibuliformis, intus coccinca, externe albida, margine ut plurimium crenato. - Ad ramos mortuos nnnc liberos nunc terra tectos.

224. Coccinea. Acaulis magna cxspitosa dimidiato-flexuosa, coccineo-aurantia, externè albida. - Ad terram secus vias et in pascuis incunte auturuno.

225. Eanuginosa. Sessilis, infernè rubiginosa linata, supernè ex albo-grisea, urceolata dein hypocrateritormis. - Id terran locis humidis.

226. Crennta. Cinerea, primùm sessilis, dein brevi stipitata, hypocrateriformis, margine dissecto. - Ad terram in fossis humidis.

227. Fycoperdnides. Magna subcæspitosa sessilis glabra urceolata, cratera è vesiculosa marsupiiforma, margine crenato. - In fimetis et ad terran.

228. Labellum. Sessilis lata labelliformis subtìs villoso-tomentosa, cratera suburceolata hypocrateriformi tandem plana, margine arancoso. - Ad terram.

22y. Cochleata. Acaulis cæspitosa auriformis contorta, externè albida, intùs pallescente-fuliginea, basi sæpiùs perforata. - Ad terram in sylvaticis.

\section{IV Peziza gelatinosce.}

23o. Auricula. Cæspitosa tenuis flexuosa concava nigrescens, subtìs plicata subtomentosa olivaceo-cinerea. - In senioribus arborum truncis, præsertim sambuci nigræ.

23ı. Tremelloilea. Cæspitosa carnoso-tremellosa firmula carneorubra, externè subvenosa. - Ad truncos crsos subputrirlos.

232. Gelatinosa. Mollissima truneato-plana subrepanda fusco-nitens, stipite obliquo. - In tamis exsiccatis salicis caprex.

233. Nigra. Gregaria magna atro-inquinans, demùm convexa obconica, extus rugosa subumbrina. - Ad candices cæsos præsertiu quercinos.

\section{O. T $\mathrm{R}$ E $M$ M E L L L A.}

Fungus gelatinosus, forma admodium diversa et mutabili. Semina per totam superficiem sparsa.

23\%. Ustulata. Exigna vesiculosa subgelatinoso-carnosa fusco-nigricans, superficic flexuoso-sulcata. - Super fructus carnosos semi-putrescentes, in citro. 


\section{F U N G I.}

23\%. Clanelulosa. Applanata effusa crassiusenla nigra, papillis conicis spiculosa. - Autummo ad truncos satis frequens.

236. Amethystea. Lobata violacea glabra, sæpiùs sulcata. - Ligno putrido inimacitur.

237. Persistens. Sulicoriaceo-cartilaginea tenuis glibra dimidiata undulata vinoso-violacea. $\mathcal{F}$. Super truncos et ramos juniperi sabinx habitat.

238. Deliquescens. Minima flavo-fusca globosa vel turbinatu glabra deliquescens. - Ad truncos.

23). Cerebrina. Maxima, valdè gelatinosa, intis minime divisa, gyris flexuosis sulcata. - Ad truncos semi-putridos vel in ligno liumido.

2fo. Mesenterifnrmis. Gelatinosa subcartilaginea profundè lohata plicata. - In ligno mostuo.

2'́r. Melveloides. Gelatinoso - tremula roseo-anrantiaca crecta, stipite basi sulcato frondescente margine sinuato. - Ad terram in faginetis.

\section{I. II E L V}

Fungus stipitatus, pilco ut plurinùm diformi utrinquè lævi, facie infera tautum seminifera.

2'2. Acaulis. Undulata effusia spadicca, subtùs fibrillosa pallida. - In sylvaticis ad terram inter muscos.

243. Nttra. Major, pileo inflato libero ant stipiti adnato nigrescente-livido, stipite sulcato-lacunoso albicante. - $\Lambda \mathrm{d}$ terram in sylvis.

2狧. Elastica. Albido-pallescens, pileo libero subinflato glabro, stipite lævi longo attenuato fistuloso. - Ad tcrram.

245. Gelatinosa. Flavo-virens subtremellosa, pileo lævi convexo difformi undulato, stipite fistuloso basi ventricoso. - Gregatim ad terram inter folia delapsa.

2\{6. Bulliardi. Fragillima, stipite elongato niveo undulato, pilco ovato obtuso aurantio. - Gregatim nascitur super folia semiputrida.

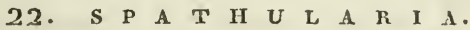

Fungus clavæformis. Pileus compressus membranaceus latere utrinquè in stipitem decurrens.

24\%. Flavida. - In pinetis gregatim.

$$
\text { 23. C L A V A R I } 1 \text {. }
$$

Fungi simplices vel ramosi, plerumquè carnosi, aliquando coriacei, pileo à stipite minimè diverso, ex omnibus superficiei punctis scmina cmittentes.

๑. I. Carnosre simplices.

2 ;. Pistillaris. Maxima glabra firma, apice clavato. - Ad terram. 249. Micans. Minuta obovata micante-rosea, stipite brevissimo albieante. - In herbis et foliis aridis. 
25o. Eburnea. Nivea glabra tereti-elongata, basi attenuata. - Ad terran.

251. Fistulosa. Subfuliginea teres fistulosa gracilis, pilis deciduis operta. - In foliis semi-putridis arborum.

252. Lutea. Tereti-elongata glabra luteo-aurantiaca, stipite clavam ferè rquante. - Ad terran.

253. Fresciculata. Aurantiaca glabra, stipitibus ad basim fasciculatis, ad apices compressis. - Ad terram in sylvis.

\section{§. II. Carnose ramosex.}

254. Bifurca. Lutea fragilis glabra, primim simplex depressa sulcata, demum bifida, apicibus acuminatis. - Ad terram.

255. Fulifrirmis. Puhescens elongata gracillima, apicibus fistulosis albidis pilosis. - In foliis semi-putridis.

256. Aculeifinrmis. Exigua lutea fragillima simplex aut bifida, apice acuminato. - In ligno semi-putrido.

257. Rugosa. Fragilis glabra basi attenuata, superficie plicatocorrugata. - Ad terram.

$25 z^{*}$. Mucida. Gregaria minuta simplex ramosaque albida, apice ochroaceo, basi tomentulo iusidens. Pers. Syn. 595. - In truncis putrescentibus.

258. Penicillata. Exigua elongata gracilis lutea glabra, apice penicillatim rissecto. - In ligno putrido.

250. Bissnides. Minima, ramulis prinum niveis glabris clavatis, demùn cinereis depressis coralloidibus pilosis. - In ligno semiputrilo.

26n. Mrtscnides. Exigua fragilis glabra coralloideo - distineta veluti arborea, ramis gracillimis subcylindricis. - In ligno semiputrido.

26r. Fastigiata. Flavescens crespitosa, canle brevi, ramis geniculatis divaricatis, ramulis subfastigiatis obtusis. - In pratis et collibus graminosis.

262. Ciralloiles. Simplex aut coralloideo-distincta fragillima glabra, ramis subcylindraceis, superficie undulati..- Ad terram.

263. Cinerea. Murina, ramis coralloideis apice dilatatis obesis glabris nec fistulosis. - Ad terram in sylvis.

26ł. Amethystea. Ramosissima lævis tota violacea. - Ad tcrram in sylvis.

\section{III. Coriacea simplices.}

265. Oplinglossnides. Coriacco-molliuscula nigra glabra, apice spatulata. - Ad terram.

5. IV. Coriacece ramosie.

266. Thermalis. Coriacca, siccatione durissima, ramis cylindricis. 
ncuminatis simplicibus vel irregulaniter divisis. - In thermalibus loci dicti Commayour in valle Angusta, trabibus humielis adnata.

267. Lacinirla. Subrlecumbens incrustins, ramis apieibus submembranace is cristato-fimbriatis. - Ad terram.

268. Corincen. Coriaceo-molliuscula, ramis corralloilibus longitudinaliter striatis. - Ad terram.

2fig. Anthecepleale. Fusco-purpurascens, ramis palmatis approximatis, apice albicantibus nitidis. - Adterram.

27o. Tomentosa. Sabfusca tomentosa, tomento brevi molli gossypiaceo. - In subterrancis.

$$
\text { 24. T H E L L E P II O } \mathrm{R} \quad \boldsymbol{A} \text {. }
$$

Pilens coriaccus, sessilis, difformis, latere vel dorso adfixus, facie inferione levi ant papiliosa seminitera.

\section{I. Pileo integro infundibuliformi centro arlfixo (GRATERELLA).}

27r. Cariopla l'́et. Varia cannsa mollis, pilen infundibuliformi fusco-purprascente radiatin fluccoso-striato, magine ut plurimum inciso stherispo. - In pinetis ad terram.

\section{S. II. Pileo dinidiato latere alfixo (STEREUM).}

272. Tremelloirles. Tremelloideo-cartilaginea Incida zonata, snpernè pilosi, infernè glabra sinuosa rel variè plicata. 2 . In liguo putrido.

273. Fermginea. Ferrnginen - nigra coriacea zonata glabra, subtùs porosa vel potiùs papillosa. - In candicibus.

274. Reftexa. Carspitosa coriacea tenuis, supernè strigoso-lirsuta, subtus glabra. 2 . In trabibus et ramis mortnis.

\section{III. Pileo superficie sterili adfixo (CORTICiUm).}

255. Muscigena. Minuta gregatia carnoso-membranacea candida. Gregatim inter mascos.

2;6. Pap rina. Mollis, superué villosa zonata, infernè lævis demàm porosa. $\odot$. Crustas efformat in truncis putridis.

27\%. Corticalis. Resupinata longitudinalis coriacea rugosa glabra subcarnea, margine subinvoluto subtisque umbrino. - In ramis mortuis.

278. Phylacteris. Maxima membrinacea glabra basi plicata, albida demùin nigrescens. ç. Ad terram.

279. Coerulen. Grumosa effusa coeruiea mgosa subtomentosa. In cortice arborum semi-putricírtum.

279*. Cruenta. Glabra coriacea tuberculata sanguineo-rubra. In Alpibns ad cortices arborum.

2So. Personnii. Suborbicularis tomentosa latè effusa ferruginea. Ad fissuras truncorum. 


\section{$+\dagger+$ Fungi surperficie fructifera aculeis aut tubis insliucla.$$
\text { 2.5. H } \mathrm{Y} \quad \mathrm{D} \quad \mathrm{N} \quad \mathrm{U} \text { M. }
$$

Pilens varius, subtus aut extùs aculeis cylindricis (interdìm sublamellosis) textus.

\section{I. Pileo manifesto nullo. Fungi ramosi (nericium).}

281. Caput Medusce. Albo-griseum carnosum, trunco crasso brevi, aculeis undulatis contortis terminato. - In ligno mortuo.

282. Erinaceus. Majus convexum è candido flavicans coriaceum, aculeis longissinis gradatim dependentibus. - Ad caudices quercuum annosarum.

283. Coralloirles. Magnum ramosissimum, ramis confertis incurvis, aculeis terminalibus subfasciculatis. - In sylvaticis ad truncos arborum annosaı un,

\section{§. II. Pileo manifesto nullo. Fungi super truncos effusi (ODONTIA).}

284. Niveum. Latè effusum album, margine byssino, aculcis confertis brevibus. - Intrà corticem quercuum.

285. Barba-Jobi. Flavo-rufescens membranaceum sessile coriaceum, acnleis primum albis obtusis, filamenta flava ramosa demùm emittentibus. - In ramis arborum ad tcrram delapsis.

2S6. Membranaceum. Rufo-ferrugincum coriaceum ligno ubiquè arctè adbærens, aculeis cylindricis crassis subbrevibus, aliquandò ramosis. - In ramis nortuis.

9. III. Pileo manifesto. Aculeis cylindricis vel conicis (H $\mathrm{rDNUM}$ ). 287. Gelatinosum. Gelatinosum albido-glancum, pilco utrinquè jlano, stipite laterali. - Ad truncos semi-putridos ín umbrosis hnmidis.

285. Auriscalpium. Stipitatnm spadiceum, pileo dimidiato coriaceo, stipite birsu to pleno. - Ad conos pini terra delapsos.

289 . Cinereum. Suhgregarium griseo-fuscum stipitatum, stipite basi incrassato, pileo toto aculeato turbinato dein infundibuliformi, sericeo vel subsquanıoso. - Ad terran.

29o. Ciathiforme. Subcespitosum confluens, pileo suberoso infundibuliformi fasciato spadiceo, aculeis tenuibus fusco-griscis, stipite brevissimo subtuberoso. - Ad terraun in sylvis.

29ı. IIybridum. Carnoso-suberosum obconicum, pileo planiusculo flexuoso-rugoso cincrascente, aculcis badiis, stipite brevissimo confluente. - Ad terram in pinetis.

292. Repandum. Incarnato-paliidum carnoso-fragile, pileo rugoso flexuoso sublobato glabro, aculeis crassinsculis, pluribus compressis, stipite tuberoso subexcentrico. - Adterram in faginctis.

293. Squammostine. Pilco carnoso-coriacco umbilicato umbrino 
squammoso, squamis crassis suberectis obscurioribus. - Ad terram subsulitarimm.

9. IV. Pileo plius minusve manifesto. Aculeis lamellosis ( $\operatorname{sys} \operatorname{sitRF} M A)$.

291. Sulilanellosum. Gregarinm album pallescens, pileo carnoso tlexuoso confluente, lanellis decurrentibus albidis. - Ad terram.

295. Bienme. Stipite contracto limato, pileo cyathiformi crasso subfermgines, tubis cinereis labyrinthiformibus. - Ad terram vel in ligno putrido.

296. Decipiens. Dinudiatum imbricatum tomentosum albidum, subtùs purpurascente-violitceum. - liarius ad truncos.

$$
\text { 26. } 3 \text { o } \quad \text { L } \quad \text { E. } T \text { U } \mathrm{S} \text {. }
$$

Pilens sessilis aut stipitatus, facie infcriore et interdùm superiore instructa tubis gongyios recondentibus.

\section{I. Tubis liberis inter se minimè coalitis (FISTULrNA).}

297. Mepaticus. Carnosus sangnineus dinidiatus, tubulis Intescentibus. - Ad eaudices quercinos autumno.

\section{II. Tubis coalitis; pileo obliterato (PORIA).}

298. Ramosus. Coriacen-fragilis luten-fulvus, in ramos subcylindraceos undicue tubulosos expansus, carne subalbescente, unbis brevibus. - In lapidicinis et cryptis super semi-putres trabes.

299. Coplarum. Coriaceo-spongiosus sessilis effuso-reflexus subfuligineo-ferrugineus temis, supera parte labrosa hiante, tubis longissimis. - Super trahes in cryptis.

300. Farus. Effusus subresupinatus coriaceo-suberosus subrecntitosetaceus zonatus fuligineo-fucescens, tubis elongatis latissimis subfuligineis, arium favum imitantibus. 2 . In truncis arborum emortuarum aut languentium.

๑. III. Tubis coalitis a pilei came laaind separabilibus (BоLETUs).

$$
\text { * Pileo sessili. }
$$

3ог. Versicolor. Cespitosus coriaceus, pileo tenui zonato multicolore coruleo, poris albis. - In arburibus emortuis et trabibus vulgaris.

302. Pelloporus. Subreniformis coriacens sessilis subtomentosus, suptà griseo-cinereus, infrì subniger, tubis brevissimis poriformibus. - In truncis et ramis mortuis.

303. Unicolor. Inbricatus suberosus zonatus, suprà fuliginco-cincreus, pileo dimidiato hirsuto subtùs cinereo. - In caudicibus.

3of. Cnccineus. Gregarius unicolor cinnabarinus, pileo crassiusculo ruguloso obsolete zonato subtomentoso. - Ad ramos pruni avium dijectos. 
3ิo5. Imberbis. Coriacens subrotundatus flavo - albidus zonatin sulcatus, tubis sinuosis flavo-pallescentibus. - In truncis arborum mos tuarum.

306. Suberosus. Primò subaquosus, dein coriaceus, glaber rufescens, forma mutahilis supernè rugosus vel zonatus, tubis latis lacunis interjectis. - In truncis.

307. Pseudn-igniarius. Subcoriaccus rubro-ferruginens, vel suligriseus, zonis suprà destitutus, tubis elongatissimis. - Ad truncos arborum.

3os. Ungulatus. Ungulaformis nigro-ferruginens sulcatus, primum nollis filamentusus, dein ligueus, tubis angustis concoloribus. - In cortice arborum.

3og. Ottusus. Dimidiatus obtusus suberosus nigro-ferrugineus levis int vix sulcatus, tubis angustis pileo concoloribus. $2 \mathcal{C}$. In diversis arboribus.

3 го. Labyrinthiformis. Coriaceo-ligncus scabroso-zonatns lateritiofuscus, sinulis labyrinthifornibus cinereis. - In tranco crategi torminalis.

3ix. Fraxineus. Coriaceo-suberosas sessilis glaber, carne crassa subrutilo-straminea. $\iota$ ubis brevibus subferrugineis. 2 . Super fraxini languescentis truncos.

3 r2. Suaveolens. Coriaceo-suherosus ex niveo subfulvus glaber, carne stramineo-fuliginea, tubis longissimis subrufidis. - In truncis salicinis.

313. Laricis. Subconicus suberoso-carnosus lævis inæequalis, suprå incrementis convexis circulariter fimbriatus et gradatus, tubis brevissimis vix perspicuis. - Ad trnncos laricis.

314. Imbricatus. Coriaceo-fragilis luteo-fulvus sessilis imbricatus, carne subalbescente, tubis subfulvo-ferrugineis brevibus. - Ad truncos arborum emortuarmm aut languescentium.

315. Salicinus. Submollis sessilis glaber subsinuosus albidus, zonis destitutus, tubis albidis demùm rufis. - Solitarius in truncis salicinis.

316. Cuticularis. Nigro-rufescens subcarnosus scaber zonatns, margine sinuato, tuhis pileo concoloribus. - Solitarius ad truncos arborum cinortuarum.

31;. Hispidus. Ferrngineus, pileo crasso villoso-strigoso subtùs jallido, tubis longiusculis orificio ciliatis. - In trunco quercûs juglandis et mali.

318. Sulfureus. Mnllis glaber, snprà flavo-auratas mbescens, subtìs sulfureus, tubis vix conspicuis, pulvere seminali copioso albo. In annosis quercubus.

\section{** Pi'en stipitato. Stipite laterali v'el excentrico.}

3.9. Crlcenlus. Coriaceus, pileo dimidiato tenui sublateritio tigrino sessili aut breviter pedicellato, tubis brevibus. - Ad truncos axborum morbidarun. 
320. Jugglaudis. Magnus, pileo carmoso suberuso ochraren, diseo squanisfue umbrinis nigrescentilus, ponis magnis flexuosis, stipite crasso laterali. - lin vartis arhoribus praesertinn in jughande.

32.1. Obliquatus. Pileo coriacen cistanco nitido conecutrice sulcato, ports minutis albis, stipite laterali nitido fusco. - In cutudicihus.

322. Acanthoides. Maximus respitosus mollis et fragilis lateritioruliginosus, stipite basi cylindrico supra latescente, pilco sinuato undulato, suprà zonato, subtits reticulatos. - In candicitus.

$322^{*}$. Infundilu/iformis. Pilco carnoso infundibuliformi cx allido fuliginoso, poris albidis, stipite deorsim incrassato nigrescente. Pers. ic. pict. p. 8. 1. 4. f. 1.-In truncis salicinis.

$$
\text { *** Pileo stipitalo; stipite centrali. }
$$

323. Nummularius. Glaber parvus, pileo duro convexo-plano ex albido pallescens, stipite deorsìm nigro. - Ad ramos delapsos exsiccatos.

32ł. Perennis. Coriaceus tenax cinnamomeus, pileo tenni zonato velutino ut plnrimum comnato, stipite basi sæpiùs hirsuto. $\sigma^{\star}$. $\Lambda d$ terram et truncos antiquos.

325. Fimbriatus. Gregarius vel solitarins umbrinus, stipite cylindrico subtenui, pileo sericeo vel glabro zonato margine fimbriato infundibuliformi, tubis brevibus irregularibus. - Ad terram.

326. Polyporus. Subcoriaceo-mollis, stipite ochralevco basi rubescente, pileo cupulari subfuliginco - cinerascente, carne nivea teniaissima. - Ad terram.

\section{IV. Tulis coalitis à pileo facilè separabilibus (surtuds).}

327. Betulinus. Majusculus substipitatus, pileo carnoso-suberoso reniformi fuligineo-rufescente, subtis albido. - l'assim ad candices betulæ albæ.

328. Rubeolarius. Nagnus, stipite clongato rulicundo reticnlato subbulboso, pilco pulvinato fuscescentc-olivareo, poris aqualibus primò rubris denum aurantiacis. - Ad terran in sylvis.

329. Freus. Stipite longo flavo-fuscescente suberguali reticulato, pilen rnen-nigricante, carne inmmtabili crassissima firmu, tubis brevihus sulphureis. - Ad terram in sylris.

33o. Edulis. Stipite tuberoso subventricoso reticulato subrnfescente-cinereo, pileo pnlrinaio latissino fuscescente-vaccino, carne immutabili, poris primò farctis albidis dein dilutè flavis. - In nmbrosis ad terram.

331. Castaneus. Stipite lævi castanco-lateritio, pileo stipiti coneolore, carne nivea, tubis ex albo Juteis. - Ad terram in sylvis.

332. Felleus. Stipite subreticulatoventricoso pileoque fulvo, carne nivea molliuscula, demùm rosea, tubis ex albo subcarneis. - Ad terram. 
333. Cyanescens. Pileo lato subfuligineo, stipite lavi ventricoso concolore, apice niveo, poris albis, carne secta coruleseente. Ad terram.

334. Piperaius. Stipite basi intisque flavo, pileo crassiusculo pulvinato flexuoso cimnamomco, poris majusculis convexis rufo-ferrugineis. - Ad terram.

335. Chrysenternn. Mediocris, stipite subtenui medio rnbicundo aut unicolore lutescente, pileo pulvinato convexo plano subtomentoso gilvo ant flavo-cinerascente, carne mutabili, poris majusculis. - In locis paluilosis.

336. Scrber. Stipite attenuato squamulis nigrescentibus scabro, pileo subrugoso opaco fuligineo-cinereo, poris pallescente-albis circà stipiten depressis. - Ad terram in sylvis.

337. Auraniacus. Stipite longo albo, squamulis verruciformibus aurantiis onusto, pileo carnoso nitido subaurantiaco, poris minutis candidis. - Ad terram in sylvis.

338. Parasiticus. Stipite flavo basi subattenuato, sub finem squamnıoso, pileo umbrino areolis angulosis diviso, lacunis subprofundis interjectis, carne tubisque flavis. - In lycoperdo verrucoso rarus.

339. Annularius. Stipite annulato, pileo pulvinato campanulato viscoso flavescente-livido, macnlis è lateritio rufis variegato, poris luteis. - Ad terram.

\section{$+\dagger+\dagger$ Fungi facie fructifera lamellis aut rugis proe- minentibus instructa.}

\section{M E R U L I U S.}

Pilens carnosus aut membranacens subtirs venosus. Venis ant plicis sæpius tumidulis inter se anastomosantibus.

\section{I. Pilco stipitato convexo.}

3 fo. Lycoperdoides. Pileo subgloboso albo tomentoso, rugis aut lanellis radiantibus subgelatinosis crassis nigrescentibus subprominulis, stipite cinerescente. - In agaricis præsertim in A. fusiformi.

\section{II. Pilen stipitato concrivo.}

34 r. Cantharellus. Gregarius flavescens, pilen carnoso glabro depresso sæpe irrcgulari. - Frequens ad terram in sylvis.

3.12. Nigripes. Pileo infundibuliformi flaveseente, stipite longo nigro-fuliginoso. - Ad terram circà Parisios.

3ł3. Lutescens. Pileo umbilicato glabro lutesecnte subdifrormi, venis cinereo-rutilis, stipice cavo flavo-aurantiaco basi incrassato. - Gregatim ad terram post pluvias.

3 亿́. Tuba'formis. Gregarius minor, pileo membranaceo unbilicato rugoso-sqnamuloso fusco, plicis rectis flavo subcinereis, stipite flavo subincrassato. - Ad terram.

3ij. IIjdrolips. Cespitosus, pileo subinfundibuliformi squamuloso 
nigrescente, plicis cinereis nitidis, stipite cavo nigrescente. Ail terran.

3:6. Cornucopiniles. Cespitosus nigrescens, pileo membranaceo squammloso, venis obsoletis. - In sylvis.

3 17. Undulatus. Livido-pallens, pileo suberiaceo depresso, margine erecto undulato-crispo, subtùs rugoso. - $\Lambda d$ terratu.

\section{§. III. Pileo sessili.}

3彳亍8. Muscigenus. Stipite laterali brevi crassiusculo, pileo dimidiato pallescente-fusco, plicis ranosis. - In muscis vivis.

349. Retirugus. Membranaceus tenuissimus verticalis subrotundus, suprà lavis albo-cincreus, subtus reticulatinı venosus subfuligineo-cinereus. - In muscis et ramis vivis et mortuis.

35o. Tenellus. Fragilis subgelatinosus suprà niger, infrà fuscescens, venis prominulis inaqualibus radiantibus. - Sessilis in trabibus putridis.

35ı. Tremellosus. Acaulis imbricatus carnoso-tremellosus, pileo effuso-reflexo tomentoso albo, plicis subporifornibus acutis rubicundis. - In trabibus putridis. - Nonnc potius ad telephora genus referendus?

$351^{*}$. Crispus. Dinudiatus subimbricatus, pileo subcarnoso tomentoso rufo, margine albido, plicis crispis albidis. Pers. ic. et deser. p. 32. t. S. f. 7 . Syn. p. $49^{5}$. - Autummo ad truncos et ramulos fagineos ct coryleos.

352. Lacrymans. Effusus magnus flavo-iuber, margine albido-tomentoso, plicis amplis poroso sinuatis. - Super trabes in lacis lumidis.

$$
\text { 28. A G A } \mathbf{R} \text { I }
$$

Pileus plerùmque stipitatus subtùs lamellatus, lamellis ferè nunquam inter se anastomosantibus, gongylis lamellis intermixtis.

§. I. Volva nulla. Stipite mulln, marginali vel excentico.

$$
\text { ( PLEUKOPUS ). }
$$

353. Quercinus. Sessilis dimidiatus coriaceus crassus suberosus ligneo-pallens, lamellis ramoso-sinuatis, sinulis maguis. - Ad truncos arborum omni avo.

354. Abietinus. Sessilis coriaceus fuligineo-nuhrinus subcespitosus, pileo brevi lato crasso. - Ad trabes presertim abietinos.

355. Tricolor. Sessilis coriaceus versicolor, lanellis sinuatis dichotomis, pileo reniforni suprà tomentoso. - In truncis betulæe albæ.

356. Coriaceus. Sessilis pallescens zonatus tomentosus, zonis concentricis nigris. - Ad truncos exsiccatos frequens.

357. Rufo-velutinus. Sessilis subcespitosus rufescens, pileo tomentoso coriaceo-mollinseulo, lamellis parùm numexusis concoloribus. - In subterraneis Observatorii Parisiensis. 
355. Alneus. Subsessilis subeoriaceus albirlo-griseus, lamellis fissis margine revolutis subpurpuraseente-cinereis, pileo sæè multifido.

- Ail truncos abborum prescrim alni.

350. Elixy/nn. Suhs ssilis ex crulco ardesius, lancllis inæqualibus distinctissimis, prumò purpuraseentibus, tandem nigris. - In truncis resectis interdiun centro adfixus).

36o. Variali'iv. Sessilis au centro stipitatus, lactens, pileo subglabro sicen, lamellis teisuibus ferrugineis inæqualibus. - In ligno mortuo et ad terram.

$360^{*}$. Dyctiorth zus. Pileo subsessili candido semi-nrbirnlari margine sinuato, busi fibrilioso, radicibus tomentosis albis reviformibns, lanclis inæqualibus pileo concoloribus. - In argilla humida.

36r. Sispticus. Cespitosus, pileo snbenriacen emarginato alutaceo, stipite compresso adscendente apice dilatato. - Ad trancos exsiccatos.

362. Petaloides. Frectus, pileo ex fusen-illhidn, disco farinoso, stipite marginali semzi-cyliudrica supià canaliculato. - Ad terram in unibrosis.

363. Glandulnsus. Suhsessilis badins, lamellis candidis decurrentibus, ad latera glandulosis. - In syivaticis.

36f. Incnnstans. Pilen cochleariformi margine sinuato, stipite laterali, lamellis favescentibus in petiolum decurcentibus. - Ad truncos arborum.

365. Palmatus Cespitosus, pilen lamellisque oparis rufo-spadiceis, stipite excentico substicto albido - In truncis.

366. Tesselatus. Pileo carmoso convexo tessellato, tessellis ferè hexagonis, stipite tereti subexcentrico. - In trabibus aut truncis.

36-. Oreel'us. Gresarius, pileo elliptico aut orbiculari, stipite pallido subexcentrico, lamellis confertis inearnatis. - In truncis.

368. Ulmarius. Pileo carnoso latissimo unicolore pallescente aut Jitm is variegato, lamellis latissimis subemarginato adnexis, stipite adscendentc. - In arbos un truncis.

5. II. Volva nulla; stipile centra!i; lamellis requalibus margine annulari haud terminatis ( RCSSCLA).

369. Pectinaceus. Pileo subdepresso margine striato, stipite albido cylindrico, lamellis adnexis. - Passim in sylvis.

37o. Foetens. Magnus foetidus sordide-pallidus, pileo depresso, margine fornicato tuberculato-sulcato, lamellis nounullis dimidistis. - In sylvaticis.

37r. Furcalus. Pileo sub-infundibuliformi ex pallido-viridi, lamellis albidis ferè omnibus furcatis. - In sylvis casis.

3-2. Ruber. Pileo sangnineo, lamellis albis in pediculum subdecurrentihns, bi-aut-trifurcatis, stipite primù pleno dein spongioso. - In sylvis. 
§. Ilf. Volva mulla; stipire rentrali; lamellis inaqualibus; succo lacteo sapius albo, interdium flavo aul rubro (1.ACTARIC's).

373. Acris. Alhus, laminis numerosis sapec bifurcatis aliquando flavis aut rubris, sueco acri. - In sylvis.

374. Dyemogralus. 'J'otus albus, sueco lacteon insipido, pileo zonis griseis alifuando notato. - Solitarius in sylvis.

3-5. Zonarius. Pileo unbilicato zonato dibue ochracen, margine: revoluto villoso, succo acri. - In graminosis, passim in sylvaticis.

3-6. Theingalus. Ninor, pileo infundibuliformi depresso stipiteque ruto, succo flavo. - Passim in sylvis.

377. Pyrogalus. Pileo planiusculo plumbeo-livido zonato, lanellis numcrosis rubescentibus, stipite recto fuliginoso, succo primum subdulei, demùm acerrimo. - In sylvaticis.

3z8. Aznnites. Pileo sublubato ex griseo rufescente, laminis et stipite basi flavis. - Pissim ad terram.

379. Deliciosns. Pileo umbilicato subanrantio, exsiccato sordide pallido, lanellis succoqne aurantio-lateritiis. - In pinetis.

3So. Necator. Pileo umbilicato zonato dilntè ochraceo, margine revoluto villoso, lancllis alljis. - In sylvaticis passim.

381. Subdulcis. Pileo infundibuliformi rufescente, aliquandì zonis nigris concentricis inscripto, lamellis pallescente-incarnatis, succo albo subelulci. - In gramincsis.

382. Plumbeus. Pileo latissimo infundibuliformi stipiteque nigrescente-fuligineis, lamellis lutescentibus, succo acerrino. - In sylvis.

S. IV. Volva nulla; pediculo centrali nudo vel rariüs annulato; lamellis incequalibus, demime nigrescente-liquescentibus; pileo membranaceo fugace (COPRINUS).

383. Typhoirles. Gregarins, pileo conico squamoso albido, sub finem nigrescente, sfuamis flavescentibus, lamellis congestis primò allido purpurascentibus, stipite longissino, anuulo mobili. - In graminosis ad sepes.

384. Ephemernides. Pilco conico albido centro flavescente, margine striato, stipite fistuloso basi bulboso filmm hirstutum intus recondente, annulo nunc fixo nunc mobili. - In fimetis.

355. Lacrymabundus. Pileo campanılato rufescente sulitomentoso, lamellis luteo-nigrescentibus, stipite nudo. - Ad terram in sylvalicis.

386. Picaceus. Pileo campanulato tenuissimo albido, in squamas latas sparsas demùn rupto, lamellis denudatis confertis umbrinis, stipite longissimo bulboso nudo. - In regetabilibus aggregatis putridis.

387. Cinereus. Pileo conico sulcato subtomentoso cincreo, apice lavi livido, margine demìm lacerato inflexo, lamellis linearibus 
punctatis subflexuosis, stipite longo nudo squanuloso.-In hortis, passim et in sylvis.

38s. Tonientosus. Pileo (oblongo) ab initio pyramidali, posteà campaniformi lacerito, lamellis numerosis angustis pallidis, nargine atris, stipite nudlo brevi cylindrico tomentoso utrinquè attenuato. - Ad terram in pratis et hortis.

389. Atramentarius. Gregarius, pileo ab initio globnloso, deindè campaniformi, elongato, lutescente, maculis subnigris præsertim in disco notato, stipite aibo nudo cylindrico. - In locis humidis.

39on. Nícaceus. Cespitosus, pileo campanulato sulcato ferrugineo, lamellis nitentibus primò roseis, dein cinereis, tandem nigrescentibus, stipitc nudo tereti. - In pratis, sylvis et hortis haid infrequens.

391. I'seudo-extinctorius. Stipite nudo subcylindrico longinsculo, basi tumirliusenlo, pileo canıanulato, margine inæquali, sursùm sqquamuloso pallido, apice fuscescente, margine demùm lacero inciso. - In fimetis.

393. Gossypinus. Cespitosus, pileo lato subplicato campanulato ochraceo, lamellis distinctis liberis, stipite nudo villoso deorsüm incrassato. - Ad terram.

393. Digitaliformis. Pileo ab initio ovoideo, deindè digitaliformi, centro rufescente, margine striis nigris notato, stipite tenui nudo stricto. - In truncis mortuis, salicum vulgò.

39i. Ephemerus. Gregarius minor, pileo campanulato demìm partito striato glabro subcinereo, disco rufescente, stipite nudo longo glabro. - In stercorariis.

395. Stercorarius. Minntissimus grisens, pileo demùm planiusculo radiato-fisso, disco ochraceo, lamellis distantibus, stipite filiformi nudo. - In fimetis.

396. II ydrophorus. Cespitosus, pileo ab initio campaniformi deindè conico, disco rufescente, margine lacero striato griseo, sursìm replicato, stipite subradicato nudo. - Ad terram in pratis sylvis ct liortis.

397. Deliquescens. Pileo griseo striato, ab initio lemispherico, deindè campaniformi elongato, lamellis liberis, primò albidopupurascentibus deindè nigris, stipite nudo. - Gregatim in pratis et liortis.

39 s. Congregatus. Confertus, rilen digitaliformi, sub finem latescente, colore dilute flavo, lamellis albis, dein nigrescentibus, stipite nudo. - In umbrosis, frequens in xstate et antumbo.

399. Fimiputris. Pileo campanulato-viscoso suhflavescente, lamellis adscendentibus cinereo-nigrescentibus nebulosis, stipite longo annulato fusco. - In fino vaccino gregarie.

40n. Papilinnaceus. Pileo campanulato fuligineo subnigreseente, lamellis tntis adnexis cinẹreo-nigrnque variis, margine albidis, stipite nudo. - In sylvaticis super foliis nortuis.

for. Coprophilus. Pileo subcarnoso latì umbonato rufescente fuli- 
gimen, lamellis latis ventrieosis arenatn-adnexis, lividis ant gilvis, stipite nulo hirsuto cinerascente. - In finetis.

402. Bullacens. Gregarius parvulus, pileo hemispharico, margine striato obscurè rufo, lamellis latissinis cimmancmucis planis, stipite nudo subbrevi limuginoso pallescente-albo. - In fimeto.

fo3. Titubans. Nitidus fragilis, pileo campanulato striato viseoso pallesecnee, disco flivo, lamellis distiuctis incarnatis, stipite lutescente nudo basi piloso. - Ad terram, super folia mortua.

S. V. Volva nulla; stipite centrali nudo vel annulato; lani"is nigrescentibus nunquam. vero liquescentilus; pileo carnoso (PRATELLA).

40 . Striatus. Pileo conico, demùm convexo, tandem plano, rufoalbicante, striis profundis ant plicis raliantibns notato, stipite mudo albo cylindrien tenui. - Ad terram in sylvis et pratis.

405. Conocephalus. Subsolitarius, pilco campanulato-conico cinero-livido striato, lameliis liberis obscure-rufis, stipite nudo longo albilo. - Ad terram.

406. Violaceo-lamellatus. Cespitosus, pileo griseo-rufescente, diseo calloso, margine substriato, lamellis egregie violaceis, stipite nudo albido. - Ad terram.

4n:- Aquosus. Pilco ex abbo-fucescente aquoso molli, stipite nudo fusco, radiculos plures enittente. - In umbrosis, xstate vergente.

408. Campanulatus. Gregarius brunnens, pilen campanulato obtuso lervi, lamelis confertis latissimis liberis, stipite longo juniorum subannulato. - Ad terram.

qog. Pellospermus. Pileo flavo-pallescente, aliquandò margine striato, laminis fediculo adnatis ex violaceo-nigrescentibus, stipite nudo albido, nune glabro, nunc basi hirsuto. - In sylvis super folia mortua.

410. Semi-orbicularis. Pileo concolore lavi nitido hemisplaærico, laninis liberis mnnquam nacnlosis, stipite rufo firmo nudo. In graminosis ad vias.

4ir. Pulverulentus. Cespitosns ochracens, pileo in merlio protnberante, laminis adnatis, prima ætate olfectis membrana alba ad marginenı pilei lacera persistente. - In caudicibus putridis.

4r2. Amarus. Cespitosus magnus, pileo carnoso subviscoso lateritio, unargine flavescente, lamellis distinctis subnebulosis virescentecinereis, stipite longo stabsolido, annulo fugaci nigrescente. Ad truncos putrescentes.

413. Nigricans. Majusculus, pilco depresso olivacco-cinereo, demùm nigrescente adesto, lamellis crassis albidis, stipite solitin brevinsculo cinereo nudo. - In faginetis, freqnens autmuno ad terram.

414. Appendiculatus. Cespitosus congestus frasilis, pilen snhaquoso glabro fucescente-livido, ex sircatione ruguloso pallescente, lamellis 
confertis incarnato-fuscis, obtectis membrana demùm lacera ad marginem pilei persistente. - In sylvis et hortis.

415. Sphaleromorphus. Solitarius, pileo hemisplırico convexo albido, lamellis confertis decurrentibus, futescentibus dein vigrescentibus stipite anumbto sububeroso şabro. - In Galia.

416. Melanospermus: Pileo convexo-flavescente, lamellis rotundatis subarlnexis, primi flavescentibus, demum nigris, stipite albilo annulato, leorsum incrussato. - In Galia.

417. Cianeus. Pileo glutinoso xuginoso, ex siccatione flavescente, lamcllis planis adnexis purpurascentibus fusco-variegatis, stipite squamoso, annilo fingaci. - In sylris ad truncos.

418. Edulis. Gregarins magnus, pileo candido lævi aut obsoletè squanoso, lamellis rabris, stipite lougo bulboso, annulo manifesto. - In pineis aut in pratis montosis.

5. VI. Volva nulla; stipite centrali; laminis terminatis in annulum communem pedicuíum circunulantem ( ROTULA).

4'9. Rotula. Stipite tereti nigrescente, pileo albo profundè sulcato, lamellis omnibus in amulum terminatis. - In sylvis ad stipites et folia decidua.

420. Stylobates. Stipite basi in discum latescente albo, pileo concolore è campaniformi plano, lanellis longioribus in annulum terminatis. - In ligno mortuo.

5. VII. Volva annuloque nullis; stipite centralifistuloso; laminis nunquam nigrescentibus; pileo haiud umbilicalo ( 1 XCENA).

42r. Arundinaceus. Stipite clongato pallido compressinsculo vel sulcato basi subhirsnto, pileo obtusè ninbonato pallesecnte-rufo striato, lamellis distantibus liberis. - In pratis antumno.

422. Nigripes. Cespitosus, stipite tomentoso nigrescente-badio, pileo snbcarnoso repando glabro brunneo, lumellis ventricosis latescentibus. - Ad truncos autumno et hyeme.

423. Alliaceus. Stipite subrubello ad apicem attcunato basi subhirsuto, pileo ex albido-rufescente, plisno vel convexo, rel centro gibboso, laminis concoloribus liberis. - In sylvosis autumno.

424. Ventricosus. Albito-rulescens, stipite basi ventricoso, radice simplici acuminata, pileo prisùu campaniformi deindè convexo, laminis a uis sinuosis, hanuo terminatis. - In sylvis.

425. Fistulosus. Cespitosus, stipite levi radicato exsucco, basi strigosn-lirto, pileo membranaceo umbonato livide-lucescente, lamellis distinctis albis. - Ail truncos frequens autmuno.

426. Polygrammus. Solitarius, stipite candato longitudinaliter striato argenten-cresio, pileo campanulato umbonato subcinerco. - In caro truncorum.

427. Filopes. Stipite longióre tenuissinu al apicem attenuato basi hirsutissino, pileo conicn vel eampaniformi, striis tuhs radiantibus notito. - In sylvaticis inter muscos. 
428. Linculus. Siccus, pileo striato-lineato Raveseente-npaen, lamellis alistantibns althidis basi vemosis, stipite basi subtementoso alloo. - In faginetis inter muscos solitinius.

429. Foraminulosus. Fuscus glaber, pileo campaniformi sirpius onnien munquàm suprà striato, lamellis inequalibus liberis, stipite cylindrico tenui. - Autumno ad vias solitarius.

430. Melinoides. Gregarins ochrace-lutrolns expallescens, jilıo carnoso membanacen hemispharico planiusculo, lamellis subconfertis planis, stipite mediucri sursim subincrassato. - In graminosis el muscis atummo.

4î. Squarrosus. Rufescens, pileo henispharico regulari, demim conrexo vel plano sinuoso, margine squamis albidis terninato, stipite hasi jucrassato squamoso, squamulis erectis acuminatis. - Giregarie ad terraru.

432. Pliysaloiales. Pileo flavescente, margine uon striato glabro, campaniformi dein plano, laminis rufescentibus latissimis sul,decurrentibus, stipite cavo luteo vel flavo. - Solitarius ad terram.

433. Perpendicularis. Pileo alutaceo primùm convexo dein plano, laminis liberis albescentibus, stipite tenui nitido Jevi rufescente, radice perpendiculari hirsuta. - In faginetis ad terram.

434. Epiphyllus. Pileo plus minìsve convexo rotundato ex albidorufescente margine substriato, laminis angustis, stipite tenuissimo filiformi pleno. - In sylvis ad tolia lecislua.

435. Hulsoni. Gregarins, pileo convexo albo stipiteque pilosis, pilis sparsis strictis rubris, - Super folia ag̣tufolii mortua, autumno.

436. Adonis. Gregarius, pileo lævi campanulato albido roseo ant viridi vario, lamellis subuncinatis adnexis albis, stipite filiformi albido. - In sylvaticis.

437. Variegatus. Gregarius majusculus, pileo sulıcarnoso campanulato laevi aut papillato lituris rufescentibus variegato, Jamellis uncinato-decurrentibus, stipiteq̆ne albis.-In graminosis ad terçan.

438. Roseus. Gregarius parvus roseus, pileo campanulato papillato, lamellis albidis, stipite filiformi pallescente. - Arl ramulos.

439. Clavus. Gregarius minutus, pileo subcarnoso papillato anrantio ant rubescente, lamelítis albis latiusculis, stipite solido. Ad terram folia aut tonncos putrescentes.

4fo. Corticalis. Pusillus stipitatus parvus, pileo campannlato fucescente striato, lanellis alhidis subdecurentibus, stipite brevi incurvo. - In caudice et rimis corticis arborum præsertim quercnum ant salicum.

4́fr. Pumilus. Solitarins parvus, pileo ex albido flavescente conico convexo tandeu plano margine lacero, laninis latis hamo terminatis, stipite glabro' gracili. - Ad pedes arbormm.inter muscos.

ff2. Pygmaeus. Pilco primùm convexo dein plano rufo, margine striato, laminis rufis, stipite tenui cavo albo basi pilis hirsuto. - In ligno mortuo. 
\$. VIIf. Iolva anmuloque nullis. Stipite centrali fistuloso aut pleno. Pi'eo umbilicato. Laminis nunquam nigrescentibus, ferè semper decurrentibus ( OMP11 $\mathrm{L} 1 \mathrm{~A}$ ).

443. Drynphilus. Gregarius, pileo subcarnoso hemisphærico umbilicato lamellisque pallidis, stipite cavo lutescente-rutilo. In sylvis et pinetis autumno frequens.

44亿. Cupnluris. Solitarins, pileo subcarnoso latè umbilicato flavescente, lamellis confertis obscuriorilsus, stipite longo tenui caro albicaute. - Ad terram.

4́á. L'mbi'icatus. Pileo convexo centro prorsùs concavo, margine reflexo, laminis flavis latis, nonnulis hamatis subdecurrentibus, stipite listuloso. - In sylvaticis iestate.

4f6. Aidnsiaceus. Majusculus, pileo primùm convexo dein subinfuncibnliformi plumbeo, lamelis confertis liberis subferrngineis, stipale cavo lon ro plumbeo. - In pratis lumidis antumno.

敒. Ilydrogrammus. Cespitosus nnicolor totus albus ant rufus, pileo striato, stipite cavo undulato subincurvo crassiusculo. Super folia decidina.

448. Virgineus. Gregarius subparvus candidus, pileo carnoso primò convexo, dein plano-depresso, arlult is margine subinflexo stiiato, lanellis distantibus decurrentibus venoso-connexis. - In pratis, collibus graminosis.

449. Pseudn-androsaceus. Gregarins totus griseus membranaceus, pileo convexo denium infundibuliformi, lamellis distantibus basi latissimis, stipite mediocri solido. - In ericetis aut sylvaticis arenosis ad terran.

450. Fibu! a. Parvus, pileo lavi ochraceo-rubescente, lamellis distantibus albidis, stipite longiusculo solido. - Autumno iuter muscos.

45̃ . Amade'pluss. Parvulus gregarins, pi!eo flavo-pallescente, prinum convexo dein plano in centro concavo, laminis rubescentibus, stipite pleno albido incurvato adscendente, basi subhirsuto. - In cortice arborum.

452. Tigrinus. Pileo carnoso albido, squamis subpilosis nigrescentibus, stipite pleno dmo subsquamuloso. - Gregatim in sylvis super schiores truncos.

453. Infindibıliformis. Gregarius subuagnus flavo-fermgineus nitidus, pileo infundibnliformi rigido imargine reflexo, stipite pleno crasso subtuberoso. - In sylvis abietinis.

45\%. Mnllis. Pilco subcarnoso infundilunliformi mollissimo, margine mox reflexo, laminis flivis angnstissimis inxqualibus, stipite solido ex albo-flavescente. - In irnucis putrilis.

455. Cyalhiformis. Elasticus nigrescente-nmbrinus, pileo infundibulifurmi margine reflexo lavi, stipite tereti albo pleno. - In umbrosis inter unuscos. 
4.6. Contiguus. Magnns, pileo carnoso depresso lepaticn, margine revoluto comentoso, lamellis dichoromis hasi subporiformibus, stipite tereti [pleno. - Solitatius in sylvaticis.

457. Pyidatus. Gregatius, pileo cupulari sen infundibuliformi striato subspaticeo, lamellis lutescentibus, stipite clongato solido pillito. - Ad tcram.

458. Anetlystens. Gregarins sublenax recens letc violaceus, deminn canescens, lamellis distantibus, stipite longo fibrilloso attemnto solido. - Passim in sylvaticis umbrosis.

5. IX. Volva et anmulo nuliis. Stipite pleno. Pilen carnoso. Laminis nunquim nigrescentibus (GYмNopd).

\section{* Laminis in stipilem decmrrentibus.}

4.9. Pellucidus. Subparvus rufescens, pilco carnoso membranaceo striato campanulato, Jamellis latissimis, stipite longinsculo tenui. - Solitarius ad terram.

46o. Geotropus. Albiulus vel flavo-pallescens major, pileo rotundato centro mammoso, lamellis inxqualibus decurrentibus, stipite concolore aliquandò basi subhirsuco. - Solitarius ad terram.

461. Pileolarius. Pileo primùn hemisplatico dein convexo margine reflexu griseo fucescente pulvernlento, laminis griseis, stipite albido fibrilioso basi ventricoso striato, striis griseis vel flavicantibus. - Solitarius in sylvaticis.

462. Vinosus. Pileo rufo nigrescente primùm rotundato tandem sinuato vel lobato tomento tenui obtecto, laminis rufis numerosis, stipite subcylindrico rufescente. - In arenosis autumno.

463. Ficoides. Fulvo-rubescens subdurns, pileo campanulato seu obtusè umbonato aut planiusculo glibro, lamellis crassis distantibus, stipite brevi subtenui deorsum attenuato. - In pratis gregariè.

464. Erincephalus: Rufescens, pileo primùm campanulato dein convexo, imprimis margine gossypino, lamiuis inxqualibus subdecurrentibus, stipite cylindrico attenuato. - Gregariè in ligno mortuo.

465. Undulatus. Parvulus, pileo tenui umbonato planiusculo zonato albido, lamellis confertis subargillaceis, stipite longiusculo subflexuoso undulato. - Ad terran.

466. Eלurneus. Gregarius candidns, pileo subcarnoso viscoso convexo plano, margine lavi, lanıllis subdistantibus parum decnrrentibus, stipite longo apice squamuloso. - In sylvis autmuno.

46-. Ericetorum. Gregarius albidus, pilen llavescente convexo raro centro proninulo, lamellis subdistantibus, stipite tereti apice fistuloso non squamuloso. - In ericetis.

498. Odorus. Pileo carnoso planiusculo lævi virescente, lamellis enfertis sublecurrentihus albidis, stipite solido sublexuoso concolore aut viridi. - In pinetis antumuo. 
469. Acertus. Subcespitosus magnus, pileo carnoso helvolo margine involuto, lamellis confertis attenuatis pallidis, stipite solido subrrasso punctato squamuloso pileo concolore. - Ad terram.

47o. Albellus. Alutaceus, pileo splhærico dein campanulato quàm maximè carnoso, margine parim revoluto, laminis contertissinis inxqualibus, apicibus acummatis, stipite plerumquè basi incrassato sublirsuto. - In sylvis.

47r. Lignatilis. Cespitosus, pileo umbonato glabro cinnamomeo, lamellis sublecurentibus pallidi formgineis, stipite squamoso subtenui cylindrico. - Ad truncos putrescentes frequens.

473. Fusipes. Cespitosus, pilen subtenaci rufescente-raccino, lamellis distantibus albido-rufescentibus, stipite sulcato ventricoso radicato glabro. - Autummo ad truncos putrescentes.

4-3. Cupniocephalus. Pileo flavo seniore ad centrum et margines nisro, laminis rufis inæqualibus intas emarginatis, stipite cylindreo basi parum attenuato flaveseente fongitudinaliter striato. - Solitarius......

\section{** Laminis stipili adnexis.}

474. Ovinus. Gregarius, pileo carnoso subcampanulato rufescente glabro aut squanuloso, margine sæpiùs inciso, lanellis distantibus ad Jatera venosis albido-ciucrascentibus, stipite cavo fuligineo. In pascuis.

475. Fusiformis. Cespitosus, pileo fusco-flavescente convero campanulato, seniore sulsinwoso, stipite lævi, apice cylindrico medio ventricoso basi acuminato concolore. - In sylvosis.

4-6. Grammopndius. Cespitosus spadiceus, pileo campanulato, disco dilatato obtusissimo piloso squamoso, lamellis confertis subdecuirentibus obscurioribus, stipite glabro flexuoso connato. - Solitarius ad terram.

477. Pamnsus. Lacteus, pileo hemispharico dein convexo orbiculari, laminis inæqualibus ad insertionem stipitis dilatatis. stipitibus cylintricis basi longè connatis et tamos simulantibus. - In pulvere quercino vergente autumno.

478. Tuberosns. Gregarins parvus albidus, pileo convexo papillato, stipite brevi subrufescente tuberibus innato. - Autummo frequens in agaricis putridis.

479. Brevipes. Subgregarius, pileo carnoso umbonato ant lavinsculo cinereo, disco nigrescente, lame!!is confertis emarginacis cinereis, stipite brevissimo concolore. - Solitarius ad terram.

48o. Glaucus. Pileo carnoso membranacen stipiteque cresio, lamcllis subenarginatis roseis latiusculis. - Crescil solitarius.

48r. Purus. Varié coloratus, pileo conico canıpanulato, vel prorsìs plano, margine sepiìs sinuoso, laminis basi venosis, stipite plerumque pilis numerosioribus basi ornato, per totam longitudinem fistuloso. - In sylvis antumno.

4S2. Cumelco. Gregarius subparrus viscosıs, pileo umbonato, 
stipiteque fuho viridique vario, lamellis aureis. - In pratis attนเแแno.

483. Butyraceus. Pileo convexo glabro mfescente-badion (clilute castaneo), lancllis flexuosis allsidis, stipite subeonico ubiguẻ piloso rubro-castaneo. - Ad terram.

48f. Areuatis. Varius, pileo campanulato denùn depresso rufesconte - griseo, lamellis latinsculis arcuatis subdecurrentibus palliscentibus, stipite solido subbulboso. - P'rovenit ad crram.

455. Molibdocephalus. Subcespitosus maguns, pilco umbonato fusco-anco, lancllis latissinis cinerco-pallidis, stipite solislo apice squamuloso. - Ail terram.

486. Innides. Pileo campanulato denimm depresso stipiteque solido ruturis, lanellis subarcuatis cendidis ant sublutescentibus. - Solitarius ad terram?

487. Sinuatus. Nagnus carnosus, pilen Jato sinuato drin depresş alhido rufescente, Jamellis confertis latis rufis, stipite brevi crasso. - Solitarius ad terram.

458. Hariolorum. Cespitosus, pilen convexo tenui alutaceo-pallido, lamellis confertis angustis subconesloribus, stipite toto liirsuto deorsion incrassato. - In sylvis super folia putrida.

489. Curneus. Subparvulus, pileo cannoso convexo subflexuoso carneo rufo, lanellis confentis adnexis albis, stipite mediocri subincrassato pileo concolore. - In graminosis.

49o. Sulphureus. Subsulfureus odoratus, prileo carnoso subumbonato glabro, lamellis distinctis emarginatis, stipite longo cavo flexuoso dilutiore. - Solitarius in sylvaticis autumno.

491. Chrysenterus. Subgregarins flavo-cerinus, pileo hemispherico, stipite solido subincurvo basi albido hirto, pilis erectis. - In ligno foliisque mortuis.

$49^{2}$. Parasiticus. Suhparvus subcespitosus parasiticus, pileo campanulato subrepando albido-pallescente, lamellis distantibus crassiusculis fuscis, stipite incarvo piloso solido. - Parasiticus in agaricis putrescentibus.

493. Phaiopodius. Brnnneo-fuscus, pileo umbonato margine sinuato, laminis candidis basi arcuatis inærualibus ferè liberis, stipitc solido basi incrassato. - Solitunius ad terram.

\section{*** Xaminis stipiti minimè adnatıs.}

49\%. Longipes. Pilco umbonato viscoso rngoso fuliginen-vaccino aut fucescente, lamellis cantidis, stipite longissimo radicato, radice longa fusitormi. - Autumno ad truncos putrescentes.

495. Urens. Gregarius, pilco bemispherico levi, obscurè pallido, lamcllis angustis cinnanıoncis, stipite longissimo solidn, basi villoso striis rufescentibus maculato. - Saper folia mortua.

496. Repens. Gaudice ramosa rubescente repente, pediculos simplices vel ramosos cylindricos vix fistulosos cmittante, pircis C 3 
sulfureis orbicularihus dein irregulariter sinuosis, laminis concoloribus pediculum versus paulò latioribus. - Autumuo in sylvis super folia putrida.

497. Contortus. Radice nigra subconica, stipites flexuosos glabros fusco-nigrescentes pluimos emiltente, pileo concolore convexo centro prominulo rotundato, laminis candidis. - In sylvis arl pedem arborum.

49. Plucinccplualus. Pileo umbonato subrepando badio, lamellis lutescentibus, stipite longo solido subtuberoso. - Ad terram.

499. Fulvus. Pileo insco aut subrubro rotundato, laminis flavieantibus sinnosis basi truncatis, stipite solido basi incrassáto flavo striato, striis rubris. - Ad terran subsolitarius.

50o. Cuccineus. Gregarius totus coccineus, pileo convexo subviscosn, lancllis distantibus dentatim connexis, stipite cavo subcompresso. - In pratis aut locis coliiculosis graminosis.

5or. Gr.mmnceplulus. Pileo convexo interdùm plano, pluribus lituris nigris interruptis radiantibus notato, margine sinuato subferrugineo, laminis dilute flavis basi truncatis, stipite pleno glabro cylindı ico lutescente. - Solitarius.....

502. Phounspermus. Gregarius magnus pallescente-albus, pileo planitisculo, lamellis distinctis semina copiosa rutila gerentibus, stipite subbulboso crassiusculo pileo concolore. - In sylvaticis locis apertis.

503. Cinerascens. 'Totus cinerascens subcespitosus fragilis, pilco rotundato margine subsiunato, laminis latis densis inæqualibus, stipite pleno cylindrico. - Autumno in sylvaticis.

504. Frumentaceus. Helvolus rubescens, lituris subrubris hine inde disseminatis, pileo convexo tandem subconcavo, stipite pleno subcylindrico. - Gregariè.....

505. Mírinacens. Pileo umbrino-nigrescente sulinciso, centro intcrdum rufescente, striis nigris interjectis, laminis griseis sinuosis basi intus emarginatis latissimis densis, stipite pleno sulcato gi iseo, striis nigrescentibus sparsis. - In faginetis autumno.

5o6. Cartilagineus. Pileo nigrescente subdifformi undulato, lamellis alutaceis rotundatis confertis, stipite solido subcinereo striis ruhescentibus variegato. - Solitarius ad terram.

50;. Lividus. Pileo griseo-livido nitido lævi, concentricis zonis aliquandò notato, priuum campanulato dein plano, laminis rubris subsinnosis, stipite albido - rubescente pleno basi incrassato. Solitarius ad tcram æestate vergente.

508. Leucocephalus. Totus albus, pileo prinùm sphærico campanulato plano, margine sinuoso, laminis strictis sul,-adiłrentibus, stipite pleno suberecto, dein nigro maculato. - Gregarius vel solitarius in sylvis.

5og. Villosus. Pileo violaceo pubescentc, laminis aurantiacis, stipite eylindrico pleno candido. - Ad ramos putrescentes delapsos autumno. 
510. Sericeus. Pilen campanulato uitidu piloso-squamoso rufrescute

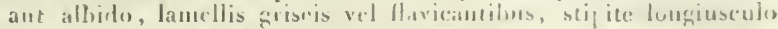
plerumeque striato fistuloses. - Antunno in sylvis.

511. Furfuraceus. Pileo pulverulento Intescente contro mammoso margine sulsinnato, maculis fuscis cencen numetusiorilous, lantellis primo allidis dein flavicantibus, stipite pleno candidn. - Sulitarius vel subeespitosus ail terram.

5r2. Columbarius. Coruleo-violacens ant clalybeus, pileo campanulato dein convexo, nargine simuato scriceo striato, striis nigreserntibus, laminis basi arcuatis, stipite glaloro subtenui ad apicem fistuluso. - In sylvis.

513. Argraraceus. Pileo subalbicante lanato, squamnlis cinereo-nigrescentilus, lantellis stipiterne longiusculo candielis. - In sylvis ad terram; naximè fragilis.

514. Crustuliniforntis. Pileo lavi nitido lateritio-rufo ant pallidoopaco flexuoso, lanellis aquosc cimnanoneis, stipite crasso fibrilloso albido. - ln sylvis et pratis.

515. Cinceus. Pilen conico acuto subvisenso, dilnti: virescente-flavido, lanellis confertis atscendentibus flavescentibns, stipite longo fulvo. - In graminosis.

516. Répandus. Pileo obtusc̀ umbonato pallescente-latcritio, margine repando, lamellis latis pallidis rotundatis, stipite cylindrico albo glabro. - Vere ad terram in sylvis.

5i7. Rimosus. Pileo conico longitudinaliter rimoso subrufescente, lamellis latinsculis olivaceo-argillaceis, nargine albidis, stipite squanmloso farinaceo pallescente. - In sylvis graminosis, in vis, ad terram.

5ı8. Pyrrospermus. Pileo fusco-ferrugineo nigro maculato conrexo dein plano, laminis albis dein rufis anrantis, stipite pleno albo vel pallide flavo. - In ligno putrido.

5r.9. Caulicinalis. Pileo albo subconvexo interdiom umbonato maculis rufis centro variegato, laminis albis basi intirs emarţinatis, stipite tenui rufo infernè subhirsuto. - In equisetis mortuis.

520. Ramealis. Gregarins parvus sabpersistens, pileo hemispherico albido, disco rufescente, lamellis an@ustis confertis, stipite incurvo pulveraceo. - Autumno in ramis mortuis.

521. Inodnrus. Albidus, pileo conico dein plano umbonato, margine subsinuoso intertim lacero, laminis ex fusco-flavis pediculum versùs acuminatis, stipite subflexuoso pleno aut fistuloso.-Solitarius ad terram.

522. Leuenpodius. Pileo tenui umbonato subrepando alutaceo, lameliis latiusculis ciunamomeis, stipite cavo nitido albo.-In sylvis, solitarius.

523 Pleopodius. Pilco flavo-pallescente lxvi conico plano, tandem subconcavo vix carnoso, laninis rufis arcuatis, stipite tenuiore alhido pleno. - Crescit solitarius.....

52i. Geophilus. Subcespitosus, nilco albido-rufescente hemisphxrico C 4 
conico dein plano, margeine lacero, laminis fuscis adscendentibus, stipite rufo pleno erecto tenui. - Ad terram.

525. Tortilis. Albido-rufescens vel fulvus, pileo subcarnoso hemisphærico dein conico, laminis paulò nagis coloratis, stipite pleno siccatione tortili. - Antummo in aridis.

526. Hnrizontalis. Rufescens, pileo convexo orbiculari glabro, laminis latis promincentibus, stipite ferè horizontali apice adscendente pleno. - In rimis truncorun pyri.

9. X. Volva nulla; stipile centrali; laminis nunquàn nigrescentibus, prima atale obtectis nembrana incompleta super pedıculum annulum filanentosum relinquente (CORTIMARIA).

527. Nudus. Colore varins, pileo in centro tantìm carnoso hemispharico, dein regnlariter convexo, tandem irregulariter concaro rel sinnato, laminis strictis, stipitem attingentibus, stipite glabro basi crassinsculo. - In sylvis.

528. Glutinosus. Pileo supremaqne stipitis parte viseosis, pileo cinnamomeo, margine revoluto, laminis albis decurrentibus, stipite pleno, basi cinnamomeo subincrassato, apice albo nigro-maculato. - Solitarius vel gregarius ad terram.

529. Psammoceplualus. Spadiceus, pileo crasso campanulato furfuraceo squamuloso, lamellis latiusculis emarginatis, stipite squamoso, apice lævi tenuiore. - Crescit. . . . .

53o. Turbinalus. Pileo convexo carnoso sordidè luteo centro fuscescente, laminis mfis stipiti adhærentibus, minimè decurrentibus, stipite basi tuberculato squamuloso solido, aunulo filamentoso rubro notato. - Autumno in sylvis imprimis faginetis.

531. Ilenjodius. Proteiformis fuscescens, pilco campanulato dein conico clongato acuto, postcà convexo vel plano umbonato, laminis ex rubro-anrantiacis, stipite apice attenuato subannulato. - Ad terram gregatius aut solitarius.

532. Ayloprilus. Alutaceus, pileo convexo dein plano margine substriato, Jaminis lattis subdecurrentibus, stipitc pleno dein fistulosa sæepiùs basi hirsuto. - In ligno mortuo.

533. Purpureus. Gregarius mediocris coccinco-ruber, pileo subsquanuloso-umbonato, margine stipiteque subbrevi flavescente. - Ad terram.

53\%. Aranensus. Pileo castanco violaceo flavo vel nigro, margine revoluto pedunculo adnato ope membranæaraneosæ, lamin is primù albis dein cinnamomeis rel castaneis, stipite pleno hasi subincrassato. - In sylvis autumno.

535. Hemneorlelis. Subolivaceus seu lutescente-fuscus, stipite oblongo subbulboso hitescente, linea ambienta rubra sæpè notato, lanellis emarginatis lutescente-cinnamomeis. - Subgregarius in fuginetis atutumn'.

556. Castanens. Gregarius subparris, pilco subcarnoso campanulato subbadio aut sordide violacco umbonato, lamellis confertis 
dilnte ferrngineis, stipite cavo subtenui fibrilloso albilo, $-\Lambda_{n-}$ tumno in tiaginetis.

53\%. Camprocephalus. Cespitosus ferruginens, pilco carnosro olıunè umbonato nitente, lamellis latiusculis lecurentibus obsemrioribus, stipite subincurvo solido. - Itabitat. . . .

538. Lamuginosus. Pileo brumneo tomento lanato concolore sensim rarescente tecto, lamellis liberis barliis, stipite pleno nigro substriato. - In candicibus at teriam inter muscos.

539. Mucnsus, Pilen carnoso umbonato viscoso crustallino, lamellis primò purpurascentibus dein feırugineis, stipite transversim in squamas eartilagineo-gelatinosas rupto, primim annulo subobsoleto cincto. - In sylvis ad terram.

5fo. Hy bridus. Pileo obconico flavo-rulescente spherico convexo plano, margine revoluto, laminis subdecurrentibus flavis mentbranat caducia alloa hine indè obtectis, stipite carnoso solido pilco concolore. - Ad terram.

54r. Hydrophilus. Cespitosns, pileo rufescente-ferrugineo, margine striato vel sinnoso, laminis ntumerosioribus cinnanomeis liberis, stipite allo fistuloso. - Abundè in sylvis post pluvias.

5:2. Squammosus. Fusco-nigricans totus squamulosus, pileo margine subciliato, laminis ferè rectis non tecurrentibus, stipite in centro molli apice albo squamis destituto. - In sylvis autumno.

9. XI. Volva nulla; stipite centrali annulato; laminis nunquilm nigrescentibus prima atate obtectis nembrana plerumquè lacera deindè in annulum nutata (LEPTOTA).

5ł3. Piluliformis. Cespitosus parrus rufesceus, pileo ferc̀ sp̣hærico rufescente, margine integro albo, laminis albis liberis, stipite albo fistuloso. - Autumno inter muscos ad pedcs arborum.

5㹐. Coronilla. Pileo fnlvo-rufescente maximè convexo umbonato, laminis liberis rotundatis rubris, stipite albo vix fistuloso, annulo rotundato integro fugaci. - Crescit solitarius.....

5.15. Nitens. Solitarius, pileo helvolo nitente campanulato dein conrexo, laminis nigro-albo maculatis, stipite albo pleno tenui, lasi subincrassato annulato, annulo persistente. - In pratis et sylvis.

546. Cepcestipes. Albirlus cespitosus, pileo campannlato striato, lamellis liberis, stipite basi ventricoso solido annulato. - In fimctis et in cortice quercino.

547. Helvenlus. Gregarins mediocris, pilco subcarnoso nmbonato subciananomeo, lamellis distantibus concoloribus, stipite longinsculo eylindrico deorsùm annulo obsoleto cincto. - In sylvis, locis graminosis, viis.

5\{8. Annularius. Cespitosus congestus, pileo umbonato pilososquamoso ochraceo fuliginco, lamellis subdecurrentibus albidis palleseentibus, stipite annulato cơnico oliraceo-cinereo. - In sylvis ad arbornm truncos.

549. Aureus. Fulvo-aureus, laminis candidis, pilen globnloso dein convexo, lituris parvis nigris variegato, stipite pleno, basi subattenuato et incurvo annulato. - In unbrosis humidis. 
5.jo. Raticnsus. Submagnus compactus durus, pileo plano-convexo obtusè umbonato pallescente maculis sordidè rufis variegato, lamellis congestis rufescentibus, stipite firmo denrsim incrassato radicato squamoso, squanis erectis. - In sylvis umbrosis ad truncos.

55r. Ochraceus. Mediocris subgregarius, pileo subcarnoso umbonato fermgineo, lamellis confertis plerumquè pallidis, stipite squamoso anuulato. - In ericetis atque pinetis.

552. liamentaceus. Solitarius, pileo planiusculo obsoletè umbonato argillaceo, diseo obseuro, margine flavescente squamuloso, lamellis dilute tuligineis subadnexis, stipite solido albido flavomaculato glabro, annulo brevi. - Ad terram.

553. ALesomorphus. Subgregarius parvus, pileo subumbonato glabro stipiteque flaveseente, lamellis latissimis liberis candidis, annulo erecto. - Ad terram.

55\%. Pudicus. Pileo albo aut fusco carnoso rotundato globuloso dein convexo plano, laminis arenatis liberis concoloribus, stipite semper flavo maculato latè annulato, annulo suprà striato. Solitarius.

555. Tngularis. Flareseens subargillaceus seu dilutè ferrug̨ineus, lamellis subventricosis demùm liberis, stipite longiusculo cavo, annulo reflexo. - Ad terran.

550. Hamatospermus. Gregarius tenuis, pilen umbonato demùm subdepresso flavescente argillaceo glabro, lamellis ventricosis liberis lateritio-rubris, stipite tenui pileo concolore, annulo parvo erecto.-Arl terram.

55-. Clypeolarius. Pileo campanulato squamoso jallescente, squamis inajusculis sparsis rufescentibus, lamellis albidis libecis, stipite longinseulo floccoso-villoso molli, ansulo fugaci. - In sylvis.

55S. Procerus. Magnus, pileo carnoso unhonato squamoso rufescente-cinereo, lamellis remotissimis albidis, stipite bulboso longissimo, annulo mobili. - In arenosis.

5. XII. Volsa prina atate fungum totum vestiente, fragninibus demium in pileo relictis (AMANITA).

\section{* Volva incompleza.}

559. Asper. Pileo carnoso compacto ruluescente-fuliginco, verrucis acutis aspero, lamellis confertis candidis, stipite longo fibrilloso subbulboso. - In sylvis restate.

560. Solitarius. Sordidè albus, pileo plano medio subdepresso verrucoso aspero, laminis latis pedienlo mininè adnexis, stipite pleno erecto bulboso squamoso annulato. - In umbrosis.

561. Muscrurius. Pileo aurantio-rubro nitido planiuseulo, verrucis lamellis stipiteque candiais. - In sylvis.

$$
\text { ** Volva comeleta. }
$$

563. Aurantiacus. Pileo campanulato aurantio-rubro, lamellis ventricosis aureis, stipite albo.- In pinetis astate ct ineunte autumno. 
563. Verruensus. Pilen hemispharico helvolo citrino, lamellis stipiteque allbis. - In sylvis arenosis.

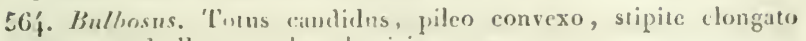
attennato bulboso. - Iu sylvaticin.

565. Vernus. Arris totns cindidus, pileo demum subinfundibuliformi, stipite longo solido cyliudrico. - In sylvis.

566. Pusillus. Pileo hemisplurrico unbonato, lamellis venticosis roseis, stipite breviusculo albido, - In sylvis et hortis.

56-. Volvaceus. Cespitosus, pileo campannlato conico piloso cinereo nigroque variegato, lamellis pulvernlentis rubro-cinnanomeis. - In vaporaris inter pulverem erriarim.

568. Vas̆matus. Pileo mubonato planiusculo striato, plumbeolividu, limellis candidis. stipite basi volva vaginato. - Ad margines nemorum, imprimis pinetorum.

$$
\text { 29. } M \text { O } R \text { C }
$$

Stipes teres volva destitutus; pilens sæpiùs stipiti intùs adharens, extus areolis lacunosns; latex seminalis unllus.

569. Agarienides. Pileo campanulato apice tantùm stipiti adlıxrente. - In sylvis circà Parisios.

5-o. Semi-libera. Pileo conico basi libern.-In sylvis circà Parisios. 571. Esculenta. Pileo ovoideo basi contracto, stipite cylindrico sæpiùs farcto. - In sylvis vere.

5;2. Tremellnules. Pileo amplo celluloso lobato undulato, stipite brevi crassissimo. - Circà Pontchartrain.

5-3. Crassipes. Pileo brevi celluloso acuminato, stipite infernè dilatato supernè attenuato. - Circà Pontehartrain.

57亿. Rimosipes. Pileo conico basi subcontracto, stipite elongato rimoso caro. - In sylvis circà Fontem-bellaqueum (Fontainebleau).

$+\dagger+\dagger+$ Fungi volvati, hymenio seu membrana fructificante in laticem gelatinosum demum soluto.

$$
\text { 50. P H A L L U S. }
$$

Stipes basi volvatus; pileus ovatus integer latice difluente obtectus.

5-5. Impudic:s. Stipite cribroso subobliqno, pileo celluloso pervio.

- In sylvis ineunte antumno.

5-6. Hadriani. Stipite tereti maculis cincraceis distincto, pileo Iævi glabro, ore prominente amplo. $-\Lambda \mathrm{d}$ ripas Ligeris propè Blesias olim reperit Clusius. $t$

$$
\text { 5I. C L A T II R U S. }
$$

Pileus sessilis, junior volvatus, cavus, ramis anastomosantibus eancellatus, latice difluente ohtectus.

577. Cancellatus. - In Gallia meridionali. 


\section{T R I B U S I I. A N G I O C A R P I.}

Fungiquorum capsulce saltem immaturo, in receptacuto undiqué clauso (peridio) inclueluntur.

+ Peridium nullum. Fungi parasitici sub epidermide majorum plantarum nascentes et ab ea protecti.

52. G Y M N O S P O R A X G I U M.

Fungus gelatinosus iu cortice juniperorum parasiticus; capsulx bilocnlares, medio transversè dehiscentes, apice pedicellorum gracillimorum longorum per massum gelatinosam transeuntium insidentes. 5-9. Conicum. Lnteo-fulvum conicum obtusum, hasi cohærens.-

In cortice juniperi communis et juniperi sabinx.

5-9. Fuscum. Luteo-fuscum conicun clongatum chlusum, basi discretum. - In cortice juniperi sabinæ et juniperi virginianæ.

58c. Clavariaforme. Lutco-aurantiacum cylindricum sulycompressum simplex aut bifurcatum, - In cortice juniperi conımunis.

\section{P U C C C I}

Peridinm nullum; capsulx uni ant multiloculares, apice dehiscentes, pedicellatæ, disco subcarnoso insertæ. I ungilli fúsei aut nigri in cespitulos $\left(^{*}\right)$ aggregati, in foliis vivis parasitici.

\section{j. I. Capsulis multilocularibus.}

5Sr. Rnsa. Cespitulis nigris hypophrllis subpulveraceis, stipitc albo filiformi basi incrassato, capsula tereti 3-5̃ocnlari nucronato-acuminata. - Ascophora disciflora a 'iod. mckl. t. 3. f. 26. - In rosa alba et rosa centifolia, super uredinem rosæ sæpè parasitica.

5S2. Rubi. Cespitulis nigris hypoplıyllis subpulveraceis, stipite albo filiformi basi incrassato, capsula tereti 3 - Inculari brevissime inucronulata. - Ascophora disciflora E. Tud. mehl. i. 3. f. 27. In rubo fruticoso, rubo cæsio.

$582^{*}$. Potentillee. Cespitalis nigris hypophyllis snbcompactis, stipite albo filiformi, capsula tercti Lloculari ibursa. - Puccinia potentillx, Pers. Syn. 229. - In foliis subaridis potentille vernæ.

5S3. Ulmi. Cespitulis fusco-nigris hypoplyllis subpulveraccis, stipite albo filiformi, capsula tereti 3-jliculari obtusa. - Iu ulmo campestri. +

58\%. Sperzula. Cespitulis fuscis sparsis compactis, stipite albo filiformi, eapsula tereti 2 -3loculari obtusa. - In spergula arvensi.

$\left(^{*}\right.$ Cespituli dicuntur hypoplyylli cirn in inferiore folii pagina, repiphylli cium in superiore, lifiontes cum sinnl isdem locis in utraque pagina, sparsi cum iniliscriminatin in duobus folii paginis in periolo et caule, petiolares ciun in petiolo, caulini cum in caule mascautur. 
585. Jasmini. Cespitulis fuscis hypophyllis compactis epidermide rupta cinctis, stupite albo filiform rigidulo, capsula tercti ubtusa isthmis 2-3loculari. - In jasmino fruticante.

\section{11. Capsulis bilocularibus.}

5S6. Adoxe. Cespiulis fuscis spausis irregularibus confluentibus, stipite brevi, capoula biluculari obtusa. - In adoxa moschatchlina.

$586^{*}$. Feronicarum. Cespitulis fuscis hypephyllis annulatis, stipite brevissino, capsulis minimis receptaculo parum adherentiblis. - In veronica pona et urticafulia.

$5 S 6^{* *}$. Limonii. Cespitulis rufo-fuscis sparsis convexis oblongorotundis, stipite albo tenui articulato capsula duplo longiori capsula clavata ilemion ovoidea. - In statice limonio.

$586^{* * *}$. Asparagi. Cespitulis fuscis sparsis ovato-oblongis convexis, stipite diseo aretè insesto, capsula oblonga obtusa isthmo biloculari. - In asparago officinali.

557. Dianthi. Cespitulis rufo-fuscis hypophyllis suljcompactis annulatim aut concentrici disposius, stipite fongo, capoula isthmo bilocnlari tereti apice subattenuata. - In diantho carthusianorum hortensi.

588. Circea. Cespitulis rufescentibus hypophyllis orbiculatis epidertuide tesstalatim rupto suloccultis, stipite Jonginsculo, capsulit istlmo biloculaı i utrinqué acuta. - In circca Lutetiana.

58 . Avicularice. Cespialilis fuscis, caulinis oblongis, lypophyllis subrotundis, perlicello longo flaccido, capsula ovoidea ubtusa biloculari. - In poligono avicularia.

5yo. Killis. Cespitulis fuscis epiphyllis orbicularibus epidermile rupta cinctis, stipite brevi, capsula cylindrica obtusa biloculari. - In ribe rubro.

591. Calcitrape. Cespitulis nigris hypophyllis hemisphæricis, stipite brevi, capsula ovato-tereti obtusa biloculari. - In centaurea calcitrapa.

$5 \mathfrak{y}^{*}$. Stachydis. Cespitulis hypophyllis orbicularibus convexis persistentibns fusen-nigris epidermide non cinctis, capsula oblonga obtusa isthmo biloculari, - In stachyde sideriti.

592. Menthe. Cespitulis nigris hypoplyyllis hemisphæricis pulveraceis, stipite brevi filiformi basi subincrassato, capsula tereti obtusa istlimo biloculari. - In mentha aquatica, mentha silvestri, mentha exigua.

593. Tanaceli. Cespitulis fusco-nigris bifrontibus epidermide rupta cinctis orbiculatis sen irregularibus, stipite filiformi elongato, capsula tereti obtusa biloculari. - In tanaceto vulgari.

594. Pruni. Cespitulis fuscis hypophyllis orbiculatis ant subconfluentibus, stipite brevi, capsula tereti isthmo biloculari scabra obtusa. - In pruno spinosa et domestica.

595. Anemones. Cespitulis fuscis hypo-et-epiplıyllis hemisphæricis sæpiàs scriatis et marginalibns, stipite hrevi, capsula isthuo profundo bilocnlari utrinquè rotundata. - In anemone nemorosit. 
596. Graminis. Cespitulis i luteo fuscis et nigris sparsis linearibus parallelis, stipite brevi, capsula biloculari subclavata, loculo ultimo majori. - In graminibus variis.

59 -. Scirpi. Cespitulis nigrescentibus caulinis compactis subrotundis epiclernide tissili et elevala suboccultis, stipite brevi, capsula biloculari subclavata, loculo ultino majori globoso. - In culmis subemortuis scurpi lacustris.

59s. Pid goni amplubii. Cespitulis rnfo-fuscis lypophyllis parvulis orbiculatis, stipite brevi, capsula biluculari. Inculo inferiore longo angnsto, superiore crasso gluboso. - In polygouo amphibio var. terrestri.

$59 S^{*}$. Polnspermi. Cespitulis bifrontibus planis rotundatis nigris vix epidermide rupta cinctis, stipit brevi, capsula ovata biloculari sepimento transverso manifesto. - In podospermo laciniato.

\section{III. Cupsulis unilocularibus.}

599. Plansentorum. Cespitulis è rufo nigris hypo-et-epiphyllis orbicularibus epidernide rmpta cinctis, stipite longiusculo, cansula ovoidea unil cculari. - Chantr. Conf, n. 61.t.24. f. 6r. - In phaseolo vulgari.

6oo. Laburni. Cespitnlis fuscis hypoplyyllis primò orbicularibus dein confluentibis, stipite brevi, capsula ovoidea uniloculari. In cytiso laburno.

6or. Pisi. Cespitulis fuscis sparsis orbiculatis sen oblongis epidermide rupta cinctis, stipite brevi, capsula ovoidea uniloculari. In piso sativo.

601*. Hedysari obscuri. Cespitulis fusen-nigris epiphyllis orbiculatis, stıpite brevissimo, capsıla uniloculari ellipsoidea utrinquè attenuata. - In luedysaro obscuro.

602. Plyteumarum. Cespitulis fuscis hypophyllis primò orbiculatis interdim eonfluentibus epidermide primo elevata demùm rupta cinctis, stipitc longiusculo, capsula ovoidea uniloculari. - In phytenma spicata et phyteuma orbiculari.

6o3. Ficaria. Cespitulis fuscis petiolaribus et hypophyllis, ab origine confluentibus, epideruide primù elevata clausis deiu rupta variegatis, stipite longiusculo, capsula ovoillea uniloculari. - In ficaria .

$603^{*}$. Cacalia. Cespitulis rufo-fuscis hypophyllis orbicularibus subplanis, capsulis ovatis numerosissimis substipitatis. - In cacalia petasite.

6o4. Trifolii. Cespitnlis rufo-fuscis sparsis oblongis ant irreqularibus epidernide rupta cinctis, capsula oroidea uniloculari substipitata. - In trifolio repente, trifolio filiformi, trifolio liybrido.

$$
\text { 34. L U L L A R I A. }
$$

Peridium nullım; capsulæe sessiles biloculares. Fungilli caspitosi sub epidermide plantarum subenortuarum nascentes.

605. Unbelliferarum. - In caulibus unbelliferarum. 


\section{F U N G I. \\ 55. U R F D O .}

Peridimm nullım; eaysule sessiles miloculares. Fungilli erspitosi sub epernide foliormm et caulium herbacearum orti et epidermide rupta faeilè dispersi.

\section{I. Pulvere nigro fusco seu rufo.}

6o6. Scutellata. Cespitulis fusco-nubrinis hypophyllis smpius arl margines folii seriatis orbieulatis planiusentis epidermide 1 upta cinctis, capsulis subglobosis. - In euphorbia ciparissia.

6oz. Excavala. Cespitnlis fnscis hypoplyllis parvulis numerosis orbiculatis subimuersis nempè epidermide subinflato cinctis, eapsulis subovoidcis. - In eupliorbia dulci.

6o8. Sedi. Cespitulis è luteo fuscis hypo-et-epiphyllis orbienlatis epideruide intlata cinctis subapertis, ore minuto depresso, capsulis globosis. - In foliis jropaginum stcrilium scdi reflexi et semperrivi montani.

Gog. Suaveolens. Cespitulis rufo-fuscis liypoplyllis planiuseulis numerosis conflucntibus, eapsulis globosis. - In serratula arvensi.

Goon ${ }^{*}$. Faba. Cespitulis sparsis numcrosissimis rotundatis vel irregularibus depressis epidermide partim relicta cinctis, eapsulis spliæricis. - In faba.

610. Vagans. Cespitulis rufo-fuscis hypophyllis rariùs cpiphyllis distantibus orbiculatis epidermide rupta cinctis, eapsulis globosis aut subovoideis. - $a$ In epilobio tetragono, $\beta$ in valeriaua silvestri, $\gamma$ in polygono amphibio, $\delta$ in viola odorata: an species plurimæ hic confuse?

6 ro*. Geranii. Cespitnlis fuscis hypophyllis orbicularibus cpidermide rupta cinetis, tanden pulvere diffuso subirregularibus, cap. sulis globosis. - In geranio aconitifolio.

611. Alhamanthre. Cespitulis è spadicco nigris hypo-et-interdùm epiphyllis distantibus oblongis seu orbiculatis, eapsulis ovoideis parvulis. - In athamantha cervaria. $t$

612. Cichoracearum. Cespitulis fuseis bifrontibus distantibus minimis orbicularibus epidernide rupta sæpius cinctis, capsulis glubosis. - In taraxaco, leontodontibus et aliis cichoraccis.

$612^{*}$. Cyani. Cespitulis fuscis hypo-et-rarius epiphyllis distantibus ovalibus parvnlis, capsulis globosis. - In centaurea cyano.

613. Anemones. Cespitulis nigris hifrontibus oblongis scu linearihns epidermide elevata et crispata irregulariter cinctis, capsulis globosis. - In ancmone nemorosa sxpè cum puccinia anemones mixta.

C14. Pifrons. Cespitulis rufis bifrontibns distantibus orbienlatis epidermide rupta cinctis, capsulis globosis. - In rumiee crispo.

615. Segetum. Cesnitulis maximis irregularibus fuse sen nigris organa fructificationis occupantibus, capsulis globosis parvulis. In glumis et fructibus hordei, tritici, avenie, panici miliacci, agrostidis punilæ, caricis, mays zcæ. In may semina usque ad an.snitudinem nucis inflat et pulvere nigro replet. 


\section{§. II. Pulvere luteo.}

616. Mycophila. Capsulis sphæricis prinù albis deindè flavo-aureis pulvere copioso fungum penetrante et obtegente. - In variis fungis prasertim in boleto chrysentero. $t$

617. Salicis. Cespitulis flavis hypopbyllis et sparsis subdepressis, capsulis pyriformibus subpedicellatis. - In salice triandra.

618. Filellince. Cespitulis anrantiaco-flavis hypophyllis conrexis orbicularibus demuin confluentibus, capsulis sphæricis. - In salice vitellina.

$618^{*}$. Capicrarum. Cespitulis aurantiaco-flavis hypophyllis conflueutibus proninulis numerosis, fulvere copioso. - In salice capria aurita et acuminata.

619. T'usilaginis. Cespitulis aurantiacn-flaris hypophyllis subconcentricis pulverulentis deuim confluentibus. - In tussilagine furfara.

620. Senecionis. Cespitulis croceo-anreis hypophyllis oblongis aut irregularibus demùn confluentibus, capsulis sphæricis. - In senecione vulgari.

621. Potentilla. Cespitulis aurantiacis sparsis convexis oblongis aut irregnlaribus, capsulis sphæricis. - In potentilla verna.

622. Rielinscopice. Cespitulis hypophyllis aurantiacis distantibus subplanis epidermide rupta cinctis, cápsulis subglobosis. - In euphorbia liclioscopia.

623. Rose. Cespitulis anreo-flavis hypophyllis orbicularibus confertis, pulrere effuso copioso, capsulis sphæricis. - In rosa centifolia.

62f. Linearis. Cespitulis ì flavo demùm fuscis bifrontibus, capsulis ovoideis. - In foliis gramincarum.

$621^{*}$. Caricis. Cespitulisè flavo demùm fuscis hypophyllis minimis oblongis epidermide longitudinaliter rupta, capsulis sphæricis. In carice cyperoide.

625. Populina. Cespitulis flavis hypophyllis rotundatis aut oblongis rupta epidermide cinctis, pulvere copiosissimo, capsulis elongatis cyliudricis ntrinquè obtusis. - In populo nigra. - Uredo populina, a. Pers. Syn. 219. Uredo longicapsula. Fi. fr. 11. 625. Lycoperdon populinum. Jacr. Coll. 5. t. 9. f. 2. 3.

$625^{*}$. Alchemilla. Cespitulis pallide-flavis hypophyllis rotundatis sæpius oblongis lincaribus subparallelis rupta epidermide cinctis, capsılis sphæricis. - In alchemilla vulyari locis montanis.

626. Confluens. Cespitulis pallide-flavis hypophyllis enncentricis confluentibus, pulvere mox effuso. - In mercuriali perenni.

627. Rubizo. Cespitulis flavo-rubiginosis hypophyllis subdepressis denium confluentibus, epidermide diversissime rupta, capsulis ovatis. - In campanulis, soncho arrensi, rubo saxatili, etc.

629. Rubi ideri. Cespitulis flavis epiphyllis distantibus annulatis, pusculis 
pustulis centro depressis, capsnlis ovatis subspharicis. - In rubu iilieo.

629. Luborum. Cespitulis anrantio-flavis mbiculatis aut olungers, hypo-et-rariins eppiphyllis, capsulis ovatss subsphatericis. - Lu variis rubi speciebus.

63o. Lini. Cespitulis Ilavo-aurantiacis sparsis plerumqnè epiplyyllis convexis ovatu-rotumlis, capsulis sphas icis. - In 'ino cathaticu.

631. Pinguis. Cespitulis flavo-rubiginosis sparsis crasnis convexis rupta epidermide cinclis, capsulis oblongis. - lu rosa ansuiaca, rosil alpina.

632. Prominens. Cespitulis flavis demum fuscis hypoplyllis epidermile mpta cinctis, convexo-planis, capsulis sphæricis. - In cuphorbia.

633. Punctata. Cespitulis flavidis hypophyllis convexis orbicularibus, punctis nigris maculatis. - Au at spheriac „entus referenda? -In varis enphorbir speciebus.

63\%. Ecidinilles. Cespitulis aurantiacis hypoplıyllis latè extensis, oblongo-sinuosis vix pulverulentis epiderne rupta cinctis, capsulis glabulosis. - In populo albo.

635. Petasitis. Cespitulis flavo-aurantiacis hy pepliyllis sinuosis, epidermide prominula granulosa, nequaquà rupta cinctis, capsulis ovatis, - In tussilagine petasite.

\section{III. Pulvere albo.}

636. E Flora gallica deleatur.

$636^{*}$. Cruciferarum. Cespitulis albis hypoyhyllis latis subdepressis, epidermide sicpius clansa tectis, pulvere copioso, capsulis globosis. - In variis crucileris.

637. Tragnpogi. Cespitulis albis sparsis oblongis minimis semper inapertis, capsnlis splıxicis. - In tragopogo porrifolio.

$6.37^{*}$. Petroselini. Cespitulis albidis sparsis rotundato-oblongis conflnentibus, epidermide hullata convexa serù rupta tectis, pulvere copiosissimo. - In apio petroselino.

\section{†† Peridiis membranaceis, pulvere filamentis non intertexto repletis.}

\section{6. 压 C I D I U M.}

Peridia manifesta teretia membranacea, apice dehiscentia, ore circulari dentato. Pulvis farinaccus, filamentis nequaquàm iutermixtns. (1 ungilli in foliis vivis parasitici.)

f. I. Periliis distinctis, nec glomeratis nec annulatim dispositis.

63S. Pini. Sparsnm exsertum, peridio pallide-flavo oblongo-compresso, pulvere aurantiaco copiosissimo, cipsulis sphæricis. - Ad corticem et in foliis pini sylvestris.

639. Pelligerce. Epiphyllum granulosum hemispluxicum cinuabarinum, capsulis sphæricis. - In peltigera canina. 
64o. Epilobii. Hypo-ct-rarius epiphyllum, peridis sparsis distinctis albidis, ore eroso expanso caduco, pulvere aurantiaco demum obscuriori. - In epilobio tetragono.

64i. Rubi. Hypophyllum planiusculum, peridii margine albido orbiculari promianlo integro vel subdentato, pulvere flavo-fusco. - In rubo fruticoso.

642. Leucospermum. Hypophyllum, peridiis cylintricis prominulis albidis, ore crasso ut plurimum dentato, pulvere copioso albo. - In anemone nemoros.l.

6ł3. Punctatum. Hypophyllum, peridiis hemisphæricis pallidètlavis, ore integro, pulvere fusco. - In anemone ranunculoide.

64千. Cuhoracearum. Sparsum sæpiùs hypophyllnm, peridiis hemispharicis albidis, ore inæquali lacero, laciniis paucis latis reflexis, palvere flavo. - In caule et foliis tragopogi pratensis et pollospermi laciniati.

6 4 5. Violarum. Sparsum, peridiis numerosis approxinatis subprominulis albidis, ore dentato, pulvere aurantiaco demum obscuriori. - In viola tricolore et viola calcurata.

6ł6. Periclymeni. Hypophyllum, peridiis numerosis, primò subglobosis dein subconicis, ore dentato, pulvere flavo-aurantiaco. - In caprifolii periclymeni foliis suprà macula flara notatis.

647. Cyparissiae. Hypophyllum, peridiis numerosissimis pallidèflavis primò punctiformibus prominulis, ore subintegro reflexo. pulvere aurantiaco demim fusco. - In euphorbia cyparissia.

6ł8. Euphorbice sylvatica. Hypo-ct-rariùs-epiphyllum, peridiis remotis, ore subintegro reflexo, pnlvere aurantiaco. - In euphorbia sylvatica.

\section{II. Peridiis in annulum circularem dispositis.}

649. Tussilaginis. Hypophyllum, macula suprà purpurascentetlava, perielis immersis conflnentibus brevissimis albidis, marmargine dentato. - Iu tussilagine farfara.

65o. Rubellum. Hypophyllum, froude suprà rubro maculata, peridiis minimis confluentibus sub-immersis pallidé-flavis, pulvere albo-flavescente. - In rumice aquatico, rheo ct centaurea.

65ı. Asperifolii. Hypophyllum, folio supernè excavato, peridiis albidis confluentibus cyathiformibus, ore lentato, pulvere anrantiaco. - In diversis borragineis.

652. Rlaamni Alpini. Hypophyllum, folio suprà subrubente, peridiis hemisphæricis flavo-aurantiacis, ore dentato, pulvere flavido. - Folio macula subrubescente.

653. Arunci. Hypophyllum, rarius petiolare, fronde suprà flavescente, peridiis paliide-flaris primò conicis obtusis dein cylinJricis, ore suberecto dentato, pulvere aurantiaco - In spirxa arunco.

65\%. C'ematitis. IIypophyllum, folio suprà macula fusca notato, perilliis pallidè flavis, ore subdentato Jemùm evanescente, pulvere flavo. - In clematite ritalba. 
65; . Nymphoidis. Epiplyllum, in zonas concentricas subregulares dispositum, penirliis confluentibus immersis, one integro, pulvere aurantiaco deminn fuscesecnte. - In villarsia nymploside.

\section{\$. III. Peridiis irregulariler glomeratis.}

655. Urtice. Sparsum confertum, peridiis campanulatis flavis, orc dentato, pulvere primina flavo, demim rufo. - In urtica dioica.

656. Barbarea. Bifrons, folio circi fusecsente, peribliis subtis confertissimis orliculatibus, ore albido crenulato, pulvere aurantiaco. - In erysimo barbarea.

657. Prenanthis. Hypophyllmm, peridiis pallide amrantiacis subelongatis, ore crasso integro, pulvere pallidiore. - In penanthe murorum et prenanthe purpurea.

658. Crassum. Sparsum, irregulariter glomeratum crassum convexum, peridio subelongato aurantiaco, pulvere concolore. - In rhanuo frangula.

659. Confertum. Hypophyllum, folio circa albescente, peridiis confluentibus albidis, ore dentato, pulvere flavo demùm fusco. - In ficaria ranunculoide, viola odorina.

66o. Irregulare. Hypoplıyllım, maculis subfuscis crassinseulis suprà punctatis, peridis pallide-flavis primò cylindricis obtusis, demùm suberanidis. - In shamuo cathartico.

66ı. Unilaterale. Hypophyllum, folio cirè fuscescente, peridiis flavo-aurantiacis in gloneros oblongos dispositis, oue crasso integro. - In anemone narcissiflora.

$661^{*}$. Bunii. Sparsum, fronde bullata difformi, peridiis numerosis subdistinctis orbicularibus vel ovatis flavo-aurantiacis, ore subiutegro. - In bunio bulbocastano.

662. Bifrons. Bifrons, maculis rotundis vel oblongis suprà planis subtus convexis nigris, peridiis campanuiatis, pulvere flavo copioso. - In aconito lycoctono.

$662^{*}$. Ranunculi. Hypophyllum, peridiis paucis in glomerulos coalitis pallidè aurantiacis subprominulis, ore lacero reflexo. - In ranunculo bulboso.

663. Erythronii. Bifrons, maculis rotundo-oblongis albidis, peridiis orbicularibus flavis, ore subintegro, pulvere aurantiaco. In erythronio dente-canis.

66'. Berberidis. Hypophyllum, cespitulis rotundis convexis, folio suprà macula rubia notato, peridiis cylindricis serò dehiscentibus flivo-aurantiacis, ore sexdentato. - In berberide vulgari.

665. Cornutum. Hypophyllım, macula granulosa aurantiaca, peridiis paucis griseo-flavis longis eylindricis sulacutis erectis deindè reflexis, ore demùm dentato, pulvere griseo-ruliescente. - In sorbo aucuparia.

666. Laceratum. Hypophyllum, peridiis in lacinias capillares apice divergentes profunde fissis. - In malo sylvestri, cratægo oxyacantha aria et cliamæmespilo. 
667. Cancellatum. Hypophyllum, folio subtis tubcrculato, peridiis in lacinias capillares apice colixrentes demùm fissis. - In pyro communi.

$$
\text { 57. M U C o R. }
$$

Peridium membranaceum globosum stipitatum, primò subaquosum pellucidum, dein opacnm; pulvere mudo filamentis haùd intermixto.

668. Ramosus. Stipite ramoso, peridiis globosis primù albidis dein rufis. - Cespitosus super fungos putridos.

669. Mucedo. Stipite sinuplici, peridio inflato primùm albido, demùm nigrescente-griseo. - Cespitosus in putrescentibus.

$$
\text { 58. L I } \mathbf{c} \text { 上 } \mathbf{A} \text {. }
$$

Peridinm sessile membranaceum fragile. Pulvis seminalis filamentis destitutus. Membrana subjacens nulla.

67o. Circumscissa. Gregaria spadicea, peridio circumscisso. - Surò autumno in ligno mortuo.

$$
\text { 59. T U B U L I N A. }
$$

Peridia plurima sessilia plerumquè cylindrica, membranæ subjacenti imposita. Pulvis seminalis filanentis destitutus.

671. Cylindrica. Peridiis cylindricis elongatis apice obtusis albidis, demùm apice subdentatis. - In liguo mortuo et humido.

6-F2. Fragiformis. Peridiis basi attenuatisapice dentatis, primù rubris posteà rubiginosis persistentibus. - In ligno mortuo humido.

\section{$\uparrow+\dagger$ Peridio membranaceo, pulvere filamentis intermixto.}

$$
\text { 40. T R I C H I A. }
$$

Peridia sessilia aut stipitata membranæ communi imposita. Filamenta stipiti aut peridio adhærentia, globuligera.

5.I. Peridio ovoideo vel sphterico, sessili aut stipitato, irregulariter dehiscente ( $\mathrm{SPH}$ жROCARPUS).

673. Chrysosperma. Conferta flavo-aurantiaca nitida, peridio sphærico sæiùs sessili persistente. - In ligno mortuo.

$63^{3 *}$. Ovala. Congestá sessilis ochracea, peridio obovato sessili. In sylvis super lignum putridum aui strata muscorum.

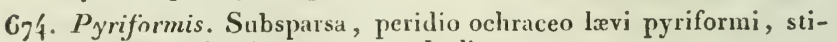
pite breviusculo nigrescente. - In liguo mortuo.

$6-4^{*}$. Botrytis. Stipitata fasciculata opaca atro-rubescens, stipitibus elongatis connatis subracemosis. - In ligno putrido.

675. Fallax. Simplex stipitata primò rubra dein argillacea, peridio infernè cum stipite plicato. - Autunno in truncis humidis.

676. Utricularis. Simplex membrana ferruginea evancscente, stipite brevi flaccido rufescente, peridio inflato lævi albirlo. - In ligno mortuo. 
677. Antiades. Stipite sippius rammso vigrescente, peridio glohoso lutescente linc is flexusis uotatusursum dehisecutc, pulvere aigrescente. - lu ligno mortuo.

6-8. I'urbinata. Stipite simplici elongato lævi, peridio anrantiaco vel rubiginoso turbinato denùn truncato, pulvere griseo-ruliescentc. - In ligno nortuo.

6-9. Allba. Stipitata cinereo-allida peridio Lenticulari glabro ruguloso nutante. - In truncis et foliis mortnis lımidis.

68o. Iutea. Stipite cylindraceo gracili, peridio lenticulari grannloso albo, capillitio llavo, puivere flavo aut fusco. - In ligno mortuo.

68ı. Viridis. Stipite gracili lateritio, peridio lenticulari.viridi granuloso, pulvere et capillitio fusco-nigrescentibus. - Ad terram et in truncis nortuis.

682. Aurantia. Stipite nigro striato deorsùm incrassato, peridio subrotundo lutesecnte, pulvere nigro. - In ligno mortuo.

6S3. Globulifera. Stipite brevi flavo ant rubro, peridio sphærico ex albo nigrescente, pulvere nigro globulis hiteis intermixto. - In ligno putrido.

\section{II. Peridio stipitatn ad dimidium evanescenie, receptaculo caljeuiato persistente (ARCIRIA).}

684. Capsulifer. Snbstipitata, peridio subovoideo primò nigrocasio deindè albido, capillitio globulisque nigreseentibus. - Super muscos.

685. Nutnns. Flava substipitata, peridio subtereti, capillitio longrissimo nutante. - In ligno mortuo.

656. Cinerea. Cinerea stipite brevi apice snbattenuato, peridio primùm albo molli, receptaculo crenulato striato. - In ligno mortuo.

687. Cinnabarina. Congesta substipitata eroceo-punicea, peridio oblongo, pulvere cinnabas ino. - In ligno mortuo.

688. Coccinea. Coecinea, stipitata, peridio sphærico, capillitio fugace. - In ligno mortuo.

9. 1II. Peridio temuissimo, aui toto, aut ad dinidium evanescente, nervos reticulatos aut cancellatos relinquente (CRIBRARIA).

689. Semi-cancellata. Stipite simpliei striato nigresecnte sub finem

nutante, peridio globoso flavo demìm rufescente.-In ligno mortuo.

69o. Reticulata. Rubra, stipite breviuseulo lævi, peridio globoso erecto. - In ligno mortuo.

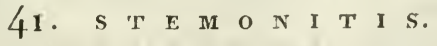

Peridia stipitata membranæ communi inposita ; pedicello axiformi, intrà peridium prodncto.

69r. Fasciculata. Cespitosa major, stipite nigro, peridio oblongo demìn elongato, cortice toto evanescente. - Autumno super truncos mortuos et muscos. 
Gy2. Typhnides. Sparsa minor, stipite nigro, peridio cylindrico subincurvo per partes reuanente. - Provenit all truncos.

693. Lencopndia. Gregaria sernens, membrana abortiva, stipite candido, peridio ovato violaceo. - Ad ramulos foliague decidua.

$$
\text { 42. D I D E R M } \mathrm{A} \text {. }
$$

Peridia membranæ communi imposita, cortice duplici, pulvere filanentis intermixto.

69' Florifnrme. Stipite simplici, cortice stellatim fisso reflexo, peridio magno obconico. - In ligno mortwo.

695 . Ramusum. Sitipitibus ramosis, capitulis subglobosis. - In trunco arborum emortuarum vel languentium.

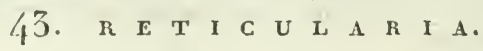

Plantæ primù pulposæ difformes effusæ molles, intùs cellulosæ pulverulente, sub finem in pulverem tenuissimum abeuntes, menbranæ communis nunquàm hospites.

696. Hemispharica. Stipite subbrevi simplici striato basi incrassato, peridio convexo tandern orbiculari albo deindè nigro, pulvere nigrescente. - In loiiis mortuis.

697. Sinuosa. Cinereo-albida compressa flexnosa elongato-sinnosa subbiralvis.- In foliis mortuis.

Gg. Nigra. Primò cinerea deindè nigra minima. - In ramis biennibus.

699. Sphar idla'is. Alba demùm rosea sparsa, insectorum ova referens, peridiis globosis sessilibus connatis.-In ramis et foliis mortuis.

70o. Rosea. Laic̀ rosea pulposa albo-rcticulata. - In rimis truncorum cesorum et humillorum.

701. Luitea. Flava eflusa subrocunda, cortice celluloso-fibroso, pulvere nigrescente. - In foliis caulibusque herbarum.

702. Hnrtensis. Albo-flava deindè fuscescens maxima, filamento gossypino obvelata, primùn spumosa tandem fragilis. - In pulvere coriario.

ro3. Carnosa. Albida vel flava globosa carnosa duriuscula persis tens, seminibus nigris in cellulis reconditis. - Ad terram.

$$
\text { 4. } 4 \text { S S P U M A R I A. }
$$

Tabitus RETICULARIE, thecis coriaceo-membranaceis seminiferis in pulpa reconditis.

204. Alba. Nigna alba, thecis ramoso-cornutis. - In caulibus et foliis Lerbarum.

$$
\text { 45. L Y } \text { Y C }
$$

Perilium subrotundum membranaceum læve, immaturum massa pulposa liquescente, maturum pulvere filis raris intertexto refertum. 705. Miniata. Rotundata sessilis subdepressa rubro-aurantiaca, succo liquido concolore deindi violaceo repleta, pulvere roseo-violaceo copioso. - In liguo mortuo gregatin. 
706. Punctata. Cespitosa rotunda subsessilis punctata subcincrea.Autumuo in tuncis putrirlis.

707. Argentea. Subhemisphærica Levis solitaria substipitata argentea.

- In tsuncis putridis.

$$
\text { 46. L Y }
$$

Peridium plerunquè globosum ant turbinatum, prima rtate carnosum deindè pulvendentum, matmè apice deliseens, pulvere copioso fusco aut virili filamentis intermixto.

7o8. Ardosiaceum. Subglobosum cesio-grisenn leve suhtìs plicatum, cortice tenui, carne firma rubra, pulvere subnigro. - Ad terram.

200. Exx cipuliforme. Magnnm alhidum varinm, peridio subgloboso, rerrucis spinulosis sparsis, stipitc longo plicato basi incrassato. Ad terran in graminosis.

710. Gossypinum. Gregarium minutum globoso-turbinatum sublanuginosum albidum denùn diiucé fuligineam. - In ligno putrilo.

73. Utriforme. Najusculum ex obovato-cylindricum diluté fuligineum, superficic læviuscula, stipite cum peridio confluente. - Ad terrau.

712. Giganteum. Sub-acaule globosum maximum ex albido pallescens, squamulis sparsis subobsoletis. - Adterram in pratis.

713. Coelatum. Magnum obconicum molle pallescente-albidum, squamis latiusenlis subtis plicatun, rarlice cespitosa.-Arl terram in collibus graminosis.

7ł 4 . Protens. Peridio hemisphærico læviusculo primò albo demùm grisen-rufescente, verrucis paucis, stipite brevissimo, radice parva. - Ad terram.

715. Verrucosum. Subglobosum rnfo-fuscescens, carne cresio-rubesccute, stipitc subelongato radicoso, squamulis confertisminoribus. - Arl terram.

716. Aurantiume. Magnum spheroidale lætè flavum radicatum, basi plicatum pertusumque. - Ad terram.

$716^{*}$. Corium. Magnum rotundum ant subreniforme lave umbrinum, cortice crasso coriaceo persistente, - Ad terram in pratis.

\section{G E A S T R U M.}

Peridium globosum, cortice duplici, exteriore stellatim fisso demùm reflexo: ore ut plurimum piloso, pulvere copioso filis paucis intermixto.

717. Multifidum. Majns, peridio globoso stipitato, cortice exteriore septem vel octofido, orificio magno rotundato ciliato. - Ad terram in abietinis.

718. Striatume. Minimum, peridio splaærico stipitato sex rel octofido, ore striato acuminato, eiliis elongatis. - Ad terram in siccis.

219. Puadrifidum. Peridio glohoso pedicellato, ore canescentc, radiis subquadrifidis revoluto-fornicatis. - In abietinis.

720. Hygrometricum. Radio mulifido inflectente, peridio reticuLato sessili, ore nou striato. - In sylvis sabulosis frequens. 
721. Rufescens. Mtaximum, radio multifulo rufescente, peridio spliarico sessili pallescente lavi, ore non striato. - In sabulosis ad terram.

$$
\text { 18. T }
$$

Peridium globosum primò carnosun deindẻ pulverulentum stipitatum, stipite cavo, ore orbiculari cartilagineo.

72x. Brumale. Albid:um depresso-globosum, stipite squamoso, peridii ore clongato. - In arenosis.

\section{$+t+\dagger$ Peridio membranaceo vel carnoso, intis non pulverulento.$$
\text { 49. с } \mathbf{Y} \text { A } \mathbf{T} \text { H U } \mathrm{s} \text {, }
$$

Fungi membranacei cratcriformes orificio membrana obvelato, intùs succo viseoso et linpido repleti; capsulæ lentilormes basi crateris filamento tenui adhærentes, membrana rupta et liquido evanido tantun evidentes.

723. Striatus. Ferrugineo-umbrinus, extùs lanatus, intùs Iongitudinaliter striatus. - Ad terram et in ligno putrido.

22\}. Lavis. Flavus, extùs glaber vel subsquamosus, intùs lævis. - In ligno mortuo.

725. Vernicosus. Extùs flavo-ferrugineus subtomentosns intùs lævis nitidus albido-plumbens, ore reflexo. - Ad terram et etiam in ligno mortuo.

726. Complanatus. Hemisphæriens, extìs cineren-ferrugineus, intùs lævis albus, capsulis repletus - In ligno putrido.

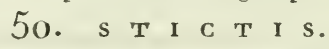

Cyathus membranaceus in cortice all dimidium immersus, primo clausus, demìm apertus, materia seminifera non palverulenta repletus. 727. Rarliata. Immersa, nre prominente niveo subfarinaceo integro aut radiatim fisso. - Ad ramos exsiceatos.

$$
\text { 5 I. P I L O B O L U S. }
$$

Receptaculum stipitiforme hydrophorum, cui imposita vesicula nuda, clasticè desilicins.

728. Cin'stallinus. Flavo-albidus, vesicula carnosa nigrcscente erecta pusteà nutante. - In fimo equino.

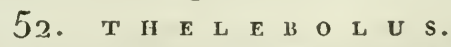

Receptaculum globoso-cupulare, nargine integrum, vesiculam sulumdan papillaformem ejiciens.

720). Klirsutus. Receptaculis albidis minurssimis subtomentosis ore rotundis, membrane grisex tenerrima impositis. - In cortice arbormu.

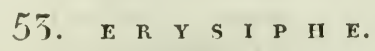

Receptaculum carnosum glohulare, primo luteum dein rufum tandem nigrum, includens capsulas plusiusas ovoideas acutas dis- 
permas. hasi insidens super filamenta radiantia plurima alba articulata simplicia aut ramosa. - Fungilli super folia viva nascentes.

730. Comli. Hypophylla, filamentis 5-6 basi dilatatis liberis. - In corylo avellana.

730*. Alni. Hypoplyylla, filamentis plurimis expansis Iongissimis liberis. - Sclerotiun erysiphe ahuea. Schl. cent.exs. n. 68. - In alno incana.

731. Fraxini. Hypoplylla, filamentis plurimis elongatis in pelliculam tennem intertextis, cireà tubercula erectis basi subdilatutis. - In fraxino elatiore.

732. Salicis. Eni-et-rariùs-lyypoplyylla, filamentis plurimis elongatis in pelliculan tenuem intertextis. - In salice daphnoide.

$532^{*}$. Aceris. Hypo-et-rarius-epiphylla. filamentis plurimnis elongatis in peliiculan tennem intertextis, uberculis demum collapsu concavis. - In acere caupestri.

733. Pol:goni. Ilypophylla, filamentis plurimis elongatis in pelliculam membranaceam intertextis, tuberculis raris. - In polygono avicularia.

733*. Populi. Epi-et-rarius-hypophylla, filamentis plurimis in pelliculam subcrustaceam inteıtextis. - In populo nigra.

73\%. Pisi. Sparsa, filamentis plurimis longissmis tenuissinis in pelliculam irregularem hinc inde intertextis. - In piso sativo.

735. Cichoracear: seniora subfuscescentia. - In scorzonera hispanica, tragopogo porrifolio, soncho arvensi.

$735^{*}$. Heraclei. Hypo-et-epiphylla, filamentis plurimis abhreviatis irregularibus liberis ant vix intestextis, tuberculis globosis sublucidis. - In heracleo sphondylio.

736. Convolvuli. Epiphylla, filanentis plurimis in pelliculam subnembranaceam adbærentem intertextis, tuberculis unc sparsis nuuc annulatim dispositis. - In convolvulo arvensi.

73-. Berberidis. Epiphylla, filamentis apice dichotomis. - In berberide vulgari.

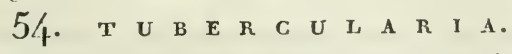

Tuberculum carnosum sessile simplex ant compositum intìs liquido densato refertmm. - Corticis arborum et quarumdam herbarum hospites; omnes rubæ.

738. Vulgaris. Gregaria amone rubra sulcato-rugosa basi angustata. - In cortice arborum.

739. Confuens. Gregaria confluens incarnato-lateritia, tuberculis parvis subrotundis oblongis angulatisque planiusculis. - In cortice aceris campestris.

źfo. Nigricans. Tuberculis najoribus sub finem nigreseentibus, basi ninimè angustatis - In ligno mortuo.

7'fr. Cinnabarina. Minima subgelatinoso-carnosa bullata miniaceo- 
subpurpurea, superficie granulosa. - In muscis diversisque herbis parasiiat.

; $\mathfrak{3}$. Rosea. Tuberculis sparsis rotundatis suhlobatis difformibus Ixté roseis. - Inter lichenes super corticem arborm.

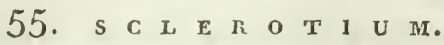

Forma rarium; cortex dura; caro plus minùsve solida (verò similiter scminifera) venis destituta.

743. Cincoŕm. Subterraneum majusculum difiorme rufum, radicibus fibrillosis cohærens. - Ad bultos croci sativi quos enecat.

Zf́. Stercorarium. 'Tuberculis nigrescentibus subrotundis aut diftormihus liberis, intus cárne solida alba farctis. - Ad terram sub fimo vaccino.

狧. Durum. Elongatum vel ovatum durum tenax nigrum intis candidum. - Corticem inter et alburnum arbustorum.

zq́i. Globulare. Globulosun nigrum nitidum subdurumı, carne gelatinosa flava intùs farctum. - In ligno putrido, in quo ad dimidium usque est demersum.

$$
\text { 56. } \mathbf{T} \text { U B } \mathbf{E} \text { R. }
$$

Subrotundum carnesum subterrancum sæpiòs eradicatum; carne venis seminiferis variegata.

747 . Cibarium. Verrucis subprismaticis exasperatum, nigrescens, radicibus planè carens, carne tenaci. - Sub terra locis arenosis.

-íS. Mnschatum. Læve subrotundum eradicatum intiss et extìs subnigrum, recens odlorem moschi valdè redolens, carne molli siceatione rugosa. - Circà Aginnum in Gallia.

;49. Griseum. Griseum lave eradicatum, allii odorem fragrans. In Pedenumtio locis arenosis.

750. Allum . Basi radicatum sublave, primò intùs et extùs aihum sub finem sordilè rufum, liueis rufis intùs variegatum. - Sub terra juxtà superficiem.

\section{O P D D O I I I. II Y P O X Y L A.}

Plantæ unne fungiformes nunc lichenoideæ, inter utrumque ordinem mediæ; seminum receptacula coriacea ant ossea feré semper nigra, poro ant rima regulari deliscentia, intus foventia gongylus in julpa plus minusve manifesta nidulantes.

TRI B US I. PSE U D O-F U N G I.

\section{Pulpa seminifera spontè è receptaculo exeunte.}

$$
\text { 57. R H I Z O MI O R P II } \Lambda \text {. }
$$

Caules elongati intìs merlulla tomentosa fareti; receptacula suhglobosa, apice poro dehiscentia, cauli adlixa nec intrà cam nídu Lintia. 
751. Fragilis. 'Teres aut compressat ramesat elongata, capillo umuled crassior. - In arborum fissuris, intrit corlicem "t lignum.

752. Setifnrmis. 'Teres filiformis simplex ant apice sulmannosit. -

In eryptis super trabes, in as buribus cavis et in foliis terra delipisis.

58. S P

Receptacula (sphaxulx) ossea subglobosa ore orbiculari stepiìs exserto apice dehiscentia, nunc solitiria, nunc aggregata in substantia effusa, nunc in canle fungiformi nidulantiat; pulpa scminilera post exitum effusa.

\section{I. Receptacula in caule elongrato fungiformi nidulantia.}

753. Ailitaris. Carnosa flavescente rubra, clavula sppharulis sul,prominentibus tuberculosa. - Ad tcram inter granina.

754. Radicosa. Molliter coriacea subuigrescens hasi intisqur flava, clavula incrassata subturgida. - Ad teramu in ericetis et pinetis.

755. Comuta. Coriaceo-suberosa nigra compressa gregaria basi hirta, apicibus albis pulverulentis. - In trabibus, vulgaris sine fructu.

756. Polymorpha. Coriaceo-suberosa nigra glahra gregaria, intùs alha, apicibus ocholencis compressis ramosis. - Ad trabes et ligna.

757. Digitata. Coriaceo-suberosa nigra glıbra, intiss alha, stipitibus basi connatis, apicibus albis pulverulentis acutis. - Ad lignum semi-putridum interdim tcrra tectum.

§. II. Receptacula super basin effusem aut patulam plus minìsve manifestam aggrigata.

758. Concentrica. Obovata subrotundaque magna, intis stratis concentricis interrupta. - Ad trunces salicis et fraxini.

759. Deusta. Late effusa crassa undulato-rugosi pustulata, primò carnosa cinereo-albida pulverulenta, demum nigra rigida. - Ad truncos in sylvis frequens.

-60. Decipiens. EFusa plina dura sordide albidi, ostiolis exsertis numerosis nigris teretibus apice truncatis, sphærulas solitarias mentientibus. - Ad truncos annosos.

$760^{*}$. Spinosa. Magna effusa dilatata, ostiolis crassis spinosis quadrigonis. - Ad ligna indurata nigref́acta.

-6ı. Granulosa. Magna subrotunda aut unilulato-plana tota nigra, sphærulis globosis prominulis. - Ad truncos aridos.

762. Scoria. Magna convexa confluens orbicularis ant oblonga irregularis nigrescens hasi albida, ostiolis vix prominulis granulosa. Spheria serpens $\beta$. Pers. Syn. 20. - Ad ligsa mortua.

763. Colharens. Gregaria confluens planiuscula, prinò lævis sordidè fusccscens, demum subbullata nigrescens. - Ad corticem fagi. 764. Bicolor. Gregaria globulosa carnosa cinnabarina intùs nigro- 
pellucida, luculis minimis conferlis. - Ad corticem juglandis et asculi.

765. Corgli. Sparsa subconfluens lavis fusco rubens, loculis submagnis orificio extùs inconspicus. - Ad corticem coryli avellanx.

766. Fusca. Fusco-lateritia rutundato-oblonga rugoso-sinuosa, ostiolis inconspicuis. - Ad corticem fugi et oxyancanthx.

76-. Peltata. Fusco-rubra lavis, centro prominulo obscuriori, hculis numernsis minimis, ostiolis inconspicuis. - Ad corticem quercûs è fạgi.

768. Glomerulata. Sphærica dura subcarnosa, junior pubescens grisea, demim nigra lieris. - Ad lignun et corticem.

760. Scabrosa. Efiusa crustacea, primò flava vel lateritin-rubig̣inosa pubescens, demìn nitida niggra rugosa, ostiolis exsertis. In ligno decorticato.

570. Melogramne. Globulosa suliseriata erumpens, primò grisea pubescens, demim nigro-badia inarqualis, ostiolis latituntibus. Ad corticem carpini alui et fagi.

77. Punctata. Carnosi coriacea, stipite brevi nigricante, disco albo orbiculari subplano, punculis nigris sparsis. - In fimo equino.

7:2. Tylnmoides. Plana, demùm convexn-orbicularis confluens, nigso-opaca, locnlis sphericis approxinatis. - Ad paginam superiorem foliormm uhui.

773. Serpens. Crustacca nigra subgranulosa, loculis subglobosis lasi nigra coalitis, ostiolo prominulo obtuso. - Ad salicum ligna.

$273^{*}$. Verrucaformis. Subrotnuda pulvinata rugosa, osticlis lititantibus. Pers. Syn. 26. - Ad ramos coryli arellane.

7ź. Stigma. Crustacea late-effusa tenuis nigra nitida loculorum orificio operculato unbilicato. - Ad candices vel ramulus arborun.

7\% D. Decorticata. Latè crustacea nigra, intus alba, Ioculis ovatis confertissimis, ostioln promiunto conico obluso. - Ad corticem fagi et quercûs quorum epirlerma destrnit.

7:6. Vummuluria. Tuberculosa orbicularis applanata nigra, loculis rotundatis, ostiolo inconspicuo. - Ail truncos et ramules mortuos.

777. Disciformis. Tuberculosa effusa applamata nigra intìs albida, punctis atris conspicnis superficialibus. - Ad corticen fagi.

7-5. Tiplygna. Crustacco-cylindracea ocliracea grumosa, nstiolis vix conspicuis. - Ad nodos culmorunı graminearum, imprimis ductylis gilonerata.

j. III. Receptacula fasciculato-glnmerata receplaculo communi haiud insita.

7.9. Craninis. Maculata nigra oblongo-linearis glabra nitida subasperulosa, loculis globulosis, ostiolo vix manifesto. - In clymo curopeano, lolio perenni, etc. 
-So. Radula. Pustulati in receptaculis ovatis clongatis cxtirs fusca intirs albida cortice insertis basi distantibns on ificio cenniventibus. - Arl querrîs corticem.

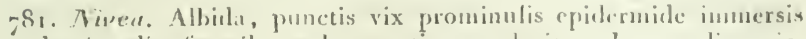
deminu discoformilus sulonucatis granulusis. - In raumlis exsiccatis populi tremulx.

782. Pustulata. Applanalia nigricans granulosa, corticem vix superans, Inculis aggregatis, ostiolo brevi constricto. - Ad corticem alni, sulicis.

-53. Coronata. Circinnata, loculis suliglolosis, ostiolis clongatis cylindricis apice conniventibus, epidesuiden vix superantibus. ln betula alba.

-Sf. Faginea. Circinnata, ostiolis acuminatis hamatis, loculis nigris pulpa concolore granulosa et aspera plenis. - Ad ramulos fagi.

783. Laburni. Cespitosa nigra, loculis congestis globosis papillatis opacis, cespitulis rupta epidermide cinctis. - In ranis mortuis cytisi laburni.

786. Céatosperma. Nigricans subrotunda convexa sparsa in cortice demersa, ostiolis spinulosis. - In cortice quercûs et rosax caninæ.

78- C!arata. Cespitulosa atra, loculis clongatis apice rotundis basi attenuatis fasciculatis pubescentilus. - In ligno decorticato.

¡S8. Berberitlis. Cespitosa nigra, sphrerulis globosis rimoso-rugosis faretis. - Ad ramos berberidis. - Pers. ic. pict. t. 2. f. 3-5.

-\$8*. Cupularis. Cespitosa nigra, sphærulis rugosis ut plurimùm collapsis. Pers. Syn. 53. - Ad ramos carpini ct tilix curopax.

\section{IV. Loculis distinctis, confertis aut solitariis.}

־S9. Gnomon. Epiplıylla, sphxrulis distinctis annulatim dispositis ut plurimìm collapsis nigits, ostiolis clongatis teretibus. - Ad folia coryli avellanx.

790. Latericolla. Cespitosa sparsa nigra levis, loculis subspliæricis demùn collapsis, ostiolo conico rigido acuminato laterali. - In ligno quercino decorticato.

791. Stercoris. Subcespitosa, loculis minimis nigris ovatis obtusis, ostiolo hand exserto vix conspicuo. - In fimo cervino.

792. Mammreformis. Simplex parvula nigra rotundata sparsa apice subacuminata. - Ad corticem fagi.

793. Peziza. Gregaria sordidè rubella, sphærnlis globosis cxsiccatis collabescendo-concavis. - In ligno semi-putrido.

79'. Tubercularia. Tubcrculosa carnosa rubra demìn fuliginosa, tuberculis rupta cpidermidc cinctis ovato-obtusis, ostiolo subdepresso. - Ad corticem juglandis.

795. By'ssiseda. Majuscula, sphærulis nigris globoso-papillatis, toinentu crasso fusco cinctis. - Ad ligna et cortices vivos et exsiccatos. 
596. Albicans. Nigricans, basi margine albido cincta, sphrrulis majusculis globoso-papillatis nonnullis confluentibus. - Ad truncos salicum semi-putridos.

797. Ovina. Sparsa, spharulis globosis oratisque liberis, tomento conpacto albido tectis, ostiolo papillato nigrieante. - Ad umncos humidos recorticatos.

79 S. Spermoitles. Congesta nigra opaca subrugosa, sphærulis globosis, ostiólo obsuleto. - In ligno mortuo decorticato.

$799^{*}$. Patella. Sparsa atra. spharnlis disco impresso-plicatis, ostiolo papillato subolsoleto. - Pers. Syn. 76. - In caulibus plantarum putrescentibus.

799. Splinrterica. Simplex gregaria minima elongata, basi attenuata, primù albida pubescens, demim nigra, ostiolo plicato infundibulifor mi piloso. - In ligno mortuo.

Soo. Sanguinea. Orata singuinea sparsa ligno demersa, ostiolo subdepresso concavo. - In ligno.

Sor. Pu'veracea. Conferta opaca glabra libera, sphærulis subglobosis, ostiolo obtuso parum exserto. - In quercu.

So2. Inquinans. Sparsa supernè atro-inquinans infernè albicans, sphærnlis cum ligno subprominulis perforatis. - In acere campestri et pseudo-platano.

So3. Tilice. Nigra sparsa subglobosa supernè depressa, orificio amplo, pulpa grisea. - In queren et tilia.

So $3^{*}$. Maculifornis. Fpiphylla, sphærulis subimmersis minutis subrotundis in marul ni nigrain inærialem conglomeratis. - Pers. Syn. 9). - In foliis alni.

So f. Cruterium. Epiphylla, disco primùm albo plano ermmpente, demùm nigro centru concaro cyathiformi. - In foliis hederæhelicis.

So5. Complanata. Sparsa, spharulis nigris minimis subconvexis, demùm planis tandem concavis, centro subprominnlo. - In caulibus herbarum.

So6. Prncriformis. Epiphylla punctiformis, spharulis nigris sparsis convexis centro subumbilicatis, ostiolo obsoleto. - Ad folia, prasertim yuercina.

8o- Lichennides. Epiplylla nigra punctiformis, folia decolorans, ostiolo haud manifesto. - Ad folia variarum plantarum.

8o8. Pustula. Epiphylla nigra applanata, pulvere nigricante compacto effnso, ostiolo obsoleto. - Ad folia exsiccata quercûs.

8og. Scirpicola. Sparsa nigra orbicularis depressa, ostiolo prominulo subconico. - In caulibus langueseentibub scirpi lacnstris.

8ı. Pilifera. Maculaformis, sphærulis minutis congestis planiusculis, pilis recto-divergentibus medio obsitis. - In caulibus exsiccatis herharmm.

8ri. Ciliaris. Sparsa ovata atra subbulbosa, bullo epidermide tecto, filo rigido erecto producto apice pellucido. - Ad ramos exsiccatos et folia quercinit. 


\section{Y P O X Y I, A. \\ 59. N ж: $\mathrm{m}$ A $\mathrm{s}$ p o $\mathrm{R}$ A.}

Pulpa seminifera solidiuscula e loenlamentis exserta in forma cyerhi aut appendicis capillaris in aqua solubilis; receptacula in pluribus ignota aut vix manifestit.

811* Epiphylla. Cyrrho albido simplici, receptaculis solitariis nigris sub epidermide mabifestis. - In foliis indi: circà arefactis saponarix officinalis reperit oculatissimus Chaillet.

S12. Leucosperma. Cyrrho all,iclo sinplici, receptaculis nigris aggregatis in massa gelatinosa intrầ corticem latente. - In cortice arborum.

813. Chrysosperma. Cyrrhis aureis plurimis ex codem ostiolo. - In cortice populi nigra.

814. Crocea. Cyrrho flavo-crocco irregulari crassiusculo solitario, interdim effuso, receptaculo non conspicuo. - Ad corticem fagi sylvaticæ vivæ aut mortur.

$$
\text { 6o. } \mathrm{x} \text { y } \mathrm{L} \text { o } M \text { A. }
$$

Epiphyllum : receptaculum duriusculnm, forma varium, sæpiis nigrum, intus suhcarnosum, clausum remanens aut vario modo ruptum.

$814^{*}$. Rubrum. Confertum orbiculare subconfluens rubrum punctulis nota: um. - In foliis Pruni domesticæ et P. spinosæ. - An hujus generis?

815. Acerinum. Maculaforme tenue contiguum subrugosum. - In foliis Aceris platanoidis et campestris.

816. Leucocreas. Crassum tuberculosnm intùs album. - In foliis Salicis capreæ, S. arbusculæ, S. herbaceæ, etc.

817. Punctatum. Maculæforme, receptaculis distinctis subrotundis aggregatis. - Ad folia aceris pscudo-platani.

$817^{*}$. Aylostei. Utrinquè prominulum annulatim dispositum. - In foliis loniceræ xylostei.

818. Multivalve. Punctiforme sparsum subconvexum, epidermide in valvulas plurimas circà tuberculum fisso. - In ilice aquifolio.

$818^{*}$. Stellare. Tenue piceum margine fibris divergentibus radiatum. - Pers. Syn. 105. - In foliis phyteumæ spicatæ. - An hújus generis?

819. Lichenoides. Punctiforme sparsum planum orbiculare aut angulosum folium circiter arefaciens. - In foliis roboris, castanear et fagi.

820. Salignum. Punctiforme sparsum orbiculare tenne, disco subconvexo. - In foliis salicis caprex.

82т. Populinum. Punctiforme sparsum applanatum lieve opacum forma varium. - In populi tremulæ foliis aridis.

$82 \mathrm{r}^{*}$. Alneum. Punctis minutis distinctis gregariis epiplyyllis rugosoplicatis. - Pers. Syn. 108. - In foliis alni incanx.

$S_{21}{ }^{* *}$. Virge aurea. Punctis minutis distinctis hypoplyllis gecgaric 
confertis rugoso-granulosis convexis. - In foliis solidaginis virgæ aurea.

$$
\text { 6r. II Y P }
$$

Receptacuhum oblongum, rima lougitudinali dehiscens, pulnam seminiferam emittens, sub epidermide arborum nascens.

822. Iylom vides. Ellipticum planum nitidum. - In foliis oxyacanthx, lauri, berberidis el ancuparix.

923. Pinstri. Ovale planum epidernide suboccultum, sæpè lineis nigris limitatum. - In folis pini sylvestris.

82\}. Conigenum. Subovatmm ninimum rugosum. - Ad squamas strobilorum abietum et pinorum.

825. Ar.ndinaceum. Ovale depressum granulosum è griseo nigrescens - Ad culinos emortuos arundinis phragmitis.

$\mathrm{S}_{2}$ f. (Muercinum. Oblnngum flexnosum snbveutricosum nigrescbntecinerenm maximum. - In ranis juuioribus quercinis.

826* Fraxini. Ovato-ohlongum convexum, rima profunda, labiis tumidulis. - Ad ramos fraxini et aceris.

826**. Crispum. Elongatum convexum subventricosum, lahiis tenuibus crispis. Pers. Syn. 101. - In cortice abietis. - Forsan hæ duæ ultimæ species ad hysteria removendæ?

T R I B US II. PSEUDO-L I C H EN ES.

\section{Pulpa seminifera obscura aut è receptaculo nunquàm emissa.}

\section{H Y S T E R I U M.}

Crusta leprosa nulla; receptaculum oblongum rima longitudinali dehiscens.

S27. Ostraceum. Bivalve dorso afixum, nempè rima profunda, labiis exsertis parallelis. - Ad ligna annusa semi-putridla.

82S. Pulicare. Uhlongum aut ellipticum gregariun striatum, labiis tumidulis. - Ad caudices annosos quercinus.

828*. Angustalum. Elongatum lineare subparallelum læviusculnm. - Ad ligna exsicicala.

829. Opegraprituiles. Oblongum gregarium interdim confluens subimmersum. - In lignis putrescencibus.

$$
\text { 63. O P E G R A P II A. }
$$

Crusta lichenoidea tenuis; teceptacula (Jirella) oblonga aut linearia, fissura longitndinali supernè notata.

\section{I. Opegraphe in arboribus nascentes.}

83o. Oucrina. Crusta subnulla, lirellis simplicibus subrotundis convexis, in maculam subroun fim congestis, - U. nacularis. Ach. meth. 24. - Ad ramos juarores quercuun. 
83r. Fasinea. Crusta subumlla, lircllis simplicibus ollongis plat-

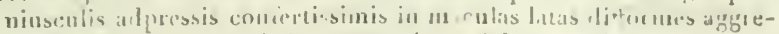
grtis. - O. chiplegit. Ach. Heth 2q. - All ramos ligineos.

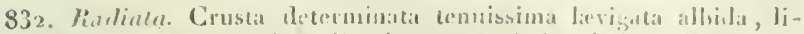
rellis depressis planinseudis elosenie stellatim fissis pedatisque. O. astroidea. Ach ancth. 25 . - Ad corlices arbormu.

833. Dispersa. Crnsta suldecerminata temuissima lepvigata allonglancescente, lireltis minutiosunis bilongis turgidis flexuosis simplicihus ranusisque.-U. epipasta. Ach. weth. 26. - Ad enticem f:

S3\%. "Rullute. Crusta althila irregnlari inxquali hinc inclè bullata, licellis vix tomvexis flexuosis subram sis oblongo-fincaribus. - Net corticem lievem quercumm.

S3ĩ. Herpetica. Consta subrugosa fusconlivacea nigro limitata, liretlis simplicibus convexis obiongis difformibus. - Ad corticem arbormm.

S36. Iiulueila. Crusta mbro-olivacea snhrugosa, lirellis simpliciluns tumidis ohlongis passim flexuosis. - Al cortices arbormm.

83\%. Ceria. Crusta alhissima effusa subpulverulenta, lirellis oblongis plano-convexis prline resin pruinatis. - Liehen lyncous. Engl. Bot. t. Son. Lecidea lyneci. Ach. meth. 52. - Ad corticem retustain vilercumsn.

838. Votha. Crusta tenui leprosa albida subpulyernlenta, lirellis simplicibus latiuseniis rotumato-diformibus - Ad cortices arbortum.

3.39. Signaln. Crnsta alha glancescente irregnlari, lirellis subflexnosis linearibus clongatis exsertis superne planis. - Ad corticem veiustian querenum.

Śfo. Aira. Cirusta tenuissina membranacea alba, lirellis linearibus prominulis confertis flexuosis simpliciius sepiusque ranonsis. (). henisrata. Ach. meth. 27. - Ad corticem arborum imprimis fraxini.

8ł. Cerasi. Crusta effusa alba, lirellis subimmersis linearibus subparallelis simplicilus ramosisque. - In cortice cerasormm.

3ұz Rufesrens. Crusta subefusa tenui membramacea info-virescente, litel!is promianlis sparsis linearibus simplicilus tri - qua-

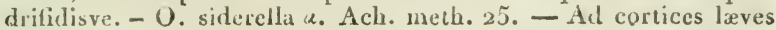
arborum.

8. $2^{*}$. Enea Crusta subefusa tenui membranacea rufo-virescente; lirellis prominulis minntis ovali-oblongis subsimplicibus. - O. siderella $\beta$. Ach. meth. 26. - Ad cortices arborum.

Sł3 Serpentina. Crusta leprosa albida, liellis imnersis confertis linearibns flexnosis simplicibus ramosisque pruinoso-subcæsiis. Adl cortices aunosils.

Sif. Pulverulenta. Ciusta effnsa allo membranacea, lirellis imnersis turgilis lineasibus pulverulentis flexuosis connato-subramosis. - All cortices arborum. 
8.j5. Limitaza. Crusta tenuissima nembranacea nitida albo-virescente nigro limitata. lirellis udis linearibus flexuosis simplicibus ramosisque. - O. scripta. Ach. meth. 3o. - Ad cortices læeres.

8f6 Crassa. Crusta crassa pallirlè ochrolenca lævi sæpiùs nigro limitata, lirellis inmersis minimis linearibus sinuosis subsimplicibus. - Ad cortices leves.

S'fo. Rimosa. Crusta crassa alba rimosa, lirellis prominulis oblongis simplicibus tandem radiatis confertis. - Ad corticem juglandis.

\section{II. Opegrapha saxatiles.}

S.j8. Saxatilis. Crusta subnulla, lirellis prominentibus oblongis simplicibus ramosisque sparsis. - Ad rupes.

S49. Cé. brina. Crusta albissima pulverulenta effusa, lirellis promineatilus oblongis simplicibus aut apice fureatis. - Ad rupes calcureas compactas Pyrenæorum.

Sõo. Tesserata. Crusta leproso-squamosa areolata sordidè alba, lirellis vix prominulis oblongis subllexunsis simplicibus aut apice furcatis. - Ad rupes micaceas ferrugineas, Alpium.

$$
\text { 64. V } \mathbf{E} \text { R } \mathrm{R} \text { U } \mathrm{c} \text { A } \mathrm{R} \text { I A. }
$$

Crusta tenuis; receptacula subglobosa nigra, poro apice dehiscentia.

\section{§. I. Verrucarice arborea.}

85̃r. Epidermidis. Crusta lactea tenuissima, tuberculis minimis rotundo-suboblongis plano-depressis. - In tenera epidermide betulæ ulbæ.

852. Atomaria. Crusta tenuissima lævigata cinereo-glancescente, tuberenlis plano-convexis parvis umbilicatis. - In cortice lævi fraxini.

853. Olivacen. Crusta subdeterminata mem?)ranacea lævi olivacea, tuberculis sparsis hemisphærico-conoideis nitidis, - V. punctiformis. Schl. cent. crypt. n. \{1. Fl. fr. 2. n. 853. excl. syn. V. olivacea. Pers. ust. ann. 7. p. 28. t. 6. f. B. a. b. V. andepta. Ach. meth. I19. - Ad cortices læves.

854. Hippocastani. Crusta tenuissima cinerea, tuberculis minutis confertis convexis umbilicatis. - V. punctiformis f. Ach, meth. I 9. - Ad corticem æsculi hippocastani.

855. Salicina. Crusta tenui inæequali cineres virescente, tuberculis orbiculatis ant ellipticis subcouvexis confertis. - In cortice vetusta salicum.

856. Cerasi. Crusta tenuissima transversali-oblonga albo-cinerascente nitilula, tuberculis ellipticis sparsis convexis. - Iu cortice cerasnrum.

85-. Hylnica. Crusta subnulla, tnherculis subglobosis parvis inter fibrillas ligneas subimuersis. - In lignis cortice denudatis. - An potius sphæria?

8j8. Nicmenrpa. Crusta crassa albida laviuscula cffusa, tuberculis minimis immersis sparsis. - In cortice levi. 
S.9. Galactices. Crusta lavi temui albissima determinata, tuluerculis? planis maculiformibus orbiculatis sparsis. - In cortice levi populorunı. - An lujus generis?

86n. Cemmata. Crusta tenui levigata alba, tuberculis sparsis bemisphreicis nitidulis. - Ach. meth. 120. เ. 3. f. 1. - In cortice arbormm.

SGı. Nitida. Crusta olivacea cartilaginen-membranacéa lrvigatr rimosa, tuberculis confertis hemisplaxricis subimuersis nitidulis. - In cortice carpini.

362. Populnea. Crusta nlivacea cartilagineo-memlranacea lrvigata rimosa, tuberculis maguis sparsis exsertis hemisphrericis nitidulis. - In cortice arborum. - Potiits prioris varictas.

863. Sanguinaria. Crusta cinerca granulosa irregulari, mberculis sparsis hemisplıricis intus sanguincis.-Lecidea sanguinaria. Ach. meth. 39. - In corticibus et rupibus.

\section{II. Verrucarice rupestres.}

S6\%. Rupestris. Crusta cinerascente tenui contigua, tuberculis globosis semi-immersis. $-V$. Schraderi. Ach. meth. 114. - In rupibus calcariis.

865. Calciseda. Crusta albissima sublevi crassiuscula, tuberculis parvis globosis punctiformibus semi-immersis. - In rupibus calcariis.

866. Purpurascens. Crusta purpurea tenui coutigua, tnberculis imnersis parvis convexis. - In rupibus calcariis compactis.

867. Corulea. Crusta corulescente tenui contigua margine albida, tuberculis minimis immersis. - In rupibus calcariis.

868. Ruderum. Crusta tenui vix distincta albo-glancescente, tuberculis sparsis nigro-cæsiis planiusculis centro prominulis. - In ruderibus et muris.

869. Dufourii. Crusta subgrisea crassinscula rimosa irregulari hine inde bullata, tuherculis hemisphæricis crusta clevata basi cinctis.

- Ad muros et lapides.

Szo. Concentrica. Crusta ocliroleuca subnulla, receptaculis nixrocæsiis convexis subiumersis in fascias concentricas dispositis. In murorum lapidibus.

8-1. Macrostoma. Crusta fusco-olivacea crassa rimosa, tuberculis semi-immersis confertis planiusculis centro prominentibus. - In murorum lapidibus.

8;2. Nigrescens. Crusta fusco-nigricante tenui subsolida, tuberculis subconicis nitidulis - V. umbrina. Ach. neth. 122. - In rupibus et lapidibus.

$$
\text { 65. } \mathrm{P} \text { E } \mathrm{R} \text { T U S A } \mathrm{R} \text { I } \Lambda \text {. }
$$

Receptacula tuberculiformia lepra concolora multilocularia, ostiolis multis pertusa.

8-3. Communis. Crusta submembranacca levigata cinerea, verrucis subhemispharicis, ostiolis nigris. - T'helotrema pertusum. Ach. meth. 13\%. - In cottice præsertim fagi. 
$\mathrm{S}-3^{*}$. Chionoea. Crusta subleprosa, verrucis confertis convexis difformibus albissinis, ostiolis fusco-nigris. - Th. chionoeum. Ach. meth. 13 r. t. S.f. 2. Pcrtusaria communis $\beta$. Fl. fr. 2. n. $573 .-$ In saxis.

87f. Wu!fenii. Crusta membranacea levigata cinerascente, verrucis rotundatis tandem dillormibus angulosis apertis, disco fuscesccnte, margine tumido irregulari. - Thelotrema hymencum. Ach. meth. 133. - In arborum cortice.

\section{O R D O I V. L I C H E I E S.}

Plantæ consistentia, colore, forma variæ, sæù virides aut in aqua virescentes, detritæ colorem viridem in parte erosa exhibentes, sæpius siccx et opacx, liquidum ambientem absorbentes et in totam substantian spontanex transvehentes. Fructificationes nunc in tubercula, nunc in scutellas, dispositæ.

+ Receptacula pulverulenta aut nulla, in crusta tenui inserta.

66. L $\mathbf{E}$ P $\mathrm{R}$ A.

Crusta irregularis pulverulenta aut subfilamentosa. Receptacula ignota.

8,5. Antiquilatis. Crusta atra tenuissima. - Lepraria? antiquitatis. Ach. meth. 7. - In rupibus.

8-6. Lactea. Crusta albissima subfarinosa. - Lepraria alba. Ach. meth. 3. - In muscis et arborum truncis.

S;7. Botryoides. Crustaviridi subpulverulenta. - Lepraria botryoides. Ach. meth. 6. - In truncis, muris et terra uda.

$S_{77^{*}}$. Fuliginea. Crusta fusca subpulverulenta. - Lepra fuliginea. Bouch. abb. p. 88. - In malorum cortice.

S-8. Odorata. Crusta rubescente tanden cinerascente, subgranalata, oculo armato subf́loccosa. - In arborum cortice.

S78*. Chlorina. Crusta flavissima subfilamentosa. - Pulveraria chlorina. Ach. meth. 1. t. I. f. 1.- In rupibus umbrosis Alpium.

S79. Obscura. Crusta è griseo ochrolenca granulata crassiuscula. Isidium coccodes. Ach. weth. I39. - In corticibus, parietibus.

$$
\text { 67. C O N I O C A R } \mathrm{P} \text { o } \mathrm{N} \text {. }
$$

Crusta tenuissima alba. Tubercula discolora pulverulenta.

88o. Cinnabarinum. Tuberculis pulvereque rubris. - Iu arbormm cortice imprimis carpini.

88r. Olivaceum. Tuberculis pulvereque è luteo olivaceis. - In cortice vetusta salicum.

882. Nigrum. Tuberculis pulvereque nigris. - In cortice carpini.

68. V $\mathbf{A}$ : $\mathbf{R}$ I

Crusta subsolida; receptacula pulvere albo granulato repleta aut adspersia. 
883. Faginea. Crusta leprosa margine subcartilaginea albo-rinerisconte, receptaculis hemisplatricis allissmais. - In arlorum corlicihns.

893*. Discoillea. Crusta leprosa pulverulenta allsa receptaculis

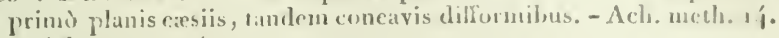
- Ar truncos arborum vetustos.

S8,. Albn-furescens. Cirusta teuni snbrimosa sordide albo-glanca, receptacalis post lapsum pulveris flavis concavis. - In a:bornos cortice.

885. Iuçtea. Crusta tenui tartarea allhissima, receptaculis hemisplaæi icis approximatis, apice mammillosis farinaceis. - Ad rup's granicicas Pyrenxoram.

SS6. Dealbata. Crusta crassa grannloso-papillata sordiclis alba, reecjtaculis primò convexis, tandem concavis ochroleucis. - Ad rupes.

\section{†† Receptacula tuberculata aut scutellata caulibus inserta.}

\section{6g. I s I D I U M.}

Caules brevissimi, ljasi conflati, crustam erassam supernè mammilIosam constituentes; tubercula glohosa terminalia.

88- Corallinum. Crusta tartarea diffracto-areolata albo-cinerascente.-Ach. meth. t. 3. f. 7.- In saxis.

888. Menanochlorum. Crusta tartarea arcolis rimosa, intùs albissima, extus ex atro-viridi glauca, ramis solidis apice albis farinosis. - In saxis propè Fonteubleaudi (Fontainebleau).

$$
\text { 70. IS P }
$$

Caules solidi rigidi cartilaginei læves ramosi ; reeptacula terminalia, rotundata, pulvere nigro fareta, demùm lacera concava vacua..

889. Clobiferus. Frnticulosus cylindricus cinereo-fnscus lævis, ramis divaricatis fibrillosis, receptaculis globosis. - Sphærophoron corallnides. Ach. meth. 13/4. - Ad terram locis saxosis et montanis.

S9o. Cespilosus. Fruticulosus cylindricas cineren-fuscus, ramis hrevissimis confertis fustigiatis nudis, receptaculis globosis nıgnis. - Sphæerephoron fragile. Ach. meth. r35. - Ad terram in montanis.

$$
\text { 7 I. S T E R E O C A U L }
$$

Caules solidi arborescentes; receptacula scutcllata compacta sparsa, primò plana, dein convexa rugosa, nunquàm ciliata.

89r. Paschale. Suffuticnlosm einereo- cæsium squammosogranulosun, receptaculis fusco-nigris. - In montibus ad saxa et campos arenosos.

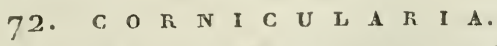

Caules solidi; receptacula scutellata membranacea plana, tandem convexa, interclum ciliato-radiata. 
$S_{92}$. Tristis. Frnticuloso-cæspitosa rigida fusca, ramis tereti-compressis atsceudentibns fastigiatis supernè nigricantibus, scutellis tes minalibus subradiatis. - In rupibus

593. Aculeala. Fruticuloso-cæspitosd rigida fusco-castanea, ramis tereti-coinpressis flexuosis apice dentato-spinulosis, scutellis demùn convexis concoloribus margine dentatis. - In ericetis.

89 . Vulpina. Cartilagineo - foliacea compressa subscrobiculata lutea, ramis apice attennatis, scutellis è fusco rufis planis margine integris. - Purmelia vulpina. Ach. meth. $26 \%$ - In Alpibus ad truncos et parictes,

S95. Ocholeuca. Fruticulosa teres læevis pallida, ramis divaricatis apice furcatis nigris, scutcllis fuscis margine flexuoso ocholeuco. - Parmelia ochroleuca. Ach. meth. 271. - In Alpibus act terram siccam.

89 f. Bico!or. Fruticuloso-cæspitosa erecta teres cartilaginca nigra, ramis filriliosis patentibus appice nutantibus cinerascentibus. - In Alpihus ad rupes inter muscos.

S9-. Díusricola. Cæspitosa tures atro-virens subgelatinosa, ramulis flexnosis fustigiatis obcusiusculis, scutellis brunneis integris. - Parmelia muscicola. Ach. weth. 2仵. - In Pyrenæis inter et supat muscos.

898. Lanata. Ciespitosa decumbens teres lævinscula fusco-nigra, ramis filiformibus implicatis dichotomis, scutellis margine granulato -radiatis. - In saxis et Incis sterilibus montiun.

S99. Intricala. Caspitosa decumbens tercs scabriuscula atra, ramis inplexis, exterioribus simplicibus, scutellis margine integris. - Cornicularia pubescens. Ach. meth. 3o5. - Ad rupes nadidas, imò inunilutas Pyrenxorum.

90o. Jubaia. Pendula ramosissima lavis teres, axillis compressis, ramis filiformibus, scutellis convexis margine integris. - Parmelia jubata. Ach. meth. 272, - In arborum imprimis coniferarum rainis.

$$
\text { 73. U S N E A. }
$$

Caules solidi ramosissimi cortice crustaceo induti; receptacula scitellata sparsa, sxpè ciliato-rarliata.

$9^{\circ}$. F\%orida. Erecta cinerco-virens, ramis subfastigiatis, ramulis iibrilosis horizontalibus . scutellis terminalibus radiatis. - In corticibus, parietibus et saxis

9n3. P'iratr. Pendula fil:ımentosa albo-pallescens, ramis implexis, scute'lis tadiatis. - In arborum inmprinis abietum ramis.

9o3. Burbata. Pendula filamentosa cinereo-vircus, ramis filurillosis, scutellis sparsis courexis subcarneis margiue integris. - Ad arbores in sylvis Alpium Pyrenzorumgrue.

9o. . Flaccirla. Pendula mollis compressa ochroleuca, ranis diraricatis, scutellis planis margine integris. - Parmelia divaricata. Ach. metin. 269. - Ad pinormm abjetunque ranos.

905. Ailiculata. Pendula subdivisa hine indè articulata ciucreo- 
candicans, ramis apice eapillaceis, sentellis convexis sulcarnosis fescentibus integris. - Lstica barbata $\beta$. Ach. mech. 313. - Ad atbores et arcirant.

$$
\text { 7\%. Б O C C E I. L A. }
$$

Canles solidi corincei undiquè subpulverulenti; receptacula lıemisphacriea sparsat sessilia margine integra.

9of. Tïncentia. Ciable tereti subliviso ciuereo-glanco, receptuculiz nigris. - Parmelia roecella. Ach. meth. 274. - Ad rupes ec muos regionum minitimarum.

907. Fuciformis. Caule compresso dichotomo cineren-atho, reeptaculis nigricantibus. - Parmelia fuciformis. Ach. Meth. 258. $\alpha$ In rupibus, $\beta$ in arboribus regionum maritinarum.

$$
\text { 75. C L A D O N I A. }
$$

Caules fistulosi ; receptacula tuberculata fungosa subglobosa sessilia solitaria terminalia.

9o8. Fermicularis. Prostrata albila simplex aut snbdivisa subulatofiliformis.-Boesunyces vermicularis. Ach. meth.35. - In Alpibus et l'yrenxis ad terram inter muscos et gramina.

9og. Sululata. Erecta cinereo-virens sul'simplex ant variè ramosa, ramis erectis acnto subulatis, axillis imperforatis. - Baeomyces subulatus, B. furcutus et B. spinosus. Ach. meth. 357.- Ad terram in sylvis ericetis montanis.

9ro. Rangiferina. Erecta albo-cinerascens cæspitoso-ramosissima, axillis perforatis, ramulis apice deflexis, tuberculis fuscis. - Bo:omyces rangiferinus. Ach. meth. 355 . - Ad terran in montanis.

911. Ceranoides. Erecta albo-virescens cæspitosa, ramis apice stellato-denticulatis perforatis, tuberculis spadiceis. - Boconyces uncialis. Ach. meth. 35̃2. - Ad terran in montanis.

$9^{\mathbf{1}^{*}}$. Papillaria. Erecta albida cæspitoaa, caulibus basi cohærentihus bifurcatis subventricosis upice integris subobtusis, tuberculis 1ufo-fuscis. - Boonnyces papillaria. Ach. meth. 323. Jacq. coll. 3. t. 3. f. 2. Engl. Bot. t. $90^{\circ}$ - - Ad terram in summis Alpibus.

$$
\text { 76. s }
$$

Caules fistulosi, interdum foliosi, apice iu scyphum seu infundibulum basi clausum dlilatati; receptacula subglolsosa carnosa ad margines scyphi.

912. Difusus. Foliis erectis laciniato-incisis glancescentibus, caulibus ramosis, scyphis obsoletis, tuberculis badiis. - Boomyces parechus. Ach. meth. 350.-In montanis sterilibus ad terram.

9r3. Convolutus. Foliis erectis convolutis sinuatis albido-ochroleneis, scyphis parvis turbinatis, tubercalis fuscis. - In locis aridis et suxusis ad terram. - E flora exclud. syn. Achar.

9r. . Cervicomis. Foliis erectis apice subconvoluzis è viridi glaneis, scyphis subcylindricis, tuberculis fuscis. - In Alpibus ad terram.

915. Cocciferus. Foliis patulis parvis aut obsoletis lohato-crenatis, 
scyphis turbinatis, tuberculis coceneis. - liceomyers cocciferns,

B. digitatus, B. deformis, B. bacullan is. Agh. meth. 329-334. Adterram in ericetis.

916. Pr:xilatus. Foliis patulis parvis aut ubsoletis lobeto-crenatis, scypliis tmrbinatis aut elongatis, tuberculis fuscis. - Boonyces pyxidatus, B. fimbriatus, B. spatassus, B. radiatus. Ach. weth. $337-3.6$. - Ad terram, muros et trunces humidos.

917. Cornutus. Foliis patulis parvis aut obsoletis lobato-erenatis, caulibus aliis cornuto-subnlatis, aiiis in parvum seyphum dilatatis, tuberculis fuscis.-Boomyces cornutus, B. gracilis. Ach.meth.3 $\mathbf{q}^{3}$.

- Ad terram.

$$
\text { 77. II } \quad \text { E } \quad \text { L }
$$

Caules fistulosi interdum foliosi apice subdilatati in infundibnlum basi perviun ; receptacula carnosa subglobosa ad marginenı infundibuli.

918. Delicatum. Foliis minutissimis subimbricatis laciniato-crenatis, scy phis subfiliformibus, receptaculis è fusco nigris. -Boeomyces delicatns. Ach. meth. 327. - In ligno putrido.

i † Receptacula tuberculata aut scutellata, sessilia aut pedunculata, in crusta granulata imposita.

$$
\text { 78. В }
$$

Tubercula fungosa subglobosa pedicello simplici erecto insidentia, interdum in crusta sessilia.

\section{§. I. Tuberculis pedunculatis.}

919. Fricetorum. Crusta albicante, tuberculis carneis simplicibus subglobosis. - Boemyces roseus. Ach. meth. 321. - Ad terram argillosam.

920. Rufus. Crnsta virescente tenui, tuberculis breviter pedieellatis fuscis supernè planiuscnlis. - Boeomyces rupestris 8 . Ach. meth. 322. - Ad terranı arenosam.

92 . Rupestris. Crusta glanco-virescente rugosa, tuberculis rufo-fnscis subglobosis glomeratis. - Ad rupinm fissuras et terram glareosam.

\section{§. II. Tuberculis sessilibus.}

922. Fruginosus. Crusta virescente, receptaculis centro adfixis, subturbinatis, supernè depresso-concavis. - Lecidea icmadophila 't $\gamma$. $\Lambda$ cls. meth. 58. $-\alpha$, in truncis putridis; $\beta$, in sphagnis, et $\gamma$ in rupibus.

923. Elveloides. Crusta albescente, receptaculis tota superficie adnatis convexis tandem rugosis. - Lecidea icmadoplila $\beta$. Ach. meth. 59. - Ad terram.

\section{C $A$ L}

Receptaeula suberosa, pedicellata aut rarissimè scssilia, supernè polline tccta, globosa ant depressa, sæpissimè nigra; crusta obsoleta. 
92.;. Clavellum. Crustit alhescente. pediecllis teretiluns, tuherculis lenticularibus nigris subties rufis. - Ad ligna denudata salicunn et castanearum.

925. Quercinume. Cirusta cinerea, pedicellis basi attenuatis, tulyerculis subghohosis subtus conereis interdum hispirlulis. - Ad conticem querenum.

$9^{2} 5^{*}$. Sulphureum. Crusta $\dot{e}$ Iuten virescente glebulosa, perlicellis gracilibus crusta concoloribus, uberculis globosis tandem fuscis. - Ad cortices arbortum.

926. Abietinum. Crustit Intea, pedicellis gracilibns, tuberculis superne convexis, sultus griscis. - Ad eorticem abietum.

927. Bevipes. Crusta lutea, pedicellis crassis brevissimis, tuberculis turbinatis subtus albidis. - Ad ligunn denudatum abictum.

928. Turbinatum. Crusta fusco-viridi, pedicellis brevissimis, receptaculis turbinatis supernè concavis, nargine allbo, $-\Lambda \mathrm{d}$ corticenı quercuum.

929. Sessile. Receptaculis sessilibns snhenncavis. - Calycinm strigonellum. Ach. meth. SS. - Ad cortices sapè parasiticur in lichenum crustis.

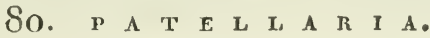

Crusta subsolida; scntellæ sessiles primò concavæ dein planæ tandem convex , marginatæ aut immarginatæ.

\section{§. I. Scutellis subcarnosis, nigris.}

93o. Immersa. Crusta subcontigna albo-cinerascente, scutellis crustæ immersis marginatis demìm convexis. - Lecidea immersa. Ach. meth. 34. - In rupibus imprimis calcatiis.

93r. Exigua. Crusta leprosa tenui obscurè cinerea, scutellis minutis aggregatis planis atris margine albo cinctis, tandem convexis margine fuscescente. - Parmelia exigua. Acl. meth. i54. - In cortice rimosa quercuum.

932. Punctiformis. Crusta tenui pulveraceo-granulosa cincrascente, scutellis uinutissinis confertis planis, margine concolore.-Parmelia exigua $\beta$. Ach. meth, 155 ? - In cortice pini et alni.

933. Myriocarpa. Crusta tonni pulveraceo-granulosa cinerascente, scutellis minutis confertissimis convexis immarginatis. - In ligno salicum cavarum.

934. Leucoplaca. Crustà levi albissima, scutellis atris sparsis primò coneavis margine integro nitido, tandem convexis subimmarginatis. - In cortice populi fastigiatæ.

935. Macrocarpa. Crusta tenui griseo-rufescente subnulla, scntellis sparsis primò hemisphæricis, tandem plano-concavis narginatis maximis. - In rupibus micaceis.

936. Parasema. Crusta tenni contigna cinerascente, sapiùs nigro limitata, scutellis sparsis planiusculis. - In cortice arborum ficчquens. 
937. Glonerulosa. Crusta crassiuscula pnlveraceo-granulata cinerascente nunquàm nigro limitata, scutellis sparsis planiusculis. - In cortice arbormm.

935. Alboznnaria. Crusta crassiuscula glomerulosa albido-ochroleuca, scutellis demim convexis atris intus zona alba notatis. - In cortice arborm et lapidibus.

939. Cíavus. Crusta tenui all,issima subpulverulenta, sentellis primo sessilibus planis, tandem exsertis pediccllatis convexis. - In rupibus calcario-arenosis Pyrenæornm.

9́o. Petrcea. Crusta tenui orbiculari rquabili albo-cinerascente subradiatim rimosula, scutellis plano-depressis sepè concentricè dispositis. - Lecidea petræa. Ach. meth. 37. Lichen concentrieus. Engl. hot. t. 246 . In rupibus.

941. Crenata. Crusta subgranulosa cinerascente, scutellis planis, margine exserto crenato concolore. - In rupibus.

9' 12. Fumosa. Crusta determinata rimosa xquabili cinereo-fuliginosa, scutellis depressis planiusculis marginatis. - In rupibus.

$94^{*}$. Tigillaris. Crusta effusa areolata plicato-verrucosa glabra flavescente, verrucis elevatis scutelliferis, scutellis planis marginatis. - Lecilea tigillaris. Ach. meth. p. 46. t. 2. f. 1. - In cortice laricis.

9ł3. Muscorum. Crusta tenui subpulverulenta albicante, scntellis planis marginatis demìn hemisphæricis conflıentibus. - Lecidea muscorum. Ach. meth. 33. - Suprà muscos destructos.

1. II. Scutellis subcarnosis à crusta non marginatis, brunneis griseis aut glaucis.

9任. Sinapisperma. Crusta tenui granulosa albida, scutellis globosis rufo-fuscis, intus cinereis. - Super nuscos semi-destructos.

91́t . Granulosa. Crusta leprosa granulosa albicla ant cinerea, scutellis planiusculis demùm couvexis rufescentibus. - Lecidea granulosa. Ach. meth. 65. - Ad terram.

975. Virilescens. Crusta leprosa effusa tenui granulosa virirli, scutellis convexiusculis demùm rugosis fusco-nigricantibus. - Lecideas viridescens. Ach, meth. 62. - Ad truncos humidos putrescentes.

9;6. Brunnea. Crusta granulata subimbricata viridi-fusea semi-gelatinosa, scutellis confertis plano-convexiusculis rutis, margine crenulato. - Parmelia brunnea. Ach. meth. 186. - Ad terram et saxa.

947. Uliginosa. Crusta effusa granulosa ferrugineo-fusca, scutellis planiusculis marginatis demùn convexis confertis fusco-nigricantibus. - Lecidea uliginosa. Ach. meth. f $^{3}$.

9:8. Fuscoatra. Crusta effusa tenuissima rimosa fusca opaca sæp̀ areolis nigris intermizta, scutellis plano-conrexis nigricantibus. In rupibus et saxis.

9 19 . Silacea. Crusta tartarea ruberrima, scutellis planis marginatis demù convexis subconfluentibus atris polline glanen subconspersis. - Lecidea silacea. Ach. meth. 46. - In saxis silaceis. 
950. Albocorulescens. Cinsta tartarea iefuabili contigua allues-

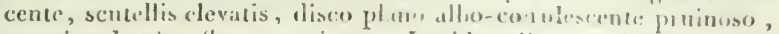
margine deruiu flexunso nigro. - Lecideat albo-corulescens. Ach. meth. 53. - $\Lambda \mathrm{d}$ sixa el rupes.

95r. Dichsonii. Crusta ferrugineo-ochracea, scuteilis elevatis planis atro-cornlescentibns obtuse margmatis pruinosis, -Lecidea Dichsonii. Acl. meth. 55. - In rupibus.

952. Glaucoma. Crusta equabili rimosa albescente, scntollis confertis, primò planis co'nuleo glaucis margine crenato cinctis, dein convexis difformubus nigricantihus, - Parmelia glaucoma. Ach. mcth. 160. - In rupibus Pyrenæorum.

953. Detrita. Crusta contigua subpulverulenta albida, scutellis snbimmersis difformibus confertis cinereo-crsiis inarginatis planiusculis. - Parmelia impolita. Ach. meth. 160. N n p prodr upso teste. E flora eliminanda synonyma. - In cortice arborum.

954. Corticola. Crusta effusa inequali rimosa albissima, scutellis minutis adpressis confertis è concaro tandem subglobosis cinereocæsiis. - Lecidea corticola. Ach. meth. 53. - In cortice arbor um.

955. Epipolia. Crusta tartarea glebulosa subimbricata albida, scntellis confertis demùn convexis casiis pruinosis. - Lecidea epipolia. Ach. meth. 53. - Ad lipides et muros.

956. Cretarea. Crusta effusa pulverulenta albissima, scutellis sparsis planis cæsiis pruinosis, margine calloso sæpe pulverulcnto. - In rupibus calcariis.

957: Biformis. Crusta effusa subrimosa flavida scutellis carnosis nigricantibus intùs allis, primo scmi-immersis planis marginatis, tandem exsertis convexis inmarginatis. - In rupibus Pyrenæornm.

958. Sulfurea. Crusta tartarea rimosa sulplmrea, areolis tmmidulis, scutellis convexis subconfluentibus fuseo-nigris pruinosis. - Parmelia sulphurea. Ach. meth. 159. - In rupibus arenosis.

959 . Lutescens. Crusta efiusa subpulverulenta virescenti-nchrolcuca, scutellis sparsis raris marginatis, primò planis flavescentibns, ucin convexis rufis. - In cortice arborum sine fruch frequens.

\section{§.III. Scutellis subcarnosis roseis, rubris, aurantiis aut luteis.}

960 . Ventosa. Crusta tartarea crassa rimosa cinereo-flavescente, areolis plicato-verrucosis, scutellis tumidulis irregularibus rufofuscis, margine tenni pallido.-Parmclia ventosa. Ach. Meth. IC6. - In saxis montium.

96r. Hrematonıme. Crusta tartarea pulverulenta areolato-diffracta subsulphurea, scutellis depressis demum convexis ruberrimis, margine pulverulento cinctis. - Lecidea hrematomma. Ach. mech. 63. - In saxis et rupibus.

962. Craspediu. Crusta grannlata inæquali albida, scntellis sanguineo - rubris planinsculis, margine tumidulo granulato erusta concolori. - In lateribus.

263. Rosella. Crusta tenui granulosa cinerascentc, scutellis è carnce 
rufis pluniusculis exsertis, margine tmmido albido tandem subevinescente. - Lecidea rosella. Ach, meth. 57. - In cortice arborum.

96. . Cupularis. Crnsta tenuissima, scutellis exsertis hemisphæricocupularibus dilute Iateritiis, margine elevato lavi exalbido. - Lecidea eupularis. Ach. meth. 56. - In rupibus calcariis.

965. Rubella. Crusta gramulosa cinereo-rirescente, scutellis concavis disco rubellis margine pallido, tandem couvesis immarginatis è rubro lutescentibus. - Lecidea luteola. Ach. meth. 6o. - In corlice arbormm.

966. Effusa. Crusta tenui effusa pulverulenta cinereo-virescente, scutellis parvis numerosis planiusculis oliraceo-rufis, margine tenui pallido. - Parnelia effusa. Ach. meth. I 7.- In salicibrss cavis.

967. Curnea. Crusta tenui granulata orbiculari virescente, scutellis centrabibus conrexis hemisplıæricis carneis pruinoso-albidis. - In rupibus.

968. Sphreroidea. Crusta effusa tennissima albido-virescente, scutellis sparsis subghlnosis incirnatis aut pallidè rufo-ferrugineis. - Lecidea vernalis. Ach. meth. 68. - Ad strata muscorum.

$9^{6} 9$. Obliterata. Crusta granulosa irrcogulari tumidula pallidè ochrolenca, scutellis sparsis aurantiaco-rufis è plano-courexis, margine pallido tenuissimo. - In sixis.

97o. Lamprocheila. Crusta arcolata irregnlari cæsia aut suboclirolenca, scutellis sparsis anrantiaco-rufis planis, margine tumido nitido concolori, - In saxis.

97. Ferruginea. Crusta tenni effusa inæruabili subrimosa albocinerea, scutellis planiusculis subconfluentibus inxqualibus rnfofuscis. -Lecidea cinereo-fusea. Aeh. meth. 68.-In cortice arborum.

9:2. Aurantiaca. Crusta determinata rimosa iuxquabili albo-cinerascente, scutellis confertis demum convexn-hemispliæricis anruntiacis, margiue dilutiori. - Lecidea aurantiaca. Ach. meth. 69. - In cortice arborum.

973. Ulmicola. Crusta tenui cinerascente snbgranulata, scutellis luteo-aurantiacis confertissimis minutis é plano convexis, margine dilatiori. - Iu cortice ulmi senescente.

974. Candelaris. Crusta elfusa virili-flava pulrerulento-gramulata, scntellis planis marginatis concoloribns. - Parmelia citrina, var. $\delta$. Ach. meth. 1 So. -In truncis et saxis, freqguens sine fructu.

9-5. Flavo-virescens. Crusta tenui leprosa granulata flavo-virescente, scutellis fulvo-anrantiis subconrexis, margine dilutiorivix prominulo. - In cortice arborum et in rupibus.

976. Vilellina. Crusta leprosa gramulata inæquali vitellina, scutellis planis marginatis confertis concolorihus, denium convexinsculis difformilous fusco-luteis pruinosis. - Parmelia vitellina. Ach. mieth. I $; 6 .-\mathrm{Ad}$ parietes.

977. Varia. Crusta ฐranulata inæquabili pallidè flavo-virescente, scutedis confertis, disco planiusculo fuscescente varioque margine 
subinflexu irregulari erustac encolori.-P'aruelia varia. Ach. metle , 178. - In parictibus ligncis.

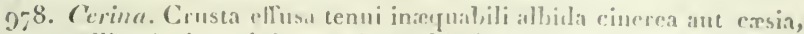
seutellis planis ceriuis margine subinflexo cincreo. - Parmelia cerini, Ach. meth, 175, - in cortice arbormu.

979. Rupestris. Crusta tenuissima fugaci allo, interdum punctis luteis fere obtecta, scutcllis luteo-aturantiis hemisplnacricis. - In rupibus.

980. Incrustans. Crusta cvanescente, scutcllis parvis lnten-aurautiis in lapide immersis prinu coneavis marginatis, tandem demisphxricis immarginatis. - In rupibus calcariis.

5. IV. Scutellis membranaceis cinclis margine crusta comformi.

98r. Rubra. Crusta effusa granuloso-pulverulenta alba, scutellis confertis, disco concavo diluti: rubro, margine convexo suberenulato albo pulverulento. - Parmelia rubra. Ack. nieth. 1;o.In cortice arborum.

982. Badia. Crusta tartarea verrucoso-rimosa olivaceo-fusca, ambitu radioso plicato, scutcllis confertis planiusculis badiis demùm convexiusculis subangulatis, margine clevato.-Paruclia fuscata. Ach. meth. $189 .-$ In saxis.

983. Hypnormm. Crusta leprosa pulverulenta nivea, scutellis sparsis planis lievibus castaneo-purpurascentibus, margine elevato. - Parmelia epibryon. Ach. lich. 157. - Super strata mascorum.

$9^{94}$. Sulfusca. Crusta tenui contigua lævigata albo-cinerascente, scutellis sessilibus sparsis, disco convexiusculo rufescenti-fusco, margine integerrimo tumido. - Parmelia subfusca excl. var. \&. Ach. meth. 167.- In arboribus frequens, etiam in saxis.

955. Tephromelas. Crusta rugoso-granulata cinereo-albida, scntellis deminn convexiusculis atris, margine albo tandem flexuoso crenulato. - Parmelia atra. Ach. meth. 154. - In rupibus et cortice arborum.

986. Dispersa. Crusta tenui cincrascente, scutellis numerosis parvis planis pallidè rufis, tandem rufo-fuscis, margine crenulato subgranulato albo. - In muris et cortice arborum.

987. Angulosa. Crusta tenui inæquabili albo-cinerascente, scutellis plano-convexinsculis pallidis pruinosis confertis pressione subangulosis, margine subevanescente. - Parmelia angulosa. Ach. meth. 162. - In cortice arborum.

985. Populicola. Crusta grannlata inrequabili cinereo-nigricante, ambitu albo subzonato, scutellis planiusculis subpruinosis albis, tanden subolivaceis. - Parmelia subfusca $\varepsilon$. Ach. meth. 168. In cortice populi albi.

989. Tartarea. Crusta tartarea granulata inæquabili albo-virescente, scutellis planis rufis demùn convexiusculis rugulosis, margine tumente albo. - Parmelia tartarea. Ach. meth. 165. In rupibus, stratis ususcornen et arboribus. 
990. ITpsatiensis. Crusta tartarea subramulosa albo-glaucescente, scutellis ochrolencis planis, nargine tumido albo. - Super strata nuscorum in Alpibus.

991. Parella. Crust. tartarea effusa rimosa rugoso-verrucosa alba, sctitellis contertis ecenculoribus è concavo planis, margine tumido tandem flexuoso. - Parmelia parelia. Ach. nieth. 164. - In rupibus et rarius arboribus.

\section{t†t† Scutellis inter aut suprì squamas foliaceas} insidentibus.

SI. R II I $\quad \boldsymbol{z}$ O

Statum tenuissimum fibriliosum nigrum, snstinens squamas foliareas distinctas plano-convexinsculas et scutcllas inter squamas collocatas, nigras, planas, mirgine vix tumıdulo.

992. Gengruphirum. Squamis flavo-virescentibns adpressis minutis confertis subrotundis, scutellis planinsculis atris orbiculatis aut oblongis. - Lecidea atrovirens. Ach. metỉ. $4^{5}$. - In rupibus graniticis.

993. Cinfervoides. Strato fibrilloso radiante, squamis pancis minimis griseo-ilbis, scuteliis atris planis, centro sæè prominulo. - Lecidea atro-alba. Ach. meth. 45. - In saxis siliceis.

991. Ainrio. Squanis confertis lavissimis planis flavo-cupreis nigro variis, scutellis atris planis vix margiuatis. - In rupibus graniticis Pyrenæorum.

995. Armeniacum. Squamis confertis flavo-armeniaceis subconvexis ætate rugosis, scntellis atris planis subragosis. - In rupibus calcariis Pyrenaortm.

996. Almbrunneum. Squamis subdistantibus magnis convexis brunneo-atris. scutillis atris planis orbiculatis aut diformibus, margine ennvexn subnitido. - In rupibus schisto-micaceis Pyrenæorum et Alpiun.

$$
\text { S2. } p \text { s o r } A \text {. }
$$

Squamæ distinctæ planæ ant convexæ in crustam irregularem confertæ; scutellæ margine squamarum adnatæ, prino planæ marginatæ, demùm subconvexæ.

\section{S. I. Squamis convexis.}

997. Tabacina. Squamis fulvo-rufis confertis crnstam crassam grumnsam constituentiblis, scutellis atris subconvexis interdùm difformibus. - In rupibus schistosis Pyrenæorum.

998. Galbulus. Squanis citrinis confertis sublobatis, scutellis atris crassis planis vix marginatis, tandem confluentibus. - Ad terram in Pyrenæis.

999. Vesicularis. Squamis cinereo-viresecntibus distinctis basi ram licatis turgilis suhlobatis, scutellis atris planis marginatis, tandem irregularihus. - Lecidea vesicularis. Ach. meth. - 8 . Lichen coerulen-nigricans. Engl. Bot. t. 1139. - Ad terram in montanis. 1000. Opuntioides. Squamis cinereo-virescentibus turgidis distinctis 
sinuosis eradicatis, scutellis atris subcrsiis parvis orbiculatis. Ad terram in montanis.

10ог. Candida. Squamis albis sinnoso-lobatis turgidis subimbricatis quasi promosis, seutellas atris polline carsio srpe couspersis planis vix manginatis.-Lecidea cimdida. Ach. meth. 79. Lichen tumidulus. Smith. trans. Linn. 1. t. f. f. 3. - Ad terram in montiuis.

\section{§. II. Squamis plano-concavis.}

1002. Decipiens. Squanis rufo-fulvis concariusculis subrotundis suhtis margineque abis, denum convexo-flexunsis, sentellis atris tandem convexjs. - Lecidea decipiens. Ach. meth.30. - Ad terram in moutibus.

1003. Lurida. Sqnamis viridi - fuscis subtìs pallidioribus concaviusculis orbiculatis crenatis, scutellis atris demiun convexis. - Lecidea lurida. Ach. meth. 77. - Ad terram et rupes terra subtectas.

$$
\text { 85. U R C } \mathbf{E} \text { O } L \text { L A } R \text { I A. }
$$

Squamæ planinsculæ, confertæ in crustam areolatam aut frustnlosam, apice dehiscentes et gerentes scutellam imucrsam, margine proprio donatim, et accessorio à crusta cinctam.

\section{I. Scutellis semper inmersis.}

100\%. Contorta. Squamis subdistantibns albo-glancis depressis subcontortis, scutellis fuscis concavinsculis, margine accessorio ruguloso pulverulento albido. - In saxis.

1005. Castanea. Squamis subsparsis castaneo-fuscis parvis convexiusculis apice poro scutellifero dehiscentibus. - In rupibus schistosis Pyrenæorum.

1006. Opegraphoides. Squamis planis albidis crustam levigatam areolatam constituentibus, scutellis parvis nigris immersis confluentibus et indè lineas nigras interdùm efficientibus. - In saxis.

1007. Tessulata. Squamis planis cinereis ochroleucis aut cresis crustam levigatam arenlatam constituentibus, poros $1-3$ nigros impressos gerentibus. - In rupibus.

5. II. Scutellis primò imnersis, demiım subexsertis.

1ooS. Scruposa. Crusta effusa tartarea rugoso-plicata granulata albo-cinerascente, scutellis nigris, margine accessorio tumidulo subcrenulato. - Ad rupes, terram et muscos.

1009. Ocellata. Crusta effusa verrucosa albirla, squamis convexis suhpapillatis, scntellis planinstulis nigricantibns tandem diformibus, nargine accessorio tumido flexuoso. - Urceolaria gibbosa. Ach. meth. Ifí? - Ad rupes calcarias.

10 10. Lamarckii. Crusta effusa verrucosa albida, squamis convexis, scutellis planiusculis infis tandem difformibus, margine accessorio tumido flexuoso. - Ad rupes tenui terra tectas.

$$
\text { 84. V o L V A R I A. }
$$

Tubercula membranacea prima ætate clausa apice tandem dehis- 
eentia, in crustam tenuem strata, massam compactam et caducan includentia.

10rт. Conchylinirles. Crusta subuulla, tuberculis rotundatis applanatis albis sublepressis, post lapsum receptacnii nigri orbicularis lentiformis cyathiformibus. - In rupibus silaceis circà Staupas (Eiarıpes).

1ог2. Exanthematica. Crusta tenui cinerascente, tuberculis minimis cruste ad dimidiun immersis, murgine crasso albido prominulo, disco concavo carneo lutescente. - Urceolaria exanthematica. Ach. meth. I $\{6$. - In Alpibsus et Pyrenæis ad rupes calcarias.

ror3. Truncigena. Crusta albida inæquali, tuberculis apertis concavis intus carneis, margine mbmbranaceo inflexu. - Theluttema lepadinum 6. Ach. meth. ı32. Lichen inclusus, Engl. Bot. t. 6-8. - In cortice annosarum quereumm. - An hujus generis?

$$
\text { 85. S Q U A } M \text { M A } \mathrm{R} \text { I A. }
$$

Squamæ distinctæ vel coalitæ, sæpiùs imbricatæ, è centro radiantes, suprà scutelligeræ, tuberculis vel scutellis in crustam haìd immersis.

sorf. Electrina. Flavo-citrina, squamis centralibus convexis prominulis, receptaculis convexis concoloribus immarginatis. Ad saxa in Pyrenicis.

ıог5. Insulata. Squamis primò distantibus demùm confluentibus, crusta crassa intùs alba extus flavo-pallescente, scutellis marginatis rufis. - Ad rupes calcarias in Pyrenæis.

ror6. Smithii. Crusta glanco-pallescente viridi intìs alba, squamis foliaccis sinuosis, scutellis rugosis narginatis, margine albo spirali. - Lecidea? Smithii. Ach. meth. 83. - Ad terram et rupes calcarias.

гог7. Crassa. Crusta imbricata albo-virescente, lobis Iobato-crenatis undulatis subtus fuscescentibus, scutelis numerosis sparsis rufo-fulvis. - Parmelia crassa. Ach, meth. 1S3. - Ad terrain.

ror S. Lentigera. Crusta orbiculuri alba subflexu/sa inbricata, scutellis plano-rufescentibus, margiine integetrimo albo.-Parmclia lentigera. Ach. meth. 192. - In montanis ad terram.

1ог9. Cartilaginea. Crusta imbricata subpulvinata rufo-pallescente flava, scutellis in eentro numerosis fulvis, margine albicante demùm flexuoso crenulato. - Parmelia cartılaginea. Ach. meth. 184. - Ad saxa in Pyiencis.

ro20. Melanophthalma. Crusta cartilaginea lobata imbricata, subtìs et margine nigrạ, suprà flavo-pallescente viridi, scutellis nigris, margine flavo-albescente. - Ad sixa in Pyrenæis.

1021. liubina. Crusta curtilaginea lobata imbricata, snbtis et nargine nigra, snpri flavo-pallescente virili, scutellis lateritio-ruhris, margine albo integro. - In Alribus ct Pyrenxis ad rupes graniticas et schistosas.

3022. Pellata. Crusta sulscoriacea, suprì flavesecnte, sublìs nignra, intus 
intus alloa sublobata, receptaculis sparsis fulvis, margine subcrasso Alexuoso. - In Pyrencis et $\Lambda$ Ipibus ad saxa.

\section{†十+† Receptacula in thallo foliaceo inserta.}

$$
\text { 86. P I A C O D I U M. }
$$

Thallus stellato-radiatus orbicularis, centro granulosus, anbitu foliaceus; receptacula scutcllata in cruste parte granulosit sita.

1033. Fu/gens. Crusta citrina plicato-flexuosa, scutellis rulerrimis, marginc crusta concolosi demim obliterato. - Parmelia fulgens. Ach. neth. 192, - Super muscos.

ros'f. Candelarium. Crusta virili-flava, foliolis lobatis latis planis, scmellis planis marginatis concoloribus. - Parmelia candelaria. Ach. meth. 187. - In muris rupibus et arbormen truncis.

1025. Murorum. Crusta flavo-virescente, fuliolis angustatis lobatis convexis, scutellis subconcoloribus margine dilutioni, - Parnelia murorum. Aciı, meth. 195̃. - In muris.

1026. Elegans. Crusta flavo-aurantiaca, foliolis radinsis subdiscretis, scntellis marginatis concoloribus, - Parmelia elegans. Ach. meth. 193. Exelude syomymon Hoftuanni in Flora gallica. In rupibus calcariis micaceisque.

1027 . Ochroleucum. Crustapallido-virescente, scutullis fulvis, margine albido crenulato. - Parmelia saxicola. Ach. rueth. 191. - In saxis,

1028. Canescens. Crusta tartarea glauco-candicante, scutellis cæsionigris, margine alhido vix conspicuo. - Lecidea? canescens. Ach. meth. S3. Engl. bot. t. 582. - In muris et truncis arborum.

1029. Albescens. Crusta tartarea grisea suborbiculari, scutcllis palJide carneis marginatis, margine albido vix manifesto. - Parmelia galactina. Ach. meth. 19o. - In muris.

1030. Versicolnr. Crusta tartarea centro virescente, ambitu candicante, scutellis rufescentibus marginatis. - In muris.

1031. Radiosum. Crusta tartarea medio nigricante, ambitu cinerascente, scutellis centralibus confertissimis nigricantibus, margine tenuissimo cinereo. - Parmelia circinuata. Ach. meth. 189. - Ad lapides calcarios et muros.

$$
\text { 87. } \quad \text { C }
$$

Thallus foliaceus gelatinosus forma varius; receptacula scutellata. 1. I. Foliolis parvis crassis imbricatis aut parim distinctis.

1032. Nigrum. Crusta tenui subinbricata nigra maximè adhærente, scutellis concoloribus concavis temùm planis. - Lecidea nigra. A ch. meth. -6. - Ad lapides calcarios.

1033. Variabile. Crnsta tartarea subgelatinosa, centro dilutè umbrino, anbitu albido-cincreo, scutellis confertis fusco-cæsiis, margine albido. - Parmelia variabilis. Ach. meth. 19o. - Ad lapides calcarios. 
ro3\%. Micrnphy!lam. Crusta effusa imbricata cinerea fusco-nigricaute, lohis confertis minutis inciso-erenatis, scuteilis rufis demim convexis, margine t nuissimo coneolore. - Lecidea inicrophyila. Ach. weth. -6. - In tuncis arborum.

1035. Grannsum. Crusta viridi-nigricante, granulis tuberculosis opacis aspersa, scntellis rufescentibus convexis, margine granulato. - Ad terram humidam.

1036. Symphoreum. 'Thallo atro-viridi, foliolis crispis erectis, scutellis inversè turbinatis concoloribus, margine prominulo. - Parmelia myriococca. Ach. nieth. 238. - In saxis.

1037. Fasciculare. Thallo imbricato atro-viridi, foliolis lobatis ant crenulatis fasciculatis, scntellis turbinato pedicellatis obseurè rutis, margine prominulo.-Parmelia fascicularis. Ach. meth. 239.-Ad terrain et in truncis.

1038. Crispum. 'Thallo imbricato atro-viridi, scutellis magnis sparsis badiis marginatis. - Parmelia crispa. Ach. mell. $23 \%$ - Ad terrain inter nuecos.

\section{§. II. Foliis liberis crassiusculis.}

ıoło. Corniculalum. 'Thallo pallidè fusco-virescente, laciniis membranaceis linearibus multifidis, scutellis sparsis rufu-fulvis. - Parmelia pilmata. Ach. meth. 2 z2. - Ad terram.

rofı: Lacerum. Thallo membranaceo subpellucido glancescente, lobis confertis erectiusculis laceris ciliatis, scutellis sparsis parvis concavis rubris, marcine integro pallido. - Paruelia lacera. Acl. meth. 225. - Inter muscus.

1oi2. Jarobece-folium. Thallo fusco-atrovirescente imbricato, lobis lacero-laciniatis crispis, scutellis planis rufo-purpurascentibns,

1 margine granulato. - Parmelia melæna. Ach. meth. 2́o. - Ad terram el rupes humidas.

1of3. Nigrescens. Thallo membranaceo semi-pellucido monophyllo orbiculato depresso rugoso atro-viridi, scutellis centralibus confertis rufo-fuscis. - Parmelia nigrescens. Ach. meth. 227. Engl.

- bot. t. 3 f́5. - In truncis arborum.

1o $3^{*}$. Microcarpum. 'Thallo membranaceo semi-pellucido orbiculato depresso rugoso viridi, scutellis numerosis centralibus rufofuseis, margine dilutiori. - Lichen nucrocarpus. Schl. cent. 4. n. 66. Collema nigrescens, f. Fl. Gall. n. 10 ₹3. - In truncis arborum.

roł́. Furvum. Thallo membranaceo atro-subvirescente rugoso-plicato granuloso, lobis incisis crispis, scutellis sparsis planis nigrofuscis, - Parmelia furva. Ach. meth. 230. - In truncis arhorum.

ro 45. Saturninum. Thallo coric ceo-membranacco atro-rirente, subtus subtomentoso, lobis undulatis maximis, scutellis elevatis planis rubris. - In truncis arborum, præertim juglandis.

$$
\text { 88. I } \mathbf{M} \text { B } \mathbf{R} \text { } \mathbf{R} \text { I } \mathbf{A} \text {. }
$$

Thallus foliacens stellatus subini ins suitus fibrillosus; scutella centro tantum adfixis, ad paginam folior; $m$ superiorem sitis. 
j. I. Foliis sublus hirlis, lobis linearibus.

1o/6. Cersiu. 'Thallo allo-subcinerascente subtis nigro-fibrilloso, laciniis pulvere casio gramblatis, scutellis sparsis fylaco-nigris, margine albirlo. - Parmelia casia. Acl. meth. 197. - Ad lapides, muscos et cortices.

zo $f^{k}$. Speciosa. Thallo cartiligineo-membranaceo albo-subcorulescente, subtus niveo vel cinereo-fibrilloso, laciniis marginibus subciliatis, scutellis rufo-fuseis, margine inllexo suberemulato.-Lichan speciosus. Wulf. Jacq. coll. 2. p. 119. t. 7. Parmelia speciosa. Ach. meth. 193. - In arborum trucis.

so 7 . Stellaris. Thallo primò rugoso cincreo subtìs albido, filurillis cinereis, scutellis planis nigro-carsiis, demum concavis atris, margine: integro cinereo. - Parmelia stellaris. Ach. meth. 20y. In cortice arbortum.

10\{8. Aipolia. Thallo cinereo-cæsio subtus nigro-fibrilioso, scutellis casiis planis marginatis, margine albido ummido crenulato. - Parmelia aipolia. Ach. meth. 209. - $\Lambda \mathrm{d}$ tunncos arborum.

10 19. Pulverulenta. Thallo è cinereo rufescente granis prominulis supernc pulveralento, subtus nigro-tomentoso, scutellis fuscis cæsiis, margine tumirlo involuto cinerascente. - Parmelia pulverulenta. Ach. meth. 2 to? - In truncis arborum.

so5o. Grisea. Thallo subcinereo in medio pulverulento subtìs albiclo fibrilloso, scutellis nigro-griseis marginatis, unargine prominulo albido crenulato. - Lichen pityreus. Ach. lich. prod. 12'́. - In truncis arborum.

1051. Cyclose'is. Thallo submembranaceo cinereo-glauco subtùs nigro-fibrilloso subspongioso, margine et centro pulverulento, scutellis fusco nigris, nıargine cincreo inflexo. - Parmelia cycloselis. Ach. weth. I99. - In truncis arbortum.

1053. Ulothryx. Thallo cinereo-glanco subnigro subtìs nigro-fibrilloso, scutellis fusco-nigris subtìs ciliatis, margine integro cinereo. - Parmelia ulothrix. Ach. meth. 200. - Ad corticen arborum.

1053. Aquila. Thallo cartilagineo-membranaceo obscurè fusco, subtùs pallidiori nigro-fibrilloso, scutellis glabris concoloribus, margine dilutiori crenulato.- Parmelia aquila. Ach. meth. 201 . 6 . Collema cristatum. Fl. fr. n ${ }^{\circ} \cdot 1039$. excl. syn. - In saxis maritimis.

1054. Retiruga. Thallo cinereo-glancescente scabriuseulo lacuuoso reticulato, subtìs nigro tomentoso, sentellis badiis, margine tenni inflexo albo crenulato. - Parmelia saxatilis. Ach. meth. 20\%. - In saxis et truncis arborum.

1055. Adusta. Thallo fusco-olivaceo læviusculo, subtùs nigro tomentoso, scutellis badiis, margine tenui inflexo albo crenulato. Parmelia saxatilis, var. 4 ch. meth.20'́- - In saxis et truncis arborum.

$$
\text { ๑. II. Foliis subt', 'irlis, lobis latis rotundatis. }
$$

3056. Quercina. : glauco subpruinoso, snbtùs fusconnigricante, fibrillis nigris, icntellis sparsis subluscis, margine subintegro. - Parnelia tiliacea. Ach, meth. 215. - In arborum truncis. 
105j. Coerulescens. Thallo cinereo-plumbeo subtis atro-coerulescente spongioso, sentellis ferrugineo-fuscis, margine prominulo albido crenulato. - Parmelia aftuis. Ach. weth. 212. Lichen affnis. Engl.

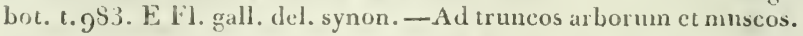
1058. Plumbea. Thallo cinereo-plumbeo subiùs atro-corulescente spongioso, scutellis fuscis planis immarginatis. - Licheu plumbeus. Engl. bot. t. 3j3. Parmelia plumbea. Ach. meth. 212. - In truncis arborum.

x 059 . Pityrea. Thallo griseo-albescente margine crispo, subtìs cuernleo virescenti tomentoso, centro pulverulento, scutellis rufoferrugineis, margine prominulo crasso pulverulento. - Lichen cerulco-batius. Schleich. cent. exs. 12. 21. - In stratis muscorum.

ro5 $9^{*}$. Aleurites. 'Thallo albo-cinerascente rugoso pulverulento, subtùs ad ambitum fusco subnudo, scutellis elevatis ferrugineo-fuscis, maryu: crenulato pulverulento. - Imbricaria aleurites. Ach. neth. 208. - In trabibus adque corticem pini sylrestris.

\section{§. III. Foliis sultius glabris, lobis latis rotundatis.}

1o6o. Parietina. Thallo flavo-aurato subtis albido, scutellis concoloribus, nargine tenui integro. - Parmelia parictina. Ach. meth. 2r3. - Ad parietes, truncos arborum et saxia.

ıo6r. Olivacea. Thallo olivaceo-fusco nitido subtùs fuscescente, scutellis subconcoloribus, margine inflexo crenulato. - Parmelia olivacea. Ach. meth. 213. - Ad truncos arborum et saxa.

1062. Acetabulum. Thallo glanco-virescente, subtùs nigro-fusco, scutellis concavis amplissimis rubro-fuscis, margine crenulato ant rugoso. - Parmelia corrugata. Ach. rueth. 215. - In truncis arborum aceris , fraxini, fagi.

1063. Caperata. Thallo palliclè-flavo virescente, subtùs atro-hispido, scutellis concavis rufescentibus, nargine crenulato pulverulento.Paruelia caperata. Ach. meth. 216. - Ad arbores et saxa.

๑. IV. Foliis subtius glabris, lobis linearibus.

so6'. Conspersa. Thallo glauco-virescente sxpiùs nigro-punctato, subtus nigro-fusco, scutcllis subplanis hadis, margine inflexo subintegro. - Parmelia conspersa. Ach. meth. 205. - In saxis.

1065. Diatrypa. Thallo passim perforato cinereo, subtìs albo subfibrilloso, laciniis apice inflatis, sentellis parvis dilutè rubellis, margine albo integro. - Parmelia diatrypa. Ach. meth. 251. - In arboribus.

1066. Plysodes. Thallo albicante, subtìs nigro-fusco, laciniis apice inflatis, scutellis magnis subrubris, margine inflexo tenui integro. - Parmelia physodes. Ach, meth. 250.- In truncis arborum, ad saxa. 1067. Incurva. Thallo suberustaceo griseo-ochirnleuco subtus subnigro, laciniis apiee inflexis, scutellis centralibus subrubris, margine prominulo cinereo integro.- Parmelia recurva. Ach. meth. 201 ? - In rupibus calcariis.

ro68. Ambigua. Thallo pallido-virescente subtùs nigro-fusco, scutellis sparsis fuscis, margine pallido subintegrovix proıninulo. Parmelia aubigua. Ach. meth. 20\%.- In cortice abietino. 
1069. Encausta. Thallo nitente aibielu-ciucreo, sultios nigre-viult

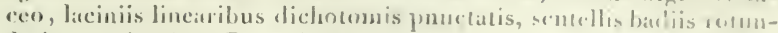
datis marginatis. - Parmelia cucausta. Ach. meth. 202. - Ad territur in $\mathrm{Al}_{\text {pilus. }}$

sozo. Falzlumensis. Thitlo cartilaginen-nembranacen mringue nigm, laciniis maltilido-dichotomis, scutcllis flanis magnisulivacco-fuscis. - Parmelia falıhuensis. Ach. med., 203. - In saxis Alpinis.

$$
\text { Sg. P II Y S C I A. }
$$

Folia libera suberecta neringuè glahra aliquandi ciliata sapiòs corrugata dissecta, laciniis seutclias et ublereula farinosa gerentibus.

5. I. Foliorum laciniis elongatis, sublus longitudinaliter curvatocanaliculatis.

roz!. Leptalea. 'Thallo cinerascente, sntius albielo, laciniis apice nigro-subciliatis, scutellis fusco-nigris, margine allide integro prominulo. - Parmelia leptalea. Ach. meth. 195. - In arboribus ct saxis.

10-2. Tenella. Thallo ntrinquè cinerascente, laciniis apjice adscendentibus fornicatis ciliatis, scutellis nigro-casis, margine alliclo prominulo. - Parmelia icuelia. Ach, meth. 250. - Ad cortices arborum.

yoz.3. Ciliaris. Thaỉlovirescente-glauco subtus albo, laciniis margine cilia, clongata nigrescentia gerentibus, scutellis terminalilus snbstipitatis nigro-casiis, margine albido prorninulo, - Parmelia ciliaris. Ach. meth, $255 .-$ - In cortice arborum.

roza. Furfuracea. 'Thallo cincreo pulverulento subtìs violaceonigro, scutellis cyathiformibus fusco-rnbris. - Parmelia furfuracea. Ach. melh. 254. - Ad truncos arborum in Alpibns et Pyrenais.

\section{II. Foliorum laciuiis plınis, elongatis.}

1075. Prunasiri. 'Thallo memluanaceo molli rugoso-lacunoso alliclo, subtìs albissimo, scutellis sulmarginalibus coneavis badiis, - Parmelia pranastri. Ach. meth. 25\%. - Ad candices arbormu.

so-6. Farinacea. Thallo cartilaginen ntrinquè cineren-glatien, tıberculis pulverulentis marginalihns convexis albis, sculdlis marginalibus snbstipitatis planiosenlis oclunlenon-carneis. - Parmelia farinacea. Ach. metis. 263. - In truncis arbormm.

1077. Squornsa. 'Thallo cartiagineo cinereo sublacunoso hine inde pulverulento, seutellis subterminalibus sessilibus albis. - Parmelia pollinaria. Ach. meth, 26f f. - In truncis arborum.

so-8. Fraxinen. Thallo cartilaginco cinerascente-virirli rugosn, simplici aut subramoso, scutellis marginalibus lateralihusque planis pallidis.-Parmelia fraxinea. Ach, meth. 258.-In truncis $\vdots$ rbormm.

1079. Fastigiuta. 'Thallo subeartilagineo cinerascente, laciniis sursim incrissatis fastigiatis, scutellis terminalibus sessilibns concoloribus. - Parmelia fastigiata. Ach. meth. 260. - In truncis a:borum. 
Io\&n. Islandira. Thallo cartilagineo viridi-castanco sinnato-laciniato, laciniis ciliatis ferc spinosis, scutellis orbicularibus ciliatis sessilibus. - Cetraria islindica. Ach. meth. 293. - Ad terram in pratis montanis.

ıo8ı. Cucullata. Thallo cartilaginen albo-viridi-flavescente sinuoso erecto tubuloso canaliculato, scutellis carneo-fuscescentibus cucullatis submarginalibus. - Cetraria cucullata. Ach. meth. 293. Ad terram in collibus aridis.

r082. Nivalis. Thallo membranacen lacunoso albo-flavicante, laciniis planis crispis crenatis, scutellis marginalibus carneis, margine crenulato. - Cetraria nivalis. Ach. meth. 294. - In Alpibus et Pyrenæis.

\section{§.IV. Foliorum lobis rotundatis aut irregulariter dissectis.}

ro\$3. Juniperina. Thallo pallidè flavo subtis flavissimo, laciniis complicatis eroso-crenatis, scutellis badiis elevatis, margine tenui flavo crenulato. - Cetraria jnniperina. Ach. meth, 298. - In Pyrenæis ad truncos juniperinorum.

so8'. Pinastri. Thallo sinuato-lobato flavo, laciniis pulverulentis flavissinis, scutellis rarissimis badiis. -Cetraria juniperina, B. Ach. meth. $2 S^{8}$. - Plecunquè ad radices pini in Alpibus meridionalibus et Pyrenais.

roSร̃. Chry'sophtalma. Thallo cartilagineo flavo-aurantiaco laciniato ciliato, scntellis terminalibus coucoloribus nudis aut radiatociliatis. - Parmelia chrysophtalma. Ach. meth. 267. - In truncis arborum.

1086. Sepincola. Thallo membranaceo castanco subtìs dilutiori ragè lobato, laciniis subcrenatis, scuteliis submarginalibus concoloribus, margine tenni crenulato. - Cétraria sepincola. Ach. meth. 297. - Ad ramos juniperinos, in Pyrenæis.

$108 \%$. Glauca. Thallo membranacen utrinquè levi , supernè glanco, suhtus nigro, scntellis rufo-fuseis sparsis. - Cetratia glatica. Ach. meth. 296 . - Ad truncos arborum ct saxa.

1088. Fatiax. Thallo numbranaceo cinereo subtùs albo niggro submaculato inciso lobato, laciniis latero-crispis, scutellis magnis spadiceis. - Cetraria fallax. Ach. meth. 296. - Ad truncos arborum el saxa.

$$
\text { 90. L }
$$

Folia coriacea membranacea libera lobata, Iobis latis rotnndatis subtìs hirsutis, supernè scutelligeris, scutellis sparsis subsessilihus.

yo89. Scrnbiculata. Thallo sulicoriacen expanso lavi glanen-viescente, subtis ferrugineo-nigricante villoso, seutellis sparsis fuscis, margine integro. - Parmelia scrobiculita. Ach. meth. 219. - Ad terram et arbores inter muscos.

ıо9о. Pulmonaria. Thallo subcartilagineo lacunoso - reticulato vixidi-fusco, subtus flavo-ferruginco hirto, scutcllis submarginalibus 
rufo-fuscis, margine integro. - Parmelia pulmonacen. Ach. meth. 220. - All arlurinu truners in sylsis.

1ogr. Perluta. Thallo levi glauco-virescente, subtis fusco-nigro subvilloso, lobis subcrispis, sculcllis cyathiformibns is ruber fuscis.-Parmelia perlista. Ach, meth. 216 , - In arboribus.

1092. Kerbarea. Thallo cxpanso lavigato herhacen, sublus alhiclo fusco-subiomentoso, scntellis rulo-finfis planiusculis, margine integro - Parmelia herbacea. Ach. weth. 218. - In arbusibus inter miiseos.

1093. Glomu'ifera. Thallo subcoriacen cineres-glaucescente, sublis allu fuscescentrque tomentosn, pulrinulis filamentosis intertextis axillaribns, scutellis rufo-fulvis, margine crenulato. - Parmelis glomuliferd. Acis. meth. 210. - Ad caudices annosarmm arbortus.

$$
\text { 91. S T I C T } \mathbf{A} \text {. }
$$

Folia menhranacea supernè sentellas aut pellas gerentia, subtùs fossulis (cyphellis) glabris sparsis intrit tomentnm instructa.

soýf. Fuliginosa. Thallo depresso sinuato cinereo - glanco scabro, subtis lacunriso sublutco villoso, scutellis lateralibus planis fertugineis. - Lu irunco arborum.

sog5. Syluatica. Thallo adscendente sublacunoso inciso-lobato glaucofusco, subtus ferrnginen-fusen villoso, scutellis peltafnumibus fuscis submarginalibus adscendentibus. - Sticta sylratica. Ach. meth. 28 ?.

$$
\text { 92. P }
$$

Folia coriacea rotundata lubata, marg̣ine plerumqué gerentia receptacnla (pelias) depressa ant applanata, tota superficic adliærentia.

\section{I. Pelta submarginales antica.}

1096. Venosa. Thallo cinereo, subtìs albo renis tomentosis cinerenfuscis, peltis nurginalibus horizontalibus rotundis fuscis. - Peltidea renosa. Ach. meth. 282 . - In ter ra ad margines viarum et fossarum, locis unbrosis humidis glareosis.

1097. Spurix. Thallo cinerco digitato-lobato, subtìs alho venis alhi . dis, peltis rotundis fuscis verticalibus. - Peltidea spuria. Acls. uncth. 393. t. 5. f. 2. - Ad terram.

sog. Horizontalis. Thallo glauco-virescente subtìs nigro-fusco reticulato-venoso lobato, lobnlis peltigeris elongatis Jorrizontalibus, peltis transversimal)longis rufo-fnscis. --Peltillea honizontalis. Ach. weth. 282. - Smprà saxa et muscos locis montanis syfvaticis.

rog9. Canina. 'Thallo cinerascente subtis albidiori venis fibrillisque fuscescentibns, lobulis peltigeris adscententibus, peltis spadiceorufescentibus. - Peltidea canina. Ach. meth. 283 . - Suprà terram in sylvaticis frequens.

sıo. Aphtosa. Thallo læè viridi verrucis sparsis fuscis, subtis albn-rufescente, peltis adscendentibus rotmudis rubris. - Peltidea aphtosa. Ach. $28 \%$. - Suprò terram in pinetis.

I 
fibrilloso, Jobulis peltigeris attenuatis peltis subrotundis adscendentibus nigro-fuscis. - Peltide polydactyla. Ach. meth. 286. Ad terram in sylvis.

\section{II. Pelte sulmarginales postica.}

rox. Resupinata. Thallo plumbeo-virescente, subtùs pallescente, lobulis peltigeris lorevissimis, peltis reniformibus rufis. - Pelidea resupinata. Ach. meth. 289. - Suprà terram saxa et arbores.

\section{III. Peltce subdepressee in disco folii sitce.}

1ro3. Crocea. 'Thallo cinnamomeo subtùs venoso-villoso croceo, peltis sessilibus planis spadiceis. - Peltidea crocea. Ach. meth. 290. - Ad rupium latera terra tecta, in Alpibus et Pyrenæis.

I $о$ f́. Saccatr. Thallo cinereo-virescente subtìs albo-fibrilloso, peltis sparsis saccato-immersis nigro-fuscis. - Peltidea saccata. Ach. meth. 290. - Suprà tersanı ad rupes et arborum radices, in Alpibus et Pyrenæis.

$$
\text { 93. U }
$$

Folia cartilaginea lobata centro adfixa; receptacula semper nigra, supernè ruxis concentricis aut spiralibus sæpissimè exarata.

\section{I. Foliis subtis hirsutis.}

1 105 . Saccata. Thallo griseo levi, subtìs sordidè albo, margine papilloso centro albido fibrilloso, scutellis nigris thallo immersis. - Pelidea? velleiformis. Ach. meth. 291. - Ad saxa in Pyrenæis.

Irnf. Ilirsutn. Thallo griseo-fuseo, subtìs nervoso è nervis fibrilInso, margine levi, scntellis sparsis sessilibus demim hemisphoricis. - Gyrophora hirsuta. Ach. meth. 1ng. - Ad saxa in Pyrenæis.

I 10 - Spadochroa. 'Thallo rigido griseo-fuscescente, supernc̀ elevato punctato, subtizs atto-hirsuto, fibrillis ramosis, scutellis sparsis convexis sessilibus. - Gyrophora spadochroa. Ach. meth. 1o8. Ad saxa in Pyrenais.

r 108 . Cirrlensa. Thallo rigido glauco-cinereo crispo margine conduplicato, subtus nigro, fibrilis crassis simplicibus. - Ad rupes graniticas Pyrenxorum montium.

xing. Pellita. Thallo amıitu plicato sinuato-lobato, suprà subnitidlo fusco-æenco, subtùs atro-lirsnto, scutellis sparsis subglobosis. - Cyrnphora pellita. Ach. meth. p. ios. - Ad saxa.

11 10. Proboscilea. Thallo glauco-cinerascente, subtis rufo-flavicante, scutellis spársis turbinatis, sæpiùs apice perforatis. - Gyrophora cylindrica et G. proboscidea. Ach. meth. 107-105. - Ad saxa in Pyrenæis et Alpihus.

\section{§. II. Foliis subtius glabris.}

111. Leiocarpa. Thallo utrinquè levi grisen-nigricantc, suhtùs rimis nigris reticularibus notate, peltis levibus nigris infundibuliformibus, margine prominulo. - Ad saza in Pyreneis. 
In2. Pustulata. Thallo suprì papuluso cinerou-viresente, subtus lavi lacumoso arregiate-fuscon, seutellis sparsis atris, - I.ecided f ustulata. Ach. meth. 85. - In saxis.

113. Emsa. 'Tluallo suprì nigro ambitu cribroso eroso-laciniatn , subtis concro-fusco subgamulato subfibrilloso, scutellis convexiusculis. - Gyrophora crosid. Ach. meth. 103. - Acl suxa in Alpilius.

I14. Papillosa. Thallo rotundato sublobato nigricante rugoso hinc inde fisso, subtis fuseo papillis albidis scabro, scutellis atris masnis rugosissimis. - Ad saxa in Pyrenzis.

i1 5. Nurina. Thallo lobato utringue clevato-punctato, suprit murino, subtìs nigru-fuseo, seutellis sparsis convexinscnlis submarginatis. - Gyrophora murina. Ach. meth. 1 10. - Ad saxa.

1 1 6. Flocculısa. 'T'hallo snprà centro squamuloso griseo-nigricante, subtùs atro lavi glabro. - In Pyenæis ad rupes graniticas.

11 7. Glabra. Thallo inxerualiter lobato atro-virente suhtus atro, utrinquè levissimo, receptaculis demum subglobosis. - Gyrophora glabra. Ach. meth. ror. - Ad saxa in montanis.

$$
\text { 94. E N D O }
$$

Thallus cartilagincus ccutro adfixus; receptacnlis in thallum ipsum immersis, pagina superiore rrominulis, orificio aperto vix conspicuo.

11 8. Flusiatule. Thallo cartilaginen crispo flexunso lobato complicato cincren-virente, punctis subnigris maculato, subtìs rufescente. - Eurlocarpon Weberi. Ach. meth. r2S. - In rivulis ad lapides aqua suffusos.

I rg. Complicatum. Thallo complicato-subimbricato cinereo-fusco, punctis elevatis nigro-fuscis, subtis fusco-nigricante. - Endocarpon complicütum. Ach. weth. 128. - Ad saxa imprimis maritima.

1r20. Minialum. 'Thallo albo-cinerasecnte tenuissimé excavatopunctato, subtins rubiginco lrevi denum rugoso. - Endocarpon miniatum. Ach. meth. 12 j. - Ad saxa.

112 . Hedwigii. Thallo subcartilagineo crassiusculo, lobis subdiscretis parvis obscuri viridibns, margine et subtus albis. - Endocarpon Hedwigii. Ach. meth. 1 25.-Ad terram, saxa, muros, etiam inter muscos.

\section{O R D O V. H E P A T I C AF.}

Frondes vircscentes, nunc expansæ membranacer lichenilus foliaccis analogæ, numc canle radiculis ramis et foliis (sicut in muscis) dicinctis gaudentes; organa sexualia sede distincta, monoica aut interdium dioica. MASC. Globuli liquore fecundante pleni, aggregati in calice sæpì̀s sessili. Fevin. Ovaria nula aut perichretio cincta; capsula sxpiìs pedunculatx, semper nperculo destitute; semina (in plurimis) filamentis spiraliter tortis (elateriis) adhærentia. 


$$
\text { 95. R I C C I } \Lambda \text {. }
$$

Capsula subglobosa, intrà frondem nillulans, tubo brevi vix prominulo apice perforato instructa.

1122. Natans. Frondibus obcordatis subtìs ciliato-fibrillosis. - In aquis stagnantibus natans.

1123. Fluitans. Frondibus dichotomis planis linearibus. - In stagnis furis et rivis quietis fluitans.

1124. Nodosa. Frondibus dichotonis linearibus planis hinc indè nodosis. - In aquis circà Abbatis-Villam.

1125. Car'ernosa. Frondibus è centro radiantibus dichotomis poris irregularibus cribrosis. - Humo madido adlærens.

3126. Glauca. Frondibus è centro radiantibus dichotomis planis (lenie) reticulatis. - Humo madido adhierens.

1127. Bifurca. Frondibus è centro radiantibus dichotomis supernè canaliculato-concavis, reticulo inconspicuo. - Ad terram madidam, imò inundatam.

$$
\text { 96. в L A S I A. }
$$

Capsula obliqua, in fronde immersa, tubo persistente coronata, perichrtio destituta.

1128. Pusilla. Frondibus è centro radiantibus dichotomis undulato-crispulis semi-pellucidis. - Ad terram madidan.

$$
\text { 97. T A R G I O N I A. }
$$

Capsula globosa, calyce bivalvi diù clauso demìm aperto cincta. 1129. Hypophylla. Fronde oblongo-spatulata, subtis purpurea fructifera. - Ad, terram et in rupibus sublinmidis unbrosis.

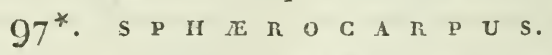

Capsula globosa intrà calycem uniralvem apicc perforatum cylindrico-turbinatum inclusa.

¥130. Michelii. Frondibus suborbiculatis apice truncatis pellucidis, supernè glomeratim fructiferis. - Targionia sphærocarpus. Fl. fr. n. 1130. Spliarocarpus terrestris. Engl. Bot. t. 299. - All terram rara et oculos parvitate fingicns.

тribus Ir. Hepatica muscosce. Capsula in valvulas longitudinales dehiscens; semina elateriis adfixa.

$$
\text { 98. A } \mathbf{x} \text { ' } \mathbf{H} \text { H }
$$

Capsula longissima subulata bivalris, placentam linearem intus fovens.

113r. Punctatus. Frondibus indivisis sinuatis margine crispis. Ad terram locis humidis umbrosis.

3. 2. Leevis. Frondibus indivisis planis margine vix subundulatis. - Arl terram locis huridis aut umbrosis. 


\section{9?. $\mathbf{M}$ A $\mathrm{R}$ C}

lieceptaculum pediculatum, lobato-radiatum, discoidenn ant campanulatum, subtùs gerens capsulas globosas dependentes quallivalves.

133. Polymorplut. Receptaculis planiusculis, femineo profunde 10-partito lobis linearibus, maseulo S-Iobato dentibus latis rotundatis. - Ad terram et lapides locis humidis unbrosis.

1134. Hemispharica. Receptaculo feminco hemisplaxico obusè 5-6lobo, pericliatio nullo. - In locis umbrosis Alpium, Calloprovincia Monspelii.

113. F $^{*}$ Triandra. Recptaculo femineo hemispharico subintegro tricapsulari, perichætio nullo.- M. triandra. Scop. caın. 2. P. 35 f. t. 63. Balb. diss. p. 4. f. I. - Super lapides Taurini.

$113 \mathfrak{\uparrow}^{* *}$. Quadrala. Receptaculo feminen hemispharico quadricostato quadricapsulari, perichatio nullo. - M. qualrata. Balb. diss. p. 5. t. 2. - Locis humidis et umbrosis circì 'Taurinum.

1135. Fregrans. Receptaculo femineo hemisphærico obtusè 5-6-1obo tricapsulari, perichætio fumbriano - N. fragrans. Ball. diss. P. 6. f. 3. - In locis humidis Alpium Pedemontanarum et circà Aquas Tarbellicas (Dax).

1136. Conica. Receptaculo feminco conico subovato 5-7-lobo 5-7capsulari. - In locis hmmidis nmbrosis.

113\%. Angustifolia. Receptaculis ........, fronde membranaceo semi-pellucido margine subsinuato poris destituto. - In Alpium locis umbrosis.

1135. Cruciata. Receptaculo feminco profundè 4-5-partito lobis subtubulosis. - In locis humidis umbrosis.

\section{IOO. J U N G E R M A N N I A.}

Capsula globulosa longè pelicellata solitaria quadrivalvis, matura apice dehiscens.

\section{I. Frondibus folium simplex referentibus.}

1139. Epiplyylla. Frondibus sinuatis medio capsuliferis. - Ad terram in sylvaticis humidis et ad marginem fossarnm.

1140. Pinguis. Frondibus oblongis sinuatis, pedicellis ex margine frondis inferiore ortis. - Ad terram humidam et propé aquas.

11 11. Multifula. Frondibus multifidis aveniis, lobis angustis plerumquè bipartitis, pedicellis ex axillis loborum propè basim ortis. - Ad terram liumidam, in truncis putridis, ad marginem rivorum.

11 ́2. Furcata. Frondibus glabris lineari-ramosis subciliatis, nervo longitudinali instructis. - In truncis arborum.

11 $4^{3}$. Pubescens. Frondibus tomentosis ramoso-furcatis lincaribus olitusis, nervo longitudinali instructis. - Inter muscos, ad saxa ct truncos arborum.

yı 1 Palmata. Minima, frondibus digitato-palmatis hasi capsuliferis. - In sylvis Alpium ad cortices arborum semi-putridarum, ad terram. 


\section{II. Frondibus pinnatis.}

1145. Pusilla. Frondibus brevissimis simpliciter pinnatis, foliolis dentatis ant obtusi lobatis. - Ad terran humidan.

1146. Scalaris. Frondibus simpliciter pinnatis, folinlis integerrimis ovatis distichis alternis canle apice glcobulifero. - In nemorosis.

1 1 f. Baibata. Frondibus simpliciter pinnatis apice medioque capsuliferis, foliolis 3-4-dentatis. - In Alpibus et Pyrenæis locis umbrosis luumirlis.

r f. Fissa. Frondibus radicantibus, distichè pinnatis apicc globuliferis, foliolis ovatis acutè dentutis. - Ad terram humidam.

x. 19. Bicuspiclata. Frondibus simpliciter pinnatis medio capsuliferis, foliolis imbricatis bidentatis. - In nmbrosis humidis.

1 50. Pidentala. Frondibus simpliciter pinnatis apicc cupsuliferis, foliolis orato-rotundatis apice emarginatis bidcutatis. - In sylvaticis ad terram et truncos putrilos.

I5r. Birostrala. Frondibus distichis, foliolis apice hilobatis, lobis linearibus tenuissimis. - In sylvaticis ad rmncos arborum.

1152. Viticulosa. Frondibus subramosis distichis, foliolis obtusè rotundis integris, pedicellis sparsis. - In sylvis humiais.

1 53. Polyanthos. Frondibus simpliciter pinnatis basi capsuliferis, foliolis subrotundis subimbricatis couvexis integerrimis. - In nemoribus.

1 5 4. Lanceolata. Froudibus simpliciter pinnatis apice capsuliferis, folinlis planis obtusis integerrinis. - Ad terram in uubrosis humidis.

1 55 . Aspleninides. Frondibus simpliciter pínnatis rlongatis subramosis cespitosis apice capsnliferis, foliolis magnis pellucidis ovato-rotundatis. - In umbrosis humidis.

115. Lavigata. Frondibus subpinnatis maximis atro-virilibus nitillis ramosis, foliolis brevibus latis subtruncatis mucronatis. - In Alpibus.

Ir 5 . Trilntala. Fronơibus subpinuatis, snbtù flagellatis, simplici ordine stipularum tectis, foliolis apice contractis tridentatis. In sylvis montosis.

158. Reptans. Frondibus simpliciter pinnatís subtìs flagellatis, simplici ordine stipnlarum tectis, foliolis stipulisque pellucidis subquadridentatis. - In ligno putrido.

IJ̃. Platyplyllla. Frondibns pinnatis procumbentibns subtìs stipularun triplici ordine tectis, foliolis imbricatis adpressis cordatis. - Ad truncos arbortum et saxa.

rGo. Tamarisci. Frondibus decompositis pinnatis, snbtìs stipulis triplici ordine teetis, foliolis imbricatis adpressis subrotundis. In truncis arborum et saxis. - Sxpiùs atro-purpurea.

161. Dilatala. Frondibus decompositis pinnatis apice capsuliferis, subtirs stipalis triplici ordine tectis, foliolis imbricatis convexis rulumdatis. - Ad truncos arborum et saxa. 
162. Complanata. Frombilus decompositis pinnatis, follolis imbricatis complanatis rotumdatis infende atureulatis. - In truncis arbormu ficifuens.

163. Temorosa. Frondibus crectis simplicibns ant subramosis, foliolis aureulisque ciliatis. - In nemoribus humidis.

116 . Undulatu. Fronlibus pinnatis, foliolis supernc auriculatis, foliolis auriculisque morlulatis integris. - In uliginosis montosis.

1165. Riesupinata. Fromlibus subsiniplicibus intricatis, foliolis apice subiubricatis subalternis rutundatis superuè auriculatis denticulatis. - In Alpibus ad fissuras saxorum.

1 66. Albicans. Frondihus pinnatis confertis, foliolis inferne auriculatis, folinlis aurieulisfue lincari-lanceolatis recurvatis distichis. - In locis umbrosis.

167. Tomentella. Frondibus decompositis bipinnatis, foliolis tomentosis ciliato-multifilis. - In umbrosis lumidis.

1 68. Trichophylla. Frondibus teretiusculis, foliolis capillaceis fasciculatis. - in Alpibus.

169. Setifnrmis. Frondibus canlescentibus simplicibus teretibus erectis, foliolis partitis, laciniis lato-subulatis, externè canaliculatis, internc curinatis. - In Gallia anstrali.

ı по. Julacea. Frondibus caulescentibus teretibus subcompressis, fuliolis aretè imbricatis adpressis bifariis argenteis. - In montibus Grallix australis.

\section{O R D O V I. M U S C I.}

Flores hermaphrorliti dioici ant monoici, terminales ant laterales, discoidei gemmiformes ant capitati, semper minimi, foliis flovalibus (perichatio) cincti. MAsc. Utriculi pedicellati, filis articulatis sterilibus intermixti. Fem. Ovaria cylindracea, iisdem filis intermixta. Fructus urna seu capsula pedicellata unilocularis, axi centrali instructa, apice operculo dehiscente clausa et calyptra ciduca seu menbrana extinctoriforma superati; ore nunc nudo nunc cincto peristomate ciliato aut dentatn, ciliis simplici aut duplici ordine dispositis; semina numerosissima pulvcracea. - Herbæ parrula, virescentes, froudosæ, perennes.

\section{† Musci peristomate destituti.}

IOI. P H A S C U M.

Capsula terminalis ovata subsessilis; operculum minimum non dehiscens; calyptra minima.

1171. Muticum. Acanle, foliis ovatis muticis concavis conniventibus, capsula sessili. - Ail sepes et aggeres.

1172. Cuspidatum. Caulesceus, foliis ovatis cuspidatis patulis terminalibus erectis conniventibus, capsula subsessili. 2 . In hortorum arcis, muris.

I 73 . Curvicollum. Subacaule, foliis perigonialibus rectis, peinnculo incurvato, capsula ovata. - In sabulosis aridis, Geneva. 
117f. Serratum. Acaule, foliis ovato-lanceolatis planis serratis erectis. - In terra humida.

1 75. Crispum. Caulescens ramosun, foliis caulinis minimis patulis, perigonialibus ¿̀ lata concava basi longè acuminatis contortilibus. - Ad lacum Lemannm.

11-6. Pi!iferum. Caulescens, foliis oblongis piliferis erectis. 2 . In muris argillosis et sylvis aritis.

1177. Subulatum. Caulescens, foliis lanceolato-linearibus patulis, summis è latiuscula basi subulatis rigidis, capsula 3absessili. 2 . Ad vias freçuens.

\section{†† Musci peristomate nudo instructi.}

IO2. S $\mathbf{P}$ I

Capsula lateralis aut terminalis, pedunculata, calyptræ transversim sectæ reliquiis basi cincta; peristoma nudum.

I -S. Latifolium. Foliis ovatis subobtusis concavis imbricatis apice couniventibus, capsulis sphæricis. $\mathcal{F}$. In paludibus.

1179: Capillifolium. Foliis lanceolatis acutis concavis imbricatis apice conniventibus, capsulis ovalibus, 24 . In paludibus montanis et sylvaticis.

I 80 . Squarrosum. Foliis ovatis acuminatis basi imbricatis apice divergentilus. 2 . In paludibus sylvaticis, Parisiis.

IISr. Compactum. Foliis ovatis subobtusis imbricatis, capsulis ovato-oblongis. $2 \xi$. In paludibus.

$$
\text { I 03. G } \mathbf{Y} \text { M } \mathbf{N} \text { O } \mathrm{S} \text { T }
$$

Capsula terminalis, ovita, calyptræ reliquiis basi nunquàm cincta ; peristoma nudum.

9. I. Floribus monoicis, calyptris basi lacinialis (A NуCTANGIUM).

1182. Aquaticum. Caule elongato apice ramoso, foliis lineari subulatis subsecundis ad apicem ramorum incurvis, capsulis oblongis, operculo obliquè rostrato. $\%$. Ad lapides in aquis illuentibus.

I 83 . Lapponicume. Caule subramoso, foliis elongato-lanceolatis siccitate crispis, capsulis turbinatis striatis. - In umbrosis Alpium.

1184. Ciliatum. Caule ramoso, foliis ovato-lanceolatis concavis apice diaphanis denticulatis, capsulis ovatis subsessilibus. $\mathcal{C}$. In rupibus.

9. II. Floribus dioicis, calyptris lateraliter fissis (G м.оотомом).

11S5. Pyriforme. Caule brevissimo, foliis ovato-acutis explanatis, capsulis erectis pyriformibus, operculo obtusè conico. $\mathcal{Z}$. In pratis marlidis et fossis.

1186. Truncatulum. Caule brevissimo, foliis ovato-lancelatis apiculatis, capsulis ovatis truncatis erectis, operculo obtusè rostrato. 2. In arvis et auris frequens.

1197. Heimii. Caule erecto, foliis clliptico-lanceolatis muticis 
apice denticulatis, eəpsulis oblongis erectis, opereuln obliqne rostrato.- Circà Sanctum - Valaticum S Saine-Valery-sur-Somme). † 11S8. Oltusum. Caule brevissimo, foliis lanceolatis acutis, capsulis obovatis trumcatis, opereulo subulato. - In lapiclibus et areuosis.

${ }_{188^{*}}$. Tenue. Caule exigno simplicissimo, foliis oblongis concavis obtusinseulis, capsulis obusè ovatis. opereulo conico. - Hedw. spec. p. 37. t. 4. f. 1-4. - Ad rupes arenosas suprì Lausannam.

1189 . Curvirostrum. Caulc ramoso cespitoso, foliis subulatis recurvatis interrupti: fasciculatis, capsulis ovatis, operculo subulato cnivato. - In $\Lambda$ Ipibus.

1190. Ovatum. Canle simplicissimo, foliis ovatis concavis piliferis, capsnlis ovatis. - Ad muros saxarue.

191. Microstommm. Caule simplici, foliis è latiore basi lanceolatis siccitate crispulis , eapsulæ ore coarctato, operculo obliquè conico. - Ad vias circá Bex.

\section{$\dagger+\dagger$ Periscomate simplici ciliorum serie instructo.}

$$
\text { IO/. T } F \text {. T } R \text { A } P \text { II I } S \text {. }
$$

Capsula terninalis, oblonga; peristoma simplex, dentibus 4 pyramillatis.

1 192. Pellucida. $\Psi$. In locis nmbrosis udis.

$$
\text { 105. A N D R E E A. }
$$

Capsula terminalis; peristoma simplex, ultrà capsulæ dimidiun scissum in dentibus 4 basi divergentibus, apice operculo minimo connexis.

1193. Rupestris. Foliis lanceolatis concavis obtusis , dorso muricatulis, perigonialibus lævibus aeutis ublongis, pedunculo pallidé lutescente. $2 \mathrm{~F}$. In Alpibus Valesiacis.

19'. Alpina. Foliis lanceolato-acntiusculis dorso lævibus, pcdunculo purpureo. 2 . In Alpibus.

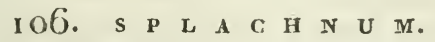

Capsula terminalis, ovata ant cylindrica, apophysi umbracnliformi seu obeonicæ intus eavæ insidens; peristoma simplex dentibus nunc 8 sulco longiturlinali notatis, nunc 16 per paribus approximatis.

1195. Ampullacenm. Foliis ovato-lanceolatis acntis, apoplysi viridi - purpurea lata inversè ampullæformi. 2 . In paludibus turfosis.

I96. Sphericum. Foliis oblongo-lancenlatis integerrimis, apophysi globosa viridi. $\mathcal{F}$. In depressis subalpinis.

1197. Frolichianum. Foliis inferioribus linguæformibus, superioribus spatulatis obtusis, apophysi obliqua obconica. $\mathcal{F}$. In Alpibus. $1197^{*}$. Mninides. Foliis lanceolatis longiùs cuspirlatis erectiusculis, apophysi exactè enica. - Ledw. spec. p. 51. - In udis ad lacum Arnonaz vallis Saanen. 
I 19 . Tenue. Foliis ovatis acutis serratis submuticis, apophysi obconica attemuata fusca. - In Alpibus.

1199. Serratum. Sinıplex, foliis lanccolatis extremitate serrulatis cuspilatis, apophysi contracta obconica, capsula cylindrica. - In Alpibus Helveciæ vicinis, locis pinguibus.

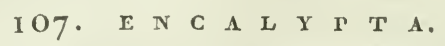

Capsula termintlis; peristoma simplex, dentibus 16 integris erectis spatio aquali discinctis; calyptra magna, læris, extinctoriiformis, lateraliter non dehiscens.

1200. Yulgaris. Calyptra laxa conica ore integra, caule subsimplici, foliis laticcolatis. $\mathcal{F}^{\mathrm{T}}$. Ad muros et saxa frequens.

s20r. Fimbriula. Calyptra luxa conica ore laciniata, caule ramoso, foliis lanccolatis. $2 f$. In montibus.

1202. Streptncrirpa. Calyptra ore I ciniata, capsulis spiraliter striatis, caule ramoso, foliis imbricatis oblongo-Ianccolatis. $\mathcal{4}$. Ad rupes Alpium.

$$
\text { IOS. W E I S S I A. }
$$

Capsula terminalis, oblonga ant cylindrica; peristoma simplex, dentibus 6 linearibus acutis apice conniventibus; calyptra lateraliter fissa.

1203. Crispata. Canle erecto ramoso, foliis linearibus undulatis contortis obsoletè denticulatis, capsula in medio contracta, operculo subulato incurvo. - Grimmia striata. Smich. I1. brit. 1185. 2f. In paludosis.

320\%. Cirrhata. Caule erecto innovationibus diviso, foliis lanceolatis carinatis siecitate crispis, capsula erecta oblongs-ovali, operculo tenuiter subulato. $\mathcal{F}$. In sylvis, aggeribus, tectis stramiueis.

1205. Controversa. Erecta, foliis acute lanceolatis, siccitate perquàm contortilibus, capsulis ovatis. 2 . In locis sabulosis ndis.

1206. Pusilla. Caule exiguo simplici, foliis capillaribus, capsula ovata læevi ore dilatata. - In nubrosis lumirlis.

1207. Curvirostra. Foliis lancenlatis imbricato-patulis, capsula gracili orato-cylindrica, operculi rostello recurvo. 2 . In locis sabulosis, Genevæ.

1208. Nigrita. Caule subdiviso ercto, foliis cordato-acuminatis nigrescentibus, capsulis sphæroideis ceruuis nigris splendentibus. $\mathcal{F}$. In turfosis circà lacum Lemanum.

$$
\text { I Og. G } \mathrm{R} \text { I } \quad \mathbf{M} \quad \mathbf{M} \text { I } \mathbf{A} \text {. }
$$

Capsula terminalis ovata; peristoma simplex, dentibns 6 basi latioribus apice divergentibus; calyptra sapuius basi laciniata.

\section{§. I. Calyptra latcralicer fissa.}

1209. Recurvata. Caule simplici, foliis setace is, eapsulis pyrifornibus, pedicellis arcuatis recurvatis. 2 . In rupibus nudis propè lacun Lcmanuı. 
2210. Canceolata. Caule erecto simplici divisogue, foliis lancesslato-concavis apiculatis, capsulis ovatis. F. Ail munos argalluceus liapidesutuc.

\section{11. Calyptra basi Lacera.}

12r1. Apocarpa. Caule rauoso, foliis ovato-acnminatis cariudis apice nurlis, capsula oblonga striata subscssli. 2 . All tumeos arborum humidos.

1212. Apocaula. Caule subramoso, foliis superíribus ovato-acuminatis piliferis, capsula striata subsessili. 2j. Ad moros lapideorire.

1213. Alpicola. Canle ramoso, foliis larecolatis obtusiusculis, capsula ovato-nrceotata lievi subsessili, operculo obliqué rostrato. Arl rupes humidas Alpium.

121/. Cribrosa. Canle simplicinseulo, foliis lanceolatis confertim imbricatis piliferis, pedicello foliis breviore, capsula obovata, peristomii dentibus pertusis. $2 \%$. Ad lapides et tecta.

1215. Nigricans. Caule simpliciusculo, foliis lanceolatis siccitate imbricatis piliferis, pedicallo foliis tripló longiore, capsula oblongu. - In montibus editioribus Arvernix, Alpium et Pyrenseorum.

1216. Plagiopodia. Foliis imbricatis ovali-oblongis piliferis, capsula ovata nutante, pedicello bievi arcuato. - Ad muros.

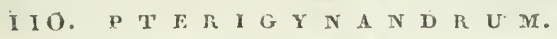

Capsula literalis, oblonga; peristoma simplex, dentibus $x 6$ integris esectis; calyptra lateriliter lissil.

j. I. Calyptra glabra (pterogovitur).

1217. Gracile. Caule repente, ramis fasciculatis teretibus, foliis lanceolatis enervibus imbricatis, capsulæ oblongæ operculo conico. 2). Ad truncos fagineos.

3218. Filiforme. Canle debili subramoso decumbente, foliis lanceolatis concavis enervibus imbricatis, capsule cylindraces opereulo rostrato. $2 \%$. In sylvis montanis.

3219 . Catenulatum. Caule adscendente diviso, foliis concavis ovatolanceolatis acuminatis nervo instructis densissinc imbricatis. $\mathscr{T}$. In nontibus.

1220. Medium. Cáule repente irregulariter pinnatifido, foliis ovatis acutis nervo instructis patulis, capsulæ cylindricæ operculo conico. భ. In Alpibus.

1221. Ramondii. Caule subsimplici erecto elongato, capsula ovata pedicello gracili brevi. - In Pyrenæis.

\section{II. Calyptra hispida ( I. EPTODON).}

1222. Snithii. Caule procumbente ramosissinı, ramis pinnatis arefactione ineurvis, perichæriis pedicello subæqualibus. $2^{F}$. Ad arborum truncos.

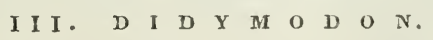

Capsula terminalis, oblonga, apophysi destituta; peristoma sinplex, dentibus 16 seu 32 filiformibus per paria approxinatis; calyptra Jateraliter íissa. 
§. I. Fiore terminali hermaphrodito ( Crvoxtonium).

1223. Copillaceum. Foliis capiliaceis semi-vaginantibus, capsula eylindricit crecta, operculo conico. - In locis udis et turfosis Alpium ansiraliorum.

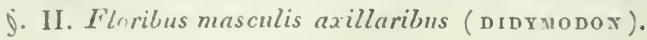

I22i. Pusillum . Foliis ex ovata-concava basi subulatis, capsula erecta ovali-oblonga, operculo rostellato obliquo. $\odot$ ? In arenosis apricis, Gilloprovincix.

1225. Hnmımallum. Foliis ì latinscula basi capillaribus secundis, capsula oblunga subinxquali, operculo conoideo obliquo. - In monte Simplon.

1226. Rizidulum. Foliis lanceolatis è nervo medio cuspidatis rigidulis, operculo subulato curvulo. $2 \mathcal{T}$. $\Lambda d$ numros et saxa.

\section{I 2. T $\mathrm{T}$ I}

Capsula terminalis, oblonga; peristoma simplex, dentibus I 6 ulerà mediun bi-aut-tripartitis, laciniis erectis capillaribus.

\section{§. I. Caule simplici.}

1227. Pallidum. Caule brevissimo, foliis capillaribus, capsula ovatocylindracea, opreulo conico. $\odot$ ? In lutosis nemorosis.

\section{f. II. Caule ramoso.}

I22S. Canescens. Caule crecto, foliis confertis recurvis, mucrone diaplano, capsulis ovatis. $\mathcal{\Psi}$. In arenosis apricis.

1229. Lanusginosum. Caule procumbente pinnatim raunuoso, foliis lineari-lanceolatis denticuliatis, mucrone diaphano, capsulis ovatis. $2 \mathcal{Y}$. In arenosis montanis.

123o. Heterostichum. Caule ramoso difuso, foliis lanceolatis, mucrone diaplumo serrato, capsulis oblongis. 2f. Ad lapides saxaque.

${ }_{2}$ ir. Fasciculure. Caule procuubcute, ramis confertis brevibus, foliis lanceolatis acntis muticis revolutis, capsulis ovato-oblongis. 2. Ad saxi in Gallia meridionali.

1232. Serralum. Caule erecto subramoso, foliis linceolatis apice denticulatis nuticis contortilibus, cupsulis ovali-oblongis, operculo sulunlato. 2 . In Pyrenzis et Alpibus.

1233. Microcarpon. Caule erccto ramoso, foliis ob!ongo-lanceolatis acuminatis apice subdiaplianis, capsulis ovali-oblongis, operculo rostrato. $\frac{2}{i}$. Ad saxa alpina.

12.;. Fnntinaloides. Caule ramoso elongato, foliis lanceolatis patulis, superioribus capsulam brevissimè pelunculatam obtegentibus. $\mathcal{F}^{2}$. Ad lapides et ligna in aquis fluentibus.

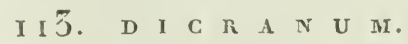

Capsula terminalis aut lateralis, oblonga, apoplysi interdium donata; peristoma simplex, dentibus 16 bifidis, lacinis sæpiùs introrsint flexis; calyptra subulata, lateraliter fissa. 
§. 1. C'apsula apopleysi destiluta, floribus alericis; neasculis cripituliformibus anu gemeniformilus termunulubs.

\section{* Foliis secundis.}

1235. Scoparium. Canle ramoso, foliis ovato-lanceolatis acuninatis carinatis falcatis, pedicellis vaginatis solitariis, 2 . In sylvis et ericetis.

1236. Uutulatum. Caule ramoso, foliis subsecundis orato-lancenlatis acnminatis undulatis apice seruulatis, pedicellis vaginatis aggregatis. $\mathcal{H}$. In sylvis.

1237. Ileteromallum. Caule subsimplici, foliis capillaribus uninervihus basi dilatatis, capsula ovata, operculo longè rostrato. $\mathcal{Z}$. lu sylvis frequens.

1238. Flagellare. Canle ramoso, foliis sctaceis basi dilatatis, capsula cylindrica erecta. 2 . In Alpibus Lemano vicinis.

1239. Varium. Caule simpliciusculo, foliis subsecundis, inferiorihus lauceolatis, superioribus subulatis, capsula urccolata subceruua, operculo conico. 4 . In sylvis, collibus, ad vias.

124o. Aciculare. Caule erectiusculo ramoso, foliis lanceolatis nervo prominulo instructis patulis subsecundis, capsula ovali-oblonga, operculo longè rostrato. $2 F$. In lapidibus ad aquas fluentes.

\section{** Faliis directione aquali.}

I2fr. Orale. Caule ramoso fastigiato, foliis lanceolatis piliferis, capsula ovata, operculoque rectis. 2 C. Ad saxa Alpiunı.

12 2. Spurium. Caule ramoso fastigiato, foliis ovatis acuminatis concavis carinatis, capsula cylindracea areuata sulcata, operculo conico acuminato. $2 C$. In Alpibus.

I2 $\{$ 3. Flexuosum. Caule subramoso, foliis setaceis rectiusculis, capsula ovato-cylindracea suleata, pedicello flexuoso. ₹ . Ad terran, saxa et truncos putrefactos.

124\}. Mnntanum. Caule ramoso, foliis lineari-lanceolatis apice subulatis siccitate crispis, capsula cylindracea recta. 2 . Ad truncos putridos sylvarmm Lemani vicinarum.

12 4 . Schreberi. Caule ercetiusculo subsinupliei, foliis ex ovata amplexicaule basi longè sululatis, capsula ovata cernua, operculo subconico levissimè cuspidato. 2 F. In locis argillaceis udis, propè Lemann m lacum.

1246. Pelluridum. Canle ramoso fastigiato, foliis ovato-lanceolatis acuminatis siccitate incurvis, capsula ovata lævi, operculi rostro incurvo. $2 \mathcal{L}$. In locis udis vallis Alpinx Saaz.

1247. Glancum. Canle ramoso fastigiato, foliis imbricatis ovalolanceolatis enervibus albidis, capsula ovata sulcata. $2 i$. In sylvis et ericetis.

12 f 9 . Purpureunı. Caule dichotomo, foliis lanceolatis siccicate tortilibus nervo purpureo instructis, capsula elliptica, operculo conico. - Ad terram, muros saxaque frequens. 
S. II. Capsula apophysi ad bacim instructa, floribus monoicis aut dioicis.

12.19. Cerviculatum. Monoicum, caule simplici, foliis capillaribus enervibus patentibus laxis, capsula ventuicosa erectiuscula, apophysi hine gibbosa. - In locis turfosis montis Jurassi.

1250. Ervltropum. Dioicum, caule ramnso, foliis lanccolatis acntis uninervibus patulis siccitate crispis, capsula nutante sulcula, apophysi hinc gibbosa, operculo conico. - In locis mosis montis Jurassi.

225r. Strumiferum. Monoicum, caule ramoso, foliis lineari-subulatis siccitate tortilibus unincrvibus, capsula arcuata sulcata, apophysi hinc gihbosa, operculi rostro incurvo. 2 . In pratis humidis et saxis umbrosis Alpium.

9. III. Capsula apophysi destituta; floribus monoicis; nıasculis gemmaceis axillaribus.

* Foliis caulem undiquè cingentibus.

×252. Polycarpon. Caule ramoso, foliis lineari-subulatis siccitate tortilibus, capsula olsovata erectiuscula sulcata. 24. Ad saxa montium.

1253. Pulvinatum. Caule ramoso fastigiato, foliis lanceolatis piliferis, capsula elliptica nutante, operculo subulato. $\mathcal{F}$. Ad muros lapidesque frequens.

I25\%. Sciuroides. Caule ramoso repente, foliis imbricatis lanceolatis sulcatis muticis, capsula cylindracea, operculo conico. $\mathcal{\psi}$. Ad truncos vetustos frequens.

\section{** Foliis bifariis.}

1255. Firidulum. Caule brevi, foliis I.nceolatis, pedicellis terminalibus, capsulis erectis. 2 ; ? In umbrosis humidis.

1256. Taxifolium. Caule brevi, foliis lanceolatis, pedicellis subradicalibus, capsulis erectis. 2 ? In umbrosis humuilis.

1257. A tinnthoides. Caule clongato ramoso, foliis lanceolatis basi vaginantibus, pedicellis lateralibus, capsulis subcrectis. 2 . In pratis sylvisque uliginosis.

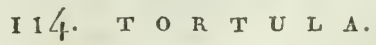

Capsula terminalis, cylindrica ; peristoma simplex, ciliis r 6 seu 32 spiraliter convolutis et interdim inter se coalitis; calyptra subulata, latcraliter fissa.

S. I. Peristomii dentilus inter se conlitis; floribus monoicis. ( SXNTRYCHIA.)

1258. Subulata. Caule subsimplici brevi, foliis ovato-lancenlatis cuspirlatis, capsula cylindracea, operculo longè conico. 4 . In aggeriribus, viis cavis, fissuris rupium frequens.

125n. Pilosa. Canle ramoso, foliis lanceolatis carinatis, pilolongissimo terminatis, capsula ovato-oblonga. 2L. Circá Lemanum lacum. 
§. II. Peristomii dentilus distinctis; floribus monoiris (BA R RE LA).

1260. M/uralis. Caule subramoso, foliis oblongis acutis piliferis, capsula cylintrical. $\mathcal{~}$. Ad monos saxaque frequens.

1261. Tortunsa. Caule ramoso fustigiato, foliis linearibus subulati carinatis siceicate tortihibns, eapsula cylindracea. $\mathcal{H}$. Ad radices vetustarum arborum in montanis.

§. 111. Peristomii dentibus distinctis; floriths dioicis; mascults capituliformilus cermualibus ( TORTUA).

1262. Ruralis. Caulc ramoso, foliis obtusis recurvis appice piliferis capsula cylindrica, operculo conico. 24. Ad muros, agros, lecta strammea.

3263. Rigida. Caule brevissimo, foliis patentibus involutis rigid:s obtusis enervibus, capsula oblonga, operculo conico. $\odot$ ? Ad nus limosos, et in collibus apricis.

I264. Nerros $\pi$. Canle ranoso, foliis lineari-lnnecolatis earinatis nanticis siccitate contortis, capsula cylindracea, onerculo subulato. 2 . Ad muros et terran aridin.

1265. Unguiculata. Caule subramoso brevissimo, foliis patentil, . lineari-lanceolatis carinatis mucronatis, capsula cylindracea, operculo subulato arcuato. 2 . In mur et collibus aridis.

3266. Fallax. Caule ramoso foliis recurvalompatnlis, perigonialibr:s enervibus, capsula oblonga, operculo obliquè rostrito. 2 . Ad nut ros et ambulacra.

126-. Convoluta. Caule ramuloso, foliis caulinis lanceolatis carinatis, perichatialibus obtusis in cylindrum convolutis. 2 . Ad fossas viasque.

†††† Perisloma simplex, dentibus apice membrana (epiphragmate) coalitis.

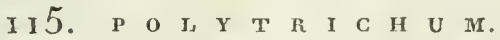

Capsula terminalis; peristoma simplex dentihus 32 , lo aut 64 epiphragmate apice coalitis; calyptra parra obliqua, indusio magno pilis numerosis ab apice at basim diectis constante onusta.

§. I. Capsula apophysi destiluta, ovalis aut cylindrica; cunle simplioi aut nullo.

1£68. Nanum. Caule brevissimo, foliis lineari-lanceolatis acutis subcarnosis, capsulà ovali-rotunda cenua, opereulo obliquè roszrato. 2 . In ericeris et abietinis.

1269. Subrotundum. Caule brevissimo, foliis lanceolatis integerrim is rigidis, capsula unbinata exectiuscula, opercuio obliquè rostrato. 2. In sylvis aridis.

12:0. Crassisetum. Canle erecto Inngiusculo, foliis oblongis crassis subohtusis integerrimis, capstala ovali-rotunda, operenli mucrone recto. $2 \mathcal{C}$. In $A$ lyibus $V$ alesia vicinis.

327r. Aloides. Caule subsimplici, foliis lineari-lanceolatis rigidis 
apice serratis, capsula cylindracea obliqua. $\underset{T}{T}$. In ericetis et abictinis.

\section{If. Capsula quadrangulari apoplysi instructa.}

1272. Cummune. Caule simplici, foliis lincari-lanceolatis serrulatis, capsula maturitate cernua, apopliysi subrotunda. $\underset{Z}{\mathcal{C}}$. In ericetis sylrisque vulgare.

12-3. Piliferum. Caule simplici, foliis lanceolatis integerrimis apice piliferis, apophysi depressa. $2 ;$. In apricis aridis.

г $273^{*}$. Juniperimum. Caule plernmque simplicissimo, foliis linearilancenlatis integerrimis planiusculis subpatentibus, apophysi depressa.-Smitl. 11. brit. p. 1375. Engl. bot. t. 1200.24 . In eriretis et sylvis aridis.

I2-1. Strictum. Caule basi ramoso, foliis lanceolatis marginibns inflex is integerrimis ercctiusculis, apopliysi depressa. 2 . In apricis montosis. 12-5. Longisetum. Canle simplici, foliis lincari-lanccolatis erectiusculis serratis, capsula obliqua ovata subangulata, apophysi miniua. 2...In turfosis montis Jurassi.

12 6. Formosum. Caule simplici, foliis lanceolato-subulatis serratis, capsula subangulata cylindracea, apopliysi minima quadrangulari, operculo rostrato basi coccineo. 2 . In sylvis subalpinis.

\section{§.III. Capsula apopleysi destituta, ovalis aut cylindrica; caule ramoso.}

1277. A! pinum. Foliis lanceolato-subulatis serrulatis, capsula ovata cernua, apophysiobscura. $2 \mathcal{C}$. In ericetis etmontibus editiorihus.

1278. Arcticum. Foliis lanceolato-subulatis serrulatis, capsula cylindrica suberecta, peristomii dentibus 48 . 2 C. In Alpibus.

1279. Nigrescens. Foliis lineari-subulatis serrulatis, inferioribus basi alornpte dilatatis, capsula elliptico-rotunda, operculo longissinci subulato. $2 \mathrm{C}$. In Alpibus.

${ }_{2} \mathrm{~S}$ ก. Crmigernum. Foliis lineari-lanceolatis serrulatis acutis, capsula evlintrici infrà peristonium angustata, peristomii dentibus 32 . 2\%. In ericetis et sylvis montanis.

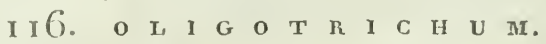

Capsula terminalis, cylindrica; peristoma simplex, dentibus 32 apice epiphraguate coalitis; calyptra cylindracea, hine indè hirta pilis sursum directis.

1281. Inululatum. Foliis lanceolatis serratis undulatis siccitate crispis, capsula cylindrica, operculo subulato. $\odot$ aut $\sigma^{7}$. In sylvis et minhosis.

1282. Heryninum. Foliis lincaribus subcarnosis concavis, capsula cylincirica, operculo conico. $\mathcal{H}$. In turfosis circà Aguas-Tarbellicas ( / $a x$ x).

\section{$+\dagger+\dagger+$ Musci peristomate duplici.}

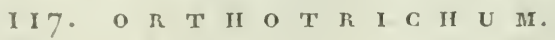

Capsula terminalis, cylindrica; peristoma simplex aut duplex, 


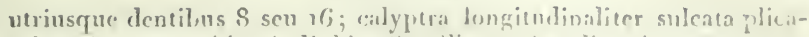
tula, plerumegue hine inde hircella pilis sursum directis.

\section{I. Peristomale simpliri.}

128?. Anomalum. Caule ramoso, foliis lancoolatis carinatis revolntis, capsula pedicellata, calyptrat conica hispida. ZF. Arl muros, saxa et tectia.

128;. Cupulafum. Caule ramoso, foliis lancenlatis carinatis revolntis, capsula subsessili, calyptra lemisplecrica hispida. ₹f. A.] arborum truncos $\mathrm{ct}$ ad saxil.

\section{פ. II. Peristomate duplici.}

1285. Affine. Canle ramoso, foliis lanceolatis integerrim is, calyptra dentata, peristomio interno. 8 dentato. 2 . Ad numos el truncus.

I2S6. Striatum. Canle ramoso, foliis laneolatis apice denticulatis, calyptra subintegra, peristomio interno ifi-dentato. $2^{*}$. Ad truncos murosigue.

${ }_{128}$ 7. Dimplanum. Caule subramoso, foliis lanceolatis aruminatis apice diaplánis, calyptra nudiusenda denticulatis. 2?. Ad truncus et muros.

1288. Crispume. Caule ramoso, foliis lineari lanceolatis siccitate recurvis undulatis, pedicellis clongatis. $\mathcal{F}$. In truncis arborum.

$$
\text { I I 8. F }
$$

Capsula terminalis - pyriformis; peristoma duplex, rxterins dentibus 1 fiobliquè tortis et apice coalitis, interius ciliis 16 planis menbranaceis; calyptra magna, basi ventricoso-tetuagona, alice subuluta.

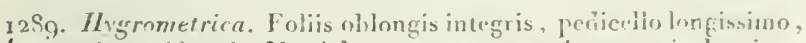
capsula pyriformi. 2?. Ad rupes terra teuui tectas, in hortis et ambulacris neglectis fierguens.

1290. Muhlenbergii. Foliis perichæulalibus denticnlatis, pediccllo brevi, capsula turbinata. - In rupibus V'alesiæ, Galloprovincie.

$$
\text { I I ?. T I M MI I A. }
$$

Capsnla terminalis, ovata; peristoma dnjlex, exterius dentibus 16 acutis, interius ruembranaceum sulcatum upice fissum in lacinias sub:quales sæ̣è perforatus.

1291. Megapolitana. Foliis lincari-lancenlatis, capsula nrata nutante, operculo convexo umbilicato, peristomii externi deutulus rubentibus. 2f. In rupibus schistosis (alloprovinciæ.

1292. Austriaca. Foliis basi vaginantibus sululatis, capsula nvaliohlonga, operculo conico, peristomii dentibus albidis. 27 . In rupibus umbrosis et sylvis Galloprovincix.

$$
\text { I 20. } \mathrm{P} \text { O }
$$

Capsula terminalis, oblonga, basi apophysilonga donata ; peristoua duplex, exterius dentibus 16 extus reflexis, interius membranaceum laciniis 16 sequalibus.

$$
\text { G ; }
$$




\section{IO/ $\quad$ A C O T T LED O NES.}

3203. E: Inngata. Camle erecto, fnliis lineari-lanceolatis, pedicellis in apupliysin incrassatis, - In Alpibus Pyrenzisque.

\section{2 I. MI E E S I A.}

Capsula terminalis, oblonga, pyriformis, longè pedicellata ; peristoma duplex, exterius dentibus 16 brevibus obtusis, interius ciliis 16 acutis distinctis atut reticulato-connexis.

129\%. Longiseta. Caule ramoso elongato, foliis patulis ovato-lanceolatis acutis, pedicello longissimo, capsula turbinata, operculo exactè conico. - In paludibus urrósis.

1295. C'liginnsa. Caule simplici brevi, foliis lineari-oblongis obtusis, capsula pyriformi, operculo convexo. - In paludibus turfosis.

\section{22. B $\mathrm{R} \quad \mathrm{Y} \quad \mathrm{U} \quad \mathrm{M}$.}

Capsula terminalis, ovalis aut oblonga, sæpe nutans; peristomi duplex, exterius dentibus 16 acritis, interius membranaceum plicatum marghine laciniatum, laciniis alternatim latioribus et ciliformibus.

\section{I. Floribus liermaphroditis (WEвERA).}

1296. Tutans. Caule subsinıplici, foliis lanceolatis acutis carinatis, capsula obovata cernua, opereulo convexo brevissimè mucronato.

25 . In locis siccioribus sterilibus, nec non in uliginnsis.

1297. Pyriforme. Canle simplici, foliis setaceis superiorihus longissimis, capsula pendula pyriformi. $\odot$. In arenosis humidis.

\section{II. Floribus dioicis ( $\mathrm{BR} \times \mathrm{UM})$.}

1398. Alpinum. Canle ramoso crecto, foliis orato-lanccolatis acutis imbricatis, capsula oblonga subpendula. $2 \underset{j}{ }$. In fissuris rupium Alrinarum.

1299. Carneum. Caule subsimplici, foliis lanceolatis acutis integcrrimis reticulatis reuctiusculis, capsula pendula ovata. $2 \%$. In umbrosis humidis.

r3on. Argenteum. Canle basi ramoso cxespitoso, foliis oratis concavis mucronatus imbricatis glanco-argenteis, capsula ovato-oblonga pendula. 2 . In muris, tectis, terra sabulosa frequens.

r3ว. Decipiens. Caule hasi ramoso, foliis ovato-lanceolatis pelluciz dis carinatis subserratis, capsula obovata peudula. $\mathcal{T}$. In locis humidis, ad fossas.

\section{III. Floribus monoicis ( мучи u).}

* Floribus muscrilis capitatis; pedicélis solitariis.

3n2. Androgmenum. Foliis lanceolatis acutis imbricato-patulis, capsula erccia oblonga, operculo conico. 24 . In sylris umbrosis humidis frecunens.

303. Palusire. Caule erceto elongato ramoso, foliis lanceolatis carinatis acutis, superioribus arcuato-secundis, capsula nblonga suberecta, operculo conico acuto. $2 \mathrm{~L}$. In nemoribus humidis et paludibus frequens. 
*** Floribus masculis discoileis; pedicellis soluariis.

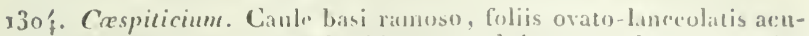
minatis imbricatis, capsula oblonga pendula, operculo eonvexo. 2 . Ad muros, tecta, aggeres.

305. Capillare. Caule cespitoso, foliis ovatis patulis piliferis, capsula obconica clongata pendula, operculo conico. 2 . In sylis humidis, fossis.

13o6. Bimum. Canle ramoso, foliis lineari-lanceolatis acuminatis patulis, capsula exactè obconica cermua. $\sigma^{7}$. In paludibus.

1307. Tubinatum. Canle ranıoso, foliis ovatis acutis integris, capsnla pyriformi pendula. $\mathcal{H}$. In arenosis humidis.

-1308. Ventricosum. Caule ramoso, foliis lanceolatis patulis, capsula ventricosa pendula. 4 . In paludibus apricis.

1303. Crudum. Caule simplici, foliis lanceolatis acutis integerrimis, summis angustatis denticulatis, capsula oblonga cernua. $\underset{j}{\mathcal{C}}$. In udis Alpinis.

ז310. Stellatum. Canle simplici, foliis lanceolatis scrrnlatis, capsula ovata cernua, operculo convexo. $\underset{j}{\mathcal{C}}$. In sylvis paludosis.

*** Floribus masculis discoideis; pedicellis sapuïs ağgregatis.

I3 3 . Punctatum. Canle erecto subsimplici, foliis obovatis integerrimis punctato-reticulatis, capsnla ovata, operculo subulato incurro. 2 . In pratis humidis umbrosis.

1312. Rosemm. Caule crecto, foliis confertis stellatis oblongis integerrimis acutis, capsula oblonga, operculo conico. 4 . In sylvis et cricetis humidis.

1313. Cuspidatum. Foliis ovato-lanceolatis serratis, capsula ovata pendula, operculo conico obtuso. 4 . In umbrosis humidis.

1314. Rostratum. Foliis ovalibus oblongis serrulatis undulatis, capsula ovato-cylindrica, operculo subulato incurvo. $2 \mathcal{F}$. In montosis.

1315. Ligulatun. Caule basi repente, foliis oblongis mnlulatis serratis, capsula orata, operculo convexo. 2 . In umbrosis lumidis.

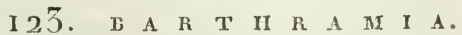

Capsula spliærica, terminalis aut lateralis ; peristoma duplex, exterins dentibus 6 cuneifornibus intùs subflexis, interins membranaccum conicum plicatum apice fissum in lacinias 16 bilidas.

\section{I. Pedunculis terncinalibns.}

3316. Trulgaris. Pelicellis erectis, foliis subulatis apice tantim dentisulatis siccitate subcontortis. 24 . Ad terram saxaque humida.

13т. Crispa. Pedicellis erectis, foliis subulatis crispis margine serratis siccitate maximè contortis. 2广. In montanis.

131S. Ithyphylla. Caule brevi, pediecllis erectis, foliis subulatis basi dilatatis subintegris siccitatc minimè tortilibus. $\mathcal{~}$. In montanis.

1319. Ederi. Caule elongato gracili, pedicellis erectis, foliis lineari- 
Janccolatis serrulatis siccitate ix tortilibus. - B. gracilis, Smith.

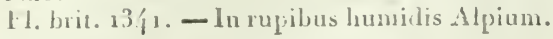

1320. Fontana. Ramis fisciculatis, foliis ovato-lanceolatis integerrinis, capsulis obliquis striatis. - In palulibus, ad fontes.

\section{§. II. Pedunculis lateraiibus.}

132 . Hal!eriana. Pedicellis luteralibus arcuatis, foliis è dilatata basi longe subulatis, capsulis ovatis sulcatis. 24 . In montanis inter lapides et saxa.

$$
\text { I 2\%. B U X }
$$

Capsula terminalis, ovata, obliqua, lateraliter rentricosa; peristoma duplex : exterius dentibus : 6 uncutis, interius nembranacem elongato-conicum plicatum apice subuuncatum.

1322. Foliosa. Acaulis, capsula subsessili, foliis lineari-lanceolatis. - Ad vias umbrosas sylranm.

3323. Aplogllu. Apliylla, pedunculo elongato. - In cricetis, locis sterilibus, rupibus.

$$
\text { 1 25. L E S K E A. }
$$

Capsula lateralis, oblonga ; peristoma duplex, exterius dentibus 16 acutis, interius membranaceum apice fissum in lacinias 16 æquales.

r32ł. Luens. Caule ramoso, foliis ovatis obtusis reticulatis enervibus, capsula ovata subecrnui, operculo subulato. $\mathcal{F}^{\mathrm{C}}$. In sylvis humidis.

1325. Trichomanniries. Caule subpinnato, foliis bifariis medio tenus uninervibus ovatis obtusis mulicis, capsula oblongiuscula, operculo subulitio incurvo. 2 In sylvis ad corticcm arbormm.

1326. Complanala. Caule pinnato, foliis biforiis complanatis subencrvibus ovato-obiongis mucrorulatis, calpsula ovata, operculo conico obliquo. $2 \mathrm{~F}$. Ad inpes, muros, tuncos arborum.

1327. Seligeri. Surculis simplicibus, foliis hifariis ovato-lanceolatis acuminatis integerrimis, cansula cylindracea, opereulo conico.Ail truneos putridos in sylvis Alpinis.

132S. Subli'is. Caule repente, ramis filiformibus, foliis linearilanceolatis acutis enervibus laxiusculis, operculo conico. 2 \% Ad radices arbonum, in montanis.

329). Polyantha. Caule procumbente, ramis gracilibus apice incurvis, fnliis lanceolatis acuminat is encrvibus, operculo conico incuso. 25 . In sylvis ad radices arboruu.

133o. Polycarpa. Caule gracili repente, foliis ovato-lanceolatis uninervibns, capsula cyliudrica erecta, operculo conico. 2 . In sylvis ad radices et truncos arbornm.

1331. Sericea. Caule repente, ramis adscendentibus confertis, foliis lancenlatis trinervibus imbricatis, operenle conico subincurvo. $\mathcal{F}$. Ad truncos arbormum muros lapidesfiuc frequens.

1332. Vendicides. Ciale erecto simplici, ramis fastigiatis termi- 
nalilus, foliis ovatis mincruibus serrudtis, operenlo rostrato. $\mathcal{F}$. In sylvis et pascuis udis.

9333. Allenunta. Canle raunsissinn, ramis incurvis, foliis ovaris uninervibus imbricalis, summis subscundis, uperculo conicu. 2 . .Ad radices arborum.

$$
\text { I 26. II Y } \mathrm{P} \text { N U } \mathrm{Mr} \text {. }
$$

Capsula lateralis, olılonga, sapiiss subeerna; peristoma duplex, cxterins dentihns 16 acutis, inferius membranacenm, apice fissum in lacinias 16 latiores, ciliis 16 interjectis.

\section{I. Caulibus pinnatis; foliis undiquè imbricatis.}

133\%. Tamariscinum. Canle tripinnato, foliis cordatis acutis adpressis opacis integerimis uni-vel-trinerribus, operculo subulato. 24 . In sylvis et pomariis frequens.

3335. Splendens. Caule bipinnato, foliis ovato-lanceolatis sulenervibus nitidis arpressis, operculo subulato recurvo. $\mathcal{F}$. In sylris.

1336. Abietinum. Caule pinna po villoso, foliis ovato-Ianceolatis integerrimis uninervibus bisulcis, operculo conico. 2 . In locis aridis, sylvis abietinis.

1337. Prelonglim. Canle pinnato repente, foliis orato-Janceolatis acuminatis serratis uninervibus patentibus, operculo subulato incurvo. 2 . In sy!vis ad truncos putridos.

3335. Clarioni. Caule pinnato repente, foliis corrlatis longissimè acuminatis nervo brevi instructis serrulatis, operculo subulato incurvo. 2 . In truncis vetustis.

I339. Cuspidatum. Caule pinnato suberecto, ramis cuspidatis, foliis ohlongo-lanceolatis enervibus levibus, operculo conico. $\mathcal{~}$. In fossis, rivulis frequens.

13. fo. Corlifolium. Canle erceto, ramis cuspirlatis, foliis cordatis uninervibus remotiusculis, capsula ovata, operculo conico. 2 . In fossis et paludibus.

s34. Muticum. Canle pinnato compressiusculo, foliis natis concavis ohtusinsculis encrvibus, operculo conico elongato. 2f. Ad margines sylvarum, in pratis liumidis.

т3 2. Purum. Caule pinnato, foliis ovalibus ventricosis ohtusis mucromulatis basi uninervibus, operenlo conico acuto. $2 \%$. In sylvis et pratis.

13/3. Il'ecelrum. Caule vagè ramoso, ramis obtusis, foliis ovatis ventricosis obtusis mucromulatis obsoletè uninervihus. 24. In sylvis pratisque.

13 łł. Nicens. Caule erecto, ranis subcompressis simplicibus, foliis lanccolatis acmminatis uninervibus striatis, operculo convexn inucrounlato.

\section{II. Caulibns pinnatis; foliis secundis.}

13 \{5. Glaucum. Caule vagè pinnato, ramis ap̧ice incurvis, foliis 
ovato-lanceolatis acuminatis basi nervosis, perichatialibus striatis acuminatis, pedicellis subterminalibus. $2 j$. In paludibus et rivulis.

33 6. Compressum. Caule subpinmato, foliis lanceolatis acuminatis nervo prominulo ad apicem extenso instructis, perichatialihus brevibus. pediceliis lateralibus sparsis. 2 . In sylvis AJpinis.

33ł. Filicinum. Canle pinnato villoso, foliis imbricalis oblongis acuminatis nervo a!l apicem extenso instructis, pedicellis è basi caulis ortis. $2 \%$. In pratis et sylvis humidis.

13 f8. Hedwigii. Caule bifariam yinnate, ramis glabris planiusculis, toliis encribus striatis, perichætialibus elongatis. 2C. In sylvis lıumidis.

1349. Crista castrensis. Caule inordinatè pinnato, ramis apice recurvatis crispis, fohis cnervibus levibus lucidis, perichæcialibus brevibus. $2 \%$. In sylvis humidis et turfosis.

3350. Falcutum. Caule repente, ramis erectis elongatis inordinatè pinnatis, foliis lanceolatis acutis carinatis nervo prouinulo persistente instructis. $2 \zeta$. In uliginosis $\mathrm{A} /$ pinis.

\section{III. Caulibus inordinatè gamosis; foliis secrundis.}

135r. Uncinatum. Caule procumbente subpinnato, foliis subulatis falcatis uninervihus striatis, perichætialibus elongatis muticis, operenalo convexo mucronulato. $\frac{2}{2}$. In sylvis montosis ad radices arborum.

1352. Cupressifirme. Caủe prostrato subramoso, foliis ovato-lanccolatis falcatis enervibus, operculo cuspidato. $2 \zeta$. Ad terram saxil truncosque.

335. Incurvatum. Caule repente, ramis divisis, foliis lanceolatis enervibus cuspidatis, superioribus falcato-secundis, operculo conico obtuso. 2. Ad tertam in sylvis.

1354. Palustre. Caule repente, ramis ercetis simplicibus, foliis ovatolanceolatis cnervibus, perichatialibus intcrioribus nerrosis, operculo conico. 2 . In paludibus et ad margines rivulnsum.

3355. Fluitans. Canle gracili, ramis simplicibus, foliis lanceolatis acuminatis uninervilus laxiusculis, operculo convexo mucronulato. $F$. In aquis limpidis stagnantibus.

1356. Aduncum. Caule erecto, ramis simplicibus, foliis lanccolatis falcatis uninervibus, perichatialibus brevibus cuspidatis, operculo conico. $\underset{j}{2}$. In paludibus, fossis et sylvis hunidis.

э3ว̃7. Revolvens. Caule erectiusculo, foliis enervibus hasi concavis imbricatis, apice capillarihus patnlis tortilibus. $2 \underset{j}{ }$. In paludibus.

1358. Diastrophyllum. Caule procumbente, foliis lanceolatis acuminatis imbricatis apice revolutis uninervibus. 2 . In sylvis humidis.

1359. Scrorpioiles. Caule adscendente subpinnato, ramis arl apicem iucutris, foliis ovato-lanceolatis muticis concavis cnerribus imbricatis. 24. In paluribus.

136n. Rugosum. Canle ramisque erectis, foliis imbricatis lanceolatis, Lasi transversè rugosis, apice denticulatis. - In sylvis ct inontanis. 
๑. IV. Caulibus inorlinate ramosis; folies uncinalis.

1361. Coreum. Caule repente clongato, foliis lanceolato-linearibus, basi concavis striatis, apice patulis denticulatis, capsulis ovatis, operculo convexo apiculato. $\mathcal{Z}$. In lucis nubrosis sicciorilus.

1362. Squurrosum. Canle arlscendente, foliis carinatis encrvihus, basi ovatis adpressis, apice acmminatis recurvis patentibus, capsula ovata, operculo hrevi conico. $\mathcal{F}$. In sylvis et pratis humidis.

«363. Squarrosulum. Caule adscendente, foliis lineari-lanceolatis subiullesis, capsula cylindrica arcuata, operculo conico acuto. 2 . In sylvis montanis.

136i. Stellatum. Caule debili procumbente, foliis ovatis longè acuminatis enervibus integerrimis patentissimis, capsula objonga, uperculo obtusè apicutato. 2 2 . In paludibus et pratis turfosis.

1365. Halleri. Caule repente, ramis erectiusculis simplicibus, foliis linceolatis enervibus è basi imbricata recurvis, capsula oblonga, operculo conico. 2 . All muros et rupes.

\section{§. V. Caulibus inordinate ramosis: foliis aqualiter imbricatis aut patulis.}

1366. Striatum Canle repente, ramis sparsis erectis, foliis ovatodeltoide is acuminatis 3-5-nervibus, capsula cylindrica, operculo subulato. $2 \%$. In sylvis et pomariis.

1367. Triquetrum. Canle suberecto ramoso, foliis deltoideis acunuinatis striatis subenervibus undiquè pateutibus, capsula ovata, operculo conico obtuso. $\mathcal{F}$. In sylvis pratis pomariis frequens.

1368. Rulabulum. Caule procumbente, ramis crectis subsimplicibus, foliis ovato-lanceolatis acuminatis uninervibus, pedicello scabro, operculo conico. $\mathcal{H}$. All terram et truncos arborum frequens.

1369. Albicans. Caule ascendente, foliis ex ovato longè acuminatis inbricatis basi trinervihus, capsula ovata torulosa, operculo conico subapiculato. 2 . In arenosis aridis.

1370. Lutescens. Caule procumbente ramoso, foliis imbricatis lancenlatis acuminatis 3-striatis, pedicello scabriusculo, operculo conico acuto. - Ad terram aridam, muros et saxa.

1371. Plumosum. Caule repente, ramis irregulariter pinnatis crectis, foliis lanceolatis acuminatis 3 -striatis, pedicello levi, operculo conico. 2 . Ad saxa arbormmine radiees.

1372. Tumidiusculum. Canle erecto, ramis compressis, foliis imbricatis uninervibus, aliis planinsculis ovato-oblongis mucrounlatis, aliis carinatis acutis, capsula oblonga gracili. - Ad radiccs arborum in monte Aureo.

1373. Stramineum. Caule subsinplici crectn gracili, foliis ellipticolanceolatis enervibns imbricatis, capsnla ovata subgibbosa, operculo brevi conico. 24 . In ericetis humilis.

137千. MYurum. Caule repente, ramis adscendentibus subfusiforuibus arcuatis, foliis ovato-lanceolutis acutis uninervibus, eapsula oblonga erecta, operculo longè conico. Y. Ad truncos arborum. 
3-5. Iyosuroides. Caule repente, ramis adscendentibus teretibus rectis : foliis imbrieatis oratn-lanceolatis uninervibus, capsula oblonga cernua, operculo longé conico. - Ad truncos in sub. Alpinis.

13-6. Alopecurum. Caule erecto infernè denudato supernè ramosissimn, foliis orato-acuninatis apice serrulatis uninervibus, capsula cernua, operculo subulato incurvo. 2 . In sylvis humidis.

137\%. Sirigosum. Ramis fasciculatis simplicibus, foliis ovato-lanceolatis denticulatis uninervibus, capsula ovata cernua, operculo subulats subincurvo. 2 . Ad terram in sylvis.

13-8. Lamarchii. Caule procumbente, foliis lanceolatis acutis, basi uninervibus integerimis, eapsula oblonga cylindracea arcuata, operculo subnlato incurvo. $2 \mathrm{f}$. In sylvis ad radices arborum.

137:). Serpens. Gude repente, foliis laxiusculis minimis lanceolatis acuminatis basi subuninetvibus, capsula elongata obconica, operculo convexo mucronulato. 2r. In umbrosis frequens.

38o. Firide. Canle repente, foliis iubricatis ovato-acuminatis nervo ad apicem extenso instructis, capsulis ovato-oblongis infernè sulugibbosis, operculo conico acuto. - In sylvis ad truncos arborum,

1351. Repens. Caule repente, foliis laxinsculis lanceolatis acuminatis minervibus, eapsulis oblongis, operculo convexo vix conico. 2 . Arl terram liunidium, radices arborum.

332. Velutinum. Canle repente, foliis confertiusculis lancenlatis acuminatis unihervilus denticulatis, perichatialihus criniformibus, capsula ovata, operculo conico obtuso. $2 \%$. In sylvis et pratis.

33S3. Intriculum. Caule repente, doliis pratulis lanceolato-acuninais minervibus denticulatis, periclatialibus oblongis, capsula ventricosa, opereudo conico. $2 \mathcal{C}$. Ad radiees arbortum et lapides.

139'. DIo'endinariım. Caule procumbente, ramis gracilibus infernè dennclatis, foliis imbricatis oratis integerrimis basi uninervibus, capsula ovita suberecta, operculo convexo mucronulato. - Ad muros hismirlos.

385. Murale. Canle repente, fuliis imbricatis surerne suhdistichis ovato-acutis integerrimis, capsula orata ccrnua, opereulosul,ulato arcuato. $\mathcal{~}$. Ad muros lapides aggeres.

\section{VI. Caulibus inordinatè ramosis aut subsimplicibus; foliis aisliclits.}

386. Rusciforme. Canle repente ramoso basi denudato, foliis imbricatis ovatis acutis serrulatis minervibus, operculo subulato arcuato. $\mathcal{~}$. In sylvis humidis, ad margines rivulorum.

138\%. Riparium. Caule ramoso patulo, foliis laxis orato-lanceolatis integerrimis uninervibus, operenlo convexo uneronulato. $2 \mathrm{~F}$. Ad lapides trabesque in aquis flucntibus.

3SS. Trutulatum. Canle promubente, foliis imbricatis ovatis acnminatis transtersè rugosis enervibtis, capsula orato-oblonga. 2 . In sylvis nubrosis, ad radices arbon $11 \mathrm{~m}$. 
139.9. Sylvaticum. Surcnlis divisis, foliis imbricatis compressis apice patulis ovato-lanceolatis integerrinis enceribus, operculo subulato. - In sytuis.

1390. Denticulalum. Suculis simplicilus, fuliis imbricatis compressis apice patulis ovato-lancerolatis integerrimis enervibus, operculo conico. 24. In sylvis ad terram et truncos abormu.

\section{N E C K E R A .}

Capsula lateralis, oblonga; peristoma duplex, exterius dentibus I 6 acutis, interius ciliis 16 distinctis.

\section{S.I. C'apsula pedunculata; foliis imbricatis.}

39r. Curtipendula. Caule ramoso diffuso, foliis ovatis acuminatis planis patulis, capsulis cernuis. 24. In sylvis ad saxa et radices arloornu.

1392. Viriculosa. Caule procumbente, ramis erectis cylindraceis, foliis ohlongo-lanceolatis subsecundis, capsulis erectis. 4 . Ad tunces arbortum et lapides.

1393. Cladortizans. Caule procumbente, ramis compressis extremitate radicantibus, capsulis oblongis erectis. - Ad muros propè Lemanum lacum.

\section{§. II. Capsula pedunculata; foliis Lifariis.}

1394. Crispa. Ramis pinnatis, foliis oblongis transverse rugosis. 4 . Ad saxa terramque in sylvis et montanis.

\section{§. III. Cupsula subsessili; foliis distichis.}

1395. Pennata. Caule decumbente ramoso, foliis bifariis ovatolanceolatis transversè rugosis, pedicellis lateralibns brevissimis, operculo obliqno. 2 Ad truncos quercinos vetustos.

\section{j. IV. Cipsula subsessili; foliis imbricatis.}

396. IIeteromalla. Canle ramnso difisso, foliis ovato-lancenlatis acutis uninervibus, capsulis lateralibus subsessilibus. $\mathcal{C}$. Ad truncos atborum.

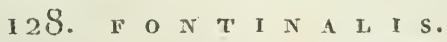

Capsula lateralis, oblonga, subsessilis, perichætio subocculta; peristoma duplex, exterius dentibus 16 latiusculis, interius conicum reticulatum.

1397. Antipyretica. Foliis trifariis ovato-lanceolatis carinatis acutis, perichretialibus obusis. $2 ;$. In aquis fluentibus stagnisque.

ז398. Squammosa. Foliis imbricatis lanceolato-subulatis concavis, perichætialibus obtusis, $2 F$. In rivulis et torrentibus. 


\section{CLA S S I S S E C U N D A.}

\section{O N O C O T Y L E D O N E S.}

$\mathrm{P}$

L A x T 无 contextu celluloso, vasibusque lymphaticis spiralibus et propris constantes; pori corticales in tuliis ant apice caulis herbiceo. Canles medulla centrali radiis medullaribus corticeque vera plane destituti, fibris sparsis nec concentricè dispositis constantes, apice tantim crescentes, in margine magis quàm in centro indurati, interlìm abortivi subterranci radiciformes. Folia sæè̀ vaginata, integra nervis simplicibus aut lobata nervis ramosis, nunquàm verè composita. Seminis corculum simplex seu cotyledone unico donatum.

\section{MONOCOTYLEDONES ChYPTOGAMÆ.}

\section{O R D O V I I. F I L I C E S.}

Frnctificationes gregariæ, sxpius indusio juniores tectæ, in facie inferiore foliorum sitæ, in pancis spuriis terminales spicatæ. Masc. Antheræ mininæ sparsæ in foliis vix evolutis præsentes, nembrana tenui tectæ. Fem. Capsula nuiloculares, sæpins annulo articulato elasticè dissiliente cinctæ, rariùs bivalves, senuinibus numerosis minutissimis repletæ. - Folia alterua, psendo-radicalia, sæpè lobatodecomposita, juniora in plurimis ab apice ad busim conroluta.

\section{+ Capsula annulo elastico cincte.}

$$
\text { I 29. H Y M E N O P H Y L L U M. }
$$

Capsu?æ in punctis marginalibus subersertis, columellæ indusium non superante adsidentes, intrà indusia bivalvia.

1399. Tunbridgense. Frondibus subbipinnatis ovatis decurrentibus pinnulisque serratis, fructificationibus supra-axillaribus solitariis. 2. Inter muscos, al truncos in Armoracia matimis.

$$
\text { I 30. A D I A }
$$

Capsulx in puncta discreta seu lineolas ad marginem frondis distributa, indusiis i margine ortis replicatis interius dehisentibus tectæ.

1 foo. Capillus Veneris. Frontihus decompositis, pinnulis cuneatis apice rotundatis lobatis, stipite lævi. $\mathcal{Y}$. Ad foutes umbrosos in provinciis meridionalibus.

1 for. Fragrans. Frondibus bipinnatis, jimnulis ovatis obtusis sublobatis subtis mulis, stipite palcacen. 2\%. Ad muros et rupes humidas propè Olbiam, Segusium, Augustan-T'aurinoru:n. 


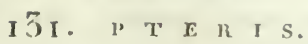

Cap̣sulx in lineam continuam marginalem dispositx, indusio i: margine fromlis inflexo, interius dehiscente lecta.

3402. Crecice. Fronde pimata, pinnis oppositis lanecolatis elongrtis Easi angustatis, infimis tripartitis. 2F. In Corsica, circt Nicitan, '́eudau.

1403. Aquilina. Jironde suprat-decomposita, pinnis lanceolatis refandis, infintis pinuatilidis, superionibus minoribus. \&. In canpestribus et sylvaticis sterilibus.

1 fof. Crispa. Fronde suprit decomposita, pinnulis sterilibus sul,rotumelis incisis, fertilibus oblongo-lineatibus integris. 2f. In pratis saxusis montiun.

$$
\text { I 32. B L E C H N } \mathrm{V} \text { M. }
$$

Capsulx in lineas longitudinales solitarias continuas costa frondis parallelas dispositæ, inchsio superficiario continuo interius dehiscente tectx.

r405. Spicant. Frondibus sterilibus pinnatifidis, laciniis lanceolatis obtusiusculis parallelis, fructiferis pinnatis, pinnis linearibus acuminatis. 24 . in nemoribus montanis.

$$
\text { 133. S C O L O P E N D } \mathrm{R} \text { I U M. }
$$

Capsula in lineolas sparsas gemiuas intervenias dispositæ, indusiis superficiariis sutura longitudinali dehisentibus tect

1.406. Officinale. Frondibus cordato-lingulatis. $\%$. Locis humidis unut,rosis.

1407 . Hemionitis. Fromlibus hastatis basi subcordatis auriculis maximis acutis. $\%$. Massilix.

$$
\text { I 3/. A S P L E N I U M. }
$$

Capsulæ in lineolas rectas sparsas dispositæ, indusio laterali intcriùs dehiscente tectæ.

1 fo8. Septentrionale. Stipitibus nudis glabris supernè bipartitis, lobis linearibus apice laciniatis. 2 . In fissmis rupimet locis petrosis.

צ 409 . Germanicum. Frondibus altcrnatim sublecompositis, pinnulis subcuneiformibus apice incisis. 2 . In nuris et rupibus submontanis.

I fro. Trichomanes. Frondibus pinnatis, stipitibus nigrescentibus, pinnis subrotumdis crenatis. 2 . In muris et rupibus umbrosis hu: midis frequens.

141, Viride. Frondibus pinnatis, stipitibus hasi fuscis, pinnis rlombeo-subrotundis serratis. $\mathcal{F}$. Ad fissuras rupium in montibus.

1412. Marinum. Frnndibus pinnatis, pimnis trapezio ovatis nhtusis serratis basi sursum lobatis. 2 . In maritimis Armoracia circi Brivatem et Dariorigum, et in insulis Stachadum.

34r3. Ruta-muraria. Frondibus alternatim decompositis, pinnulis 
I 4 MONOCOTYLEDONES.

cuneato-rhomboideis subtrilolato-crenulatis. 2 . In muris et rupibus umbrosis frequens.

Í̛́. Alianthum-nigrum. Frondibus subtripinnatis, pinnulis ovatolanceolatis inciso-serratis. $2 \mathcal{H}$. In locis unbrosis et nemoribus hamidis.

I 1 í. Lancenlatum. Frondibus bipinnatis, pinnis ovato-lanceolatis, pinnulis obovatis argntc̀ dentatis. 24. Asplenium lanceolatum. Engl. bot. t. 2q́o. Athyrium fontanum. Fl. fr. n. rq́16. Excl. syn. Lin. - Ad fissuras humidas rupium in montibus.

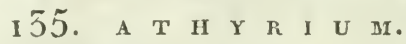

Capsulæ in puncta elliptica sparsa dispositæ, indusio laterali interiùs dehiscente tectæ.

3416. Filix fiemina. Pinnis pinnatifidis pinnulisque lanceolatis, laciunlis acutis apice dentatis. $2 \%$. In sylraticis et montanis.

$$
\text { I 36. A S P I D I U M. }
$$

Capsula in puncta subrotunda sparsa dispositæ, indusio ab apice ad basin utrinqued dehiscente acutissimo tectæ.

3 f т. Fragile. Pinnis bipinnatifidis oppositis, pinnulis ovatis incisis, lacinulis obnvatis dentatis. 24 . In sylvaticis montanis et fissuris rupium. - Multiforme.

1418. Montanum. Suprà-decompositum, foliolis tcrnis tripinnatifidis, lacinulis subfalcatis obtusis apice dentatis. $\mathcal{F}$. In sylvaticis montanis.

$$
\text { I 37. P }
$$

Capsulx in puncta subrotunda sparsa dispositæ, inclusio umbilicato nempè centro adfixo et margine tuto dehiscente tectr.

Í19 Filix-mas. Fronde bipinnata, pinnulis oblongis crenatis apice serratis, basi duobus punctis fructificationis utrinquè donatis, stipite paleaceo. $\mathcal{\psi}$. In sylvaticis et sterilibus.

I 4 20. Abbrevintum. Fronde bipinnata, pinnulis oralibus olutusissimis crenatis, basi unico fructificationis puncto ntrinquè donatis, stipite palcaceo. 2 . In sylvaticis circà Aquas 'Tarbellicas. †

I $\{21$. Rigidum. Fronde pinnata ovato-lanceolata, pinnis bipinnatifidis cordato-lanccolatis, laciniis oblongis obtusis apice dentatis, stipite paleaceo. $2 F$. In Alpium locis sylvaticis petrosis.

I 22. Lonchitis. Fronde pinnatil, pinnis lunulatis ciliato-scratis, stipite paleaceo. 2 . In sylvis montanis.

צ'23. Aculeatum. Fronde pinnata, pinnis pinnatifulis lunulatis mucronato-dentatis, stipite palcaceo. 24 . In sepibus, sylvisque montanis.

1. $\{2$. Spinulosum. Fronde bipinnata, pinnulis oblongis acutis mucronato-serratis, stipite paleaceo. $2 \mathcal{i}$. In sylvis montanis.

3 \{25. Tanacelifolium. Fronde bipinnata, pinnulis oblongis pinnatifilis, laciniis linearibus apice serratis, stiphite subpaleaceo. 2 . In montibus Arvernie et in Vogesis. 
3426. Callipteris. Fromle subbipinnata, pimis cordato-oblongis inferioribus pinnatis, superionibus pinnatefidis, piumulis ovatis obtusis denticulato-serrulatis, tipite paleaceo. 24 . In paludosis circà Abbavillam.

1427. Thelypteris. Fronde pinnata, pinnis pinnatifilis subcrenatis basi distinctis decussantibus, punctis fructiferis conflucutilus, stipite nudo. $\mathcal{4}$. In sylvis subpaludosis.

1428. Oreopteris. Fronde pinnata, pinnis pinnatifidis integerrimis, punctis fructiferis marginalibus subconfluentibus, stipite nudo. 4. In sylvis montanis et ericetis.

I 38. P

Capsulæ in pructa rotunda sparsa aggregatæ, indusio nullo.

1429. Vulgare. Fronde pinnatifida, lohis oblongis subscratis obtusis, radice squanmata. 4 . In muris tectis et arborum truncis.

430. Phagopteris. Fronde pinnata, pinnis Janceolatis acuminatis pinnatifid is basi coadunatis, imfima reflexis. 4 . In montosis humidis Arverniæ et Vogesorum.

1431. Dryopteris. Fronde ternata bipinnata patalo-deflexa, laciniis obtusis subcrenatis, radice filiformi. 2 . In unbrosis sylvarum imprinis in montanis.

$$
\text { I 59. A }
$$

Capsulæ in maculau irregularem per totam frondis superficiem. effusam confestæ, indusio nullo.

3432. Leptoplyyllum. Frondibus bipinnatis glaberrimis, pinnulis cuneiformibus rotundato-lobatis, puncto fructifero primum oblongo. 24. In maritinis Galloprovinciæ et Armoracize circà Brivatem et Legionem.

$$
\text { I40. C E T E R A C H. }
$$

Capsulæ sparsæ aut variè aggregatæ, squamis scarioso-fuscis membranaceis ant piliformibus obtectæ.

1433. Officinarum. Fronde pinnatifida, laciniis alternis confluentibus obtusis, subtùs densè squamosis. 2 . Ad rupes et muros.

1434. Marantce. Fronde subbipinnata, pinnulis opposito-coadunatis, basi subdentatis, subtis densè squamosis. $2 L$. Ad rupes Pedemontii.

rá35. Alpinum. Fronde subbipinnatifida, pinnis cuncatis 3-5-lobatis, lobis crenulatis, subtùs hirsutis. 2 . Polypodiun arvonicum. Smitb. Fl. brit. 1115. - In Alpibus et Pyrenæis, rariùs.

\section{$\dagger+$ Capsulce annulo elastico destituta.}

$$
\text { I/fI. O S M U N D A. }
$$

Capsulæ confertæ subglobosæ pedicellatæ uniloculares bivalves, in racemmm seu in dorsmu frondis dispositze.

1436. Regalis. Frondibus bipinnatis, omnihus fructiferis, raceno terminali suprà decomposito. $\mathcal{H}$. In sylvis huuidis. 


$$
\text { I } 42 \text {. B } 0 \text { T } \mathrm{T} \text { Y } \mathrm{C} \text { H I U } \mathbf{M} \text {. }
$$

Capsulæ snbglohosæ distinctæ sessiles uniloculares, ab apice ad basia dehiscentes, in spicam racemosin congestæ.

1437: Lunarin. Fronde solitaria pinnata, pinnis lunatis. $\mathcal{Y}$. In pascuis montanis.

$$
\text { I/13. O }
$$

Capsula subglobosæ sessiles uniloculares transversè dehiscentes, in spicam subarticulatam disticham connatæ.

I438. Vu'gatune. Fronde ovati. 2 . In pascuis humidis. $I_{4} 33^{*}$. Lusitanicum. Fronde Janceolata. 2 . In arenosis maritimis Armoraciæ circà Brivatem et Legionem.

\section{O R D O V I I I. L Y C O P O D I A E AE.}

Fructificationes crustaceæ, sessiles, adaxillas nunc foliorumet tunc axillares, nunc bracteatum et tunc spicalæ dictæ; aliæ vulgatiores (forsan masculx) globulis sphæricis pulveraceis repletæ; aliæ iariores (verù-similiter femincæ) includentes semina spliærica subscabra subtùs costis tribus prominulis notata.

$$
\text { I 44. L } \quad \text { I } C \text { C }
$$

Dioica aut monoica. Masc. Coccula bivalvia pulvere plena. Fems. Coccula quadivalvia $x-\{$-sperma. - Herbe habitn siceo vario, foliis caulinis numerosis imbricatis ant bifarian dispositis.

\section{§. 1. Species coccula bivalvia tantim gerentes.}

I $\{3$ ?. Alpinum Foliis quadrifariam imbricatis acutis carinatis, floralibus ovato-lanceolutis plauis, ranulis fastigiatis erectis. $\mathcal{F}$. In sylvis montanis.

I4́no. Comp'anatum. Foliis quadrifariis basi connatis, duobus majoribus bifariam dispositis, duobus minimis adpressis, spicis geminis pedunculatis, 2 . In sylvis circa Parisios, in Perlemoniso, etc.

1441. Juniperifolium. Foliis sparsis subserratis muticis quinruefariis, floralihıs dilatatis abbreviatis, ramis floriferis anuotino-articulatis. $2 \zeta$. In sylvis montanis.

442. Clavatum. Foliis sparsis apice filamentosis, floralibus dilatatn-membranaceis, manis floriferis infernè strigosis, apice bitrifidisve. 2 . In ericetis et sylvulis montanis.

14;3. Selagn. Foliis sparsis integerrimis lanceolatis muticis uniformibus octofariis, canle dichotomo erecto fastigiato. 4 . In ericetis montosis lumidiusculis.

144. Inundatum. Foliis sparsis integerrimis lineari-lanceolatis muticis, floralibus basi dilatatis patentiusculis. 2 . In ericetis inundatis. 
5. II. Species coccula alia bivalvise alia quatrivalvin gerentes.

3475. Seluginoides. Foliis sparsis ciliatis langmatis, flomalibus ma-

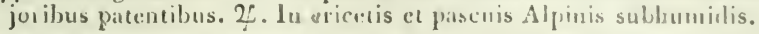

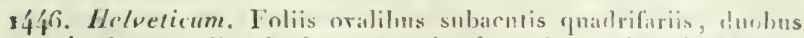
majoribus patulis, duobus minimis adpressis, ranle sadicunte. In Alpibus ard radices arbormu et in rupibus mmbersis.

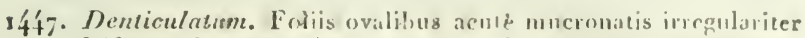
quadrifariis, duobns majonihns prenlis. Junhus minimis arlptessis, caule radicante. - Ad perles ar bonum Gallupovineix, Monspelï.

$$
\text { I/15. I S a E T E S. }
$$

Frnctificationes sulradical's, basi froulis immersæ; coccula oblonga non dehisentia polysperma. - Folia rádicalia.

3448. Lacustris. Foliis subulatis semi-tcretibus. $\mathcal{~ F . ~ I n ~ f u n d o ~ l a c u u m ~}$ Armoracix, Aquitanix, Monspelii.

\section{O R D O IX. F H I Z O S P E R II AE.}

Fructificationes radicales; involucrum subspl ericum, non dehiscens, coriaceum ant membranaceum, uni-ant-muhilrculare, organa atriusque sexus, deintic scmina plurima foress. - Herla aquaticæ.

† Involucra corincen multilocularin; folia juniora filicum more apice convoluta.

$$
\text { I 46. P I L U L A B I A. }
$$

Involucra snlitaria, subsessilia, globosa, coriacea, quadrilocularia. з4́9. Glnbulifera. Folijs filiformibus. $2 \%$. In inundatis ad littora paludum.

$$
\text { r/17. M A R S I L E A. }
$$

Involucra $2-3$, pedicello communi insidentia, ovoidea, coriacea, incùs disscpimentis tenuissimis multilocularia.

1450. Quarlrifolia. Foliis Innge petiolutis quadrifoliolosis, foliolis margine integris. - Nattans in aq̣uis Alsaliæ, De!̣̂nhinatûs, et circå Anilegavum, Eporedians.

\section{tt Involucra membranncen unilocularia; folia op- posita non convolula.}

$$
\text { 148. S A L V I N I A. }
$$

Involucra 4-9, aggregata, subrotunda, membranacea, unilocularia.

145r. Natans, Foliis ovato-subcordatis obtusis sultùs pilis fascic!nlatis scabris. - Natans in aquis quetis, in Arvernia, Delphinata, Pedemontio, Monspelii. 


\section{O R D O X. EQ U I S T A C E AE.}

Fructificationes terminales, dispositæ in amentum squamis peliatis intùs floriferis constans; involucella bivalvia; semina numerosá, muda, filamentis quatuor polliniferis lygrometricis circumplicata. Plantx apliyllæ, ramis verticillatis sulcatis articulatis, artiçulis vagina monophylla cinctis.

$$
\text { I 49. } \mathbf{E} \text { Q U I S E T U M. }
$$

Caracter generis est caracter ordinis.

1452. Hiemaie. Caule nudo basi subramoso, vaginis subcrenatis albidis basi apiceque nigris. $\mathcal{F}$. In sylvis humidis.

1453. Arvense. Caule fructifero simplici, vaginis laxis distantibus basi albidis apice fuscis profunde inciso-laceris, caulibus sterilibus verticillatim ramosis. 24 . In arvis humidis.

I 45 4. Telmateja. Caule fructifero simplici crasso lavi albo, vaginis approximatis Iongis dilatatis basi albis apice profundè incisolaceris, caulibus sterilibus verticillatim ramosis. 24 . In nemorosis humirlis.

1455. Fluviatile. Canle fructifero simplici, vaginis approximatis fuscis apice inciso-laceris, caulibus sterilibus verticillatim ramosis. 2F. In palustribus et ripis fluviorum.

456. Limosum. Caule fructifero nunc simplici nunc in ramos breves verticillatos diviso, vaginis adpressis distantibus virescentibus apice in 20 dentes fuscos laceratis, amento ovato. 24 . In stagnis et fossis.

1 455 . Palustre. Caule fructifero profundè sulcato ramos verticillatos emittente, vaginis subalpressis distantibus virescentibus apice in ro dentes fuscos laceratis, amento tereti. 4 . In palustribus spongiosis.

$145^{-*}$. Ramosum. Caule ramosn, ramis sparsis sæpiù è collo ortis plurimis amento oblongo terminatis, vaginis distantibus arlpressis vircscentibus, apice in dentes fuscos breres divisis. $2 \mathcal{L}$. In fissuris rupium et glateosis Vallesiæ, Argentorati.

1 455 . Sylvaticum. Canle ramoso, ramis verticillatis compositis arcuato-deflexis scabris. 4 . In nemorosis umbrosis hunidis.

\section{O R D O XI. NA Y A D E S.}

Herbatencræ, aquaticæ; flores axillares, pauci; stamina in quoque flore solitaria aut gemina.-Ordo artificialis et in posterum delendus.

$$
\text { I50. C H A } \mathrm{R} \text { A. }
$$

Flores axillares, perigonio destituti, monoici. Masc.? Disci solitarii orbiculares rubri, annulo albo cincti. Fem. Fructus ovatus, crustaceus, unilocularis, indusio membranaceo tectus, pulpa granulifera (seminifera) repletus.

1459 . Vulgaris. Caulibus striatis inermibus, ramulis basi nudis, 
fructibus subquaternis spiralites striatis, bractcam snperantihus. 2f. In aquis pigris.

Iffo. Tomentosa. Caulibus sulcatis apice subhispidis, ramulis basi folinsis, fructibns solitariis spiraliter striatis, bractea breviuribus. $\odot$. In fossis.

346r. Hispida. Ciulilus sulcatis lispidis, ramulis hasi subfoliosis, fructibus solitariis spiraliter striatis, bractea brevioribus. $\odot$. In fossis.

1462. Capillacea. Caulibus lavibus semi-pellucidis, ranis verticillatis elongatis, fuctibus solitariis ovoideis sublævibus, bractea subbrevioribus. $\odot$. In aquis pigris.

7463. Flexilis. Caulibus lxvibns semi-pellucidis, ramis subverticillatis elongatis, fructibus aggregatis ovoideis sublævibus, brictea lon gुoribus. $\odot$. In aquis pigris.

1464. Batruchosperma. Caulibus lævibus semi-pellucidis, ramis approximatis verticillatis, fructibus subquaternis ovoileis spitaliter striatis, bractea brevioribus. $\odot$. In aquis pigris.

1465. Syncarpa. Canlibus Javibus semi-pellucidis, ramis verticillatis, fructibus subternis, bractea destitutis. ๑. In aquis pigris.

$$
\text { 15I. IN } \Lambda \text { Y A S. }
$$

Flores monoici. Masc. Perigonium bilobum aut nullım; stamen unicum apice quadrivalre. $\mathbf{F}$ em. Perigonium nullum; ovarium ovoideum; stylus 1 ; stigmata $2-3$; capsula ovoidea, 1-sperma.

1466. Major. Foliis lanceolatis planis, perigonio florum masculnrum bilobo. - Nayas monosperna. Wild. Spec. 4. p. 33ı. ๑. In fluminibus et paludibus submersa.

146-. Minnr. Foliis linearibus ad apicem caulis confertis recurvis, perigonio florum masculorum nullo. - Caulinia fragilis. Wild. spec. 4. 1. 182. Q. In lacubas et fluminibus.

$$
\text { 152. I E MI N A. }
$$

Flores monoici. Masc. Perigonium 1-phyllnm; stamina 2. Fem. Perigonium 1-phyllum; stylus I; capsula 1-2-locularis, 2-f-sperma,

1468. Trisulca. Foliis lanccolatis in petiolum attenuatis cruciatim colırentibus, radicibus solitariis. 2 . Sub aquis pigris puris.

3469. Minor. Fohiis cllipticis utrinque planis basi cohærentibns, radicibns solitariis. 2F. Ad superficiem aquarum quietarum.

1970. Gibbn. Foliis ellipticis subtìs bullato-convexis basi cohærentibus, radicibus solitariis. $\mathcal{F}$. Ad superficiem aquæ quictæ.

1471. Polyrhiza. Foliis ellipticis planis basi cohærentibus, raciicibus fasciculatis. $\odot$ భ Ad superficiem aquarum quictarum.

r'f2. Arhiza. Foliis elliptico-subroundis geminis subtus convexis eradicatis. - Ad superficiem aģuarum quietarum. 


\section{MONOCO'TYLEDONES PHANEROGAMI.}

\section{Staminibus hypogynis.}

\section{R D O X I I. G R A M I N E AE.}

Flores glumacei, hermaphroditi ant rariùs diclini; gluma exterior sen spatha sæpius bivalvis, uniflora aut flores plurimos distichè spicatos includens; singulo flori perigonium gluma analogum, plerumquè biralve; stamina sæpius 3 hypogyna; ovarium a liberum; stigmata 2 ; finctus siccus monospermus semen nudum simulans; corculum parvum, monocotyledoneum, ad basin perispermi farinacei.Culmi cylindrici, nodis bine inde distincti, herbacei, sæpiùs simplices; folia alterna, vaginantia, vaginis longitudinaliter fissis; flores panicnlati aut spicati.

\section{† Flores paniculati aut spicato-digitati; spiculce zuniflora.}

\section{I53. A N T H O X A $\mathbb{N}$ T H U M.}

Gloma uniflora, bivalvis; perigonium bivalve, valvis acutis dorso aristulatis; stumina 2 .

14-3. Odoratum. Panicula ovato-oblonga spiciformi, flosculis arista longioribus. $\mathcal{4}$. In pratis.

$$
\text { I } 54 \text {. C R Y P S I s. }
$$

Gluma uniflora, bivalvis; perigonium bivalve, valvulis inæqualibus lancenlatis inermibus gluma Iongioribus; stamina 2 seu 3. - Panicula spiciformis.

14-4. Schennides. Panicula ovata, vagina foliacea cincta. 24. In locis petrosis hunidis Occitanix.

1'́f 5. Acu!cata. Panicula subrotunda, foliis vaginantibus brevibus pungentibus ciacta. $2 f$. In arenosis maritimis Galloprovinciæ et Occitaniæ.

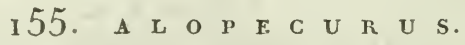

Gluma nniflora, bivalvis, inermis; perigonium univalve, valvula basi dorso aristata. - Panicula spiciformis.

I4-6. Pratensis. Panicula cyiindrica, glumis villosis, culmo erecto. 2 . In pratis.

14:7. Agrestis. Panicula cylindrica, glumis glabris, culmo erecto. $2 \%$. In pratis, agris, vineis.

1478. Geniculatus. Panicula cylindrica, glumis apice subvillosis, culmo geniculato. $Y$. In paludosis et fossis, interdum natans.

1479. Bulbosus. Panicula cylindrica, glumis villosis, culno erecto basi bulboso. 4 . In pratis paludosis aut subsalsis.

$$
\text { I 56. } \quad \text { P }
$$

Gluma uniflora, bivalvis, valvula utraque aristata; perigonium bivalve, gluma minus, valvula altera aristata. 
I48o. Monspeliense, Panirula subcoarctata, glumis pubescentibus, margine ciliatis. $\odot$. In maritimis incultis cthmidis.

$$
\text { 157. P II r E U M. }
$$

Gluma uniflora bivalvis, valvulis apice retusis, carinis prominentibus bicuspislata; perigonium bivalve, gluma minus, incrue. Panicula spiciformis.

148 . Pratense. Panicula cylindrica clongata ciliata, culmo erecto. 24. In pratis.

1482. Nodosum. Panicula cylindrica parva, culmo adscendente basi bulboso. 2 . Ad fossas lumidas et margines viarum.

x. 83 . Asperum. Panicula cylindrica glabra, glumis suhcartilagineis gibbis, culno erecto. $\odot$. In agris a Moguntia ad Galloprovincian.

1 48 f. Alpinum. Panicula ovato-cylindrica ciliata, glumis longè bicounibus. 2 . In paseuis Alpiun, Pyrenæorum, Montis aurei.

1485. Gerardi. Panicula subrotunda ciliato-villosa, glumis longé bicornibus, vaginis ventricosis. 2 . In editioribus Alpibus et Pyrenais.

$$
\text { J58. P H A } \mathbf{I} \text { A } \mathbf{A} \text { I } \mathbf{s} \text {. }
$$

GIuma uniflora, biralvis, valvulis æqualibus carinatis; perigonium hivalve, valvulis inaqualibus concavis acntis gluma minoribus. Panicula spiciformis.

\section{I. Glumis dorso ciliatis nec appendiculatis.}

1486. Arenaria. Panicula obovata eiliata, vaginis ventricosis, culmo basi ramoso. $\odot$. In arenosis præsertim maritimis.

I487. Pubescens. Panicula oblongo-cylindrica subvillosa, glumis $\mathrm{r}$-3-floris, foliis nolliter pubescentibus. $\odot$. In lumidis arenosis Pedemontiiet Galloprovincix.-Kæleria villosa. Pers. Fnch.1.p.97

1488. Phleoides. Panicula cylindrica, glumis glabriusculis, vaginis subrentricosis, culmo simplici. 2C. In pratis et sylrarum marginibus.

1489. Alpina. Panicula cylindrica, glumis cirinatis mucronatis dorso longè ciliatis. $2 C$. In Alyibus Delpl. Pedem. et in sunmo Jurasso.

๑.II. Glumis carinatis dorso alato-appendiculatis nec ciliatis.

1490. Canariensis. Panicula ovata, vagina superiore non involuta, glumis navienlaribus integris, perigoniis inermibus. $\odot$. Locis naritimis Galloprovincix et Occitaniæ.

I $490^{*}$. Bulbosa. Panicula cylindracea, superiore vagina basi iuvoluta, glumis apice mucronulatis, cuhmo hasi bulboso. 2 Y. Phalaris bulbosa. Lin. Spec. 79. Cav. ic. 1. t, 6\%. - Circil Camnas et Antipolim reperit Balbis.

149r. Utriculuta. Panicula ovata, hasi vagina superiore rentricosa involuta, perigoniis dorso aristatis. $\odot$. In pratis humidis Occitaniæ, Burgundix.

1492. Paradoxa. Panicula oblonga, è superiore vagina vix cxserta, 
flosculis infmis eroso abortivis, glumis acutis. $\odot$. In Galloprovincia.

1493. Cylindrica. Panicula arctè cylindrica. glumis glabris obtusis integris, margine menbranaccis. -Circà Toloneun et Saviglianum.

$$
\text { 150. L }
$$

Gluma nulla; perigonium bivalve clausum, valvulis compressonavicularibus muticis.

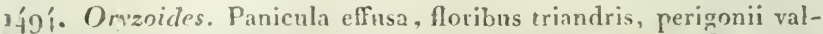
vulis oblongr-ovalibus carina ciliatis. - In pratis humidis et oris sylvarm paludosis, in Normandia, circà Parisios, Lugdunum, Befortium, Segusium.

$$
\text { I } 59^{*} \text {. o } \mathrm{R} \text { × } \mathrm{z} \text { A. }
$$

Gluma uniflora bivalvis; perigonium bivalve æqıale nnnc muticum nuuc aristatum; stanina 6 .

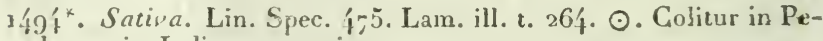
demontio Italiz contermino.

$$
\text { I 60. T R A G U s. }
$$

Gluma nniflora univalris ovalis convexa acuta rigida extùs spiuulis uncinatis aspera; perigonium bivalve.

1495. Racemosus. $\odot$. In arenosis.

$$
\text { I6I. P A I I c U } \mathrm{r} \text {. }
$$

Gluma uniflora hivalvis, valvula tertia extus ad basin floris addita; perigonium bivalve, persistens.

1496 . Verticillatum. Panicula spiciformi cylindrica, spiculis verticillatis 'fuaternis, involucellis unifloris bisetis scabris, culmis subdiffusis. $\odot$. In arvis.

צ'97. Viride. Panicula spiciformi cylindrica, racemulis confertis, involucellis bifloris multisetosis scabriusculis, culmis suberectis. $\odot$. In arvis.

I 978 . Glaucum. Panicula spiciformi ovato-cylindrica, spiculis confertis, involucellis bifloris multisetosis, semine transversim rugoso. $\odot$. Ad margines agrorum et viarum.

1499. Italicum. Panicula spiciformi densa basi interrupta subramosa, spiculis glomeratis, rachi hirsuta, involucellis setaccis. $\odot$. Ex India otta, in Gallia meridionali culta.

1500. Tindulatifolium. Panicula spiciformi, spiculis subsessilibus alternis remotis villosis, valrulis longè aristatis, vaginis pílosis. In umbrosis Alpium Pedemontii.

15nr. Crusgalli. Panicula spiciformi decomposita, spiculis alternis conjugatisqur subdivisis, glumis aristatis hispidis, rachi subquinquangulari. $\odot$. In arvis et cultis.

1502. Miliacerım. Panicula laxa flaccida, foliorurn vaginis hirtis, glımis mucronatis nervosis, $\odot$. Ex India orta, in usum Gallinacearum cul!a. 
15o3. Copillare. Panicula rapillari ramosissima patente, vaginis hirsutissimis, glumis acuminatis læribus. ○. Circà Niciean.

$$
\text { 162. I' } \mathrm{A} \text { S P A L U M. }
$$

Giuma uniflora bivalvis membranacea, valvula accessoria nulla; perigonium bivalve persistens suberustaceum. - Flores subspicuti unilatcrales biseriales.

150\%. Sanguinale. Spicis digitatis basi interiore nolosis, floriluns geminis, vaginis foliisque papilloso-pilosis. $\odot$. In cultis frequens. 1505. Ambigumm. Spicis digitatis basi interiore nodosis, floribus geminis, vaginis foliisque glabris. $\odot$. In cultis rarius.

1506. Dactylon. Spicis digitatis basi interiore villosis, floribus solitariis, sarmentis repentibus. $\mathcal{H}$. In arenosis frequens.

$$
\text { I63. A G } \mathrm{r} \text { O } \mathrm{S} \text { T I S. }
$$

Gluma uniflora hivalvis; perigonium bivalve glabrum; valvula altera interdùm dorso aristata. - Flores paniculati.

\section{S. I. Perigonii valvula altera dorso aristata.}

1507. Paradoxa. Panicula laxissima, glumis levibus perigonio longiorihus, seminibus nitilis nigris. F. Monspelii, Niceæ, in GalIoprovincia et Delphinatu anstraliori.

1508, Lentigera. Panicula spicata Iyramidata, flosculis subnitidis batsi ventricosis. $\odot$. In arvis circa Nicæam, Gratianopolim, Monspelios, Nannetes, Parisios.

1509. Spica venti. Panicula clongata patula, aristis rectis strictis longissimis. $\bigcirc$. Inter segetes.

з 5 го. Interrupta. Panicula elongata coarctata interrupta, aristis rectis longissimis. $\odot$. In agris arenosis circà Parisios, Lugdunum, etc.

351. Militcea. Panicula subdiffusa, aristis rectis ssrictis spicula vix duplù longioribus, culmo erecto, pedicellis seni-verticillatis. $\odot$. In arenosis Occitanix.

35r2. Rubra. Panicula per anthesin patente, antè et post eam conIracta, aristis tortilibus recurvis spicula longioribus, culmo esecto. $\odot$. In pratis et ad vias.

513. Canina. Panicula per anthesin patente, antè et post cam contrarta, aristis recurvis spicnla longioribus, cnlmo prostrato. $\mathcal{F}$. In pratis subhumidis.

151/. Filiformis. Panicula attennata erecta, aristis rectis spicula sublongioribus, culmo crecto, foliis setaceis, pedicellis geminis. - Ad vias circà Brigantiam et lacum Lemanum.

1515. Alpina. Panicula primo coarctata demium patula, aristis spiculalongioribus, culmo erecto, foliis setaceis. $\odot$. In pratis Alpium et montium Arvernix.

15.6. Rupestris. Panicula patula, aristis spicula duplò longioribus, culmo erecto, foliis sctaccis. $\odot$. In pratis siccioribus $A l_{\text {pium. }}$

1517. Dubia. Panicula coarctata, aristis brevissimis, glumis levibus. $\underset{f}{\mathrm{f}}$. In sylvis et collibus aridis circà Parisios. 


\section{§. Il. Perigonii valvulis mulicis.}

1518. Effusa. Panicula laxa, spiculis dispersis læribus, gluma perigonio mulì majore. $\mathcal{F}$. Iu sylvis.

3519. Pumila. Panicula patula, glnmis dorso hispidinsculis, culmis fasciculatis erectis. 2 . In sylvis et collibus. - Seyuentis varietas sec. Sulth.

1520. Vu/garis. Panicula patula, glumis Iorso hispieliusculis, cnlmo subadscendente, florente erecto, pesignii valvula interi re dupls breviote rethsa. 25 . In pratis arvis et sylvis. - Agrostis sylvatica hujns est varietas floribus quibusdans (ustilagine?) conuptis et elongatis.

3521. Alba. Panicula patula, glumis carina subbispidis, culmo basi repente. 2 . In liumidis.

3522. Sonlnafera. Panicula coarctata, floribus congestis, glumis dorso pubescentibus, culmo repente ramoso, fuliis planis. $\mathcal{F}$. In agris liumidis et ad fossas.

1523. Pungens. Panicula contracta spicæformi, glumis lævibus, culmo ramoso repente, foliis involutis rigidis. $2 \mathcal{C}$. In arenosis maritinis Narbonensibus.

152\%. Marilima. Panicula contracta spicaformi, glumis earina hispidiusculis, culmo erecto, foliis involutis rigidis. $2 \zeta$. In arenosis marilinis Natbonensibus.

$$
\text { I6/. c A L } ~ \Lambda \text { M A G } \mathrm{R} \text { O }
$$

Gluma uniflora biralvis; perigonium bivalve, extùs basi aut dorso villis longis sericcis onustum. - Flores paniculati.

1525. Arenaria. Panicula spicxformi, perigonio mutico basi villoso, fo!iis involntis mueronato-pangentibus, radice repente. 24 . In arenosis maritimis.

1526. Argentea. Panicula incrassata, perigonii cxtùs lanati valvula exteriore apice aristata, culmo sxpius ramoso. 2 . Locis siccis et calidis Alpium inferiorum, Monspelii.

1527. Arundinacea. Panicula oblonga, perigonii basi pilosi valvula exteriore propè basin aristata, arista tortili geniculata. 2 . Locis Inumidis unbrosis.

52S. Colnirla. Panicula oblonga, perigonio basi piloso muticn, foliis planis, radice fibrosa. 4 . Locis bumidis.

1529. I.ancenlata. Panicula lanceolata contracta, perigonii basi pilusi valvula exteriore dorso aristata, arista reeta brevi. 4 . In sylvis, secus rineas et in pratis unbrosis.

$$
\text { I65. S T I } \mathbf{P} \text { A. }
$$

Gluma uniflora, hivalvis, acnta; perigonium bivalve, valvula exterinte apice aristam longam basi articulatanı deciduam gerente. 153n. Pennata. Aristis longissinis plumosis basi glabris, foliis filiformibus. 2 . In locis siccis montanis lapidosis. 
153r. Juncea. Aristis longissimis nulis, foliis convolntis filiformibus intirs pubesecutibus, panicula laxa pallida. 2f. In collibus aridis.

1532. Copillata. Aristis longissimis nudis, foliis convolutis sul,filiformibus intus vialnsis, panteula laxa demum a ufescente. 25. In collibus arillis. - Prionis vallictas?

1533. Aristella. Aristis mudis flosculo vix duplo longinrilus, foliis superiqribus planıs. 2 . Locis siccis petuosis, Monspelii, Nicca.

$$
\text { I }(6) \text {. L A } \mathrm{G} \text { U } \mathrm{R} \text { U } \mathrm{s} \text {. }
$$

Gluma uniflora bivalvis, valvulis villosis acutissimis; perigonium bivalve coriaceum triaristatam, aristis duabus terminalibus, tertia dorsili.

1534. Ovatus. $\odot$. In arvis provinciarnm mediterranearum.

$$
\text { 167. S A с с н } \mathbf{\text { a }} \text { в U } \mathbf{M} \text {. }
$$

Glnma uniflora bivalvis, valvulis extus lanugine sericea coopertis; perigonium bivalve glabrum.

\section{j. I. Panicula cylindrica spiciformi (imperata).}

1535. Cylindricum. Panicula spicata cylindrica, fuliis convolutis.

4. In arenosis maritimis Nicex, Galloprovinciæ.

$$
\text { j. II. Panicula laxa (saccharem). }
$$

1536. Ravennre. Panicula laxa, raclii lanata, fuliis planis. 2 . Sccus rivulos in Gallopıoviucia, propè Cettam.

\section{†† Flores paniculati; spicule multiflora.}

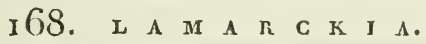

Spiculæ aliæ steriles ternæ pendule muticx arl basin fertilium involucrum mentientes, alix fertiles geminatæ; gluma 2-valvis, 2-3flora; perigonium 2-valve, valvula extesiose longè aristata.

1537. Aurea. ๑. Chrysurus cynosuroides. Pers. cnch. So. - Ad rupes Galloprovincix australioris et Nicex.

$$
\text { I 69. II E L I C } \boldsymbol{A} \text {. }
$$

Gluma hivalvis scariosa 2-3-flora, floribus I-2 hermaphroditis, I terminali abortiva; perigonimm bivalve subventricosum.

$$
\text { ๑. I. Perigonio glabro. }
$$

1538. Uniflora. Floribus hermaphrolitis solitariis, panicula lixa pituciflora, foliorum vaginis oppositifoliis. 24 . In sylvis.

1539. Montana. Floribus hermaphroditis binis, pauicula nutante secunda simplici. $2 \zeta$. In sylvis montanis.

1540. Ramnsa. Floribus hermaphroditis binis, panicula laxa pyranidata, foliis convolatis rigidis. $\mathcal{F}$. Ad rupes apricas Delphinatûs et Galliæ narbonensis. 


\section{II. Perigonio extus villoso.}

15 1́. Ciliata. Panicula spiciformi elongata, perigoniis ciliato-villosissimis. 2 . In collibus sterilibus saxosis,

15 f2. Bauhini. Panicula laxa suhsecunda, ramulis inferis divaricatis, perigoniis ciliato-villosis. 24. Ad rupes apricas Niceæ.

$$
\text { I 7O. D A }
$$

Gluma multiflora hivalvis, valvulis maximis concavis ; perigonium bivalve, ralvula exteriore apice fissa, et ex ima fissura aristam nunc longan tortam, nunc ferc̀ abortivam emittente.

15\%3. Decumbens. Arista subabortiva, glumis 3-4-floris, foliis pubescentibus planis. $\mathcal{Y}$. In collibus et sylvis siccioribus.

154. Prnvincialis. Arista longa tortili, glumis 5-6-floris, foliis glabris ore pilosis, inferioribus convoluto-setaceis. 2 . In Galloprovincia propé Segesteronem, in Delphiuatu propè Vapincum.

$$
\text { I7I. A V E N A. }
$$

Gluma bivalvis bi-aut-multiflora; flores onnes hermaphroditi aut interdium abortu mascnli; perigonium bivalve, valvula exteriore dorso aristam geniculatam gerente.

\section{I. Floribus omnibus hermaphroditis; perigonii valvula exteriore apice incegra.}

1545. Sativa. Panicula laxa, glnmis dispermis, seminibus lievibus perigonio involutis. $\odot$. In agris culta, interdum abortu mutica.

15f6. Nurla. Panicula laxa, glumis trispermis, seminibus lævibus denudatis, flosculo ultimo nutico. $\odot$. Colitar ut prior.

1547. Fatua. Panicula laxa, glumis 3-5-floris, flosculis basi hirsutissimis, foliis planis. $\odot$. In arris.

15 f3. Sempervirens. Panicula subpatula, glumis 3-floris, flosculis lanatis, foliis rigidis subinvolutis intus striatis. $\mathcal{H}$. In montosis apricis Peden. Delphin. Pyren.

15:9 Pubescens. Panicula erecta subsimplici, glumis 3-floris, flosculorum rachi babata, foliis planis pubescentibus. 2 . In pratis montanis et collinis; variat rarius foliis glabris.

3550. Distichophvlla. Panicula erecta angusta, glumis 2-3-floris, flosculis hasi villosis, culmo ascendente basi ramoso, foliis ramorum juniorum distichis. $2 \mathrm{~F}$. Ad rupes in $\Lambda$ pibus.

1551. Versicnlor. Panicula erecta angusta, glumis 5-6-floris, flosculorum rachi pilosa, foliis planis. 4 . In Alpibus et montibus Lugdunensibus et Arvernix.

1552. Amatlystina. Panicula erecta angusta, glumis 2-floris, flosculo inferince uniaristato, supcriore biaristatu.-In Alyibus Galloprovincialibus.

$1553^{*}$. Serlenensis. Panicula erecta contracta, pedicellis geminis, glumis $2-3$-floris, flosculorum basi villosorum valvula interiore bifida. - In Alpibus Galloprovincialibus. 
1553. Selacea. Panicula erecta contracta, flumis $2-3$-floris, fuliis conroluto-setaceis, vaginis lanuginosis. $2 \mathcal{f}$. In Alpibus P'edem. ct Delphin.

1554. Aimiles. Panicula evlindriea spicxformi, glumis 2-3-floris,

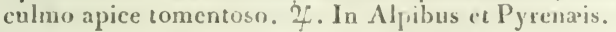

1555. Pratensis. Panicula erecta sul,spicati, pedicellis solitariis aut geminis, glumis 5-8-floris, flosculorume rachi pilosa, foliis sul,involutis glabris margine aspenis. $2 F$. In pratis, ad sylvarum. margines.

1556. Fragilis. Spiculis sessilibus, spica fragili articnlata, glnmis 4-6-floris. $\odot$. In prov. mediterraneis, Delphinatu, inter Genevam ct Sanctum-Julianmu.

9. II. Floribus omnilus hermaphroditiis : perigonii valvula exteriore apice fissa biaristata et dorso uniaristatu (TRISETUM).

1557. Laplingiana. Panicula conferta subspiciformi, foliis puhescentibus. - Triselum hispanieum. Pers. ench. 97. - In vallibus Pedemontanis Augustana et Segusiana.

1558. Tenuis. Panicula tenui laxa, glumis $2-4$-floris, perignnii valvula exteriore lævi, foliis glabris. $\odot$. In campis aridis Delphia. et Pedem.

1559. Strigosa. Panicula tenni laxa, glumis 2 -floris, perignnii valvula exteriore apice striata, foliis glabris. $\odot$. In provinciis mediterrancis.

156o. Flavescens. Panicula subcontracta (flavescente), glumis $2-5$-floris, foliis inferioribus pubescentibus. 2 . In collibus et pratis siccis.-Trisetum pratense. Pers. cnch. 97.

566r. Sesquitertia. Panicula contracta gracili (purpurascente), glumis 2-5-floris, foliis inferioribus pubescentibus. - In montibus Lemani conterminis.

\section{III. Floribus polygamiis.}

1562. Elatior. Panicula subcontracta nutante, glumis lærihus 2-floris, flore hermaphrodito snbmutico, masculo aristato, foliis glabris, radice repente. 4 . In pratis.

1563. Lanata. Panicula contracta cylindrica, glumis 2 - floris villosis, vaginis lannginosis. $2 f$. In pratis.

156ł. Mlollis. Panicula contracta cylindrica, glumis 2-floris lavibus carina ciliatis, raginis glabrinsculis, nodis villosis. $\mathcal{Z}$. In pratis.

1565. Odorata. Panicula laxa, glumis trifloris, foliis glaluris. $\mathcal{F}$. In pratis humidis et fossis Arverniæ, Monspelii, Moguntiæ, Belgii. - Variat floribus muticis et aristatis, staninibus 2-3.

$$
\text { 172. A I R A. }
$$

Gluma biflora, bivalvis; perigonium bivalve, valvula exteriore ' basi aristam geniculatan emittente. - Flures paniculati nitcntes.

1566. Caspitosa. Foliis planis nerrosis, ligula suprema bifida, pani. 
cula patente, aristis rectis flore vix longioribus. 24 . In pratis et sylvis.

156-. Flexitosa. Foliis setaceis, ligulis bifidis, panicula laxa panciflora flexuosa, aristis flore duplò longioribus. $భ$. In sylvis et montanis.

1565. Curinphyllen. Foliis setaceis, lignlis acutis integris, panicula divaricatit trichotoma, aristis flore paulo longioribus. 24. In siccis et arenosis.

1568*. Articulata. Foliis planis siccitate convolutis, panicula primò coarctata demin patula, aristis medio articulatis apice clavatis. $\odot$. In arenosis matimis propé Savonam, finarium et Loanum. -Aira articulata. Desf. atl. 1. p. - - t. 13. Balb. misc. 10.

3569. Canescens. Foliis setaccis, panicula coarctata, aristis merlio articulatis apice clavatis. $\odot$. In arenosis.

157o. Precen. Foliis setaceis, panicula coarctata subspicæformi, aristis medio articulatis apice filiformibus. $\odot$. In arenosis.

$$
\text { I73. A R U N D O. }
$$

Gluma multiflora bivalvis ; perigonium bivalve extùs villosissimum.

157r. Phragmites. Glumis 2-6-floris, panicula laxa, culmo herbaceo rigido. 4 . In lacubus, fuviis, stagnis puris.

1572. Donax. Glumis 3-6-floris, panicula densa, culmo suffruticoso. 2 . In collibus Galloprovincix.

$$
\text { I 74. F E S T U C A. }
$$

Gluma bivalvis multiflora; perigonium biralve, valvulis acutissimis, arista terminali sæp̣ donatis.

\section{I. Periggonii valvulis acutis arista destitutis.}

1573. Corulea. Spicnlis 2-3-floris cylindricis, panicula coarctata, culmo subuniundi. $2 \mathcal{L}$. In sylvulis et pratis unbrosis.

I57ł. Serotina. Spiculis 3-5-floris, panicula prumò erecta demùm divaricata, foliis convolutis rigidis pungentibus. 2 . Locis siccis apricis Peclem. Gallopiov.

15-5. Maritima. Spiculis 6-8-floris compressis lanceolatis glancis, panicula subramosa, pedicellis angulatis primù erectis demùn divaricatis incrassatis. - In arenosis secus mare Nediterranem.

15-6. Spadicea. Spiculis 1-5-floris ovatis nitido-aurcis, yanicula erecta, foliis lævibus subpungentibus. $\%$. In pratis montanis Arverniæ et Gialliæ meridionalis.

1577. Sylvatica. Spiculis 3-5-floris oblongis, panicula crecta, foliis planis margine scabris, vagina lavi, culmis collu squamatis. 2 . In sylvis Delphinatûs.

1578. Loliacea. Spiculis 7-1 I-floris distichis alternis subsessilibus, panicula simplici erecta. ₹f. In pratis humidis circà Parisios, $\Lambda$ bbavillans. 
1579. Elatior. Spiculis 7-?-floris subteretibus olutnsiuscniis, panicula suhdiffusa secunda. ₹f. ln pratis.

1580. Arundinacea. Spiculis . -6 -floris ovntis compressis glaberrimis, panicula erecta subdillusa, aristis brevissinis sub anpece ortis. 2i. Secus rivulos Alpium, Jurassi, ctc.

1581. Inermis. Spiculis 10-15-floris linearihus compressis, paniculir erecta demim diffusa, aristis brevissimis suberminalibus soj]us abortivis, $\mathcal{Z}$. In pratis secus rivulos.

§. 11. Perigonii valwulis aristam iisdem breviorem gerentibus glume valvulis subaqualibus.

1582. Ovina. Spiculis 3-S-1loris glaberrimis muticis aut brevi aristatis, panicula secunda coarctata, foliis setaceis seabris, culmus subtetragono. 2 . In pascuis siccioribus et apricis, - Var. $\beta$ HI. gall. est Poa sctacea. Krel. gram. 162. excl. syn, ipso teste.

$1582^{*}$. Flavescens. Spiculis 4 -5-floris glaberrimis, perigonii valvulis margine membranaceis subaristatis, panicula erecta eoarctita, foliis setaceis elongatis, culno tereti. 2 . In dumetis Alpium Pedemontii.

\583. Rubra. Spiculis 5-6-floris glaberrimis aristatis, panicula ereeta sublaxa, foliis inferioribus sétaccis, superioribns planiuscn!is suprì pubescentibus. $2 \mathcal{C}$. Locis siccis et sterilibus.

158'. Duriuscula. Spiculis 5-6-floris glaberrimis aristatis, panicula ererta secunda, foliis strictis brevibus inferioribus setaceis, superioribus planis suprà glabris. $\mathcal{Z}$. In pratis siccis.

1585. Cinerea. Spicniis 5-7 foris, perigoniis tomentosis aristatis, panicula erecta, foliis subglaucis fifformi-convolutis extìs lævibus intìs pubescentibus. 24. In pratis sićcis montanis et maritimis.

1586. Glauca. Spiculis 2-5-floris, perigoniis glabris aut apice pubescentibus aristatis, panicnla subdivaricata, foliis glancis tiliformiconvolutis extìs lævibus intùs pubescentibus. ₹f. In arenosis siccis circà Parisios, in Vogesis ę Jurasso.

58 7. Heteinphylla. Spiculis 5-6-floris glaberrimis aristatis, panicula secunda sublaxa, foliis laxis longis, inferioribus filiformibus, superioribus planis supràpubesentibus. 2 . In sylvaticis umloroșis.

1585. Prmila. Spiculis 4-floris subteretibus oblongis glabris aristatis, panicula collecta, foliis setaceis duriusculis. $2{ }^{\circ}$. In Alpibus.

1589. Eskia. Spiculis 6-ro-floris compressis ollongis subaristatis glabris, rachi pilosa, panienla collecta, foliis complicato-filiformibus pungentibus. $\mathcal{F}$. In Pyrenæis.

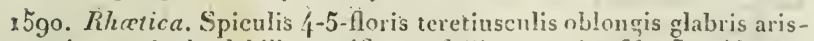
tatis, panicula debili pancillora, foliis setaceis. $2 f$. In Alpibus Vallesia conterminis.

159r. Halleri. Spiculis 4-5-floris teretiusculis oblongis aristatis, rachi glalora, perigonii valvula exteriote pubescente, paricula stricta, foliis setaceis. $\psi$. In Alpibus.

1502. Hirsuta. Spicnlis 2-floris hirsutis aristatis, panicnla cylindrica spiceformi basi subinterrupta. Zf. Iu Alpibus Vallesiacis. 
1593. Phleodiles. Spiculis 3-5-floris aristatis, panicula cylindrica spicatormi, perigonii valvula ex(criore durso ciliata. ๑. In Pedemuntio, Deiphinatı, Galloprovincia, Uccitania.- Noelcria phleoides. Yers. elach. 9;.

1. III. Perigonii ralvulis aristam iisdem Inngioren gerentilus; slume ralvulis incequalibus.

159'. My'urus. Spiculis $\{$ - (j-floris glabriusculis, panicula longa subspicatit nutance. $\odot$ Afl muros, locis glareosis et arenusis.

159\%. Ciliila. Spiculis 4 6. floris ciliato-hirsutis, panirula longa subspicata nutante. ๑. A.l upes Monspelii, in arenis Druentiæ, circù Aginumm.

159fi. Bromeirles. Spirulis f-6-floris subglabris, panicula spicæformi erecta, ligulis ubsoletis. $\odot$. In campis et puatis arenosis.

1597. i niglumis. Spiculis 4-6-fluris giabris, panicula spicæformi erecta, Humse valvula altera hrevissima, pedicellis compressis dilabutis. ๑. Circà Paıisios, Nannetcs, in Galloprovincia, etc.

$$
\text { 175. P o A. }
$$

Gluma bivalvis, multiflnra; spicula ovata, mutica ; perigonium bivalre, valvulis sxpè margine scariosis. - Flores paniculati.

I598. Negastarlina. Spiculis 20 -floris lanceolatis. $\odot$. In arenosis, mur is et marginibus viarum, Arverniæ, Alsatiæ, etc.

r599. Eragrostis. Spiculis ro-floris oblongis, panicula patenie, foliorum oris et vaginis pilosis. $\odot$. Locis inenltis Gralliæmeridionalis.

$1593^{*}$. Pilnsn. Spicnilis 7-8-floris oblongis, panicula patente tennissima, perlicellis flexuosis, foliorum oris pilosis, vaginis glahris. $\odot$. Poa pilosa. Linn. sp. ıno. Schencliz. gram. p. s93. t. 4. f. 3. Locis arilis circà lacmm Lemanum ad pa:-um Bex.

1600. Fluitans. Spiculis $7-12$-floris linearibus tereti-compressis, paricula ramosa erecta, perigonii valvulis obtusissimis. 2 . In tossis aquaticis.

16от. Maritima. Spiculis 5-r2-floris teretinsculis, panicula contricta aut patula subsecunda, flusculis distantibus obtusissimis, colmo adscendente. 2 . In arenosis maritimis.

16r2. Distans. Spiculis f-6-foris teretiusenlis, panicula patula. flosculis distantibus obtusissinis, culmo adsceudente. 2 . In prai, humpirlis salsis. - An prioris varietas?

16n3. Aquatira. Spiculis 6-8-floris linearibus, panicula ampla difusa, foliis lacissimis. 2:. Ad oras lacumu ct fossarum.

I6n' Trinervata. Spiculis $\{-6$-floris acutis, panicula eliffusa perigonii valvala exteriore tri-interiore-binervata. $\mathcal{\Psi}$. In sylvaticis Gullıa orientaiis.

1605. Rubens. Sirculis 4-5 floris acutis, panicnla patnla , perigonii valvula extriore subquinquenervia, culuus recto compresso. $\mathcal{F}$. In sy!vaticis $\Lambda$ pium, Jurassi, Vogesorum.

16n6. Annur. Spienlis 3-1 foris ovatis, panicula divaricata, flosculis remntinsculis subquinquenerviis, culmo obliquo compresso. $\odot$. In ruderatis cultis frequens. 
1607. Scabra. Spiculis 3-4-floris ovatis, panicula diffusa, perigonii valvulis lanceolatis basi pubescentilus, vaginis ruluougue scalnis. 2r. In pratis freynens.

160 $7^{*}$. Kaderi. Spiculis 3-1 foris ovatis, panicula diftusa, perigonii valvulis danceolatis basi pubeseentibus, vaginis scabris, culuo lavi. 27. Poa trivialis. Koel. gram. 157. ipso teste. - In prati. Moguntix.

36o8. Palustris. Spiculis 3-4-floris ovatis, panicula diffusa, perigonii valvulis lanceolatis subglabris, vaginis culmoque lavibus, fuliis latis planis. 24. In pratis paludosis.

160y. Pratensis. Spicnlis 3-f-floris ovatis, panicula diffusa, perigonii valvulis lanceolatis basi villo comnexis, vaginis culmoque levibus, foliis planis. 2 . In pratis.

$1609^{*}$. Rhenana. Spiculis 5-7-floris ovatis, panicula patula, ligulis abortivis ore calloso subciliato, foliis levihus complicato-cantaliculatis. - In arenosis paludosis circà Moguntian ad officinam laterariam Nombacensem.

16rn. Angustifoliu. Spiculis 3-4-floris ovatis, panicula angusta sul,diffusa, perigonii valvulis lanceolatis subpubesceutibus, vaginis culnoque lievibus, toliis inferioribus convoluto-setaceis. $\mathcal{F}$. In pratis et campestribus.

161 Nemoralis. Spiculis 2-3 floris (pallidis) parvis, panicula attemnata, pedicellis mui-et-multifloris, glumis valvulisque acutis, ligulis subnullis. F. In nemoribus.

$16 \mathrm{I}^{*}$. Glauca. Spiculis 2-3-floris (coloratis) ovatis, panicula attenuata, pedicellis unifloris, glumis valvulisque acutis, ligulis nullis. - Poa glauca. Vahl. Fl. dan. t. 964. non Will. nec Schl. - In Pyrenæis, in Alpibus Genevensibus.

16 12. Compressa. Spiculis 3-9-floris ovatis, panicula subcoarctata secunda, flosculis angulosis basi villo connexis, culmo adscendente compresso, ligulis brevibus obtusissimis. $2 \mathcal{f}$. In pratis siccioribus et muris.

$1612^{*}$. Cenisia. Spiculis 6- 7 -floris ovatis, panicula subdiffusa, peri. gonii valvulis pubescentibus, culmo adscendente compresso, ligulis $\therefore$ lanceolatis acutis. 2 . Secus torrentes exsiccatos in monte Cenisio.

16.3. Bullosa. Spiculis 4-floris ovatis, panicula sccunda patentiuscula subflexuosa, culmo basi bulboso. $\mathcal{Y}$. In pratis.

$1613^{*}$. Brevifolia. Spiculis 6-floris ovatis, panicula contracta ovata, glumis carina scabris, perigonii valvulis basi et dorso villosis, fuliis rigidis brevibus, ligutis magnis erosis. 2 \% Poa alpina. Kael. gram. if6. excl. syn. - In arenosis Moguntix.

16rł. Alpina. Spiculis 4-6-floris ovato-cordatis, panicula diffusa, flosculis remotiusculis basi villosis, ligulis inferioribus brevibus, superioribus lanceolatis. 2 . In pratis montanis et Alpinis.

1615. Flegans. Spiculis 3-floris oratis, panicula laxa pauciflora, flosculis margine dorsoque pubrscentibus, ligulis lanceolatis. 24 . In Alpibus Sabaudiæ, Galloprovincie, et in Pyrenzis. 
1616. Mzo'inerii. Spiculis 79 -tloris corlato-lancelatis, panicula contracta, floscniis basi pubescentibus. 2 . In Alpibus Pedemontanis.

16rz. Disticha. Spiculis 4-5-floris subsessilibus listichis, panicula spiciformi compessit ovata, perigonii valvasu extcione tridentata. 2F. In pratis editioribus Alpium Pedemontanarum et Pyrenæò um. 1618. Littoralis. Spiculis 8 -ro-fluris subsessibhus teretinsculis, panicula secunda densè contracta spiciforni, cuims prostrato. $2 L$. In maritimis Mouspelii et Gulioprovinciæ.

1619. Miliacer. Spiculis 2-floris ovatis, panicnla crecta sublaxa, perigonii valvula exteriore enervia dorso malgincque pubescente, culuio erecto. - In Pyrenæis.

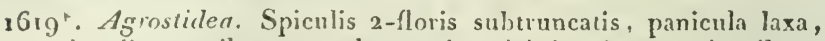
perigmiis temibus membranaceis glibris gimmit minnribus, culmo busi geniculito ant radicante. - In littoribus Ligeris propé Nannetes reperit Delaroche.

1630. Aimiles. Spiculis 2-floris, panicula laxa, perigoniis sulcatoplicatis oblougis gluma majoribus. $2 F$. In fossis aqnaticis.

1621. Cristata. Spiculis 2-3-floris, panicula cylintrica spicæformi subinterupta nitida, perigoniis acutissimis, gluma rachicue pubescentibus. 24. In cullibus siccis - Koleria cristata. Pers. Euch.97.

622. Dirarica!a. Spiculis f-floris minimis, panicnla divaricata, pediceltis apice incrassatis, foliis filiformibus. - Nonspelii.

1623. Rigidu. Spiculis 6-r2,floris linearibus glabris, panicula lanceolata subramosa secunda, rachi marginata. $\odot$. In arenosis aridis. 1624. Dura. Spiculis 3-5-floris obtusis glabris allpressis subsessilibus, panicula secumla congesta, glumis margine scariusis. $\odot$. Locis glareosis aridis, circà Moguntiam, lacun Lemanum, Gratianopolin.

$$
\text { - I } 76 . \text { в } \mathrm{r} \text { I z } \mathrm{a} \text {. }
$$

Gluma hivalvis, multiflora; perigonium biralve, valvulis ventricosis corrlatis obtusis, interiore minuta.

162.. Maxima. Spiculis 15-17-floris cordatis. $\odot$. In provinciis mediterraneis.

1626. Media. Spiculis 5-7-floris oratis, panicula basi nuda. $\odot$. In pratis et sylvis freyuens.

169-. Vireñs. Spiculis $5-5$-floris ovatis, panicula basi folio superiore involuta. $\odot$. In sylvis rarior.

\section{B r O M U S.}

Gluma mnltiflora, bivalvis; valvulis aqualibus; perigonium bivalve; valvula exteriore majore, concava, aristum sub apice gerente; interiore minore, duplici ciliorum serie extùs onusta.

1628. Secalinus. Panicula laxa nutante, spicnlis ovatis glabris compressis, flosenlis distinctis, vaginis glabris, foliis suprà pilosiusculis. $\odot$. In arvis.

r629. Grossus. Panicula laxa subnutante, spiculis ovatis compressis 
BROMU $\boldsymbol{s}$.

pubescentibus, flosculis distuctis, culnis vaginis foliisrue glitbuis. $\bigcirc$. In sterilibus secus vias.

16\%. Mollis. Panicula sublaxa crecta, spiculis ovatis pulescentibns, crilmis vaginis foliisque mullissime villusis. C. In lattis siccis, seeus vias.

$3630^{*}$. Racemosns. Panienlacecsiuscula difrusa, perlunculis simplicibus, surenlis oratis 6 - Horis glabris, fosculis imbrocatis orista

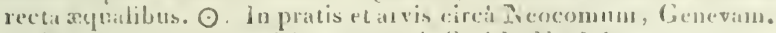
- Broums racemosus. Lion. sp. r1. Smith. Engl. bot. 1. 10:9.

363x. Muliff rus. Panionla laxa snberecta, spieulis lanceolatis pubescentihus, vagini, menlisque molliter villosis, culmo loblisque glabris. $\odot$. In coliibus et arvis.

1632. Siquarrosus. Panicula laxa nutante, pedicellis simplicibus, spiculis ovatis comporssis glabris, aristis divaricatis, vaginis pubescentihns. $\odot$. Ad agrorum margines imprinais in provinciis andoalibus.

3633. Erectns. Panicula crecta, pedicellis subsimpliciluns, spiculis limeari-oblongis scahris, foliis inferioribus angustis piosis, superiosibas latioribus glabris. Yf. In gratis.

э63\%. Aruensis. Panicula patente, pedunculis ramons, spiculis lancentatis glabuinsenlis, anistis rectis flosculo brevicribus, foliis subpilosis. $\odot$. In arvis.

1635. Pratensis. Panicula erectn-patente, pedunculis subsimplicibus, spiculis nvatu-lanceolatis compressis, at istis flosculi ameatndine, vaginis inlerioribus molliter tomentosis, folis pilosis. $2 \mathrm{f}$. In pratis el arvis.

1636. Asper. Panicula laxa ramosa, spiculis linenri-oblnngis nentantibus, vagiuarum inferiorum pilis deflesis. 2?. In scpubus ct ncmorosis.

363-. Gigantens. Panienla laxa, spiculis 4-floris nntantibus arista brevioribus. 2 . In nemorosis et pratis unbrosis.

363. Sterilis. Panicula laxa, spiculis lanceolatis pendulis glabris, flosculis nervosis sulcatis, aristis longis, foliis pubescentibus. $\odot$. Secus sepes et musos locis sterilibus.

163g. Tectorum. Panisnla laxa stabsecunda, spiculis lincaribus pen. dulis pabescentibus 5 -1loris, aristis longis. $\odot$. Ad tectit $\mathrm{ct}$ in incis sterilitus.

16 fo. Madritensis. Panicula crecio-patente coarctata subramosa, pedicellis apice incrassatis, spiculis lincariburs retrorsùm scabris, floseulis diandris. $\odot$. In arvis australiorilus Monspelii ? circà Manoscam in Giall pprovincial.

16ł. Rubens. Panicula fasciculata. spiculis subsessilibus villosis, aristis ercetis. $\odot$. In arvis CaHoprovincie circà Manoscam, segesteronem.

$$
\text { I } 78 \text {. D } A: \text { C } T \text { Y } \text { Y L I S. }
$$

Gluma multiflora, hivalvis, valvulis inæqualihns carinatis acutis ; perigonimm bivalve, valvulis carinatis, alıcra apicc aristam breviosiuan gerente. 
16 2. Glonerata. Panicula secunda glomerata, culmo erecto. 2 .

In pratis ubiquè frequens.

$+\dagger+$ Spicula sessiles, secus rachin spicate.

$$
\text { I 79. T R A C H Y N O T I A. }
$$

Gluma uniflora bivalvis, valvulis angustis carinatis, altera apice breviter aristata; perigonium bivalve, valvulis glumæ comformibus. 16 3. Stricta. Spicis geminis erectis, spiculis secundis pubescentibus, culmo foliisque strictis. 2 .Limnetis pungens. Pers. Ench.-2.

- Ad maris littora circà Rupellam.

$$
\text { I 80. E C II I N A } \mathrm{R} \text { I A. }
$$

Gluma bivalvis membranacea 2 -3-flora, flosculis aliis hermaphroditis aliis masculis; perigonium hivalve, valvula exteriore $\{-5$-fida, laciniis rigiris longis subulatis, interiore minore $2-3-$ fida.

1Gif. Capienta. Capitulo terminali subrotundo. $\odot$. Locis aridis Gallix australis.

$$
\text { I } 8 \text { I. c } \quad \text { y } \quad \text { N }
$$

Bractea foliacea lacera arl basim spiculæ; gluma bivalvis, 2-5-flora; perignnium bivalve, valvulis integris.

16,5. Cristalus. Practeis pinnatifidis, spicis subdistichis. 2 f. Locis sterilibus secus vias.

1646. Echinatus. Bracteis pinnatis aristatis, spiculis in capitulum ovatum aggregatis. $\mathcal{C}$. In incultis Gallix australis.

$$
\text { 182. S E S L E } \mathbf{R} \text { I A. }
$$

Bractea nnlla; gluma 2-3-flora bivalvis ; perigonium bivalve, valvula cxteriore apice trifida, interiore bifida. - Flores capitati vel densi spicati.

${ }_{16} 6 f^{*}$. Cylindrica. Spica densa cylindrica elongata, foliis acutissimis.

2:. Locis calidis Alpium maritimarum. - Sesleria cornlea, $\beta$. Fl.

fi. n. $36 \%$ \%

${ }_{16} 6$. Coerulea. Spica subdensa oblonga, foliis subobtusis. 2 . In rupibus et pratis montium.

3G’̧S. Micrncepluala. Capitulo spherico (corulescente), glunıx valunla exteriore 5 -aristata, interiore 2 -aristata. 4 . In rupibus montis Conisii.

s6行. Leucocephala. Capitulo sphærico (albiclo), glumæ valvula exteriore 3-dentata, interiore integra. 2 2 . In Alpibus Germanicis, forsan in Gallicis. - Cum priori diù confusa.

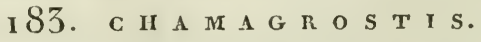

Gluma uniflora bivalvis, valvulis æqualibus oblongis obtusis trunratis; perigonium membranacenm pubescens minimum urceolatum margine lacerum. - Hores spicati subsecundi.

1650. Minima. ๑. Sturmia verna. Pers. enclı. ;2. Sturmia minima. Sturm. Fl. germ. fasc. 7. t. I. Knappia agrostidea. Engl. bot. t. 1127. - In arenosis primo vere. 


\section{S\%. N a n I) U $\mathrm{s}$.}

Gluma oniflora, bivalvis, acutissima; perigenium nullum; stigma anicuus.

3651. Strictn. Spica setitera recta securde funihus appreximatis,

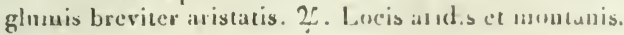

1652. Aristata. Spica se:acea sermola tlexunsa ant nutante, floribus distantibus. glmmis longè atistatis. Jocis arilis Pestemoutii, Delphinatûs, Monspelii.

$$
\text { 1 85. } \mathrm{R} \text { o }
$$

Gluma nunc univalis et unicnu florem luermeph:oditum gorens,

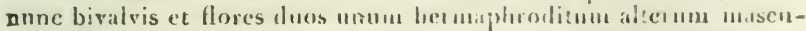
lum includens; perigonum birave gluma minus, valvulis inæquilibus.

1653. Incurvata. Spica tereti subulata, glmma calycira bivalvi adpressa subukata. $\odot$. In campis Galliae nerilionalis et in matimis usque ad Nametes et Portum-Liratix.

$$
\text { 186. } \text { 8 G } 1 \text { L } 0 \text { P } \mathrm{s} \text {. }
$$

Gluma 3-fiora, enriacea, hivalvis, valvula extcrine apice 3-5 aristas rigidas gerente, flosenlo internetion masculo, perigmium hivalve, valvulit exteriure apice 3-f aristas getence. - Fiores on raehi excavatia scmi-immersi.

1654. Ovata. Spica ovata aristata, glumarum ounninm valvula exteriore triaristata. $\mathcal{C}^{7}$. Secus vias in penvinciis meridionalibus.

1655. Triuncialis. Spica oblonga aristata, ghinnarmu inferiorum valvula exteriore biaristata. 2 . In sterilibus circa Parisios et imprimis in provinciis meritionalilus.

$1655^{*}$. Squarmas. Spica oblonga aristis longiore, glumarum ralvula exteriose 1-3-aristata sulcata nervosil. 4 . In vineis vallis Angustanæe.

$$
\text { I 87. T }
$$

Rachis dentata; spicule in quoque racheos dente solitariæ, rachi oppositæ; gluma bivalvis mulufl na; perigonimu bivalve.

\section{S. I. Spica densa imbricata.}

1656. Sativum. Spira simplici, slumis / floris ventricosis, flosculis omnibus hermaphroditis. $\odot$. Colitur uiviquè.

1657. Compositum. Spica composita, ghumis 3 floris ventricosis, flosculis omnibus heruid;

1658. Srelta. Spica simpliri, glumis 4 -floris cartilagineis truncatis, florihus 23 hermaphroditis, $2-1$ neutris. $\odot$. Culitur in provinciis Helvetiæ conterminis.

1659. Mnnnenccum. Spica simplici compressa disticha, glumis apice trilntatis 3 -floris, flore unico fet tili. $\odot$. Colitur locis montanis aridis. 
1642. Glomerata. Panicula secunda glomerata, culmo erecto. 2 .

In pratis ubiquè frequens.

$+\dagger+$ Spicula sessiles, secus rachin spicate.

$$
\text { I 79. T R A C H Y N O T I A. }
$$

Gluma uniflora bivalvis, valvulis angustis carinatis, altera apice breviter aristata; perigonium bivalve, valvulis glumæ comfur mibus. 16ł3. Stricta. Spicis geminis erectis, spiculis secundis pubescentibus, culnu foliisque strictis. 2f.Limnetis pungens. Pers. Ench.72.

- Ad maris littora circà Rupeilam.

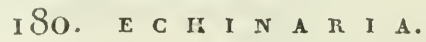

Gluma bivalvis membranacea 2-3-flora, flosculis aliis liermaphroditis aliis masculis; perigonium hivalve, valvula exteriore $\{-5$-fida, laciniis rigialis longis subulatis, interiore minore 2-3-fida.

1Gif. Capilata. Capitulo terminali subrotundo. $\odot$. Locis aridis Gallix australis.

$$
\text { 18I. C Y N o S U R U s. }
$$

Bractea foliacea lacera ad basim spiculæ; gluma bivalvis, 2-5-flora; perigonium bivalve, valvulis integris.

1675. Cristalus. Practeis jinnatifidis, spicis subdistichis. 24. Locis sterilibus secus vias.

1646. Echinalus. Bracteis pinnatis aristatis, spiculis in capitulum ovatum aggregatis. 2 . In incultis Gallix australis.

$$
\text { 182. S }
$$

Bractea nnlla; gluma 2-3-flora bivalvis; perigonium bivalve, valvula exteriore apice trifida, interiore bifida. - Flores capitati vel densi spicati.

$16 f^{*}$. C.lindrica. Spica densa cylindrica clongata, foliis acutissimis.

27 . Locis calidis Alpium maritimarum. - Sesleria cornlea, $\beta$. Fl.

fi. แ. 36 彳亍

s6 彳 . Coerulea. Spica subdensa oblonga, foliis subobtusis. 2F. In rupibus et pratis montium.

I6łS. Micrncev/lala. Capitulo sphærico (coerulescente), glunix valvula exteriore 5-aristata, interiore 2-aristata. 25 . In ripihus montis Cenisii.

36行. Leucocephala. Capitulo sphærico (albiclo), glumæ valvula rxteriore 3-dentata, interiore integra. 2 . In Alpibus Germanicis, forsan in Gallicis. - Cum priori diì confusa.

$$
\text { I 83. C H A M A G R O S T I S. }
$$

Glnma uniflora bivalvis, valvulis æquaiibus oblongis obtusis truncatis; perigonium membranacenu pubescens minimum urceolatum margine lacerum. - Flores spicati subsecumdi.

1650. Minima. ○. Sturmia verna. Pers. ench. 72. Sturmia minima. Sturm. Fl. germ. fasc. .. t. 1. Knappia agrostidea. Engl. bot. t. 1127. - In arenosis primo vere. 


\section{$1 \$ \frac{1}{4}$ N a $\mathrm{n}$ n $\mathrm{U}$ s.}

Gluma nnifora, hivalvis, acutissina; perigonium nullum; stigma anicum.

1651. Strietn. Spica seturea recta secumda forilus appoximatio, ghunis breviter an istatis. 2P. Locis atid.s et momtunis.

1652. Aristatn. Spica setarea sermula tlexnosi ant nutante. Anribus distantibus. glumis longe an istatis. ¿. Locis arilis Perlemontii, Delphinatûs, Monspelii.

$$
\text { 185. } \mathrm{R} \text { o }
$$

Gluma nunc univalis et micnm floreu lieruldphenditum gorens,

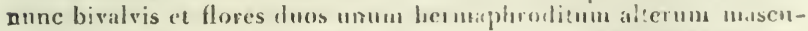
lum includens; perigomum birave gloma minus, valvulis inæqualibus.

653. Incuruata. Spica tereti subulata, gluma calycina hivalvi adpressa subulata. $\odot$. In canpis fillixe neridionalis et in matimis usque ad Namnetes et Portun-Liratix.

$$
\text { I } 86 \text {. स. G } 1 \text { L } 0 \text { p s. }
$$

Gluma 3-fina, coriacea, hivalvis, valvula extcrione apice 3-t aristas rigidas gerente, tlessenlo internedion masculo; perigonium hivalve,

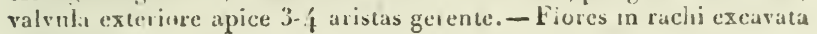
semi-iumersi.

1654. Ovata. Spica ovata aristita, glumarum ounnium ralvula exteriore triaristata. $C^{7}$. Secus vias in provinciis meridionalibus.

1655. Triuncialis. Spica oblonga aristata, ghmmarum inferinrum valvula exteriore biaristata. Z In sterilibus ciccà Parisios et imprimis in provinciis ueritionalihus.

$1655^{*}$. Squariosa. Silca oblonga aristis longine, glumarmm ralvula exteriore $1 \cdot 3$-aristata sulcata nervosa. 4 . In vineis vallis Angustanæe.

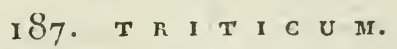

Rachis dentata; spicula in quoque racheos dente solitariæ, rachi opposite; gluma bivalvis multufl ua; perigonium bivalve.

\section{S. I. Spica densa imLricata.}

1656. Sntivum. Spica simplici, shmis / floris ventricosis, flosculis omnibus hermaphrolitis. $\odot$. Colitur ubiquè.

1657. Compositum. Spica composita, slumis 3 floris ventricosis, flosculis onnibus heruza;

1658. Srella. Spica simpliri, glumis 4 -floris cartilagineis truncatis, flosibus 23 hermaphroditis, $2-1$ neutris. $\odot$. Culitur in provincis Helvetiæ conterminis.

1659. Monnonccum. Spica simplici compressa disticha, glumis apice trilmntatis 3 floris, flore unico fertili. $\odot$. Colitur Incis montanis aridis. 
plrorlitæ sessiles, ex apice perigonii aıislatæ; gluma extus pilosa. Flores spicato-digitati aut subpariculati.

168- Grol/us. Panicula laxa, spiculis ternis pilis flavescentit us hasi circumdatis, intermedia hermaphrodia biaristata. 24. Locis siccis Petem sntis Arventix et prov. australiormus.

1689. Ischremum. Spicis 6-10 crectis subdigitatis, pediecllis villosis, spriculis geminis purpurascentibus, altero hesmaphrodito uniaristatu 2i. Lecis siccis, Parissis, etc. elc.

1689. Prvincinle. Syicis $4-5$ erectis subdigitatis, pedicellis villosis, spiculis geminis (virescentibus, altero hermaphrodito uniaristato. 2. In Galloprovincia.

69\%. Distachyon. Spicis 2 crectis subterminalibus, pedicellis villosis, spiculis geminis, maseulo breviter aristato, glumis glabris. 25. In siccis et lapidosis Niceæ, Galloprovinciæ, Asverniæ.

IG9 . Hirlum. Spicis a erectis subterminalihus, pedicellis viliosis, spiculis geminis, mascol, breviter atistate, glumis hirtis. 2 . Locis sterilibus el Lipidusis prov. Nedstes rancarum.

1692. Alinnii. Spira solitaria crecta terminali, flosculis geminis, hinc mascuiis glabris nuticis, indè femineis pubescentibus longè aristatis, aristis villosis contortis. - In collilus et saxis Pedemoutii circà Eporedian et Segusium.

$$
195 \text {. H o L c U s. }
$$

Spicuiæ r-2-floræ, aliæ misculæ membranaceæ muticæ, aliæ hermaph oditæ coriaceæ uristatæ. I lores pan culati.

3603. Al'ppensis. Panicula laxa, spiculis subglabris, aristis è receptaculo ortis. 2 . In Gallia meridionali culta.

$1693^{*}$. Snrghum. Panicula sulllaxa nvata, spiculis villosis, aristis ex apice glnumanm ortis. $\odot$. In Gallia meridronali, imptimis in Pedemontio culta.

$$
\text { I 94. M A Y s. }
$$

Spicula mascula biflora paniculatæ terminales; feminex unifloræ spicila laterales; stigmata longissima; semina subrotunda lavia seriation dispesita.

${ }_{169}$ f. Zea. $\odot$. Colitur in Burgnndia et in Gillia australi.

\section{O R D O XIII. C Y P E R A E AE.}

Flores glunacei, spicati, lıermapluroditi ant declini; gluma nnivalvis ; perigonium proprimu nullum; stamina 3 ; ovarimuliberum simplex; stylus 1 ; stignala 2.3 ; finctus (cariopsis) monospermus non dehisens; perispermum lininacenm. - Herba fremnes gramineis similes sed eltodes; folia vagiuantia, vaguina intesgra.

$$
\text { I95. C A R E } \mathrm{x} \text {. }
$$

Flores monoici ant rarius dioici, spireulis nnnc androgynis nnnc unisexualihus; stigntata $2-3$; liccolus persistens, ovasium et posted semen includens, apice perforatus, capsulatornis. 
1. I. Spica unica simplici; stigmatibus 2.

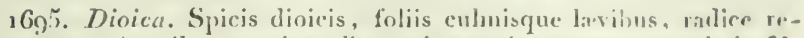
pente, finetibns enectinsculis ovatis margine snperne serrulatis. 2 f. In pratis spongiosis montanis.

s696. Damalliana. Spicis dioicis, foliis culmisque retrorsim scabris, radice fibrosa, fructibus recurvatis oblongo-lanconlatis to iquetris nervosis margine supernè scabris. $\mathcal{H}$. In pratis spongionis montanis.

1697. Pulicaris. Spica androgyna supernè masenla, fructibus ablongis teretiusculis glabris reflexis utrinqui attenuatis squanı persistenti longioribus. $2 \mathcal{L}$. In pascuis limosis.

\section{II. Spica unica simplici; stigmatibus 3 .}

1699. Ramondiana. Spica androgyna supernè mascula, fructibus bblongis patenti-reflexis breviter rostratis squama caduca vix longioribus. 2 . Carex pyrenaica. Wild. Sp. 4. 1. 214. - In Pyrenæis.

1699. Fontanesiana. Spica antlogyna snpernè mascula, fructibus oblongis utrinque acuminatis crectis. $\mathcal{H}$. In summis Pyrcnxis. - Prioris varietas sec. Ramond.

17no. Pauciflora. Spica androgyna subquadriflora, terminali mascula subsolitaria, fructibus lanceolatis teretibus reflexis, squanis fermineis carlucis. 7 . Iu pratis paludosis Alpium et Jurassi.

๑.III. Spicispluribus androgynis supernè masculis; stigmalibus 2. 1702. Arenaria. Spienlis alteruis confertis, superioribus masculis, inferioribus femineis, intermeliis androgynis, fructibus ovatis marginatis bifidis margine scabris. culmo incurvo. 24 . In arenosis imprimis maritinis.-Carex repens. Bell, est secundium Wilden. species à $\mathbf{C}$. arenaria distincta.

1703. Disticha. Spiculis alternis confertis inferinrihus renutiusculis, superioribus et inferioribus feminejs, intermediis masculis, fructibus ovatis marginatis bifidis ciliato-serratis, culmo erecto. 24. In paludosis.

эzoł. Schoenoides. Spiculis oblongis confertis, fructibus ovatnacuminatis bifidis multinerviis patentibus, bracteis serrulatis. $\mathcal{F}$. Hab.......

1705. Vulpina. Spicnlis numerosis aggregatis oblongis, fructibus ovatis bidentatis compressn-triquetris patentibus lævibus, bracteis serrulatis. 2 . In paludibus.

r-o6. Divisa. Spiculis subsenis ovatis interruptè coarctatis, fructibus ovatis subalatis bidicutatis adpressis, bractea foliacea erecta stricta. 24. In paludosis circà Abbatis-Villam, Parisios.

y.o7. Divulsa. Spiculis ovatis supcrioribus approximatis, inferioribus remotis, fructibus ercetiusculis ovatis plano-convexis marginatis bidentatis, margine glabris. $\mathcal{H}$. In nemorosis humidis.

rjo8. Muricata. Spicnlis ovatis approximatis, fructihus horizontalibus ovatis plano-convexis bidentatis basi marginatis, margine ciliato-serratis. 2 . In nenorosis humidis. 
1709. Firens. Spiculis ovatis approxisatis, functibus herizontalihus ovatis plano-convexis bitientatis basi marginatis, margine ciliato-serratis, bractea infera foliacea culmum sujerante. $2 \%$. In nemorosis lamidis. - An proris varietas?

1; ro. Futila. Spiculis in capitulum ovatum aggregatis, fructibus ellipticis terctiusculis acununatis bifidis. hracteis squanisque ovatis inucronatis. $2 \mathcal{C}$. In hunidis summarum Alpium.

1zr1. Chnrlothiza Spiculis subternis arproximatis, fructibus oratis acumnatis, culno basi ramoso, foliis culweis erectis. 2f. In turfosis Jurasoi.

17r2. Iuncifnlia. Spiculis in capiulum subrotundo orato-aggregatis, fructibus ovatis semi-globosis tavibns rostratis ore shilinteger rimis, squamis ovatis acutis subnucronalis. $2 \%$. In summis Alpibus Subaudia et Pedenontii.

7.r3 Tripartian. Spiculis tribus oblongis alternis confertis, fructibus ellipticis acuminatis nervosis. ${ }^{2}$. In Alpibus Gulloprov. Pelem.

: 王价. Paradoxa. Spiculis anguste paniculatis, ramis inferinribus remotinsculis, frectibus subotundo-ovatis rostellatis lidentairs, margine superuc ciliate-serratis. $2 \%$. In limosis sects sivulos.

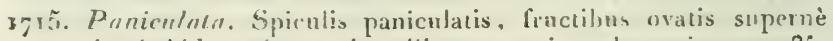
marginatis hidentatis margine ciiiato-serratis, culmo triquetro. 3 . In paludibus.

§. IV. Spicis pluribus andingynis apice masculis; stigmatibus 3.

176. Cursulu. Spiculis iu capitulum oblongum aggregatis, capsulis oratis rompressis acmminatis, squamis ovatis uncronatis, toliis duris curvuis. ?. In smmis Alpibus.

9. V. Spicis pluribus androgyris apice femineis; stigmatibus 2.

I:17. Cyperoides. Spiculis aggregatis globoso-capitatis involucratis, fructibus lanceolatis bicuspidatis. 2 . Sclielhammeria capitita. Maneh. suppl. 119. - In lumidis arenosis, propè Sezanne in Bria.

1718. Ovalis. Spicnlis subsenis subrotundo-ellipticis alternis subapproximat is, fructibus ovatis marginatis bidentatis ciliato-serraris. $\frac{2}{J}$. In pratis urlis.

$17 \mathrm{~S}^{*}$. Leporina. Spiculis tribus suhrotundo-cllipticis alternis congestis, fructibus ellipticis compressis acuminatis ore integris margine glabris. 2 . In Alpibus ad montem Cenisimm et magni S. B̈ernhardi taontem.- C. lepnrina. L. sp. 13.Sr. Wiid. 4. 1.2 2 g. Sclk. car. f. 79 et r29. C. approximati. Inoffm. germ. 4. P. 201.

1719. Sehreberi. Spienlis quinis ovato-oblongis alternis confertis, fructihus ovatis bidentatis, radice repente. 24 . In arcnosis graminosis siccis.

1720. Brizeides. Spiculis sulquinis alcemis suldistichis cnrvatis oblorg -fanceolatis approximatis, fructibus ov atis marginatis bifidis, radice fibrosa. $2 f$. Secus sylvas et sepes iri l'yrenapis. 
721. Curla. Spiculis subsenis alternis approximatis nvatn-cylindra-

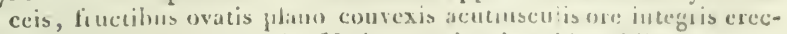
tis, squanis ovatis actutis. 2 . In graninosis sublamuilis.

1722. Sicellulala. Spiculis subquatcrnis remotiusculis, functihus ovato-acuminatis bicicntatis matgune ciliatn-scratis hurizontabibus, squinuis uvatis acutis. ? L. In pratis lumuidis.

1723. Remota. Spienlis alternis remotis solitaiis, Mracteis foliaceis lonerisonis, fructi!ns ovatis acumiuatis subbilidis compressiusenlis. $2 \%$. In mubrosis subhumidis.

1 z2 Elungata. Spiculis subduolenis alternis approximatis cylindraceis, isuctibns svato-acuminatis enarginatis netrosis patulis, squamis oratis obusis. $\mathcal{Z}$. In nemorosis humidis.

172 f*. Bicolnr. Spiculis ternis pedunculatis terminalibus crectis, fructibus obovatis obtusis, squamis ovatis obtusis. 2 . In monte Cenisio.

S. VI. Spicis pluribus andmgynis apice femineis; stigmntibus 3.

1725. Atrala. Spicis tribus quinisve pedunculatis confertis, fructiferis nutantibus, fructibus subrotundo ovatio breviter rostratis bidentatis, squanis ovatis acutis. $Z^{\circ}$. In $\mathrm{Al}_{\text {pium puscuis. }}$

5. VII. Spicis pluribıs sexu distinctis; stiğmatibus 2.

1727. Macrmaln. Spica mascula snlitaria sessili, frminea subsolitacia appoximata ellipico-subrotunda sessili, fonctihu, oblongotriquetris incurvato rostristis bidentatis, ghumis oblongis acutis. $2 \digamma$.

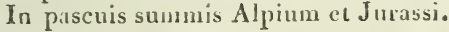

1723. Cospritosa. Spica mascula solitaria, femineis cylindraceis obunsis subternis listantibus, fructibus ovatis obtusis ore pertusis, squamis oblongis obtusis, foliis patulis. 24. In limosis.

1729. Stricta. Spica mascula solitaria, femineis cylindraccis attenuatis subtribus distantihus, linctibus ovatis acntiusculis ore pertusis, squanis lanceolutis acueiusculis, foliis strictis reticulo basi connexis. 2 . In paludibus.

173̂o. Grarilis. Spicis masculis binis tcrnisve, femineis suluquaternis subpedunculatis subnutantibus cylindraceis remotis, fructibus oblougis brevissimè rostellatis ore integro pertuso, squanis oblongis acutis. $2 ;$. In paludosis pratis.

5. VIII. Spicis pluribus sexu distinctis; stigmatibus 3 ; fructu pubescente aut villoso.

* Spica mascula solitaria.

1731. Pracox. Spicis femineis subternis oblongis subsessilibus, fructibus subgloboso-triquetris pubescentibus, squanam ovatum acutam æquantihus. 2L. In siccis sterilibus montosis.

$1731^{*}$. Umbrosa. Spicis femineis subternis oblongis sulbsessilibus, squamis dorso ciliato-asperis, tructibus ovato-triquetris pubescent:bus rostratis ore bidentatis, squamau oralem æequantibus. ? . In collibus unbrosis 'Tutrivensibus. 
1732. Tomentosa. Spicis fomincis subgeminatis ovato-cylindraceis subapproximatis sessilibus, fructibus subrotundis tomentosis squama cvata acuminata majoribus. $\mathcal{F}$. In pratis.

1733. Montana. Spicis femineis subgeminis approximatis ellipticis sessilibus, fructibus oblongis brevissinè rostratis pubescentibus squama ovata longioribus. $\mathcal{H}$. In nemorosis montanis.

3734. Pilulifera. Spicis femineis subternis approximatis ellipticosubrotundis sessilibus, fructibus subrotundis breve rostratis pubescentibus squama oblonga acuta brevioribus. 2F. In nemorosis.

1-35. Ericetorum. Spicis femineis subgeminis approximatis oblongis sessilibus, fructibus subrotundo-obovatis pubescentibus squama oblonga obtusa majoribus. 2 . In collibus siccis et ericetis Palatinatûs, et Alpium rariùs.

1736. Humilis. Spicis femineis binis subtrifloris remotis subsessilibus subinclusis, bracteis maryine membranaceis obliquis vaginatis, fructibus obovatis obtusis hirtis. $2 \mathcal{F}$. In collibus siccis et rupibus.

1737. Gynnbasis. Spicis femineis ternis quinquefloris, binis approximatis sessilibus, infima radicali longissinè pedunculata, fructibus obovato-oblongis vix pubescentibus. $\mathcal{H}$. In collibus et humilioribus montibus Gallix meridionalis.

1738. Ornithopoda. Spicis femineis subquaternis linearibus digitato-confertis, hracteis vaginatis pedicellos xquantibus, fructibus obovatis rostellatis triquetris pubescentibus squama obovata majoribus. 2F . Carex pedata. Hl. tr. et onun. antorum excepto Linnæo. Carex ornitbopoda. Wild. Spec. 4. 1.255. - In montibus demissioribus.

1,39. Digitata. Spicis fomineis subternis linearibus subdigitatis remotiusculis, bracteis vaginatis pedicellis dimidio brevioribus, fructibus obovatis rostratis triquetris pubescentibus squamam obovatam mucronatam æquantibus. 2 . In nemorosis umbrosis.

17亿. Erecta. Spicis fenineis tribus distantibus filiformibus pedicellatis erectis, fructibus ovatis inflatis triquetris margine sublis pidis rostratis apice bidentatis, squama ovata submucronata longicribus. 24. Carex Mielichloferi. Wild. Spec. 4. p. 2;6. - In Alpibus? et Jurasso.

17-22. Spadicea. Spicis femineis tribus distantibus filiformibus pedicellatis patulis, fruetibus oblongis mucronatis ore bidentatis jubescentibus squama ovali subacuta longioribus. $\mathcal{F}$. In $\mathrm{Al}$ pium nmbrosis.

\section{** Spicis masculis duabus aut pluribus.}

1740. Filiformis. Spicis masenlis geminis, femineis geminis ovatuoblongis sessilibus distantibus, fructibus ellipticis bifurcatis lanatis squamam oblongo-lanceolataru subaristatam aquantibus. 2 C. In palndibus circa Parisios et in Alpibus.

1543. Glauca. Spicis masculis geminatis, femincis cylindricis subteruatis pedunculatis pendulis, finctibus ellipticis obtusis sca- 
brinsenlis squamam ovito-cuspilatau xquantibus. $\mathcal{F}$. In paludibus.

rzfi. Hera. Spicis masculis pluribus hirtis. feunine trihus l,reve pedunculatis, fruetihus oblongis acmminatis hirtis bicuspidatis squana oblonga aristata majoribus, foliis subhirtis. 24. In sabulosis.

6. IX. Spicis pluribus sexu distinctis; stigmntibus trilus; fructibus glabris aut ad angulos tantien ciliato-scabris.

\section{* Sprica mascula solitaria.}

17f5. Flava. Spicis femineis subternis subapproximatis ellipticis inclusè predunculatis, fruetibus ovatis reflexis rostratis, rostro curvalo bideutato, squama ovata lanceolata longioribus. $\mathcal{4}$. In pratis humidis.

$1745^{*}$. Nigra. Spicis femineis subgeminis subse'ssilibus confertissimis oljlongo-ovalis, finctibus ablongo ovartis eompressis squamau ovatan xquantibus. F. 1.1. fr. u. 1,26. huc tsansferendus.In sllumis Alpibus.

17f3. Firma. Spicis femineis subtribus distantibus, infuma exsertè pedunculatis, fiructibus oblongis margine hispidis rostratis, ore obliquo, sequania ovato-nblonga majoribus. $2 \mathrm{f}$. In Alpibus Vallesiacis et Pedertuontanis?

17千7. A'pestris. Spi is femineis tribus oblnngis listantibus, infima peinncolata, fructibus subrotundo ovatis brevissimè rostratis, ore obliquo squanam ovatau obtusam æquantibus. F. In siccioribus montanis.

$177^{S}$. Brachystachys. Spicis femineis quaternis distantibus filiformibus, inferiorihus pedunculatis, fructibus lanceolatis bilentatis glabris, squana oblonga nucronata longioribns. 2 $\mathrm{F}$. In Alp̧ibns.

гว 9 . Pilosa. Spicis femineis subternis distantibus bin is inferioribus temotis, fructibus ovatis rostratis, ore membranaceo obliquo cmarginato, squama ovata majoribus, foliis ciliatis. 2 C. In collibus T'aurinensibus et Segusianis.

175n. Ferruginea. Spicis femincis ternis distantibus, binis inferioribus pednnculatis, fructibus ublongis compresso-triquetris angulis ciliatis, ore membranacen bilobo, squanta oblongal longioribus, spica mascula acuta. 2 . In Alpibus Jurasso et Pytenæis.

17.51. Frigida. Spicis femineis ternis distantibus, binis inferinribus pedunculatis, fructibus (nigris; lanceolatis triquetris angulis ci-

- liatis bicnspidatis, squana oblonga longioribus, spica mascula obtusa. 2 . In humillis summarum Alpium et Pyrenzorum.

1752. Alba. Spicis femineis geminis pedunculatis subquinquefloris, fructibus obovato-glohosis sulcatis rostratis obliquè truncatis, bracteis membranaceis vaginatis hyalinis. 2 . In montosis sylvaiticis Alpium Jurassi.

1753. Canillaris. Spicis femineis subternis longè pedunculatis cernuis suboexlloris, frucibus ellipticis rostratis distantibus, ore 
obliquo, squama ovata longioribus. $\mathcal{F}$. In pratis udis summarum Alpiun et Pyrenæorum.

1754. Mrxima. Spicis emineis subquinis cylindraceis pendulis sessilibus, infina exsertè pedunculata, fructibus ellipticis brevissimc̀ rostratis ore hidentatis squamam ovatam submucronatan equantibus. $\%$. In sylvaticis udis.

I $55 i^{*}$. Strigosa. Spicis femineis quaternis pendulis filiformihus distantibus, inferinribus exserte pedunculatis, capsulis oblongolanceolatis nervosis, ore obliquè truncatis, squania ovato-lanceolata longioribus. 2̧. Carex strigosa. Good. soc. Lin. 2. t. 20. f. f́. Carex leptostachys. Liu. f. suppl. 41 亿.-In sylvaticis udis Alsatix sccus Rihenum.

I75\%. Fulva. Spicis femineis tribns oblongis distantibus, suprema sessili, reliquis pedunculatis, fiuctibus ovato-ellipticis rostratis bidentatis, struma ovata obtusa majoribus. 24. In pratis humidis rarius.

1756. Distans. Spicis femineis tribus ovatis distantibus, suprema sessi?i, reliqnis pedunculatis, fructibus ovatis acuminatis bicuspidatis squatram ovatam acuminatam subrquantibus. $\mathcal{Y}$. In pratis.

I757. Limos 7 . Spicis femineis binis ovatis pedunculatis pendulis, fructibus ellipticis compresso-triquetris brevissimè rostellatis ore intesro squamam nvatam mueronatam xquantibus, bracteis anplexicauibus, radice repente. 24 . In paludibus turfosis.

758. Pallescens. Spicis femineis subternis pedunculatis cermuis ellipticis, fructibus obovato-oblongis obtusis squamam oblongam cuspidato-nucronatam æquantibus, foliis subpubescentibus. $2 \mathcal{}$. In pratis humidis.

3759. Panicea. Spicis femineis subbinis remotiusculis, suprema subinclusè, infima longè pedunculata, fructibus oratis obtusis, squama ovata majoribus. 2 . In pratis udis.

1;60. Patula. Spicis femineis quaternis remotis filiformibus pedunculatis cernuis, forctibus ovatis rostratis bifilis, squanım ovatam membranacean mucronatam subxernantibus. 24. Carex drymeia. IVild. Spec. 4. p. 296. - In nemorosis udis.

$\mathbf{r}-6 \mathbf{r}$. Pseudo-ryperus. Spicis femineis quaternis geminatis pednnculatis pendulis rylindricis, fructibus ovato-lanceolatis bicuspidatis reflexis squamam setaceam xquantibus. 2 . In ndis et fossis.

\section{** Spicis masculis ciualus aut plurious.}

1762. Hordeistichns. Spicis quinis, femineis tribus oblongis remotinsculis, infima subudicali, fructibus ovatis compressis bidentatis angulis ciliato-serratis, squamam oblongo-lanceolatam æquantibus. 2. In paludosis Delphinatûs ct agri Pürisiensis.

1763. Vesicaria. Sipicis quinis, femineis subgeminis pelnneulatis cylindraceis, fructibus oblongis inflatis rostratis bicuspidatis, squama lanceolati majoribus, culmo acuti triquetro. $\xi^{4}$. In paludibus sylvaticis. 
$1 ; 6$. Ampullacer. Spicis quinis, femincis binis cylindrareis breve pedunculatis erectis, trucubus subglobosis inllatis rostratis bifurcatis, squama lanceolata majoribus, culumo obtusè triquetro. 2 . In paludihns.

y 65. Paludosa. Spicis quinis, fonimeis ternis crectis cylindraceis attenuatis inferioribus pedunculatis, fructibus ovalis nervosis bidentatis, squama lanceolata aristata latioribus eanque arquantibus. 2 . In paludibus.

y 66. Riparia. Spicis senis, femineis tribus erectis cylindraceis attenuatis inferioribus pedunculatis, fructibus ovatis rostratis multinerviis hifureatis, latitudine ct longitudine squamæ ovatæ aristatæe. 24. Ad fluviormu ripas.

$$
15^{5^{*}} \text {. к о в R E s } 1 \text {, Wild. }
$$

Flores monoici, masculi et feminei in isdem spicis permixti et. sxpius sub iislem squamis geminati et squamula distincti; semina eriquetra in urceolo minimè inclusa.

$x=66^{*}$. Scirpina. Spica solitaria simplicitereti. Wild. Spec. 4. p. 205. Garex Bellardi. Fl.fr. 11. 1701. 4 . In summis Alpibus Sabaud. Delph. et Pedem.

$\eta=66^{* *}$. Caricina. Spicis tribus quattorve alternis superne masculis. Wild. Spec. 4. p. 206. 2 . In monte Cenisio.

$$
x \text { 9 } 5 * * \text {. E R I O P H O R U i. }
$$

Flores hermaphroditi; giumæ paleaceæ undiquè imbricatæ; semen. basi setis longissimis cinctum.

\section{J.I. Spicis pluribus pedunculatis.}

1767. Polystachium. Culmo tereti, foliis planis, pedunculis nutantibus sæpè ramosis. $2 \zeta$. In pratis palustribus frequens.

7-68. Angustifolium. Culmo tereti, foliis canaliculato-plicatis, pedicellis omaibus simplicibus. 2 . In pratis paluJosis rarius.

I:69. Gracile. Culmo triquctro, foliis canaliculato-plicatis triquetris, pedicellis simplicibus erectis. $\mathcal{H}$. In pratis palndosis rarius.

\section{II. Spicis solilariis terminalibus.}

I570. Vaginatum. Radice fibrosa cespitosa, culmo vagiuato, spica ovata scariosa. $\mathcal{Y}$. In paludosis turfosis uontanis.

177r. Capitatum. Radice repente, culmo basi vaginato, spica sub. rotunda. 2 . In paludibus Alpium et Pyreuæorum.

272. Alpinum. Radice subrepente, culmo angulato gracili, spica ovato-cylindrica, setis ad quodque semen senis. 2 . Trichophorum alpinum. Pers. Ench. 7o. - In paludosis Jurassi et Alpinm.

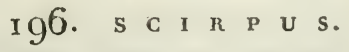

Flores hermaphroditi; glumæ paleaceæ undique imbriçat: omnes fertiles; semen nudum aut setulis gluma brevioribus basi cinctupu. 
5. I. Semine basi setulis cincto.

* Spicis solitariis.

I773. Palustris. Radice repente, culmo tercti, spica ovato-oblonga nuda, seminibus compressis. 24. In paludibus et tossis.

1774. Ovalus. Radice fibrosa, culmo subcompresso filiformi, spica ovata nuda, seminibus compressis. 22. In humidis.

1775. Caspitosus. Radice fibrosa, culmo tereti sulcato rigido basi multiplici-squanose, spica ovali-oblongi, glumis externis m.ıimis, seminibus compressis. $\mathcal{~}$. In paludosis montanis et ericetis turíosis.

1776. Boenthryon. Radice fibrosa, culmo tereti striato fere squamis rad:calibus destituto, ghtumis externis spicæ: brevioribus inæqualibus, seminibus triangularibus. 2 . Scir pus paucitlorus. Engl. Bot. t. 1122. - In paludosis.

1777. Campestris. Radice fihrosa, culmo tereti striato, glumis externis æqualibus spicam ferè superantibus, semiuibus triangularibus. $\mathcal{F}$. In campestribus humidis.

\section{** Spicis p/uribus.}

1778. Lacustris. Culmo tereti elongato nudo, spicis ovatis sessilibus pedunculatisque terminalibus. $\mathcal{H}$. In paludibus et lacubus.

1779. Triqueter. Culmo triquetro nudo, spicis quasi lateralibus subsessilibus pedunculatisque : nucrone recto. 2 . In palustribus.

278n. Mucrnnafus. Culıno triangulo nudo, angulis exsertis, spicis quasi lateralibus sessilibus, mucrone patente. $\mathcal{F}$. In pratis humidis.

17S1. Cariris. Culmu subtriquetro nudo, spiculis sessilibus approximatis distichis et spicam oblongam compressam constituentibus. 2 . In pratis humidis.

Ig.2. Mari'imus. Cnlmo triquetro, panicula conglobata, foliis plurimis obvallata, spicularmm squanis trifidis, dente intermedio subulato. 2 . In lacubus et fossis.

xz83. Sv'vaticus. Culmo triquetro folioso, cyma foliacea, pedunculis nudis siprà-decomposttis, spicis confertis, squamis indivisis. 2f. In nemorosis humidis.

\section{II. Semine basi nudo.}

* Spicis solitnriis.

178 . Acicularis. Culmo simplici quadrangulo gracili, basi vagina mutica, spica ovitu acuta terminali, glumis exterioribus majoribus. 2 . In paludibus et inundatis.

1785. F/mirulrs. Culıno tereti inlioso flaccido, perlunculis alternis nudis, spicis solitariis terminalibus. $2 \zeta$. In fossis et stagnis.

** Spicis "gstregatis.

1796. Setarews. Culmo setacen gracili simplici, spicis ad apicem culni lateralibus suberminis sessilibus ebracteatis, seminibus compressis. 2द. In inundatis. 
787. Supinus. Culmo tereti simplici, spicis sessilibus in mrdio culum gloneracis, seminibus triquetris. $2 f$. Ad margmes paluchum.

xz85. Holosrheruss. Culmo elongato tereti nudo, capitulis sulgglobosis pluribus gloneratis peduneulatis sessilibusque, involucro diphyllo inexguali mucronato. 24 . In pratis lumidis.

I 59 . Romanus. Culmo elongato tereti nudo, cappitulo lateriti sessili conglobato, bractea teflexa. 2F. Cinm priori cujus videtur varietas monoceplaala.

7790. Mlichelianus. Culmo triquetro, capitulo globoso, involucro polyphyllo longo. $\odot$. In pratis et arenis humidis Pedemontii, Aquitanix, Armoraciæ.

7791. Annuts. Culmo triquetro nudo, spicis oblongis subumbellatis pedunculatis, iutermedia sessili, foliis pubescentibus. $\odot$. Cirè̀ lacus Pedemontii.

$$
\text { I97. s c II \& N U s. }
$$

Flores hermaphroditi; glumæ paleaceæ undique imbricatit inferiores steriles; semen nudum aut setulis gluma brevioribus basi cinctum.

\section{j. I. Semine setulis basi cincto.}

r792. Nigricans. Culmo tereti nudo, capitulo ovato, involucri diphylli valvula altera subulata longiore. 2 . In paludibus et inumlatis.

I793. Ferrugineus. Culmo tereti nudo; capitulo ovato subbilobo, iuvolucri diphylli valvulis subæqualibus spicas non superantibus. 2f. In montibus Jurassi et Galloprovinciæ.

э794. Albus: Culmo filiformi folioso, floribus fasciculatis (albidis), foliis setaceis. 24. In turfosis et paludosis.

1795. Fuscus. Culmo filiformi folioso, floribus fasciculatis (fuscis), foliis canaliculato-setaceis. $\mathcal{H}$. In pratis humidis.

\section{§. II. Senuine Lasi nudo.}

1596. Mariscus. Culmo tereti fulioso, foliis margine dorsoque aculeato-serratis. 4 . In paludibus.

1797. Mucronatus. Culmo tereti nudo, foliis canaliculatis, spiculis ovatis fasciculatis, involucro polyplyyllo patente. 24 . In maritimis meridionalibus.

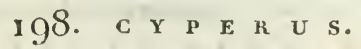

Flores hermaphroditi; glumæ paleaceæ distichè inbricatæ; spicula compressæ; semen basi nudum.

1798. Junciformis. Culmo subtereti, spiculis sessilihus aggregatis, spatha diphylla foliolo altero spiculis breviore. $\mathcal{F}$. In humidis circà Nicæam.

1799. Fuscus. Culmo triquetro, umbella subcomposita tripliylla, spicis linearibus confertis, seminibus acutè triquetris. $\odot$. Iu paludosis.

I8oo. Flavescens. Culmo triquetro, umbella subcomposita tri- 
phylla, spicis lanceolatis confertis, seminibus ovoideo-compressis. $\odot$. In paludosis.

18ox. Longus. Culmo triquetro folioso, umbella fóliosa suprà-decomposita, pedunculis nudis, spicis alternis linearibus. $\odot$. In paludosis.

ऽSo2. Esculentus. Culmo triquetro nudo, umbella foliosa, radicum tuberibus subrocundis terminalibus. $\mathcal{H}$. In humidis Galloprovinciæ.

1803. Rolundus. Culmo triqnetro nudo, umbella foliosa, radicum fibrillis binc indè in tuberculos ovatos inflatis. 2F. Monspelii.

1804. Monti. Culmo triquetro, umbella decomposita paniculata, spicularun flosculis distinctis, involucro hexaphyllo. 2F. Ad Pedemontii lacus, propè Aturum circà Aquas Tarbellicas (Dax).

ISof ${ }^{*}$. Fascicularis. Culmo triqnetro, involucro polyphyllo, spicis lincar-lanceolatis corymboso-capitatis confertissimis. 2F. Circd Nicæam secus Varum.

\section{O R D O X I V. T Y P II A C E AE.}

Flores monoici in amenta unisexualia aggregati; perigonium triphyllum. Masc. Stamina 3. Fem. Ovarium I liberum; stylus i; stigmata $I-2 ;$ fructus monospermns; corculum rectum in centro perispermi carnosi aut farinacei; radicula infera. - Herbæ enodes aquaticæ; folia alterna subvaginantia.

$$
\text { I 99. } \mathbf{T} \text { Y } \mathbf{P} \text { II } \mathbf{A} \text {. }
$$

Amenta cylindrica; fructus pedicellatus, pedicello basi pilis longis pappi instar cincto.

1805. Latifolia. Foliis linearibus planis, spica mascula femineaque approxinuatis, ntraque cylindrica. $\mathcal{F}$. In paludibus.

1806. Angustifolia. Foliis linearihns canaliculatis, spica mascula fenineaque remotis, utraque cylindrica. $2 \xi$. In paludibus.

I $806^{*}$. Media. Foliis linearibus planis, spica mascula femineaque remotis utraque cylindracen. 24 .Typha medlia. Schl. cat. 59.'T. minor. Sm. Fl. brit. 3. p. $9^{61}$. non Lob. T. angustifolia, $\hat{k}^{\circ}$ Linn. spec. I 3;8. - In paludosis Genevi.

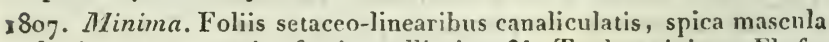
femineaque remotis, feninea elliptica. $\psi$. Typha minina. Fl. fr. excl. syn. Sm. Linn. - In arenosis udis Alsatix.

$$
\text { 200. S P A R G A N I U M. }
$$

Amenta snbrotunda; fructus sessilis turbinatus setulis basi destitutus.

1808. Ramosum. Foliis basi triquetris Jateribus concavis, pedunculo communi ramoso, stigmate lineari. $\mathcal{H}$. In fossis et ad ripas fluviorum.

3809. Simplex. Foliis basi triquetris lateribus planis, pedunculo communi simplici, stigmate lineari. $\mathcal{H}$. In stagnis.

18ı. Natans. Foliis decumbentibus planis, pedunculo communi 
simplici, stigmate ovato brevissino, capitulo masculino subsulstario. 25 . In rivulis stagnis ec lacubus.

\section{O R D O A V. A R O I D E AE.}

Flores monoici, sessiles circà spadicem sinplicem, sxpius spatha monoplylla involutum; perigonium nullum. Masc. Siamina definita ant iudefinita, spadici inserta. Fem. Ovaria nune staminihus comruixta, nunc ah iisden segregata; styli stignataque totidem; functus baccatus rotundatus; cosculum sectum in centro perisprormi carnosi aut farinacei, radicula infera. - Herlæ acaules at caulescentes; folia alterna aut radicalia, petiolata, basi subvaginantia, interdum pedata alt basi cordata.

\section{A R U MI.}

Spadix apice nudus; antleræ multiseriales ad dimidium spadicis longitudinem; glandulx acuı (stamina abortiva) 2-3-seriales popes antheras spatici insertæ; ovaria basi spadicis inserta; bacca unilocularis, monosperma.

IS 1 . Dracunculus. Foliis radicalibus pedatis, lobis integris, spadice lanceolato spiatla ovata plina glabra longiore. 2f. In uubrosis incultis Gallice meridionalis.

${ }_{1}$ II $^{*}$. Pictum. Folìs radicalibus cordatis crassiusculis venis canaliculatis et interdìm albidis insculpris, sparlice clavato subacuto spatha breviore. $2 \%$. Arum pictum. Linn. f. suppl. 410. Lam. Dice. 3. p. 10. - E Corsica misit Lasalle.

1812. Vulgrare. Foliis radicalibas hastatn-sagittatis, lobis deffexis, spadice clavato spatha breviore. 2 f. fad sepes et sylvas.

1813. Lialicum. Foliis radicalibus albo-venosis hastato-sagittatis, lobis auriculatis divaricatis, spadice clavato spatha breviose: 2 . In locis sylvaticis et submontanis Gallix meridionalis.

1814. Arisarum. Foliis radicalibus lastato-sagittatis mucronatis, lobis deflexis oblongis obtusis, spadice cylinciraceo incurvato sparha encullata breviore. $\mathcal{F}$. In. locis umbrosis et petrosis, Monspelii, Nicææ, et in Galloprovincia.

1815. Tenuifolium. Foliis radicalihus lineari-lanceolatis, spadice lanceolato spatha oblonga lanccolata spiraliter torta breviore. 4 . Monspelii.

\section{C A L L A.}

Spadix undiquè tectus staminibus et ovariis intermixtis; bacca multilocularis, polysperma.

18ı6. Palustris. Foliis cordaris, spatha plana, sparlice undiquè antheris ovariisque tecto. $\mathcal{F}$. In fossis aquosis Alsıtix, Belgii.

$$
\text { 205. Z O S T E R A. }
$$

Flores monoici ant dioici, nidulantes in folio spatlıæ vicem gerente, unilateraliter dispositi; stylus bifidus; capsula monosperma.

s $\mathrm{S}$ 7. Marina. Floribus monoicis, foliis integerrimis, canle teretiuseulo. 2f.In Oceano et mari Mediterranco.

$$
\text { K } 3 .
$$


18 8 . Mfedicerranea. Floribus dioicis, foliis integerrimis, cânle teretiusculo. 2 . In mari mediteraneo. $t$

\section{MONOCOT'YLEDONES PHANEROGAM $\mathbb{R}$.}

\section{Staminibus perigynis.}

\section{O R T) O X V I. J U N C E AE.}

Flores hermaphroditi; perigonium liberum, sæpiǹs glumaceum, sexpartitnm; stamina sæpiùs 6 , coran perigonii laciniis ; ovarinm I; stylus I; stigmata 3 ; capsula 3 -valvis, aut 3 -locularis; valvulis nunc medio septiferis et polyspermis, nunc septo destitutis et scínen unicum basi gerentibus; perispermum carnosum. - Herhæ Cyperaceis habitu sinules; folia vaginantia; flores paniculati aut corymbosi rarius spicati, bracteis scariosis glumaceis instructi.

$$
\text { 204. C A U L I N I A. }
$$

Flores spicati, duplici spatha involuti; stamina 6 ; squamæ 3 concaræ ovariun cingentes; ovarium cylindricum; stylus I ; pericarpiom ovoidenm pulposum, loco seminis gemman nudan gerens.

I819. Oceanica. 2 . In Oceano et mari Mediterraneo sub aqua florens.

$$
\text { 205. A C O } \mathrm{R} \text { U S. }
$$

Flores in spicam teretem lateralem dispositi; perigonium glumaccum 6-petalunı; stamina 6 ; ovariun I ; stylus o; capsula 3-angularis, 3-locularis.

1820. Calanus. Scapi mucrone longissimo foliacco. 4 . In fossis aquaticis Belgii, Alsatiæ, Delphinatîs, Pedemontii.

$$
\text { 206. Ír U Z U Is } \mathbf{A} \text {. }
$$

Perigonium 6-partitum, glumacenun; stamina 6 ; capsula $\mathrm{r}$-locularis, 3-sperma, 3-valvis; valvulis septo destitutis.-Folia plana hinc inde pilosa.

182x. Niver. Foliis pilosis, corymho compositn, pedunculis subquinquefloris, perigonii lobis acntis, intcrioribus duplù longioribus, radice repente. 2 . In Alpibus et montanis.

182x. Albidn. Foliis pilosis, corymbo decomposito, pedunculis subquadrifloris, perigonii lobis mucronatis, interioribus paulo longioribus, radice fibrosa. 2 . In nemorosis.

1823. Lutea. Foliis glabris, corymbo composito conferto, pedunculis multifloris, perigonii lobis acutiusculis splendentibus. F. In summis Alpium et Pyrenæorum pratis.

182 f. Sparlicen. Foliis glabris, vaghinis fauce pilosis, corymbo decomposito divaricato, peduncuís subguadrifloris, perigonii lobis mucronatis capsula acuta brevioribus. 2 . In pratis humulis $\mathrm{Al}$ pium et montium Arvernix.

I $82 \hat{\imath}^{*}$. Forsceri. Foliis pilosis, corymho subsimplici, pedunculis unifloris erectis, perigonii lobis ovato-acuminatis, capsula nucronato-icuis? f. Juncus forsteri. Smith. Cl. brit. 3. p. 1395. Engl. bot. t. 1203. - In nemırosis Jurassi circà pagos Allemands, et Cherops dictos in depart. Dubis. 
1825. Vernalis. Foliis pilosis, coryuloo suhsimplici, pedunenlis unifun is motantilus, perigonii lobis ovatis acnus, ciposulis oftusis. $2 F$. iu sylvis vere fiequens.

38. Dínina. Foliis pilosis. corymbo decomposito, pedınenlis elongatis divariatis subtufl 1 is, perigonii lobis aristatis longitudine capsulx. 2 . In montosis sylvillicis.

1827. Campestris. Foliis pilosis, spir is pedunculatis umbellatis, intermedia sessili, perigonii foliolis mucrouatis. 2f. Folsa glabra in var. א. - In pascuis, nemorosis et montanis.

1828. Spicata Foliis glahris lauce pilosis, spica racemosal nutante

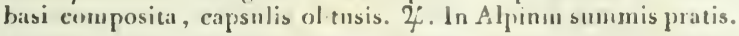

IS29. Pediformis. Foliis pilnsis, spica racenosa nulante basi comfosita et lobata, capsulis acutis. 2 . In montibus Delph. Prov. et Pedem.

$$
\text { 2.07. J U N C U S. }
$$

Perigonium 6-partium, glumaceun ; stamiua 6; capsula 3-localaris, 3-ralvis, vaivnlis medio septiteris; semina numerosa septo adfixa. - Folia teretia glahra.

\section{I. Caulibus nudis; foliis radicalibus.}

1830. Maritimus Culmo nudo tereti, panicnla terminali prolifera, involncro dipliyllo spinosu erecto, eapsulis subrotundis perigonior xqualilus. 24. Juncas aculus. Smith. Fl. brit. 3-7. - In arenosis maritimis.

183r. Acutus. Culmo nudo tereti, panicula terminali prolifera, involucro diphyllo spinoso erecto, capsulis ohlongis perigonio duple longioribns 2 . Juncus maritimus. Sm. F1. br. $375 .-1 n$ paludosis maritimis.

IS32. Cong!omeratus. Culmo nudo tercti, panicula laterali conglobata, capsulis brevibus obtusis. If. Iu paludosis.

1833. Effusus. Culno nudo tereti striato, panicula laterali effusa suprà-decomposita, capsulis obtusis. $\mathcal{4}$. In paludosis et pascuis humidis.

1834. Glaucus, Culmo nudo tereti striato glanco apice inflexo, pitnicula laterali effusa erecta, capsulis ellipticis acutis. 2\%. Juncus glaucus. Engl. bot. t. 665. Juncus inflexus. Fl. fr. 17. is3. . nou Linn. - In locis bumidis Galliz anstralis.

1835. Filiformis. Culmo nudo filiformi nutante, panicula Jaterali bracteata subsimplici, capsulis subrotundis. $\mathcal{F}$. In paludibus tarfosis montanis.

3836. Ericetorum. Culmo nndo filiformi, foliis filiformibus canaliculatis, capitulo terminali subrotundo sessili subsolitario involucrato. $\odot$. In glareosis subudis.

3837. Trifidus. Culmo nudo, bracteis floribusque tribus terminalibus. 4 . In Alpibus et Pyrenxeis in glareosis.

1838. Squarrosus. Culmo nudo, foliis setaceis subcarinatis, panicula 
terminali apbylla, capsulis ovatis obtusis. $\mathcal{F}$. In locis humaidis ct palurlosis.

1839. Arcticus. Culno nudo stricto basi squamato, umbella laterali, pedunculis multifloris, floribus sessilibus (fusco-nigricantibus). 25. In Alpibus Pedemontanis Genevensibus.

\section{§. II. Caulibus foliosis; foliis nodis transversalibus destitutis.}

18 4o. Jacquini. Culmo folioso basi squamoso, foliis subulatis cylindricis fistulosis, capitulo terminali, squamis imbricatis (nigris) nitidis cincto. 25. In Alpibus Delphin. Pedem. Genev.

ıS fr. Triglumis. Culmo basi folioso, capitulo trifloro terminali erecto aphyllo bracteato, capsulis tumidiusculis ovato-oblongis. 24 . In Alpibus Sabaudiæe, Delplninatûs, Pedemontii.

ı́ł2. Bulbosus. Culmo compresso, foliis linearibus canaliculatis, panicula cymosa, capsulis subrotundis. 4 . In paludibus et pratis humidis.

1843. Tenageya. Culmo ramoso paniculato, foliis erectis setaceis, fluribus solitariis sessilibus, perigonii laciniis ovato-oblongis, capsulis subglobosis. $\odot$. In paludibus cxsiccatis circà Parisios.

s844. Bufonius. Culmo dichotomo racemoso, foliis linearibus angulatis, floribus solitariis sessilibus. $\odot$. In pratis paludosis, ad vias locis humidis frequens.

1845. Pygnacus. Culmo crecto tenui ramoso, foliis linearibus canaliculatis, capitulis nudis terninalibus, capsulis triangularibus. $\odot$. In pratis subtarfosis circà Parisios, Monspessulanum.

1846. Supinus. Culmo ercctinsculo ramoso, foliis linearibus canaliculatis, eapitulis triphyllis, capsulis triangularibus. 2 . In paludibus semi-exsiccatis.

\section{III. Caulibus foliosis; foliis norlosis.}

1847. Fluilans. Culmo bulboso tenui radicante, foliis setaceis subnodoso-articulatis, capitulis trifloris subproliferis. 2 C. In fossis et paludibus aquaticis.

18.j8. Aiticulatus. Culmo adscendente, foliis nodoso-articulatis compresso-teretiusculis, panicula composita, perigonii laciniis obtusiuscnlis requalibus. $\mathcal{F}$. In paludibus et fossis humidis.

I8 9 . Sylvaticus. Culmo erecto, foliis nodoso-articulatis, panicula cymosa decomposita, floribus fasciculatis, perigonii laciniis aristatis, interioribus Iongioribus. $\mathcal{F}$. In sylvaticis humidis.

¿S5o. Alpinus. Culno erecto, foliis subarticulatis, panicula simplici, perigonii laciniis subaristatis «qualibus nitidis. 24 . In $\Lambda \mathrm{l}$ pibus Eelphinensibus, Sabaudis.

$$
\text { 208. А P H Y L L A N T H E S. }
$$

Perigonium 6-partitnm, laciniis basi in tubum coalitis, limbis patentibus; stamina 6 ; capsuld turbinata, 3-locularis, 3-valvis, puIysperma.

1851. Monspeliensis. - In lapidosis Galliæ meditcranex. 


$$
\text { 200. } \wedge \text { B } \wedge \text {. }
$$

Perigonium 6-partitum; stamina 6; filamenta lanuginosa persistentia; ovarimn pyramidale; stylus luevis; capsula 3-locularis, 3-valvis; senuina numerosa, ovato-oblonga, utringuè appendiculata.

1853. Ossifraga. Foliis ensiformilus, florihns laxè spicatis subsessilibus. 24. In locis humidis Gallia septentrionalis.

$$
\text { O R D O X V I*. P A L M AE. }
$$

Perigoniun sexpartitum, persistens; stamina sæpiùs 6 , imis perigonii laciniis inserta; ovarium I superum; styli $\mathrm{I}$ aut 3 ; fructus baccatus aut drupaceus, 1-3-locularis, r-3-speruns; semina ossea; corculum minimum in cavitate perispermi nagni denum cornei. Caulis fruticosus; folia petiolata, basi vaginantia, pinnatn-ant-pilmato-lobata; spadix incer folia nascens, spacha muxima involutus; flotes numerosi sxpiùs abortu diclini.

$$
209^{\not} \text {. C H A II } \text { 死 } \mathrm{R} \text { O } \mathrm{p} \text { S. }
$$

Spatha univalvis; flores nune masculi nune hermaphroditi; perigonii lacinire 3 externe minores bracteiformes; stamind 6 , filanentis crassis coalitis; styli 3 ; baccæ 3 , monospermx.

r $\$ 52^{*}$. Humilis. Frondibus palmatis plicatis, caudicibus spinosis. $b$.

Circà Nicæan.

\section{O R D X VII. A S P R A G E AE.}

Flores hermaphroditi aut diclini; perigonium petalnideum, liberum ant ovario adhærens, sæpiùs 6-partitum, interdum 6-fidnu ant 4-8partitum ; stauina tot quot perigonii laciniæ, iisdem basi arlhærentes; ovarium 1 ; stylus $1-4$; stigmata $3-4$; bacca sphærica $3-4$-locularis; loculis 1-3-spermis; corculum ad basim perispermi cornei. - Herbæ ant suffrutices habitu vario; folia non vaginantia, interdum rerticillata, rariins ad axillam stipulæ nasceutia; flores ad axillam bracteolæ siti, variè dispositi.

\section{† Flores hermaphroditi; ovarium liberum.}

$$
\text { 2IO. A S P A } \mathrm{R} \text { A G U S. }
$$

Perigonium liberum, 6-partitum; stamina 6 ; bacca 3 -locularis, loculis dispernis.

1853. Officinalis. Caule herbaceo tereti erecto ramosissimo, foliis setaceis fasciculatis, floribus stepius abortu diclinis, perlunculis medio articulatis. 2 . In arenosis maritimis Galliæ australis et Belgii.

1S54. Tenuifolius. Caulc herbaceo tereti erecto ramosissimo, foliis tenuissinis fasciculatis, floribus hermaphroditis, pedunculis longis sub flore articulatis. 2 . In pratis umbrosis et montosis Gallix australis.

1855. Acutifolius. Caulc fruticoso incrmi augulato, foliis acifor- 
milus rigidulis perennantibus mucronatis æqualibus. $y$. In sterilibus et lapidosis Galtiæ mediterraneæ.

$$
\text { 2 I I. S S T R }
$$

Perigonium 6 partitum, laciniis fovea basi nectarifera ; stamina 6 ; antleræ filamentis longiores; bacca lævis, cortice tenui.

1856. Amplexifnlius. Foliis amplexicaulibus cauleque glabris. 2 . In

Alpibus Pyrenæis Jurasso, montibus Arverniæ, etc.

$$
\text { 212. P A R I S. }
$$

Perigonium expansum 8-partitum, laciniis 4 externis latiuribus calicem, $\left\{\right.$ internis angustioribus cotollam nontientibus; stamina $S_{\text {; }}$ antheræ mediis filamentis actuatæ; stignata 4 ; bacca 4 -lucularis, loculis $6-8$ sper mis.

1857. Quadrifnlia. $\%$. In nemorosis.

$$
\text { 213. C O N V A I I A R I A. }
$$

Perigonium globosum vel cylindricum 6 - dentatum; stamina 6 ; bacca globosa antè maturitatèu maculata, 3 -locular is, luculis Ispermis.

\section{I. Floribus cylindricis ( родтgonatum).}

1858. Verticillata. Citule recto, foliis rerticillatis eilipticis. 24. In umbrosis.

I859. I'olignnatum. Caule ancipiri, foliis nratn-lancenlatis alternis amplexicanlibus, pedunculis axillaribus subunifloris. 2 . In nemorosis et dumetis.

186o. Lntifnlin. Canle angulato, foliis aleernis amplexicanlibus latis obovatis, pedunculis axilaribus multifloris, bacea coerulea. భ. In nontosis.

1861. Multifl ra. Caule tereti, foliis alternis amplexicauliljus nvatoellipticis, pedunculis axillaribus multifloris, bacca rubıa. $\mathcal{Y}$. In nemorosis el dumetis.

\section{II. Floribus campanulatis.}

1862. Majalis. Scapon nulo, foliis ovatn-lanceolatis, floribus racemoso-spicatis perlicellatis nutantibus. 2 . Ad sejes, in nemorosis.

$$
2 \text { ! 4. M A Y A N T H F. M U M. }
$$

Perigonium 4-6-partitum, laciniis patentibus; stamina 4-6; bacca siepiùs antè maturitatem maculata, 2-vel-3-Incularis, loculis 1-spermis. 3863. Pifnlium. Foliis alternis corditis subpetiolatis, floribus quadifidis tetrandris. $₹$. In sylvis montanis.

\section{$+\dagger$ Flores dioici; ovarium liberum.}

$$
\text { 215. S M I I A } \mathrm{x} \text {. }
$$

Perigoninm campanulato-patens, 6-partitum. Masc. Stamina 6, distincta. Femin. Ovarium I; styli 3 ; stigıata 3 ; bacca globosa 3-locularis. 
I86'. Aspera. Canle subdumoso spinoso hine inde flexo, foliis cordiformibus dentato-aculeatis. b. In proviuriis mediturraneis.

1865. Mauritanica. Canle seamlente subspinosn, foliis corlatis subincrnibus. b. In Corsica et insulis Stirchadum.

$$
\text { 2 I } 6 \text {. } \mathrm{n} U \mathrm{~s} \text { c u s. }
$$

Perigoninm 6-partitum sxpiùs expansum; filamenta coalitn in tubun apud femineos flores nulum, apud mares antheras 6 gerentem ; stylus I; stigua I; hacea globosa 3-locularis, loculis 2-spermis.

1866. Aculeatus. Caule rigido ramoso, foliis suprd floriferis nudis. b. In umlirosis.

1867. Hypnglnssum. Caule flexunso subramoso, foliis nitidis medio floriferis, glomerulis flormm basi foliolo acuto instructis.b. In lapidosis et sterilibus circì Nicram.

\section{$\dagger+\dagger$ Flores dioici; ovarium adharens.}

$$
\text { 2I7. T A M U S. }
$$

Perigonium campannlatum 6-partitum, in marihns hexandris patens, in fenineis ovario adhærens et suprà constrictum; stylus 1 ; stigmata 3 ; bacea 3 -locularis.

1865. Contmunis. Foliis cordatis indivisis. 24. All sepes et in nemornsis.

\section{- ORDO X VIII. A L I S M C E AE.}

Flores spathacci, sapius terminales, hermaplıroditi ant diclini; perigonimu liberum $\{-6$-partitum virescens aut coloratuin; stumina 1-25; nvaria plurima; styli et stigmata totiden; capsula uniloculares, 1-3-sperua; corculun incurvum perisperus destittitum. Herbx aquaticæ, habitu varia; radices fibrosæ.

\section{† Stamina I-4; perigonium. herbaceum (FLUVIALEs).}

\section{I S. Z Z A}

Flores solitarii, monoici. Masc. Stamen r, nulum. Fem. Perigoninm campanulatum; ovaria 26 ; capsulæ 1-spermæ, sessiles, compress $x$, gibbosæ, extius crenulatæ.

1S69. Palustris. Anthera 4-loculari, stigmatibus integerrimis, seminibus dorso denticulatis. $\odot$. In rivis et fossis aquaticis.

$$
\text { 2I } \text { I. R U P P I A. }
$$

Flores hermaphroditi, distichi in spadice solitario; perigonium caducum 2 -ralve; stamina 4 ; oraria 4 ; capsula vel nuces 1 -spermx, ovaț, longè pedicellatæ.

18\%o. Maritima. $\odot$. In stagnis et fossis maritimis.

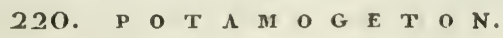

Flores hermaphroditi, spicati, spicis spathis a basi instructis; perigonium 4-partitum; stamina 4 ; ovaria 4 ; nuces 1 -spermæ, sessiles. 
IS: r. Natans. Foliis natantibus petiolatis ellipticis acutis basi rotundatis subcordatis. $\underset{i}{\mathcal{C}}$. In agitis stagnantibus.

1872. Fluilans. Foliis superioribus natantibus longè petiolatis lanceolato-ovatis basi attenuatis, inferioribus imncrsis linearibus elongatis. $\mathcal{Y}$. In rivis et fluviis Pyrenæorun.

1873. Heterophyllum. Foliis superioribus natantibus petiolatis ellipticis oblongo-acutis membranaceis utrinque attenuatis, inferioribus immersis confertis sessilibus sublinearibus. $\mathcal{Z}$. P. palustre. Teesd. trans. Liun. 5. p. 43. - In aquis stagnantibus circa Parisius.

18-4. Gramineum. Foliis immersis lineari-lanceolatis alternis sessilibns stipula latioribus. 2 . In aquis stagnantibus.

18-5. Lucens. Folits immersis ovato-lanceolatis planis in petiolns desinentibus nitidis renosis, stipulis internodio rqualibus. 2 . In lacubus et fluminibus.

8 $85^{*}$. Alpinum. Foliis immersis, inferioribus alternis, superioribus oppositis aut verticillatis lanceolato-acuunatis, stipulis internodio dimidio brevioribus. $2 \%$. In Alpibus Pedemontanis et Vallesiacis.

18-6. Perfnliatum. Foliis immersis cordatis amplexicaulibus nitidis nerrosis. $2 i$. In stagnis lacubus et fluviis.

$18 \%$. Densum. Foliis immersis ovatis acuminais oppositis confertis, caulibus dichotomis, spica 4-flora. 2 . In rivis et fluminibus.

18-8. Crispum. Foliis immersis lanceolatis alternis oppositisve undulatis, stipulis apice lacero-ciliatis. 2f. In fossis, rivis.

1879. Oppositifolimu. Foliis Janceolatis oppositis subnndulatis, stipulis minimis integris, caulibus longc̀ ramosis. 24 . In rivis.

1SSo. Compressum. Foliis linearibus subobtusis, caule compresso, spicis pancifloris. 2 . In aquis stagnantious.

1881. Pectinatum. Foliis setaceis alternis, duobus superioribus oppositis parallelis approximatis basi vaginantibus, spica florum pedunculata gracili sæepè interrupta. 2 . In Sequana circà Parisios trequens, in fossis et paludibus.

1832. Marinum. Foliis linearibus alternis distinctis vaginantibus, vaginis margine scariosis, spicis paucifloris valdè interruptis. In maritimis Gallize?

1883. Pusillum. Foliis linearibus oppositis aiternisque distinctis basi patentibus, eaule tereti tenuissimo ramoso, spicis multifloris. $\odot$. In paludibus.

\section{†+ Stamina 6-25; perigonium coloratum (ALISMOIDEE).}

\section{I. A L I S M A.}

Perigoninm 6-partitum; laciniis 3 exterioribus persistentibus calicinis, 3 interioribus coloratis petaloicheis; stumina 6 : ovaria $6-25$; rapsulæ distinctæ sæpiits 1-sperma caduca, non dehiscentes.

j. I. Capsulis senis (DamasoxuvM).

ıS84. Damnsoniturn. Foliis cordaio-oblongis, capsulis $\sigma$ steltatim patcatibus subulatis. $\underset{\mathcal{C}}{\mathcal{H}}$. In stagnorum vris. 


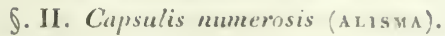

1855. Plantagn. Foliis ovatis acutis, capsulis obtusè 3-gonis. 2f. In fossis aquaticis, stagnis.

1856. Parnassifoliu. Foliis cordalis, nervis Inngitulinalibus 9 notatis, capsulis aristatis. 2 . In P'edemontio, Delphinatu, liscescia.

I857. Natans. Foliis elliptieis obtusis, pedunculis solitariis, capsulis striatis. $2 \mathcal{F}$. In stagnis purioribus sy!rie Fontisbieatudi.

1S8S. Ranunculnides. Foliis lincari-lanceolatis, capsulis pentagonis incurvis globoso-aggregatis. $2 F$. In aquosis.

$$
\text { 222. S A G I T T A R I A. }
$$

Monoica. Perigonium 6-partitum; laciniis 3 exterioribus persistentibus calicinis, 3 interioribus coloratis petaloideis. Masc. Stamina circiter 2 f. Fem. Oraria numerosa, receptaculo globoso imposita; capsulie compressæ, narginatæ, I-spcrmie.

1899. Sagittaf folia. Foliis lanceolatis acuminatis sagittatis, lobis lanceolitis rectis, scapo simplici. $2 \%$. In stagnis, fossis et ad oras fluminum.

$$
\text { 223. B U T O M U S. }
$$

Perigonium 6-partitum; stamina 9,3 interiora; ovaria 6 ; styli 6 ; capsulæ polyspermæ.

189o. Umbellatus. 2 4 . Secus aqras lentè fluentes.

$$
\text { 224. S C H E U C II Z E R I A. }
$$

Perigonium 6-partitum; stamina 6, antheris Iongis; ovaria 3-6; capsulæ compressæ, inflatæ, 2-valves, 1-2-spermæ.

1891. Palustris. 24 . In paludosis turfosis Alpium et Jurassi.

$$
\text { 225. T R I G L O C H I N. }
$$

Perigonium 6-partitum, Jaciniis 3 interioribus petaloideis; stamina 6 brevissima; ovaria $3-6$ conniventia; styli nulli; capsulx 3-6 erectæ I-spermæ connirentes.

1S92. Palustre. Capsulis 3-locularibus lrevibus linearibus hasi attenuatis. $\sigma^{3}$. In paludibus et pratis humidis.

1893. Maritimum. Capsulis 6-locularibus sulcatis ovatis. 2?. In maritimis et pratis salsis Lotharingiæ.

\section{O R D O X I X. C O L C H I C A C E AE.}

Flores sæpiùs hermaphroditi; perigonium coloratum, 6-fidam ant 6-partitum ; stamina 6, perigenii laciniis allnata ; ovarium r, liberum ; styli $1-3$; stigmata 3 ; capsula 3-valvis, 3-locularis, v'alvularum. marginibus introrsim inflex is dissepimenta constiluentibus; semina plurima margine valvularum interiore adfixa ; corculum intrà perispermım carnosum, - Herbæ habitu variæ, inter Alismaceas et Liliaccas medix.

$$
\text { 226. T O F I E L D I A. }
$$

Perigonium 6-partitune, involucro minimo 3-partilo basi cinctum; 
stamina glabra; capsula 3-6-iocularis, loculis polyspermis basi junctis.

189\%. Palustris. Foliis lineari-ensiformibus nervosis. 4 . In humidis Alpium, Jurassi et Pyrenæorum.

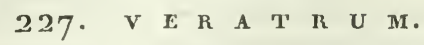

Perigonium 6-partitum; ovaria 3 basi juncta, in plurimis floribus abortiva; styli 3 breves; capsulæ oblongæ, 2-valves, polyspermx; semina margine membranacea.

1895. Album. Racemo suprà decomposito, perigoniis subpatentibus (albo-virescentibus). $2 \mathcal{F}$. In pascuis montanis.

1896. Nigrum. Racemo composito, perigoniis patentissimis (nigricantibus). 2 . In pascuis montium Alsatiæ, Burgundiæ.

$$
\text { 228. C O L C H I C U M. }
$$

Perigonium tubulosum, longum, bulbo innascens, limbo campannlato 6-partito; stamina apice tubi inserta; antheræ oblonga versatiles; ovarium I ; styli 3 longissimi; stignatta totidem adunca; capsula 3-lobata, lobis inflatis erectis basi coalitis polyspermis.

1897 . Autumınale. Bulbo submultifloro, floribus folia longè præeuntibus, foliis planis lato-lanccolatis. $\mathcal{F}$. In pratis humidis frequens. 898. Alpinum. Bulbo unifloro, foliis cum flore subprodeuntibus linearibus, laciniis perigonii ovato-oblongis. $\mathcal{F}$. In pratis humidis Alpium.

1899. Montanum. Bulbo submultifloro, foliis cum flore prodeuntibus sublinearibus, laciniis perigonii linearibus. $\mathcal{H}$. In Cursica? Alpibus? Pyrenais?

$$
\text { 229. M E R E N }
$$

Perigoninm 6-partitum, laciniis unguicnlatis staminiferis; antheræ erectæ hastatæ; ovarium I; styli 3 elongati apice erecti; capsula 3lobata, Jobis erectis minimè inflatis.

xgoo. Bulbocodium. $\mathcal{H}$. In graminosis editiorum Pyrenæorum.

$$
\text { 230. B U L B O C O D I U M. }
$$

Perigonium 6-partitum; laciniarum unguibus angustis conniventibus, apice staminiferis; ovarim I; stylus simplex elongatus; stigmata 3.

19ог. Vernum. 2广. In Alpibus Delphinensibus, Galloprovinciæ, circà Nicæam.

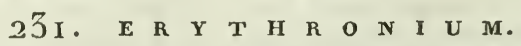

Perigonium campanulatum, patentissimun, 6 partitum, laciniis petaloideis, 3 intcrioribus hasi intus bicallosis; stylus 1 elongatus; tigmata 3 ; capsula globosa, basi angustior; scmina rotundata.

I902. Dens-canis. $2 \mathcal{F}$. In umbrosis montanis, Monspelii, Genevæ,

Segusii, Taurini, Cristæ-Deæ Vocontiorum, in Beugesia. 
Flores hermaphroditi; perigonimn petituileum, libernm ant ovario adliærens, 6 - lislum ant 6 partitum; s/amina 6 , perigonii laciniis opposita et cmu isolem sapiius athata; ovarium 1 ; stylus 1 ; stigma'a 3 ant a triquecrum; capsula 3-locularis, 3-valvis; valurelis medionsepriferis; semina pluriua, angulo loculi intesuo adlaxis; corculum intra perispenum carnosum atul cartilagneum. - llerbie nunc hulbose foliis ralicalibns, nunc caulescentes follis caulinis; folia vaginantia ant sessilia, nervis sepissince parallelis simplicibus; flores spathacei ant undi, racimosi ant umbeilati.

T R I B U S I. L I L I A C E E.

Ovarium liberum; semina pluna; stigmata tria. 252. T U L I P A.

Perigoniun campanulatum, 6-petulum au 6-partitum, laciniis basi non nectariferis; stigmata crassa sessilia; capsula oblonga trigona.

r9o3. Silvestris. Cáule unifloro glabro, flore subnutante, petalis lanceolato-acuminatis apice barbatis, staminibus basi hirsutis. $2 \%$. In pratis montanis.

19\%. Suaveolens. Caule unifloro cum foliormu pagina superiore pubescente, flore erecto, petalis acutis glabris. 2 . Lil. t. Ir. - In hortis culta.

19o5. Cessneriana. Caule unifloro glabro, flore erecto, petalis obtusis. 24 . In hortis culta; spontanea in montibus Subaudiæ et circà Nicæam?

1906. Oculus-solis. Caule unifloro glabro, petalis tribus exterioribus acuminatis apice glabris, interioribus apice obtusiusculis. $\mathcal{F}$. In arvis cultis circà Aginnum, et in Galloproviucia.

\section{F R I T I L L A R I A.}

Perigonium campanulatum 6-partitum, laciniis basi forea nectarifera ovata excavatis.

1907. Meleagris. Foliis omnibus ahernis linearibus canaliculatis, caule unifloro. 2 C. In pascuis humidis montanis.

198. Pyrenaica. Foliis inferioribus oppositis, caule 2-3-floro. $\mathcal{F}$. In montilus Galloprovincix, Delphinatûs, ct Pyrenzis.

19o9. Imperialis. Racemo comoso infernè nudo, floribus reclinatis. 2. Ex oriente orta; in hortis culta.

$$
23 \% \text {. L I L I U II. }
$$

Perigonium campanulutum, laciniis 6 profundis rectis ant extis revolutis, suprà sulco longitudinali fimbriato vel nudo ad basim excavatis.

\section{†. I. Lilia 2'era; floribus campanulatis; petalis sessilibus.}

19ro. Candidum. Foliis lanceolatis sparsis undulatis, floribus pedunculatis terminalibus intùs glabris. 2f. In hortis cnlta, in Jurasso furtè spontanei. 
1911. Bulbiferum. Foliis sparsis, floribus campanulatis erectis, intùs scabris. 24. In Alsatia et Galloprovincia locis montosis humidis, in Alpibus et Pyrenæis.

\section{J. If. Martagones; corollis revolutis.}

1912. Pomponium. Foliis sparsis lineari-subulatis, floribus intùs papilloso-dentatis. 2 . In Galloprovincia.

1913. Pyrennicum. Foliis sparsis lanceolatis, floribus pancis (flavis) subunibellatis. 2 . Lil. t. 1 5. - In Pyrenæis.

91 午. Martagon. Foliis verticillatis ovato-lanceolatis. 2 ?. Lil. t. I 6 . - In sylvis montanis.

\section{T R I B U S I I. A S P H O D E L I.}

Ovarium liberum; semina rotundata vel angulosa; sligma unicum.

$$
\text { 235. A S P H O D E L U S. }
$$

Staminum filamenta basi dilatata, fornicato-recurvata, ovarinin obtegentia.

19r5. Luteus. Caule folioso, folïis triquetris striatis. $\sigma^{7}$ Ex Sicilia orta in hurtis culta.

1916. Fistulosus. Canle nudo, superne subramoso, foliis strictis subulatis striatis subfistulosis. 24 . In Gallia australi.

1917. Ramosus. Caule nudo ramoso, foliis ensiformibus carinatis lievibns. 4 . In montibus Galloprovincir et vallis Segusianæ.

1918. Albus. Canle nurlo simplici, foliis linearibus carinatis levibus, pedunculis confertis longitudine bractearum. - In Galloprovincia et Pyrenzis.

$$
\text { 236. H E M E R O C A L L I S. }
$$

Perigonium magnum, persistens, infrà infundihuliforme, suprà campanulatum 6-fidum; stamina declinata.

1919. Fulva. Foliis linearibns carinatis, floris laciniis tribus interioribus obtusis undulatis, nervis exterioribus ramosis. 2 . In Galloprovincia, juxtì Tarbanı, Cenomanım.

1920. Flava. Foliis lincaribus carinatis, floris laciniis planis acutis, I.ervis indirisis. 2 . In sylvis humidis Pedemontii, in Helvetia pronè Lemanum lacum.

192x. Liliastrum. Foliis planis scapum simplicem subæquantibus, floribus subsecnndis. 2 . In pascuis $A$ lpium.

$$
\text { 237. H }
$$

Perigonium tubulosum 6-fidum, laciniis patulis; stamina circa mediam perigonii longitudinem inserta; capsula obtusè trigona.

1922. Amethystinus. Floribus campanulatis basi eylindricis, bracteis solitariis pedicello sublongioribus. 2 . In Pyrenæis.

1923. Orientalis. Floribus infundibuliformibus basi ventricosis, bracteis 
bracteis geminatis pedicello brevioribus. 2 . Ex Oriente orta, in hortis culta.

1934. Serotinns. Floribus campanulatis secuntis, laciniis exterioribus longioribus patulis, interioribus connatis, bracteis hastatus pedicello longioribus. 4 . In Pyrenxis prope Valletriam, vere.

$$
\text { 238. M U S C-A R I. }
$$

Perigonium ovatum medio iuflatum, sexdentatum; capsula trigona, angulis prominulis.

1925. Ambrosiaceum. Floribus confertis ovatis omnibus xqualibus subsessilibus, apice callosis hexagonis, foliis ferc̀ linearibus caule sublongioribus. 24. Lil. t. r.32. M. moschaturn. Gawl. bot. mitg. t. -3 午. M. Muscarimi. Ust. ann. 2. p.15. M. racemosus. Mill. Diel. n. 3. - Monspelii, Nemansi.

1936. Racenosum. Floribus confertis ovatis, summis sessilibns, foliis laxis dependentilus carinatis linearibus. 24. In locis cultis.

3927. Botryoiles. Floribus globosis inferioribus remotioribus, foliis strictis sublinearibus basi angustatis. 2F. In Gallia australi.

3928. Comosum. Floribus angulato-cylindricis, summis sterilibus longiùs pedicellatis. 24 . In arvis et locis cultis.

$$
250 \text {. P H A r A N G I U IM. }
$$

Perigonium sexpartitum, plìs minùsve patens; filamenta staninum sæepissimè glabra, filiformia, laciniarurn basi inserta; radices fasciculatie.

1929. Bicolor. Foliis planis, canle ramoso, floribus laxè paniculatis, filamentis pubescentibus. $\mathcal{L}$. Ad sepes, in arenosis Galliæ occidentalis.

1930. Riamosum. Foliis linearibus, canle ramoso, floribus laxè paniculatis, pistillo erecto. $\mathcal{H}$. In montanis sterilibus.

193r. Liliago. Foliis planis, caule simplicissimo, floribus racenosis, pistillo declinato. $\mathcal{H}$. In sylvis montosis herbosis, Parisiis, etc.

I 32 . Serotinum. Foliis crassiusculis subulato-linearibus, scapo unifloro, capsula oblonga. 2 . In Alpibus Delphinatûs, Pedemontii.

$$
\text { 2/10. S C I L L A. }
$$

Perigonium sexpartitum, sæpiùs patens et caducum; staminum filamenta glabra filiformia; semina rotundata; radix bulbosa.

\section{§. I. Floris laciniis in tubum basi conniventibus.}

1933. Nutans. Foliis strictis linearibus scapo subbrevioribus, racemo immaturo cernuo, floribus tubuloso-campanulatis apice revolutis. 2. In pratis et neworibus.

1934. Patula. Foliis lanceolatis scajum æqumtihus patulis, racemo recto, floribus campanulatis apice revolutis.- Ex Gallia australi? colitur nuuc in hortis. 


\section{II. Florilus pateniibus.}

1935. Autumnalis. Foliis filiformibus linearibus scapo brevioribus, floribus corymbusis. 2 . In siccis arenosis aut glareosis, Parisiis et in Gallia anstrali.

1936. Bifnlia Foliis lanceolatn-linearibus subbinis scapo vix longioribus, floribus racemosis cbracteatis. $\mathcal{F}$. In umbrosis et pascuis.

1937. Amoena. Scapo angulato, floribus laxis subcernnis, bracteis obtusis brevissimis. 24. Lil. t. $130 .-$ In sterilibus et arenosis propè Marencin, in agro Syrtico.

1939. Umbellata. Foliis linearibus crassiusculis subcarinatis ercctis, scapo cylindrico brevioribus, floribus racemoso-umbellatis. Zf. In Pyrenaris et sabuletis circà Aquas Tarbellicas et Brivatem.

3939. Tilin-Hyacinthus. Foliis lancenlatis hnmi adpressis scapo brevior ', $m$, floribus pancis racemosis ebracteatis, bulbo squamato. 24 . In Grillia australi, in Pyrenæis et sabuletis circà Aquas Tarbellicas et Aurcliam.

I9fo. I'alica. Foliis lancenlatis scapi longitudine, bracteis pedicellum subæquantibus, racemo conico. 2 4 . In lapidosis umbrusis circà Nicæam.

I 9 1. Maritima. Foliis lanccolatis, racemo conico elongato, bracteis refractis subtùs calcaratis. $\mathcal{H}$. In a renosis et rupibus maritimis $\mathbf{A r}$ nuoraciæ et Normandix.

$$
24 \mathrm{I} \text {. O R N I T H O G A L U M. }
$$

Perigonium sexpartitum, persistens, basi connivens, supernè patens; staminum tria filamenta segrnentis perigonii exterioribus insita, sæpiùs hasi dilatata, interdùm bicuspidata.

\section{§. 1. Floribus luteis; staminum filamentis basi non dilatatis.}

- 19 2. Luteum. Scapo angulato basi monophyllo, pedunculis umbellatis glabris, perigonii laciniis lanceulatis. $\mathcal{F}$. In cultis pratis et hortis.

د9 $\{$ 3. Minimum. Scapo angnlato nudo, foliis radicalihus planis, pedunculis umbellatis subramosis pubescentibus, perigonii laciniis lanceolatis acutis. $2 \%$. In locis cultis et arvis.

x9任. Fisculosum. Scapo folioso subunifner, foliis radicalibus filiformibus fistulosis, peilunculis nilosiusculis, perignnii laciniis lanceolatis obtusinsculis. 2 . In Alpium et Pyrenæorum udis.

5. II. Floribus ochroleuris, alhis nut virescentibus; staminum filamentis basi dilatatis.

1915. Pvrennicum. Racemo longissiono, perigonii laciniis linearibus ohensis, bracteis membranaccis basi diatatis acutissimis. 24. In pratis et sylvniis circà Parisios, Genevanı ; $f$, in Pyrenxis, Monspelii, etc. - Flures ochroleuci.

196. Narhanense. Raceino ohlongo, pedunculis floribusque patentibus, foliis latis. 24 . In provinciis australibus. - Flores albi. 
1917. Arabicum. Raccuno subeorymboso multifloro, filanentis :nbulatis, perigonio lati: campinulato, bracteis pedicellos subaquantibus, ovario nigricante nitido. ff. In Corsica.

1948. Umbellatum. Raceno subeorymboso paucifloro, filamentis subulatis, pedunculis bracte is longioribus. 2 . In arvis et pratis.

1949. Nutans. Floribus racemosis secundis pendulis, filanentis staminum alternis majoribus bicornibus. 2C. In pratis circì Genevan, Gratianopolim, Aureliam, Ablavillam.

$$
\text { 24. A L L I U M. }
$$

Flores umbellati, terminales, ì spatha bivaivi orti; perigonium (ipartitum, seppius patens; stigna simplex; capsulse 3 -quetre, loculis prolundè bipartitis, axi filiformi pust valvularum dehiscentian superstite.

\section{I. Foliis planis; staminibus alternis tricuspidatis.}

I95n. Porrum. Unbella capsulifera globosa, foliis crassinsculis subcarinatis, bulbo tunicato. $\odot, \zeta$. Ex Helvetiæ vineis orta, in hortis culta.

351. Ampeloprasum. Umbella capsulifera globosa, foliis crassiusculis linearibus, bullo sobolifero. F. In provinciis australibus?

1952. Sativum. Umbella bulbifera globosa, foliis linearibus integerrimis, bulbo sobolifero. $2 \%$. In hortis culta, forsan in Galloprovincix maritimis spontanea.

395. Scorodoprasum. Umbella bulbifera globosa, foliis linearibus undulato-subcrenatis, caule antè maturitatem contorto. $\mathcal{F}$. In provinciis australibus spontanea, in hortis culta.

9. II. Foliis planis; staminilus onınibus simplicibus.

1954. Carinatum. Umbella bulbifera pauciflora, foliis linearibus carinatis, spatha longa inæqualiter bicorni. $\mathcal{F}$. In agris et vineis Galliæ australis.

1955. Ambiguum. Umbella capsulifera globosa, foliis lincaribus, staminibus exsertis, floribus bracteatis, spatha bicorni umbella breviori. 2f. $\alpha$, In arenosis circa Aquas-Tarbellicas; $k$, in saxusis Pyrenæorum.

956. Sublirsutum. Umbella capsulifera plana, foliis linearibus subhirsutis. 2\%. In maritimis Corsica, provinciarum autraliorum et circà Nannetes.

6957 . Roseum. Unbella capsulifera (rariùs bulbifera) planiuscula, foliis linearibus, staminibus brevissimis, perigonii laciniis obtusissimis. 2 . In agris et vincis prov. Mediterr.

1958. Angulosum. Umbella capsulifera hemispharica, foliis linearibus subtus convexis, scapo nulo ancipiti. 2 . In humidiusculis Alpium Genevensium, Delphin., Galloprov.

1950. Triquetrum. Umbella capsulifera plana pauciflora, foliis radicalibus carinatis subtriquetris, scapo triquetro. 7 . Narbonis, Vinadii.

196o. Grandiflorum. Umbella capsulifera plana, pcrigonii segmentis 
mucronatis erectis, foliis lineari-subulatis scapo tereti brevioribus. 2. In saxosis Alpium Delphin. et Galloprov.

196i. Pedemnntanum. Umbella capsulifera convexa pauciflora, foliis linearibus obtusis, scapo subtetragono. 2 . In montibus Arvernia et Pedumontii.

962. Nigrum. Umbella capsulifera convexa multiflora, perigonii segmentis patentibus, foliis lanceolatis, scapo tereti, bulbo sobolifero. 2 . In arvis Monspelii, Gralloprovinciæ.

963. Victorialis. Umbella capsulifera globosa, staminibus exsertis, foliis urali-oblongis, caule tereti, radice oblonga. 2 . In montibus Arverniæ, Occitaniæ, Delphinatûs, Sabaudiæ, Foresii et Jurassi.

I96\%. Moly. Umbella capsulifera plana, foliis lanceolatis suluamplexicaulibus, scapo tereti. 24. Circà Parisios, Abbatis-Villam, Nannctes, Monspelium, in Pyrenæis. - Flores lutei.

1965. Chancemoly. Unubella capsulifera subradicali pauciflora, foliis linearibus subpilosis seapo Jongioribus. 2L. In Corsica.

1966. Ursinum. Umbella capsulifera plana, foliis ovato-lanceolatis petiolatis, scapo subtriquetro. 2 . In sepibus et pratis umbrosis.

๑. III. Foliis teretibus; staninibus omnibus simplicilus.

1967. Cepa. Umbella capsulifera globosa, scapo fistuloso infernd ventricoso foliis teretibus longiore. $\sigma$. In hortis cnlta.

1968. Oleraceum. Umbella bulhifera laxa, foliis semi-teretibus snlcatis, scapo tereti. 4 . In vineis el lucis cultis.

1969. Moschatum. Umbella capsulifera plana pauciflora, perigonii segmentis acutis, foliis subulato-setaceis, caule teseti. 24 . Locis siccis et editioribus provinciaruı Mediterıaucarum.

I97n. Flavum. Umbella capsulifera laxa, floribus pendulis nbtusis, staminibus cxsertis, toliis semi teretibus. $\mathcal{T}$. In arvis sepibus et dunusis passinn.

I971. Pailens. Umbella capsulifera laxa, floribus pendulis truncatis, staminibus subinclusis, stylo brevissino, foliis scmi-teretibus. 2f. In collibus et locis cultis passim.

r9-2. Panicu'atum. Umbella capsulifera laxa, pedicellis capillaribus efinsis, spatha longissind, staminibus subexsertis, foliis semiteretibus. $3^{\circ}$. In montanis et incultis.

1973. Schoenoprnsım. Umbella capsulifera conferta, foliis teretibns subulate-filiformibus, scapos nuilos cespitosos æquantibus. $\underset{i}{\mathcal{C}}$. Ia hortis culta.

r $97^{3^{*}}$. In'insum. Umbella capsulifera conferta. foliis teretibus subulato-filiformibus, aliis radicalibus, aliis ad basin caulis insertis. \%. In Alpibus.

5. IV. Foliis teretibus; staminibus alternis tricuspidatis.

э974. Asculnnicum. Umbella capsulifera globosa, foliis subulatis, scapo tercti. 2广. Ex Urieutc orta, in hortis culta. 
1975. Sphorencephalum. Umbella capsulitiva glniosa, staminilus

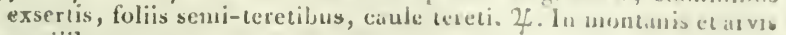
sterilibus.

3976. Vineale. Umbella bulbifera globosa, foliis teretibus fistulesis, caule tereti. 2F. In rineis et sepibus.

\title{
I $\mathrm{R}$ I B U S I I I. N A $\mathrm{R}$ C I S S X.
}

\section{Ovarium perigonio adharens.}

\author{
2/3. A M A $\Omega$ Y L L I I S.
}

Perigonium infundibuliforme, sexpartitum, faucesquamulis 6 instructum; stigma trifidun; stamina 6 sæpiùs declinata ant inaqualia. 1977.Luter. Spatha indivisa obtusa, flore sessili, perigonio campranalato erecto basi breve subuloso, staminibns erectis, alternis brevioribus. 2 . Lil. t. 148. - In pratis cirsà 'Taurinum et Sinsano, ct in insula Nigri-Monisterii.

$$
\text { 244. P A N C } \mathrm{R} \text { A } \mathrm{T} \text { I } U \text { M. }
$$

Perigonium infundibuliforme, limbo patente 6 -partito; stamina 6 apice tuli inserta, filamenta coalita ope coronæ seu membraux subeylinaricæ; stigma simplex.

1978. Maritinutin. Spatha multiflora, foliis lineari-lanceolatis, cnrone sinubus bidentatis. 2 . In arvis cultis, et rupibus maritimis. Meditertanei.

$398^{*}$. Illyricum. Spatha multiflora, foliis lanccolatis, coronæ sinubus dentacis, chentibus aentis bifidis patentibus. 24. Lil.t. 153.In arenosis maritinis circì Rupellam (Moris.).

$$
\text { 245. N. A R. C I s. S u s. }
$$

Perigonium infundibuliforme, limbo patente sexpartito; corona (nectariun, L.) ad faucem petaloidea cylindrica vel campanulata integra aut divisa; stamina 6 tubo inserta, intra coronam latitantia. 1979. Poeticus. Spatha uniflora, corona rotata brevissima scariosa, foliis ensiformibus. 24. In pratis imprimis Galliæa austrulis.

Ig8o. Pseudo-narcissus. Spatha uniflora, corona campanulata erecıa undulata segmenta ovata æequante. 2 . In nemorosis.

398r. Bulboco.7um. Spatha uniflora, corona subinata segmentis majore, genitalibus declinatis. $2 \mathcal{L}$. Abunde circà Tasban; Soricii ?

s981*. Odhrus. Spatha subbiflora, corona campanulata sexfirla segmentis dimidio bı eviore, foliis semi-cylindricis. 2 . Lin. Spec. 416. Curt. bot. mag. t. 78. - In Corsica.

1982. Tazetta. Spatha nultiflora, corona campanulata plicata tuncata, perigonii laciniis altemè latinribus triplò breviore, foliis planis. 2 . In locis humidis et maritinis Gallia australis.

1983. Jonquilla. Spatha multiflora, cornna campanulata brevi, foliis su'sulatis. $\mathcal{H}$. In Oecitania, Galloprovincia, prope Abbavillam. 


\section{L $\mathrm{E}$ U C C O I U $\mathrm{M}$.}

Perigoninm tubn brevi, limbo campanulato sexpartito æquali, laciniis apice crassiusculis; stigna simpiex.

$$
\text { 5. I. Siylo apice clevato. }
$$

I9S'. Vernum. Spatha uniflora. $\%$. In pratis humidis et umbrosis montium.

I985. Astivum. Spatha multiflora. 24. Lil. t. 135.- In pratis umbrosis Gallix australis.

$$
\text { 5. II. Siylo filiformi. }
$$

1986. Autumnale. Spatha monophylla biflora, petalis ovatis apice tridentatis. $\%$. Lil. t. 150 f. 2. - In saxosis Nicææ, Monspelii.

1986*. Trichophyllum. Spatha diphylla nni-ant-multiflora, petalis lanceolatis acutis. 2 . Lil. t. ז 50. f. I. - In insula Corsica.

$$
\text { 2/47. G } A \text { L } A \text { N } \quad \text { T } \quad H \quad U \text { S. }
$$

Perigonium sexpartitum; laciniis 3 interioribus externis duplò hrevioribus emarginatis; stigma simplex. ${ }_{19} \mathrm{~S}$. Nivalis. 2 . In pratis umbrosis montanis.

$$
\text { 248. P O L L Y A N } \mathbf{N} \text { T H E }
$$

Perigonium infundibuliforme, limbo sexfido patulo; stamina 6 perigonii fauci inserta; ovarium liberum perigonio obtectnm; stigma 3-fidum.

1988. Tuberosa. Foliis linearibus scapo brevioribus. 24. Lil. t. 147.

- Ex America meridionali orta, in hortis culta.

$$
\text { 249. A G A V E. }
$$

Pcrigonium tubulosum, infundibuliforme, ovario adhærens, sexpartitum; stamina 6 exserta ; antheı $æ$ versatiles; capsula ovata, utrinquè attenuata, obtusè trigona, 3 -locularis, polysperma.

1989. Anericana. Acaulis, foliis dentato-spinosis, scapo ramoso, tubo perignnii medio angustato, stylo staminibus longiore. 2 . Fx - America meridionali orta, nunc spontanea in provinciis Mediterraneis.

\section{O R D O X X I. I R I D E AE.}

Perigonium ovario adhærens, petaloideum, sexfidum aut sexpartitum, sæpè irregularc; stamina 3 segrientorum perigonii externoı um basiinserta; anthere lineares exlmrsum deluscences; ovariun 1; stylas 1 aut nullıs; stigma 1 ant 3 ; capsula 3-locularis, 3-valvis, valvulis medio septiferis; semina angulo foculorum interno adfixa; corculum intrà perispermun corıeum. - Herbæ radicihus tuberosis, foliis ensifornibus aut linearibus, spathis bivalvibus unifloris.

$$
\text { 250. I } \mathrm{R} \text { I } \mathrm{s} \text {. }
$$

Perigonium sexpartitum, laciniis tribus externis majoribus patulis, tribus interioribus minoribus erectis; stamina distincta; 
stylus brevis lacinias tres maximas petalnideas, srpjïs emarginatas

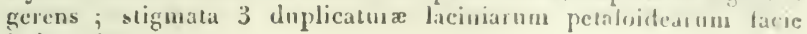
infera sitx.

\section{\. I. Laciniis floris exterioribus intius basibarbatis.}

199\%. Germanica. Barbata, foliis cusifnrmibus glabris falcatis caule multifloro brevionibus, tubo ovario longiore. 24 . Ad nauros ct tecta.

1991. Pumila. Barbata, scapo unifloro foliis ensiformibus glabris breviore, tubo exserto. 4 . Ad muros, circà Foutcmbleandi

1992. Lutescens. Barbata, scapo subunifloro toliis cusilornilus glabris longiure, tubo spallis incluso. 2 . In lapidosis sub alpinis.

\section{j. II. Lnciniis fonris externis imberbibus.}

3993.Pseudacorus. Inberbis, foliis ensiformibus, canle mulzifloro, perigonii laciniis alternis stigmate minoribus. 24 . In stagnorum oris et fossis aquaticis.

199\%. Fotidissima. lmberbis, foliis ensiformibus, caule uniangu-

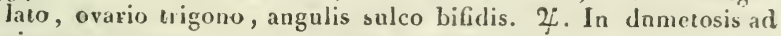
vias.

1995. Nyphioiles. Imberbis, foliis ensiformibus canaliculato-subulatis, caule bifloro, ovario trigono acutè angulato. 2 . In Pyrenæis circà Valletriam.

1996. Graminea. Imberbis, foliis linearibus, caule compresso subbifloro, ovariis hexagonis. 4 . In collibus circà Taurinun, inter Rupellam et Rupifortium.

1997. Pratensis. Imberbis, caule subtriftoro tereti fistuloso. foliis linearibus longiore, ovariis trignonis, spathis scariosis. $\mathcal{7}$. In pratis lıumidis Delphinatûs, Alsatiæ.

199 S. Spuria. Imberbis, eaule subtiflorotereti, foliis linearibus, ovariis liexagonis, spathis viridibus. 2 . In pratis Gallix australis, circà Narbonem.

$$
\text { 25I. G L A D I O L U s. }
$$

Perigonium infundibuliforme, limbo 6-fido inxquali bilabiato ; stignsa trilobatum patens; semina arillata.

1999. Communis. Flore subringente, spathis tubo Jongioribus, floribus secundis, foliis ensiformibus nervosis. $\mathcal{H}$. Glarliolus segetum. Gawl. in Curt. bot. mag. t. 719. - In arvis Galliæ australis.

$$
\text { 252. I } \times \text { I A. }
$$

Perigoninm tubo pius minisve clongato, limbo patente 5 -partito xquali; stigma 3-partitum, laciniis filiformibus patulis sæje bifidis. 200n. Bulbncodium. Scapo unifloro, foliis linearibus canaliculatis angulatis. 2 . Iu uaritimis circì Brivatem, Narbonem et in Corsica.

$$
\text { 253. C R o c U s. }
$$

Perigonii tubus gracilis limbo duplu longior, limlus 6-partitus qualis erectus; stigmata 3 crassa convoluta sæpiùs cristata. 
20or. Sativus. Stigmate tripartito Inngitudine perigonii reflexo, foliis linearibus margine revolutis. 2. . Sponte in Mauriena, in agı is culta.

2002. Multifalus. Stinmate trifido multifido erecto perigonio subaquali, flore aphyllo. $2 ;$. In Pyrenæis et Pedemontio.

2003. Yernus. Stigmate trifido erecto perigonio breviore, foliis linearibus planis 25. In pratis Alpium et Pyrenæorum. - E flora exclude var. $\gamma$ flore aurco qux nunc Crocus mosiacus. Gawl. ex Oriente ortus, in hortis cultus.

2004. Nanus. Stigmate trifido erecto perigonio breviore, foliis tenuissimis filiformibus. $2 \%$. In Corsica.

\section{MONOCOTYLEDONES PHANEROGAMT.}

\section{Staminibus epigynis.}

\section{O R D O X XII. O R C H I D AE.}

Perigonium petaloideum, ovario arlhærens, sexpartitum, laciniis irregularibus, 3 exterioribus, 3 interioribus, 5 superioribus florem quasi verè constituentibus, inferiore (labello) forma semper directione sæpius dirersa; antheræ I-2, uni-ad-quadri-loculares, sessiles super stylum utunc ad apicem nunc ad latus sitæ; pollen in massam agglutinatum; stylus columnaris simplex; stigma orliculare viscosum positione varium; capsula unilocuraris trivalvis tricarinata inter nervos lateraliter dehicens; semina numerosa scobiformia receptaculis tribus mediis valvis alnatis imposita; corculum ad basim perispermi carnosi, - Herbx, radicibus nunc fasciculatis nunc tuberosis, tuberibus ovatis aut palmatis, foliis integris amplexicaulibus, floribus bracteatis spicatis.

\section{5\%. O R C H I s.}

Perigonium personatum , 6-partitum, suprł fornicatum, labello basi calcarato; stignna convexum anticun; anthera bilocularis terminalis.

\section{S. I. Radice tuberculis duobus integris instructa.}

2005. Bifnlia. Labello lineari integerrimo obtuso, calcare ovario duplì longiore, foliis canlinis vaginantibus brevissimis, radicalibus binis oblongis basi attenuatis. $2 f$. In nemorosis liumidis et pratis umbrosis.

2006. Globosa. Labello 3-partito, lacinia media emarginata, perigonii segmentis apice mucronatis, calcare ovario dupld breviore, spica densa ovata, foliis lanceolatis. 2 . In pascuis montim, in Alpibus Sahaudiæ, Pedemontii, Delphinatûs.

2007. Pyramidalis. Labello 3-partito laciniis integris, perigonii segmentis subovatis æqualibus, calcare ovarimu subacquante, spica rensa oblonga. 2 . In pascuis siccis Jurassi, circà Fontembleaudi.

2008. Coriophora. Labello 3-partito laciniis 2 lateralibus crenatis, 
perigonii segmentis comniventibus, (alcare conicn adscendente ovario triplò breviore. 2 . In pratis humidis circà Pulisios, Generam, Gratianopolim.

$2005^{*}$. Provincialis. Labello 3 -fido pubescente laciniis 2 - lateralibus deflexis, intermedia minore emarginata, calcare atscendente ovarium æquante. $\mathcal{4}$. Balb. ined. - In Galloprovincia ad sylvam de LEsterelle.

2009. Morio. Labello 4-fido laciniis 2 lateralibus crenulatis reflexis, perigonii segmentis obtusis adscendentibus, caleare conico adscendente ovario breviore. $\mathcal{F}$. In graminosis et collibus aridis.

20 го. Mascula. Labello f-fido crenulato, laciniis a internediis longioribus, perigonii segmentis acntis, 2 superioribus erectis patentibus, calcare obtuso subrecto ovarii longiturline. $2 \mathcal{C}$. In pratis.

20r1. Laxiflora. Labello 3-partito, lacinia media subemarginata, 2 latcralibus crenulatis longioribus, perigonii segnentis apice patentibus, calcare apice subemarginato, spica laxissima. 24 . In pratis humidis circà Parisios, Gratianopolim, Carionnm.

20r2. Ustulata. Labello 4-partito, laciniis lateralibus punctatoscabris, intermediis minoribns, perigonii segmentis erectis acntis apice subconniventibus, calcàre uncinato ovario triplò breviore, bracteis ovarium subrquantibus. $\mathcal{F}$. In pratis.

2or3. Militaris. Labcllo 4-fido punctato-scabro, laciniis oppositis, 2 superioribus rotundatis integris vel crenulatis $\mathrm{cum}$ mucronc interjecto, 2 inferioribus integris linearibus, perigonii segmentis conniventibus acntis, calcare ovario dnplo breviore, bracteis membranaceis aristatis ovario duplò brevioribus. $\mathcal{F}$. In nemoribus et pratis umbrosis.

2014. Variegata. Labello 3 -partito lævi, laciniis ohtusis oblongis, intermedia bifida serrata cum mucrone interjecto, perigonii segmentis acutis conniventibus, calcare recto subulato ovario duplo breviore, bracteis ovarium subæqnantibus. $\mathcal{F}$. In pratis.

20r5. Galeata. Labello 4-partito, laciniis extremis valdè divergentibus mucrone interjecto, perigonii segmentis connirentibus acutis, calcare ct bractea ovario duplò brevioribus, spica conica densa. భ. In pratis submontosis Lutetix, Monspelii.

20r6. Simia. Labello 4 -partito laciniis omnibus gracilibns linearibus, mucrone lineari interdùm apice projecto, perigonii segmentis conniventibus acutis, calcare ovario duplò breviore, bracteis brevioribns obtusis. 2 . In pratis et sylvis siccis.

20r7. Papilionacea. Labello obovato indiviso dentato emarginato, perigonii segmentis nervosis conniventibus, calcare subulato ovario breviore, bracteis memhranaceis coloratis ovario longioribus. 2 . In sylvis et pratis sterilibus.

2018. Pallens. Labello leviter 3-lobo, dente intermedio retuso, perigonii segmentis lateralibus patentibus, calcare conico ovarium subæquante, spica coaretata. $\mathcal{F}$. In sylvaticis.

2o r. Hircina. Labcllo 3-partito, laciniis lateralibus lineari-subulatis, 
media elongata ovario uiplò longiore lineari bifitla, perignnii seguentis conniventibus, calcate bievissimo conico scrotiformi. $\mathcal{~}$. In pratis montanis, ad marginem sylvarum.

5. II. Radice tuberculis palmatis v'el fibris cylindricis constante.

2020. Sambucina. Labello leviter 3-lobo crenato, perigonii segmentis obusiusculis patulis, calcare conico ovario breriore, bracteis florum longitudinc. $2 \mathcal{C}$. In montosis A:veruiæ, Delphinatûs, Pedemontii, propè Abbatis-Villam.

2021. Latifnlia. Labello leviter 3 -lobo lateribus reflexo dentato, perigonii seguentis superioribus connirentibus, ealcare conico ovario breviore, bracteis flore longioribus. $\mathcal{H}$. In pratis humidis frequens.

2022. Maculata. Labello subplano 3-lobo, Inbis lateralibus dentatis, medio integro acuminato, perignnii segmentis superioribus conniventibus lateralibus patentibus, calcare cylindraceo ovario breviore, bracteis longitudine ovarii. 2 . In pratis montosis et sylvis.

2023. Odnratissima. Yabello obtusè 3 Jobo, perigonii segmentis lateralibus patentilus, calcarc rccurvo germine duplo breviore $2 \%$. In pratis Galize australis.

2024. Conopsea. Labello obunsè 3-lobo, perignnii segmentis patentissimis, cornu subulato ovario dupld longiore. 2 . In pratis montosis.

2025. Tiridis. Labello lineari apice 3 - dentato, perigonii segmentis conniventibus, calcare ohtuso scrotiformi, bracteis ovario longioribus. 4 . In pratis humidis.

2026. Nigra. Labello ovato-acuminato indiviso, perigonii segmentis patentibus, calcare obluso scrotiformi, spica densa ovata, foliis linearibus. 24 . In pratis nontosis.

2027. Albida. Labello 3-partitn, laciniis lincaribns acutis, internedia obtusa, pesigonii segmentis connireutibus, caleare ovario triplo breviore obtuso. 22. In pratis humiclis Alpium.

$$
\text { 255. O } \mathbf{P} \text { I H } \mathrm{R} \text { Y } \mathrm{S} \text {. }
$$

Pcrigoninm 6-partitum, segmentis patentibus, labello ecalcarato ; stigma convexum anticum; anthera bilocularis terminalis.

2028. Mnnorchis. Caule nndo, labello tripartito, laciniis linearibus lateralibus divaricatis, bracteis ovarii longitudine. 2 . In pratis montaus.

202n. Alpina. Canle nudo, labelln lanceolato indiviso obtuso utrinque nnidentato, bacteis ovario longiorilus, foliis lineari-setaceis. 2f. In Alpibus Vallesix, Pedemontii, Delplinatûs.

2030. Antmpophorn. Caule folioso, labello ovarin longiore lineari 3 -fido, lacinia media elongata 2 -fida, perigonii scgmentis conni- ventihos. $2 ;$. In pratis.

203 I. Blyodes. Caule folioso, labello pubescente 3-partito, laciniis 
lateralibus lineari-lanceolatis, media oblonga libola longiore, perigonii segmentis patentibus, 3exterioribus lancentatis obtusis, a interiotibus linearhas brevissimis. 2 . In pascuis montosis. - U. unscitera. Engl. bot. t. (6).

$203 \mathrm{t}^{*}$. Aranifera. Caule folinso, labello villoso cam line is 2 glabris 3-lobo, lobo medio obovato emarginato, perigonii sementis patentibus, 3 exterimihns oblongis obtusis, 2 interinribus lancenlatis acutis brevioribus. 4 . In pascuis cretaceis glareosis. - O. ararlinites, B. Fl. fr. 11. 2032. O. aranifera. Engl. bot. t. 65.

3032. Arachnites. Caule folioso, labello villoso 3-lolı, lobo medio obovato apice brevissinè 3 -lobo, perigonii segmentis patentilus, 3 exterioribus oblongis obtusis, 2 interioribus lineari-lanceolatis brevissimis. 24 . In pratis el prascuis montanis. $-U$. arachnites. Wild. spec. 4. p. 67. non Fl. fi. - Hall. Helv. t. 24. f. I.

$2032^{*}$. Apifera. Canle folioso, labello villoso 3 -lobo, lobis lateralibus ohlongis, medio obovato eiongato $3-1$ bo, lacinia terminali subulata recurvata, perigonii segmentis patentibus, 3 exterioribus ellipticis obtusis, 2 interioribus lanceolatis brevissimis. 2 . Engl. bot. t. 383. O. arachnites a. Fl. fr. n. 2032. - In pratis et pascuis cretaceis.

\section{S E R A P I A S.}

Perigonium 6-partitum ; segmentis 5 superiorilus cucullato-coalitis, Jabello concavo acuto pendulo cealcarato ; stigma concavum anticum; anthera 2-locularis terminalis.

2033. Lingua. Labello 3 -partito, laciniis lateralibus obtusis erectis conniventibus, merlia oblonga lanceolata glabriuscula dependente acutinscula. 24. In montosis circà Taurinum, in Pyrenais et pratis maritimis Galloprovinciæ.

2034. Cordigera. Labello 3-partito, laciniis lateralibus obtusis erectis conniventibus, media ovata acuminata disco pilosa dependente. 2f. In Galloprovincia, Pyrenæis, Corsica.

$$
\text { 257. N E O T } T \text { I A. }
$$

Perigonium 6 - partitum, laciniis 5 superiorihus basi conniventibus apice liberis, labello basi ventricoso cucullis duobus in ovarium productis instructo; stylus acutè appendiculatus; stigma terminalis anticè obliquum; anthera 2-locularis postica.

2035. Spiralis. Foliis radicalibus oblongis subpetiolatis, spica tortili, floribus secundis, labello ovato. $\mathcal{F}$. In graminosis et collibus siccis.

2036. Astivalis. Foliis sublincaribus, canle florifero folioso, spica tortili, floribus secundis, labello ovato. 2 . In pratis humidis circà Parisios, Abbavillam et in Pedemontio.

2037. Repens. Foliis radicalibns ovatis petiolatis reticulatis, scapo vaginato floribusque pubescentibus, floribus secundis, labello segmentisque lanceolatis. $\mathcal{H}$. In sylvaticis montanis. 


\author{
258. E P I P A C $\mathbf{T}$ I $\mathrm{S}$.
}

Perigonium crecto-patens 6 partilum, labello integro vel lobato ecalcarato; stigna obliquum terminale antheræ auticum; anthera opercularis 2-locularis ovata margine postico styli adnata, post pollinis granulosi emissionem persistens.

\title{
9. I. Labello apice integro.
}

2038. Palustris. Foliis lanceolatis amplexicaulibus, bracteis flore brevioribus, floribus pendulis, labein crenato obtuso perigunii segmentis aquali, ovariis pubescentibus. 2f. In pratis paludosis frequens.

2039. Latifolia. Foliis oratis amplexicaulibns, bracteis inferioribus flore longioribus, floribus pendulis, labello acuminato perigonii segmentis breviore, ovariis pubescentibus. $\mathcal{F}$. In umbrosis et sylvis.

2040. Ensifolia. Foliis lanceolatis acuminatis subdistichis, bracteis minutissimis subulatis, floribus erectis, labello obtuso segmentis perigonii dupld breviore, ovariis glabris. 2 . In sylvis et pascuis montosis.

2041. Lancifolia. Foliis oblongo-Jancenlatis sessilibus, bractris flore longioribus, floribus crectis, labello obtuso segnentis perigonii breviore, ovariis glabris. $\mathcal{Y}$. In sylris circà $\Lambda$ bbavillam, Genevam, etc.

20f2. Rubra. Foliis lanceolatis, bracteis ovario longioribus, floribus erectis, lahello acuto lineis elevatis undulatis, ovariis glabris. $\mathcal{\digamma}$. In umbrosis montanis.

\section{II. Labello lobato.}

20.13. Nidus avis. Caule aphyllo vaginato, labello obcordato segmentis obtusis duplò longiore. 24. Cirsà Parisios, Geuevam.

204f. Ovala. Caule bifolio, foliis ovalis oppositis, labello 2-firlo lineari segmentis obtasis triplò longiose. 2 . In sylvis et pratis umbrosis.

2045. Cordata. Caule bifolio, foliis cordatis oppositis; labello 3-fido, laciniis lateralibus brevissimis, intermedia longissima 2-partita lincari.2f. In Jurasso, Arvernia, inter muscos et pinetos.

$$
\text { 25g. M A L A } \mathrm{x} \text { I s. }
$$

Perigonium 6-partitum inversum; labellum superum, concavum, stylum basi amplectens; stylus gibbosus anticè excavatus; stigma concavum labelium spectans; anthera opercularis caduca terminalis hemisphærica 2-locularis.

30 6. Loselii. Foliis binis ovato-lanceolatis, scapo 3-gono, labello apice ovato recnrvato. $\mathcal{H}$. In paludibus circà Parisios, Bethuniam, Dunikerkam et Insulas (Lille).

$$
\text { 260. с } \mathbf{Y} \text { M в I D I U } \mathbf{M} \text {. }
$$

Perigonium 6-partitum, labellum inferum basi concavam ecal- 
earatnm stylo minind adnatum; stigma anticum; authera opercularis decilua temuinalis hemisplaxrica, a-vel-f-locularis; pollen granulosmu pedicello antico aslixum.

20 f7. Corallorhiza. Canle vagrinato aphyllo, floribus pedicellatis, perigonii sefmentis hanceolatis, binis inferioribus linearibus deflexis, libelio oblongo acnto. 2 . Iu sylvis Uecitaniæ, Jurassi, Galloprovincix.

$$
\text { 26i. L I } M \text { O }
$$

Perigonium 6-jartitum subpatens; labellum nunc inferum nnnc superum calcaratum, stigma anticmm; anthera cadnca terninalis hemispharica 2-vel-4-locularis; pollen granulosum pedicello antico adtixum.

2048. Abortivum. Aphyllum, caule vaginato, perigonii segmentis erectis, labello ovato undulato, calcare subulato ovarii longitudine. 24 . In umbrosis montanis.

2049. Epipogium. Aphyllum, caule vaginato paucifloro, floribus pendulis resupinatis, labello 3 -lobo concavo, calcarc adscendente ovato. 24. In faginetis, circà lacun Lemanum, in Jurasso, Delphinatu, Monspelii.

$$
\text { 262. C } \mathbf{Y} \text { P }
$$

Perigonium 6-partitum, labellum inferum maximum obtusnm inflatum calceolatim; stylus appeadiculatus stigma obtegens; antheræ 2 distinctæ laterales basi appendice lanceolato instructæ.

2050. Calceo/us. Canle folioso, lobo styli elliptico obtuso, labello perigonii segmentis breviore compresso. 2f. Iu pratis umbrosis aut montanis passim.

\section{O K D O X X I I. H Y D R O C H A R D E AE.}

Flores hermaphroditi aut diclini; perigonium petaloidem, sexpartitum, in femincis ovario allıæens; stamina $2-20$, in hermaphroditis ovario, in masculis ovarii loco insetta; ovarium simplex;

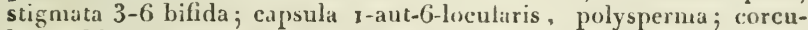
lum arl basin perispermi. - Herbæ aquaticæ, habitu varix; radices fibrosæ. - Ordo artificialis.

\section{† Capsula sexloculari.}

\section{II $\mathbf{Y}$ D $\mathrm{R}$ ○}

Dioica. Masc. Spatha 2-partita, 3-flora; perigonium 6-partitum petaloideum, laciniis 3 interioribns majoribus; stamina ?, trino ordine, germini abortive imposita. Fem. Spatha nulla; perigonium ovario adnatum, cæteriu $n$ in maribus; styli 6 , in dou stignata acuta fissi; capsula coriacea, rotundata, 6 locularis, polysperma. 2051. Morsus-rance. $\mathcal{F}$. In aquis staguantibus circà Parisios, Aureliam, Abbavillam, Lugdunum. 


$$
\text { 264. S T R A T I O } \mathrm{T} \text { E } \mathrm{s} \text {. }
$$

Spatha compressa, persistens, profundè bipartito-carenata, Iflora ; perigonium tubulosum, limbo 6-partito, laciniis 3 exterioribus mininis virescentibns, 3 interioribus uagnis coloratis; stamina circiter 20, apice tubi vel in ararii margine inserta; styli 6 bifidi; capsula carnosa, apicibus attenuata, 6-gona, 6-locularis; semina subangulosa, vaivarum sepimentis alligata.

2052. Hloides. Foliis ensiformi-triangularibus ;ciliato-aculeatis. $\mathcal{F}$. In fossis Belgii.

\section{$+\dagger$ Capsula uniloculari.}

$$
\text { 265. v A L L I S N E R I A. }
$$

Dioica. Masc. Spadix terminalis conicus parvus, spatha 2-3-\{partita, floribus minimis sessilibus tectus; singulis perigonium 3-parritum; stamina 2 (germini abortivo imposita?). Fem. Scapus spiralis longissimus; spatha tubulosa, 2 -fida, 1-flora; pcrigonium elongatun 6-partitum, laciniis alternis linearibus; stylns o; stigmata 3 ovata, 2 -fida, mcdio appendiculata; capsula elongata, cylindrica, 3-dentata, 1-locularis, polysperma, ad parietes seminifera.

2053. Spiralis. 2 . In canali Occitanico, in Rhodano propè Arausionem, in Sequana circà Parisios? in Axona juxtà Suessonun, circà Domfrontium. 


\section{A S S I S TER 'T' I A. \\ D I C O T Y L E D O N E S.}

$\mathrm{P}$

I. A N T F. contextu cellulıso, vasisque lymplaticis spiralibus et propriis constances, poris corticali!ns instructæ. Corculum dicotyfedoneum. 'T'snens fintescentiumi constans, $1^{\circ}$. medulla centrali in canali inchusa. puoluctiones mudullares radiantes undiquè enuittente; $2^{\circ}$. stratis ligneis aunuis, circa medullam concentriec disnositis, exterioribus junioribus et minus induratis; $3^{\circ}$. stratiscorticalibus à ligno distin.tis inter se olscurionihus, interioribus junioribus, exterioribus atate fissis. Folia sapè super caulem articulata ant composita, nervis semper anastomosantibus instructa. Flores perigonio duplici sæpius donata. Stamina rarò ternaria.

\section{DICOTYLEDONES INCOMPLETR.}

\section{Nempè perigoniis duobus in unicum coalilis.}

\section{O R D O X X I V. C O N I F F R AE.}

Flores sexu distincti. Masc. In amentum dispositi, squama ct sæpè perigonio instructi; stamiua numcete varia, perigonic aut squama inserta, sæpe moniulelpha. Fem. Solitarii, capitati atut in strobilum dispositi, squamis inubratis instructi; perigonium monophyllum, interdum squama perigonii lueo; ovarium simplex aut nultiplex, singulum uonustylum; cariopses osseæ ant membranaceæ, nunc in squamarum axillis sessiles, nunc squamarum coalitione in unicum fructum conflati; corrulum cylindricum in centro perispermi carnosi. - Arbores aut fiutices, succo resinoso, foliis sempervirentibus.

$$
\text { 266. P I N U s. }
$$

Monoica. Masc. Amenta racemosa conpacta et terminalia squamosa, :quanis apice staminiferis; stamina 2 ; antheı a 1 -loculares. Fem. Amenta simplicia imbricatia, squamis acuminatis; ovaria 2 ; stignata glandulosa; strobili squamæ oblongæ clavatæ ligueæ, apice nmbilicato anguloso; cariopses geminæ, $x$-spermæ , menliana appendicnlata ohtectæ; cotyledoncs digitato-partitæ. - Folia bina aut plurima ex eadem vagina.

205\%. Sylvestris. Loliis geminis rigidis, strobilis ovato-conicis acutis longitudine foliorum subgeminis basi rotundatis, thurioniluus virescentibus. ๖. In montosis, sylvas efformans.

so55. Rubra. Foliis geminis brevioribus glancis, strobilis parvis mucronatis sub-cymosis acutis, corenlo 5-lobo, thurionibus rubentibus. b. In Alpibns et Pyrenxis.

2055*. Uncinnta. Foliis geminis longiorihus strictis snbglaucis, strobilis ovato-oblongis obtusis , squanis umbilicato-uncinatis, corcul 7-lobo. 万. In Pyreuxis editiuribus. 


\section{DICOTYLEDONES.}

2056. Mugho. Foliis geminis trinisve tenuioribus rigidis, strobilis pyramidatis acutis basi rorundatis, squamis obtusis. b. In editioribas montibus Delphinatîs.

2057. Mari ime. Foliis geminis squama reflexa basi donatis, strobilis oblongo.conicis obtusis glaberrimis lucidis foliis brevioribus , squamis echinatis. ๖. In arenosis maritimis Galliæ australis et Burdigalæ.

2058. Pinea. Foliis geminis primordialilus ciliatis, strobilis ovatis obtusis subinermilus foliis longioribus, nucibus duris. b. In montibus Gallia australis frequens.

2059. Alepensis. Foliis geminis filiformibus, strobilis ovato-oblongis deorsim inflexis, squamis lævibus obtusis, ramis patulis. 7 . In maritimis circà Forum Julii.

206n. Laricin. Foliis geminis longissimis difformibus, strobilis conicis acutis brevibus nutantibus, squamis basi angustioribus, apice crassissimis non angulatis. b. In Corsica.

2061. Cembra. Foliis quinis, strobilis ovatis obtusis, squamis adpressis ovalibus concavis. b. In montibus Galloprovinciæ, Delplinatûs, Pedemontii, Sabaudir.

$$
\text { 267. A B I E s: }
$$

Monoica. Masc. Amenta solitaria non racemosa, squamis apice staminiferis; stamina 2 ; antheræ uniloculares. Fem. Amenta simplicia ; ovaria 2 ; stigmata glandulosa ; strobili squamæ imbricatæ te nues, apice rotundatæ, haìd incrassatæ nec angulosæ nec dorso $11 \mathrm{~m}-$ bilicatæ; cotyledones digitato-partitæ. - Folia solitaria ex vagina communi prodeuntia.

\section{I. Strobilis pendulis; foliis sparsis (EPICEA).}

2062. Excelsa. Foliis 4-gonis, strohilis cylindricis, squamis rhombeis complanatis margine repandis erosis. ๖. In Vogesis, Jurasso, Alpibus, Pyrenæis.

\section{II. Strobilis erectis; foliis distichis ( A BIES).}

2063. Pectinata. Foliis planis emarginatis, squamis strobili obtusissimis adpressis. b. In montibus cxcelsis.

\section{I A R I $\mathrm{x}$.}

Monoica. Omnia nt in Abiete, sed cotyledones simplices nnnquảm lobatæ; strobili laterales; folia caduca in primordio cespitoso-fasciculata, demùm solitaria.

2064. Europaa. Strobilis ovato-oblongis obtusis. b. In Alpibus editioribus.

$$
\text { 269. J U N I P IE } \mathrm{R} \text { U } \mathrm{s} \text {. }
$$

Dioica, rariùs monoica. Miasc. Amenta ovata, squamis verticillatis peltato-perlicellirtis; antherx 4-8, uniloculares. Fem. Amenta glohosa squamis 3 concavis coadunatis; stigma hians; bacca conflata ex tribus cariopsibus osseis I-spermis cinctis squawis coalitis et carnosis. 
2065. Communis. Foliis ternis patentibus mucronatis bacca longioribus. b. In collibus aridis et siccis.

2066. Oxycedrus. Foliis ternis patentibus nucronatis bacea brevioribus. b. In Gallia anstrali.

2067. Sabina. Foliis oppositis erectis decurrencibus, oppositionibus pyxidatis. ๖. In Gallia australiori et Alpium vallibus calidis.

2069. P/henicea. Foliis ternis imbricatis obtusis ovatis convexis. b. In Gallia anstrali.

$$
\text { 270. T } \mathrm{A} \times \mathrm{U} \text { s. }
$$

Flores dioici vel monoici, squamis plurihus cincti. Masc. Stamina 8 -ro, filanentis mondelplis, antheris peltatis 6 8-locularibus, loculis subùs dehiscentihus, Fem. Stylus o; stigma concavum; drupa carnosa apice hians; nuclens 1 -speruus.

2069. Baccata. Foliis approximatis. ๖. In subalpinis et Jurasso frequens.

\section{I. E P H E D R A.}

Flores dioiei in amenta brevia dispositi. Masc. Perigonium 2-lobum; stamina 6-8, filamentis monadelphis, antheris 1 -locularilus, extius dehiscentibus. $F \mathrm{~cm}$. Squamæ $/-5$ persistentes concavæ truncatæ imbricatæ pose inflorescentiam carnosæ; ovaria 2, monostyla; bacca orata 2 -sperma, seminibus hinc planis indè convexis.

207o. Distachya. Pedunculis oppositis, amentis geminis. b. In sabulosis maritimis Gullia australis à Nicæa ad Nannetes usque.

\section{OR D O X X V. A M E N T A E AE.}

Flores dioici, monoici aut rariùs hermaphroditi. Masc. In amentum dispositi, squama atu etiam perigonio squamifero instructi; stamina squamæ inserta, ferè nunquàm monadelpha; antheræ biloculares. Fem. Solitarii, fascieulati aut julacei, squama aut perigonio instructi; ovarium liberum, simplex aut rariù multiplex; stigmata plurima; pericarpia tot quot ovaria, ossea aut membrunacea; perispermum nullum; corculum rectum, planum; radicula sæpiùs supera. - Arbores ant frutices, foliis alternis caducis, junioribus basi stipulis binis stipatis.

\section{+ Flores dioici.}

\section{S A I I $\mathrm{x}$.}

Flores dioici, rarissimè monoici, julacei; squamæ unifloræ, imbricatæ; glandula genitulia cingens. MIasc. Stamina $1-5$, sæpiùs 2. Fem. Ovarium 1; stylus bifidus; stigmata 2 seu 4 ; capsula r-locularis, 2-valvis, polysperma ; semina comosa ; radicula infera.

\section{§. I. Capsulis glabris.}

2071. Alba. Arberea, foliis lanceolato-acuminatis serratis subpabescentibus, serraturis infimis glandulosis, libro vircscente. b. Ad vias, ripas et prata humida.

2072. Vilellina. Arborea, foliis lanccolatis acntis serratis subpubes. 
centibus, serraturis infumis glandulosis, libro vitellino. ๖. In pratis lıumidis culta.

20-3. Incana. Frutex, foliis lineari-lanceolatis margine revolutis subtis tomentosis, staminum filmentis bifidis. b. a In Galloprovincia; $\beta$, salix angustifolia. Poir. in Duh. arb. ed. 2. v. 3. t. 29.) in Pyrenxis.

207ł. Triunilra. Arborea, foliis oblongo-lanccolatis serratis glabris, stipulis parvulis, staminibus ternis. b. In arenosis secus flumina.

20-5. Amygdalina. Arborea, foliis oblongo-lanceolatis elongatis serratis glabris, stipulis maximis, staminibus ternis. ๖. Locis humidis.

20-6. Babylonica. Arborea, foliis lineari-lanceolatis subserratis glabris, rauis elongुatis flexililus pendulis. b. Ex Oriente orta, in liumielis culta.

20-7. Phvlicifolin. Frntex, foliis ovato-lanceolatis glabris margine undulato-serratis, supı ̀̀ viridibus splendentibns, subtùs incanoglaucescentibus. b. In Alpibus Pedemontanis (All.).

20-8. Daphnoules. Frutex, foliis elliptico-acuminatis serratis glabris, subtù glancis, supernè viridibus nitidis, junioribus subrillosis, amentis brevibus crassis densé tomentosis. b. In Alpibus Delphinatûs, montis Cenisii et Vallesiæ.

2079. Pentanilre. Arborea, foliis elliptico-lanceolatis crenulatis glahris sulsviscosis, staminibus 5-7, ovariis subsessilibus. b. In Alpibus, Pyrenæis, montibus Arverniæe et Jurassi.

2087. Fragilis. Subarborea, foliis oblongo-lanceolatis serratis glabris inferioribus minoribus obovatis, ovariis pedicellatis. b.Secus rivulos et flumina.

208ı. Herbacea. Suffruticosa, foliis orbiculatis serratis glabris,

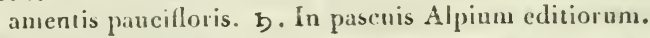

20.2. Retusa. Sufruticosa procumbens. foliis obovatis obunsissimis subscratis glabris, anentis paucifloris. b. In Alpibus, Pyrenæis, montibns Aiveruix et Jurassi.

\section{§. II. Capsulis villosis.}

2083. Reticulata. Suffuticosa procmmbens, foliis ovatis obtusis integerrimis, subtus albiclis retioulatu-nervosis, glabris aut lana caduca villosis. b. In lapidosis Alpium editiorum.

208ł. Cupren. Subarbrra, foliis ovatis rugesis subtus tomentosis undatis supernè denticulatis, capsulis basi ventricosis. b. In sylvaticis et sepibus.

208\%. Aurila. Frntex, foliis obovatis rugosis subtùs villosis reticulato-nervosis, stipulis di ui liato-cordat is, staminmm filamentis basi coalitis, capsulis ovali-oblongis b. All sepes, Incis umbrosis.

2086. Acuminata. Suharhorea, foliis ovato-oblong's acutis suberenatis reticulito-nervosis subtios tomentosis, stipulis rotundatis, capsulis longè pedicellatis. ๖. In pratis et sepibus. 
20S7. Ilelvetica. A 1 buscula, foliis oblongo-lanceolatis integerriuis supernè primò pubesentibus demim glaluis atro-viridibus, subtus tomento albo lanatis. Ђ. In Alpibus Sabatulis et Vallesiacis.

2088. Sericea. Arbuscula basi procumbens, foliis ohlongis aculis integerrimis utriuquè sericen-villosis. b. In montosis subhumulis montis Aurer, Alpium Delplinatûs ct Cenisii.

2089. Pyrencica. Sufruticosa repens, foliis obovatis subobtusis integris diaphanis, primo pubescentibus, deuum glabris. b. In Pyrencis ad nives perpetuas.

209o. Cilinta. Sufruticosa adscendens aut repens, foliis oblongolanceolatis acutis integris, junioribus subvillosis, demim villis scriceis ciliatis, capsulis remotiusculis. b. In Pyrenæis orientalibus.

209r. Incubacea. Arbuscnla, foliis oblongis subacutis integris supernè pubescentibus, subtus scriceo-villosis, ramis virgatis. b. In humidis.

2092. Arenuria. Arbuscula, foliis oblonģis acutis subdentatis snpernè glabris, subtùs sericeo-pubescentibns. b. In liumidis arenosis.

2093. Depressa. Arbuscula ascendens, foliis ovato-oblongis acutis integerrimis supernè glabris, subtùs sericeo-pubescentibus. b. In humidis.

2091. Casia. Arbuscula, foliis ovali-lanceolatis acutis integerrimis glabris, amentis brevibus, squamis glabriusculis. ๖. Secus rivulos in Alpibus editioribus.

2095. Arbuscula. Arbuscula, foliis ovatis subdiaphanis subserratis glabris, subtùs pubescentibus, amentis clindricis, squanis villusis. b. In vallibus humidis Alpium Galloprovinciarum (Ger.).

2096. Myrsiniles. Arbuscula, foliis ovatis acutis glabris serratis reticulato - venulosis. Ђ. In Alpibus editioribus Delphinatûs, Sabaudiæ.

2097. Fæetida. Suffruticosa depressa, foliis ovatis obtusis superne glabris, subtùs pubescentibus serratis, serraturis glandulosis. b. In Alpium vallibus cditioribus.

209S. Viminalis. Frutex, foliis lanceolato-linearibus longissimis integerrimis, subtùs sericco-pubescentibus, junioribus margine revolutis. b. Locis humidis.

2099. Monandra. Subarborea, foliis lanceolato-linearibus apice subdentatis, staminibus solitariis. b. Ad ripas.

$$
\text { 273. P o P U L U s. }
$$

Dioica. Amenta cylindrica, squamis apice laceris. Masc. Stamina 8 - 3n, squamularmm basi ex urceolo oblique truncato prodeuntia. Fem. Ovarium r; stigmata ł; capsula 2-valvis 2-locularis polysperma; semina comosa; radicula supera.

6. I. Populi alber; turionibus tomentosis vel hirtis; staminibus 8. 2100. Alba. Foliis cordato-subrotundis lobatis dentatis subtus 
tomentoso-niveis suprà glabris, amentis ovato-oblongis. b. Ubiquè, præcipuè in humidis.

2101. Canescens. Foliis subrotundis angulato-rotundis dentatis subtùs subtomentosis suprà glabris, anentis cylindraceis longis. b. In nemorosis et humidis.

2103. T'renula. Foliis suborbiculatis dentatis utrinquè glabris, petiolis compressis, amentis oblongis. b. In frigidioribus subhumidis.

๑. II. Populi nigrae; turionibus lavibus el glabris; staminibus $\mathbf{2}$ vel ultria.

2ro3. Nigra. Foliis deltoidibus acuminatis serratis utrinquè glabris, ramis patulis. $b$. In aquosis et cultis.

210 f. Fastigiata. Foliis subdeltoidibus inæqualiter serratis utrinquè glabris, ramis erectis strictis. b. Ex Oriente? orta, in aubulacris subhumidis culta.

$$
\text { 274. I Y R I C A. }
$$

Dioica. Amenta ovata, squamis lunulatis. Masc. Stamina 4-6; antheræ $f$-valves. Fen. Ovarimu I; stigmata 2 ; drupa I-locularis Isperma.

2ro5. Gale. Foliis lanceolatis subserratis, caule fruticoso. b. In aquosis et paludosis circà Parisios et in arenosis maritiuis Belgii.

\section{† Flores monoici. \\ 275. В E T U L A.}

Monoica. Amenta elongato-cylindrica. Masc. Squamæ ternatæ, media staminifera; stamina 12. Iem. Squamæ 3 - lobatæ; styli 2 ; ovarium compressum 2-loculare, loculo uno abortivo; nuculæ compressæ margiue membranaceæ uniloculares.

2106. Alba. Foliis deltoidibus acutis duplicato-serratis glabris, strobilorum squamis lobis lateralibus rotundatis, petiolis glabris pedunculo longioribus. b. In sterilibus arenosis frigidioribus.

2107. Pubescens. Foliis deltoidibus acutis subcordatis duplicatoserratis subtùs ramulisque pubescentibus, strobilorum squamis lobis lateralibus rotundatis. J. In turfosis Jurassi, circà Valletriam, Marliacum.

2ro8. Ovata. Foliis ovatis duplicato-serratis glabris subtùs in nervis pubescentibus, pedunculis femineis ramosis, strobilorum squamis lobis æqualihus truncatis nervosis. b. In montibus editiosibus Delphinatûs, Sabaudiæ et Pedemontii. - Alnus viridis. Fl. fr. n. 2 III.

2I09. Nana. Foliis orhiculatis crenatis glabris subtùs reticulatovenosis. ๖. In humidis Jurassi. - An hujus generis?

$$
\text { 276. A L N U s. }
$$

Monoica. Masc. Anıenta elongato-cylindrica; squamæ pedicellatæ cordiformes, subtus squanulis ternis instruct $x$, basi floriferæ; stamiua 
4 ex urceolo 4 -lolon. Fem. Amenta uvato- lobosa pedicellis ia-

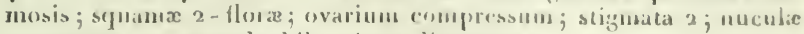
compressa ovate undat biluculares dispermas.

2, in. Glulunsa. Foliis subrotmulo-euncatis obtusis subretusis ghntinnsis, axillis venartum subtus villosis. b. Secus rivos et in locis humidis.

2111. Incana. Foljis oblongis acutis sultìs pubescentibus, axillis venarum nudis, stipulis lanceolatis. b. In unontosis.

$$
\text { 277. C A R P I N U S. }
$$

Monoica. Mrasc. Amenta elongato-cylindrica; squamæbasi riliate; stamina 8-1'f apice subbarbata. Fem. Strobili laxi, squamx foliacere biflors; ovarium apice denticulatum 2 -Joculare, loculo uno antè maturitatem abortiro; stigmata 2 ; nux ossea.

2112. Betulus. Strobilorum squamis 3-partitis, laciniis integris lanceolatis, intermedia elongata. 3 . In sylvis.

$$
\text { 278. F A G U S. }
$$

Monoica. Masc. Amenta pendula globosa densa; perigonium 6-lobatum; stamina 8 . $F \mathrm{em}$. Bini in involucro 4 - loho, extus spinis mollioribus muricato; pei igonium ovario adnatum, tomentosun, 6-lobım ; stigmata 3; ovarinm 3-gonum, 3-loculare, Joculis 2 ä̆ortivis, tertio superstite 1-2-spermo.

2113. Sylvatica. Foliis ovatis glahris obsnleti dentatis margine ciliatis. b. Sylvas constituit prxcipuè, in calcariorum montium declivibus.

$$
\text { 279. C. A S T A N E A. }
$$

Polygama. Masc. Amenta longissima cylindrica floribus hinc indè glomeratis; perigonium 6-partitum; stamina 5-30. Herm. Involacrun subtrillorum, f-loban, extias spiuis durioribus et ranosis muricatum ; perigonium ovario alnatum, 5-6-lobum, tomento rigilo iatùs obteetum; stamina 12 , rubra, abortiva; gernen 6-loculare, loculis 2 -spermis, 5 abortivis; styli 6 ; nux 1 -locularis; semiua $\mathrm{I}-3$, rugosa.

2114. Vulgaris. Foliis oblongo-lanccolatis acnminatis inucronatoserratis, utrinquè glabris. b. In montosis et glareosis.

$$
280 \text {. c o } \quad \mathrm{r} \quad \mathrm{Y} \text { L } \mathrm{U} \text { s. }
$$

Nonoica. Masc. Amenta cylindrica, squamæ 3-lobatæ deltoidex, lacinia media latiore laterales tegente; stamina 8 ; antheræ $\mathrm{I}$-loculares. Fem. Flores plurimi in gemma squamosa inclusi ; stignata 2 ; ovariun. I, primò denudatum, dein perigonio subcoriaceo margine lacero cinctum; nux ovata, levis, basi involucrata, r-sperma.

2115. Avellana. Stipulis obtongis obtusis, involucris fructus campanulatis apice patulis lacero-dentatis, foliis orato - cordatis acnminatis. $๖$. In sepibus.

$$
\text { 28r. Q U E R. C U S. }
$$

Monoica. Masc. Amentum laxum et pentnlum; perigorium lacerum; stamina 5-10. Fem. Involicerum squamosum, squamis imbri- 
catis, in cupulam hemisplıaricam ct coriaceam coadunatis; perigoniun ovario-adnatum 6-lobatmm orarium 3-loculare, loculis 2 abostivis; stigmata 3 ; nux (glans) I-locularis, I-sperma, cupula basi cincta.

\section{§. I. Foliis deciduis.}

2116. Racemosa. Foliis subsessilihus glabris ollongis apice dilatatis sinuato-lobatis, lobis rotundatis, fructibus oblongis lungè pedicellatis. b. In sylvis princeps.

2117 . Sessiliflora. Foliis petiolatis snbglabris oblongis sinuatolobatis, lobis rotundatis, fructibus olslongis subsessilibus. b. Plıres hujusce arboris snnt varietates, forsan in posterum species? a, in sylvis Fontisbleandi; $k$, in sylvis frequens; $\gamma$, in lapidosis montosis; $\delta$, ad I ontembleaudi; $\varepsilon$, in siccis et lapidosis; $\zeta$, in Pyrenæis, circà Burdigalam et Aginnum.

2118. Cerris. Foliis oblongis pinnatifido-sinuatis subtus hirtis, basi angustatis, lobis oblongo-lanceolatis dentatis̀, cupula hemisphærica echinata. b. Circà Parisios? in Pedenontio; $\beta$, in Burgundia ; $\gamma$, in agro Syrtico, Pyrenæis, Engolismæ?

2119. Egilops. Foliis ovato-oblongis levissimè sinuatis, subtùs cano-pubescentibus, lobis brevissimis nucronatis, cupula liemisphærica squamosa, squamis lanceolatis patentibus..b. In sylvis calidioribus Pedernontii, Fontisbleaudi? circà Nannetes.

2】20. Humilis. Foliis ovatis dentato-serratis breviter petiolatis subtùs subtomentosis, fructibus sessilibus oblongis, cupula brevi planiuscula. b. In sabuletis circà Nannctes frequens. - Pedem vix superans. $t$

\section{§. II. Foliis persistentibus.}

2121. Ilex. Foliis ovato-oblongis indivisis serratisque subtù incanis, cortice integro, nnce ovata. D. In Gallia australiori frequens, in Nigri-Monasterii insula.

2122. Suber. Foliis ovato-oblongis indivisis serratisque subtùs tomentosis, cortice rimoso fungoso. b. In Gallia australiori.

2123. Coccifera. Foliis oblongis indivisis spinoso-dentatis basi cordatis nerinquè glabris, squamis cupulæ patulis. b. In Gallia australiori et Nigri-Monasterii insula.

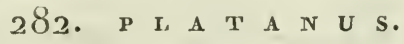

Monoica; amenta globosa. Mlasc. Stamina numerosa, squamis linearibus intermixta. Fem. Squamx spathulatx; ovaria filiformia apice incrassata, stigmate adunco terminata; semen undum ciavatum basi papposum.

212 . Orientalis. Foliis 5-lobo-palmatis laciniis lanceolatis sinnatis, stipulis subintegerrimis. b. Ex Oriente orta, in ambulacris culta.

$2124^{*}$. Occidentalis. Foliis 5-angularibus obsoletè lobatis dentatis basi cuneatis subtius pubescentibus. b. Ex America septentrionali orta, in ambulacris culta. 
Hermaphrodita vel polygama. Perigoniun 5-Jolum; stamina 5, subsessilia ; styli 2 ; drupa globosa, 1-sperma.

2125. Australis. Foliis ovato-lanceolatis subhin sntis. b. In (Occitania, Galloprovincia, vallibus Pedemontii Angustana et Segusiana ad rupes.

$$
\text { 284. U L M U S. }
$$

Hermaphrodita. Perigonium cımpanulatum , 4-5-dentatum, coloratnu, persistens; stanina 3-6; ovarinm conpuessum ; stigmata 2; eapsula suborbiculata, plano-compressa, nembranacea, micdio tumidis, 1-sperma.

2126. Campestris. Foliis iluplicato-serratis basi inxqnalibns, floribus subsessilibus conglomeratis. b. Ad vias, in sylvis montosis.

2127. Effusa. Foliis duplicato-serratis basi inæqualibus, floribus longe pedunculatis eftusis. b. Lntetix in horto Armamentarii, ad moenia Suessionum.

\section{O R D O XX V I. U R T I C E AE.}

Flores parvuii, virescentes, monoici ant dioici, solitarii, amentacei aut involucro monophyllo cincti; perigoninm monol liyltum, lobatum. Masc. Stamina definita, basi perignnii inserta. F ғ. Ovirimu simplex, liberum; styli 2 ant , bifurcatus; fructus in utraque tribu varii; radicula sæpiùs supera. - Herbæ aut arbores foliis sapiùs hispidis.

T R I E U S 1. A R T O C A R P E E.

Flores receptaculo communi insiti; fiuctus crmosi; semina perispermo donata; corculum curvatum.

\section{F I c u s.}

Nonoica. Flores numerosi pedicellati, receptaculo carnoso, apice umbilicato intìs caro inclusi; perigonium 3-5 lobum, Iobis acuminatis. Masc. Umbilico vicini; stamina 3-5. Fem. Ovarium liberum (1)esf ), semi-adnatum (Goertn.); stylus 1; stigmata 2; drupi sive utricula I-sperma, in receptaculi pulpa nidulans; nuclei cortex liagilis, crusticeus.

2ra8. Carica. Foliís palmatis. b. In siccis et lapidosis Gallix aus

tralioris, et in Pedemontir raibibs.

$$
\text { 286. } \mathbf{3} \text { o } \mathrm{n} \text { U s. }
$$

Alonoica. Amenta unisexualia; perigonimm f lobum, Inhis concavis. Mase. Stamina á jerignnii lecinis alterna. Fem. Ovarima liberum; stigmata 2 ; semina $1-2$, perigonio pulposo olstecta.

2129. Nigra. Foliis cordatis nvatis lohatisve inaquaiter dentatis scabris crassiusculis. 3. Ex Persia aut China orta, in hortis eula . 
3130. Alba. Foliis profundè cordatis basi inæqualibus ovatis lobatisve serratis lævibus tenuioribus. Ђ. Ex Oriente orta, nunc subspontanea, secus rivos Galliæ australis.

\section{T R I B U S I I. U R T I C E E.}

Flores solicarii, amentacei vel spicati; fructus nunquàm carnosi; perispermum nullum; corculum sapius rectlam.

$$
\text { 287. H U M U L U } s \text {. }
$$

Dioica. Masc. Perigonium 5-partitum; stamina 5. Fem. Strolili constantes squamis magnis, persistentibus, concavis, axilla unifloris; ovárium I; styli 2 ; semen 1 , arillatum ; corculum spiraliter tortum. 2r3ı. Lupulus. 2F. Ad sepes, in Belgio imprimis çulta.

$$
\text { 288. U R } \mathbf{T} \text { I } \text { C A. }
$$

Mlonoica, rarìs dioica. Mrasc. Racemosi ; perignninm 4-partitnm; stamina $f$, filamenta antè florescentiam curvata. Fem. Capitato-racemosi; perigonium 2 -valve; ovarium I; stigma I; semen I, perigonio cinctum.

2132. Dinica. Foliis oppositis cordatis ovato-lanceolatis grossè serratis, floribus dioicis, spicis paniculatis glomeratis geminatis peticlo longioribus. 24. Arl sepes et in hortis.

2133. Urens. Foliis oppositis ellipticis sub-5-nerviis, argutè scrratis, spicis glomeratis geminatis. $\odot$. In cultis ad pagos, areas.

2134. Pilulifera. Foliis oppositis ovatis serratis, amentis fructiferis globosis. $\odot$. In arvis Galliæ australioris, in Corsica.

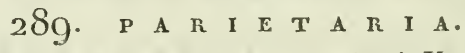

Flores polygani, involucro multipartito cincti.Herm. Perigonium 4-partitum; stamina 4, filamentis primù incurvis, elasticè dehiscentibus; ovarium 1; stylus 1 ; stigma 1 ; semen perigonio elongato et suprà counirente tectum. Fem. Stamina o; cætera hermaphroditis similia.

2135. Otficinalis. Foliis lanceolato-ovatis acuminatis, suprà ?sublucidis, subtus hirsutis nerrosis. $\mathcal{~}$. Ad muros et sepes.

2136. Jiudaica. Foliis oratis pubescentibus, floribus maribus elongáto-tubulosis: - In Gallia australi, circà Aureliam.

$$
\text { 290. C A IN N A B I S. }
$$

Dioica. Masc. Perignnium 5-partitum; stamina 5. Fem. Perigonium oblongum latere fissum; orarium I; styli 2 ; capsula crustacea $2-v a l v i s$, ralvis subglobosis perigonio obtectis; corculum incurvum. 2137. Sativa. ๑. Ex India orta, circà pagos culta.

$$
\text { 29I. A M B R O S I A. }
$$

Monoica. Masc. Involucrum I-phyllum; receptaculum nudum; perigronium tubulosım 5-fidum; stamina 5. Fen. Tribracteati; perigonium integrum, ventre extìs 5-tuberculato; ovarium liberum; styli 2 , basi coaliti; semen 1, perigonio obtectum. 
213S. Maritima. Foliis bipinnatis ohusis sublins canis, racemis terminalibus solitariis, canle divaricato, ramis villosis. $\odot$. In arenosis maritimis circì Nicram.

$$
\text { 292. X A N } \mathrm{T} \text { H I U M. }
$$

Monoicum. Masc. Involucrum poly plyyllum, multiformm, receptaculo paleaceo; perigonium tubulosum, 5-lobum; stanina 5. l'cin. Involucrum 1-phyllum, extis muricatum, intus in loculos 2 mifloros divisum; perigonimn nullum; ovarium 1 ; styli 2 ; semina involucro indurato obtecta.

2139. Strumarium. Caule incrmi, foliis cordatis trinerviis. $\odot$. Ad sepes et vias.

21 fo. Spinosum. Spinis ternatis, foliis trilobis. $\odot$. Ad agros et vias Monspelii, Nicæe, inter Tarasconem et Suncti-Remigii fanum.

\section{O R D O X X VII. E U PHO R P A C E AE.}

Flores monoici ant dioici, solitarii, spicati aut involncro cincti; perigonium multipartitum, in femineis sxpè nullum. M A sc. Stamina receptaculo inserta, filamentis sæjè nedio articulatis. ГЕм. Uvarinm liberum, sæpiùs stipitatum; styli sæpiùs 3 (interdinm a ant 1 ) bifidi; capsula 2-3-creca, valvnlis elasticè dehiscentibus 1-2 spermis; semina arillata, ad apicem columellæ centralis adfixa; corculum planum, sæpiùs rectum, perispermo carnoso involutum; radicula supera. - Herbæ aut frutices, sncco sæpissimè lacteo accrimo.

\section{M E R C U R I A I, I s.}

Dioica aut rariùs monoica. Perigonium 3-partitum. Masc. Stamina 9-12. Fem. Ovarium 2-gibbosum, 2-sulcatum, filamentis 2 sterilibus brevibus ex quoque sulco prodeuntibus cinctum; styli 2 bifurcati; capsula 2-cocca, 2-sperma.

2141. Perennis. Caule simplicissimo, foliis scabris, floribus longè pedicellatis. $\zeta$. In sylvis.

2142. Annua. Caule brachiato, foliis glabris, floribus spicato-glomeratis. $\odot$. In locis cultis frequens.

2143. Tomentosa. Caule suffruticoso, foliis ovatis tomentosis. 2 . In Gallia australiori, Monspelii, Narbonis.

$$
\text { 294. E U P H O R B I A. }
$$

Flores monoici, cincti involucro monophyllo campanulato $S$ - 10loho, lobis alternatim exterioribus callosis sæpiùs bicornibus patulis, interioribus membranaceis erectis. Masc. Plurimi; perigonium multipartitum, laciniis sulpplumosis; stamen I, flamento medio articulato. Fem. Solitarii, ccntrales, perigonio destituti; ovarium pedicellatum; stigmata 3, bifurea; capsula exserta, 3-cocca, 3-sperma.

\section{Đ. I. Capsulis glabris lavibus.}

2141. Chamcesyce. Dichotoma procumbens, foliis crenulatis subrotundis glabris, floribus axillaribus solitariis, seminibus tetragonis transversè rugosis. $\odot$. In arenosis provinciarum australiorum. 
2145. Peplis. Dichotoma procumbens, foliis integerrimis semi-cordatis, floribus solitariis axillatilus, caulibus jucumbentibns, seminibus ovatis lævibus. $\odot$. In arenosis maritimis à Galloprovincıa, ad Nannetes.

2146. Peplus. Umbella 3 fida dichotoma, bracteolis ovatis, foliis integerrimis obovatis petiolatis, semuibus subhexagonis foveolatis. $\odot$. In cultis, vineis, sepibus.

214- Falcala. Um?,ella $2-5$-fida dichntoma, bracteolis subcordatis mucronatis. folis lancelatis mucronulatis, seminibns subtetragonis transversè sulcatis. ๑. In cultis Gener

2r48. Exigua Umbel!a 2-j-fida dicioonna, bracteolis lancenlatis, foliis lincaribus, seminibus subtetragonis transrersè sulcatis. $\odot$. In arvis.

21 49. Tenuifnlia. U mbella 3-5-fila dichotoma, bractcolis subrhombeis, foliis lincaribus. 2 . In Delphinatu. $f$

2150. Lathris. Umbella 4-fida dichotoma . foliis oppositis integerrimis, seminibus oratis reticulatis. $\delta$. In cultis et secus vias.

2151, Terracina. Umbella 3-5-fila dichotnma, foliis lineari-lanceolatis interdim apice entaginatis, seminibus ovatis lavibus. $\odot$. Taurini? Segusii? in Corsicu? et Delplinatu?

2152. Pityusa. Umbella -fida 2-fida, bracteolis ovatis, foliis lanceolatis inferioribus reflexis retrorsum imbricatis, seminibus oratis læribus. 4 . In arenosis Galloprovinciæ, Sabandiæ.

2153. Paralias. Umbella sub-5 fida 2 -fit? , bracteolis cordatis reniformibus ; foliis tanceolatis sursum imbricatis, seminibus ovatis lævibus rufo-maculatis. $2 \mathrm{C}$. In arenosis maritimis.

215\%. Segetalis. Umbella 5-firla dichnenma, bracteolis cordatis acntis, foliis lineari-lancenkatis, superioribus latioribus, seminibus ovatis reticulatis. $\odot$. Inter segetes prov. australiormm.

215 $4^{*}$. Portlandica. Umbella 5-filla dichotoma, bracteolis subeordatis concavis mncronulatis, foliis lineari-lanceolatis patentibns, scminibus ovatis reticulatis, involucri lubis externis integris. 2 . In arenessis maritimis propè Nanuetes olservavit Delaroche. $-\mathrm{E}$. portlandica. Lin. sp. 656. Sm. Fl. brit. 515. Ray. angl. t. 24. f. 6.

2155. Helinscopia. Umbella 5-fida 2-fida dichotoma, bracteolis obovatis, foliis cnncitormibus serratis, seminibus ovatis reticulatis. $\odot$. In hortis et cultis.

2156. Serrata. Unbella 5 - fida 3 -fida dichotoma, bracteolis reniformibus, foliis amplexicaulihus serratis acutis, seminibus ovatis lævibus. 2 . Secus arva et vias in prov. australiouibus.

2157. Pinifolin. Unbella 5-7-fida dichotoma, bracteolis ovatis obtusis mucronulatis, foliis linearibus, caule basi frutescente. $\mathcal{F}, \boldsymbol{b}$. In provinciis australibus. $t$

2158. Cyparissias. Umbella multifida dichotoma, bracteolis subcordatis, ramis sterilibus, foliis linearibus confertis, seminibus ovatis lavibus. $\mathcal{F}$. In sterilibus frequens.

2159. Esula. Umbella multifida 7 -fida conferta, bractcolis ovatis 
obtusis, foliis linearibus inferiorihus syuaniclormilous, seminibus ovatis lavibus. 2 . Secus vias in sterilibus.

2160. Gerardiana. Umbella multifida dichotoma, brarteolis subrotundis nucronulatis, foliis lineari-lanceolatis, seminibus ovatis levibus, involucri lohis externis integerinis. 2 . In stenilibus et glareosis.

216r. Nicaensis, Umbella multifida 2-fida, bracteolis cordato-subrotundis, foliis lanceolatis mucromatis subcoriaceis, scuimulus subtecragonis lavibus. $2 F$. In sterilibus.

2162. Myrsinites. Umbella sub-8 fida 2 -fida, bracteolis ovatis mucronatis, foliis spatulatis patentibus carnosis mucronatis, seminibus tetragonis transversè sulcatis. 2 . Monspelii, Nicræ.

2163. Sylvatica. Umbella multifida 2 -fida. bracteolis perfoliatoconnatis subcordatis, foliis lanceolatis integerrimis, caule basi frutescente, seminibus ovatis lævibus. ๖. In sylvaticis.

2164. Dendroides. Umbella multifida dichotoma, bracteolis subcordatis, caule arboreo, semiubus ovato-rotundis lavibus. b. In Corsica, insulis Stæchadum, Nicææ, Oncliæ.

\section{§. II. Capsulis pilosis.}

2165. Characias. Umbella multifida 2 -fida, bracteolis perfoliatis emarginatis, foliis lancelatis, caule frutescente, capsulis tomentosis. b. In montosis lapidosis provinciarum Mediterranearnm.

2166. Pilnsa. Umbella 5-fida 3-fida, bracteolis ovatis, foliis lanceolatis subpilosis apice serrulatis, capsularmn pilis sparsis. $\mathcal{F}$. In Galloprovincia et Occitania.

2167 . Dulcis. Umbella 5-fida 2-fida, bracteolis subovatis denticulatis, foliis lanceolatis obtusis apice denticulatis, capsulis pilosis demùm verrucosis. $\mathcal{Y}$. In sylvaticis. An vera civis?

\section{§. III. Capsulis glabris tuberculoso-verrucosis.}

2 I68. Purpurata. Umbella 5-fida 2 -fida, bracteolis subcordatis, foliis lancenlatis obtusis integris, capsulis verrucosis glabris. $\mathcal{\zeta}$. In sylvaticis Pyrenzorum, Parisiis, etc.

2160 . Spinosa. Umbella sub-5-fida simplici, bractcolis ovatis, foliis oblongis integerrimis, canle fruticoso, ranis senescentibus subspinosis. b. In Corsica, Galloprovincia, Nicæx.

2r7o. Carniolica. Umbella 5-fida 2-fila, virginea nutante, bracteolis ovatis supernè glabris, foliis lanceolatis acutis utrinquè villosis. 25, ๖. In Pedemontio, Galloprovincia.

2i71. Verrucosa. Umbella 5-fida sub-3-fida 2-fida, bracteolis ovatis, foliis lanceolatis serrulatis subviilosis, canlibus basi patulis. 24. In humidiusculis sylvarum et riarum,

2r-2. Platyphyllos. Umbella 5-fida 3-fida dichotoma, bracteolis car ina pilosis, foliis lanceolatis serratis, caule erecto. 2 . In siccioribus campis et secus vias.

21;3. Pubescens. Umbclla 5-fida 3-fida dichotoma, bracteolis 
foliisque serrulatis mucronatis pilosis, seminibus ovatis lævibus punctato-naculatis. $\mathcal{Y}$. Cireà Narbonem.

217ł. Hyberna. Umbella 5-6-fida dichotoma, bracteolis ovatis, foliis integerrimis subglabris, ramis sterilibus nullis, capsulis verrucoso-eclinatis. $\%$. In Alpibus, Pyrenæis, montibus Arverniæ.

2175. Palustris. Umbella multifida sub-3-fida 2 -fida, bractcolis ovatis, foliis lanceolatis glabris, ranis sterilibus. 2 . In palndibus, secus rivos.

$$
\text { 295. B U X U s. }
$$

Monoica. Perigonium 3-4-partitum. Masc. Squama 2-loba; stamina 4 , germinis rudimento inserta. $F_{c m}$. Squanıulæ 3 , minimæ; styli 3 ; stigmata 3 , obtusa ; capsula 3-cornis, 3-locularis, 6-sperma.

2176. Sempervirens. Foliis ovatis, petiolis margine pilosiusculis, antheris ovato-sagittatis. b. Ad sepes.

$$
\text { 296. } \text { R I c I N U s. }
$$

Monoica. Masc. Perignnium 5-fidum; stamina plurima filantentis coalita quasi ramosa. Fem. Perigonium 3-partitum; styli 3 , bifurci ; capsula tuberculis spinosis hirta, 3 -locularis, loculis Ispermis.

2177. Communis. Foliis peltatis palmatis, lobis lanceolatis serratis, caule herbacen pruinoso, stigmatibus 3 apice 2 -fidis, capsulis echinatis. $\odot, ~$ J. Ex Barbaria et Oriente orta, in hortis culta.

$$
\text { 297. C R o T } 0 \text { N. }
$$

Monoicum. Perigonium 5-10-partitum, laciniis alternis 5 minoriJus petaloideis. Masc. Stamina 8-15 filamentis coalita; glandulæ 5 , receptaculo affixæ. Fenı. Styli 3 ; stigmata 6 rel pluria; capsula 3coccá 3-sperna.

21-8. Tinctorium. Foliis ovato-rhombeis repandis basi integerrimis utrinqué canis, pedunculis terminalibus sub-3-floris, capsulis squanato-pubescentibus pendulis. $\odot$. Nicææ, in Corsica et Occitania.

\section{OR DOXXVIII. A R ISTOLOCH I AE.}

Perigonium ovario adhærens, monophyllum; stamina numero definita, epigyna, sessilia; stylus brevis; stigma divisum; capsula aut bacca coriacea, multilocilaris, polysperma; corculum ad basim perispermi eartilaginei.

$$
\text { 298. A R I S T }
$$

Perigonium tubulosum, basi ventricosum, apice dilatatum et in ligulan extensum; antherx 6 , subsessiles, stylo inscrtæ; stigma 6fidnm; capsula 6-gona, 6-locularis.

\section{§. I. Floribus solitariis.}

2i 79. Pintunda. Foliis cordatis ovatis subsessilibus, radice rotunda. 2. Ad ririeas et in arvis $G_{a}$ alliæ atstralis. 
2180. Longa. Foliis petiolatis cordatis ovatis inlegerrimis, radice longa simplici. 2 . In arvis, ad sepes et vincas Giallia anstralis.

2181. Pistolschia. Ioliis pediolutis condatis ovatis crenatis scibloris, radice fasciculatit. 2 . In stentibus Gilloprovincie et Uccitanise.

\section{j. II. Floribus confertis.}

21S2. Clematitis. Foliis petiolatis subrutundo-cordatis abtusiusculis, floribus axillaribus confertis. 2 . In lapidosis sterilibus.

$$
\text { 299. A } S \text { S A R } \quad \text { U } \quad \text { Mr. }
$$

Perigonium campanulatum, 3-lobum; stamina 12, ovario imposita; antheræ mediis filamentis adnatæ; stylus brevis; stigma stellatum, 6-lobatum; capsula 6-locularis.

2183. Europeum. Foliis reniformibus obtusis subhirsutis. 24. In umbrosis suxosis.

$$
\text { 300. C } \quad \text { I } \text { T I N U S. }
$$

Perigonium campanulato-elongatum, 4-5-lobum, basi 2-squamosum; antheræ 8 ant 16 , stylo insertæ sub stignate; stylus oblongus; stigma obtusum, 8-fidum; bacca coriacea, S-locularis, coronata.

218 f. Hypocistis. 24. Parasiticus in radicibus cistorum.

\section{O R D O X,X I X. E L AE A G N E AE.}

Perigonium ovario adharens, monophyllum, tubulosum, extùs foliis comforme, 2-5-lobatum; stamina summo perigonio inserta, ejusdem laciniis numero dupla aut æqualia; stylus 1 ; stigma sæpiùs simplex; fructus monospermns; corculum rectum intrà perispermun carnosum. - Frutices aut rariùs herbæ; folia alterna integra; flores sæpì̀s hermaphroditi ant dioici.

$$
\text { 30I. T H E S I U M. }
$$

Perigonium 4-5-firlum; stamina 4-5, perigonii lobis opposita; capsuli monosperma, non dehiscens, perigonio persistente coronata. 2185. Linophyllum. Floribus pedunculatis pentandris. $\psi$. In collibus, pratis siccis et montosis.

2186. Alpinum. Floribus subsessilibus tetrandris. 24. In Alpibus et Pyrenæis, Vogesis, Jurasso.

$$
\text { 302. O } \mathbf{S} \text { Y } \mathbf{R} \text { I } \mathrm{s} \text {. }
$$

Abortu dioica; perigonium 3-fidum. Masc. Stamina 3 brevia, ovarii rndimentum. Fem. Stigna triplex; bacca globosa, sicca, umbilicata; nuclsus I-spermus.

2187 . Alba. b. In Occitania et Galloprovincia.

$$
\text { 303. H I P P O P H A E. }
$$

Dioica. Masc. Perigonium 2 -partitum; antheræ 4, subsessiles. Fem. Perigonium 2-fidum; stigma crassiusculum; bacca globosa, I-locularis, I-sperma.

2189 Rhamnoides. Foliis lanceolatis. b. In sabulosis humidis, secus mare Mediterraneum, in Alpibus secus flumina. 


$$
\text { 304. E L Æ A G N U S. }
$$

Perigonium campanulatum, 4-lobum, intùs coloratum, extùs squamosum; stamina 4 , subsessilia, perigonii lobis alterna; drupa nucleo 1-spermo.

2189. Angustifolia. Foliis lincari-lanceolatis. ๖. In Galloprovincia, Pedemontio.

\section{O R D O X X X. 'TH Y M E L E AE.}

Perigonium liberum, monophyllum, 4-5-lcbum, coloratım; stamina summo perigonio inserta, ejustem laciniis numero dupla; ovarium I; stylus I sæè lateralis; stigma I ; fructus unicus, monospermus, perigonio tectus, siccus aut baccatus; perispermum nullum; corcufum rectum; rarlienla supera. - Frutices; folia simplicia integra alterna; flores sæpiùs hermaphroditi, interdìm abortu dioici.

$$
\text { 505. D A P II N E. }
$$

Perigonium tubulosum, 4-lobum; stamina' 8 ; stylus brevis; bacca 1-locularis, 1-sperma.

219o. Mezereum. Floribus lateralibus sessilibus ternis, foliis lanceolatis post flores evolutis deciduis. b. In sylvis montosis.

219r. Thymelaca. Floribus axillaribus sessilibus infernè solitariis supernè aggregatis, foliis lanceolatis glaucis, ramis simplicibus. b. In provinciis mediterrancis.

2193. Laurenla. Floribus axillaribus redicellatis quinis, foliis lanceolatis glabris perennantibus. b. In syivis mortosis.

${ }^{2} 9^{3}$. Alpina. Floribus sessilibus aggregatis lateralibus, foliis lanceolatis obtusiusculis subtìs pubescentibus. b. In lapidosis Alpium.

2194. Tartort'raira. Floribus sessilibus lateralibus aggregatis, basi squamis imbricatis, foliis obovatis utrinquè sericeis. b. In Galloprovincia, Corsica.

2rg5. Cneorum. Floribus fasciculatis terminalibns sessilibus, foliis lanceolatis nudis mucronatis. b. In montibus Alsatiæ, Alpibus et Pyrenæis.

2196. Gnidium. Racemis terminaiibus paniculatis, foliis lineari-lanceolatis acuminato-cuspidatis. b. Locis aridis provinciarum mediterranearum et occidentalium.

$$
\text { 306. P A S S E R I N A. }
$$

Perigonium tubulosum, q-lobum; stamina 8 ; stylus filiformis lateralis; senen corticatum.

2197. Dioica. Floribus dioicis axillaribus geminis ebracteatis, foliis lineari-lanceolatis glabris confertis. $b$. In Pyrenæis et montibus Pedemontii.

2 I98. Nivalis. Floribus dioicis axillaribus solitariis bracteatis, foliis lineari-lanceolatis glabris. $\mathrm{b}$. In summis Pyrenxis. 
2 r99. Calycina. Flowihus hermapluoditis axil arihus solitariis bracteatis, foliis utrinque acuminatis glabris. b. In Pyrenæis onientialibus.

2200. Mirsuta. Florihus hermaphroditis axillaribus, foliis earnosis ex! is glabris, caulibus tomentusis b. In lapidosis sterilibus provinciarmu mediterraneartum et Corsica.

$$
\text { 507. S } \text { T }
$$

Perigonium tubulosum, 4-lobum; stamina 8 ; stylus brevis; stigma pitutum; sesuen durmm, nıtidum, rostratum.

o1. Passerina. Floribus axillaribus sessilibus 4-fidis, foliis lineaibus. $\odot$. In agris.

\section{O R D O XXXI. L A U R I N EAE.}

Perigonium libcrum, monophyllum, persistens, 6-fidum ant 6-parant; stamina iusts laciniis inserta, nunc 6 ordine simplici, nunc sa line duplici digesta; antherce filunemto adnatce, à busi ad apicem luiscentes; ovarinm $\mathrm{r}$; stylus $\mathbf{1}$; stigma simplex atut divisum; drupa t bacca I-locularis, I-sperma ; perispermum nullum; corculum recIn, radicula supera. - Arbores aut frutices; folia alterna; flores rmaphroditi aut abortu dioici.

$$
\text { 308. L A U R U s. }
$$

Perigonium 4 -6 fidum, xquale; stamina 8-1 2 duplici serie dispoita; exteriora omnia fertilia, interiora alterna sterilia, alterna ferilia et basi 2 appendiculata aut 2-glandulosa; drupa carnosa.

2202. Nnbilis. Foliis lanceolaris renosis perennantibus, floribus 4fillis, dioicis. b. In Pedemontio, provinciis mediterranes et in occidentalibus usque ad Armoracian sub dio crescit.

\section{OR D O X X I I. POL Y G O N E AE.}

Perigonium liberum, monophyllum, divisum; stamina definita, imo perigonio inserta; antheræ bil:culares, quadrisulcatæ, lateraliter rima duplici deliscentes; ovarium 1 ; styli plures aut stigmata plurima sessilia; cariopsis perigonio tecta, 1-sperma; corculum laterale aut centrale, sapè curvatun; perispermum fariunceum.-Herbæ aut rariùs irutices; folta allerm, basi vaginantia aut vagine intrafoliacea adnata, juniora subtins revoluta.

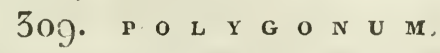

Perigoninm $\{-6$-partitum, persistens; stanina 5-9 sæpiùs 8; ovaria $2-3$; stylos totidem(ne stignata gerens; eariopsis ovata aut triangularis; corculum laterale vel centrale; radicula supera.

๑. I. Florum spica so ilarixe terninales; staminn 9 ; stigmata 3 ; cariopsis triangularis; corculum laterale (BISTORTA).

2203. Bistorta. Canle simplicissimo monostachio, foliis ovatis undulatis, radicalibus in petiolum decurrentibus. 24 . In pratis et pascuıs mọtosis. 
2204. Viviparum. Caule simplicissimo monostacbyo, foliis lanceolatis margine revolutis. 2 . In pascuis Alpium.

9. II. Flores spicati vel paniculati, axillares aut terminales; stamina 5-8; stigmata 2 interdium 3 ; cariopsis ovata; corculum laterale (PERSICARIA).

2205. Amplibium. Floribus pentandris semi - digynis spica ovata, foliis lanceolatis acutis serrulatis glabris. 4 . In paludibus, fossis aquaticis.

2206. Hydropiper. Floribus hexandris semi-digynis, foliis lanceolatis undulatis immaculatis, spicis filiformibus nutantibus, caule erecto. $\odot$. In aquosis et ad fossas humidas.

220\%. Pusillum. Floribus hexandris submonogynis, foliis lanceolatolinearihns immaculatis, spicis gracilibus, caule basi radicante. $\odot$. In numidis et sabulosis.

2208. Persiraria. Ploribus hexandris semi-digynis, foliis ovatolan eolatis sæpiùs maculatis, spicis ovato-oblongis, pedunculis lævibus, stipulis ciliatis. $\odot$. In locis humidis, ad margines fossarum et viarum.

2209. Incanum. Floribus hexandris digynis, foliis oblongo-lanceolatis subtìs pubescentibus, vaginis glabris, spicis oblongis, caule adscendente. $\odot$. Ad segetes et margines sylvarum.

2210. Lapathifolium. Floribus hexandris digynis, spicis trevibus, caule erecto, foliis nvato-lanceolatis glabris, vaginis subhirsutis. 2 . In paludosis circà Parisios.

$22 \mathrm{I1}$. Orientale. Floribus hexandris digynis, spicis cylindricis pendulis, canle erecto, foliis ovatis subtùs pubescentibus, vaginis hirtis. $\odot$. In hortis cultum.

S. III. Flores axillares; stamina 8 ; stigmata 3 ; cariopsis rotundata; corculum lalerale ( POLYGoxum).

2212. Thritinum. Floribns axillaribus, vaginis bilobis membranaceis, foliis ellipticis obtusis subcarnosis, caule suffruticoso. $4, \mathbf{b}$. In arenosis maritim!s.

22เ3. Aviculare. Floribus axillaribus, foliis elliptico-lanceolatis margine scabris, caule procumbente herbaceo. $\odot$. Ad vias, in agris et locis incultis.

2214. Bellardii. Floribus axillaribus, vaginis ciliatis, foliis lanceolatis acutis, caule erceto. $\odot$. In agro Pedemontano.

6. IV. Flores corymbosi vel paniculali; stamina 8 ; stigmata 3 ; cariopsis triangularis; corculum centrale; cotyledones plicata. (FAGOPYRUM.)

2215. Alpinunı. Floribus racemoso-paniculatis, foliis ovato-lanceo latis glabris margine ciliatis, canle ramoso, vaginis membranaceis barbatis. 2 . In pascuis Alpium. - An hujus sectionis?

2216. Fagopyrum. Foliis cordato-sagittatis, caule erectiusculo inermi, seminum angulis integerrimis, $\odot$. Lu arvis cultum, ex Asia orlum. 
22r7. Convolvu?us. Foliis coriluto-sagittatis, caulc volubili angulato, lacinis perigonii olstuse carinatis. $\odot$. In agris frefuntus

2218. Dumetorum. Foliis triangularibus sagittatis, caule volubili substriato, valvulis seminalibus alatis. $\odot$. Ad sepes ct in umbrosis.

$$
\text { 310. } \mathrm{n} U \text { nI } \mathrm{E} x \text {. }
$$

Perigonimm $4-6$ partitum, laciniis interionibns persistentibus fructum tegentibus, exterioribus minoribus reflexis; stamina 6 ; styli $2-3$; stigmatu totiden dissecta; cariopsis triangularis; radicula supera.

9.I. I'erigonium 6 partilum; slyliel stigmula 3 ; corculum laterale, periphericum, valvula perigonii interiores basi cubercululu; sapor minimé acillas. ( LAPATIL M.)

\section{* Valvulis perigonii interioribus inlegris.}

2219. Patientia. Floribus hermaphoditis, valvula unica granifera, foliis ovato-lanceolatis. $2 \mathcal{C}$. Jnxti rivos in Pedemontams Alpibus.

2220. Alpinus. Floribus polyganis, valsulis $r_{-2}$ graniferis, foliis ovato-cordatis ohtusis rugosis. $\mathcal{W}$. In Alpibus, Pyrenæis et montibus Arverniæ circà stabula.

2221. Aqualicus. Floribus hermaphroditis, valvulis ovatis obsoleti graniferis foliis cordato-lanceolutis acutis. 2 . In stagnorum, fossarum aquaticurum oris.

2222. Crispus. 1loribus liermaphroditis, valvulis oratis omnibus graniferis, foliis lanceolatis mululatis acutis. F. In hassis ad vias.

2233. Nemolapathum. Floribus hermaphroditis, valvulis lincaribus obtusis graniferis, verticillis remotis, ranis patentibus, foliis inforioribus cordato-lanceulatis, superioribus lanceolatis. F. In sylvaticis humidis et paludosis.

2224. Sanguineus. Floribus hermaphroditis, valvulis oblongis, unica præcipuè granifera, foliis cordato-lanceolatis, nervis sanguineis. 4 . In paludosis et secus rivos.

\section{** Valvulis perigonii interioribus dentatis.}

2225. Pulcher. Floribus hermaphroditis, valvula unica præcipud granifera, foliis radicalihus panduriformibus, caule glabro divaricato. 2 . Ad sepes et vias.

2226. Aculus. Floribus hermaphroditis, valvulis oblongis subdentatis omnibus graniferis, folies cordato-oblongis acuminatis, racemis foliosis. 2 . Ad fossas.

2227. Obusifolius. Floribus lermaphroditis, valvulis dentatis graniferis, foliis radicalibus cordatis obtusiusculis, caule scabrinseulo. 25. In sterilibus et humidis.

2228. Maritimus. Flnribus hermaphroditis, valvulis deltoideis setaceo-dentatis graniferis, foliis linearibus, verticillis contertis. $2 \hat{f}$. In palnsuribus præcipuè maritimis.

222 $9^{*}$. Palastris. Floribns hermaphroditis, valvulis lanceolatis graniferis basi dentatis, foliis lineari-lanceolatis, verticillis distantibus. $2 F$. R. palustris. Sm. Fl. brit. 39 f. R. maritimus, 8 Fl. fi. n. 2228. - In paludosis, tossis et rularatis humidis, Parisis. 
6. II. Perigonium 6-partitum; stamina 6; corculum laterale, periphericum; valvula perignii interiores basi externa granulis destiluta; sapor acidus. ( A CETOSA.)

\section{* Valvulis perigonii interioribus dentatis.}

2229. Buceplualophorus. Floribus hermaphroditis ternatis, pedirellis planis reflexis incrassatis. $\odot$. In sabulosis Monspelii, Nicææ, in Galloprovincia et valle Augustana.

\section{** Valvulis perigonii interioribus integris.}

223o. Tuberosus. Floribus dioicis, foliis lanceolato-sagittatis, hamis patentibus, radice tuberosa. $2 \zeta$. In pratis circà Ničeam.

2231. Acetosa. Floribus dioicis, foliis oblongis sagittatis, hamis retrorsum porrectis. 2 . In pratis et pascuis.

2233. Arifo'ius. Floribus dinicis, foliis onnibus petiolatis oblongis hastatis, hamis brevibus rectà divaricatis. $2 \%$. In pascuis Alpinis.

2233. Acetosellı. Floribus dioicis, foliis lanceolato-hastatis, hamis acutis recurvis. $\mathcal{F}$. In sabulosis.

223\%. Scutatus. Floribus hermaphroditis, caule tereti, foliis cordato-hastatis, hamis reflexis divergentibus. $\mathcal{F}$. In lapidosis.

๑. III. Perigonium \{-partilum; stigmata 2 ; valvule perigonii interinres granulis destilutce; corculum centrale rectum; sapor acidus. ( oXYRIA.)

2235. Digvnus. Floribus hermaphroditis digynis, valvulis ovatis, foliis orbiculatis emarginatis. $\odot$. In Alpibus, Pyrenæis et montibus Arverniæ, ad nives æternas.

$$
5 \text { I I. P II E U M. }
$$

Perigonium persisteus, 6-fidum; stamina 9 ; stigmata 3 sessilia; cariopsis trigona, membranacea; corculum rectum in centro peri sperni; radicula infera.

2236. Rluapnnticum. Foliis obtusis glabris, venis subtìs pilosiusculis, sinu baseos dilatato, petiolis suprà sulcatis margine rotundatis. 2 . In montibus Arvernix.

\section{ORDO X X XIII. C II E O P O E AE.}

Perigonium liberum, monophyllum, partitum ; stamina imo perigonio iviserta, ejustem ldciniis numero equalia; ovarium I; stylus simplex aut undtiplex; fructus nunc bacea multilocularis polysperma, nunc cariopsis baccata seu perigonio demùm palposo obtecta, nune cariopsis nuda ant perigonio membranacen obtecta; perispermam sapius farinareum, cenirale; corculum circulare ant spiraliter torum; radicula infera.-Herbæ; folia alterna, simplicia, stipulis vaginisque destiluta; flores parvuli, virescentes, sæiùs hermaphroditi.

\section{† Fructus baccatus; perispermum. fariuaceum.}

$$
\text { 312. P If } \mathbf{Y} \text { T }
$$

Perigonium 5-partitum; stamina $8-20$; ovarinm 8 -10-striatum; stigutata 8-10; bacea 8-10-locularis, loculis monospermis. 
2237. Decandra. Florilus decandris decagynis. 2F. Frequens in

Helvetia australiori, Pedemontio, Pyrenxis, agur Syrtico.

†† Semen calice tectum; perispermum farinaceum.

$$
\text { 3 } 13 . \text { B L I 'T' U M. }
$$

Perigonium 3-partitum; stamen 1; styli 2; semen calice baccato tectum.

2238. Virgatum. Floribns glomeratis, capitulis sparsis diteralibus.

$\odot$. In humidis et cultis.

2239. Capuatum. Floribus glomeratis, capitulis spicatis terminalibus. $\odot$. In hmaidis e cullis.

$$
\text { 3I 4. B E T A. }
$$

Perigonimm 5 partitum, basi ovario semi-adharens; stamina 5 ; styli 2 ; semen reniforme basi calicis capsulari involutum.

22 fo. Maritima. Caule basi prostrato, floribus solitariis aut binis. o. In maritimis Belgii, Galloprovincia.

22 r. Vulgaris. Canle erecto, floribus ternis aut quaternis. $\sigma$. Colitur in hortis oleraceis.

$$
\text { 3 I5. S P I IN A }
$$

Dioica. Mlasc. Perigonium 5-partitum; stamina 5. Fem. Perigonimm 2-4 partitum; styli $\{$; senen tectum perigonio persistente et post inflorescentian increscente.

22 q2. Spinosa. Foliis sagittatis, fructibus cornutis. $\odot, ठ \cdot$ In lortis oleraceis culta.

2243. Inermis. Foliis ol,longo-ovatis, fructibus incrmibus. $\odot, ð$. In hortis cultil.

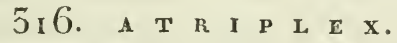

Polygama. Hermophr. Perigonium 5-partitum; stamina 5. Fem. Perignnium 2-partitum, laciniis adpressis, post inflorescentiam crescentibus et scmen tegentibus.

22任. Ilalimus. Caule fruticoso, foliis alternis deltoidibus in petin.

lum decurrentibus. Ђ. Ad sepes et in fossis circà Nannetes, in arenosis maritinis Nicææ.

22 5. Portulacoides. Caule fruticoso, foliis oppositis obovatis. Ђ. In paludosis maritinis à Portu-Gratix, ad Nicæam.

22f6. Glauca. Caule fruticoso, foliis alternis sessilibus ovato-rntundatis integerrimis, interioribus subientatis. b. In Occitanixe maritimis, circà Tolosam.

224j. Pedunculata. Caule herbaceo recto, foliis ohlongis integerrimis, floribus femineis pedunculatis cunciformibus. $\odot$. In maritimis circà Abbatis-Villam.

22 f8. Rosea. Caule herbacen, raunis patulis, foliis incanis inæqqualiter dentatis, fructibus 4 -angularibus dentatis. $\odot$. Circa Nicram, Rupellain, Nannetes et Claromontem.

2240. Laciniata. Caule herbaceo diffuso summitatibus pubescen- 
tibus, foliis subtus argenteis deltoidibus dentato-sinuatis, inferioribus oppositis, fructibus sub- 4 -gonis obtusis. $\odot$. In maritimis Galloprovinciæ,

$22 \tilde{j n}$. Hizstuta. Caulc herbaceo erecto, ramis diffusis, foliis latis triagularibus hastatis glaberimis, valvulis seminalibus maguis delioidibus dentato-spinosis. $\odot$. Ad muros et sepes.

235:. Prostrata. Canle herbaceo prostrato ramosissimo, foliis triangularibus anriculatis glaberrimis, valvulis seminalibus inermibus. $\odot$. Circà Sanctum-Valaricum et Portum-Gratiæ.

2252. Angustifolia. Canle herbaceo patulo, foliis lanceolatis integerrimis, infimis subhastatis, valvulis seminalibus hastatis leviusculis. $\odot$. A. angustifolia. Sm. Fl. br. 10y2. A patula. Fl. fr. non Linn. - Ad rias et margines agrorum.

2253. Littoralis. Caule herbaceo erecto, foliis omnibus linearibus integris dentatisve, valvulis seminalibus sinnatis disco muricatis. $\odot$. In maritimis septentrionalibas, etiam circà Parisios.

225\%. Hortensis. Caule herbaceo erecto, foliis hastato-deltoidibus, valvulis scminalibus integris. $\odot$. Ex Asia orta, in oleraceis culta.

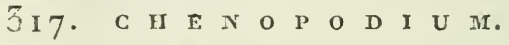

Perigonium 5-partitum, persistens, nec tuberculosum, nec post inflorescentiam accretum; stamina 5 ; stylus bifidus; stigmata $2-3$; semen orbiculare, nudum.

5. I. Foliis ovatis ant rhomboideis, scepirts dentatis aut lobatis.

2255. Bonus ITenricus. Foliis triangulari-sagittatis integris, spicis compositis terminalibus erectis a phyllis. $\mathcal{F}$. In ruderatis, secus vias. 225̌6. Truicum. Foliis triangularibus dentatis, racemis confertis strictissinis cauli approximatis longissimis. $\odot$. Circà urbes et pagos.

2257. Rubrum. Foliis cordato-triangularibus obtnsiusculis dentatis, subtis glaucis, racemis erectis compositis subfoliosis caule brevioribus. $\odot$. In ruderazis et fimis.

2258. Niuralc. Foliis ovato-deloidibus inæqualiter dentatis acutis nitidis, racemis terminalibus corymbosis nuilis, caule ramoso subpatulo. $\odot$. Ad muros ct vias.

2259. Leiospernum. Faliis rlomboideo-ovatis crosis posticè integris, superioribus oblongis integerrinis, scminibus læribus. $\odot$. Freguens ad vias et in agris.

226o. Ficifolium. Foliis hastato-sinuatis erosis posticè integris, su. periorilus oblongis integerrimis, seminibus punctatis. $\odot$. In locis cultis.

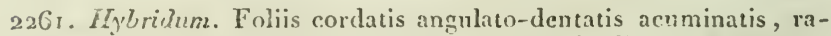
cemis ramosissimis subcymosis divaricatis aplyllis. $\odot$. In arvis et Jocis cultis.

2262. Botr's. Foliis oblongis pinnatifido-sinuatis viscidis sublirsutis, racenis nulis multifllis. $\odot$. In arenosis Gallix australis.

2203. Ambrosinides. Foliis lanccolatis remotè dentatis, racemis foliatis simplicibus. $\odot$. Circà '́olosam, Nannctes. 


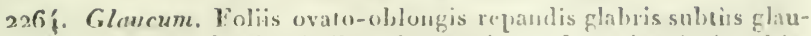
cas, racemis nudis simplicihus glomeratis. $\odot$. In arvis ee locis cultis.

2265. Vulvaria. Foliis llombeo - ovatis subintegen rimis, lloribus conglomeratis axillaribus, caule difluso. $\odot$. Ad vias, muros et in hortis.

2266. Po! sspernum. Foliis ovalis integerrimis, racemis cyuusis divaricatis aphyllis, canle decumbente. $\odot$. Locis cultis.

y. II. Foliis linearibus integris.

2267. Scoparia. Foliis planis lincari-lancenlittis, margine cirhatis, racemis subfoliatis axillatibus. $\odot$. Circh Nicam.

2268. Mfaritimum. Foliis glabris snliulatis carnosis scmi-teretilus, floribus gloncratis axillaribus. $\odot$. In paludosis marimis Occani et Meditermeine

2269. Fruticosnm. Foliis glabris carnosis teretibus obussis inbricatis, caule fruticoso glabro, flosibus axillanibus solitariis. b. Fn maritimis circà Nannetes, Ogam et secus mare Mlediterraneum.

2270. Kirsutum. Foliis teretibus obtusis tomentosis, caule herbacen difuso, floribus axillaribus. $\odot$. In maritimis Oecitanix.

$$
518 . \text { S A L S O L A. }
$$

Perigonium 5-partitum, persistens, lixciniis post inflorescentia:n appeudice scarioso (peraphyllo) dorso instrnctis; stamina 5; stigmata $2-3$; semen solitarium; corculum peripliesicun.

227 r. Prostrata. Canle frutescente prostrato sublirsuto, foliis linearibus pilosis inermibus, floribus polygamis, antheris p.urpuras:centibus. b. In agris subsalsis circà Naboncu, secus vias in valle Auguslana.

2272. Arenaria. Caule herbacen prostrato subhirsuto, foliis suhglabris, floribus polyganis, antheris lavis. $\odot$. In sabulusis atgillosis cirè̀ Moguntiăı, Mombach.

22-3. Soda. Caule erecto adscendente licrbaceo glaberrino ramoso, foliis inermibus linearihus carrosis, flnrihus hermaplnocitis axillaribns solitariis. $\odot$. In maritimis Gallia australis.

22,-f. Trigns. Caule herbacen erecto, foliis subulatis spinosis lavibus, floribus bracteatis axillaribus solitariis, fractcis brevilus spinosis. $\odot$. In maritimis Galliæ australis, etian circà Nannetes.

2275. Kali. Caule herbaceo prostrato, foliis subulatis spinosis scabris, perigonii laciniis margine scatiosis. ๑. In marititais Mediterranei et Uceani.

$$
\text { 5I I. S A I, I C O K N I A. }
$$

Perigonium integrum; ventricosım, $\hat{f}$-gonum; stansima $1-2$; stylus 2-fidus; stignata 2 ; semen perigonio inflato obtectnm.

23-6. Herbncea. Canle lierbaceo carnoso ramoso articulato, articulis apice compressis emarginato-bifulis, spie is axillarims nppositis pednnculatis, squamis obtusis. $\odot$. In paiudosis maritimis, et in salsis Lothatingies. 
227\%. Fruticosa. Caulc erccto frutioso, articulis ramulorum ancipitilus, squamis floralibus truncatis nembranaceis. 5. In maritiusis Mediterranei et rarius Uceani.

$$
\text { 320. C O } \mathrm{R} \text { I } \mathrm{S} \text { P } \mathrm{E} \text { R } \mathrm{M} \text { U } \mathrm{M} \text {. }
$$

Pcrigonium 2 partitum; stamina I-5; scmen ovatum, compressum, line planum, indè convexum, nudum, margine nembranacem. 22-S. IIysonifolinm. Foliis lincaribus nuticis. $\odot$. In Occitania, Agathie, Monspelii.

\section{†† Frucus capsularis; perispermum camosum.}

\section{I. C A M P H O $\mathbf{R}$ O $\mathbf{S}$ M A.}

Perigonium urceolatum, 4-partitum, lacinis alternis majoribus; stamina 4 exserta; stylus a-fidus; capsula monosperna.

22,9. Binspeliacn. Foliis hirsutis lincaribus. b. In sabulosis ad vias in Galloprovincia, Occitania.

$$
\text { 322. } \quad \text { P }
$$

Pcrigonium 5-partitum; stamina 3; stylus 2-fidus; capsula Ispermat nom deliscens.

2280. Arvense. Wriandrum, foliis subulatis triquetris, caule diffuso.

$\odot$. In arvis.

$$
\text { 325. T H E L I G O N } \mathbf{U} \text { M. }
$$

Monoicum. Rilasc. Pcrigonium turbinatum 2-fidum, lacinïs revolutis; stauina 12-19. Fem. Perigonium 2-fidum, persistens; sty-

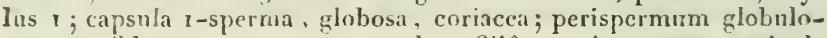
sum, 2-fidum, carmosum; corculum filiforme incurvum; racticula infera.

22S1. Cunncrambe. $\odot$. In rimis saxorum umbrosormm Segusii, II onspelii, Nicææ, in insulis Siæchadum et Corsica.

\section{ORDO X X X I . A II A R N THA CE AE.}

Perigonium (aut calix?) liberum, persistens, divisum, sæpi coJoratum; stamina 3 aul 5 , h^p 3 vna, libera aut monadelpha ; orarimu 1 ; stylus et stigna simplex aut multiplex; eapsnla 1 -locularis; semina solituria aut rarius fulurima receptaculo centrali adfixá ; perispermum furinacem, corculo curvato insolutum. - Herbæ; folia alterna aut opposita, interdim stipulacea, integra; flores parvi, interdim sexu distincti, sepe squanis coloratis cincti.

$$
\text { 324. A II A R A N T II U S. }
$$

Monoicus. Perigoniun 3-5-phyllum. Masc. Stamina 3 ant 5. Fem. Styli 3 ; stygitata 3; capsula 1-speruna, 3-rostris, circumscissa. 2282. Hlitum. Floribns triandris gloneratis latcralibus, foliis ova-

lis rutusis ant cmarginalis, caule diffuso. $\odot$. $\Lambda d$ muros in vicis pagorum.

$2282^{*}$. Albus. Floribus triand is glomeratis axillaribus, glomerulis 
a-partitis, bracteis subulatis, foliis ovato ob!ongis setula mucronatis, canle ramasissimo arecto. ○. Mumpelii.

2283. Spreatus. Foribus triandris deuse spreatis terninalihus, foliis ovato-ohlongis, caule erecto subramoso. $\odot$. In agris sterilibus, lapidosis, ruderatis.

$2283^{*}$. Prostratus. Floribus triandris densi spicutis lateralibus rel terminalibns, foliis ovato-sulnhomboideis obtusinsculis relısis, caule prostrato ramoso striato. Y In Pedemontio et Delphinatu, secns muros.

$$
\text { 325. P A } \mathrm{R} \text { O } \mathrm{N} \text { X C II I A. }
$$

Perigoninm 5-phyllum, foliolis subnlatis sul,cartilagineis; stamina 5, squamnlis totirlem filiformibus interjectis; styli 2 ; cansulis I-sperma, 5-valvis, perigonio obtecta.

228\}. Cymosa. Canle ramoso erecto, foliis subteretiluns glahris aristatis, floribus cymosis, bracteis brevissimis. ๑. In Gebennensibus, circà Aranisionem.

2285. Echinata. Caulibus prostratis, foliis obovato-acmninatis scabris, floribus verticillatis aristatis. $\odot$. In maritimis Galloprovinciæ et Corsicæ.

2286. Ferticillata. Canlihus prostratis filiformilus glabris, foliis snbrotundis, floribus verticillatis 5-8onis aristatis. $2 \%$. In humidis et aquilegiis circà Parisios, Sorriciun, Ho:spelium.

228 \% . Polygnifolia. Caulibns prostratis, foliis ovato-lanceolatis glabris, floribus subacutis lateralibus terminalibusque. of. In Delphinensibus mointibus.

22SS. Pubescens. Caulibus prostratis ramosis, foliis orato-oblongis hirsntis, floribns axillaribns hirsntis. $2 \mathcal{\text { }}$. In Pyrenæis, circà Aqnas-sextias, Lugdunum.

$32 S_{9}$. Serpilifolir. Canlibus nodosis ramosis prostrato-repentihus, foliis obnvato-lanceolatis margine ciliacis subcamosis, floribus bracieis nccultatis terminalibus. $\frac{2}{j}$. In an enosis secus torrentes, in Deiphinatu, Pysenxis.

2290. Argenten. Caulibus nodosis subhirsutis ramosis, ramis hevibus prostrato-repentibns, foliis ovato oblongis mucronatis subglabris, floribus terminalibus glomeratis, bracteis argenteis occultacis. $2 \%$. In siccis Gallix anstralis.

2291. Capitatu. Catulibus snberectis durinsculis, foliis Jincaribus carinatis cilia! is subitis suhhirsutis, stipulis lincaribus foliorun Inngitudine, flotilus terminalibus capitatis, bracteis argenteis occultatis. $\odot$ : In monte Aurco, valibus Alpinis Pedemontii ct Delphinatûs:

$$
\text { 526. H E R N I A R I } \Lambda \text {. }
$$

Perigonium 5-partitum; stumina 5, squanumlis 5 filiformilus interjectis; styli 2 ; stighuata 2 ; citpsula 1-sperma, non deliscens, perigonio tectit.

22n3. Clazbra. Caulibus ramosissimis prostrato-repentibns glahris, florum glimerulis axillaibus mufifloris glabrib. $\odot$. In sabulosio. N 4 
2293. Hirsuta. Caulibus durinsculis ramosissimis prostrato-repentibus hirsutis, florun glomerulis axillaribus paucifloris hirsutis. $\odot$. In arvis.

22g4. Alpina. Caulibus patulis basi frutescentibus pubescentibus, florihns glomeratis subterminalibns 5-tidis hirsutis. 2 . In Alpibus et montibus Occitanix.

22g5. Polygonoieles. Caule erecto dichotomo frutescente, floribus terminalibus glomeratis $2-5$-floris sessilibus. ๖. In collibus maritimis Galloprovinciæ.

\section{O R D O XXX V. PLA N T A G N EAE.}

Perigonium dnplex; exterius (calix?) 4-partitum; interius (corolla?) tubulosum, hypogymum, scariosum, persistens, basi staminifer; stamina' f filamentis exscrtis; ovarium liberum, simplex; stylns et stigma 1 ; capsula circumscissa, in $2-4$ loculamenta divisa ope dissepimenti longitudinalss mobilis nunc plani nunc tetragoni; semina parietibus disscpimenti aífixa; corcu'um rectlim intra perispermum subcomeam; radicnla infera. - Herbx nunc acaules nune caulescentes; flores spicati vel capitato-spicati, hemaphroditi aut rariùs dioici.

$$
\text { 527. P L A N T A G O. }
$$

Flores hermaphroditi; capsula 2-4-locularis, di-aut-polysperma.

§. I. Dissepimento plano, utrinqué polyspermon (Plantago).

2296. Mnjor. Scapo nudo, foliis ovatis septemnervis integris vel subdentatis, spica $30-40-f l u r a . ~ 2 \zeta$. In aridis ad vias.

2297. Minima. Scapo nudo, foliis ovatis trinerviis integris vel subdentitis, spica 3-6-flora. 4 . In humidis ontisbleaudi et in Alpibus.

§. II. Dissepimento plaro, semen unicum utrinquè gerente ( PSYLLIUM).

* Caule subnullo, pedunculis et foliis radicalibus.

2298. Media. Foliis ovato-lanceolatis pubescentibus, spica cylindrica, scapo tereti. $\zeta$. In aridis fiequens.

2299. Lanceolata. Foliis lanceolatis, spica subovata nada, scapo angulato pubcscente. 4 . In pratis siccis frequens.

2300. Lagopus. Foliis lanceolacis subdenticulatis, spica ovata hirsuta, scapo tereti. 4 . In Gallia australi.

23or. Montana. Foliis lanceolatis 5-nerviis subglabris, spica ovata subglobosa nuda, scipo tereti hispirlo. 2 . In Alpibus Siabaudicis, Villesiacis, Pyrenais.

2302. Fictorialis. Foliis lineari-lanceolatis hirsutis, spica globosa 13-20-flora basi subhirsuta, bracters flore brevioribus, scapo tereti pubcseente, pilis rufescentilus basi circumdato. 25 . In monte Sancta-Victorix Galloprovincix, circa Vapincum et in valle Pisanà Pedemontii. 
23o3. Argentea. Foliis linearibus ohlongis scriceo-argentris, spicat ovato - sphaxica densa, bracteis Hore brevionibus, scapo tereti furbescente. Y. In Galloprovineia, circi Narbonrm, m l'yunts.

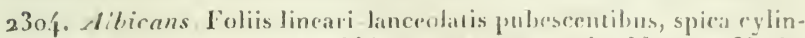
drica sappios incerrupta subhirsnt:1, scapo tereti sublantu 25 . In sterilihus Galloprovincix, Occilaniae, Delplinatûs austruliokis.

2305. Pilosa. Foliis linearibus hirtis, spica ovata hispidat densa, bracteis snbulatis flore longioribns, scapo tereti híto. $\odot$. In sterilibus Gallia nediterranea circà Nicæam, Narbonem.

33n6. Maritima. Foliis semi-cylimbraceis integerrimis carnosis, collo lanato, spica cylindrica densa, scapo tereti pubescente erecto vel basi adscendente foliis longiore. $\mathcal{F}$. In maritimis Mediterranci et Oceani.

2307. Craminea. Foliis sublinearibus planis snbdentatis, basi glabris, spicat cylinclica, scapo tercti foliis vix longiore. $2 C$. In paludosis maritimis, ad ostium Sequanx, ctiam in Gallia australi et propè Claromontem.

23o8. Alpina. Foliis lineari-lancenlatis planis glabris integris mollibus, spica cylindrica, bractris flore brevioribns, scapo tereti foliis duplò longiore. $\mathcal{4}$. In pascuis $\Lambda$ ppium ę Pyrenæorum.

2309. Incana. Foliis lineari-lanceolatis planis tomento abido ohtectis, scapo dimidio-brevioribus, spica oblongo-cylindrica, bractris flore brevioribus, seapo tereti tomentoso. 24. Locis humidis in Py renais et montibus Gubennensibns.

23ro. Capitellata. Foliis linearibus glabris basi tomento circumilatis, spica globosa 3-6-flora, bracteis flore brevioribus, scapo tereti gracili subtomentoso. 25 . In Pyrenacis editioribus.

231 . Serpentina. Foliis linearibus glahris basi nudis, spica cylindrica sapiùs curvata, bracteis subulatis flore longioribus, scapo pubescente subflexuoso. 2 . In Grallia australi.

2312. Subulata. Foliis linearibus snbulatis duris, spica cylindrica, bracteis flore brevioribus, scapo tereti pubescente subflexuoso. 2 F. In lapidosis et arenosis Galliæ australis et circà Andegavum.

* Caulilus elongatis foliosis; perlunculis axillaribus.

2313. Cýnops. Canle ramoso hasi sufirnticoso, foliis linearibus strictis, basi ciliatis, capitulis pubeseentibus foliatis. b. In stcrilibus Gallix australis.

2314. Genevensis. Caule lignoso ramosn, foliis linearihus confertis basi ciliatis, capituiis subglabris subaplyyllis. 万. Circi Genevam.

2315. Arenaria. Caule herbaceo ramoso erecto, foliis linearibus puhescentilus viscidis, capitulis ovatis foliaceis subhirsutis. 24 . In sterilibus et arenosis.

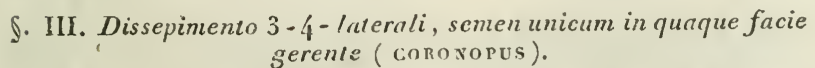

3316. Cornnopas. Foliis sulhirsntis pinnatifidis, scapo tercti pubescente. $\odot$. In graminosis el stcrilibus. 
Monoica. Mrasc. Perlicellati, 4-partiti. Fem. Sessiles, 3-partiti; capsula 1 -sperma?

231 \%. Lacustris. 2 . In herbosis liumidis inundatis, circà lacus, stagna et aquilegia.

\section{ORDO XXXVI. PLU M B A IN E AE.}

Perignnium duplex, persistens; exterius (involucrum? calix?) monophyllum, tubulosum, integrum aut tentatum; interius corollaceum, hypngynum, mono-aut-polypctalum ; stamian 5, in monopetalis receptaculo inserta, in polypetalis imis petalis adnata; ovarium simplex, liherum; styli plures, ant unicus stignata plurima gerens; capsula monosperma; corculum conpressume perispermo farinaces cinctum.- Herbæ ant suifrutices; folia sinplicia, integra, alterna aut radicalia; flores hermaphroditi, capitati aut spicati.

$$
\text { 329. S T A T I C E. }
$$

Perigonium-extcrnum scariosum, plicatum, integrum; internum 5-petalum coloratum persistens; stamina 5 , petalis inserta; styli 5 ; capsula non dehiscens, duplici perigonio obtecta; placenta filiformis ex apice capsulæ orta, seminis recti basim attingens.

f. I. Foliis subrartira'ibus confertis; scapis nudis plurilus; foribus terminalibus capitalo-involucratis, involucro communi imLricato scarioso scapum vaginante (ARMERIA).

23 , 8. Armeria. Scapo nudo simplici capitato, foliis linearibns planis obtusis. $2 \mathcal{C}, a$, in maritimis; $\%$, in collibus aridis ; $\gamma$, in Alpibus editioribus.

3319. Plantaginea. Scapo nndo simplici capitato, foliis oblongolauceolat is 3-5-nerviis. 2 . In Pyrcnxis, Alpibus, Pedemontii et Arvernix montibus.

2320. Frsciculata. Sicapo nudo simplici capitato, canle fruticoso supernè folioso, foliis fasciculatis canaliculatis lincaribus. b. In Corsica circà Urcinium ( Ajaccio).

§. II. Foliis caulinis spursis; floribus sessilibus, secus ramos longa serie dispositis, squamis scariosis cinclis.

2321. Limonium. Caule paniculato tereti, foliis margine undulatis oblongis glahris obtusis subtus mucronatis. 2 . In maritimis Mediterranci et Uceani.

23 32. Aurirulof fía. Caule paniculato tereti, floribus secundis, bracteis foilaceis obtusis, foliis spatulatis obtusis glaucis. 2:. In arenosis maritimis.

2323. Bellidifolin. Canle tereti dichotomo, floribus subcorymbosis, hracteis scariosis obtusis, foliis oblongis spatulatis obtusis. 24 . In maritiun Oceani et Mediterranci.

232 . . Echioines. Caule erecto paniculato tereti articulato, foliis 
bracteis calicibusque tuberculato-legrosis. $\odot, \sigma$. In Gallopuvincia el Monspelii.

2325. Reticulata. Canle difuso panculato, ramis sterilihus retroflexis, hracteis subscariosis levibus. $2 ;$. In atenosis mathinis, Monspelii.

2326. Oleafolia. Caule paniculaı erecto, ramis angulitn-alatis, foliis lanceolatis moromato-enspidatis margine cat ilagineis. $2 ;$. In maritimis propec Narbonem.

2327. Diffusa. Cault ramosissimo diffuso, bracteis scariosis subulato-cuspirlatis, foliis glabris tinearibus caducis. 2 . In maritimis circà $\mathbf{N}$ arbonem.

2328. Minuta. Canle funticoso nano ramoso, foliis cuncatis glabris muticis, ramis pancifloris. b. In maritimis Galloprovinciæ circà Massiliam.

2329. Monopetala. Caule futicoso folioso, foliis lanceolatis vaginantibus tuberculosis, floribus solitariis monopetalis. b. Circa Narbonem.

$$
\text { 530. P L U MI B A } \text { G } 0 \text {. }
$$

Perignnium-externum hirtum, tubulosum , 5-dentatum; internum petaloidenm, infundibuliforme, r-phylium, 5-Jolsum; stanina 5-hypogyna, basi dilatata: stylus r; stignata 5 ; capsula apice dehiscens, 5 -valvis; placenta filiformis è basi capsulæ orta, semius inves si basim attingens.

233o. Eurnpaca. Foliis amplexicaulibus lanceolatis scabris, caule stricto. 4 . In Gallia australi.

\section{O R D O X X X VII. N Y C T A G I E AE.}

Involncrum caliciforme, monophyllum, uni-ant-multifnrum ; perigoniun monophyllum; coloratum, persistens, cum ovario non adhærens, supra ovarium coarclatum; stanina defuita, inseru disco glandnloso ovarium ambienti; ovariun $x$, perigonio t:ctum; stylus I; stigna capitatum; semen disco stauninifero et perigonio tectun; ; perispermum farinaceum corculo involutum. - Herbs aut frutices; folia sæpiùs opposita.

\section{I. N Y}

Involucrum monophyllum, campanulatum, 5-lobum, uniflorum; perigonium campanulatum, limbo patulo, 5-gono, 5-lobo; stamina 5; semen obectum basi perigonii coriacea rt densa, ejusden parte superiore marcescente et post inflorescentiam decidua.

23.3ı. Julape. Floribus congestis pedunculatis, foliisque glabris. $2 \mathrm{C}$,

$\odot$. E Pernvia orta, in hortis cn!ta.

2332. Longifora. Floribus congestis sessilibus, foliisque pubescentibus. 4 . Ex cditioribus Mexici montibus orta, in hortis culta. 


\title{
II. DICO'TLEDONES MONOPETALT,
}

Sive perigonio duplici, interno monophyllo instructe.

\author{
O R D O X X X V I I I. G L O B U L A R I AE.
}

Flores capitati, inxolucro polyphyllo ciucti, receptaculo paleaceo impositi; calix simplex, monophyllus, tubulosus, 5 -Jobus; corolla hypgrna, reeptaculo inserta, tubulosa, inxuaviter 5-Joba; stamina 4 imæ corolla inserta; ovarium liberum; stylus ct stigna i; senen solitarium, calicc tectum; corculum rectum; radicula supera; perispermum carnosum.

$$
\text { 352. G L }
$$

Vide earacterem ordinis.

2333. Alypum. Caule erecto fruticoso, foliis lanceolatis integris apice interdiun 3-dentatis, capitulis terminalibus. 5. In lapidosis Gatliæ Meditcrrancæ.

233\%. Nudicaulis. Scapo nudo, foliis radicalihus integerrimis ovatis oblongis. 24 . In Alpibus meridionalibus et in Pyrenxis.

2335. Vulgaris. Caule herbaceo, foliis radicalibus 3 -dentatis, caulinis lanccolatis. $2 \Gamma$. In sterilibus et pratis siccis.

2336. Cordifolia. Caule subnudo unifloro, foliis cunciformibus tricuspidatis, dente intermedio minimo. b. In saxosis et apticis Alpinu.

2337. Nana. Canle fruticoso prostrato ramoso, scapis nudis brerissimis, folìs ovato-spatulatis integerrimis. b). Circà Narbonem, in Pyrenæis.

\section{ORDOXX I I. P R I U L A E AE.}

Calix monophyllus, persistens , 4-5-lobatus; corolla monopetala, staminifcra, sapiùs regularis, lim!o diviso; śtamina coralle lobis numero aqualia, et iisciem opposiu; ovarium liberum; stylus 1 ; stigma simplex; capsula r - locularis, polysperma, receptaculo seminifero centrali libero; corculum rectum intrà perispermum carnosum; radicnla infera. - Herbe; folia simplicia sæp piùs integra.

$$
\text { 333. C E N }
$$

Calix 4-lobus; corolla rotata, 4-loba; stamina 4 ; capsula globosa, circumscissa.

2338. Minimus. Foliis alternis ovatis, floribus scssilibus. $\odot$. In nliginosis, pascuis et ericetis inumdatis.

$$
\text { 334. A N A G A L I I s. }
$$

Calix 5-lobus; corolla rotata, 5-loba; stamina 5; capsula globosa, circuunscissa.

3339. Corulea. Caule erectiusculo, foliis oppositis ternisve ovatis subacutis subtins punctatis, lobis corollx apice subdentatis. $\odot$. In eamy is ct cultis. 
239o. Placenicea. Ciule subprocumbente, foliis oppositis ternisque ovatis obtusis subtirs punctatis, perlanculis folio longioribus, Iobis

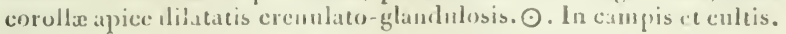

$23 \mathrm{f}^{*}$. Repens. Cianle ranisque rejentibus, fuliis sessilibus ovatis oppositis, pedicellis folio subxyulibus. 2f? In montibus Galloprovincia Sedenensibus detexit Cilarion.

23亿. Monelli. Caule erecu, foliis oppositis verticillatisque lanceolatis acutis, peduneulis fuliformibus, laciuies calicinis linearibus accrosis. 24 . In agro Nicxensi?

23. 'a. Tenella. Caule prostrato filiformi, foliis oppositis ovatis acutis petiolatis, pedunculis folio longioribus. 24 . In humidis et palurlosis.

2373. Crossifolia. Canle repente, foliis alternis subrotundis crassis subpetiolatis, pedunculis folio brevioribus. 24. In uliginosis turfosis circà Aquas-Tarbcllicas.

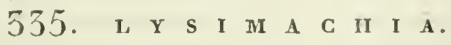

Calix 5-partitus ; corolla 5-fida, rotata; stamina 5 (filamenta in quibusdam basi commata); capsuld globosa, apice dehiscens, multivalvis.

5. I. Peclinculis multifloris.

23 亿4. Vulgaris. Foliis oppositis ternisque lanceolatis, panicula terininali. 2 . Ad ripas et paludes.

2345. T7eyrsifnra. Foliis oppositis oblongis, racemis pedunenlatis lateralibus. 2 . In Gallia septentrionalis paludibus. - Naumburgia guttata. Monch. Suppl. 33.

๑. II. Peclunculis uniforis.

23 6. Punctata. Foliis ternis sen quaternis subsessilibus, canle erecto, pedunculis axillaribus verticillatis. 2f. In Pedemontio circà aquas Stattiellas et in Belgio, inter arundines.

23íz. Nummu!aria. Folis subrotundis subcordatis, caule repente, pedunculis solitariis, laciniis calicinis ovatis acutis. 2 . In pascuis humidis et umbrosis.

23 9. Nentorum. Foliis ovatis acutis, caule procumbente, pedunculis solitariis, laciuiis calicinis lanceolatis acutis. $\mathcal{F}$. In nemoribus montanis.

23 9 . Linum stellatum. Canle erecto ramosissimo, foliis oppositis sessilibus angustis, calice corollam superante. $\mathcal{Y}$. In Gailiz australis herbosis et vineis.

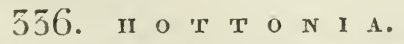

Calix 5-partitus; corolla tubo brevi, limbo plano 5-lobo; stamina 5 subsessiiia; capsula glolosa, acuminata.

235̃o. Palustris. Foliis pectinatis verticillatis, floribus pedunculatis verticillatis. $\mathcal{F}$. In arguis stagnantibus.

$$
537 \text {. c o r I s. }
$$

Calix ventricosus, 5 -dentatus, dentibus basi spinis exsertis; corolla tubulosa, limbo 5-fido inzquali; stanina 5; cansula globosa, 5-valvis, 5-sperma. 
2351. Monspeliensis. $\odot$ ? $\mathcal{Y}$ ? In Galliæ Mediterraneæ maritimis aridis,

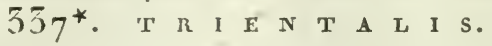

$\mathrm{C}_{2 l i x}$ 7-partitus; corclla rotata, 7 -partita; stamina 7 ; bacca exsuccd, suluris dehiscens.

2351*. Fí ropaca. 2 . In Ariluenna sylva circà Sanctam-Hubertum legit Ricdount.

$$
\text { 558. A N D } \mathbf{R} \text { o } \mathrm{S} \text { A C } \mathbf{E} \text {. }
$$

Culix persistens, semi-quinquefidus; corolla liypocrateriformis, fance coaretata 5 -glandulosa, limbo 5-lobo; stamina 5 brevia; capsula globosi, 5 -valvis.

\subsection{Pudunculis nudis unifloris solitariis (ARETIA).}

2352. Pubescens. Foliis ol.longís planis pubescentibus, pilis simplicibus, pedunculis axillaribus terminalibusque folio breviori-

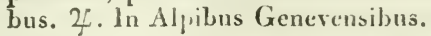

2353. Prenaica. Foliis carinatis subrecurvis ciliatis subpubescentibus, pilis simplicibus, pedunculis folio longioribus recurvis. 24 . In Pyrenæis, ad rupes frigiliores muscosas versùs Layeran.

2354. Cylundrica. I oliis obinngis pilosis, pilis simplicibus, pedunculis suhterminalibus longis pilosis, caule simplici. 2 . In Pyrenæis.

2355. Imbricata. Foliis oblongis imbricatis coriaceis pubescentibus, pilis stellatim ranosis, floribus snbsessilibus terminalibus. $2 ;$. In petrosis summarum Alpium et Pyrenzorum.

23:6. Bryoides. Foliis ololongis imbricatis pilosis, pilis simplicibus, floribus ses:ilibus terminalibus. $2 \%$. In Alpium rupibus.

2357. Alpina. Ioliis annolinis oblongi- pabescentibus, pilis ramosis, pedunculis terminalibus axillaribusque, lobis corolla emarginatis. $2 C$. In sunumis $A l_{\text {pium. }}$.

2358. Ciliata. Foliis oblun planis margine ciliatis, pilis simplicibus et furratis, peúunculis folio longiorilons, lobis corollæe integris. 2 . In Pyrenais.

5. II. Pedurnculis umbelliferis involucratis (ANDROSACF).

2359. Villosn. Vilioso-sericea, pilis longis simplicibus, foliis oblongis obtusis, pedunculo 5-floro, pedicellis involucro brevioribus. 2f. In Alpibus et Pyrenæis.

236o. Carnea. Foliis subulatis glabris, peduncnlo jubescente, pilis ramosis, mubella 2-12-flora, pedicellis involucro sublongioribus. 24. In Alpibus, Vogesis, Pyienxis, Arvernie montibus.

236r. Iaclea. Glabra, foliis linearibns margine scabrinsculis, pedunculo clongato, umbella 2-5-flora. 2 . In Alpibus, Jurasso et Gebennis.

2362. Chrmmrejasme. Foliis oblongis basi angustatis integris ciliatis, pilis sin!̣licibus, pedunculo elongato, pilis mininis ramosis, umbella sub- $q$-flora, involucro pedicellis minore. $\mathcal{Y}, \vec{C} \cdot \ln \mathrm{Al}$ pibus. 2303. Septentrinnalis. Foliis lancenlatis dentatis glabris, pedunculo recto rigido, umbella mnliflora $(30)$, inrolucro ninuto. $\odot$. In Gallix anstralis frigidioribus.

236 f. Diaxina. Foliis glabris ovatis acutis dentatis, pedunculis 
congestis, umbella 3-G-flora, involucro maximo foliolis oratis, calice corollam superante. ○. In cultis Wousprelii, Melplinatûs, Galloprovincian, S.gusii, Vogescrum et 'T'uarcii.

$$
\text { 55). P } 1 \text { L } 1 \text { M U I. } 1 \text {. }
$$

Calix 5-dentatus; corolla hypocratcriformis, tubo cylindrico, fance glandulis destiluta; stamina 5 non exserla; capsnla multivalvis.

236.i. Gramliflora. Folicis ovato-oblongis rugosis dentatis, scapis mifloris, laciniis calicinis lanceolatis acutis tubum aquantibus, limbo corolla plano. 2 ; In nenoribus, scpibus, cte.

2366. Filatior. Foliis ovatis rugosis subdentatis, scapo mnltifloro, dentibus culicinis accrosis acntis vix merlium tnbi corolle xquantibus, limbo corollx pluno. $2 \mathrm{f}$. In pascuis et sylvis liumidis.

2367. Officinalis. Foliis ovato-oblongis rugosis sublentatis, pedunculo mulifloro, floribus nutantibus, dentibus caicinis obtusissimis, limbo cor llix concavo. $2 \mathrm{~L}$. In sylvis pascuis.

2365. Farinosa. Foliis ovato-oblongris suberenulatis glabris subtùs farinosis, nmbella crecta. IC. In Alpibus, Pyrenæis, Jurasso.

2369. Longifora. Foliis serratis glaluris subtis farinosis, umbella nutante, corolla tubo longissimo. $2 F$. In Alpibus Pedenontanis, Vallesiacis.

237o. Auricula. Foliis obovatis subcarnosis glabris crenatis, scapo multifloro, catice brevi subfarinoso. 2 . In Alpibus Delphinatûs, Sabandize, Pedemontii spontanca; in hortis culta.

237r. Crenata. Foliis obovatis subeamosis glabris serrato-dentatis albo-marginatis, scapo imultifloro. $2 \%$. In Delphinatu circà Gratianopolim et in Alpibus Pcdemontii.

2372. Viscosa. Foliis ovatis villoso-viscosis apice crenatis, staminibus in functo tnbi scssilibus, stylo medium tubi superante. 2 . In Alpibus et Pyrenris.

23-3. Hirsuta. Foliis ovatis villoso viscosis, tubo corollæx gracili Iongo, staminibus in medio tubi insertis, stylo breviore vix caliccin superante. 24 . In Alpibus.

23-4. Integrifolia. Foliis integris ellipticis carnosis ciliatis, calicimis dentibus obtusissimis. 2 . In Pyrenæis, Alpibus, Gebennensibus et Corbariensibus montibus.

23-5. Vilaliana. Foliis linearihus recurvatis, floribus subsessilibus, tubo clongato. $2 \mathrm{~F}$. in Alpibus, Pyrenxis.

$$
\text { 540. C O R T U S A. }
$$

Calix 5-partitus; corolla tubo subnullo, limbo subcampanulato, 5-Jobo; stamina 5; capsula bivalvis (Goertu.).

23-6. Matthioli. Culicibus corolla brevioribus. 2;, ơ. In Alpibus Pedemontanis.

$$
\text { 34. I. S O L }
$$

Corolla campanulata, laccro-multifida; stamina 5 ; capsula multivalvis, spiraliter striata. 
237\%. Alpina. 2 . In Alpibus propè nives deliquescentes.

$$
\text { 3/2. D O D E C A T H E O N. }
$$

Corolla rotuta 5-loba, lobis reflexis; stamina 5, filamentis brevibus, anthet is approximatis longissimis; capsula oblonga 5-valvis.

23-8. Mendia. 2f E Virginia orta; in hortis culta; forsan circà Alentionem spoutanea?

$$
\text { 54. 3. C Y C L A M E N. }
$$

Corolla subrotata, tubo brevi limbo 5-partito reflexo; stamina 5, antheris approxiciatis; capsula canosa, globosa, 5-valvis.

2379. Eumprum. Foliis orbiculatis cordacis crenatis. F. In sylvis umbrosis et lapidosis montium.

238o. Linearifolium. Foliis linearibus integerrimis. 2F. In Galloprovincia circà Draguiguanum, in sylvis humidis.

$$
34 \% \text { S S } 4 \text { M } 0 \text { L U s. }
$$

Calix semi-adlæerens, persistens; corolla hypocrateriformis, 5-loba, squamis 5 filiformibus introflexis è coroll simubus ortis; stamina 5 , inæ corollæ inserta; ovarium semi-inferum; capsula scmi-5-valvis.

238 r. Valerandi. Caule crecto. 2F. In paludosis.

\section{O R D O X L. RH I N A N T H A C E AE.}

Calix divisus, persistens, sæpè tubulosus; corolla hypngyna, irregularis, sepè ringens; stamina unmero definita $(2,4$ ant $\mathrm{S})$, corollæ inserta, bina interdism breviora; antheræ in plerisque basi bisetosæ; ovarium liberum; stylus simplex; capsula bivalvis, valvulis numc distinctis et semina in nervo longitndinali gerentibus, nunc coalitis dissepinento medio seminifero; perispermum carmosum; corculum rectum; cotyledones semi-teretes. - Herbæ, sxpè siccitate nigrescentes; folia opposita aut alterna aut nulla; flores singuli bracteati.

T R I B U S I. R H I N A N T H A C E

Capsula bilocularis, bivalvis; valvis nervo medio seminifero coadunatis.

\section{+ Siamina non didynama. \\ 345. P O L Y G A L A.}

Calix 3-aut-5-partitus, laciniis inæqualibns; corolla convoluta in tubum suprà fissum. limbo 2-lubiato; labiosuperiore bipartito, fisso; inferiore concavo, subtus barbato aut imberbi, intirs obtegente stamina 8 , in 2 fasces collecta; antheræ uniloculares; stigna subbifidum; capsula conspressa, obenrclata.

§.I. Corollis barbatis; calyce 5-partito colorato, laciniis 2 niajoribus alcefrimibus (POLYGALA).

2382. Vulgaris. Foliis lineari-lanceolatis unifornibus, alis calicinis ovatis capsula vix longioribus. 2 . In pascuis, siccis et sylvis. 
2383. Amara. Foliis superiorihus lineari-lanceulatis, radicalibus obuvatis, alis calicinis ovatis. $\underset{j}{j}$. In montusis.

238f. Linnspe'iaca. Foliis lineari-laneeolatis ancu!is, alis calieinis ublongis capsula longruribus. $\odot$. In collibus siccis Gallix anstralis.

2385. Snxatilis. Catule fiuticroso decumlente, foliis oblongo lasceulatis mucronatis. b. Circì Narbonem in fissuris rupimm.

5. II. Corollis imberlibus; calice 3-parlilo, lacinia superiore majore (CHAMAluxus).

2386. Chanucebuxus. Florihus imberbilus, pedunculis ierminalitus axillaribusque subbifloris, caule truticoso, foliis ublongo-lanceolatis acutis. b. In Alpibus et Alsatia montibus.

$$
3 / 46 \text {. }
$$

Calix 4-rarò-5-partitus; corolla rotata, 4-lolıa, inaqualis; stamiua 2 ; caproulit compressia, ovata ant obcordata.

\section{§. I. Racemis nxillaribus.}

2387. Mnneaina. Racemis laxis, foliis netiolatis ovatis obtusis gresse serratis, caule prostrato petiolisuge hírtis. 2 . In umbrosis lumidis.

2388. Urticrefolia. Racemis clonsatis, foliis sessilibus cordatis acutis argutè serratis, caule stricto. 2 C. In unoutosis nemorosís.

238y. Chamodrys. Foliis ovatis sessilibus rugosis dentatis, caule bifariam piloso. 20. In pratis ad sepes.

239o. Teucrimm. Foliis ovatis acutis rugosis dentatis, laciniis celicinis inrqualibus $p$ thescertibus, caulibus adscerdentibus villosis. 2.. In pascuis siccis.

2391. Prostrata. Foliis lincari-lancenlatis serratis integerrimisque, laciniis calicinis inægnalibus glaberrimis, caulibus prostratis. ?ं. In cullibus, pascuis siccis.

2392. Scutellata. Racemis laxissimis, pedicellis fructiferis penilulis, foliis linearibus subdentatis, caule debili decumbente. $\mathcal{Z}$. In inundatis.

23.3. Anagallis. Foliis lanceolatis serratis sessilibus, canle erecto. 2 . Ad fossas inque inundatis.

239 . Beccabunga. Foliis ovatis obtusissimis serratis petiolatis, caule repente. $2 \zeta$. Ad scaturigines.

2395. Dubia. Foliis ovatis dentatis basi angustatis, caule basi ralicante adsceudente, pilis sparsis vel bifariam dispositis. 2\%? In Alpibus?

2396. Offrinalis. Foliis obovatis dentatis, pilosis rugosis, canle procumbente hirtn. $2 F$. In sylrestribus sterilibus.

2397. Aliinnii. Foliis subrotundis rigilis nitidis eauleçue subrepente glaberrimis, raceno spiciformi subovato. $\mathcal{F}$. In Alpubus Delphinatûs, Galloprovinciæ et Pedemontii.

23.93. Aphylla. Sureulis repentibus apice foliusis, pedunculo mudo corymhifero axillari, capsulis obcordatis. 2f. In silpium fi $i$ gidis umbrosis. 


\section{II. Pedunculis solitariis unifloris (annuæ).}

2309. Peregrina. Glabra, floribus subsessilibus, foliis linearibus oblof is obtusis integerrimis dentatisque, caule ranıosissimo erecto ve procumbente. $\odot$. In Gallix anstralis arvis, cultis.

2400. Acinifolia. Subpubescens, floribus pedunculatis, foliis ovato oblongis obtusis glabriusculis crenatis, caule erecto. $\odot$. In humidis, cultis, etc.

2 for. Verna. Pubescens, floribus subsessilibus, foliis digitato-partitis, snmmis indivisis, caule stricto subsimplici. $\odot$. In aridis.

2fo2. Procox. Villoso-pubescens, floribus pedunculatis, foliis cordatis petiolatis profundè dentatis, superioribus integris, caule ramoso erecto. $\odot$. In agris cultis.

2fo3. Digitata. Floribus sessilibus, foliis omnibus digitato-partitis, laciniis linearibus, caule stricto. $\bigcirc$. In agris Monspelii.

2404. Arvensis. lloribus subsessilibus, foliis ovato-cordatis incisis floralibus alternis oblongis integerrimis, seminibus plurimis planis ellipticis. $\odot$. In arvis cultis.

2405. Triplayllos. Pubescens, floribus pedunculatis, foliis 3-5-digitato-partitis, infimis cordatis dentatis, caule patulo. $\odot$. In arvis cultis et humidis.

2.106. Agrestis. Floribus pedunculatis, pedunculis folio longioribus, foliis cordato-ovatis inciso-crenatis, caule patulo diffuso, seminibus plurimis umbilicato-concavis extùs corrugatis. $\odot$. In agris, hortis, ad muros, cte.

2407. Hederafolia. Foribus pedunculatis, pedunculis folio vix brevioribus, foliis petiolatis cordatis 5-lobis, caule ramoso patulo, seminibus in quoque loculo binis. $\odot$. In ruleratis, agris, hortis.

$2407^{*}$. Repens. Glabra, floribus pedunculatis, foliis ovato-rotundis integris pedicello æqualibus, caule repente. - In Corsicæ Dzontibus.

\section{III. Racemis terminalibus (perennes).}

2fo8. Spicata. Racemo spiciformi, foliis oppositis oblongis crenatis obtusis apice integerrimis, caule adscendente. 2 . In sylvaticis. - Variat spicis pluribus.

2fog. Longifolia. Polystachia, foliis oppositis verticillatisque lanceolatis serratis acuminatis, caule erecto. $2 \mathcal{L}$. In sylvaticis Alsatiæ.

2f10. Ponce. Floribus racemosis, foliis cordato-ovatis dentatis sessilibus, canle simplicissimo. 2 . In Pyrenæis orientalibus.

2'́11. Fruticulosa. Racemo corymbiformi laxo, foliis lanccolatoovatis subdentatis acmminatis, calicinis foliolis subacutis, canlibus fruticulosis ercctis. 4 . In Alpibus et Pyrenxis.

2fra. Saxatilis. Racemo corymbiformi, foliis ellipticis obtusinsculis subintegerrinis, calicinis laciniis subobusis, caulibus diffusis fruticulosis. F. In Alpibus et Pyrenxis.

2. 13. Nummularia. Racimo brevi conferto, foliis subrotundo-ovatis 
confertis, calicinis laciniis obtusis ciliatis, caulibus prostratis fruticosis. 24. In Pyrenxis.

24 r. . Bellidioides. Racemo conferto, foliis villosis ovato.oblongis obtusis apice erenatis, ealice villoso, canle simplici adscendente subnudo. 2f. In Alpibus, Pyrenais.

2415. Alpina. Ruceno conferto, foliis ohlongo lanceolatis acutis dentatis aut subintegris, calicibus hispidis, caule simplici crecto folioso. 2f. In Alpibus, Pyrenxis.

2416. Serpillifolia. Floribus solitariis racemosis, foliis ovatis glabris obtusis, inferioribus crenatis nppositis, caule basi repente. 24. In sylvaticis et pratis subhumidis.

$$
\begin{aligned}
& \text { t t Slamina 4, didynama. } \\
& \text { 347. S I в T н о R P I A. }
\end{aligned}
$$

Calix 5-partitus; corolla subrotata, tuho brevi, limbo regulari 5lobo; stamiua 4 , didynama; stigma capitutum; capsula compressa, orbicularis, apice dehiscens.

247 . Europaca. 2 . In udis aggeribus, ad margines rivulorum Gullize occidentalis.

$$
\text { 3/.8. I U P } \mathbf{H} \text { R A S I } \mathbf{A} \text {. }
$$

Calix f-fidus; corolla tubulosa, bilabiata; labium superius emarginatum, inferius trilobum æquale; stamina 4 , didynama; antheræ interiores basi acuminatæ; capsula ovata, cumpressa.

2418. Officinalis. Foliis ovatis dentatis, dentibus acuminatis, lobis labii corollæ inferioris emarginatis, laciniis calicinis subulatis. $\odot$. In pascuis aridis.

2., M. Mininta. Foliis ovatis obtusis crenatis, lobis corollæ inferioris brevioribus emarginatis, laciniis calicinis lanceolatis, caule subsimplici. $\odot$. In pascuis aridis Alpium. - Flos Iuteus.

2\{2o. Alpina. Foliis ovato-lanceolatis setaceo-dentatis, lobis labii corollæ inferioris emarginatis, laciniis calicinis lineari-setaceis. $\odot$. In Alpium pascuis aridis.

242t. Latifolia. Foliis ovatis dentato-palmatis, floribus spicatis, corollis tubulosis, lobis labii inferioris, obtusis, caule subsinplici. $\odot$. In Galliz australis pascuis montosis, collibus.

2422. Odontices. Foliis lineari-lanceolatis serratis, lobis labii corollæ inferioris obtusis, caule ramoso. $\odot$. In arvis pascuisque sterilibus.

2423. Lutea. Foliis linearibns serratis, superioribus integerrimis, calicibus pubescentibus, lobis lateralibus labii corollæ inferioris denticulatis. $\odot$. In aridis.

$2\{2\}$ : Linifolia. Foliis linearibus omnibus integerrimis, calicibus glabris. $\odot$. In aridis Galliet australis et vallium apricarum $\mathrm{Al}$ pium.

2\{25. Viscosa. Foliis lineari-lanceolatis trinerviis subintegerrimis, calicibus viscosis, lobis lateralibus labii corollæ inferioris emarginatis. ๑. In Galliz australis sterilibus. 


\section{3/49. B A R}

Calixnon ventricosus, f-fidus, inæequalis, apicibus coloratis; co . rolla tubulosa bilabiata, labium superius erectum integrum, inferins reflexum 3-fidum minimun; stamina $\{$, didynama; antheræ tomentosæ; capsuli ovata compressa.

2426. Alpina. Foliis oppositis ovato-coldatis obtusè serratis, dentibus crebris, florum spica subinterrupta foliacea. 2F. In Alpibus. 2q27. Spicata. Foliis oppositis cordiformibus obtusè serratis, dentibus remotis, floribus imbricato-spicatis. 2 . In Pyrenais.

2428. Trirago. Tomentosa, caule simplici, foliis oppositis lanceolatis obtusè serratis. $\odot$. In Galliæ australioris maritimis humidis. 2/29. Versicolor. Pubescens, caule simplici, foliis suboppositis line:ui-lanceolatis, superioribus basi obusè serratis. $\odot$. In maritimis Nicæensibus.

2429*. Maxima. Pubescens, caule ramoso, foliis supcrioribus altcrnis oblongis obtusè dentatis. $\odot$. In pascuis macilentis circà Antipolim.

2430. Viscosa. Pubescens, caule simplici, foliis lanceolatis acuminatis serratis, superioribus alternis, florihus distantibus lateralibus. $\odot$. In palndibus ad rivulos, ì Nicra ad Nannetes.

\section{R H I N A N T H U S.}

Calix f-fidus, ventricosns; corolla tubulosa bilabiata, labio supe-riore compresso, inferiore plann 3-lobo; stamina 4, didynama; capsula compressa, obtusa, calice tecta.

2 ; 1 . Glabra. Calicibus glabris. $\odot$. In pratis.

2ł32. Hirsuta. Calicibus villosis. $\odot$. In pratis siccis.

$$
\text { 35I. P E D I C U L A R I s. }
$$

Calix ventricosus, 5-fidus; corolla tubulosa bilabiata, labio superinre compresso galeato sæpiùs cmarginato, inferiore plano patulo trilobo; stamina 4, didynama; cap̧sula compressa, mucronata, sæpè obliqua et ealice longior.

\section{I. Caule ramoso.}

2\{33. Palustris. Caule ramoso, foliis pinnatis, pinnis lanceolatis pinnatifido-dentatis, calicibus ovatis inflatis bipartitis cristatis, corolle galea obtusa truncata. $\odot$. In paludibus.

$2\{3$ f. Sylvatica. Caule basi ramoso, foliis pinnatis, pinnis ovatis acute dentaris, calicibus oblongis inflatis inæqualiter 5 - ficlis cristatis, corollex galea obtusa truncata acute bidentata. $\odot$. In sylvis paludosis.

\section{§. II. Caule simplici; foribrs purpureis.}

2ł35. Recutita. Foliis profundè pinnatifidis, pinnis lanceolatis pinnatifidis dentatis, spica conıpacti foliosa, calicibus glabris quinquedentatis, corollæ galea oblasissima. 2 . In Alpibus.

$2\left\{3 i^{*}\right.$. Atrorubens. Ioliis profundè pinnatifidis, pinnis lanceolatis 
dentatis, calicibus villosulis quinqueficlis. cornller galor nncianala lereviter acmminato-trnncata. - Schleich. Cent. exs. n. 65. - In suano Sanct-Bernhardi inonte.

2.\{36. Inrumata. Inoliis profunde pinnatifidis, pinnis inrqualiter dentatis lincari-lanceolatis, calicibus villosis j-fidis, corolla galea nncinata longè acuminata. $\odot$. In Delphimstus et l'edemontil $\Delta 1$ pibus.

2\}37. Terticillata. Foliis caulinis pinnatifidis quaternis, pinnis oblongis ohtusis rentatis, spica capitata, calicabus hirsutis 5-dentatis, corollx galea ohtusissinta. 2 . In Alnibus et P'yrenxis.

3/38. Rostrata. Foliis pinnatis, pinnis oblongis pinnatifidis dentatis, calicilus hirsutis 5-fulis cristatis, cotollat galcal uncinato-acuminata truncita. 2f. In Alpibus et Pyrenais.

$2,7^{3} \mathrm{~g}$. Cirmplexa. Foliis pinnatis, pimnis prolandie pinnatifidis obtusis, calicibns 5 -ficlis cristatis glabris, corollie gillea uncinata obtusa enarginata hidentata. $2 f$. In $A]_{\text {pibns. }}$

2fín. Fasciculata. Foliis pinnatis, pinnis profundè pinnatifidis, pinuis linearibus dentatis, calicibus 5 -fuclis cristatis, corolla galea adunca apice tridentata. 2 . In Pedemontii Alpibus.

xfí. Rosec. Foliis pinnatis, pinnis pinnatifidis lincarihns acntis, calicihus hirsutis 5 -fitis, corollia gajea obtusa. $2 \%$. In Alpibus.

\section{j. III. Caule simplici; foribus fasis.}

2fí2. Flammea. Foliis pinnatis, ninnis inubricatis oratis obtusis duplicato-dentatis, calicibus 5-dentitis, corollæ galea abtrisa. 2 \% In Sabandix et l'edemontii Alpibus.

2łł3. Tuberosa. Foliis pinhatis, pimnis profundè pinnatifulis dentalis, calicihus 5-fulis subcristatis, corrller galca uncinata acuninata cmarginata. 2 . In Alpibus ct I'yrenxis.

24î. Comosa. Foliis pinnatis, pinnis pinnatifilis subrentatis, spica foliosa, calicibus 5-fidis, corollæ galea bidentata. 25 . In Alpibus et Pyrerixis in pratio.

2亿彳̆. Folinsa. Foliis canlinis profundè pinnatifidis, pinnis lanceo-

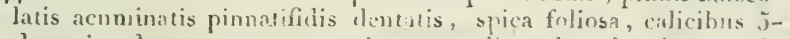
dentiltis, dente: superore miximo, corodis gisied obtusissina. $\sigma$. In Alpibus et Pyrenais.

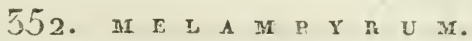

Calix tubulosus, f-fidus; corolla tnijulosa, 2-labiata, compressa, labio supcriore galeato mirgine replicato, inferiore sulcato 3-fido; stamina! didynuma; capstrla oblonga olsliçui acuminaia compressa, loenlis nonospermis.

2if6. Ariense. Spicis conicis laxis, bracteis dentato-setaceis coloratis, cahcum dentibns scabris. $\odot$. In agris.

2.fí7. Cistatzm. Spicis quadrangularibus, bracteis cordatis compact is denticulatis imhricatis. $\odot$. In sylvaticis.

2fiS. Fomorosum. Floribus secuudis Iateralibus, bracieis dentatis 
cordato-Janccolatis, summis coloratis sterilibus, calicibus lanatis.

○. Iı Delphinatûs Pelemontii et Jurassi nemoribus.

2449. Pratense. Floribus axillaribus sccundis, corollis clausis. $\odot$. In pratis.

2450. Sylvaticum. Floribus axillaribus secundis, corollis hiantibus. $\odot$. In sylvis montosis.

$$
\text { 353. T } 0 \text { z } \quad \text { z } \quad \text { I A. }
$$

Calix tubulosus, brevis , 5-dentatus; corolla tubulosa, limbo subxquali suprà 2 lobo, infrà 3 -lobo; stamina 4 , didynama; antheræ basi setula aristatæ; capsula sphærica, 2-valvis, 1-sperma.

$245 \mathrm{r}$. Aipina. 2 . In asperis humidis, in Alpibus et Pyrenæis.

$$
\text { T R I B US II. O R O B A N C H E E. }
$$

Capsula I-locularis, 2-valvis; valvulis liberis in nervo longitudinali seminiferis.

$$
\text { 35作 O R O B A N C H E. }
$$

Calix bipartitus, laciniis 2-lobis; corolla tubulosa, bilabiata , 4-5loba, stamina 4 , didynama; ovarium basi glandulosum; stylus I; stigma 2-lobum.

\section{§. I. Floribus nnibracteatis; corollis 4 -lobis.}

2,552. Major. Canle simplicissimo, corollis quadrifidis inflatis, staminibus infernè glabris, stig̨mate bilobo, Jobis distantibus, stylo supernè pubescente. $2 \%$. In nemoribus siccis, parasitica imprimis radicum Leguninosarum.

2453. Vu!garis. Caule simplici, corolla inflata fimbriato-crispa, labio inferiore laciniis obtusis requalibus, staminibus intus basi hirsutis. 24. In agris nemoribusque.

2454. Minor. Caule simplicissimo, corollis quadrifidis, staminibus infernè pilosis, stigmate reflexo, stylo supernè glabro. $\mathcal{}$. In agris et pascuis.

2455. Elatior. Caule simplicissimo, corollis quadrifidis, staminibus infernè pilosis, stigmate obcordato, stylo supernè glabro. $\mathcal{H}$. In agris et sylraticis.

2\{56. Epithymum. Caule simplicissimo pancifloro, pilis subglandulosis, corollis quadrifidis crenulatis lobis obtusis, staminibus basi hirsutis, styio snpernè glabro. 2 . Circà Lutetiam, in aridis montosis, parasitica in Thymm seıpyllum.

\section{II. Floribus 3-bracteatis; corollis 5-lobis.}

2,57. Corulea. Caule snbsimplici, calicibus semiquadrifidis tubulatis. $\odot$ ? ? ? In agris pascuis ct collibus graminosis.

2458. Ramosa. Caule ramoso, calicibus brevibus profundè quadrifidis. 4 ? $\odot$ ? In agris aridis montosis, parasitica in radice Cannabis sativie. 
Calix campannlatus, 4-fidus; corolla tubulosa, 2-Iabiata, lahio superiore galeato; stamina 4 , didynama; ovarium basi glandulosum ; stylus I; stigna 2-lobum.

2459. Clandestina. Caule ramoso subterrestri, floribns erectis solitariis. 2 4 . In umbrosis.

2460.Squammaria. Caule simplicissimo, corollis pendulis, lubio inferione trifido. $\Psi$. In frigidis umbrosis.

\section{O R D O XLI. A C A N T II A C AE.}

Calix divisns, persistens, sæṗ bracteatus; corolla irregnlaris ; stamina 2 aut f didynama; ovarium liberum; stylus I ; stigma bilobum; capsula bilocularis, sæpè polysperna, elasticè bivalvis, dissepimento valvis opposito, iisdem mediis innascente, scissili ab apice ad hasim in receptacula duo utrinquè seminifera et continua valvis indè senu-bilocularibus; perispernum nullum; radicula infera; cotyledones foliaceæ.

$$
\text { 556. A C A N T H U S. }
$$

Calix 4-partitus, subbilabiatus; corolla tubo brevi villis clauso, h.bio unico inferiore maximo 3-lobo; stamina 4, didynama; antheræe anteriùs villosæ; stigna bifidum; capsula ovata, loculis 1-2-spernis. 2461. Mollis. Foliis sinuatis inermibus. $\psi$. In Galliæ mediterrancæ humidis et umbrosis.

2462. Spinnsus. Foliis pinnatis margine spinosis. 4 . In Gralliæ mediterraneæ humidis et umbrosis.

\section{O R D O X L I. J A S MI I N E AE.}

Caliz tubulosus; corolla tubulosa, regularis (in Fraxino nuila aut polypctala); stamina sæpiùs 2 , corolla inserta; fructus nunc capsula Acanthacearum nore bivalvis, nunc drupa aut bacca, nunc 2 -locularis 2-spermus, nune 1-locularis 1-4-spermus; corculum rectum planum, in plerisyue perispermo carnoso involintum. Arbores; folia ramique oppositi; flores opposité paniculati aut corymibosi.

\section{R I B U S I. I I L A C E IE.}

\section{Fructus capsularis.}

$$
\text { 357. I I } \Sigma \text { А c. }
$$

Calix parvus, 4 -dentatus; corolla tubulosa, limbo 4 -partito ; stamina 2 , inted tubum; capsula ovata, conpressa, 'z-locularis, medio 2-valvis, 2-sperna; valvé naviculares, medio semi-septiferæ.

2463. Vulgaris. Foliis cordatis. ந. Ex Oriente orta, nunc ferè spontanea, in monte dicto Uzore in Forensi agro invenit Berger. 2\{6\}. Persica. Foliis lanceolatis integris pinnatifidisque. 5. Colitur in hortis. 


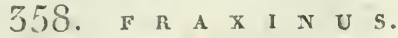

Caliso, vel 3-4-partitus; corolla o, vel 4 partita, quasi 4-petala; stamina 2 ; capsula plana, linguiformis, pendula, basi monosperma. §. I. Floribus nudis, nunquàm hermaphroditis; antheris sessilibus. (FRAXINCS.)

2f65. Excelsior. Foliolis subsessilibus lanceolato-oblongis attenuaıis serratis, capsulis apice obliquè eınarginatis. b. In subhumidis.

9. II. Floribus caliculatis tetrapetalis; antheris pedicellatis. (oRvis.)

2f(i6. Flnrifera. Foliolis lanceolatis attenuatis petinlatis serratis. $\mathbf{b}$. Ornus Europæa. Pers. Ench. 9. - In Gallix australis moutibus.

T R I B U S I I. I A S M I N E E.

Fructus baccalus aut drupaceus.

$$
559 \text {. о L } \mathrm{E} \text { A. }
$$

Calix parvus, 4-dentatus; corolla tubo brevi, limbo f-fido, laciniis cratis; stamina 2 ; laciniæ stigmatis emarginata; drupa nace 2-loculari, 2-sperma, abortu I-loculari monospermá.

2467. Eumpar. Foliis lanceolatis integerrimis, paginis discoloribus, racemis paniculatis. 1). Culta in Gallia Mediternanea.

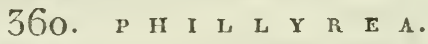

Calix minimus, 4-lentatus; corolla brevis, 4 -fida; stamina 2 ; bacca 1-locularis, monosperma.

2.469. Latifolia. Foliis lancenlatis nblongisque, integerrimis serratisque. b. In Galliæ australioris collibus.

$2\} 60$. Angustifolia. Foliis lineari-lanceolatis integerrimis. ந. In Gallia australi.

$$
\text { 36I. J A S MI I IN U IM. }
$$

Calix 5-ficlus; corolla tubulosa, limbo 5-partitn plano, lacinits obiiquis; bacca bilocularis, loculis monospermis; semina arillata.

247o. Officinale. Foliis oppositis pinnatis, foliolis acuminatis, gemmis erectiusculis. b. Ex India ortum; in hortis cultum.

2.:1. Fruticans. Folits alternis ternatis simplicilusque, foliolis snbcmeatis, laciniis calicinis subulatis. J. In Gallia autrali, ad sepes et vineas.

$$
\text { 362. L I G U S }
$$

Calix minimus, 4-dentatus; corolla tuho brevi, limbo 4-fido patente; stamina 2 ; bacca unilocularis, 2-4-sperma.

34; 2. Vulgare. Foliis cllipticn-lanceolatis glabris, racemis compositis coarctatis. b. In glaceosis, ad sejes. 


\section{O R D O XLIII. PY}

Calix unbulnsus, smpè persistens; corolla tutulosa. sappiizs irregularib; stamina 4, didynamat, 1 arius 2 ant 6; ovarmu liberum; stylus 1; stigma simplex aut 2-lobum; periearpium cau nosum, 1-4 pyrina monosperma continens; semina aut pyrena interalim membrana mericulari inclusa; corenlum rectum; radicula infera; perispernum nullum. - Herba ant frutiees; folia upposita.

$$
\text { 563. V } \quad \text { I } \quad \text { T } \quad \text { E } \quad x \text {. }
$$

Calix brevis, 5 -dentatus; cornlla thho temui, limbn plano subbilabiato 5-6-loho inxquali; stamina f, didynama; drupa sieca tenuis, putamine ossen 4-loculari, 4-spermo.

2473. Agnus-Castus. Foliis digitatis septenatis quinatisve, foliolis lanceolatis subintegerrimis, spicis verticillatis paniculatis. b. In Gallia australioris paludosis.

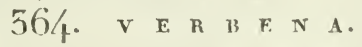

Calix r.fulus; corolla limbo subbilabiato 5 - loho inæquali; stamina $\{$ didynama; textus utricularis nectens semina 4 .

2 f7 f. Officinalis. Foliis multifido-laciniatis, spicis filiformibus paniculatis, caule erecto solitario. $\odot$. In ruderatis.

2,-5. Supina. Foliis bipinnatifulis, spicis filiformibus solitariis,

caulilus ramosissimis decumbentibus. $\odot$. In Galloprov. caupis.

\section{O R D O X L I V. LA B I A T AE.}

Calix tubnlosus, 5-fidus aut bilabiatus; corolla tubulosa, irregularis, sæpiùs hilabiata, labio superiore sæpiùs bifidn, inferiore trifido; stamina rariùs 2 , sæpissimé f́didynanıa, sub labio corolla superiori inserta ; orarinn liberum, q-Jobum; stylus $\mathrm{r}$, inter ovarii lobos enatus; stigma bifidum; semina \& nuda (cariopsides) imo calice recondita, interdim pilis obtecta; perispermum nullum; corculum rectunı; radicula infera; cotyledones planx. - Canlis herbacens aut sufrutescens, tetragonus; folia oppesita; flores oppositi aut veıticillati, axillares ant spicati, bracteis sæpè stipati.

\section{† Stamina 2, fertilia. \\ 565. ᄂ y c o $\quad$ p u s.}

Catix tubulosus, 5-fidus, ore nudo; corolla tubulosa q-loba subæqualis, lobo superiore latiore emirginato.

2द ;. Europrus. Foliis siuuato-serratis appendiculatis, 2 . In lacubus, ad ripas.

24́77. Exaltatus. Foliis pinnatifidis, cáule altissimo. ₹. In Gallize anstralis humidis.

$$
\text { 366. c U N I } 4 \text { A. }
$$

Cilix cylindricus ro-striatus 5-dentatus, ore villis clauso; corolla bilabiata, sıperiùs erecta plana emargirıta, inferiùs 3-loba. 
2'fร. Thymoirles. Foliis ovalibus integerrimis, florihus verticillatis. $\odot$. Monspclii.

$$
\text { 367. } \mathrm{R} \text { O } \mathrm{S} \text { M A } \mathrm{A} \text { I } \mathrm{N} \text { U } \mathrm{S} \text {. }
$$

Calix compressus, bilabiatus, suprả integer, infrà 2-fidus, ore nudo; corolla bilabiata, superiù 2-fielit, inferius 3 -fida.

2479. Officinalis. Foliis sessilibus. Đ. In Galliæ Nediterraneæ montanis apricis.

$$
\text { 368. S A L V I A. }
$$

Calix subcampanulatus, bilabiatus, labio superiore 3-dentato, infero 2 -fido, ore nudo; corolla ringens, superiùs fornicata cmarginata; stamina transversè pedicello affixa.

\section{I. Pedicello in medio filamenti affixo (sa svia).}

2\{9o. Officinalis. Foliis lanceolato-ovatis crennlatis, verticillis paucifloris, calicibus mucronatis bracteas superantibns. b. In Gallia australi.

\section{II. Labio corolla superiore compresso ( $S C L A R E A)$.}

248 r. Pratensis. Foliis cordato-oblongis crenatis, snmmis amplexicaulibus, verticillis subnudis, corollis galea glutinosis. $\mathcal{4}$. In pratis.

2481*. Pyrenaica. Villoso-viscosa, foliis dentato-sinuatis obtusis, staminibus corolla duplù longioribus. 4 . Sulvia pyrcnaica. Liun. Syst. 7 . Herm. parad. p. is7. ic. - In Pyrenxis.

2482. Sylvestris. Foliis subcordatis rugosis biserratis, bracteis coloratis calice brevinribus, pilis canlis calicisque simplicibus. $\mathcal{Z}$. In Gallia anstrali, in vineis ct ad margines agrorum.

2483. Sclarea. Foliis rugosis cordatis oblongis villosis serratis, bracteis coloratis calice longioribus. $\sigma$. Iu aridis montosis.

2 亿̊. Glutinnsa. Villoso-viscosa, foliis cordato-sagittatis grossè serratis acuminatis. $\mathcal{Y}$. In sylvis montanis.

2:f5. Ethiopis. Foliis oblongis erosis verticillisque lanatis, bracteis recurvatis subspinosis. $\sigma^{7}$. In Gallix australioris aridis.

\section{III. Labio corolla superiore fornicato, non compresso}

$$
\text { ( LORMINUM). }
$$

2\{86. Horminum. Foliis obtusis crenatis, bracteis summis sterilibus majoribus coloratis, stylo labio superiore longiore. $\odot$. Secus agros Nicx et in vallibus Pedemontii.

2487. Viridis. Foliis oblongis, bractcis summis stcrilibus non coloratis, stylo galea suborbiculata breviore. $\odot$. Oneliæ.

2\%88. Verbenaca. Foliis serratis sinuatis læviusculis, corollis calice angustioribus. $\mathcal{H}$. In pascuis siccis montanis.

$2\} 89$. Werticillata. Foliis cordatis crenato-dentatis, verticillis snhnudis, stylo corolla labio inferiore incumbente. $\odot$. Ad agrorum et viaruni margines.

źgo. Hispanica. Foliis ovatis serratis, petiolis utrinque mucrona- 
tis, spicis imbricatis, bracteis ovatis ciliatis attenoatis. $\odot$. In olivetis Onelix.

$$
\begin{gathered}
\text { t Stamina 4, didynama, fertilia. } \\
369 \text { × J U G } .
\end{gathered}
$$

Calix 5-fidus, subxqualis; corolla tubulosa labiata, lahio superiore minimo bidentato, interiore trilobo, lobo medio magno obcordato; cariopsides reticulatæ.

\section{〕. I. Floribus axillaribus, spicatis (BUGULA).}

249 r. Reptans. Stolonibus reptantibus. $2 \mathcal{C}$. In sylvaticis humidis. 2492. Alpina. Foliis caulinis integris radicalia requantibus. 24 . In sylvis montosis.

2493. Pyramidalis. Tetragono-pyramidalis villosa, foliis radicalibus maximis, labio coroll inferiore majore trilobo, intermedio emarginato. $\sigma$. In sylvaticis.

249'. Genevensis. Villosa, foliis radicalibus caulinis sublobatis minoribus, lobo intermedio labii corollæe inferioris breviore. $\mathcal{4}$. In aridis sylvaticis.

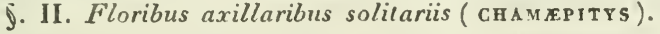

2495. Chanıcepitys. Foliis trifidis, floribus axillaribus solitariis folio brevioribus, caule difluso. $\odot$. In agris arenosis lapidosis.

${ }^{2}\left\{9^{6 .}\right.$ Iva. Foliis linearibus anticè dentatis, floribns axillaribus solitariis. $\odot$. In Gallia Mediterranea.

$$
\text { 370. T E U C R I U } \mathbf{M} \text {. }
$$

Calix tubulosus, rarò campanulatus, 5 -fidus; corolla tubo brevi Jabiata, labio superiore 2 - partito laciniis ad latera reflexis, inferiore 3-lobo, lobo medio majore; stamina intrà fissuram labii superioris exserta; cariopsides laves.

5. I. Floribus axillaribus, calicibus campanulatis (TEUCRIUM).

2ł97. Fruticans. Caule frutescente, foliis lanceolatis integerrimis subtìs niveis, floribus solitariis. b. In sterilibus siccis Galliæ australioris.

\section{§. II. Floribus axillaribus vel racemosis terminalibus \\ ( CHAM EDRY ).}

249S. Botrys. Foliis multifidis, verticillis dimidiatis. $\odot$. In apricis cultis.

2499. Pseudo-chamapilys. Foliis tripartitis trifidis linearibus, floribus racemosis, caule hirto. 2 L. In sterilibus maritinis Massiliæ.

250o. Mrartm. Foliis integerrimis ovatis acutis petiolatis, subtùs tomentosis, floribus racemosis secundis. F. In maritimis Galloprovinciæ et insulis Stæclıadum.

250x. Scorodonia. Foliis cordatis subpubescentibus dentatis petiolatis, racemis axillaribus secundis, caule erecto. 4 . In sylvis arenosis.

2502. Resupinatum. Foliis cuneiformi-lanceolatis serratis villosis, 
racemis axillaribus terminalibusque, corcllis resupinatis. $\odot$. In Gralliæ Narbonenšis montibus Corbariensibns.

2jo3. Scordium. Foliis oblongis sessilibns dentatis nudiusenlis, floribus axillaribus pedunculatis geminis, canle diffuso pubescente. 24. In palndosis.

250 f. Chamadrys. Foliis cunciformi-ovatis incisis crenatis petiolatis, floribus ternis, caulibus subprocumbentibus villosis. 2 . In apricis sylvaticis.

2505. Lucidum. Foliis ovatis inciso-scrratis glabris, verticillis dimidiatis, caulibus erectis levibus. 24 . In sylvis Alpinm australiorum.

2506. Flavum. Foliis ovatis crenatis, floribus integerrimis, verticillis dimiliatis in racemos digestis, caule fruticoso pulsescente. b. In collibus asperis Galliæ Mediterranex et Burgundiæ.

2507. Massiliense. Foliis ovatis rugosis inciso - crenatis incanis, caulibus erectis suffruticosis, racemis rectis secundis. b. In maritimis insularum Stachadum et circìt Villamfrancam.

2508. Pyrenaicum. Corymbis terminalibus, foliis cuneiformi-orbiculatis crenatis pilosis. 24 . In Pyrenais, Arvernia.

2509 . Iontanum. Procumbens, corymbis terminalibus, calicis dentibus acutis muticis, foliis lanceolatis integerrimis subtus tonentosis. 2. In saxosis rupestribus siecis.

2510. Polium. Capitulis subrotundis pedunculatis, foliis lanceolatnoblongis obtusis crenatis tomentosis, caule decumbente. b. In Gallie australis montosis et matitimis.

$2 j$ 1. Flavicans. 'Tementosum, capitulis subrotmodis subsessilibus, foliis linearibus anticè crenatis velovatis serratis, summitatibus flarescentibus. b. In Galliæ australis rupestribus.

25:2. Capilalum. Capitulis subrotundis breviter perlunculatis , foliis linceolatis linearibusque crenatis tomentosis nivcis, caule erecto. 3. In Gullize australis suxosis aridis.

$$
\text { 37I. S A T U R E I A. }
$$

Corolla limbo 5-Ioho subrequali; stamina distantia.

j. I. Calix campanulatus, lavis, ore nudo (sATUREIA).

2513. Capilata. Floribus spicatis, foliis punctatis ciliatis. b. In Gilloprovincia.

251 f. Hortensis. Pedunculis axillaribus biforis, foliis lanceolatis integerrimis $\odot$. In Gallix australis aridis et agris.

2515. Thymbra. Verticillis subroundis hispidis, folitis obnvatooblongis acuminatis punctatis hispiais. 24 . Ad colles lap,idosns agri Nicacusis.

2516. Afomana. Pedunculis axillaribus subcymosis, foliis lincarilanceulatis incegerimis mucronatis, $2 C$. In Gallia australis monlassis. 
5.II. Culix cylindricris in-striatus, fructiferus villis clausus

( $\triangle A$ BATTIA) .

25r7. Julianu. Pedunculis axillaribus 3-6-1loris, foliis lanceolatolinearibus. 2L. In aridis Nicare.

2518. Creeca. Pedunculis axillaribns 3-6-floris, bracteis calice brevioribus, foliis ovatis hispidis subtus venosis. $\mathcal{F}$. In aridis Nicax.

$$
572 . \text { T H } \mathbf{Y} \text { M } \mathbf{B} \text { R } \mathbf{A} \text {. }
$$

Calix compressus, fauce nuda, extùs utrinquec linea villosa exaratus; corolla 5-loba subrequalis.

2519. Spicata. Floribus spicatis. b. In Pedemontii aridis.

$$
\text { 373. н у s s. o } \mathbf{p} \text { U s. }
$$

Calix substriatus, fance nuda; corollæ labium supes ius brevè emarginatum, inferius trilobum lobo intermedio majore obcordato crenulato.

2520. Officinalis. Floribus verticillatis racemosis secundis, lacinia corolla intermedia biloba integerrima, foliis lanceolatis. $\mathcal{F}$. In $\mathrm{col}-$ lihứs Pedemontii, Galloprovincixe et circà Vapincum.

$$
\text { 374. N E P E T A. }
$$

Calix cylindricus, fauce nuda; corolle tubus longus, faux patens, limbus 2-labiatus suprà emarginatus, infia trilobus, lobis lateralibus brevissinis reflexis, medio majore erenato concavo.

2521 . Cataria. FInribns spicatis, verticillis subpedicellatis, foliis petiolatis cordatis dentato-serratis. 2 . In Japidosis, campis.

252. Lanceolata. Floribns cymosis, verticillis superioribus confertis, foliis pubescentibus lanceolatis profundè dentatis acutis, inferioribus subcordatis. $\underset{f}{ }$. In Galliæ australis montanis.

2523. Nepetella. Cymis perlunculatis, foliis cordatis oblongo-lanceolatis profunde serratis crenatis. $\mathcal{H}$. In montis Cenisii locis humilioribus apricis asperis.

252 \% Nuda. Florum raccmis verticillatis nudis, foliis cordatooblongis sessilibus serratis. $\%$. In Galliz australis pascuis, collibus. 2525. Latifolia. Panicula ramosa subnuda, foliis sessilibns ovatolanceolatis ohtusè dentatis, calicinis dentibus ciliatis, caule villoso. - In Pyrenæis orientalibus.

$$
\text { 375. L A V A N D U L A. }
$$

Calix ovatus, intus nudus, bractea suffultns, subbilabiatus, superì̀s integer, inferius 2-lobns; corolla tubo longo, limbo 5-lobo subæquali; stamina non exserta.

2526. Spica. Foliis sessilibus lanceolato-linearihus integerrimis, spica intermptá nuda. b. In Galliæ anstralioris sterilibus.

2527. Stharhas. Foliis sessilibus linearibus tomentosis integerrimis, spica coarctata comosa, hracteis subtrilobis. \$. In Gallia anstraliori.

$$
\text { 376. S I D } \quad \text { E } \quad \text { R } 1 \text { I }
$$

Calix 5-lobns; corolla calici xqualis aut sxpius longior, 2 labiata, 
superiùs integra aut emarginata, inferiùs triloba, lobo intermedio latiore crenulato; stamina non exserta; stigma alterum longius breviore altero involutum.

S.I.Bracteis nullis; calicibus villis clausis, bilabiatis; labio superiore lato ovato, inferiore quadridentalo (BURGSDORFIA).

2528. Romana. Herbacea decumbens, calicibus spinosis. ๑. In Galliæ anstralis aridis.

5. II. Bracteis nullis; calicibus villis clausis, bilabiatis; labio superiore tridentalo, inferiore bilobo (HESIODIA).

2529. Montana. Herbacea prostrata, calicibus corolla majoribus spinosis. $\odot$. In Galliæ australis montanis.

๑. III. Floribus bracteatis; calice quinquefido nudo (s I DER Iт Is). 253o. Perfoliata. Herbacea piloso-hispida, foliis superioribus lanceolatis amplexicaulibus denticulatis, bracteis cordatis acnminatis reticulato-nervosis, margine pilosis. $\mathcal{F}$. In arenosis Monspelii.

253r. Incana. Suffruticosa tomentosa, foliis lanceolato-linearibus integerrimis, bracteis dentatis, lobis lateralibus corollæ labii inferioris acutis. b. In Pyrenæis.

2532. Hyssopifolia. Herbacea subglabra, foliis lanceolatis subintegerrimis, bracteis cordatis dentato-spinosis, cálicibus æqualibus, verticillis approximatis. 2 . In Alpibus et Pyrenæis.

2533. Scordioides. Herbacea subvillosa, foliis lanceolatis subdentatis, bracteis ovatis dentato-spinosis, calicibus æqualibus, verticillis inferioribus remotis. 4 , ๖. In Galliæ australis aridis.

\section{M E N T H A.}

Corolla calice paulò longior, 4-loba, subæqualis; lobo superiore latiore sæpiùs emarginato; stamina distantia.

§. I. Calice intùs nudo, lobo superiore corolla emarginato ( MENTHA).

2534. Sylvestris. Spicis oblongis subcontinuis, foliis ovatis oblongisque sessilibus tomentosis argutè inæqualiter serratis, bracteis subulatis calice longioribus. 24 . In ruderitis, humidis.

2535. Rotundifolia. Spicis oblongis interruptis, foliis subrotundis rugosis crenatis sessilibus, bracteis lanceolatis. 24. In aquosis.

2536. Viridis. Spicis interruptis gracilibus acutis, pedicellis glabris, foliis lanceolatis glabris serratis sessilibus. 2 . In humidis, Parisiis.

2537. Piperita. Spicis obtusis infernè interruptis, foliis petiolatis subovatis glabriuscnlis, calice basi glaberrimo. 4 . In aquosis.

2538. Hirsuta. Floribus capitatis, foliis ovatis petiolatis subsessilibusque serratis pubescentibus, pedicellis calicibusque hirsutis. $\mathcal{F}$. In aquosis.

2539. Sativa. Floribus verticillatis axillaribus, foliis ovatis acutiusculis serratis, calicibus cylindricis. $\mathcal{Y}$. In humidis. 
25 fo. Arvensis. Floribus verticillatis axillarilus, foliis ovatis arculis serratis, calicilus campammlatis pedicellisque hirsutis. 2 . In canpis humidis fiequens post messe's.

25: Centilis. Floribus verticillatis axillaribus, foliis ovalis acutis serratis, calicibus subeampanulatis margine hirsutis, basi et pedicellis glabiis. $2 \mathcal{H}$. In aquesis.

25:2. Rubra. Floribus verticillat is axillaribus, foliis ovatis, caule erecto flexuoso, pedicellis calicibnsque glaberrinis, dentibus hirsutis. 2 . In aquosis.

\section{j. II. Calice villis clauso; lobo superiore corollce integro}

$$
\text { (PULEGIUM). }
$$

2543. Pulegium. FIoribus verticillatis, foliis ovatis obtusis subcrenatis, caulibus repentibus. 2 . In inundatis, arl ripas.

254f. Cervina. Florihus verticillatis, foliis linearibus punctatis. $\mathcal{F}$. In Gallia australis hunudis.

$$
\text { 378. G L E C H O } \mathbf{M} \text { A. }
$$

Calix striatus, cylindricus, fructiferus nudus; corolla calice duplú longior, 2-labiata, labio superiore 2 -fido, inferiore 3 -fullo, lacinia intermedia majore eraarginata; antheræ per paria in geminam crucem conuiventes.

25 45 . Ilederacea. Foliis reniformibus crenatis. 24 . In sepibus, paluilosis.

25\%6. Grandiflora. Foliis ovatis lobato-crenatis, floribus solitariis. - In Corsica.

$$
\text { 379. O R V A I A. }
$$

Calix 5-dentatus, nudus, apice patens; corollæ faux inflata utrinquè appendice trilobo, labio supcriore fornicato dentato, inferiore triloho, lobis lateralibus minimis reflexis, medio majorc emarginato; antheræ glabræ.

2547. Lamioides. Foliis cordatis inæqualiter argutèque serratis. 4 . Lucis umbrosis montanis Pedemontii, circà Nannetes.

\section{SO. I A MI I U $\mathbf{M}$.}

Calix 5-dentatus, aristatus, nudus, apice patens; corolla longior, fance inflata, limbo labiato suprà fornicato integro, infrà trilobo, lobis lateralibus minim is reflexis, medio majore enarginato; antheræ extùs hirsutæ.

25 9 . Gaıganicum. Folis cordatis pubescentibus, verticillis ro-floris, corollis fauce inflata, dente utrinquè unico (gemino, L.). 2$\}$. In Alpibus Manrianensibus et Pedemontanis rarius.

2549. Album. Foliis cordatis acuminatis serratis petiolatis, verticillis 20-floris. $Y$. In incultis.

2550. Maculatum. Foliis cordatis acuminatis serratis petiolatis, verticillis ro-floris. 24. In Alsatia et Galloprovincia.

2551. Lavigatum. Foliis cordatis rugosis serratis petiolatis, caule 
sublavi, calicibus glabris longitudine tubi corolla, verticilis sub6-floris. 2 . In Alsatiæ iucultis, in Gallia atustrali?

3552. Hirsutum. Foliis cordatis acutis duplicato-serratis cauleque pilosis, verticillis subsexfloris. 2 ? In monte Aureo.

2553. Purpureum. Foliis cordatis obtusis æqualiter obtusè dentatis petiolatis, verticillis $8-10$-floris. $\odot$. In cultis.

255\%. Hy bridum. Foliis cordatis acutiusculis inciso-dentatis petiolatis, corollis calice angustioribus. $\odot$. In cultis.

2555. Amplexicaule. Foliis floralibus sessilibus anıplexicaulibus obtusis, corollæ tubo gracili. $\odot$. In cultis ruderatis.

$$
\text { 58I. G A L E o P S I s. }
$$

Calix campanulatus 5-dentatus spinosus; corolla tubo brevi, fauce dilatata bidentata, limbo 2-labiato suprà fornicato crenato, infıà 3lobo, lobis inæuualibus; antheræ intùs subhirsutæ.

2556. Ochrolenca. Foliis ovatis petiolatis serratis, verticillis distantibus, corollis longè tubulusis. $\odot$. In agris.

2557. Ladinum. Foliis lanccolatis subintegris, verticillis distantibus, calicibus pubescentibus. $\odot$. In agris, cultis.

2558. Parviflora. Foliis ovatis aqualiter serratis petiolatis, corollis calice hirsuto vix majoribus. $\odot$. In cultis, agris.

2559. Tetrahit. Foliis ovatis hispidis serratis, caule hispido, internodiis caulinis incrassatis, corolla calice pungente dujlò Inngiore. $\odot$. In arvis.

2560. Versicolor. Foliis oblongis serratis, caule hispido, internodiis supernè incrassatis, corolla calice pungente triplò longiore , galea ventricosa. $\odot$. In agris.

$$
\text { 582. B E T O N I C A. }
$$

Calix 5-dentatus aristatus, fauce nuda; coroll $x$ tubus gracilis, limbus bilabiatus, suprà erectuosubrotundus integer vel emarginatus, infrù trifidus.

2561. Oficinalis. Spica interrupta, corollæ galea integra, lacinia intermedia labii inferioris emarginata, calicibus glabris. 24 . In pascuis, sylvaticis.

2562. Stricta. Spica oblonga, corollæ galea integra, lacinia intermedia labii inferioris crenato-tandulata, calicibus pilosis. 3 . In pratis montosis.

2563. Hirsuta. Spica ovala oblusissima foliosa, corollæ galea integra, laciniis lateralibus la! ii inferioris augustioribus acuminatis, calicibus glabriusculis. $2 \mathcal{C}$. In Alpibus.

2564. Orientalis. Spica integra, corolla galea latiore subrotunda, laciniis lateralibus labij inferioris obtusis, calicibus tuberculatis pubescentibus. 2 . In sylvis Meldæ? An sata?

2565. Alopecuros. Villosa, spica ob!onga lasi foliosa, corolla: galea curarginata, labio inferiore longiore. $\mathcal{Y}$. In Alpibus. 


\section{L $\Lambda$ B I A T $\mathbb{A}$. \\ 58\%. S T A c II $\mathrm{Y}$.}

Calix angulatus, 5-dentatus, acuminatus; corolla tubo brevi, limbo suprà fornicato enarginato, infrì trilobo lateribus reflexis; stamina deflorata ad latus utringuè reflexat.

2566. Sylvaticr. Verticillis sexfloris, foliis cordatis ovatis petiolatis. $\mathcal{2}$. In nemoribus umbrosis.

2567. Palustris. Verticillis subsexforis, foliis lance latis subglabris sessilibus semi-amplexicaulibus. 2 . In lımiclis aquosis.

2568. Alpina. 'Tomentosa, verticillis subsexforis, foliis cordatis ovatis obtusis petiolatis, corollis labio superiore plano. 2 . Ln umbrosis.

2569. Germanica. Lanata, verticillis multifloris, foliis ovatis acutis, serraturis imbricatis. 2 . Ad margines agrorum.

25\%o. Glutinosa. Glabra ramosissima, ramulis spinescentibns, pedunculis axillaribas solitariis unifloris bi-bracteatis. $b$. In Corsica.

257r. Maritima. Foliis cordatis obtusis tomentosis crenatis, superioribus ovatis integerrimis, verticillis $2-6$-floris. 2f. In Galliæ Mediterranex maritimis.

2572. Hirta. Verticillis sexfloris, caulibus prostratis, foliis cordatis crenatis, laciniis calicinis spinosis, labio superiori corollæ æqualibus. 24 . In saxoxis collibus Nicæx, Monspelii.

2573. Sideritis. Verticillis subspicatis, foliis cordato-ellipticis crenatis scabris, canlibus arlscendentibus. 2 . In arcnosis, sterilibus.

257 f. Annua. Verticillis sexfloris, foliis ovatn-lanceolatis trinerviis ixibus petiolatis, catle erecto. $\odot$. In cultis, ad agrorum margines.

25-5. Arvensis. Verticillis sexfloris, foliis cordatis obtusis nudiusculis, corollis longitudine calicis, caule debili. $\odot$. In arvis, vineis.

$$
\text { 38\%. в A L L }
$$

Calix campanulatus, 5-gonus, 10-striatus, 5-flentatus; corolla bilabiata, superiùs concava crenata, inferiùs 3 -loba; lobo medio majore emarginato; semina triangularia.

25-6. Futida. Foliis cordatis indivisis serratis. $\%$. In ruderatis.

\section{M A $\mathbf{R}$ R $U$ U B}

Calix cylindricus, ro-striatus, 5-ant-to-dentatus; corolla calice paulo longior, hilabiata, superiùs angusta 2-fida, inferiùs 3-fida, lacinia media latiore emarginata.

2577. Vulgare. Caule erecto, foliis subrọtundo-ovatis dentatis ri1goso-venosis, calicibus ro-dentatis, dentibus setaceis uncinatis. 24. In rudcratis incultis.

25\%8. Supinum. Caule decumbente, foliis snbrotundis crenatis rugoso-venosis, calicibus 5-dentatis, dentibns setaceis rectis villosis. 2. In Occitania. 


\section{L $\quad \mathbf{E}$ o}

Calix cylindricus, pentagonus, 5-dentatus, fauce nuda; corolla calice vix longior, 2 -labiata, superius villosa integra concava, inferiis reflexa 3-partita subæqualis; antheræ punctis nitidis adspersæ.

9. I. Staminibus villosis; ovariis apice tomentosis (CARDIACA).

2579. Curdiaca. Foliis petiolatis, inferioribus cnneiformi-ovatis trilobis dentatis, summis indivisis, lacinia media labii corolla inferioris acuta, calice pungente. $2 \mathcal{F}$. In dumetis ruderatis.

\section{S. II. Staninibus ovariisque glabris (CHA1TURUs),}

25So. Marrubiastrum. Foliis oblongis dentatis, corollis calice subpungente vix longioribus. $2 \zeta$. In cultis siccis.

$$
\text { 387. G A L E O }
$$

Calix campanulatus, 5-dentatus, dentibus inæqualibus, acntis; corolla calice longior, 2-labiata, suprà fornicata integra, infrà trifida, laciniis acutis intermedia longiore.

25S . Luteum. 24. In nemoribus montosis.

\section{P H L O IM 1 s.}

Calix angulatus, 5-dentatus, fauce nuda, dentibus patulis ; corolla oblonga, labiata, superiùs villosa formicata compressa incumbens subbifida, inferiùs triloba, lobo medio majore emarginato.

2582. Lychnitis. Foliis lanceolatis tomentosis, floralibus sessilibus ovatis, bracteis setaceis lanatis calicis obtusè dentati longitudinc. ๖. In Gallia mediterranea.

2583. Herba-venti. Foliis ovato-lanceolatis serratis subtùs hirtis, calicinis dentibns lanceolato-subulatis erectis, bracteis subulatis cauleque hirtis. 4 . In Gallia mediterranea.

$$
\text { 389. M о L U C E L L A. }
$$

Calix maximus, turbinatus, campanulatus, dentato-spinosus; dente superiore remotiore; corolla minor in fundo calicis.

2584. Frutescens. Calicibus infundibuliformibus ro-dentatis spinosis, foliis petiolatis ellipticis obtusis subquinquedentatis. b. Inter rupes circà Tendam et Sospellum.

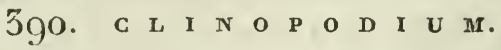

Calix labiatus, fauce nuda, limbo suprà 3-fido, infrà bipartito; corolla tubo brevi, fauce sensim ampliata, labio superiore erecto emarginato, inferiore 3-fido, lacinia media majore emarginata.

2585. Vulgare. Canle subsimplici foliisque remote dentatis pilosis,

bracteis setaceis. $\mathcal{H}$. Ad oras sylvarum.

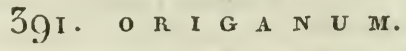

Calix varius, nume 5-dentatns, nunc 2-labiatus, aut 2-partitus; corolla tubo compresso, labiata, superiùs erecta emarginata, infedius 3 -fida subæqualis; semina subrotunda. 
1. I. Calice cylindrico 5-dentato, fructifero villis clauso (ORIGA NUM).

2586. Fulgare. Spicis subrotundis paniculatis congloneratis, bracteis calice longioribus ovatis, foliis ovatis. 2 . In rupestribus.

2587. Creticum. Spicis aggregatis longis prismaticis rectis, bracteis nembranaecis calice duplo longioribus. 24. Monspelii.

9. II. Calice fructifero nudo, bilabiato, labio superiore majore tridentato, inferiore bilobo (MAJORANA).

2588. Majoranoides. Spicis subrotundis pluribus glomeratis pedunculatis, foliis petiolatis ellipticis obtusis tomentosis, caule sulfruticoso. ๖. Colitur in hortis.

$$
\text { 392. T H Y M U s. }
$$

Calix striatus, fauce villis clausa, limbus Jajiatus, suprà 3-dentatus, infrà bisetus aut bifidus; corolla brevis labiata, suprà emarginata, infrà 3-loba, lobo medio latiore integro aut emarginato.

\section{§. I. Corolla labii inferioris lobo medio integro (тнумеs).}

2589. Serpillun. Floribus capitatis, canlibus repentibus, folis planis obensis basi ciliatis. 2 . In aridis apricis.

259o. Lanuginosus. Florihus capitatis, caulibus repentibus hirsutis, foliis subrotundis obtusis villosis. $2 C$. In sylvaticis sterilibus. 259r. Zygis. Florbus verticillato-spicatis, caule suffruticoso erecto, foliis linearibas obtusissimis enerviis, margine revolutis, basi ciliatis. b. In ericetis Monspelii.

2592. Vulgaris. Erectus suffruticosus, foliis ovatis aut oblongis, floribus verticillato - spicatis. b. In Galliæ australis moncosis, saxosis.

\section{§. II. Corolla labii inferioris lobo medio emarginato} (CALAMINTHA).

2593. Acinos. Verticillis 6 - floris, pedunculis unifloris, canlibus subramosis suberectis, foliis oblongis acutis serratis. $\odot$. In glareosis, cretaceis, siccis.

259'. Alpinus. Verticillis 6-8-floris, foliis subrotundis obtusiusculis subserratis, corollis inflatis. 24. In Alpestribus saxosis.

259.5. Piperella. Pedunculis multifloris lateralibus, foliis ovatis obtusis glabris nerrosis integerrimis. 24. In Alpibus maritimis, ad rupes.

2596. Grandiflnrus. Pedunculis axillaribus 3-4-floris, bracteis lanceolatis sessilibus, fuliis ovatis acutis argutè serratis. 2 . In montosis umbrosis.

2597. Calamintha. Pedunculis axillaribus multifloris dichotonis corymbosis, foliis ovatis obtusis argutè serratis cauleque hirsutis, dentibus calicinis inferioribus villosis longioribus. 2 . In collibus saxosis.

2598. Nepeta. Pedunculis axillaribus multifloris dichotomo-corym- 
hosis, foliis ovatis obtusis subserratis cauleque sublirsntis, dentibus calicinis subrqualibus, superioribus duobus erectis. 2 . In aggeribus glareosis.

3509. Creticus. Racemis terminalibus, pedunculis sulbsolitariis subnultifloris, foliis ovatis subintegris. b. Circà Monspelium et Lucerame in Pedemontio.

$$
\text { 395. M E L I S } \mathbf{s} \text { A. }
$$

Calix apice patens, fauce nuda, 2-labiatus, suprì planus 3-dentatus, infrà 2-lobus; corolla tubo cylindrico, 2-labiata, superius fornicata emarginata, inferius triloba, lobo medio obcordato.

260o. Officinalis. Verticillis dimidiatis, foliis ovatis acutis serratis, caule ramoso. $\mathcal{F}$. In montosis, sepibus, etc.

26ог. Pyrenaica. Caule subnudo simplici, floribus verticillatis, foliis oblungis obtusè dentatis. $\mathcal{F}$. In summis Pyrenaicis et $\mathrm{Al}$ pibus Vallesiacis.

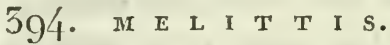

Calix magnus, 3-fidus, suprà sæpè emarginatus, inæqualiter 3labiatus, tubo corollæ amplior; corolla calice duplò longior, limbo dilatato patente labiato, suprà integro plano, infrà 3-lobo, lobis nagnis inxqualibus; semina subrotundo-triangularia, extus villosa. 2602. Melissophyllum. $\odot$. In sylvis umbrosis.

$$
\text { 395. D R A c O C } \mathbf{E} \text { P }
$$

Calix 5-fidus, 2-libiatus vel subæqualis; corolla fance inflata, 2-labiata, superiùs fornicata aut emarginata, inferius triloba, lobis lateralibus brevibus ercetis, medio integro aut emarginato.

26o3. Austriacum. Floribus spicatis, foliis sessilibus lincaribus mucronatis, caulinis $3-5-$ partitis, rameis simplicibus, floralibus tripartitis. $\mathcal{4}$ ant $\delta^{7}$. In montibus Delphin. Galloprov:

260 . Ruyschiana. Glabra, fioribus spicatis, foliis bracteisque lanceolatis indivisis muticis. 2F. In Alpibus Pedem. et Delphin.

$$
\text { 5g6. B R U N E L L A. }
$$

Calix labiatus, fauce nuda, suprà planus subtruncatus 3-fidus, infrà brevior bifidus; corolla labiata, supcriìs concava integra ant 2-Ioba, inferiùs 3-loba, merlio majore emarginato; filamenta apice bifurca sen bidentata, dente altero antherifero, altero nudo.

2605. Trulgaris. Foliis petiolatis oblongo-ovatis, basi dentatis, calicis labio superiore truncato triaristato, caule adscendente. 2 ? In pascuis.

2606. Laciniata. Foliis petiolatis ovato-oblongis, superioribus lanecolacis dentatis pinnatifidisque, calice labio superiore trilobo, lobis brevissimis obtusis mucronatis. $\mathcal{F}$. In pascuis sylvaticis.

$260 \%$. Grandiflora. Folis petiolatis oblongo-ovatis hasi dentatis, calicis labio superiore trifido, galea in medio flexa. 2 . In siccis, zujestribus. 
26ns. Hysenpifolia. Foliis sessililus lanecolatis integerrimis sciabris, caule erecto. $2 f$. In Gibltis auscualis pascuis humilis arbillusis.

$$
\text { 597. C r. } \mathrm{x} \text { o } \mathrm{N} \text { I A. }
$$

Calix fance villis clausa; stigma $\mathbf{f}$-fidum. Cxtera ut in Brunclla.3609. Kusitanica. $\odot$. In Occitania inter Carcassonem et Sorriciuitun.

$$
\text { 5gS. o } \quad \text { C } \quad \text { Y } M \text { U } \mathbf{M} \text {. }
$$

Calix labiatus, suprà latior orbiculatus, infrà 4-fidus; corolla resupinata, tuho brevi, 2-labiata, labio altero longiore indiviso crenato, altero -lobo; filamenta declinata, 2 breviora, basi appendiculata.

26ro. Basilicum. Foliis ovatis obtnsis planis glabris integris, calicibus ciliatis. $\odot$. Colitur in hortis.

26rr. Bullatum. Foliis ovatis concavis bullatis integris incisisque.

$\odot$. Colitur in horis.

26r2. Mininum. Glaherrimum, foliis subrotundo-ovatis integerrimis planis. $\odot$. Colitur in hortis.

$$
\text { j99. S C U T E I I A R I A. }
$$

Calix brevis, labio utroquè integro, squamula concava superiùs irrcumbente; corolla longior, basi flexa, limbo. labiato, suprà compressa fornicata ad ortum bidentata, inferiùs latior emarginata; senina calice clauso tecta.

2fir3. Columne. Foliis. oblongis cordatis serratis pubesceutibus, spicis elongatis secundis, bracteis petiolatis ovatis calice brevioribus. 2 . In Alpibus Pedemontanis.

261年. Alpina. Foliis cosdatis inciso-serratis crenatis, spicis imbricatis rotundatis, bracteis flore duplò brevioribus. 2 . In Alpibus et Pyrenseis, in arilis saxatilibus.

2615. Galericulata. Foliis cordato-lanccolatis crenatis, floribus axillaribus geminis. 2 . In palustribus.

2616. Minor. Foliis cordatis ovalis integris, floribus axillaribus geminis. 24. In paludibus inundatis.

\section{O P D O X V. PERSONATAE:}

Calix divisus, sæpè persistens; corolla irregularis, limbo diviso; stamina raic $\mathbf{2}$, sapuius q́, Ilillynama, corollæ inserta; ovarium liberum; stylns 1; stigma simplex aut bilobum; capsula uni-aut-bilocularis, bivalvis, valvis concavis, plus minisve segregatis, intertum bipartitis; dissepinento centrali v'alvis parallelo nunc bilsero sinplici, nanc duplici valvis introflexis coalito; scmina numerosa medio dissepinento adfixa; perispermum carnosum; corculam rectum; cotyledunes semi-cylindric:e. - Herba; folia opposila aut alterna; flores bracteati. 


\section{+ Stamina duo; capsula unilocularis. 400. U T R I C U L A R I A.}

Calix bipartitus, deciduns; corolla bilabiata, suprà erecta integra staminifera, infrà major integra, palato prominulo, basi calcarata; stigma simplex.

2617. Vulgaris. Nictario conico, labio snperiore integro, foliis pinratifico-mnltifidis, laciniis capillaribus. $\mathcal{F}$. In aquis stagnantibus.

26,8. Minor. Nectario carinato, labio superiore emarginato, foliis tripartitis, laciniis capillaribus dichotomis. 2 . In aquis stagnantibus.

$$
\text { 40I. P I N G U I C U I A. }
$$

Calix campanulatus, 5-fidus; corolla bilabiata, superiùs triloba, inferiùs 2-loba brevior, basi calcarata; stigma bilamellatum.

26ı. Vulgaris. Nectario conico recto longitudine corollæ, labio superiore bilobo, inferiore tripartito, scapo glabro. 4 . In uliginosis.

2620. Grandiflora. Nectario subulato recto longitudine floris, corollæ labio superiore patente emarginato maximo, inferiore trilobo. 2 . In Alpibus et Pyrenæis occidentalibus.

$1620^{*}$. Lnngifolia. Nectario recto longitudine corollæ acuto, corollæ labio superiore $2-$ lobo, inferiore duplò lengiore trilobo, scapo subpubescente, foliis oblongis. 2 . In Pyrenæis.

262 т. Alpina. Nectario conico adscendente corolla breviore, labio snperiore emarginato, inferiore laciniis truncatis, capsula rostrata. భ. In Alpibus, Pyrenæis, Armoracia et circà Cenomannm.

†† Stamina 4, didynama; capsula unilocularis.

$$
\text { 402. L I M O S E L L A. }
$$

Calix 5-fidus; corolla minima, campanulata, 5-loba, æqualis; stamina 4 didynama; stigma globosum.

2622. Aquatica. Foliis lanceolato-spatulatis, scapis foliis brevioribus. 2 . In inandatis ad fluviorum ripas.

$$
\text { 403. L I N D E R N I A. }
$$

Calix 5-partitus; corolla tubulosa ringens, suprà brevissima emarginata, infrà 3 -fida inæqualis; stamina 4 didynama : filamenta breviora apice bidentata, altero dente nudo, altero antherifero; stigma emarginatum.

2623. Pyxidaria. Foliis ohlongo-ovatis integerrimis sessilibus, pedunculis axillaribus solitariis unifloris. $\odot$. In paludibus spongiosis inundatis.

$$
\begin{gathered}
t+t \text { Stamina 4, didynama; capsula bilocularis. } \\
\text { 404. E R I N U s. }
\end{gathered}
$$

Calix 3-fidus; corolla tubulosa, limbo plano 5-lobo subæquali, 
Jaciniis apice cordato-emarginatis; capsula ovata, bivalvis, valvis bifirlis.

263 . Alpinus. Floribus racemosis, foliis spatulatis. 25. In montium locis lapidosis apricis.

$$
\text { 405. S C R O P H U L A R I A. }
$$

Calix 5-lohns; corolla glohosa, limbo coarctato bilabiato, snpra biloba sqnama intis sxpe interjecta, infra brevior triloba; stigma 1 ; capsula subrotunda acuminata, valvis integris basi iutroflexis, dissepimento duplici.

2625. Nodosa. Foliis cordatis lanceolatis acntis dentatis, caule obtusangulo. 2 . In unbrosis succulentis.

2626. Vernalis. Foliis cordatis pubescentibus duplicato-scratis, paniculis axillaribus dichotomis. 8 . In Gallia Narbonensi. ,

2627. Aquatica. Foliis cordatis petiolatis decurrentibus obtusis, caule membranis angulato, racemis terminalibus. $\delta$. Ad ripas ec in aquaticis.

2628. Scorndonia. Foliis cordatis duplicato-serratis pubescentibus, pedunculis terminalibus trichotomis foliatis. 24. In agri $\mathrm{Ni}$ cxensis locis lıunidis.

$2628^{*}$. Frutescens. Foliis subcarnosis superioribus sessilibus dentatis glabris apice recurvis, panicula racemosa, pedunculis bifidis multifloris. b. In Corsica.

2629. Peregrina. Foliis cordatis lineatis lucidis, pedunculis axillaribus 2-f-floris, caule 4-G-augulo. $\odot$. In Galloprovincia, Corsica, Nicææ, circà Aquas Tárbellicas.

263o. Auriculata. Foliis oblongis cordatis subtùs hirsutis duplicato-dentatis, hasi appendiculatis, petiolis aqualibus, racenis terminalibus. $2 f$. In agro Nicæensi.

2631. Trifoliata. Foliis glabris, inferioribus ternato-pinnatis obtusis, superioribus simplicibus, pedunculis subtrifloris axillaribus. $\delta$. In Corsica.

2632. Canina. Foliis pinnatis, pinnis lohatis, racemo terminali nuslo, pedunculis bifidis. () Linn. \& Vill. In lapidosis et sterilibus.

2633. Lucida. Foliis inferioribns bipinnatis subearnosis glaberrimis, racemis bipartitis, bracteis oblongis, palato corollie subtits appendiculato. of All. 4 Linn. In arenosis Nica.

$$
\text { 406. L I N A R I A. }
$$

Calix 5-partítus, laciniis 2 inferiorihus remotis; corolla ringens basi calcarata, tuho inflato, limbo 2-labiato suprì 2-fido reflexo, infrả 3-lobo, pa!ato ad faucern proutinalo; capsula ovata apice multivalvis; semina marginata.

\section{S. I. Folïis angulatis.}

263\%. Cymbalaria. Foliis cordatis quinquelobis alternis glabris, canlibus procumbentibus. $₹$. In rupibus et inuris antiquis. 
2635. Pilosa. Foliis reniformibus crenatis pilosissimis alternis, caulibus procumbentibus. $2 \mathrm{C}$. In $\mathrm{Al}$ pibus? ę Pyrenæis?

2636. Elatine. Foliis hastatis alternis, caulibus procumbentibus. $\odot$. In arvis.

2637. Spurium. Foliis, pilosis alternis ovatis, inferioribus oppositis obsoletè dentatis, caulc procumbente. $\odot$. In arvis.

\section{II. Foliis integerrimis, inferioribus verticillatis.}

263S. Reflexa. Foliis ovatis sessilibus glabris ternis, floralibus alternis, perlunculis axillaribus, fructiferis recurvatis, caulibus patulis. $\odot$. In Cossica.

2639 . Triply $2 l l a$. Foliis ternis ovatis obtusis trinervis, spica terminali, floribus pedunculatis, canle erecto. $\odot$. In Santonia.

26 o. Versicolor. Foliis lineari-lanceolatis, inferioribus ternís quateruisque, caule erecto spicato, calicibus pedicellisque villosom viscirlis. $\odot$. In Gallia australi,

26ł1. Strinta. Tolis linearibus confertis alternis sparsisque infimis verticillatis, caulibus pauiculatis suberectis, radice repente, flaribus lineatis. $\odot$. In campis sterilibus, ad muros, cte.

26 2. Thymifnlia. Foliis ovalibus oppositis ternatisque glabris, floribus capitatis, caulibus procumbentibus. - In arenosis maritimis \$ayonnæ.

26ł3. Purenaica. Foliis lanceolato-linearibus, inferioribus ternis quinisre, superiofibus oppositis, sumnis alcernis, florihus racemosis, caule adscendente apice hirto, calcarc recto. - In Pyrenais propie Valletriam.

2641. Supinn. Foliis subquaternis linearibus, superioribus sparsis, caule diffuso apice subpiloso, calcare recto, floribus racemosis. $\odot$. In arcnosis.

$26 \mathrm{f}^{*}$. Flava. Foliis lanceolatis alternis, inferioribus ovatis ternis oppositiscque, floribus capitatis, calicibus glabris, caule simplici erecto. $\odot$. In Corsica.

$2644^{* *}$. Maritima. Foliis omnibus verticillatis linearibus glaneis, caulibus plurimis decumbentibus glabris, floribus subcapitatis, lobis calicinis ovatn-oblongis obtnsis. $2 \%$ ? In arenosis maritimis, ad Lecroisic propé Nannetes detexit Delaroche.

2645. Aruensis. Foliis linearihus inferioribus quaternis, calicibus piloso-viscosis, floribus racemosis, calcare recurvo, caule erecto ramoso. $\odot$. In arvis cultis.

2646. Simplex. Foliis sublincatibus, inferioribus quaternis, calicibus piloso-viscosis, floribus racemosis, calcare recto, caule erecto simplici. $\odot$. Iu Gillia Narbonenși.

$266^{*}$. Juncea. Foliis linearibus carnosis alternis, infimis ternis, caule paniculato virgato, floribus racemosis, calcare recto. $\mathcal{F}$. Inter segetes circà Aquas-Tarbellicas.

26鿉. Chalepensis. Foliis lineari-lanccolatis alternis, inferioribus. 
verticillatis, floribus racemosis, calicibus corolla Inngiorihus, calcare longissimo, caule rrecto. $\odot$. Monspclii, in cultis.

26\}S. Pelisseriana. Foliis linearibus altomis, inferioribus ternis quaternisque, caule erecto subsinplici, floribus racemoso-capitatis. 2 . In saxosis rupestribus.

26. $\mathrm{S}^{*}$. Gracilis. Caulis foriferi erecti stricti gracilis foliis lincaribus sparsis, surculorum sterilium foliis tcruis ovatis, fluribus paucis, calcare recto. $\odot$ ? Antirrhinum gracile. Pers. ined. Monspclii.

26.1.9. Saxatilis. Foliis lanceolato-linearibus sparsis villoso-viscosis, inferioribus verticillatis, caule decmmbente, floribus spicatis. $2 F$. In Armoracie maritimis.

265o. Alpina. Foliis quaternis lineari-lanceolatis glaueis, inferioribus ovalibus, caule difinso patulo, floribus racemosis, calcare recto, 8 . In Alpibus et Pyrenxis.

265r. Origanifolia. Foliis obovatis oppositis, foralibus alternis cauleque adscendente pubescentibus, calcare recto. $\odot$. In Gallix australis rupestribus.

2652. Minor. Foliis lanceolatis obtnsis ellipticisque alternis, inferioribus oppositis : caule ramosissimo diffuso. $\odot$. In cultis, ruderatis, glareosis.

\section{S. III. Foliis omnibus alternis integerrimis.}

2653. Genistifolia. Foliis lanceolatis acuminatis, caule suprà paniculato virgato flexuoso. $\mathcal{F}$. In Alsatia, Delphinatu.

265y. Fulgaris. Foliis lanceolato-linearibus confertis, caule crecto, spicis terminalibus sessilibus. 2 . In ruderatis.

\section{A N T I R R H I N U M.}

Calix 5-partitus; corolla non calcarata, basi gibba, tubo inflato, limbo et palato ut in Linaria ; capsula bași obliqua, apice foraminulis tribus dehiscens.

3655. Majus. Foliis lanceolatis alternis, rameis oppositis, floribus racemosis, laciniis calicinis ovatis obtusis. $\sigma^{7}$. In maceriis sazosis.

2656. Orontium. Foliis lanceolatis angustis, floribus subspicatis, laciniis ealicinis linearibus corolla lungioribus. b. In agris et arvis.

2957. Sempervivens. Foliis ellipticis sempervirentibus oppositis cauleque frutescente divaricato-pubescentibus, pedunculis axillaribus. $2 \mathrm{C}, \boldsymbol{b}$. In Pyrenxis.

265̃. Molle. Foliis ovatis oppositis tomentosis, caulibus procumbentibus. $2 C$. In Alpibus.

2659. Asarina. Foliis oppositis cordatis erenatis, caulibus procumbentibus diffusis villosis. 4 . In Gallia Narbonensi.

$$
\text { 408. A }
$$

Calix 5-partitus; corolla tubulosa, intcrelùn calcarata vel basi deor- 
sim promincns, fance patente, palato prominulo destituta; capsula subrotunda, apice foraminulis duobus deliscens.

366o. Bellidifolium. Foliis radicalibus obovato-lancenlatis obtusis serratis, caulinis partitis integerrimis. $\sigma$. In sterililus Galliæ australis.

$$
\text { log. D I G I T A I I S. }
$$

Calix 5-partitus, inæqualis; corolla campanulata; limbo oblique \{-lobo inæquali; stigma simplex aut bilamellatum; capsula ovata, acuminata.

266r. Purpurea. Calicinis foliolis ovatis acutis, corollis obtusis, labio superiore integro. $\delta$. In montibus sylvaticis.

2662. Thapsi. Calicinis foliolis ovato-lanceolatis, foliis decurrentibus. 4 . In Sabaudiæ? frigidis.

2663. Grandiflora. Calicinis foliolis lanceolatis, corollis inflatis galea emarginatis, foliis subtùs pubescentibus. 2 . In montosis umbrosis Alsatiæ, Alpium, Jurassi, etc.

2664. Parviflora. Calicinis foliolis lanceolatis, corollis acutis, labio superiore bifido, foliis glaberrimis. 2F. In saxosis rupestribus.

2665. Ferruginea. Glaberrima, foliolis calicinis oblongis obtusissimis, corollæ labii inferioris lobis latiralibus acutis, intermedio oblongo hirsuto concavo, floribus distantibus, bracteis lanceolatis glabris ealicis longitudine. $\mathcal{F}$. In Pedemontii collibus.

$$
\text { lio. G R A } \mathbf{T} \text { I O }
$$

Calix 5-partitus, basi 2-bracteatus; corolla tubulosa subbilabiata, labio superiore emarginato, inferiore trilobo; stamina 4 , 2 sterilia; capsula ovata, hilocularis dissepimento simplici.

2666. Officinalis. Foliis lanceolatis serratis subtrincrviis, floribus pedunculatis. 2 . In humidiusculis.

\section{O R D O X L V I. S O L A N E AE.}

Calix 5-fidus aut partitus, sæpiùs persistens; corolla regularis 5fida; stamina 5 basi corolla inserta, ejusdem lobis alterna; ovarium liberum; stylns 1 ; stigma simplex aut bisulcum; fructus bilocularis polyspermus, nunc capsularis bivalvis, dissepinento valvis parallelo, nunc baccatus receptaculis seminiferis centralibus; semina numerosa; perispermum carnosum; corculum annularevel spirale; cotyledones semi-teretes. - Herba aut frutices; folia alterna; flores sæpè extràaxillares; interdùm quinta pars floris demitur.

\section{† Fructus capsularis.}

$$
\text { Y I I. C E I S I } 1 .
$$

Calix 5-partitus; corolla rotata; stamina 4 didynama, filamentis villosis; stigma I.

36rin. Orientalis. Foliis bipinnatifulis, $\odot$. In Pedernontio circd $\Lambda \mathbf{u -}$ urustau. 
412. V E $\mathrm{n}$ B $A$ S $\mathrm{C}$ U $\mathrm{M}$.

Calix 5-partitus; corolla rotata, 5-loba, inxqualis; stamina 5, inxqualia, filamentis inclinatis nt plurimum basi villosis; capsula 2 -valvis, ovata aut globosa.

\section{I. Foliis decurrentibus.}

2668. Thapsus. Foliis decurrentibus utrinquè tomentosis, canle simplici. 2 . In glareosis.

2669. Thapsoides. Foliis decurrentibus, caule ramoso. $\sigma^{3}$. In collibus saxosis Pedemontii, in Delphinatûs campis.

267o. Crassifolium. Foliis ovato-olilongis subdecurrentibus tomentosis, filamentis staminum glabris. - In Vallesia, Gallia Narbonensi et circà Suessones.

\section{§. II. Folits non decurrentibus.}

26-r. Plilomoides. Foliis ovatis acutis utrinquè tomentosis crenatis, inferioribus in petiolum attenuatis, filamentis staminum barbatis flavescentibus. $\sigma$. In ruderatis et ad margines viarum.

26-2. Lyclınitis. Foliis cuneiformi-oblongis suprà nudis, canle angulato paniculato, filamentis barbatis flavescentibus. $\mathcal{F}$. Ad vias, in montosis sterilibus.

2673. Pulverulentum. Foliis ovato-oblongis subserratis utrinquè pulverulento-tomentosis, canle tercti paniculato, filamentis barbatis albis, antheris miniatis. $\sigma$. In ruderatis ad margines viarum.

267ł. Mixtum. Foliis oblongis acutis obsoletè crenatis sessilibus pulverulento-tomentosis, inferioribus subpetiolatis, ramis paniculæ villosis, filamentis barbatis violaceis. - In Pyrenæis.

2675. Nigrum. Foliis oblongo-cordatis petiolatis crenatis subpubescentibus, filamentis barbatis purpurascentibus. 4 . Ad vias.

26-6. Alopecurus. Foliis ovatis subincanis crenatis, inferioribus petiolatis, spica elongata subsimplici, filamentis barbatis purpureis. - In aridis circà Lutetiam.

2677. Phaniceum. Foliis ovatis nudis crenatis, radicalibus petiolatis, caule subnudo subracemoso. $\delta$. In Pedemontii collibus aridis.

2678. Blattaria. Caule ramoso, foliis amplexicaulibus crenatis oblongis glabris, radicalibus sinuatis, pedunculis solitariis. $\odot$. In argillosis ad ripas.

2679. Blattarinides. Foliis oblongis amplexicaulibus crenatis nudiusculis, radicalibus sinuato-crenatis, pedunculis subbifloris. $\delta$. In Lntetiæ ripis.

268o. Chaixi. Foliis oblongis cordatis petiolatis dentatis subrillosis, radicalibus pinnatifidis, floribus aggregatis. $\sigma$. In Delphinatu et Pedemontio.

268r. Sinuatum. Foliis radicalibus oblongis pinnatifido-repandis tomentosis, canlinis amplexicanlibus rameisque cordatis nudinsculis. $\mathcal{F}$. In aridis ad margines viarum, in Gália australi. 


\section{I3. R A M O N D I A.}

Calix 5-partitus; corolla rotata, 5-loba, subiniequalis, hasi sil lobnrum sinus hirsuto-maculata; stamina 5 , approxinata; antheris apice perforatis; capsula unilocularis 2-valvis, valvulis margine introflex is septiferis.

36is. Pyrenaica. 24. In Pyrenæorum et rariùs Pedemoutii umbrosis.

$$
\text { 414. H } \mathrm{Y} \text { O } \mathrm{S} \text { C I A II U S. }
$$

Calix tubulosus, 5-firlus; corolla infundibuliformis, limbo patente obliquè j̃ - Jobo inaquali; stamina 5; stigma capitatum; capsula ovata utrinquè compressa ct sulco exarata, apice circunascissa seu operculata.

2683. Niger. Foliis amplexicaulibus sinuatis, floribus subsessilibus. б. In ruderatis.

2684. Albus. Foliis canlinis petiolatis cordatis sinnatis acntis, floralibus integerrimis, flotibus subsessilibus, corollis ventricosis. $\odot$. In Gallia Mediterrauea.

3685. Aureus. Foliis petiolatis dentatis acutis, floribus pedunculatis, fructibus pendulis. $\circlearrowright$. In Gallia Mediterranea.

$$
\text { 415. N } 1 \text { I C O }
$$

Calix urceolatus, 5-fidus; corolla multò longior, infundibuliformis, 5-fida, regularis; stamina 5; stigma conarginaimu; capsula 2valyis.

2686. Tabacum. Foliis lanceolato-ovatis sessilibus decurrentibus. $\odot$.

Ex America, anno 1560 , allata ; in Gallia australi inque Alsatia culta.

2687. Rustica. Toliis petiolatis ovatis integerrimis, floribus obtusis.

$\odot$. Culta in Galiia australi.

$$
\text { 4i6. D A T U R A. }
$$

Calix magnas, tubulosus, ventricosus, 5-angnlaris, apice 5-filus, eaducus, basi orbiculata peltata persistente; corolla mixina infundibuliformis tubo longo. limbo 5-angulari, 5-plicato, 5-acuminato; stamina 5; stigma bilamellatum; capsula celsinata aut læxis, ovata, 2-locularis, loculis dissepimento prominente bi-aut-multipartitis.

2685. Stramonium. Pericarpiis ovatis spinosis, foliis ovatis sinuatio glabris basi in petiolum attenuatis. $\odot$. In ruderatis.

$$
\begin{aligned}
& t+\text { Fructus baccatus. } \\
& 417 \text {. II A N D R A G O R A. }
\end{aligned}
$$

Calix turbinatus, 5-fidus; corolla vix calice duplò longior, campanulata , 5-fida; filamenta 5 basi dilatata ct conniventia; ovariume. basi biglandulosum; bacca glolosa, receptaculis intius prominulis. 2C\&. O. Ojucinalis. $;$. In valle Augustana. 


$$
\begin{aligned}
& \text { SOLA N E A.. } \\
& \text { 4. }
\end{aligned}
$$

Calix campanulatus, 5-fidus; corolla campanulata, calie duplis Iongios, 5-loba, exqualis; lilanenta 5, filiformia; bacca globusa, calici insidens.

260o. Belladona. 2. In montibus sylvaticis.

$$
\text { 4ro. P H X S A I, I s. }
$$

Calix 5-fidus; corolla rotata , 5-filla; anther:e 5, oblongx, erect $x$, comniventes; bacea globosal, calice ampliato vesicario tecta.

' 26 1. Alkckengi. Eoliis geminis integris acutis, caule herbaceo. $2 f$. in humidis, umbrosis, scrobibus.

$$
\text { 420. S O L A N U M. }
$$

Calix 5-filus; corolla rotata, tubo brevissimo, limbo 5-ficlo patente; anther:e 5, erectie, conniventes, apice poro gemino dehiscentes bacea subrotunda; corculum spirale.

26g2. Dulcamara. Canle incrmi fruticoso seandente, foliis cordatis glabris, supcrioribus auriculatis, corymbis op [ositifoliis. b. In sepibus.

2603. Nigrum. Caule incrmi herbacco, foliis ovatis dentato-angula . tis, racenuis nutantibus. $\odot$. In ruderatis cultis.

269 . I Tllosum. Caule inermi herbaceo apice villoso, foliis ovatis angulatis subvillosis, racemis nutantibus. $\odot$. In cultis.

2695. Tuberosum. Cande inermi herbaceo, foliis pinnatifidis inlegerrimis, pedunculis subcorymbosis. 2 . ExPeruvia ortum, ubiquè cultum.

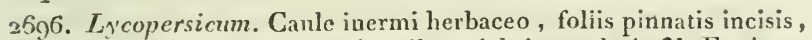
racemis lipartitis aphyllis, fructibus glabris torulosis. $\mathcal{Y}$. Ex America ortum, colitur in hortis.

2697. Melongena. Caule inermi herbaceo, foliis ovatis integris tomentosis, pednnculis pendulis incrassatis, calicibus incrmibus. $\odot$. Ex India ortum, in liortis Galliæ australis cultum.

$$
\text { 42I. C A P S I c U } \mathbf{M} \text {. }
$$

Antheræ longitudinaliter dehiscentes; bacca cxsncea; corculum semi-circulare. Cætera nt in Solano.

2698. Annuum. Caule herbaceo, pedunculis solitariis. $\odot$. Ex America meridionali ortın, præcipuè in Gallia australi cultum.

$$
\text { 422. L Y C I U } \mathbf{M} \text {. }
$$

Calix brevis, tmbulosus; corolla infundibuliformis, tubo breri, limbo 5 -fido; filamenta 5 , basi villosa; stigma sulcatum; bacca subrotunda; corculum uncinatum, subcentrale.

2699. Furopaum. Foliis ohlongis glaliris, ramis flexuosis, calicibus quinquedentatis. I). In Gallia australi.

2700. Barbarum. Foliis oblongis glabris, ramis flexuosis nutantibus, calicidus bilabiatis. b. In hortis, sepibus quasi spontancum. 


\section{O R D O X L V I I. B O R R A G I N E AE.}

Calix 5-lobus, persistens; corolla 5-loba sæpius regularis, fauce nuda aut squamis 5 obtecta; stamina 5 corollæ adfixa; ovarium liJerum, f-lobum; stylus simplex, persistens, inter ovarii lobos nascens; stigma integrum ant bilobum; nuces aut cariopsides a (semina nuda L.), 1-loculares, 1-spermæ, latere interno stylo adnatæ; perispermunı nullum; corculum rectum; radicula infera; cotyledones foliaceæ.- Herbæ aut suffrutices, foliis alternis scepiüs asperis; flores in raccmos unilaterales incurvos sæpè digesti.

\section{$\uparrow$ Corolla fauce nuda.$$
\text { 423. C E R I N T H E. }
$$

Calix 5-partitus; corolla tubulosa, ventricosa, 5-fida; antheræ erectæ vix exsertæ; capsulæ 2 osseæ, 2-loculares, 2-spermæ.

270r. Aspera. Corollis obtusis patulis calice longioribus, foliis subciliatis asperis. $\odot$. Monspelii, in Galloprovincia, in Alpibus.

2702. Glabra. Corollis obtusis patulis calice brevioribus, foliis glabris. $\odot$. In Alpibus Helveticis et Pedemontanis.

2yo3. Minor. Corollis acutis clausis calice longioribus, foliis glabris. б. In Gallia australi.

$$
\text { 424. H E L I O T H R O P I U M. }
$$

Calix tubulosus, quinquedentatus ; corolla hypocrateriformis, 5fida, dentibus 5 interjectis.

2jo.'.Peruvianum. Foliis lanceolato-ovatis, caule fruticoso, spicisnumerosis aggregato-corymbosis. D. Ex Peruvia ortum, colitur in hortis. 2705. Europaum. Foliis ovatis integerrimis tomentosis rugosis, spicis conjugatis, caule erecto lierbaceo. $\odot$. In glareosis aridis.

2706. Supinum. Foliis ovatis integerrimis tomentosis plicatis, spicis conjugatis, caule prostrato herbaceo. $\odot$. In Galliæ Mediterraneæ Junuidis.

$$
\text { 425. E C H I U } \boldsymbol{M} \text {. }
$$

Calix 5-partitus; corolla tubo brevi, limbo ampliore campanulato, obliquè 5-lobo inæquali.

2707. Vulgare. Caule tuberculato hispido herbaceo, foliis lanceo-

latis hispidis, floribus spicatis lateralibus. $\delta$. Ad vias et agros.

2708. Pyrenaicum. Caule pilosissimo herbaceo, foliis lineari-lanceolatis hirsutis, capitulis pedunculatis axillaribus, staminibus corolla pilosa longioribus glabris. $2 \xi$ vel $\delta$. in Gallia australis cullibus siccis.

2709. Violaceun. Caule piloso herbaceo, foliis oblongis, spicis unilateralibus, corollis stamina glabra æquantibus, calice dupld longioribus. $\odot$. In Gallia australi.

2710. Australe. Caule herbaceo piloso, foliis ovatis utrinquè attenuatis, corollis stamina apice villosa æquantibus. $\odot, 2 f$. Nicææ. 
27r. Plantagineum. Canle luerbacen villoso, foliis rarlicalilus ovatis petiolatis, floralibus subcordatis, staminibus glabris corolla sublongioribus. $\odot$ L., $\sigma^{7}$. All. In agro Nicaecusi.

$$
\text { 426. L I T H O S P F. R M U M. }
$$

Calix 5-partitus; corolla inlundibuliformis, parva, 5-loba; nuces nicidæe aut glabræ, lixves aut rugosa.

2712. Officinale. Nucibus lævibus, corollis calicem vix superantibus, foliis lancenlatis. 24 . In ruderatis.

27ı3. Arvense. Nucibus rugosis, corollis vix calicem superantibus, foliis ligulatis. $\odot$. In agris et arvis.

2714. Apulum. Foliis lineari-lanceolatis acntis, spicis terminalihns secundis, bracte is lanccolatis, nucibus muricatis. $\odot$. In Gallie Mediterrancæ maritimis.

2715. Purpureo-coruleum. Foliis lanccolatis acutis, floribus axillaribns, caulibus floriferis erectis, sterilibus prostrato - repentibus, nucibus lævibus. 2 . In nemoribus et agris.

2716. Tinctorium. Foliis lanceolatis obtusis, floralibus subcordatis, floribus axillaribus, staminibus inclusis, seminibus tuberculosis. భ. In Galliæ australis arcnosis sterilioribus.

2717. Fruticosum. Frnticosum, foliis linearibus hispidis, staninibus corollam æquantibus. b. In Galliæ australioris aridis.

$$
\text { / } 27 . \text { N O N E A. }
$$

Calix 5-fidus, frnctifer inflatus; corolla tubo erecto, limbo 5-lobo equali; stamina intrà tubum; nuces sulcatæ.

2718. Violacea. Foliis integerrimis, caule prostrato. ๑. Monspelii.

$$
\text { 428. } \mathbf{P} \text { U L M O N A R I A. }
$$

Calix 5-gonus, 5-fidus; corolla infundibuliformis, sub-5-loba, erecto-patens.

2719. Officinalis. Foliis radicalibus orato-cordatis scabris. $\mathcal{F}$. In nemoribus.

2720. Angustifnlia. Foliis radicalibus lanceolatis scabriusculis. $\mathcal{F}$. In sylvis montosis.

$$
\text { 429. O N O S M A. }
$$

Calix 5-fidns; corolla tubulosa, limbo erecto sub-5-lobo; stigma simplex.

2721. Echioides. Corollis cylindricis obtusis, fructibus erectis, foliis lanccolatis hispidis. 2 . In Galliæ australis aridis glareosis.

\section{† + Corolle fauce squamis instructa.}

$$
\text { 430. S Y } \mathbf{M} \text { P }
$$

Calix 5-fidus; corolla campanulata, tubulosa, limbo erecto subcoarctato 5-lobo, lobis brevibus; squamæ subulate, conniventes.

2722. Officinale. Foliis ovato-lanceolatis decurrentibus. 2f. In praz

tis humidis. 
2-23. Tuterosum. Foliis semi-rlecurrentibus, superioribus oppositis. $2 F$. In Gullix australis humidis.

$$
45 \mathrm{I} . \quad \mathrm{M} \text { Y }
$$

Calix 5-fidus; corolla liypocrateriformis, tubo brevi, limbo plano 5-lobo, Jobis emarginatis; squamulæ convexæ, conniventes; nuces læves ant scabre.

2ร2\%. Annua. Nincibus lævibus, caule ramoso foliisque pilosis, tubo corolla calicibus breviore. $\odot$. In pratis et arvis.

2535. Perennis. Nucibus læribns, foliis lanceolatis obtnsis, tubo corolla ealicibus sublongiore. $\mathcal{F}$. In rivulis, humidis inque sylvaticis.

2-36. Nrann. Nucibus margine crenulatis, caulé simplici subnullo paucifloro, foliis oblongis villosis. $2 \mathcal{F}$. In Alpibus.

2;2;. Lappula. Nucihus echinatis, foliis lanceolatis pilosis. ๑. In argillosis, ruderatis.

$$
\text { 432. A N C II U S A. }
$$

Calix 5-fidus; corolla infundibnliformis, 5-loba, erecto-patens, lobis integris; squanulæ ovatæ, prominulæ, conniventes; stigua emarginatun; nuees basi insculpiæ:

2728. Laxiflora. Racemo laxo, pedicellis nudis divaricatis, foliis oblongis acutis subsinuatis hispidis ciliatis. - In Corsica.

2729. Italica. Caule exiltato, foliis lucidis strigosis oblongis utrinquè attentratis, racemis bipartitis, floribus fauce barbatis. $\mathcal{F}$. In ruderutis cultis.

273o. Angustifolia. Foliis oblongo-lanceolatis integris, floribns spicatis, calicibus 5-fidis, bracteis lineari-lanceolatis. 4 . In Gallia australi.

2-31. Barrelieri. Foliis oblongis subintegris utrinquè attenuatis canleque simplici hispidis, pedunculis trifilis, calicibus 5-partitis. 2 . In agris Pedemontanis.

2732. Undulata. Strigosa, foliis linearibus dentatis, pedicellis bractea minoribus, calicibus fructiferis inflatis. $2 \%$. Monspelii.

2733. Sempervirens. Foliis hispidis, inferioribus ovatis subsinuatis petiolatis, superioribus sessilibus lancenlatis, pedunculis diphyllis capitatis. $\mathcal{F}$. In arvis cultis Pedemontii, Lotharingiæ, Nannetum, Aquitaniæ.

$$
\text { 433. L Y c o p s i s. }
$$

Calix 5-fidus; corolla tubo ineurvato. Cætera ut in Anchusa.

2734. Arvensis. Foliis lancenlatis hispidis, calicibus florescentibus erectis. 2 . In arvis ruderatis.

$$
134 . \quad \text { A s P E R U G o. }
$$

Calix 5-fidus, inæqualis, dentibus interjectis; corolla tubo brevi, 5-lobn; squamnlæ convexe, conniventes; semina calice conduplicato et compresso tecta.

2735. Procumbens. $\odot$. In ruderatis pinguibus. 


\section{C $\quad$ Y $\quad$ N O}

Calix 5-partitus; corolla brevis, infundibuliformis, 5-loba; squanula convexie, comniventes; stigma emarginatum; semina atl nuces depressie interivie latere stylo iflixix.

\section{j. I. F'uclibus planis rugesis.}

2736. Officinale. Foliis lato-Janceolatis basi attenuatis sessilibus tomentosis, stamiubus corolla brevionibus. $\odot$. In sylvaticis, sterilivilus.

2737. Montanum. Foliis lanceolatis lucilis nudiusculis subtùs scabris, interioribus petionatis, stamiuibus corolla brevioribus. $\odot$, Lam. ơ, Vill. 2F, Desf. In Alpibus.

2738. Pictum. Foliis lanceolatis tomentosis, superioribus basi cordatis, corollis calice subæqualibus venosis, fructibus convexis. $\sigma^{7}$. In Gallix australis aridis êt circà Turones.

2739. Cheirifolium. Foliis lanceolatis incano-sericeis, corollis calice dupld longioribus. $\odot, \sigma^{\star}$. In Galloprovincix sterililus.

2740. Apenninmm. Foliis tomentosis, inferioribus ovato-lunceolatis, superioribus ellipticis, floralibus lincaribus, staminibus corollam æquantibus. $c^{?}$. Monspelii ee in Vallesia.

\section{§. II. Fructibus lavibus calathiformibus.}

2-fr. Omphalodes. Foliis subglabris petiolatis, radicalibus ovatocorlatis, caulinis oratis. 2 . In Pedemontii nemorosis.

2742. Linifolium. Folis lineari-lanceolatis glabris margine denticulato-scabris. $\odot$. In insula Nigri-Monasterii.

$$
\text { 456. B } 0 \text { O }
$$

Calix 5-partitus; corolla rotata, 5-fida, plerumquè patens; squamulæ obtuŁæ, emarginatæ; fructus rugosi, calice connivente tecti.

2743. Oficinalis. Hispida, foliis radicalibus petiolatis, superioribus sessilibus, pedunculis ramósis. $\odot$. In hortis et cultis.

\section{OR D O X L VI I I. C O N V O L U L A C E AE.}

Calix 5-lobatus, persistens; corolla regularis, 5-loba; stamina ǰ, imæ enrollx inserta, ejustem laciniis alterna; ovarium liberum; stylus unicus aut multiplex; capsula 3-2 alvis, 3-locularis intertion 24-locularis, 2-f-valvis); placenta centralis 3-gona, anculis suturis valrularum oprositis; semina ossea, hylo inferiore notata, placentæ basi arlfixa; radicula infera; cotyledones complicatæ intrà perisper num mucilaginosum. - Futices aut sæpius herba plures volubiles plures lactescentes; folia alierna.

$$
\text { 157. c o N V o L V U L U s. }
$$

Calix 5-partitus; corolla campanulata, limbo 5-angulo, 5-plicato; stamina inxqualia; ovarium glandula hypogynæ semi-imucrsum; stylus 1 ; stigua 2 -fidum; capsala $2-3-4$-locularis, loculis 1-2-spermis. 
27亿. Sepium. Canle volubili, foliis sagittatis posticè truncatis, pedunculis tetragonis unifloris, bracteis cordatis maximis. $2 \mathcal{f}$. In sepilus.

27f5. Aivensis. Caule volubili, foliis sagittatis utrinquè acutis, pedunculis unifloris, bracteis linearibus. 24 . In agris.

2z-16. Siculus. Caule prostrato difiuso, foliis cordato-ovatis, pedunculis unifloris brevissimis, bracteis lanceolatis. $\odot$. In arenosis, in agro Syrtico.

2747. Althanides. Caule volubili, foliis cordatis sinnatis sericeis, lobis repandis, pedunculis subbifloris. 2 . In Gallia Mediterranca, ad muros et rupes.

27 í. Soldanella. Caule prostrato, foliis reniformibus glabris, pedunculis unifloris. 2 . In maritimis.

2740. Tricolor. Caule declinato, foliis lanceolato-ovatis glabris, florihus solitariis. $\odot$. Ex Hispania, Africa; colitur in hortis.

27\%o. Lineatus. Repens, caulibus erectis, foliis lanceolatis sericeis iineatis petiolatis, pedunculis bifloris congestis. 2 . In maritimis Gálloprovinciæ, Nicææ.

2-51. Cantabrica. Caule ramoso erectiusculo, foliis lineari-lancenlatis acntis sericeis, pedunculis subljifloris, calicibus pilosis. $₹$. In Delphinatûs et Galliæ Mediterraneæ rupibus.

2752. Argenteus. Foliis lanceolatis tomentosis sericeis, floribus ninbellatis, caule erectiuscnlo fruticuloso. b. In aridis Monspelii, Nicææ.

$$
\text { 438. c R E S S A. }
$$

Calix 5-partitus, 2-bracteatus, bracteis minimis; corolla vix calice longior, tubulosa, 5-fida; styli 2 ; capsula unilocularis, 2-valvis, basi dehiscens, 1-í-sperma.

27,53. Cretica. Corollis imberbibus, capsulis monospermis. $\odot$. In humidis Gallix Mediterraneæ.

$$
\text { 430. c U s c U T A. }
$$

Calix 4-5-fidus; corolla globosa, limbo 4-5-fido; stamina corollæ fance inserta, ejusrlem laciniis alterua; stigmata 2 ; capsula basi circumscissa, 2-locularis, loculis 2-spernis.

275ł Maior. Floribus subsessilibus, corolla $\{-5$-fida, staminibus basi nudis, stigmatibus acutis. $\odot$. Parasitica in uricis, cannabi, carduis.

2-55. Minnr. Floribus sessilibus, corollis $\{$-fidis, staminibus basi squana crenata instructis, stigmatibus simplicibus. $\odot$. In ericis, thymis, plantaginibus, etc.

\section{ORDOXLIX. POLEMONIA C E AE.}

Calix di isns; corolla regularis, 5-loba; stamina 5 , medio corollæe tmbo inserta, cjusdem laciniis alterna; ovarimu libeı um; stylus simI! sictuta, valvis medio intiis septiferis, sen costa prominente iustruc- 
tis, receptaculo centrali 3-gono, valvularmu septis angulatim apulicitu; corenlum rectum intrà perispermum corncmu, radicula infera; coryledones elliptica foliacear. - Herbx oppusititiolix.

$$
\text { //\%. P O L E }
$$

Calix urceolatus, 5-fidus; corolla rotata, tubo hrevi, limbo 5Jobo; staminum filamenta basi latiora; autheræ incumbentes.

2756. Cocruleum. Foliis pinnatis, floribus ercetis, calicibus corollae tubo longioribus. 2 4 . Iu monte $J$ urasso et in insulis Rhenanis circa Basilxam.

\section{O R D O L. G E N T I A N E AE.}

Calix monophyllus, divisus, persistens; corolla regularis, sæpe marcescens, limbo partito æquali, lobis numero laciniarnm calicis siepiis 5 ; stamina totidem, corollæ inserta ; ovarium liberum; sty Ins 1, ant rariùs scissione 2 ; stigma simplex aut bilobum; capsiela polysperma, bivalwis, 1-2-locularis, valvis margine intrnflexis et in bilocularibus dissepimentum constitsentibus; semina valvarum margine inserta; corculum rectum in centro perispermi carnosi; radicula sxpiùs infera. - Herbxe glabræ, amaræ; folia opposila sæpiùs integra sessilia.

\section{† Capsula unilocularis. \\ 14 I. II E N $\mathrm{Y}$ A N $\mathrm{N}$ II $\mathrm{E}$ S.}

Calix 5-partitus; corolla infundibuliformis, limbo patente 5-lobo xquali intus hirto; stamina 5 ; stylus 1 ; stigma capitatum, 2-3-sulcum; capsula unilocularis, parietibus seminiferis.

2757. Trifoliata. $¥$. In palustribus et aquosis.

$$
\text { 442. V I L L A } R \text { S } S \text { I A. }
$$

Calix 5-partitus; corolla rotata, tubo brevi, limbo patente 5-lobo, lobis margine ciliatis; stamina 5; stylus r; stigma bilobum, lobis crenulatis; capsula unilocularis, snturis parietalibus seminiferis; semina biserialia, marginc membranacea.

2758. Nymphoides. Foliis cordato-orbiculatis natantibus, floribus umbellatis, corollis ciliais. $\mathcal{H}$. Ferè omni Gallia in fluviis et aquis stagnantibus.

$$
\text { 4/3. C H L O R A. }
$$

Calix S-partitns; corolla hypocraterifornis, tubo brevi, limbo 8-partito; stamina 8 , brevissina, fauce inserta; stylus 1; stigma 4fidum; capsula unilocularis.

3759. Perfoliata. Foliis perfoliatis. $\odot$. In humidis sylvaticis.

$$
\text { 44. S W E R T I A. }
$$

Calix sub-5-partitus; corolla rotata, tubo brevissimo, limbo plano, 5-partito, laciniis lancenlatis, singulis basi intus gemina glandula ciliata instructis; stamina 5 , corolla breviora.

276o. Perennis. Corollis ecalcaratis quinquefidis, pednnculis tetra- 
gonis subulatis, canle indiviso, foliis rarlicalibus ovalibus. $\mathcal{Y}$. In turtosis montosis Alpium, Jurassi et Pyrenæorum.

$$
\text { 4/45. G E N T I A } N \text { A. }
$$

Calix 5-fidus; corolla basi tubulosa, campanulata ant infundibulifornis, limbo $4-5$-6-fido; laciuiæ integræ aut ciliatæ, interrium lacinulis interjectis distincta; stamina 5, tubo corolla inserta; antheræ interdum connatæ; stylus 2-partitus; stignata 2 ; capsula 1locularis.

5. I. Corolla subcampanulata, 4-0-ficla, fauce et limbo nudis (CELATTHE).

2-61. Iutea. Foliis latis ovatis nervosis, corollis 5-8-fidis acutis rotatis verticillatis pedicellatis, calicibus menbranaceis unilateralibus. 2 . In montium pratis.

2762. Hy brida. Foliis ovato-lanceolatis, corollis 5.8 fidis rotatis acutis verticillatis sessilibus, calicibus membranaceis unilateralibus. 2 . In Alpibus Vallesiacis.

2-63. Purpurea. Foliis ovato-lancenlatis, floribus verticillatis, corollis campanulatis 6-fidis, laciniis subrotundis, calicibus membranaceis unilateralibus. 2 . In Alpilsus et Pyrenæis.

2-64. Pannonica. Corollis subsexfidis campanulatis punctatissimis verticillatis, laciniis subrotundo-ovatis, calicibus coriaceis truncatis sexlobis, lobis tubo calicino longioribus. 2 . In summis Alpinis, Pyrenæis.

2765. Punctata. Corollis subsexfidis campanulatis punctatissimis verticillatis, laciniis orato-acutis, calicibus menbranaceis truncatis, lobis tubo calicino brevioribus inæqualibus. 2 . In Alpibus et Pyrenæis.

2\%66. Biloba. Corollis subsexfidis verticillatis, calicibus membranaceis bilobis, lobis obtusis integris æqualibus. $\mathcal{H}$. In Galloprovinciæ montibus Sedenensibus.

$2-67$. Cruciata. Corollis 4 -fidis imberbibus, floribus verticillatis sessilibus decussatis vaginantibus. $\not{\xi}$. In montosis sylvaticis.

2768. Asclepiadea. Corollis 5 -fidis campanulatis oppositis axillaribus solitariis subsessilihus, foliis amplexicaulibus ovato-lanceolatis. 2 . In Alpibus inque montibus Galliæ Mediterraneæ.

2-6r. Pneumonanthe. Corollis 5-fidis campanulatis, foliis linearibus obtusis. 2 . In pratis humidis.

2750. Acaulis. Corolla 5-fida canapanulata caulem quadrangulum subxquante. 2 . In Alpibus et Pyrenxis.

5. II. Corolla infunaibuliformi, fauce nuda, limbo non ciliato, 5-Io-fido (CALATHIA).

37ๆ . Ferna. Caule simplici pumilo, corolla 5-fida caulem excedente, laciniis acutis margine erosis, foliis ovato-acutis, radicalibus confertis majoribus. $2 \mathcal{C}$. In Alpibus et Pyrenæis.

25,-2. Bavarica. Corolla 5-fiela, laciniis obtusis serratis, foliis ovatis obtusis, radicalibus confertis imbricatis, cauliuis minoribus. $\mathcal{F}$. In il ipibus. 
27-3. Niralis. Caule sulmunfilloro, corollis 5-fillis, ramis alerums unifluris, folies calumis lanceolatis, calicibus i lincis fuscis notatis. $\odot$. In sunumis Alpihus, in Arvernia, Busundia et Fontisbleauli.

377\%. Ulriculosa. Multicaulis, foliis radicalibus ovatis confertis, corollis quinquefolis hyporateriformibus, calicibus intlatis plieato-carinatis. $\odot$. In Alpinm pratis humirlis.

2575. Pyrenaica. Corolla o-fida, lariniis alternis minorihus obtur sis crenatis, caulc infernè subramoso, foliis lanceolato-lincaribus. \%. In Pyrenais.

5. III. Corolla 4-5-fida, fauce squamis muslifidis actitis instructa (ENDOTRICHA).

2776. Germanica. Corollis 5-fidis hypocrateriformibus fance banbatis, calicihus xrmaliter 5-fidis, foliis ovato-lanceolatis, pedurculis internodiis longioribus. $\odot$. In pratis montosis.

2777. Campestris. Corollis 4-fidis hypocrateriformibus obtusis, fance babatis, calicinis laciniis duabus maximis. $\odot$. In pratis montosis.

27-8. Glacialis. Cornllis 4-fidis hypociateriformibns fance barbatis longè pedicellatis. canle infernè ramoso foliosn, calicinis laciniis xqualibus. $\odot$. In Alpibus Perlemontanis, Sabaudis.

\section{S.IV. Corolla i-fida infundibuliformi, laciniis ciliatis (CROSSOPETALUM).}

2759. Ciriata. Corollis 4 -fidis, laciniis serratis medio incisn-ciliatis, foliis lanceolatis linearibusque, caule flexuoso angulato. $\mathcal{F}$. In humidis nontium Cillia orientalis.

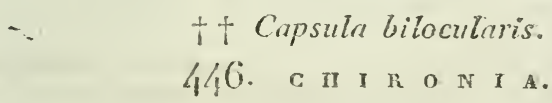

Calix 5 filus; corolla infundibuliformis, limbo 5 -lobo; stylus declinatns; stamiua 5 , tubo corollx inserta; antheræ post deflorationem spiraliter contortie; capsula bilocularis.

27So. Centaurium. Folits ovato-oblongis trinerviis, canTr elongato, floribus sessilibus fasciculato-panicnlatis, calicibus semi-quinrpefidis, tulin corollx diminio hrevioribus, laciniis subnlatis subpatulis. $\odot$. In pratis et arenosis Monspelii, ad ripas Ligeris.

278r. Pulrleella. Ramosissina, foliis oblongis, floribus pedicellatis suludichotomn-corymbnosis, calicibus sub-5-particis, laciniis subulatis adpressis tubum corollæ æquantibus. $\odot$. In sylvis et ad ripas.

2782. Maritima. Foliis oblongo-lanceohis, conle dichotomo-corymboso terct $\hat{x}$, floribus pedunculatis digynis. Q. In Gallize Merliterranex et mesidionalis maritimis.

2-83. Spicata. Foliis lancechmo-oblongis, ramis tichoionè panculatis, forihns sessilibus sulsecundis, calice bracteisque carollæ tubo subaqualibus. $\odot$. In Gablia: australis humidis. 


\section{7 . F. $\mathrm{X}$ A C U M.}

Calix 亿-partitus; corolla tubo globoso, 4-loba ; stamina 4; stylins ; stigna 2 -fidum.

2584. Filiforme. Caule filiformi subramoso, foliis radicalibus subrotundis, caulinis subulatis, corolla limbo patente. $\odot$. In pratis hunidiusculis sylvaticis.

2-85. Pusillum. Caule ramosissimo dichotomo, foliis oblongis 3-nerviis, calicinis laciniis subulatis subpatulis; corollæ limbo conniventc. $\odot$. In Gallix borealis pascuis.

\section{O R D O L I. A P O C I N E AE.}

Calix 5-lnbatus; corolla regularis 5 - $\ln b a$, fauce nunc nuda, nnnc appendicibus aucta; stamina 5 , inæ corollæ inserta, cjusteru lacinis alterna; ovarium liberum (in nostratibus) duplex, receptaculo sæpè glanduloso; stylus r aut o; stigma capitatmm; frnctus (in nostratibns bifollicularis, folliculis clongatis, $1-$ locularihus, rima interua dehisecntibus; senina arl marginem folliculi inserta imbricata plana, nuda aut coma pilosa coronata; perispermum carnosum; corculum rectum; radicnla supera. - Frutices aut suffrutices intesdium volubiles, sæpè lactescentes; folia opposita.

\section{+ Semina nuda. 448. v I $\mathbf{~}$ C $\mathbf{A}$.}

Calix 5-partitns; corolla hypocrateriformis, tubo longo, fance prominula 5-gona, limbo plano, obtusè 5-Jobo; antheıæ approximaı; stylus I; stigma capitatun basi annulatum.

2786. Minor. Caulibus procumbentibus, foliis oblongo-lanceolatis, margine glabris, pedunculis unifloris solitariis axillaribus folio longioribus. 24 . In sylvis.

2787. Major. Caulibus erectiusenlis, foliis ovato-subeordatis subciliatis, pedunculis unifloris solitariis folio (sæpiùs) brevioribus. 24. In Galliæ australis sylvis.

\section{$+\dagger$ Semina apice comosa. 449. IN $\mathbf{E}$ R I U M.}

Calix 5-partitus; corolla infundibuliformis, limbo obtnsè 5-partito, laciniis hasi intùs appendiculatis; appendices 5 sæpè latæ fancem coronantes; antheræ apice in filmm desinentes; stylus 1 ; stigma truncatum, orbiculo insidens.

2788. Oleander. Foliis lanceolatis angustis ternis, subtùs costatis, calicinis laciniis squarrosis, appendicibus planis trifidis. b. In Galloprovincia, agro Nicæensi et Corsica.

$$
\text { 450. C Y N A N C H U M. }
$$

Calix 5-dentatus, minimus; corolla tubo brevissimo, laciniis longis linearibus, corona cylindracea oblonga erecta dentata fancem ambienti. Cæetera ut in Asclepiade.

2789. Monspeliacum. Caule volubili herbaces, foliis reniformi- 


\section{R I O DO R A E E.}

eorrlatis acutis glabris. 2F. In Gallia Mediteranea, et circal linpelian.

$$
\text { 45I. A S C L E P I A s. }
$$

Calix 5-dentatus; corolla rotata, 5-partita, plana ant reflexa; nuculli 5 lariniis corolla altemi, medin corniculum exserentes ; sulusux 5, supu hà biloculares, medix inter cucullos et pistillum; corfuscula 5, nigra, nitida, intùs fissa, pistillum respicientia, hasi filimene. 2 emittentia; nvarim duplex; stylus brevis; stigma peltatum pentagonum, angulis foveolaribus.

2790. Vincetnxicume. Caule erecto, foliis ovatis acuminatis, margine tenuissime ciliatis, racemo terminali. 2F. In sylvatiris glareosis. - Hane et sequenten ad Cynanchum repellit Persoon.

379r. Nigra. Caule supernè subvolubili, foliis oratis basì harbatis, racemo terminali. $2 C$. In collibus sterilioribus Galliæ Mediterraneæ.

2792. Syriaca. Foliis planis ovalibus subtus tomentosis, caule simplicissimo, umbellis nutantibus. 2F. Nunc subspontanea in Gallia australi.

\section{OR D O L I I. E B E N A E E AE.}

Calix monophyllus, apice divisus; corolla calici inserta, monopetala, lobata ; stamina corollæ inserta, definita ant indefunita, sæpè monadclpha; ovarinm sxpiùs libernm; stylus simplex; stigma divisum; capsula aut bacca uni-aut-multilocularis, loculis r-spermis ; corculum rectnm in perispermo earnoso; cotyledones planæ. - Arbores aut frutices, foltis alternis, floribus axillaribus.

$$
\text { 452. D I O } S \text { P } \quad \mathbf{Y} \text { R } 0 \text { s. }
$$

Calix urceolatus, -6-fidrs; corolla imo calici inserta, urceolata, 4-6-fida; stamina 8-16 inax corolla inserta, interdim sterilia; stylus ; stigmata 4 quandoque bifila; bacea infetnè calice cincta, 8-12Jucularis.

2793. Lotus. Foliis ovato-nblongis discoloribus. b. In Galliat Narbonensi, inque collions Taurinensibus.

$$
\text { 455. S } \mathbf{T} \text { Y } \mathbf{R} \text { A } \mathbf{X} \text {. }
$$

Calix urceolatus, integer ant 5 -fidus; corolla imo calici inserta, urceolatu, limbo brevi 3-7-lobo; stamina 6-16; filumentis basi coalitis corollæ cubo inscrtis; stylus 1 ; stigma 1; drupa exsercca supera coriacea, nuce ossea spharica monospesma.

2794. Officinalis. Foliis ovatis subtàs villosis, racemis simplicibns

folio brevioribus. Đ. In Galloprovincix et INicra sylvis maritimis.

\section{O R D O L I I I. R II O D O R A C E AE.}

Calix 4-5-lobatus, persistens; corolla imo calici inserta , 4-5-partita ant 4 -5-petala; stamina definita, distineta, in nonopeialis enro!la, in polypetalis immediate imo calici inscrta; ovarium liberum ; stylus $\mathrm{x}$; stigma 1 ; capsula 4-5-Locularis, 4-5-valvis, valvis utroque murgine introflexin singutis loculum ennstituentibus polyspermum 
et axi centrali adnexis; semina minuta; corculum rectum in perispermo carnoso.- Frutices folisallernis, sæe ne junioribus margine revolutis.

$$
45 \% \text { L E D U M. }
$$

Calix minimus, 5.dentatus; petala 5 ; stamina 5-10, imo calici inserta.

27950. Palustre. Foliis linearibns margine revolutis, sulıtus tomentosis. $b$. In Alsatic tirfosis uliginosis.

$$
\text { 455. R II }
$$

Calix 5-partitus; corolla subinfundibuliformis, limbo patente, 5lobo ; stamina 10 , declinata.

2796. Ferrugineum. Foliis ovato-oblongis glabris subtìs leprosis, corollis infundibulifornibus. b. In Aipibus et Pyrenais.

2797 . Hirsutum. Foliis clipticis ciliatis subtù ferrugineo-punctatis, corollis infundibuliformibus. b. In Alpibus rarius.

$$
456 \text { A } 7 \text { A L E A. }
$$

Corolla infundibuliformis aut campanulata, 5-fida, ınæqualis ; stamina 5 , sub pistillo inserta.

2799. Procumbens. Ramis diffusis procumbentibus, foliis ellipticis glabris margine revolutis. $\mathrm{b}$. In Alpibus et Pyrenæis.

$$
\text { 157. II E N } z \text { I E S I A. }
$$

Calix 4 -partitus; corolla oblonga, limbo patente 4 -dentato reflexo; stamina 8 , basi corollæ inserta.

2799. Dabenci. Floribus terminalibus racemosis, foliis alternis ova-

tis revolutis subtìs incano-tomentosis. Ђ. In Pyrenæis.

$$
\text { O R D O L I V. E R I C A C E AE. }
$$

Calix persistens, 4-5-partitus, sapius liber; corolla monopetala, 4-5-fida aut partita, calıciaut glandule calicince inserta, sæp̀ marcescens et persistens; stanina definita, distincta, imæ corollæ ant glandulæ calycinæ insesta; anthera srepè basibicornes; ovarium sæjiùs liberunı; stylus 1 ; stigna 1 ; fructus multilncularis polyspermus baccatus ant sxpiùs capsularis multivalvis, valvis mecien sepliferis axi centrali infic adnexis ; semina minnta ; corculnm rectum in perispermo carnoso. - Frutices foliis sæ pè persistentibus.

\section{† Ovarium liberum.}

$$
\text { 458. E R I C A. }
$$

Calix 4-partitus; corolla campanulata, sapè ventricosa, 4-fida ; stamina 8 ; capsula 4 - 8 -lucularis, 4 - 8 -valris.

$28 \mathrm{n}$. Cinerea. Antheris aristatis, foliis ternis, corollis ovatis, stigmate capitato. $b$. In arenosis aridis montosis sylvaticis.

2Snr. Teralix. Antheris aristatis, corollis ovatis, stylo incluso, foliis quaternis ciliatis, floribus capitatis. $๖$. In uliginosis.

2802. Alboren. Antheris aristatis, corollis campanulatis glabris, stylo exserto, foliis ternis, ramulis incaro-villosis. b.In Gallia meridionali et Corsica. 
2803. Corsica. Antheris aristatis, corollis ovoilleis stylo æqualitus, foliis quaternis quinisve, floribus capitato-congestis, ramulis courctatis subglabris. b. In Corsica.

280. f. Cilinris. Antheris muticis inclnsis, cornllis ovatis inflatis, stylo exserto, foliis ternis quaternisque ciliatis, racemis secmndis. b. In Gallia occidentali.

2805. Scoparia. Antheris aristatis inclnsis, corollis campanulatis, stignate exserto peltato, foliis ternis. b. In sterilioribus.

2806. Vagans. Antheris muticis exsertis, corollis cylindraceis, stylo exserto, foliis quaternis quinisve, floribus pedunculatis. b. In Gallia neridionali, - $\beta$ Erica multiflora, Thul. par. p. 195 , circè Parisios reperta, ctiamsi gracilior, à priori non distincta videtur.

2807. Herhacea. Antheris muticis styloque exsertis, corollis subeylindraceis, foliis quaternis, floribus secundis. b. In Sabandix et Pedemontii subalpinis.

$$
459 . \quad \text { c A L L U N A. }
$$

Calix 4-partitus, duplicatus; dissepimenta receptaculo aflixa et valvularum suturis opposita. Cxtera ut in Erica. 2808. Erica. Ђ. In sterilibus sylvaticis arcnosis.

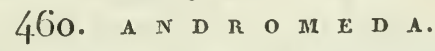

Calix minimus, 5-partitus; corolla 5-fida, laciniis reflexis ; stamina зо; capsula 5-locularis, 5-valvis.

2809. Polifolia. Foliis alternis lanceolatis revolutis, pedunculis aggregatis, corollis ovatis. b. In uliginosis circà Rothomagum et in Campiniæ Jurassique turfosis.

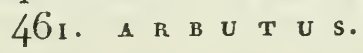

Calix minimus, 5-partitus; corolla ovata, limbo parvo, 5 -fido, revoluto; stamina so; bacca 5 -locnlaris.

§. I. Staminibus basi villosis; antheris apice biperfnratis; bacca tuberculosa, loculis polyspernis (ARBTUS).

2Sto. Unedo. Caule arboreo, foliis glabris obtusè serratis, panicula terminali. b. In Gallia Mediterranea et Occidentali, usque ad Nannetes.

1. II. Staninibus glabris; antheris apice non biperforatis; bacca levi; lnculis monospermis (UVA URST).

28г т. Alpina. Caulibus procumbentibus, foliis rugosis serratis. ๖. In Alpibus et Pyrenæis.

2812. Uva ursi. Canlibıs procumbentibns, foliis integerrimis.b. In Alpibus, Vogesis, Pyrenæis.

$$
\text { 462. P } \mathbf{Y} \text { R O L A. }
$$

Calix minimns, 5-partitus; corolla 5-partita, ferè 5-petala; stamina 10 ; stigma capitatum, 5-lobum ; capsula 5-locularis.

28ı3. Rotundifolia. Foliis obovalibus, staminibus adscendentibus, pistillo incurvo orario longiori. $\mathcal{F}$. In sylvaticis humidis. 
$281\}$. Minnr. Foliis subrutumlis staminibus pistillisque rectis. $\mathcal{F}$. In sylvaticis tiumidis.

2S15. Secundu. Foliis ovatis dentatis, raermo unilaterali, pistıllo recto. $\mathcal{F}$. In montosis sylvaticis.

29r6. Uniflora. Foliis suburbiculatis, scapn nuifloro. 24. In Alpibas, Pyrenxis, inque Belgii aggeribus arenosis.

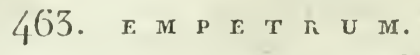

Dioicum. Calix 3-partitus; corolla 3 -petala. Masc. Stamina 3 ; filamentis lougis. I'em. Stylus subullus; stigma radiis $6-9$; bacca orbiculato-rlepressa, 6-9 sperma.

2817. Nigrum. Procumbens, foliis oblongis glabris, stigmate 9-radiato. b. In Alpibus et Arvernia.

\section{t+ Ovarium calici adhorens.

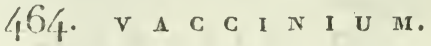

Culix adhxrens, integer ant $\mathfrak{f}$-dentatus; corolla campanulata, $\{$ fidit ; stamina 8 , receptaculo inserta; bacca globosa, mubilicata, f-locularis, oligosperma.

\section{I. Foliis deciduis.}

28,8. Myrtiflus. Pedunculis unifloris, foliis serratis ovatis, caule angulato. $\mathrm{b}$. In cricețis, sylvaticis, arenosis.

28ig. Uliginosum. Pednnculis unifloris, frilis obovatis lanceolatis glabris venosis, ramis teretibus. b. In uliginosis.

\section{II. Foliis persistentibus.}

2E20. Tilis illon. Racemis terminalibus nutantibus, foliis obovatis revolutis integerrimis subtus punctatis. b. In Alsatix, Delplinatûs sylvis montosis petrosis.

2821 . Oxyenecos. Pedunculis uniforis, foliis ovatis integersimis revolutis, caule filiformi repente. $\underset{j}{4}$. In uliginosis.

\section{ORDO L V. C U C R B I T A C E AE.}

Florcs sxpiùs monoici aut dinici. Calix ovario adltarens, suprì coarctatus, apice dilatatns in limbum 5 - fitlum ; corolla campanulata, snmmo ovario inserta, 5-loba, demùm mircescens persisters. Masc. Stamina 3-5, calicis coarctationi inserta, filamentis srepè conlitis; antherx I-loculares, oblongx, summis infixx filamentis, flexunsæe, fapitus geminatx, quinta solitaria; ovarium abortivum. Fem. Stamina abortiva; ovarium atllarens; styli aut stiguata plurima; lasere enrtice soliflo, uni-aut-multilocnlaris, polysperma ; semina sirpe anillata, horizontalia, angulo sepimentormm interno adfixa; jerispcrunn nullum; corculum rectum; cotyleflones planæ. - Herba sciundentes, sæpè asperæ, foliis petiolatis alternis suborbiculatis, yrhis axillaribus, perlumculis axillaribus nedio articulatis.

$$
\text { 465. в } \mathrm{R} \text { Y } 0 \text { N I A. }
$$

Míonoica ant dioica. Corolla obtuse: 5 - fida. Mase. Stamina 3 , 'quorum 2 basi coalita. Fem. Stylus 3-firlus; bacca globosa. 
2822. Dinica. Floribus racrunosis linicis, fritie rordatr-palnatis quinquelobis calloso-scabuis, frnctihus nubris. F. In sepilus.

$$
\text { 4.if. a }
$$

Monoica. Corolla plicata, 5-filla. Masc. Stumimm filamenta 3 , quormu 2 basi coalita; anthera connatix. Fem. I ilamenta 3, sterilia; ovarinm 3-loculare; stylus 1, stigmata 3; baccal oblonga, elontice desiliens, unilocularis; semina arillata.

2823. Elaterium. Frnctibus hispidis, cirrhis nullis. $\odot$. In Callize Mcditerancæ sterilioribus.

$$
\text { 467. с U с U м I s. }
$$

Monoicus. Corolli caupanulata, laciniis calicinis subulatis. MTasc. Filumenta 3, quorm 2 basi coalita; anthere connatie. Fem. I ilamenti1 3, stcrilia; stylus 1; stigmata 3. crassa, bipartita; bacca masna, 3-locularis, loculis partitis; seminibns ovatis compressis, margine acuto.

282 f. Melo. Foliorum angulis rotuedatis, fructibus subtorulosis, cortice reticulato. $\odot$. Colitur in lortis.

2825. Sativus. Foliorum angulis acutis rectis, fructibus oblongis scabris. $\odot$. Colitur in hortis.

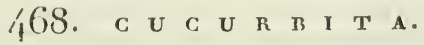

Monnica. Calix, cornlla et masc. ut in Cucumerc. Fem. Filamenta 3 , stcrilia, infrat in annulum crassinsenlum coalita; stylus brevis; stigmata 3 incrassata; bacea cncumeris sed semina margine tumida, integra aut apice cmarginati.

2826. Iagenaria. Corollis patenti simis substcllatis, seminibus apice truncato-cmarginatis. $\odot$. Colitur, ex Indiis orta ut sequentes.

$2 \$_{27}$. Maxima. Floribus campanulatis basi latiusculis, linbo reflexo rotundato compresso, $\odot$. Colitur.

2828. Pepo. Floribus canpanulatis basi angustatis, limbo erccto. $\odot$ Colitur.

2829. Anguria. Corollis subrotundis, scminibus coloratis, foliis laciniatis. $\odot$. Colitur.

\section{OR D O L VI. C A M A N L AC E AE.}

Calix nvario adharens, limbo diviso; onrolía s:mimo calici inserta, smpiìs marcescens; stamina sul, curnlla calici inserta, sxpiis 5 , corolle laciniis alternil, antheris distinetis ant coalitis; ovariun suprì glandulosnm; stylus 1 ; stigma simplex aut dis istim; capsula 2-6-locularis, sæpiùs 3-locularis, polasperme, leferibus deliscens ; semina angnlo locnlorm interiori allixa; rorculnm rectum; radicula jufera; perispermum carnosum. - lierbx sæpiùs lactesecuites, foliis alternis, floribus distinctis ant capitatis involucratis.

$$
\begin{aligned}
& \text { † Antherce distincta. } \\
& 469 \text {. с A M P A N U L A. }
\end{aligned}
$$

Calix 5-fidus, sinubus interdiura reflexis; corolla campanulata, 5- 
frka ; stanina 5 , filamentis basi lationlaus; stigma 3-ıarius-5-parlitum ; capsula 3-rarius-j-locularis.

\section{§. I. Culicis simubus non reflexis.}

2:30. Cenisia. Minnta, caulibus uniforis, foliis ovatis glabris integerrimis subciliatis. 2 . In Alpilus.

283r. Fiederacea. Glabra; foliis cordatis quinquelobis petiolatis, caule lixo. $\odot$. In umbrosis humidis.

3832. Rotundifilia. Subglabra, foliis radicalibus subrotundo-cordatis erenatis, caulinis linearibus integerrimis. $2 j$. In muris, sazosis pascuis mentosis.

2833. Pusilla. Subglalra, foliis suldentatis, radicalibus ovatis acuminatis, caulinis linearibus. 24. In rupestribus sylvaticis.

28\%. Linifolia. Glabra, foliis ommibus lineari-lancenlatis, canlibus pancifloris. $2 \xi$. In pratis frigidis Alpium, Arverniæ et Pyrenæorum.

2935. Valdensis. Pubescens, foliis radicalibus oblongo - Jancenlatis subdentatis, superioribris lancenlato linearibus, caulibus suburifloris. 2 . In fascuis Alpium, Pyrenzorum.

3836. Patula. Foliis radicalibus lanceolato-oralibus dentato-sinuatis subpubescentibus, caulinis limearibus glabris, paniculit patula, laciniis calicinis denticulatis. $\delta, 2$. In sepibus et versuris, in $\mathrm{Al}$ pibns ec Gallia meridionali.

283- Rinpunculus. Foliis undulatis pilosis, radicalibus lanceolatnovalibus, caulinis lincari-lanceolatis, panicula coarctata. $\sigma^{7}$. In sylvaticis, arsis.

2\$38. Persirifnlin. Glibra. Goliis radicalibus obovatis in petiolun attcuatis, caulinis lanccolato-lincaribus subserratis sessilibus remotis. 2 In sylvaticis.

2S3. Preamidalis. Clabra, foliis levibus serratis corlatis, canlinis lancenlatis, panicula pyramidali, foribus aggregatis lateralibus. d. In Sabaullia.

2Sin. Rhombriclalis. Glabra, foliis serratis, inferioribus sessilibus subrhombonteis, caulinis oratis acutis, floribus subspicatis secundis. 2 . In Alpibus, Delphinatûs inc[ue Galloproviucix A]pinis.

38fr. Latifnliı. Foliis ovatn - lanceolaris seabris subdentatis, canlc simplicissimo tereti, floribus solitariis pedunculatis, valicibus glabris. $2 \%$. In Pedemontii, Delphinatus, Vogesorum, Arrernix scpibas montosis umbrosis.

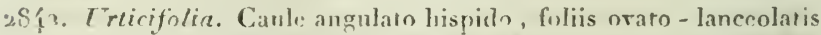
grosse serratis, pedunculis unifloris axillaribus cernuis, calicibus hirpidis. F. In montibus Jurassi.

28;3. Rapunculoides. Foliis scabris cordan-lancenlatis, caule ranuso, floribus secundis axillaribus spicatis, calicibus patentissi mis. 2j. In agris, siccissimis.

2. f $^{*}$. Simp?ex. Cante siuplici pubescente, foliis pubescenirbus 
sessilibus ovato-lanceolatis crenatis, racemo simplici, pedicellis umbloris, eavice glabo. 2;. In Pedenontii unontosis.

28 í. Trachelium. Caule angulato, foliis petiolatis condato-lanceolatis scabris acute scratis, floribus pedunculatis axillaribus, caliciluns ciliatis. 24. In sylvis.

28,75. Glomerala. Caule angulato simplici glabriusculo, foliis seabris, rudicalibus petiolatis oblongo-lanceulatis dentatis, eaulinis sessilibus scmi-auplexicaulibus, florum capitulo terminali. 2 . In aridis, collibus calcareis.

28 fj $^{*}$. Petrea. Ciaule angulato simplici pubescente, floribus sessilibus capitato-gloneratis, foliis snbtus tomentosis. $\mathcal{C}$. In Pedenontii Alpibis.

2S.f5. Cervicaria. Hispida, floribus sessilibus capitato glomeratis, foliis lanceolato - linearibus undulatis. $\sigma^{\top}$. In $\Lambda$ !pinis sylvaticis asperis.

28 f. Thyrsoidea. Hispida, caule simplicissimo, foiiis lanceolatolinearibus, racemo simplici terminali oblongo. $\mathcal{F}$. In Alpium et Jurassi locis siccis.

28,9. Elatines. Foliis cordatis dentatis pnbescentibus, caulibus prostratis, pedunculis capillaribus multilloris. $2^{\circ}$. In Pedemontii Alpinis.

2S 19. Erinus. Pubescens, canle dichotomo, foliis sessilibus ovatis profundi dentatis, superioribus oppositis, floribus axillaribus subsessilibus. 2f. In Gallix meridionalis pecrosis.

285̃o. Pygmaea. Minutu hispida, fuliis ovato-oblongis obtusis sessilibus ciliatis, caule simplici subtrifloro, pedunculis foliis longioribus. - In Corsica.

\section{II. Capsulis obtectis sinubus calicis reflexis.}

285ı. Allionii. Canle unifloro hispido, foliis lineari-lanceolatis undulatis hispidis. 2F. In Alpibus Peden. Delphin. Galloprov.

2852. Barbata. Caule simplici, foliis ovato-lanccolatis villosis, racemo terminali laxo, corullis barbatis. 4 . In pascuis montanis Lothar. Pcdem. Delphin. Sabaud.

2853. Medium. Canle indiviso erecto folioso, florihus crectis, stigmatibus 5, capsulis 5-locularibus. $\sigma$. In Galloprovincia sylvis apricis.

2854. Specinsa. Hispida, canle simplici folioso, pedunculis axillaribus unifloris, foliis lineribus smberenatis longissimis, stigmatibus 3, capsulis 3 -loculatibus. $\mathcal{\psi}$. In Pyrenais, inqূue Gallia Narbonensis montilus.

2855. Spicata. Hispida, canle simplici, foliis linearibus integris, spica laxa. $\zeta$. In Pelemontii, Delphinatus, Sabaudiæ, Vallesiæ, Galloprovincia subalpiuis.

$2855^{*}$. Sibirica. Hispida, eaule simplici paniculato, foliis sessilibus lineari-lanceolatis subunilulatis, panicula virgata. $0^{7}$. In Pedemontii collibus aridis. - Curt. mag. t. $6 \% 9$. 


\section{P R I S M A T O C A R P U s.}

Corolla rotata, limbo piano; capsula prismatica, 2-3-locularis, versis apicenu dehiscens. Cixtera ut in Campanula.

2856. Speculum . Citule ramosissimo cliffuso, foliis oblongis crenatis, floribus solitariis, laciniis calicinis corolian patulam æquautihus. $\odot$. In agris ad versuras.

28jj. Mibrilus. Ciule stricto basi subramoso, foliis oblongis subcrenatis, floribus solitaiis, laciniis calicinis corolla brevioribus. $\odot$. Inter segetes.

$$
\text { 47. } \text { I. P II Y T E U II A. }
$$

Calix 5-fidus; curolla rotata, tubo brcvissimo, laciniis 5, longis linearibus; stamina 5; stimma 3-partitum; capsula 3-locularis, foraminulis latcralibus deliscens.

- 285S. Paucifora. Fuliis banceolatis obtusis, capitulo subfolioso, bracteis subrotundo-cordatis ciliatis. $\%$. In $A$ pibus.

2859. Hemispharica. Foliis linearibus subintegerrimis, caule vix brevioribus, capitulo subroiuido, lotacteis watis ciliatis. 27. In Aipibus, Arvernia, Gebenais, Pyrenæis, in pratis montanis.

2860. Comosa. Foliis petiolatis dentatis, ruticalibus cordatis, caulinis lanceolatis, fasciculo subrotundo bracteato terminali. C. In Delphinatûs et Galliæ Narbonensis montibus.

286r. Orbicularis. Foliis ohlongo-lanctolatis serratis, 1 adicalibus cordatis, capitulo subrotundo. 2 . In montosis.

2862. Scherchseri. Foliis lincaribus capitulo subfolioso longioribus, inferioribus dentatis, biacteis linearibus. $\mathcal{4}$. In Pedemontii Alpibus.

2863. Michelii. Foliis linearibus rigidis vill 'sis subintegerrimis, capitulo subrotundo, bractcis oblongo-lanceolatis, $\mathcal{Y}$. In Pedemontii Alpibus.

2864. Charmelii. Foliis radicalibus petiolatis cordatis subdentatis, caulinis linearibus integerrimis, capitulo rotundo. 2 . In Dclphinatûs, Pedemontii Aipibus.

2865. Betonicafolia. Foliis simpliciter crenatis, radicalibus lanceolato-cordatis, caulinis lanceolatis, spica oblonga. 2 . In Alpibus ct Pyrenæis.

2366. Scorzonerefolin. Foliis subdentatis, inferioribus ohlongis petiolatis, superioribus linearibns sessilibus, spica oblonga. $\mathcal{Y}$. In Delphinatûs montibus.

286-. Spicata. Toliis radicalibns cordatis duplicato-dentatis, canlinis lineari-lanceolatis dentatis sessilibus, spica elongata. $2^{\circ}$. Ia sylvaticis humidis.

2S68. Malleri. Foliis radicaibus corratis duplicatn-dentatis, raulinis lanceolatis, spica ovata, stylis hirsnis flore longioribus cnarginato-bifidis. 2F. In Pedenuntii et Valiesia subalpinis.

$$
\begin{aligned}
& +\dagger \text { Anthera commatce. } \\
& 472 \text {. L O \& E L I } \mathrm{A} .
\end{aligned}
$$

Corolla irregularis, suprà longitudinaliter fiesa, limbo 5 - filo 
inæerpalibilabiato, suprà hipartito, infu ì trifido majore; anthera 5, in tubum connala:; stigna simplex; capsula z-3-fuculatis.

28fig. Dortmamma. Foliis linearilus bilucularilus integerrimis, scapo simplici subundo racemoso. 25. In lacubus et ripis circi Lecodium.

28\%o. Trens. Canle erectinsculo, foliis infrioribus subrotuntio crenatis, superioribus lanceolatis setratis, floribus racemosis. $\odot$. In Gallia: occidentalis oylvis humidis.

28-1. Mimuta. Foliis ovatis radicalibus subcrenatis, scapis capillaribus milluris. $\odot$. In Corsica.

287 $\mathrm{1}^{*}$. Laurentia. Canle prostrato ramoso, foliis lanceolato-ovalibus crenatis, pedınculis soiitariis unifloris. $\odot$. In Corsica et Ilva.

$$
\text { 473. J A S I o N E. }
$$

Calix 5-fidus; corolla rotata, tubo brevissimo, laciniis 5 longis linearibus; stanina 5 , antherjs in tubun conlicis; stigma 2-fidum; capsula 2 -locularis; flores aggregati in involucro polyphyllo suprit receptacuium nudum.

2872. Momlana. Foliis lineari-lanceolatis basi angustioribus undulato-crispis. $\odot$. In sterilibus siccis.

2873. Perennis. Foliis linearibus sublævibus planis obtusiusculis. 24. In Grallia áustrali.

\section{OR D O L VII. CO M POSITAE.}

Flnes in involucro communi collecti, uniformes aut difformes, receptaculo plano aut convexo, nudo ant paleaceo, impositi; cuique flosculo, calix tenuissimus, ovario adliærens, non separabilis, apice nunc in dentes producto, sæpiùs expanso in pappum pilosum plamosum aut membranaceum, semen coronantem; corolla monopetala, summo ovario inserta, 5-dentata, nunc tubulnsa, nunc longitudinaliter fissa; stamina 5 , corollæ inserta, ejusdem lobis alterna; antherw in tubum coaluce; ovarium simplex; stylus $\mathrm{x}$; stigmata $\mathrm{I}$ aut sæpiù 2 ; capsula (akena) monosperma, non dehiscens, siepius pappo coronata, semen nudum mentiens; perisperuum nullum; corculum rectum; radicula infera; cotyledones planæ. - Herbæ aut xariùs frutices, foliis alternis aut rarihs oppositis, flosculis tam arcte aggregatis nt florem unicum simulent.

\section{T R I B U S I. C I C H O R A G E IE.}

Flosculi omnes ligulati ct hermaphroditi; receptaculum vix carmosum; succus proprius in plurimis lacteus; folia alterna; flores lutei rarius carulei, scepe meteorici.

$$
\text { † Pappo nullo. }
$$

$$
\text { 474. I A M P S A N A. }
$$

Involucrum calicnlatum; receptaculum nudum; semina pappo destituta, caduca, involucrifoliolis miniuse cincta. 
$2 S 7$ f. Minimı. Scapo subtrifloro, pedunculis fistulosis clavatoincrassatis, foliis ovato-oblongis denticulatis. $\odot$. In pascuis siccis et arenosis.

2875. Fatida. Scapo unifloro, foliis runcinato-pinnatifidis, lacinia terminali rhombea. 2 . In sylvis montosis Sabaudiæ, Pedemontii, Flandriæ?

28,6. Communis. Caule erecto striato ramoso, foliis ovatis petiolatis angulato-dentatis. $\odot$. In cultis.

$$
\text { 475. R H A G A D I O L U S. }
$$

Involucrum caliculatum ; foliolis internis semina matura cingentibus; receptacalum nudum; semina non papposa, sæpiùs inflexa vel contorta, matura non caduca.

$28 ; 7$. Stellatus. Seminibus lævibus patentibus, foliis caulinis lanceolatis subdentatis. $\odot$. In arvis Gülliæ australioris.

28-8. Ldulis. Seminibus læribus patentibus, foliis lyratis. $\odot$. In Galloprovincia.

$$
\begin{aligned}
& \text { t† Pappo piloso. } \\
& \text { 476. } \mathbf{P} \text { R E } \mathbf{N} \text { A } \mathbf{~} \mathbf{\text { H }} \text { s. }
\end{aligned}
$$

Involucrum caliculatum; receptaculum nudum; pappus sessilis pilosus, simplici serie; flosculi pauci.

\section{I. Floribus purpurascentibus.}

2879. Purpurea. Foliis oblongo-lanceolatis amplexicaulibus cordatis denticulatis subtù glaucis, caule ramoso. $\odot$. In sylvis lapidosis montosis.

288n. Tenuifolia. Foliis linearibus integerrimis amplexicaulibus, caule simplici. $\mathcal{Y}$. In sylvis Delphinatûs, Pedemontii.

\section{II. Floribus luteis.}

285r. Viminea. Foliis decurrentibns, inferioribns pinnatifidis extrorsìn dentatis, snmmis lincaribns, caule ramoso divaricato viscoso. 2 . In lapidosis vincis Gallix australis.

3882. Pulchra. Foliis subscabris, radicalibus runcinatis, canlinis amplexicaulibus ovato-lanceolatis basi sagittatis, panicula corymbosat divaricata nuda. $\odot$. In cultis et viucis provinciarum centralium et australiorum.

2883. Bulbosa. Foliis lanceolato-oblongis subdentatis glabris, scapo unifloro superne hirto, involucro glabro. 4 . In Pyrenæis, maritimis Monspelii et Galloprovinciæ.

$$
\text { 477. C H o N D R I L L } \mathbf{A} \text {. }
$$

Inrolucrum caliculatum; receptaculum nudum; pappus stipitatus pilosus.

2884. Juncea. Foliis radicalibus runcinatis, caulinis linearibus integris, pappi stipite semine longiore. 2C. Ad margines arvorum.

28S5. Muralis. Foliis lyrato-pirnatifidis dentatis, lobo terminali

5-angulari, panpi stipite semine breviore. ○. Ad vetustos muros. 


\section{L A c $\mathbf{T}$ U C A .}

Involucrum oblongun, imbricatum, foliolis matrgine menubranaccis; receptaculum nudum; pippus stipitatus, pilosus, mollis, fugax.

\section{j. I. Floribus luteis.}

2886. Sativa. Foliis rotundutis caulinis cordatis, caule corymboso. $\odot$. Patria ignota, in hortis culta.

288\%. Svlvestris. Foliis simuato pinnatifulis amplexicanlibus verticalibus carina aculeatis apice acutis, floribus laxè paniculatis. ó, Sin. $\odot$, Lin. Ad margines viarun.

2858. Virosa. Foliis oblongis denticulatis horizontalibus, carina aculeatis apice obtusis. 3. Ad sepes muros et agros.

28S9. Saligna. Foliis carina aculeatis, radicalibus lanccolatis pinnatifidis, canlinis linearibus incegerrimis. $\odot$. Ad marginem agrorum et vinearum.

\section{II. Floribus cceruleis.}

2890. Perennis. Foliis omnibus pinnatifidis, laciniis linearibus sursim dentatis, floribus coryuboso-paniculatis. 7 . Ad vineas, in agris lapidosis et saxosis apricis.

289r. Tenerrima. Foliis radicalibus pinnatifudis, laciniis sursìn integris, caulinis linearibus integerrimis sagittatis, caule ramoso divaricato. 24. Circà Narbonem.

2892. Segusiana. Foliis inferioribus lanceolatis runcinato-dentatis basi attenuatis sessilibus. superioribus lineatibus sitgittatis, caule ramosissino. $\odot$. In collibus apricis circà Segusium.

$$
\text { 479. S D N C H U s. }
$$

Involucrum oblongum, imbricatum, basi ovatum; receptaculum nudum; semina longitudiualiter striata; pappus brevis, sessilis, pilosus.

\section{f. I. Floribus Luteis.}

2893. Maritimus. Pedunculis subsolitariis terminalibus nudis, foliis lanceolatis amplexicuulibus indivisis, retronsim argutè dentatis. 24 . In naritimis, à Nicæa ad Rupcliam et in stagnis subsalsis Delphinatûs.

289 f. Tenerrimus. Pedunculis tomentosis umbellatis, involues is pilosis, foliis bipinnatifidis. $\odot$. In maritimis Galliæ Mediterrancæ.

2895. Olerareus. Pedunculis subtomentosis umbellatis, involucris glabris, foliis oblongo-lanceolatis anplexicaulibus margine ciliatis subsinuatis. $\odot . a$, In cultis $\in$ t hortis; $k$, in sterilibus.

2896. Arvensis. Pedunculis involncrisque hispidis subumbellatis, foiiis runcinatis basi cordatis dentato-ciilitis. $2 \%$. In arvis.

2897. Palıstris. Pedunculis involucrisque subumbellatis glanduloso-lispidis, foliis runcinatis basi sagittatis. 2 . Ia stagnormu et fossarum or 


\section{II. Florilus cceruleis.}

${ }_{2} 898$. Alpinus. Pedunculis involucrisque hirsntis, floribus racemosis bracteatis, foliis runcinatis basi sagittatis glabris subtus glaneis. 2 . In sylvis umbrosis editiorum montium.

2Sog. Plumieri. Pedunculis bracteis involuerisque glalsis, floribus paniculato-corymbosis, foliis rmocinatis amplissiuis. $\mathcal{H}$. In umbrosis et saxosis editiurum montium Arverniæ, Pyrenæorum, Alpium.

$$
\text { 480. P I }
$$

Involucrum imbricatum, basi tumidum, foliolis margine membranaceis; receptaculum nudum; semina tetragona, subincurvata, transversè tuberculata; pappus sessilis, pilosus.

2900. Vulgare. Foliis cauliuis amplexicaulibus oblongis subintegerrimis radicalibus sublyrato runcinatis, pedunculis squamosis incrissatis, squamis cordiformilus. $\odot$. Aávias, Nicææ, Gallupıvineix, Monsprelii, Ansionis.

29or. Albirlum. Foliis cano-scabris, radicalibus runcinato-dentatis, cantinis ablongo-lanceolatis subamplexicaulibus subdentatis. $2 \%$. In lapidosis editionn montium.

$$
48 \mathrm{I} \text {. H I E R A C I U } \mathbf{M} \text {. }
$$

Involucrum imbricatum; receptaculım nudum, ant rariùs pilis sparsis semine brevioribus onustum; pappus sessilis, pilosus, sæpius sordide rufescens.

1. I. Leontodontoidea; foliis radicalibus sulglabris nec glaucis nec coriaceis; scapis usdis, uni aut paucifloris.

2902. Aureum. Scapo unifloro subnudo, involucro hispido, foliis lanceolato-spatulatis runcinato-dentatis glabriasculis. $\mathcal{L}$. In pascuis Alpinm.

2903. Pramersum. Seapo nuto racemoso, floribus superioribus primoribus, foliis ovatis sublentatis glabris, radice præmorsa. $\underset{i}{2}$. In pascuis Alpium Pedemontii, Monspelii.

290\%. Aurantiacum. Scapo basi folioso hispido, floribns corymbosis, pedunculis glomeratis, foliis oblongis acutiusculis piloso-hispiclis. 2 . In Alpibus, Jurasso, Vogesis.

2905. Alpin:um. Seapo unifloro subnurlo villoso, involuero villnsissimo, foliis lanceolatis integerriutis aentis villosis. 4 . In paseuis Alpium, montimn Arverniæ et Munspelii.

2906. Halleri. Scapo 1-2-floro subumlo involncroque piloso, foliis petiolatis subrillosis ovato-oblongis, basi runcirato-dentatis. $2 F$. In Alpibus Sabaud. Peclem. Delphin.

6. II. Andryaloidea; p'anta suboblectre pilis allis longis sub lente articulatis subp'umosis.

29.7. Schrarleri. Scapo unilloro nnto involucroque villoso, foliis petiolatis oblongis integerrimis subvillosis. $F$. In Alpibus Sabaud. Valles. 
2908. Villosum. Caule erectu subramusu foliis:pue villosis, raduralibus oblongo-lanceolatis dentatis, canlinis ovatis amplexicanli'ns subelentats, involucris villosissimis pitulis. 2 C. In pratis unontunis.

2909. Eriophorum. Cinle creeto ramoso com folits dense lanato, foliis inferioribus lanceolatis subdentatis, superioribus ovalis inte gris, involucro fanato apice glabriusculo, tarlice premorsa. 2 ? In sabuletis agri Syrtici.

2910. Lanatum. Cinle erecto subsimplici, hasi folioso lanato , floribus corymbosis lonse perluncuhtis, foliis ovatis lanatis sulnutegris, receptaculis subpilosis. 24. Locis apricis montium inprinus ànstralionum.

2911. Andrvalwides. Canle erecto subsimplici tomentoso supernè nudo, foliis tonentosis, inferioribus orali-oblungis basi runcinato-dentatis, supcro lineari integro. 25. In appibus apricis Detphin. Pedem. Sabami.

2912. Saxatile. Scapo mulo 1-4-flomo hirtello, involucro glalin, foliis ovatis villoso-lanatis integriusculis. 2 . In rupibus aprici. Pyrenæorum et Alpium Delphin. et Pedem.

§. III. Pilosella; planta glaucescentes subonriacea hirla (imprimis ad margines foliorum), pilis sparsis longis albis rigidulus.

2913. Pilnsella. Scapo unifloro nulo, stoloniluss repentiłus, folnis integerrimis ovatis subtus tomentosis. F. In locis aridis, submontanis.

2944. Auricula. Scapo nulo aut unifolio uni-aut-multifloro, foribus corymbosis, stolonibus reptantibus, foliis integerrimis oblongis oubtius nudis. $2 \mathcal{C}$. In sterilibus.

2914*. Angustifolium. Scapo unifolio hinto subtriforo, floribus confertis subsessilibus, involucris villosis, foliis lineari-lanceolatis acutis integris pilosis. $\mathcal{Y}$. H. angustifolium. Wild. Spec. 3. p. 156j. - In summis Alpibus Sabaudis et ad montem Cenisim.

2915. Cymosum. Scapo folioso hispido, floribus corymboso-pani- culatis, pedunculis ramosis, involucris lispidis, fu!is oblonzolanceolatis integerrimis hirtis. 2 . In Alpibus Delphinatuts.

2916. Piloselloides. Scapo folioso glabrinsculo, floribus corymboso-paniculatis, pedunculis ramosis, involucris lirtis, foliis lanceolatis acutis integerrimis subglabris. $2 \%$. In pratis siccis $\mathrm{Al}$ pium demissiorum, Juıssi, et ad moenia Argentorati.

2917. Staticefolium. Scapo subnudo glahro ramoso subtrifloro, pedunculis Iongis squamosis unifloris, foliis lineari-lanceolatis subdentatis glabris. 2 . In Alpibus secus torrentes.

29'8. Porrifolium. Canle erecto ramoso basi folioso glabro, foliis linearibns integris aut subdentatis carina sæpè villosis. 24 . In monlibus Delphin. Pedem. Galloprov.

29r9. Glancum. Canle erecto ranoso folioso infernè subpiloso, foliis lanceolatis sessilibus subdentatis utrinquè attenuatis. 2 . Secus torrentes Alpium Peden. Delphin.

$2919^{*}$. Rupestre. Scipo unifolio simplici unifloro ant in ramos 
pancos elongatos uniflores diviso, involucro hirto, foliis lanceolatis ruaciuato-tlentatis sultìs hix villosis. 2 . H. ruprestre. All. anct. 12. 1. 1. f. 2.-Locis saxosis unontium Pedemontii propè Encraive.

S.IV. Pulmonarice; planta caile folioso, involucro pilis nigris sapiüs hirto.

2920. Cerinthoides. Caule simplici villoso, foliis pilosis subdenticulatis, radicalibus obovatis, cuulinis ohlongis semi-amplexicaulibus, involucris hirsutis. $\mathcal{F}$. In Pyrenxis, Alpibus Pedem. et Delplin.?

292r. Prennuthnides. Caule simplici, foliis lanceolatis cordatis amplexicaulibus denticulatis pubescentibus, floribus racemostcorymbosis. 2 . In apricis Alpium, Juassi el montium Arverúiæ.

2922. Lampsannides. Canle simplici, foliis cauliuis lyrato-runcinatis amplexicanlibus hirtis, tloribns paniculatis, involucris hispidis. 2 . In sylvis et pratis Pyrenzorum.

2023. Succiscefoliunı. Caule siuplici scabriusculo, foliis integris, canlinis lanceolatis semi-amplexicaulibns, radicalibus petiolatis oblongis obtrisis scabris, floribus corymbosis. $\mathcal{H}$. In montibus Jurassi et Pidemontii.

$292^{\prime}$. Montanum. Caule simplici unifloro, foliis ovato-lanceolatis denticulatis sessilibus, receptaculo subpiloso. 2 . In pratis Alpium Sabaud. Pedena. Delph. et Jurassi.

2925. Murorum. Caule simplici, foliis ovatis subtùs villosis mollibus, basi profunde dentatis, inferioribus petiolatis subcordatis, floribus paniculatis. 2 . Ad muros antiquos.

2926. Sylvaticum. Caule simplici, foliis mollibus oblongis villosis subdentatis, iuferioribus petiolutis ovatis, floribus paniculatis. $\mathcal{F}$. In sylvis.

2927. Sabaudum. Caule simplici, foliis ovato-oblongis subglabris acutis sessilibus subamplexicaulibus basin versùs dentatis, floribus corymbosis. 2 . In neworibus.

2928. Unubellatum. Caule simplici, foliis linearibus subdentatis, floribus corymboso-umbellatis. $\mathcal{F}$. In pascuis siccis.

2929. Amplexicaule. Caule ramoso, foliis ovato-cordatis amplexicaulibus basim versùs dentatis, pednnculis involucrisque thirsutis. 24. In lapidosis Pyrenæorum, Alpium et montium Corbariensium.

2930. Albiáum. Caule ramoso hispido, foliis lanccolatis dentatis sessilibus utrinquè attenuatis, pedunculis incrassatis, involucris laxis hispidis. $\mathcal{F}$. In pascuis Alpium Delphin. Sabaud. Pedem.

293i. Tubulosum. Caule ramoso hispido-viscoso, foliis lanceolatis profunde dentatis sessilibus basi attenuatis, involucris hispirlis subriscosis, ligulis apice callosis canaliculato-tubulosis. $\mathcal{F}$. In Alpibus Delplinensibus.

2932. Grandiflorum. Caule simplici adscendente sulcato piloso-viscoso, foliis lanceolatis recurvato dentatis, caulinis subdentatis amplexicaulibus sagittato-hastatis, involucris hispidis, pappo albissimo. 24. In pascuis A!piam et montiam Arverniæ. 
29.3.9. Llatfarinides. Caule simplici snlcato glahrinsculo, foliis radicalilus oblougis hasi profundè denlatis, canlinis lancenlatis hantatu-sagiltatis amplexicaulibus dewatis, invelucris laxis pilosis. 2i. In pascuis hapilosis Pyremaorum, Alpium el Jurassi.

2) $3 \mathrm{i}$. 1'aludosum. Canle simplici, foliis glabris oblongis basi atcemuatis runcinato-dontatis, caulinis amplexicanlibus, foribus patniculatis, involncris hispidis. 2f. In lumbilis sylvosismontanis.

29)35. Sirunellafolium. Canle procumbente basi ramoso pauciflom, perhncolis involncrisque comentosis, foliis ovatis baci inaqualibus dentimlatis petioktis, petiolis dentatis. 24. In lapidosis AIjium et Pyrenæornm.

2936. Jucquini. Caule crecto basi ramoso paucifloro, pedunculis involncrisune pilosis, foliis oblongis basi subpinratifidis. $\mathcal{F}$. In rupibus montanis Delphinatûs.

2037. Cltondrilloudes. Canle erecto paucifloro, foliis glahris, caulinis lanceolatis acuminatis runcinatis, radicalibus oblongo-lanceolatis indivisis. 2 . In Alpibus? et Vogesis?

$$
\text { 182. A N } \mathrm{D} \text { R } \mathrm{Y} \text { A I } \mathrm{A} \text {. }
$$

Involncrum imbricatum; receptaculum pilis semina superantibus onustum; pappus sessilis, pilosus; in plurimis (rothia, Goertn.) seınina margitialia nuda.

293S. Integrifolia. Canle crecto corymboso, foliis iomentosis sessilibus, interioribas oblongis rumcinatis, superioribus lanceolatis sululentatis, pedunculis glanduloso-villosis. $\odot$. In sterilibus prov. anstralionum et oecidentalium.

293y. Simuata. Canle crecto corymboso, foliis subtomentosis lanconlatis sinuato-dentatis sessilibus, superioribus iutegerimis. 4 ? In Gullia anstrali.

39fo. Vemausensis. Scapo nudo multifloro, foliis runcinato-lyratis obcusis dentatis. $\odot$. In Gallia Metiterranca. - An genus novmm?

$$
\text { 485. c. A E P I s. }
$$

Inrolucrum calicnlasun, laxum, fristigcrnm sxpè costatum; receptaculum nudum; pappus pilosus, sessilis, niveus.

2941. Biennis. Folüs hispidis runcinato-pinnatifulis, summis scssiJibus lanceolatis dentalis carina hispido-aculearis, involucris pubescentibus mnricatis. 8 . In pritis frejuents.

29:2. Tectorum. Foliis glabriusculis lanceolato-runcinatís, Jaciniis adscendeatibus, summis limearibns filformi-sagittatis amplexio eaulibus, thoribas corymbosis; intolueris pubescentibus. $\odot$. In pratis et tectis stramineis.

29行. Virens. Foliis glaleris, inferioribus remete dentatis, superioribus subintegerrimis subsagitatis, canke basi sauusa diriso, involncris pubescentibus. $\odot$. In pratis. - An prioris varietas?

20亿์. Dioscoridis. Foliis radicalibus lynate-rundinatis, canlinis has. tatis !anceolatis, inferioribus destatis, canle erecto, involunis 
tnmentosis, fructigeris subrotuntiu-ovatis ingulosis. $\odot$. In siecis secus vias Alsatix, Pedemontii.

29łj. Ambigua. Foliis hispislis, inferioribns oblongo-linearibus dentatis, superioribus linearibus integris, canle giabro sulcato

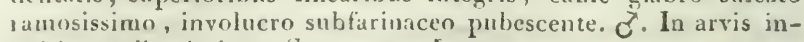
cultis et olivetis inter Savonam et Loano.

$$
\text { 484. B A R K } \text { II A U S I A. }
$$

Involucrum caliculatum, maturum sulcato-costatum, foliolis extcrioribus laxis; receptaculum nudum; pappus pilosus, stipitatus.

29i6. Alpina. Foliis ovatis cordato-sagittatis amplexicanlibns dentatis, pednuculis elongatis unifloris, involucris hispielis, squamis exterioribus membranaceis scariosis. $\odot$. In pratis Alpium Pedens. et Gallopror.

291-. Rubra. Foliis radicalibus runcinato-Jyratis, caulinis amplexicaulibus lanccolatis, inferioribus pinnatifidis, inrolueris hispidis, squamis exterioribus scariosis. $\odot$. Secus vias Nicææ, Monspelii.

29 低. Fatida. Ioliis runcinatn-pinnatifidis seabris sessilibus, summis lanceolatis basi profunde incisis, involucris ovatis pilosis ângulatis. $\odot$. In versuris et incultis.

2919. Taraxarifnlia. Foliis scabris, radicalibus lyrato-runcinatis, caulinis lanceolatis amplexicaulibus basi dentatis, involucris subtomentosis, squamis extcrioribus margine nembranaceis. $\sigma$. In pratis lapidosis.

2950. Ceontolon. Foliis glabris runcinatis dentatis, scapn nurlo multiflorn arlscendente, involucris subtomentosis, squamis exterinribus adpessis. $\sigma^{7}$. In sylvis Pedemontanis. - An potius puioris generis?

$29^{5}$. Setosa. Setis in caule, pednnculis, involucris, nervis et nris foliornn sparsis, foliis inferioribus pinnatifido-dentatis, canlinis lentatis, summis linearibus, involucri squanis exterioribus pa-

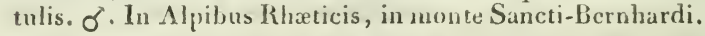

$$
\text { 485. T } \mathbf{T} \text { A } \mathrm{R} \text { A } \mathrm{X} \text { A } \mathrm{C} \text { U } \mathbf{M} \text {. }
$$

Involucrum duplex, foliolis exterioribus brevissimis sæpiùs patnJis; receptaculum nudum; pappus stipitatus, pilosns; scapi uniflori.

293̃3. Dens-leonis. Involncro exteriore reflexo, foliis runcinatis giabris, laciniis lanceolatis dentatis. $\mathcal{H}$. U bique in pratis.

2953. Palustre. Involucro exteriore erecto adpresso, foliis lancenlatis sinuato-dentatis glabriusculis. 2 . In paludosis el prati: bumidis.

$$
\text { 486. D R I } \mathbf{~ p , A ~ N ~ I ~ A . ~}
$$

Involucrum polyphyllnm, foliolis interioribus erectis, exterinribus patulis-subulatis; receptaculum favosun; semina centralia masgine meubranacen coronata $2-4$ - ilistata, marginalia paplo sessili piloso liserissimo squanuloso donatu. 
295\%. Barbaba. $\odot$. Ad margines agrom um et in azenosis Gallize australis.

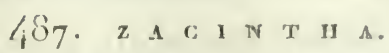

Invoincrum S-pliyllun : basi caliculaum, temin cnriaceum sulcatum; recepaculum nudum; pappus pilusus, subdentatus, sessilis, luevissimus.

20)55. Terrucosa. $\odot$. In steribibus circà Ničam, Segusium, et in Galloprovincia.

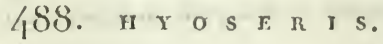

Involnerum caliculatum; receptaculnu nudun; seminnn censralium pappus pilosus inxegnalis, radii symamatus subabortivus.

2956. Radiata. Scapis unifloris nudis, foliis glabris lyrato-runcinatis dentatis, lacinia terminali 3 -fida. 2 . In collibus maritimis Gat liæa atıstralis.

2957. Scabra. Scapis mifloris nudis apice incrassatis, fohiis ly ratoponntifulis dentatis seabriusculis. O. Eporedixe at in olivetis cìcà Nicæain.

2058. Herlypnois. Canle tercti ramoso, foliis inferinribus oblongis dentatis basi attonatis, superioribus subauplexieaulibus lanceolatis, involuctis fructigeris glabris. $\odot$. Inter segetes $\mathrm{ct}$ in sterilibus Delphinatûs et prov. mediterzanearum.

29ōn. Phongadiolnides. Caule tereti ramoso, foliis oblongis dentatis sessilibus, involucris fructigeris hirtis. $\odot$. Monspelii et in De!phinatn.

"ghon. Cretica. Caule ramoso, peduncnlis tumidis apice fistulosis, foliis subdentatis oblongis subcordatis aniplexicaulibus, involucriy hirtis. $\odot$. In azvis circà Nicæam?

$$
488^{*} \text {. S E R I O L A. }
$$

Involncrum simplez; receptaculum paleaceum; pappus stipifatus, pilis paucis basi membranaceis apice subbylymosis. . .

$2960^{*}$. Ellnensis. Hisplida, foliis obovatis subdentatis. $\bigcirc$. In Ciorsica.

$$
\begin{aligned}
& \text { +t+ Pripuo plimoso. }
\end{aligned}
$$

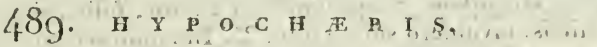

Involncrum oblongum, inbricatum; receptartilum paśdaceum;

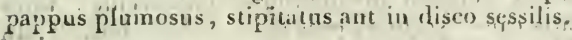

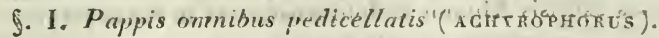

2961. Mnculata. Calite sulnudo, ramo solitario, foliis orato-ohlon6o gis snblentatis sæpitis maculatis. 2f. In ericetis et collibus sterilibus.

2062. Uuiforn. Caule simplici fuliuso miftogo, fullis oblpngo-lan.

ceolatis dentatis. 2 C. In pascuis nontosis Sabagdia , Delphipatûs, Pedemuntii.

29fi3. Rabicata. Caule ramos rado sublevi ; fotiis runcinatis 
ohtusis scabris, pedunculis squamosis. $\mathcal{H}$. Ad vias et in pratis frequens.

$$
\text { 5. II. Pappis radii sessilibus ( }
$$

2964. Glabra. Glabra, foliis radicalibus dentato-sinuatis, caule ramoso nudo. $\odot$. In sylvis humidiusculis.

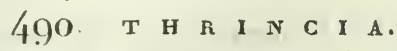

Involucrum imbricatum; receptaculum favosum; semina disci pappo sessili plumoso ec inaquali donata, radii breviter papposa, pappo aburtivu.

2965. Hirln. Scapo unifloro, involucro glabro, basi squamulis aucto, foliis lanceolatis sinuato-dentatis hirtis. 2 . In sterilibus arenosis ad vias.

2966. Hispirla. Scapo unifloro piloso, involucro canescente nudo, foliis lanceolatis obtusis dentatis, pilis furcatis. $\odot$. In lapidosís et arenosis Dejphinatûs, Pedemontii.

2907. Tuberosa Sicapo unifloro nudo apice hirto, foliis lyratis hirtis scabris, ralice tuberosa. 2 . In prátis circa Monspeliunı, Nicæam, Aquas-Sextias.

$$
49 I . \quad L \text { E O N T O D O N. }
$$

Involucrum imbricatum; receptaculum favosum; pappus sessilis, plumosus, pilis aliis squamosis aliis sericeis.

2968. Autumna'e. Scapis ramosis declinatis squamosis, foliis lanceolatis pinnatifidis glabris, pedunculis sub involucro tumescentibus. 24 . Ad margines agrorum et viarum.

29fig. Squamısum. Scapo unifloro squamoso supernè hirto, foliis oblongis glabris subdentatis, involucro hirto. $\mathcal{F}^{2}$. In pascuis montosis,

2970. Montanum. Scapis nnifloris nudis supernè incrassatis hirtis, foliis runcinato-dentatis glabris', involucris villosis. $\mathcal{Y}$. In lapidosis Alpium, Deiphinatûs et Pedemontií.

2921. Hastile. Scapo unifloro nulo involucroque glabro, foliis lanceolatis runcinato-dentatis glabris. 2 . In pascuis humidis Delphinatûs, Pedemontii, Sabaudiæ, Genevæ, Jurassi, Rothomagi.

29-2. Hispidum. Scapo unịloro glabro, foliis pinnatifido-oblongis hirtis, involucro sublirsuto. 2 . In lapidissis apricis.

2973.0 Incanim! Scapo unifloro involucroque pubescente, foliis oblongis subdentatis cano-scabris, pilis apice radiantibus. 24 . In pascuis excelsis $\Lambda$ piun Delphinensium ei in Palatinatu.

$$
\text { 492. P I c n I s. }
$$

Involncrum caliculatum; receptaculum nudum; semina transversd striata; pappus plumusus, sessilis vel subsessilis.

29-1. Hieracinides Caule scabio ramoso-divaricato, foliis asperrïmis lanceolatis dentatis, f Horibus corymbosis. 2 . In agris.

2975. Pauciflora. Caute scabro subramoso, foliis asperrimis lanceo- 
latis denticulatis, pedunculis elongatis incrassatis, seminibus apice attenuatis. $\odot$. In arvis Cialliae anstralis.

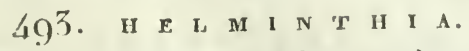

Involucrum duplex; interius s-plyyllum aquale, exterins 5-phyllum laxum; semina transversim striata; pappus plumosus, pedicellatus.

2976. Echioides. Involucri exterioris foliolis latis ovato-cordatis subspinosis. $\odot$. In aıvis et ad vias.

2977. Spinnsa. Involncri exterioris foliolis lanceolatis marginc apiceque spinosis. - In Pyrenxis.

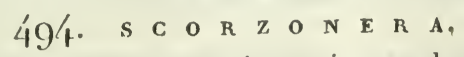

Involucrum imbricatunı, squamis margine membranaceis; receptaculum nudum; semina sessilia; pappus substipitatus, plumosus.

2978. Hispanica. Caule ramoso 5-6 floro, foliis anplexicaulibus integris basi denticulatis. 2 . In nleraceis bortis culta.

2979. Hunilis. Caule subnudo subunitloro, foliis oblongo-lanceolatis 5-7-nerviis, involucri foliolis basi latis sublanatis. F. In pratis siccis.

$2979^{*}$. Austriarn. Caule subnudo nnifloro involucrique squamis glabris, foliis lineari-sublanceolatis. 2 . E montibns Pedemuntanis propè Brissolino misit cl. Balbis. - Sc. austriaca. Wild. Spec. 3. p. $149^{8}$.

298o. Angustifolia. Canle subnudo unifloro apice tomentoso, foliis sublinearibus basi lanatis, involucri squanis tomentosis linearioblongis. 24. In rimis saxorun Alpium et wontium editionm Arven nix.

$2080^{*}$. Aristata. Canle subnudo unifloro, foliis linearibus glabris, involueri squamis inferioribus foliaceis laxis sulualatis florem xquantibus. 2 . In herbosis Pyrenæenrum editiorum.

2981 . Hirsuta. Canle unifloro hirto, foliis linearibus hirsutis, seminibus lanatis. 2 . In lapidosis sterilibus Occitaniæ.

$$
\text { 49,5. P O D O S P E R M U M. }
$$

Involucrum imbricatum, squamis margine membranaceis; semina pedicellata, pedicello cavo incrassito; receptaculum seminibus delipsis, tuberculato-muricatum; pappus sessilis, plunosus.

29S2. 'Subulatum. Caule subramoso infrà folinso sippernè nudo, foliis rigilis linearibus carinato-subulatis. 2 . Sorricinii.

$29 \$ 2^{*}$. Muricatum. Caule erectn subscabro subsimplici, foliis inferioribus linearibus, superiorihus pinnatifidis, Iobs remotis linearibus. 2 . Circà Tendam detexit cl. Balbis qui misit sub uominc Scorzoneræ muricalæ.

2983. Resedifolium. Canle basi ramoso, folis lincaribus pinnatifidis, lobis sublimearibus, superioribus simplicibus. 2 . In arvis Uccitanix, Delphinatûs, Parisiis. 
з.jí. Lariniarum. Caule ramoso crecto, foliis inferiorihus pinnatifidis, lobis oratis nucronatis, superioribus linearibus. $\sigma$. Ad marginem agrorum.

$$
\text { 496. U R O S P E R M U M. }
$$

Involucrum simplex, $\delta$-phyllum, foliolis coalitis; receptaculum nudum; scmina transrersè sulcata; pappus plumosus, stipitatus, stipite cavo conico incurro basi incrissato.

2995. Da!echamprii. Involucris pubescentibus inermibus, foliis runcinato-dentatis. $4, \sigma$. Sceus vineas et prata prov. australiorum. 3986. Picroides. Foliis runcinatis dentatis, caulinis auriculato-sagittatis, involucris hispido-aculeatis. $\odot$. Ad margines viarum in $\mathbf{G a l}$ lia australi.

2y57. Asperume. Caulc simplici nnifloro, foliis ovali-oblnngis integris subdentatis hirtis, involucris aculeato-hispidis. $\odot$. Munspelii.

$$
\text { 497. T } \text { R A }
$$

Involucrum simplex, 8- то-phyl!um, foliolis coalitis; receptaculım nudıı; semina longitudinaliter striata; pappus plumosus, stipitatus, stipite tenui.

\section{I. Floribus luteis.}

2988. Pratense. Foliis glabris basi canaliculatis; involucris corollæ ralio sublongioribus, pedunculis apice teretibus, $\sigma$. In pratis frequens.

2999. Majus. Foliis glabris planis basi latioribus, involucris 12-16phyli is corollæx radin Jongioribus, pedunculis apice incrássatis. 2 . In arvis, ad margines viarnm locis apricis.

2990. Hirsutum. Caule foliisque basi supernè tnmentosis, pednnculis apice incrassatis, involncris corolix tadio non longioribus. ర. In sterilibus apricis Gallix Nicditeraneæ.

\section{§. II. Floribus caruleis vel violaccis.}

299r. Porrifolirm. Involucris 8-phyllis corolla planissima Innginribus, canle stricto glabro. 7 . In pratis; at culina usum cultum.

2992. Crocifolium. Involucris 5-phyllis corolla Inngioribus, caule abbreviato, foliisque subtomentosis. 7 . In montosis subletbosis Galliæ australis et apricis vallium Pedemontii.

$$
\text { 198. G E R , o, P o G o } \mathrm{N} \text {. }
$$

Involucrum sinplex; receptaculum paleacenu; pappus stipitatus, disci plunısus, radii 5-aristațs.

2903. Glabrum. Foliis glabris, involucris simplicibus. $\odot$. Circa Nicæam."

$$
\begin{aligned}
& +t+\dagger \text { Pappo squamoso. } \\
& 499 \cdot \text { C A } \\
& 4 ., \text { A N A N }
\end{aligned}
$$

Involncrum imbricatum, scariosum; receptaculum paleaceum; rapus sessilis, 5 -squamosus, squameis mucronatis? : 
299i. Comblea. Involncai foliulis medin lineatis, inferinribus ovatis mucronatis, foliis villosis lunearibus basi subpinnatilidis. $\odot$, ficr.

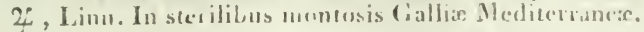

2995. Lutea. Involueri foliolis lievibus, inferioribns ovatis acutis, foliis tincaribus subcarnosis apice snbdentatis. $\odot$. In siccis circia Breglio in Pedemontio.

$$
\text { 500. C I C II O } \mathrm{R} \text { I U } M \text {. }
$$

Involucrum caliculat:m, externum 5-phyllum, internum S-phyllnui, foliolis basi coalitis; receptacnion nudun vel subpibsum; pappus sessilis, suuamosus, semine bevior.

2996. Incybus. Floribus sessilibus subaxillaribus geminis, foliis runcinatis, nervis sublirsutis. 25. $\Lambda \mathrm{d}$ rias.

2997. Endivia. Pedunculis axillaribus geminis, altern elongato 1-floro, altero brevissimo snb-f-floro, foliis oblongis denticulatis glabris. ๑. Ex India (IVild.) orta, in hortis cula.

$$
50 \mathrm{I} \text {. S C O I, Y,M U S. }
$$

Involucrum imbricatum, spinosum; receptaculum paleaceum; pappus nullus alt squamoso-pilosus.

2998. Maculatus. Foliis subixvibus margine cartilagineis, involucris pectinato-multifidis, seminibus nudis. $\odot$. Ad marginem agrorum in Gallia australi, et propè Nannetes.

2999. Hispanicus. Foliis srahris margine non cartilagineis, involucris foliaceis dentato spinosis, seminibus pappo brevissimo outstis. 24. Ad margines agrorum in Gallia Mediterranea.

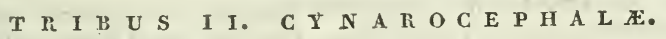

Corollula omnes tubuíosa; receptaculum carnosum paleaceum; stigma apice styli articulatum; pappus subrigidus; folia alterna supius spinosa; genitalia ex irritatione sapius contractilia.

$$
\begin{aligned}
& \text { † Pappo mullo. } \\
& \text { 502. в с н I N o p s. }
\end{aligned}
$$

Flores capitato-spharici; involucrum generalc parrum, po!sphyllum, foliolis reflexis; receptaculum generale nudnm, globosnm; flos singulus involucratus, involucro poly phyllo imbricato; semen pulsescens, papyo truncato abortivo coronatum.

3000 . Sphorrorephalus. Canle ramoso, foliis pinnatifirlis superne pubescemtiluns snbtus incano-laninginosis. 4 . In stcrilibus ct incultis provinciarum australiornmi.

30от. Ritro. Caule subsinpiici oorymboso, foliis pinnatifidis suprà glabris subtus tomentosis, 7 . In collibus sterilibus Gallia australis.

$$
\text { 503. C A R T H A M U S. }
$$

Involucrum basi ventricosnm, inbricatum, squamis apice mucromatis; flosculi omnes hermaphroditi; semina pappo destituta. 
300. Tinctorius. Caule glaberrimn, foliis ovatis integris spinosodentatis. $2 ;$. In collibus aridis circi Nicæam freriens.

$$
\begin{aligned}
& t+\text { Pappo piloso. } \\
& \text { 50/. с А r D U IN c E L L U S. }
\end{aligned}
$$

Involucrum spinnsum, imbricatum ; flosculi omnes hermaphroditi; staminnu filamenta hirsura; recptaculi paleæ longitudinales laciniatæ et scriceæ; pappus pilosus.

3oo3. Monspeliensium. Cánle unifloro. foliis spinosis pinnatifidis, involucro apice coarctato. $\odot$. In montosis aridis Gullix anstralis.

$30 n 4$. Mitissimus. Canle unifforo, foliis snbinermibus lanceolatis dentatis ant subpinnatifidis, involncro subcampanulato. $\odot$. Secus vineas circà Stampas, Parisios et Aureliam.

$$
\text { 505. O N O P O R D U ME. }
$$

Involucrnm imbricatum, squamis mucronato-pungentibns; flosculi omnes hermaphroditi; receptacnlum farosum; semina comTrressa, tetragona, transversè sulcata; pappus caducus, pilosus.

3̧o5. Acanthium. Involucri squamis patentissimis, foliis decurrentilus tomentosis sinuatis dentatis spinosis. $\sigma$. Ad margines viarum.

$30 n G$. Illyricum. Involucri squamis inferioribus reflexis, superioribus patentissimis, foliis decurrentibus tomentosis sinuatis dentatis spinosis. 2 . In siccis et sterilibus Galliæanstralis.

3007. Acaule. Acaule, involucris globosis subsessilibus, squamis lanceolatis sjinosis patentissimis, foliis petiolatis pinnatifidis dentatis spinosis tomentosis. 2 . In Pyrenzis.

$$
\text { 506. A R } \mathrm{c} \text { ' } \mathrm{T} \text { I } \mathrm{U} \mathbf{\mathrm { n }} \text {. }
$$

Involucrum imbricatum, inerme; flosculi omnes hermaphrnditi; recptaculum subfarosum; scmina levia, prismatica; pappus persistens pilosus, pilis rigidis, sapius spiraliter contortis.

3nos. Lanuginosum. Foliis petiolatis subrotundo-ovatis subcordatis crenato-dentatis inernibus tomentosis. 2. Locis schistosis et apricis Alpium Pedem. et Delphin.

$$
507 \text {. ' } 1 \text {, A P A. }
$$

Involucrum spharicum, imbricatum, squamis apice in hamum inflexis; flosculi omnes hermaphroditi; receptaculum paleaceum; pappus pilosns, brevis, persistens.

30on. Tomentosa. Involúcris arachnoideo-tomentosis. $\sigma \cdot$. Ad vias $e t$ in ruderatis.

join. Minor. Involucris glabris, floribus capitatis. 0 . In lapidosis ad vias.

3огт. Maior. Involucris glabris, floribns solitariis. $\sigma$. In nemoribus subhumidis. 
508. C A R D U U S.

Involucrum imbricatum, squanis spinosis; flosculi omnes lerenaphroditi; receptaculi palex sericex; pappus carlucus, pilosus.

3ог2. Marianus. Foliis amplexicanlibus hastato-pinatifidis albomaculatis glabris. $\odot$. Ad margines viarmon et in locis incultis.

3oเ3. Leucngruphus. Ioliis decurrentihus dentatis, pedunculis nudis longissimis mifloris apice subtomentosis, floribns inclinatis. $\odot$. Nica:e, in Cralloprovincia, Arvernia, Anreliæ.

3orf. T'enuiftorus. Foliis decurrentibus sinuatis sublùs tomentosis, involucris subcylindricis aggregatis, pedunculis appendiculatuspinosis, squamis lanceolatis crectiusculis. $\odot$. In locis incultis, ad nivros.

3015. Pycnocephalus. Foliis decurrentibus pinnatifido-sinnatis pubescentilus, pedunculis nudis nulcifloris tomentosis. 2广, Linn. $\odot$, All. Ad vias et fossas in Pedemontio.

3or6. Acanıhoides. Foliis decurrentibus sinuato-spinosis, involucris globosis subpedunculatis, squamis lincaribus recurvatis. $\odot$. In arvis incultis.

3or\%. Nutans. Foliis semi-decurrentibus spinosis, floribus cernuis, involucri squamis arachnoideo-tomentosis, externis patentibus, interioribus sursùm erectis. 3 . Ad vias.

3ог8. Podacanthus. Foliis decurrentibus oblongis sinuato-pinnatifidis spinosis, floribus congestis subpedunculatis, pedunculis spinusis tomentosis, involucri squamis patentibus lineari-subulatis glabris. - In Delphinatu.

3019. Crispus. Foliis decurrentibus oblongis sinnatis margine spinosis subtùs lanuginosis, floribus pedunculatis aggregatis terninalibus, irvolucri squamis lineari-subulatis mucronatis patulis. $\sigma$. In arvis cultis ad sepes.

3020. Defloratus. Foliis semi-decurrentibus pinnatifido-serratis subspinoso-ciliatis mudis, radicalibus indivisis, pedunculis longissimis unifloris lannginosis. 24. In lapidosis herbosis montium.

3o21. Medius. Foliis decurrentibus pinnatifidis, laciniis 3-partitis, margine ciliato-spinosis, caule unifloro, flore nutante, involucri squamis lanceolatis patentibus. - In Pyrenæis circà Valletriam.

3023. Carlinafolius. Foliis decurrentibus spinosis glabris pinnatifidis, pedunculis erectis unifloris inermibus sub flore lanuginosis. - In Pyrenæis, montibus Sedenensibus Galloprovinciæ.

3023. Argemone. Foliis decurrentibus glabris sintato-pinnatifidis ciliato-spinosis, pedunculis brcvibus unifloris tomentosis, involucri squamis linearibus imbricatis spinoso-ciliatis arachnoideotomentosis. - In Pyrenæis.

3024. Carlinoides. Foliis decurrentibus pinnatifidis tomentosis, laciniis palmatis spimosis, floribus glomeratis. 2 . In Pyrenxis et Pedcmontii montibus.

3025. Personata. Foliis caulinis semi-decurrentibus oblongis 
indivisis spinoso-dentatis subtùs subrillosis, radicalibns basipinnatifidis, floribus subsessilibus congestis, involucri squamis recurvatis. $\sigma$, Linn. $\odot$, All. In pascuis humidis montosis.

$$
\text { 509. S E }
$$

Involncrum imbricatum, squamis inermibus; flosculi omnes liermaphroditi; receptaculi paleæ simplices; pappus pilosus, rigidus, persistens.

3026. Tinctoria. Foliis argutè serratis glabris basi subpinnatifidis, corymbo fustigiato. 2 . In nemoribus et pratis umbrosis.

3027. Coronata. Foliis serratis impari-pinnatis sub-5-jugis pinnis conflnentibus, pedunculis sub-1-floris, flosculis radii maximis. 24. In montibus Pedemontii ec Sabandiæ.

3028. Heterophylír. Foliis ovatis pinnatifidorlentatis subinermilus, smperioribus sessilibus, caule uniflero, involucri squamis ovatis. 24. In Delphinatu.

3029. Nuelicanlis. Foliis radicalibus oblongis integerrimis, caulinis lanceolatis subdentatis, canle unifloro, involucri squamis ovatis mucronatis. $2 \mathrm{~F}$. In monibus Galioprovinciæ, Vapinci et Pedemontii.

3030. Cynaroides. Foliis pinnatifidis subtus tomentosis, involucri squamis margine scariosis acuminatis. 2 . In Pyrenæis.

3o3r. Rhaponticum. Foliis ovato-ohlongis basisubcordatis denticulatis subtùs tomentosis, involucri squamis scariosis ovatis laceris. 24. In pascuis Alpiam et collibus lapidosis Perlem. Delphin. et Gallopiov.

$$
\text { 510. C } \mathbf{E} \text { N } \mathbf{N} \text { T }
$$

Inrolucrum squamosum; flosculi radii steriles majores; receptaculi paleæ laciniatæ; seminis hylus lateralis; pappus pilosus.

5. I. Involucrisquamis integris foliaceis nec spinosis (CENTAUREA). 3o32. Centurium. Involucris inermibus, squamis ovatis obusis, foliis pinnatis glabris pionis argute duplicato-serratis decurrentibus, terminali lanceolata. 2\%. In Alpibus Pedemontii.

3033. Alpina. Involucris ineruibus squamis ovatis obtusis, foliis pinnatis glabris pinnis integerrinis apiee obsoletè-serratis intermediis bipartitis. $2 \mathcal{T}$. In Sabaulia propè Sanctum-Maurieium.

3o3\%. Crupina. Involucris inermibus squamis lanceolatis, foliis pinnatis scabris, pinnulis serrulatis linearibus acutis. $\odot$. In sterilibus et collibus Pedemontii, Galloprovinciæ, Occitaniæ. - An liijus generis?

\section{j. II. Involucri squamis scariosis nec ciliatis nec spinosis (RHA PONTICUM).}

303\%. Splendens. Involncris scariosis ovatis, squamis mucronatis, foliis inferioribus lipinnatifidis linearibus, superioribus pinnatis piunis linearibus subdentatis. 7 . Ad vineas et saxa in Pedenontio.

3036. Amara. Involucris scaricsis, foliis lanceolatis integerrimis, caulibus decumbenibus. $\mathcal{F}$. In collibus ardis Galliæanstralis. 
9. III. Involucri squamis ciliatis non spinosis (CY Axe's ct JACEA).

3o37. Jacea. Involucris scarioso-ciliatis, squamis ovatis apice laceris, foliis lanceolatis integer rimis radicabbus subdentutis ramis angulatis, pappo subunilo. $\mathcal{F}$. All oras sylvartur et in pratis ulininic.

3038. Nigrr Involucris erecto plumosis, flosculis acqualibus, foliis lanceolacis radicalibus subpinnatifidis, canlinis indivisis serratis. 24. In pascuis moncosis passim.

3o3y. Flnscul'sa. Involucris recurvato plumosis, flosculis xqualibus, fliis hirtis lanceolatis remote dentatis. $\underset{d}{\mathcal{C}}$. In Alpibus Pedemontii propè lenestrellam.

3nfo. Phrgia. Involucris recurvato-phmosis, foliis oblongis indivisis scabris mucronato-serrulatis. $\mathcal{F}$. In pascuis editiormo montium.

3oł1. Uniflora. Involucro recurvato plumoso, foliis lanceolatis subdentatis tomentosis, caule unifloro. $\mathcal{F}$. In pratis montosis Delphin. Pedem. Galloprov. Occitain.

3ó́ 2. Pectinata. Involucris recurvato plumosis, foliis mucronatoserratis, caulinis inferioribas sinuto-pinnatifidis, superioribus et rameis indivisis. $\underset{1}{2}$. In timis saxorum nontium Gallix australis.

3o'3. Pu!lata. Involucris lanceolatis apice ciliatis, bracteis lancenlatis involucratis, foliis petiolatis basi amplexicanibus lyratis lispidis. $\odot$ Linn. ơ Vill. Ad sepes in Gallia australi.

3o?́. Montuna. Involucris margine ciliatis, foliis Ianceolato-acuminatis decurrentibus subtomentosis integerrimis aut basi siunuto-dentatis. 2 . In pascuis montium.

3045. Cyanus. Involucris serratis, foliis linearibus sessilibus integerrinis, infinis basi pinnatifidis. $\odot$. Inter segetes frequens.

3of 6. Cinerea. Involucris cylindricis ciliatis, foliis subtomentosis radicalibus pinnatifidis, laciniis lanceolatis obtusis, superioribus b;ıs deorsìm subpinnatifidis. $\mathcal{Z}$. In montibus circà Lucerame? in Occitania?

3o.́. Muculnsa. Involucris globosis longè ciliatis squamis obtusis, foliis inferioribus bipinnatifulis, superioribus pinnatifuis, caule subcorymboso. - Propé Claromontem, Narbonem.

3oł9. Paniculata. Involucris ciliatis ovatis adpressis, foliis inferinribus bipinnatifidis, superioribus pinnatifidis, caule paniculato. $\sigma$. In arvis et stcrilibus Galliæ anstralis et arl radices Alpiun.

3o 9. Scabiosa. Involncris ciliatis pubescentibus, foliis pinnatifidis scabrinsculis, laciniis lanceolatis acutis basi pimnatifidis. $\mathcal{F}$. Ad marginem agrorum et sylvarum.

3050. Intrbacea. Involucris globosis glaberrimis ciliatis, foliis subrigidis lanceolato-linearibus pinnatifidis vel Lasi laciniatis, laciniis acutis simplicibes. $\mathcal{Z}$, Ђ. Circà Narbonem.

\section{IV. Involucri squamis spinoso-palmatis (SERIDIA).}

305. Asperu, Involucris palmato-spinosis, spina 3-5-cuspidata, 
foliis lanceolatis sessilibus sinuato dentatis scabrinsculis. $\mathcal{F}$. In arvis et sterilihns à Nicæa ad Nigri-Monasterii insulam.

3052. Seridis. Involucris palmato-spinosis, spinis reflexis, foliis oblongis incanis amplexicaulibus semi-decurrentibus dentatis , basi subucisis dentibus subspinosis. 2 . In arvis circà Nicæam, Aquas Sextias, Monsprium et in Delphinatu.

3053. Snnchijolia. Involucris palmato-spinosis, spinis reflexis, foliis oblongis glabriuscalis amplexicaulihus semi-decurrentibus repando dentatis, dentibus spinosis. $\odot$. Secus stagna ct rivos in Galloprovincia, agro Nicæensi, Avenionensi.

5. V. Involucri squamis desinentibus in spinam lateribus dentatospinosam (CALGITRAPA.

3054 Calcitrapa. Involucris subduplicato-spinosis sessilibus, folii: pinnatifilis linearibus dentatis, radicalibns lyratis, canle ramosissimu striato piloso, pappo nullo $\odot$. In sterilibus petrosis ad rias.

3o55. Calcilrap ri:les. Involucris subiluplicato-spinosis, foliis lineari uhlongis integris vel sublentatis, canle altissimo, seminibus papposis. $\odot$. Circà Nemausum et in Delphin.utu.

3056. Mvacantha. Involncris glabris, squamis apice corncis spinoso dentatis, foliis st:ssilibus lineari oblongis subtomentosis dentato-serratis vel hasi subl.tciniatis, caule ramoso glabro, pappis nullis. - Parisiis cired Vincennam.

305-. II brula. Involucris apice ciliat.) spinosis, foliis incanis pin-

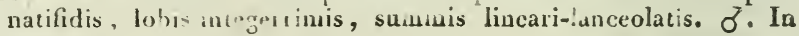
pratis siecis 'Taurinensibus.

3o58. Benerlicta. Involucris duplicato-spinosis lanatis involncratis, foliis semi- lecurrentibus dentato-spi:rosis. $\odot$. In cultis circà Aquas-Sextias, Montem-Albanum.

3059 Lanata. Involucri foliolis exterioribus pinnatifidis, interioribus cartilagineis ciliato spritosis, foliis inferioribus pinnatifidis dentatis, summis amplexicumlibus pinatifido-dentatis spinosis, caule lanuginoso $\odot$. In sterilibus ad vias.

3u6n. Solstitialis. Involucris globosis snb-palmato-spinosis, spinis rectis, foliis canescentibus lineari-lanceolatis decurrentibus integerrimis radicalibus $l_{y}$ atis. $\odot$. Ad vias in siccis.

$3 \circ 61$. Apula. Invo'ucris duplicato-spinosis axillaribus terminalibusque, foliis lanceolatis integerrimis semi decurrentibus radicalibus lyratis obtusis. $\odot$. Circà Narbonem, Monspeliunn? Nicæum.

3o62. Melitensis. Involucris sub-palmato-spinosis subgeninatis sessilibus, spinis rectis, foliis obl ongis subincanis profundè dentatis piunatifidisve, laciniis distantibus acutiusculis. ๑. In Grallia australiori, Monspelii?

3o63. Collina. Involucris extùs ciliato-spinosis, intùs scariosis, foliis caulinis pinnatifidis, radicalibus bipinnatifilis, laciniis lanceolatis. 2 . Inter segetes in valle Atugustana, Galloprorincia, Occitania. 
3o6f. Centauroides. Involucris cilinto-spinosis, foliis lyrato-pinnatis subintegermis, teminali maxima dentata. $\mathcal{f}$. Monspelii secus rivos.

\section{VI. Involucri squamis in spinam simplicem desinentilus \\ (CROCODILIUM).}

3065. Salmantica. Involncris globosis glabris in sctulam subspinosam desinentibus, foliis lanceolatis serratis rarlicalibus ly ratis, caule divaricato. 2 . In arvis et pascuis maritimis Galloprovincix, Monspelii.

$$
\begin{aligned}
& +t+\text { Pappo ramoso. } \\
& \text { 5 I I. S T IE H E L I N A. }
\end{aligned}
$$

Involucrum imbricatum, squamis acuminatis ; flosculi omnes hermaphroditi; stigmata simplicia; receptaculum angustatum paleaceum, palcis apice laciniatis ; pappus ramosus.

3o66. Arborescens. Foliis petiolatis ellipticis obtusis integerrimis subtùs sericeo-tomentosis. b. In Stæchadum insulis (Gér.).

3067. Dubia. Foliis sessilibus linearibus denticulatis subtìs tomentosis, involucri squamis interioribus lanceolatis elongatis. $\supset$. In sterilibus et siccis Galliæ australis.

$$
\begin{gathered}
+t+\dagger \text { Pappo plumoso. } \\
5 \text { r2. с I N A R A. }
\end{gathered}
$$

Involucrum imbricatum, maximum, squamis hasi carnosis superne mucronatis; flosculi omnes hermaphroditi; receptaculum carnosum, setosum; pappus longissimus, plumosus.

3o68. Cardunculus. Foliis spinosis omnibus pinnatifidis, involucri squamis ovatis. $\mathcal{F} . \alpha$, Monspelii; $\beta$, in hortis culta.

3o69. Scolymus. Foliis subspinosis pinnatifidis indivisisque, involucri squamis ovatis. 2 . In hortis culta. - Forsan prioris vurietas?

$$
\text { 513. L E U Z E A. }
$$

Involucrum imbricatum, sphæricum, squamis inermibus rotundais scariosis apice laceris; flosculi omnes hermaphroditi; receptaculam setis basi coalitis hirtum; semina tuberculosa; pappus longus, plumosus.

307o. Conifera. Foliis tomentosis radicalibus lanceolatis, caulinis pinnatifidis. 4 . In montosis sterilibus Galloprov. Delphin. Pedem. Occitan.

$$
\text { 5I4. G A L A C T I T E s. }
$$

Involncrum imbricatum, squamis apice spinosis; flosculi in centro hermaphroditi, in radio steriles majores ; receptaculnm favosum, nudum; pappus plumosus, caducus.

3ozr. Tomentosa. Foliis decurrentibus sinuatis spinosis subtùs tomentosis. 24. In sterilibus Galliæ Mediterranex et in Corsica.

$$
\text { 5I5. C I R S I U M. }
$$

Involucrum imbricatum, squamis apice subnlato-spinosis; 
flosculi omnes hermapliroditi; receptaculum paleaceum; pappts plumosus.

\section{I. Foliis decurrentibus; florilus purpurascentibus rariius albis.}

$30 \div 2$ Palustre. Foliis decurrentibus nudis lanceolatis dentatis margine spinusis, floribus racemoso-glomeratis, involucri squanis ovato-lanceolatis mucronatis adpressis. 4 . In staguis pratisque umbrosis.

30-3. Lancenlatum. Foliis decnrrentibus hispidis pinnatifidis, lacinis bilobis livaricatis spinosis, involuen is ovatis arachnoideopubescentibus, squamis lanceolatis spinosis patentibus. 0 . Ad vias et pagos.

3074 . Acarna. Foliis decurrentibus lanceolatis lanato-canis dentatis spinusis, floribus aygregatis bracteatis, involucrisquamis lanceolatis, inferioribus spina pinnata terminatis. 2 . In petrosis et sterilibus Gallize Mediterraneæ.

3o-:- Monspessulanum. Foliis decurrentibus lanceolatis glabris subrepandis inæcqualiter ciliatis. pedunculis nudis tomentosis alternis multifloris, involucri symamis oblongo-lanceolatis mucronatis. 2 . In pratis humidis Gralliæ australis.

3o-6. Prrenaicum. Foliis decurrentibus lanceolatis subtùs tomentosis subrepandis inæqualiter ciliatis, floribus glomeratis, involucri squam is ublongo-lanceolatis ntucronatis. 2 . In Pyrenæonrum pratis.

3077. Pratense. Foliis decurrentibns sinuato-pinnatifirlis ntrinque glabris, margine ciliato spinoso, pedunculis tomentosis unifloris, involucris glabris subspinosis. 2 . In pratis Galliæ australis.

\section{II. Foliis amplexicaulibus; floribus ochroleucis.}

3o-S. Spinosissimum. Foliis amplexicaulibus pinnatifidis dentatis spinosis pubescentibus, caule simplici, floribus terminalibus congestis, involucri squamis lanccolatis spinosis. $\mathcal{Y}$. In pascuis humidis Alpium.

3oẓ. Oleraceum. Foliis amplexicaulibus cordatis pinnatifidis ciliato-serratis, floribus terminalibus subracemosis bracteatis, hracteis oratis ciliatis, involucri squamis lanceolatis spinosis. $\mathcal{4}$. In pratis paludosis.

3o8o. Tataricum. Foliis amplexicaulibns oblongo-lanceolatis dentatis ciliato-spinosis, pedunculis unifloris, involucris bracteatis, squamis lanceolatis spinosis. 24. In vallibus locisque humidis Alpinm.

3osı. Rufescens. Foliis amplexicaulibus subdecurrentibus sinuatoincisis ciliato-spinosis, floribus capitatis subsessilibus bracteatis, bracteis pedunculisque piloso-rufescentibus, involucri squamis lineari-acuminatis dorso subpubescentibus. 2 . In Fyrenæis editioribus inter rupes.

3082. Ochroleucum. Foliis amplexicaulibus decussivè pinnatifidis ciliatis, pinnis lanceolatis trinerviis, summis confluentibus, pedunculis ecrnuis, involucri squanis glutinosis reflexis. $\underset{\mathcal{H}}{*}$. In pratis montanis. 
3083. Erucagineum. Foliis amplexicanlihus pinnatifidis ciliatis sub. tùs tomentosis, pedunculis undis cernuis, floribns congestis sessilibus, involucri squamis lanceokatis. 2 . In pratis figigidis Delphiuatûs et Jutassi.

5. III. Foliis non decurrentibus; floribus purpurascentibus rarius albis.

3o8ł. Tricephalodes. Foliis anplexicaulibns ciliatis nudis dentatis, inferioribus pinnatifudis, floribus glomeratis, involueri stpuanis ovato-I.nceolatis adpressis. 2 . In pascuis Juıssi, Alpium, nontis Aurei.

3o85. Ambigunm. Foliis ciliato-spinosis subtùs subtomentosis, inferioribus petiolatis oblongo - acuminatis subsinuatis, superioribus sessilibus pinnatifidis auriculatis, iuvolucro hemispharico glabro, squamis finliaceis apice subreílexis. 2 . In monte Cenisio Alpibusque Delphinensibus.

3o86. Heterophyllum. Foliis amplexicaulibus cordatis lanceolatis serratis ciliatis subtus tomentosis, inferioribus subincisis, involucri squanis lanceolatis adpressis submucronatis glabris. 2 . In pratis humidis secus vias montanas, in Alpibus, Pyrenæis.

3o87. Bulbosum. Foliis a mplexicaulibus pinnatifirlis ciliato-spinosis, laciniis bilobis basi sursum dentatis, caule subbifloro, involucri squamis lanceolatis mucronatis patulis. 2 . In hunidis herbosis.

3o88. Anglicum. Foliis sessilibus lanceolatis subdentatis ciliatis subtits lunuginosis, inferioribus subincisis, caule nudiusculo unifloro, involucri villosi squamis lanceolatis mucronatis adpressis. 2. In pratis paludosis.

3o89. Acaule. Foliis pinnatifidis dentatis ciliato-spinns's, pedunculis radicalibus unifloris, involucri squamis lanceolatis arcie imbricas tis. 4 . In herbosis et siccis.

3ogo. Arvense. Foliis lanceolatis pinnatifido-dentatis undulatis spinosis subtùs subincanis, caule pariculato, involncris primün globosis demùm cylindricis. $\psi$. In vineis et arvis frequens.

309 r. Eriophorum. Foliis sessilibus pinnatifidis hispidis, laciniis geminatis divaricatis spinosis, involucris globosis arachnoidenvillosis, squamis oblongis apice linearibus elongatis mucronatis reflexis. $\delta$. In montosis et sterilibus Galliæ anstralis.

$309^{2}$. Fernx. Foliis subdecurrentibus pinnatifidis, laciniis bilobis divaricatis, narginc et supernè spinosis, subtùs villosis, involucris hemisphæricis bracteatis subglabris, squamis subulatis spinosis patulis. $\sigma^{7}$. In montosis et collibus Gallix australis.

3og3. Casabonce. Foliis sessilibus lanceolatis integerrimis snbtus tomentosis margine spinis ternatis, floribus axillaribus sessilibus, involucri squamis lanceolatis spinosis patentibus. $\sigma^{7}$. In Stacharlum insulis, in Arverniæ Limania.

309伯. Stellatum. Foliis sessilibus lanceolatis integerrimis inermibus subtùs tomentosis, spinis axillaribus basi subramosis, floribus axillaribus sessilibus, $\odot$. Ad vias et oras agrorum circà $\mathrm{Ni}$ cram. 
3095. Alpinum. Foliis orato-lanceolatis basi angustatis dentatis subtùs tomentosis, involucris villosis inernibus. 2 . In Alpibus editioribus.

$$
\text { 5i } 6 \text {. C A R L I N A. }
$$

Inrolucrum imbricatum; foliolis cxterioribus laxis laciniatis spinosis, interioribus scariosis nitidis coloratis coronam radiantem mentientibus; flosculi omnes hermaphroditi; receptaculi paleæ membranaceæ; scmen pilis rufis sericeis hirtum; pappus plunosus.

3og6. Subacaulis. Caule simplici brevi unifloro, foliis pinnatifidis nudis, laciniis inciso-dentatis spinosis. $2 \%$. In pascuis submontanis siccis et sterilibus.

3097. Acanthifolia. Subacaulis, foliis pinnatifidis subtùs tomentosis, laciniis dentato-angulatis spinosis. $\sigma$. In collibus et submontanis siccis Delphin. Pedem. Gailoprov. Pyrenæorum.

3ogs. Tulgaris. Caule mnltifloro corymboso pubescente, foliis lanceolatis dentatis spinosis subtus pubescentibus. $\sigma$. In siccis t petrosis.

3099. Lanata. Caule lanato subbifido, flore intermedio sessili, foliis incanis lanceolatis dentatis spinosis, involucri squamis interioribus purpurascentibus. $\odot$. In petrosis et siccis Galliæ Mediterraneæ.

3roo. Corymbosa. Caule glabriusculo corymboso multifloro, foliis lanceolatis pinnatifido-dentatis glabris. $\odot$. In sterilibus Gallopro-. vinciæ et Delphinatûs anstralioris.

$$
\text { 5I7. A T R A C T Y L I S. }
$$

Involucrum imbricatum, sæpiùs bracteato-spinosum; flosculi exteriores feminini, ligulati, interiores tubulosi, hermaphroditi; paleæ angustæ; pappus plumosus.

3ror. Cancellata. Caule tomentoso, foliis aracbnoideo-tomentosis amplexicaulibus lanceolatis ciliato-spinosis, floribus bracteatis, bracteis crectis pinnatifido-spinosis. $\odot$. In sterilibus petrosis apricis, Monspelii, Nicææ.

3ro2. Humilis. Caulc glabro, foliis sinuatis oblongo-lanceolatis dentato-spinosis spinis simplicibus vel geminatis, flore terminali, involucri squamis mucronatis glabris. $\mathcal{~}$. In saxosis circà Narbonem.

T R I B U S I I I. C O R Y M B I F E R E.

Flores flosculosi aut radiati; receptaculum vix aut non carnosum; stigma super stylum non articulatum.

† Semina papposa; receptaculum nudum aut rarissimé paleaceum.

$$
\text { 5I8. C A C A L I A. }
$$

Involucrnm simplex, oblongum, basi subcaliculatum; flosculi omnes tubulosi, hermaphroditi; receptaculnm nudum; pappus yilosus. 
3ro3. Alpina. Caule herbaceo, foliis petiolatis cordatis dentatis glahris, corymbis fustigratis, iuvolncris $3-5$-floris. 7 . In saxosis hunuidis et numbrosis montium.

3ıя. Pelasites. Caule herbaceo, foliis petiolatis cordatis dentatis subtis incanis, corymbis fastigiatis, involucris 3-5-lloris. 2 . In Alpibus, Pyrenæis, Jurasso et Aureo monte.

3105. Leucophylla. Caule herbaceo, foliis petiolatis utrinquè tomentosis dentatis, inferioribus cordatis acuminatis, supetioribns lanccolatis, floribus corymbosis, involucris 15-20-floris. 2f. In petrosis montium Delphinatûs, Galloprovinciæ.

3106. Sarracenica. Canle herbaceo, foliis glabrinsculis sessilibus oblongo-lanceolatis serratis, inferioribus integris decurrentibus. 24 . In sylvis montium Arvernix.

\section{5ig. E U P A T O R I U M.}

Involucrum imbricatum, oblongum; flosculi pauci, tubulosi, hermaplıroditi; receptaculum nudum; pappos pilosus.

3107 . Cannabinum. Foliis oppositis petiolatis 3 -partitis, laciniis lanceolatis serratis, intermedia longiore. 2f. In aquaticis et fossis hummidis.

\section{X E R A N T II E M U M.}

Involucrum imbricatum, squamis scariosis, interioribus longioribus coloratis; flosculi omnes tubulosi, in centro liermaphiroditi fertiles, in radio feminini steriles; receptaculum paleaceum; seminum fextilium pappus 5-paleaceus, sterilium nullns.

3ros. Annuum. Involucri squamis obtusis scariosis, interioribus lanceolatis obtusị patentibus. $\odot$. In arvis et collibus siccis Gallix australis, Arwerniæ, Aurelix.

3ı09. Inapertum. Involucri squamis acutis margine membranaceis, interioribus lanceolatis acutis conniventibus. $\odot$. In arris collibusque aridis Galloprov., Delphin., Bressiæ, Beugesiæ.

$$
\text { 52 I. E L Y C H R Y S U M. }
$$

Involncrnm imbricatnm, squamis inæqualibus obtnsis scariosis, sæpins coloratis; flosculi omnes tubulosi et hermaphroditi; receptaculum uudum; pappus pilosus vel subplumosus.

\section{I. Involucri squamis albis.}

3го. Frigidum. Herbaceum ramosum procumbens, foliis quadrifariam inbricatis oblongis obtusis incanis, ramis unifloris, floribus sessilibus. 2 . In editioribus montibus Corsicæ.

311. Margaritaceum. Herbaceum erectum tonentosum, foliis sparsis lineari-lanceolatis acuminatis subtùs tomentosis, floribus corymboso-fastigiatis. 2 . In monte Cenisio et propè Tauriuum.

\section{S. II. Involucri squamis flavis.}

3112. Stachas. Fruticosum, foliis linearibus, corymbo composito, rauis virgatis. b. In collibus aridis et arenosis Gallix australis e: in provinciis occidentalilus ad Nannetes usque. 
3113. Arenarium. Herba cum, foliis incanis tomentosis obtusis: ralicalibus spatulato-lanceolatis, caulinis lineari-lanceolatis, coy ymbo composito. 24. In arenosis Alsatiæ, Palatinatûs, Lugduni, Aurelix, etc.

\section{G N A P H A L I U M.}

Involucrum inbricatum, squamis obtusis uargine sæpius coloratis; receptaculum nudum; floseuli omnes Inbulosi, alii hermaphroditi, alteri feminini; papus pilosus aut apicc dentatus.

\section{\$. 1. Flosculis exterioribus femineis fertilibus, pappo capillari (FILAGO).}

3114. Luten-album. Canle herbaceo simplici erecto, foliis semiamplexicaulibus liueari-lanceolatis subrepandis utrinque pubescentibus, inferroribus obtusis, superioribus acutis, corymbo glomerato. $\odot$. In lzumidis.

3115. Supinum. Caule herbaceo simplici procumbente aut minimo, foliis linea ibus acutis tomentosis, floribus capitatis. 2 . In pratis frigidioribus inter saxaret secus torrentes editiorum montium.

3ı 6. Silnticum. Caule herbaceo simplicissimo erecto tomentoso, foliis lanecolatis utrinquè atteunatis et lanatis, floribus terminalibus axillaribusque sessilibus spicatis. 2 . In sylvis. - Var. $\beta$, foliis supernè glabrinsculis.

3117. Uliginosum. Caule herbaceo ramoso diffuso lanato, foliis lineari-lanceolatis utrinquè angustatis tomentosis, florjbus terminalibus congestis. $\odot$. In paludibus et arvis humidis.

3is. Germanıcum. Caule herbaceo erecto dichotomo, folits lineariJanceolatis tomentosis acutis, floribus globoso-capitatis alaribus terminalibusque. $\odot . \Lambda d$ vias, fossas et margines agrorum.

3119. Aruense. Caule herbacen erecto paniculato, foliis oblongolanceolatis lannginosis, floribus congestis lateralibus terminalibusque tomeutosis. $\odot$. In campis sabulosis.

3127. Gallicum. Cunle herbaceo erecto subdichotomo, foliis linearibus acminatis canescentilus, floribus confertis alaribus terminalibusque. $\odot$. In arvis sabulosis.

3121. Mnntanum. Canle herbacen erecto subdichotnmo, foliis lineari lanceolatis adpressis tomentosis, floribus confertis alaribus terminalibrisque. $\odot$. In siccis montanis ad margines sylvarmu.

3122. Minimum. Caule herbaceo erecto ramosn, foliis lanceolatis acutis planis canescentibus, floribus conicis subconfertis lateralibus termiaulibusque. $\odot$. In agı Borbonio et Aurelianensi.

5. II. Flosculis aliis hermophrolitis, aliis sterilibus; flosculorum sterilium pappo, lavato (ANTENARIA).

3123 Dinirum. Sarmentis procumbentibus, caule simplicissimo, foliis raticatibus spathulatis, ros mbo coarctato, floribus dioicis, involu. ri squamis interioribus clongatis obtusis coloratis. $\mathcal{Y}$. In pratis usontosis nudis.

$3+2$. Aipinum, Caule simplicissimo, sarmentis nullis, foliis radica- 
Jibns lanceolatis, flnrihus terminalibus aggregatis sessilibus, involucri squanis interioribus elengatis acutis uembanaccis. 2 . In pascuis apricis Alpium celitiorum.

3135. Le ontopodium. Caule herbacen simplicissimo, foliis lincarilanceratas subtios tomentosis, floribus terminalibus sebsililuns aggregatis, bracteis lanceolatis lanatis radialo-patentibus, involucris villusis. $\odot$. In pasenis petrosis et umbrosis $\Lambda$ ppium.

$$
\text { 523. C o N } \text { Y } z \text { A. }
$$

Involucrum subrotundatum, iubı icatum; recptaculun nudum; fosculi.ounes tuhulosi, in centro lenuaphoditi 5 -dentati, in radio feminini steriles graciles 3 -dentati; pappus pilosus.

3!26. Squarrosa. Foliis scabris, caulinis ovato-oblongis serratis, yameis oblongo-lanceolatis subintegerrimis, caule lierbaceo corymboso, involucris squarrosis. $\bar{\sigma}$. Ad sepes et oras sylvarum in siccis.

312\%. Sicula. Foliis lincari-lanceolatis scabris subint'gerrimis marginc revolutis, caule herbaceo paniculato, pedunculis unifloris foliosis, squamis involncri inferioribus laxis. $\odot$. In fossis humidis et stagnis maritinis prov. mediterranearum.

3r28. Saxalilis. Foliis linearibus subrlentatis, pedunculis longissimis unifloris, caule suffruticoso.b. Ad muros et inter saxa matitima, prope Nicæam, Olbiam.

3 r29. Sordila. Foliis linearibus integerrimis, peduneulis longis trifloris, caule suffuticoso. b. Ad muros et saxa Galliæ Meditcraneæ, in Burgundia, propè Nannctes.

$$
\text { 52/. c H R Y s o c o M A. }
$$

Involucrnm imbricatum, hemisplıæricum vel ovatum; receptaculum subfarosum; flosculi onnes hermaphroditi, tubulosi; pappus pilosus, ciliatus.

3ı3o. Linnsyris. Herbacea, foliis linearibus glabris, involucris laxis. 27. In argillosis apricis circà Parisios et in Gallia orientali.

$$
\text { 525. E R I G E R O } \mathrm{N} \text {. }
$$

Involncrum oblongum, imbricatum; receptaculum nudum; flores sadiati, ligulis femineis pancis discoloribus linearibus angustissisnis; pappus pilosus.

3 г 3 г. Acre. Peduncnlis alternis nnifloris, pappo rufescente seminibus duplù longiore. $\mathcal{H}$. In stcrilibus ct apricis frequens.

3132. Alpinum. Caule subbifloro, foliis obtusis subtùs villosis, pappo rufescente semins longitudine. $2 f$. In Alpibus, Pyrenæis et Jurasso frequens.

3133. Nillarsii. Canle paniculato, foliis lanceolatis viscosis 3-nerviis scabris subdentatis sessilibus, radio disco hreviore, rappo candido. 2 . In vallibus Alpinis, Pedem. Dell hin. Sabaud.

3134. Canadense. Caule floribusque pauiculatis hirtis, foliis lanceeJatis ciliatis. $\odot$. In lapidosis et sylvis. 


\section{A S T E R.}

Involucrnm imbricatum, squamis exterioribus patulis ; receptacu lum nudum; flores radiati, ligulis femincis fertilibus discoloribns oblongis; pappus pilosus.

3.35. Alpinus. Caule unifloro, foliis integerrimis radicalibus lanccolato-spathulatis, caulinis lanceolatis, involucri squamis subæequalibus laneeolatis obtusiuculis $2 \mathcal{C}$. In pascuis editiorum montium.

3.36. Amellus. Caule corymboso, foliis oblongo-lanceolatis integerrimis scabris, involucris snbsquarrosis, foliolis obtusis, interioribus membranaceis apice coloratis. $2 \mathcal{f}$. In collibus el vitibus Galliæ australis.

3ı37. Tripolium. Caule glabro corymboso, foliis lineari-lanceolatis carnosis triplinerviis, inferioribus apice subserratis, involucri squanis lanceolatis. 2 . In stagnosis maritimis et in salsis Lotharingine.

3138. Acris. Caule subglabro corymboso, foliis lineari-lanceolatis glabris trinerviis, ramis foliosis, involucris inbricatis disco dupld brevioribus. $\mathcal{~}$. Ad sepes et in herbosis Galliæ Mediterraneæ.

3г39. Pyrenaus. Caule hirsuto simplici suprà corymboso, foliis oblongo - lanceolatis subscabris subamplexicaulibus apice 4-5-dentatis, involucri squamis lineari-acuminatis hirsutis. 2 . In $\mathrm{Py}-$ renæis,

3r fo. Annuus. Caule subglabro supcrnè ramoso, foliis pilosiusculis, inferioribus subovatis serratis, superioribus lanceolatis, involucris hemisphæricis, foliolis subæqualibus strigosis. $\odot$. Secus Isaram, in Vallesia.

3ı́r. Chinensis. Caule hispido, ramis unifloris, foliis ovatis grosse dentatis petiolatis, caulinis sessilibus lanceolato-acuminatis integris, involucri foliolis maximis ciliatis. $\odot$. Ex China oṛtus, in horlis cultus.

$$
\text { 527. I IN U I A }
$$

Involucrum imbricatum; receptaculum nudum ; flores radiati, ligniis concoloribus; antheræ sæpiùs basi bisetosæ; pappus nunc piIosus simplex, nunc duplex, exterior membranaceus.

\section{I. Foliis amplexicaulibus.}

3r 42. Helenium. Foliis amplexicaulibus subdentatis ovatis rugosis subtùs tomentosis, in₹olucri squamis ovatis. $\mathcal{F}$. In Flandria, $\mathrm{Pe}-$ demuntio, Parisis.

3:43. Odora. Foliis amplexicaulibns dentatis hirsutissimis, radicalibus ovatis, caulinis lanceolatis, caule paucifloro. $\mathcal{H}$. In maritimis Galloptoriocia, Pedemontii, Corsicæ.

3r4f. Oculus Christi. Foliis amplexicanlibus lanceolatis integris margine et subtùs sublirsutis, suprà ferè glabris, caule piloso scabra corymboso, involucri foliolis liuearibus. 2 . In montosis Galloprovincix et in Corsica, 
3145. Britanica. Foliis amplexicanlibus lanceolatis hasi serratis subtus pilosis, caule corymboso villoso, involucri foliolis linearibus hirsutis. 24. Secus vias et fossis, Parisiis et passin in tota Gallia, exceptis prov. mediterrancis.

3r.f6. Dysenterica. Foliis amplexicaulibus corrlato-oblonģis nudis serratis subtus pilosis, eanle pubescente paniculato, ranus lateralibus apice longioribus patulis, involucri squamis setaceis. $2[$. In fossis et humidis.

3147. Pulicaria. Foliis amplexicaulihus oblongis undulatis villosis, canle erecto paniculato, pedunculis unfloris oppositifoliis, floribus subglobosis, radio minutissino. $\odot$. In fossis humidis secus vias.

\section{§. II. Foliis sessilibus.}

3×48. Squarrosa. Foliis ovalibus rigidis serrulatis scabris reticulatovenosis, involucri squamis ovatis, exterioribus reflexis. $\mathcal{H}$. In sylvis et inter saxa, propè Segusium, Gratianopoliu ct in prov. mediterraneis.

3149. Germanica. Foliis ovato-oblongis subobtusis vix dentatis scabris, caule supernè ramoso, floribus corymbosis. 2 . In Delphinatu.

3r5o. Salicina. Foliis lanceolatis recurvis serrato-scabris, ramis angulatis glabriusculis, floribus inferioribus altioribus. $\mathcal{F}$. In pratis asperis Delphin. Galloprov. Pedem. Occit.

3.51. Hirla. Foliis lanceolato-oblongis integris rigidis pilosis, canle villoso subramoso, floribus paucis corymbosis. 24 . In pratis montosis et circà Parisios.

3152. Vaillantii. Foliis ovato-lanceolatis obsoletè serratis subtùs tomentosis, caule paniculato, floribus subcorymbosis terminalilıs. 2 . Secus rivos et oras sylvarum in Delphin. Pedem. Sabaud. Genevæ.

3153. Ensifolia. Foliis linearibus acuminatis nervosis glabris sparsis, caule subsimplici paucifloro. $\mathcal{F}$. In Pedemontii montibus.

3154. Viscosa. Hirsuto-viscosa, foliis lanceolatis subserratis, caule supernè ramoso, pedunculis lateralibus unifloris foliosis, involneri foliolis linearibus glabris. 2 . In locis incultis, ad sepes et margines agrorum Gallix anstralis.

3155. Tuberosa. Foliis linearibus rarò dentatis margine sublirsntis, ramis unifloris, caule suffruticoso, involucri foliolis linearibus. 24. In siccis et maritimis Occitanix, et in Gebenuensibus.

3r56. Saxatilis. Foliis linearibus integerrimis hirsutis glutinosis, caule simplici hirsuto, pedunculis pancis unifloris. 24 . In petrosis et montosis Galloprovinciæ, et Pyrenæorum.

315\%. Chrithmoides. Foliis linearibus carnosis tricnspiłatis. 2Z. In paludibus turfosis nıritimis secus Mediterrancum, et secus Oceanum ad Nannetes usque.

3r58. Montana. Foliis lanceolatis hirsutis integerrimis, caule unifloro, involucri hirsuti foliolis oblongo-linearibus, exterioribus previoribus. $\mathcal{Z}$. In sterilibus montium. 


\section{§.III. Foliis decurrentibus.}

3r59. Bifrons. Foliis ovato-oblongis decurrentibus dentatis apice integerrimis, floribus corymbosis confertis. $\sigma^{7}$. In ericetis et umbrosis montium.

$$
\text { 528. S O L I D A G } 0 \text {. }
$$

Involucrum imbricatum; receptaculum nudum; flores radiati, ligulis concoloribus subquinis; pappus pilosus.

$3 ı$. Vorgaurea. Caule supernè ramoso et pubescente, foliis caulinis lanceolatis ntrinque attenuatis serratis, inferioribus ellipticis pilosiusculis, racemis erectis, pedicellis flore brevioribus. 2 . In jetrosis sylvarum.

3ı6r. MTinuta. Caule simplicissimo, foliis lanceolatis acntis serratis glabris, pedunculis unifloris flore duplò longioribus. 2f. In Pyrenxis Alpibusque Pedemontanis.

3162. Graveolens. Pubescenti-viscosa, foliis sublinearibus integerrimis, ramis lateralibus multifloris. $\odot$. In arvis subhumidis Gallia australis et occidentalis.

$$
\text { 529. T U S S I L A G } 0 .
$$

Involucrum simplex, squamis margine membranaceis; flores flosculosi vel radiati; flosculi uunc omnes hermaphroditi, nunc feninini fertiles in radio, hermaphroditi in centro; pappus pilosus; receptaculum nudum.

\section{I. Floribus radiatis; scapis unifloris (FARFARA).}

3i63. Farfara. Scapo unifloro subnudn bracteato, foliis cordatis angulatis dentatis subtùs pubescentibus. 4 . In argillosis subhumidis apricis.

\section{§. II. Floribus flosculosis; caulibus unifloris basifnliosis.}

3164. Alpina. Canle unifloro subnudo, foliis reniformibus dentatis glabris. 2 . In pascuis editiorum montium.

〕. III. Floribus flosculosis; scapis multifloris (PETASITES).

3165. Petasites. Thyrso oblongo, foliis oblongo-cordatis inæqualiter denticulatis, subtis pubescentibus, lobis approximatis. $\underset{j}{\mathrm{C}}$. In hrumidis secus torrentes et fossas.

3166. Alba. Thyrso fastigiato, foliis orbiculato-cordatis duplicato argutè dentatis subtùs villoso-pubescentibus. F. In humidis montanis Jurassi, Burgundiæ, montis Aurei.

3167. Nivea. Thyrso obiongo, foliis oblongo-cordatis inaqualiter dentatis subtùs densè albo-tomentosis, lobis divaricatis. 24 . Sccus sivos in $\Lambda$ lpibus editioribus.

$$
\text { 530. S E I E E C I } 0 \text {. }
$$

Involucrum caliculatum, foliolis apice splacelatis; flores nuncflosculosi, nunc radiati; receptaculum nuduu ; pappus jilosus, mullis. 


\section{I. Rloribus fosculosis.}

3.68. Fulgaris. Foliis amplexicanlibus pinnatifidis dentatis, floriribus corymboso-coarctatis. $\odot$. In cultis frequens.

\section{§. II. Floribus ratiatis; radio revoluto.}

31 fog. Viscosus. Foliis pinnatifidis viscirlis, squamis involucri laxis lirsutis. $\odot$. Ad oras sylvarum in montosis.

31 o. Sylvaticus. Foliis pinnatifidis denticulatis, involucri squanis lavibus. $\odot$, Linn. $\sigma, \mathrm{V}$ ill. In sylvis submontanis.

3171. Nebrodensis. Foliis lyratis simmatis basi amplexicanlibus, inferioribus obtusis, superioribus acmminatis. squanis involucri lineari-ăcuninatis glabris. $\odot$. In Occitania, Pyrenxis.

5. III. Floribus radiatis; radio patente; foliis pinnalifulis.

3172. Gallicus. Foliis semi-amplexicaulibns pinnatifidis, laciniis linearibus subdentatis distantibus, caule crecto. $\odot$. In arris, vincis, ad muros et vias Galliz Mediterranca.-S. squalidus. Fl. fr. n. 3 i 2. non Sm. Engl. bot. an Lim..?

31,3. Jacobaea. Foliis lyrato-pinmatifidis divaricatis dentatis glabris, canle erecto, involucro cylindrico, seminibus hirtis. 4 In pratis, petrosis et ad vias frequens.

3174. Aquaticus. Foliis lyratis serratis glabris, inferioribus obovatis integris, involucro hemisphærico, ligulis ellipticis, seminibus glabris. 2 . In paludibus et aquaticis.

3175. Eruccefolius. Foliis pinnatifidis dentatis sulhirtis, caule crecto, involucro hemisphærico. 4. In montosis dunetosis serns fossas, in Delphinatû, Sabaudia, Pedemontio.-S. tenuifolius. Engl. bot. t. 574 . S. erncæfolius. Hnds. angl. 366 non Linn. ex Smith.

3:-6. Abrotanifolius. Foliis pinuato - multifidis linearihns nudis acutis, caule supernè sulnnudo subbifloro. $2 \mathrm{~L}$. In Alpibus Pedemontanis, Galloprovincia, Pyrenæis.

3177. Tenuifnlius. Foliis pinnato-multifidis, pinnis lineari-snbulatis subincisis, involucris cylindricis demùm longitudinaliter sulcalis, floribus corymbosis terminalibus. 2 . Circà Parisios, Aureliam, in Arvernia, Pedemontio, Pyrenxis, Monspelii.

31 ;. Incanus. Foliis utrinque tomentosis niveis pinnatifirlis, laciniis linearibus obtusis subdentatis, corymbo coarctato. 2 . In Alpibus. Grebennensibus, Pyrenæis.

3179. Uniftnrus. Foliis tnmentosis oblongis dentatis, caulc folioso unifloro. 2 . In editioribus Alpibus Pedemontanis.

๑. IV. Floribus radiatis; radio patente; foliis indivisis.

3 I8o. Paludnsus. Foliis semi amplexicaulibus lanceolatis argute serratis subtus subvillosis, corymbo terminali divaricato, caule stricto sublanato. $\mathcal{F}$. Secus fluvios et stagna in arundinetis.

3181. Persicafolius. Foliis ohlongis utringuè attenuatis subcrassis ntrinquè glabris, dentibus semi-lumatis, corymbo paucilloro. $\mathcal{Y}$. 14. Pyrenais editioribus. 
21 $\mathrm{S}_{2}$. Nemorensis. Foliis sessilibus ovato-lanceolatis serratis margine ciliatis, subtìs tenuissimè pubescentibus, corymbo terminali folioso. 2F. In montibus Gallia australis, in Pyrenæis oricntalibus.

$3_{1} S_{2}{ }^{*}$. Ovatus. Foliis ovato-lanceolatis argutè serratis utrinquè glabris subsessilibus, corymbo laxo. 24. In sylvis Moguntiæ.

3ı 33 . Sarracenicus. Foliis lanceolatis basi cuneatis argutè scrratis subscssilibus glabriusculis, corymbo paucifloro. 2 . In humidis umbrosis $\mathrm{Alpium}$ et Jurassi.

$3{ }_{1} 4$. Doria. Squamis involucri exterioribus patulis, foliis subdecurrentibus oblongo-lanceolatis glaucescentibus glabris serratis. 2. Secus rivos in Gallia australi.

3135. Doronicum. Caule indiviso subtomentoso, foliis crassiusculis serratis, caulinis sessiibus, radicalibus petiolatis ovatis subtù villosis. 24. In pascuis subhumidis Alpium, Pyrenaorum, Gebennensium.

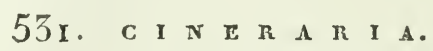

Involucrum simplex, polyphyllum, æqualc; receptaculum nndum; flores radiati; pappus pilosus.

3г89. Sibirica. Racemo simplici folioso, foliis petiolatis glabris cordatis suberenulatis, petiolo hasi dilatato, canle simplici. $\mathcal{F}$. In paludosis montanis Pyrenæorum, Arvernix, etc.

3:87. Palustris. Floribus corymbosis, foliis lato-Janceolatis dentato-sinnatis subamplexicaulibus, caule villoso. $\mathcal{H}$. In arenosis, aquosis et paludosis Belgii, Flandrie, etc.

3ıs8. Campestris. Floribus umbellatis, canle simplici, foliis touncntosis, radicalibus ovatis subcrenulatis, caulinis lanceolatis integerrimis. $\mathcal{H}$. In collibus frondosis, Parisiis, in Arvernix montibus, Pyrenæis.

3ı89. Aurantiaca. Floribus subternis terminalibus, caule simplici, foliis radicalibus ovatis obsolete crenatis, caulinis lanceolatis integerrimis, involucris sphacelatis. $\mathcal{F}$. In pratis siccis et editioribus Alpium.

319\%. Integrifolia. Floribus umbellatis, caule simplici, foliis inferioribus spathulatis dentatis, superioribus lanceolatis basi integerrimis, summis integerrimis. 4 . In humidis Alpium Vallesiæ, Pyrenæorum.

3I!). Longifolia. Floribus umbellato-corymbosis, caule simplici, foliis omnibus dentatis, radicalibus spathulatis, caulinis oblongolanceolatis. $\sigma^{7}$. In pascuis montanis irrigatis Pedem. Galloprov. Nonspelii.

3ı)z. Cordifolia. Panicula pauciflora, canle simplici, foliis omnibus petiolatis cordatis duplicato-dentatis, petiolis basi subdentatis. $\mathcal{H}$. In Alpibus editioribus circà casas pastorias.

3ı 3. Marilima. Floribus paniculatis, involncris tomentosis, foliis pinnatifidis, laciniis obtusis subtrilobis subtis tomentosis, caule suffrutescente. 2f. In saxosis calidioribus scctis IIcliterrancuns. 


\section{T A G E T E S.}

Involucrum polyphyllun, simplex, foliolis coalitis; receptaculum nudum; flores radiati; semina aristis 5 coronata.

3 Igf. P'atula. Foliis pinnato-multifidis, laciniis lancenlatis ciliatoserratis, perlunculis mifloris subincrassatis, involucris levibur, canle patulo. $\odot$. Ex Mexico orta, in hostis culta.

3ı9 ${ }^{*}$. Erecta. Foliis pimnato-muitifidis, foliolis lancolatis cilintoserratis, pedunculis uniftoris ventricoso-incrassatis, involucris angulatis, caule erecto. $\odot$. Ciun priori.

$$
\text { 535. D O } \quad \mathbf{R} \text { O }
$$

Involucri squama duplicis ordinis xunales; flores radiati, ligulis fenineis; flosenlorum semina pappo simplici coronata, ligularum nuda; receptaculum nudum.

3ı95. Parialianches. Foliis denticulatis, radicalibus cordatis longe petiolatis, mediis spathulato cordatis, summis subrotundo-cordatis, caule hirsuto subsimplici. $\mathcal{4}$. In sylvis montanis.

3ı6. Scorpioides. Foliis remotè denticulatis, superioribus oblongis amplexicaulibus, inferioribus ovatis petiolatis, petiolis alatis auriculatis, radicalibus ovatis subcordatis petiolatis, caule subglabro. 4 . In sylvis montanis Alpium, Pyrenæorum.

3197. Plantagineum. Foliis ovali-oblongis, inferioribus longè petiolatis, petiolis nudis, superioribus sessilibus amplexicanlibus, caule simplici. 2f. In sabulosis Parisiis, Sinemuri, in Vogesis.

$$
\text { 53/. A R N I C A. }
$$

Involucri squamæ duplicis ordinis xquales; flores radiati, ligulis femineis filamentis 5 sterilibus donatis; seminat onunia pappo coronata; receptacolum nudum.

3198. Montana. Foliis oppositis ovatis integris. 4 . In pascuis montanis.

3 з9.. Doronicum. Foliis remotè dentatis hirsutis, radicalibus petiolatis oblongis basi angustatis, caulinis alternis oblongo-lanceolatis. $\mathcal{F}$. In petrosis Alpium editiorum Delphinatûs, Pedemontii.

3200. Scorpioides. Foliis dentatis, dentibus acuminatis, radicalibus petiolatis elliptico-subrotundis, caulinis alternis oblongis. $\underset{T}{\mathcal{C}}$. In udis secus torrentes, in Alpibus et montibus Arverniæ.

320r. Bellidiastrum. Scapo unifloro nudo, radio discolore, foliis petiolatis obovatis repandis. $\mathcal{H}$. In sylvis montosis Galloprovinciæ, Delphinatûs, Pedemontii, Sabaudiæ.

$$
534^{*} \text {. B E L L I U Mr. }
$$

Involucrum simplex, polyphyllum; receptaculum nudum; flores radiati; flosculi 4 -dentati, tetrandri; pappus 8 paleis in pilos desinentibus constans.

$3201^{*}$. Bellidioides. Scapis nudis filiformibus. $\odot$. In herbosis Cor: sica circà Urcinium. 


\section{$+\dagger$ Pappus nullus; receptaculum nudum. \\ 555. C A I, E N D U L A.}

Involucrum poly phyllum, simplex, æqualc; flores radiati ; floscuif in disco unasculi, in radion leermaphroditi; ligulæ femineæ fertiles; semina unda, nembranacea, irregularia, curvata.

3202. Arvensis. Seminibus cymbiformibus muricatis incurvatis, exterioribus lanceolato-snbulatis dorso muricatis. $\odot$. In vineis et atvis.

3203. Offcinalis. Seminibus cymbiformibns muricatis incurvatis omnibus. $\odot$. In arvis Galliæ utustralis.

$$
\text { 536. с н R X S A N T H E M U M. }
$$

Involncrum hemisphæricum, imbricatum, squamis margine scrriosis; flores radiati; receptaculum nudum; semina nuda, membrana non coronati.

\section{I. Discu flavo; ligulis discoloribus (ze ccantramom).}

3204. Lencanthenum. Foliis amplexicaulibus lanceolatis serratis t: basi inciso-dentatis, radicalibus spathulatis in petiolum loasi decurre.utibus, caule erecto ramoso. $2 f$. In pratis frequens.

32,5. Maximum. Foliis carnoso-fragilibus, inferioribus spathulatis subiutegris, mediis sessilibus lanceolato-dentatis, summis linearious integris, caule simplici unifloro. 24 . In Pyrenæis propè Valletriam.

$3205^{+}$. Heter $p$ hlyllum. Foliis sessilihus lineari-lanceolatis serratis, canle simplici unifloro. 24. C. heterophylhum. WVild. 3. p. $214^{2}$. - In umbrosis subalpinis Pedemontii observavit cl. Balbis.

3206. Graminifo'tum. Foliis linea ibns subintegerrimis, caule simplicissimo unifloro. 2C. In colibus Gailiæ australis.

3207. Ceratopleylloides. Foliis pinnato-multifidis, pinnis linearibus acutis, caule erecto unifloro. 2 . In montibus Pedemontanis.

3208. Monspeliense. Foliis imis palmato-multifidis, laciniis linearibus pinnatifirlis. 24 . Monspelii.

1. II. Ligulis disco concoloribus (CHrysarthemem).

3209. Alyconis. Foliis lingulatis obtusis serratis. $\odot$. In agro $\mathrm{Ni}$ cæensi.

3210 . Segetum. Foliis amplexicaulibus supcrnè laciniatis, infernè dentato-scrratis. $\odot$. In arvis.

321 r. Coronariım. Foliis bipinnatifidis acntis extrorsùm latioribus, caule ramoso. $\odot$. In arvis.

$$
\text { 537. P Y R E T H ri U M. }
$$

Involucrum hemisphæricım, imbricatum, squamis margine scariosis; flores rulliati; receptaculum nudum; semina membrana prominula sæpius dentata coronata.

3212. Halleri. Foliis caulinis lanceolatis profundè dentatis, radicalibus pinnatifillis, caule unifloro. $\mathcal{H}$. In lapidosis Alpium Sabaud. Delphin. et Peden. 
3213. Alpinum. Foliis inferioribns pinnatifido-dentatis, snmmis linearibus integerrimis, caule unifloro. $2 F$. In lapidnsis Alpium et Pyrenzorum.

3214. Cor mbosum. Foliis pinnatifidis, pinnis lanceolacis pinnatifidis argutè serratis, summis confluentibus, pedunculis corymbosis. 2$\}$. Cireà Parisios, Genevam, in Burgundia, Arvernia et prov. anstralibus.

3215. Parthenium. Foliis petiolatis compositis planis, pinnis ovatis incisis, pedunculis ranosis corymbosis, canle crecto, involuero hemispliarico pubescente. $\sigma$, $\mathcal{F}$. In incultis et lapidosis.

3216. Inndorum. Foliis sessilibus bipinnatifulis, pinnis lineari-filiformilus bi-vel-tripartitis, caule ramoso patulo, pappo integro. $\odot$. In agris ad vias.

$3216^{*}$. Maritimum. Foliis bipinnatifidis, pinnis linearibus oheusis carnosis glabris trifidis, caule diffuso ramoso, pappo lobato. $\mathcal{~}$. P. maritinum. Sm. engl. Bot. t. 970. Matricaria maritima. Lin. Sp. 1256. - In arenosis maritimis propè Nannetes reperit Delarochc.

$$
\text { 558. II }
$$

Involucrum hemisphæricum, imbricatum, squamis foliaceis ; flores radiati; receptaculum nudum, conicum; semina nuda.

3217. Chamnmilla. Foliis hipinnatifidis, laciniis capillaribus, involucro subplano, squamis obtusiusculis. $\odot$. In hortis et cultis.

3218. Suaveolens. Foliis triplicato-pinnatifidis, laciniis tennissimis, squamis involucri acutis. $\odot$. Circà Nabonem, Abbavillam, in Arvernia.

\section{B E L L I s.}

Involucrum hemisphæricum, polyphyllım, simplex; flores radiati; receptaculum nudum, conicum; semina nuda.

32 ig. Perennis. Scapo nudo unifloro, foliis obovatis crenatis venosis. 24. In graminosis ad vias.

3220. Annua. Caule subsimplici súbfolioso, foliis ovalibus obusis apice crenulatis. $\odot$. In pratis sylvaticis et collibus Galliæ Mediterranez et in Corsica.

\section{C A R $\mathbf{P}$ E $S$ S I U $\mathbf{M}$.}

Involncrum henisphæricum, imbricatum, foliolis exterioribus patulis; flores flosculosi, flosculis in disco hermaphroditis 5-lobis, in rarlio femincis fertilibus 5 -dentatis; receptaculum nudum; semina nuda.

322r. Cernuum. Floribns terminalibus solitariis cernuis. $\mathcal{F}$. In humidis et umbrosis Galloprovinciæ, Pedemontii, Delphinatûs.

$$
\text { 5/I. в A L S A M I T A. }
$$

Involucrum patens, imbricatum; flosculi omnes tubulosi hermaphroditi 5-dentati; receptaculum nudum; scmina incompleta memboxana coronati. 
3332. Major. Caule subherbaceo, foliis ellipticis dentatis, inferioribus petiolatis, superioribus sessilibus basi auriculatis, floribus corymbosis. 24 . In Gallia australi.

3223. Annua. Caule herbaceo supernè ramoso corymboso, foliis radicalibus bipinuatifidis, caulinis confertis pinnatifidis pubescentibus, pinnis linearibus acntis mucronatis $\odot$. In sabnlosis incultis circà Avenionem, Vindomagum, Arelatem, Nicæam.

3224. Virgata. Caule herbaceo basi ramosn, ramis nnifloris, foliis sessilibus lanceolatis dentato - serratis. 2 All. $\odot$ Liun. In aridis agri Nicæensis.

$$
\text { 5/2. T A I A C } \mathbf{E} \text { T U M。 }
$$

Involucrum hemisphæricum, imbricatum ; flores floscolosi ; flosculi in centro hermaphroditi 5-lobi, in radio feminei fertiles 3-lobi; receptaculum nudum; semina pappo membrauaceo integro coronata. 3225. Vulgare. Foliis bipinnatifidis incisis serratis. 24. In ruderatis ad muros.

$$
\text { 543. A R T E M I S I A. }
$$

Involucrum ovatum aut rotundatum, imbricatum; flosculi omnes tubulosi, in diseo hermaphroditi 5-dentati, in radio graciles pauciores integri feminei fertiles; semina nuda; receptaculum nudura aut pilosum.

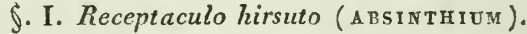

3226. Absinthium. Foliis incanis, radicalibus triplicato-pinnatifidis obtusiusculis, superioribus pinnatifidis acutis, laciniis lanceolatis, floralibus indivisis, floribus globosis pedunculatis nutantibus. $\mathcal{F}$. In lapidosis incultis et montosis.

3227. Arborescens. Fruticosa, foliis tripinnatifidis sericeis cinereis, foliolis linearibus, floribus globosis, ramulis floriferis simplicibus. b. In Pedemontio?

3228. Corymbosa. Suffruticosa, foliis palmato-multifidis, lobis linearibus 3-vel-4-particis, floribus globosis pedunculatis nutantihus, involucro pubescente. $\zeta$. In apricis demissiorum montium Delphinatûs.

3229. Glacialis. Canle herbaceo simplicissimo, foliis omnibus.palmato-multifilis candidis sericeis, floribus terminalibus glomeratis sessilibus globosis 4o-floris. $2 \mathrm{~T}$. In editissimis Alpibus.

323o. Rupestris. Caule herbaceo simplicissimo, foliis omnibus palmato-maltifidis albido-sericeis, floribus subovatis I f-floris, inferioribus pedunculatis, snmmis sessilibus. 2 . In saxosis editioribus Alpium, montium Arvernix.et Pyrenæorum.

\section{II. Receptaculo nudo (ARTEMISIA). \\ * Floribus subglobosis.}

323r. Spicata. Canle herbaceo simplicissimo, foliis cano-sericeis, radicalibus palmato-multifidis, caulinis pinnatifidis, summis tinearibus integerrimis obtusis, floribus axillaribus infimis pedunculatis. 4 . Ad rupes in suminis Alpibus, Pyrenæis. 
3232. Pontica. Caulc herbaceo ramoso, foliis subtùs tomentosis, caulinis bipinnatis, foliolis linearihus, rancis simplicibus, floribus subrotundis pedunculatis nutantibus. $\mathcal{H}$. In siecis et lapidosis Pedemontii, Jurassi.

3233. Tanacetifolia. Caule simplicissimo herhaceo, foliis bipinnatifulis subpubescentibus, laciniis lineari-lanceolatis acuminatis integerimis, racemo nudo terminali, floribus subrotundis nutantibus. 24. InAlpihus Delphinatûs, Pedemontii.

3234. Chamamelifolia. Caule crecto basi ramoso glabro, foliis subglabris, inferioribus tripinnatis, superioribus bipinnatis, foliolis linearibus acutis, floribus paniculatis pedunculatis nutantibus. 4 . In apricis Lumilioribus montium Delphinatûs, Pedemontii.

3235. Campestris. Caulc procumbente ramoso virgato, foliis cauliuis setaceis pinnatis glabris, radicalibus pinnatis, laciniis tritiths incanis, floribus subovatis pedunculatis. 2 . In campestribus lapidosis siccis.

3236. Dracunculus. Foliis glabris lanceolatis utrinquè attenuatis, floribus subrotundis pedunculatis erectis. $\&$. E Sibiria orta, in Jortis culta, in Lotharingia spontanea?

\section{** Floribus ovatis vel cylindricis.}

3237. Corulescens. Caule suffruticoso ramoso, foliis incanis lanceolatis integerrimis, rarlicalibus incisis, floribus oblongis paniculatis nutantibus. ๖. In maritimis circà Nicæam, Nannetes.

3238. Vu/garis. Caule herbaceo, foliis pinnatifido-incisis subtùs tomentosis suprà atro-viridibus, floralibus indivisis lineari-lanceolatis, floribus snbscssilibus oblongis erectis, involucris tomentosis. 2 . Ad vias in incultis.

3239 . Palmata. Caule suffruticoso ramoso, foliis subincanis pinnatis, laciniis linearibus tripartitis, floralibus indivisis linearibus obtusis, involucris oblongis sessilibns erectis subtrifloris. b. In Gallia Narbonensi Hispania contermina?

3240. Marilima. Caule herbaceo ramoso adscendente, ramulis cernuis, foliis niveo-tomentosis multifidis, laciniis planis linearibus, rameis simplicibus linearibus, floribus oblongis tomentosis sessilibus. 24 . In maritimis a Galloprovincia ad Belgium.

324r. Gallica. Caule erecto ramoso tomentoso, ramis erectis, foliis incanis bipinnatis, laciniis lineari-filiformibus, caulinis pinnatis, summis linearibus, floribus oblongis subsessilibus crectis. 2 . In maritiuis Galliæ Narbonensis et Pyrcnæis.

3242. Vallesiaca. Caule herbaceo adscendente, foliis tomentosis niveis, caulinis bipinnatis lineari-filiformibus, floralibus simplicibus, panicula simplici, Horibus oblongis sessilibus erectis. 2 . In apricis arenosis vallis Augustanæ et Vallesiæ superioris.

32 3. Abrotanum. Frutescens, caule stricto, foliis inferioribus bipinnatis, superioribus pinnatis capillaceis, involucris pubcseentibus hemisphæricis. $\Varangle$. In Gallia australiori? in bortis odoris gratia culta. 
32 年. Paniculata. Frutescens, caule ramoso patente, foliis omnibus bipinnatis capillaceis, involucris glabris hemisplıæricis. ๖. In Gallia australi.

\section{$\dagger+\dagger$ Semina nuda; receptaculum paleaceum. 5/44. M I C $\mathrm{R}$ o $\mathrm{P}$ U s.}

Involncrum 5-9-phyllum, foliolis laxis; flosculi tubulosi, in disco hermaphroditi steriles 5 -dentati pentandri, stigmatibus simplicibus, in radio feminci fertiles, stigmatibus dunbus; receptaculum conico-subulatum, in radio paleaceum, in disco nudum; semina nuda, compressa, involncri foliolis involuta.

32 f.5. $P_{\text {1 }}$ mmrus. Floribus subacaulilous sessilibus, foliis floralibus majoribus. $\odot$. In maritimis et stagnis exsiccatis Galliæ Nediterraneæ et in Lorsica.

3246 . Erectus. Foliis alternis lanceolatis, floribus lanuginosis. $\odot$. In - campis sterilibus, imprimis australibus.

32 i. Supinus. Foliis oppositis obovato-cuneatis. $\odot$. In maritimis Galloprovinciæ, agri Nicæensis.

$$
\text { 545. S A N } \mathbf{T} \text { o } \text { 工 I I A . }
$$

Involucrum lemisphæricun, imbricatunı; flosculi omnes tubulosi, hermaphroditi; receptaculum palcaceum ; scmina nuda.

32 8. Incana. Pedunculis unifloris, foliis incanis quadrifariam dentatis, dentibus obtusis, ramis tomentosis, involucris pubescentibus. 5 . In collibus Occitaniæ circà Nemausum, Narbonem, Scgusium.

3249. Viridis. Pednnculis unifloris, foliis glabris quadrifariam deutatis, dentibns subulatis rectis, ramis involucrisque glabris. $b$. In Gallia australi circà Narbonem.

3250. Rosmarinifolia. Pedunculis unifloris, foliis linearihus, inferioribus stibubescentibus margine tuberculatis, superioribus planis integerrimis glabris, ramis involncrisque glabris. $b$. In Gallia australi.

$$
\text { 5/46. D I o 'r I s. }
$$

"Involucrum hemisphericum, imbricatum; flosculi omnes tubulosi, hermaphroditi, 5-dentati, medio coarctati, basi dilatati in appendices 2 ovarium cingentes; receptaculum convexum, päleaceum; seuina nuda.

325 r. Candidissima. Pedunculis corymbosis, foliis oblongis obtnsis crenatis densè lanatis. 2 . In areuosis maritinis à Nicæa ad Nannetes.

$$
\text { 5/4. A I A c Y c L U s: }
$$

Involucrum hemispharicum, imbricatum; flosculi omnes tubulosi, in disco hermaphroditi, in radio feminei fertiles; receptaculum conicum, paleaccum; scmina margine membranacea, apice crenulata nuda.

3252. Valentinus. Flosculorum laciniis inæequalibus, duabus aristąis erectis. $\odot$. Monspelii? Carcassonis, Nicææ. 
3253. Aureus. Flnsculormm lacinios equalibus obtusiusculis. $\odot$. In proviuciis meridionalibus.

$$
548.4 \text { N T } \text { H } \text { I. MI I } \mathrm{s} \text {. }
$$

Iuvolncrum hemisphericum, squamis subequalibus margine scapiosis imbricatum; flores radiati, flusculis hermaphroditis, ligulis fanceolatis femine is fertilibus; receptaculum convexum, paleaceum; penina membrana integı vel dentata coronata.

\section{I. Disco luten; radio disçolore.}

325 f. Altissima. Foliis bipinnatifidis, laciniis lanccolatis subdentatis, dentibus inferioribus subreflexis, paleis lanceolatis cuspidatis. $\odot$. In campis Gallix australis.

3255. Maritima. Foliis pinnatifilis carnosis subtùs punctatis, laciniis incisis apice dilatatis, seminibus nudis, caule herbaceo. 4 . In arenosis secus Mediterraneum,

3256. Biaristata. Foliis bipinnatis sessilibus sericeo-tomentosis, laciniis linearibus acutis, flosculortin dentibus inaqualibus, duobus aristatis erectis, involucro pubescente. 2$\}$. In stagnis maritimis Monspelii, Narbonis, Nicæa?

3257 . Mixta. Foliis sessilibus semi-pinnatifidis, laciniis dentatis, canle crecto ramoso. $\odot$. In Solonix campis, circà Stampas, $\mathrm{Pa-}$ risios, Nannetes, Niarbonem; Monspelium, Nicæam.

3258. Alpina. Foliis pinnatifidis, radicalibus petiolatis glabris, laciniis lincari-subulatis dissitis subintegerrimis, caulinis sessilibus pubescentibus, caule $\mathrm{I}-3$-floro pubescente. 24. In Pedcmontí montibus Vesulo et Grassoney dictis (AIl.).

$3255^{*}$. Saxatilis. Foliis pinnatifidis petiolatis pubescenti-tomentosis, laciniis pancis linearibus simplicibus subacutis, caulibus erectis apice nudis unifloris. 2 . Inter suxa in Arvernia, propè SanctiFlori fanmm detexit Stein.

3259. Nobilis. Foliis bipinnatis, lacinijs tripartitis lineàri-subulatis subvillosis, canle basi ramoso decumbente. 24 . In pascuis siccis.

326o. Arvensis. Foliis bipinnatis, laciniis lineari-lanccolatis pubescentibus, receptaculis conicis, paleis lanceolatis, seminibus coronato-marginatis. $\sigma^{\circ}$. In arvis.

326r. Cotula. Foliis bipinnatis glabris, foliolis subulatis tripartitis, receptaculis' conicis, paleis setaceis, seminibus nudis tuberculosis. $\odot$. In incultis et arvis. ${ }^{-}$.

3262. Austriaca. Foliis bipinnatis lannginoso-villosis, ireceptarculis conicis : paleis oblongis mucronatis; seminibus nudis. $\odot$. In collibus lápidosis circà 'Taurinum..

3263. Montana. Foliis pinnatis pubescentibns, pinnis linearibus trifidis, caule adscendente, pedunculis elongatis' nudis tomentosis. 4. In Pyrenæis, Galloprovincia, Pedemontio, in Arvernia inter segetes.

3.264. Pyrethrum. Foliis triplicato-pinnatis, laciniis linearibus 
carnosis, caulibus decumbentibus, ramis axillaribus unifloris. $\mathcal{Z}$. Monspelii.

S. II. Radio concolore luteo.

3265. Valentina. Foliis triplicato-pinnatis, laciniis linearibus pubescentibus, caule ramoso divaricato, pedunculis subinerassatis. $\odot$. In arenosis subhumidis Galliæ anstralis, Nicææ.

3266. Tinctoria. Foliis subtùs pubescentibus tripinnatifidis serratis, caule erecto ramoso, pappo membranaceo integerrimo. $\mathcal{4}$. In provinciis australibus.

3267. Discoirlea. Foliis bipinnatis serratis glabris, caule erecto ramoso, pappo membranaceo dentato nno latere inciso', floribus floseulosis. $\mathcal{C}, \odot$. Ad sepcs et in vineis Pedemontii; propè Cuneum.

$$
\text { 549. A C H I L L I A. }
$$

Involucrum ovatum . imbricatum; flores radiati, flosculis herınnphroditis, ligulis brevibus femineis paucioribus; receptaculum planum, angustum, paleacenm; semina nuda.

\section{I. Floribus luteis.}

3268. Ageratum. Foliis oblongis obtusis serratis, in petiolum attenuatis fasciculatis glabris, corymbo composito coarctato. $\mathcal{F}$. In petrosis subhumidis Galliz australis. - Var. pubeseens, in Pyrenæis.

3269. Tomentosa. Foliis bipinnatifidis villosis, pinnis confertissimis, laciniis lineari-lanceolatis integerrimis, corymbo composito. 2. In arvis siccis et sterilibus Galloprovinciæ, Pedemontii, Delphinatûs.

\section{II. Florum radiis allis.}

325o. Herba-rota. Foliis cuneiformibus basi attenuatis serratis cauleque glabris. 2 . In editissimis Alpibus Delphinatûs, Pedemontii.

3271. Ptarmica. Foliis linearibus acuminatis rqualiter argutè serratis glabris. $2 \mathcal{f}$. In pratis subudis. - Var. pubescens, in Pyrenæis.

3272. Alpina. Foliis linearibus pectinato-pinnatifidis glabris, laciniis subserratis, corymbo composito. 2 . In Alpibus Sabaudis.

3273. Chamamelifolia. Foliis pectinato-pinnatifulis, laciniis linearibus integerrimis, corymbo composito subnudo cuarctato. 24 . In Pyrenæis loco dicto Notre-Dame-de-IVuris.

3274. Macrophylla. Foliis pinnatis glabris, pinnis lanceolatis inciso-serratis extimis confluentibus, corymbo composito. 24 . In sylvis montosis et lapidosis Alpium Sabaudiæ; Delphinatûs, Pedemontii.

3275. Nana. Foliis pinuatis villosis, pinnis dentatis linearibus, radicalibus petiolatis bipinnatis, caule simplicissimo. $2[$. In saxosis editiorum Alpium.

32;6. MLoschata: Foliis pectinato-pinnatis glabris, pinnis lincaribus 
obtnsiusculis integerrimis punctatis. 2 . Inter lapides et saxa cditiormu Alpinm.

3277. Atrata. loliis pectinato-pinnatis glabris, pinnis linearibus acuminatis subtripartitis, cyma simplici, pedunculis pulsescentilons, canls: simplicissimo. $\mathcal{F}$. In Alpibas editioribus Sabuadix et Pedemontii.

32-8. T'anacetifolia. Foliis bipinnatifidis, laciniis lanceolatis serratis, corymbo composito vatulo. 2 . In sylvis pratisque montosis Alpium Galloprovincix, Pedemontii, Dclphinatûs.

3279. Compacta. Foliis bipinnatifulis, laciniis lanceolatis incisoserratis, rachi foliacea integra, corymbis fastigiatis compositis. $\mathcal{~}$. In sylvis montusis Pedemontii, Deḷplinatûs, Juı assi.

328o. Millefolium. Foliis bipinnatis glabrinsenlis, pinnarum laciniis linearibus dentatis. 2 . Ad vias et in arvis frequens.

328 . Ligustica. Ioliis bipinnatifidis, laciniis linearibns argutè serratis, rachi alata integerrima, corymbo composito fastigiato. $\mathcal{H}$. In Pedemontanis collibus.

3283. Nobilis. Foliis caulinis bipinnatifidis, laciniis linearibus subdentatis, rachi alata dentata, radicalibus triplicato - pinnatifidis, corymbo composito fastigiato. 2 . In campis siccis et collibus Galliæ australis.

$$
\text { 550. В } \mathbf{U} \text { P }
$$

Involucrum imbricatum ; flores radiati, flosculis hermaphroditis , ligulis femincis fertilibus; receptaculum paleaceum; semina pappo membranaceo obsoleto coronata, ligularum lateribus nembranacea.

\section{§. I. Involucro foliaceo bracteiformi.}

32.83 Spinosum. Foliis alternis oblongo-lanceolatis amplexicanlibus integerrimis hirsutis, involucris foliosis mucronatis. $\odot$. Ad margines agrorum, in Gallia Mediterranea.

329 भ. Aquaticunt. Involucris obtusè foliosis sessilibus alaribus, foliis oblongis obtusis alternis subintegerrimis, canle dichotomo. $\odot$. Secns aquas Monspelii, Cettæ, Massiliæ, Nicæx.

3285. Maritimum. Involucris obtusè foliosis pedunculatis, foliis alternis spathulatis, canle herbaceo. 4 . In ntaritimis Nicææ, Massiliæ.

\section{§. II. Invoiucro brevi' subsquanıoso.}

3286. Salicifolium. Foliis alternis oblongo-lanceolatis subserratis, involucris nudis. 2 . Ad radices montium Arvernix et Gallix australis.

$$
\text { 55I. B I D E N S. }
$$

Inrolucrum caliculatum, foliolis extcrioribus longioribus patulis ; receptaculum planum, pileaceum, flores plerùmque flosculosi, flosculis omnibus hermaphrotitis, rard radiatis, ligulis nunc femincis, nunc liermaphroditis; senina $2-5$ aristis persistentibus coronata.

3287. Tripartita. Floribus flosculosis bractcatis, bracteis flore majoribus, foliis tripartitis, foliolis lanceolatis dentatis. $\odot$. In fossis et aquaticis frequens. 
328s. Cernua. Floribns terminalibus subnutantibus, bracteis lan $=$ ceolatis integris, foliis subconnatis ovato-lanceolatis serratis. $\odot$ : In fossis humidis, ad fontes. - V ariat radiata et flosculosa.

\section{H E L I A $\mathbf{N}$ T}

Involucrum inbricatum, foliolis patulis vel reflexis ; receptaculum latum, paleaceunı; flores radiati, flosculis liermapluroditis, in medio ventricosis, ligulis sterilibus; semina aristis 2 mollibus et caducis coronata.

$3_{2} \mathrm{~S}_{9}$. Annuus. Foliis omnibus cordatis trinervatis hirtis, pedunculis incrassatis, floribus cernuis. $\odot$. E Peruvia ortus, in hortis cultus.

329o. Tuberosus. Foliis triplinerviis scabris acnminatis, inferioribus cordato-ovatis, superioribus ovatis in petiolum decurrentibus, foliolis involucri ciliatis. $\mathcal{F}$. E Brasilia ortus, in hortis cultus.

3291. Mlultiflorus. Foliis triplinerviis scabris, inferioribus cordatis; superioribus ovatis acutis, involucri foliolis lanceolatis vix ciliatis. .7. E Virginia ortus, in hortis cultus.

\section{O F D O L V I I I. D I P S A E AE.}

Flores in receptaculo communi aggregati, involucro polyphyllo cincti; calix duplex, uterque persistens, ovario non adhærens; interni ovariurn arcte-cingentislimbus membranaccus ant papposus; corolla apice calicis interni inserta, monopetala, tubulosa, 4-5-loba, sæp̀ irregularis; stamina ino tubo adnata, lobis corollæ numero xqualia et iistem alterna; ovarium intrà calicem apice coarctatum ; stylus I; semen calicibus tectum ; perispermum carnosum ; corculum sectum; radicula supera ; cotyledones oblongæ. - Herbæ opposilifolice.

\section{D I P S i c U s.}

Receptaculum paleaceum, paleis spinosis; calix duplex, margine integer; corolla 4-Joba; stamina 4, exserta; semen angulosum.

$329^{2}$. Sylvestris. Foliis subconnatis serratis, paleis rectis. $ठ$. Ad vias et sepes.

329.3. Fullonum. Foliis subconnatis serratis, paleis uncinatis. $\delta$. In agris passim cultus.

3291. Laciniatus. Foliis connatis sinnatis vel laciniatis. O. In Alsa- Lia, Burgundia, propè Nannetes, Gratianopolim, Taurinum.

3205. Pilosus. Foliis petiolatis appendiculatis. 8 . Ad sepes et fossas humidas.

$$
\text { 554. S C A B I o s A. }
$$

Receptaculum pilis vel paleis hirtum; calix duplex, nterque varië divisns; corolla $;-5$-loba, inæqualis; stamina $4-5$; semen utroque coronatum calice, interiore aristaio aut rarius plumoso, exteriore sæpi membranaceo scarioso.

\section{j. I. Corollulis 4 -fidis.}

32n60: Alpina. Coro!lulis 4-fidis xrralibus, receptaculi palcis exte 
rioribus acutis villosis, floribus ceruuis, foliis pinnatis, foliulis lin-

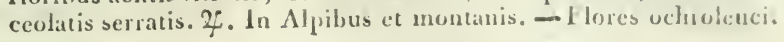

3297. Centaumides. Corollulis 4 -fidis inarualihus, receptaculi paleis exterioribus obtusis, foliis ralicalibus integris petiolatis, caulinis decussive piunatis. 2 . In Alpibus $\mathrm{G}$ allopinovincix. - Flores ochroleuci.

3298. Leucantha. Corollulis 4 -fidis subrqualibus, squamis involucri ovatis imbricatis pubescentibus, tolis pimatifidis. 2 . In montosis Gallize Mediterranex.

3299. Transylvanica. Corollulis q-fidis aqualibus, calicibus paleisque aristatis, foliis radicalibus ly ratis, caulinis pinnatifidis. $\odot$. In collibus Pedemontii.

330o. Succisa. Corollulis 4-fidis æqualibus, caule simplici, ramis approximatis, foliis lanceolatis ovatis, caulinis subdentatis, capritulis subglobosis. 2 . In sylvis ct collibus aridis.

33o1. Arvensis. Corollulis 4 -fitlis radiantibus, caule hispido ramoso, foliis pinnacifidis incisis. F. Ad vias, prata et agros. - Var. $\beta$, foliis indivisis.

3302. IJybricla. Corollulis 4 -fidis radiantibus, caule puhescente snbramoso, foliis infurioribus lyratis, lobo ultimo rotundito, superioribus oblongis sessilibus inequaliter dentatis. $\odot$. In pratis et agris Pedemontii circà Sospitello.

33o3. Sylvatica. Corollulis 4 -ficlis radiantibus, foliis omnibus indivisis subconnatis ovato-oblongis serratis, caule hispido. 2 . In sylvaticis montanis.

3304. Inlegrifolia. Corollulis 4-fidis radiantibus, foliis inferioribus spathulatis basi subpinnatifidis, superioribus lanceolatis ciliatis subdentatis. ๑. In arvis Galliæ australis, Monspelii.

\section{II. Corollulis 5-fidis.}

33o5. Columbaria. Corollulis 5-fidis radiantibus, folits radicalibus ovatis crenatis, caulinis pinnatis setaceis; seminibus sulcis 8 insculptis. 2 . In siccis monısis.

3306. I.ucida. Corollulis 5-fidis radiantibus, foliis glabris læribus, inferioribus ovato-lanceolatis serratis, superioribus pinnatifidis, lobis linearibus incisis. $\mathcal{F}$. In montibus Delphinatûs, Galloprovinciæ, Sabaudiæ.

$33 n$. Suaveolens. Corollulis 5 - fidis radiantibus, foliis radicalibus lanceulato - oblongis integerrimis, superioribus pinnatifidis, lobis linearibus integris. 4 . In siccis Fontisbleaudi.

33o8. Pyrenaica. Corollulis 5-fulis radiantibus, foliis tomentosis in-

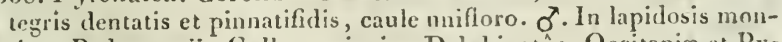
tium Pedemontii, Galloprovinciæ, Delphinatûs, Occitaniæ et Pyrenæorum.

$33 n g$. Ochroleuca. Corollulis 5 -fidis radiantibus, foliis connatis profondè pinnatifidis, laciniis linearibus. $2 \mathrm{~F}$. In pratis siceis Gallis tustrilis. - Flores ochroleuci. 
33ro. Ukranica. Corollnlis 5 -fidis radiantibus, foliis radicalibus pinnatifidis, caulinis linearibus integerrimis basi ciliatis. 4 . In sterilibus Pedemontii.

3311. Atro-purpurea. Corollulis 5-fidis radiantihus, foliis dissectis, receptaculis florun subulatis. $\odot$. Ex India orta, colitur nunc in hortis.

3312. Stellata. Corollulis 5-fidis radiantibus, foliis dissectis, receptaculis florum subrotundis, calicis externi limbo membranaceo, caule ramoso. 4 . In sterilibus maritimis Galloprovinciæ, circì Ničeam.

3313. Simplex. Corollalis 5 -fidis radiantibus, foliis dissectis, receptaculis florum subrotundis, calicis externi limbo nembranaceo, caule simplici unifloro. $\odot$. In Alpibus Galloprovinciæ.

33r4. Graminifolia. Corollnlis 5-fidis radiantibus, foliis linearilauceolatis integerrimis, caule herbaceo. 4 . In montibus Galloprovinciæ, Delphinatûs, Pedemontii.

\section{O R D O L I X. V ALER I A N EAE.}

Calix ovario adharens, limbo nunc papposo intùs revoluto, nunc dentato erecto; corolla tubulosa, apice ovarii inserta, 5-loba, sæp inæqualis; stamina $1-5$, tubo corollæ inserta; stylus 1 ; stigmata I-3; capsula non dehiscens, I-3-locularis, loculis nonospermis, sæpè abortivis; perispermum nullum; corculum rectum; radicula supera. - Herbæ oppositifolice, floribus eorymbosis aut subpaniculatis.

$$
\text { 555. V A L E R I A N A. }
$$

Calicis limbns intìs revolntus, demùm in pappum plumosum evolutus; corolla ecalcarata, subinæqualis ; stamina 3 , rariùs solitaria aue abortiva ; capsula I-locularis.

33 5. O Ficinalis. Foliis omnibus pinnatis, pinnis dentatis. 4 . In humutis et sylvis.

33,6. Phu. Foliis caulinis pinnatis, radicalibus indivisis. 2 . In montibus Alsatiæ.

3317 Prenaica. Foliis caulinis cordatis dentatis petiolatis, summis ternatis, foliolo terminali maximo. 4 . In umbrosis Pyrenæ: $\mathbf{x}$ im.

33,8. Tripteris. Foliis dentatis, radicalibus cordatis, caulinis ternatis ovato-oblongis. $₹$. In montibus et Alpibus.

33 in. Montana. Foliis ovato-oblongis subdentatis, caule simplici. 24. In montibus.

3320. Tuठerns $\pi$. Foliis radicalibus lanceolacis subpetiolatis integerrimis, caulinis pinnatifidis, lobis linearibus. 4 . In montibus Galloprovincix, Occitanix, Pedemontii. Hepledwionem.

332r. Globulariafnlin. Foliis radicalibus ovatis petiolatis integris obtusis, canlinis pinnatifidis, lobis oblongo-linearibus. $2^{\circ}$. In saxosis editiornm Pyrenæorum.-V.heterophylla. Lois, Fl. gall. 2 I. 
3322. Celtica. Foliis radicalibus ovato-oblongis integris obtusis, caulinis linearibus olusis, floribus verticillatu racemosis. 2 . In saxosis Alpium Vallesiæ, Delphinatûs, Pedesuontii.

3333. Supina. Foliis radicalibus oblongis integris obtusis, caulinis Janceolato-linearibus, floribus subcapitatis bracteato-involucratis. 24. In saxosis Alpiunı, Peclemontii et Delphinatûs.

3324. Saxatilis. Foliis subdentatis, radicalibus ovatis margine ciliatis trinerviis, cauliuis lincari-lanceolatis sessilibus integris. 2 . Circà Nicæam.

3325. Dioica. Floribus dioicis, foliis radicalibus petiolatis ovatis, caulinis pinnatis, pinnis integerrinis: 4 . In paludosis et pratis humidis.

3326. Calcitrapa. Floribus monandris, foliis pinnatifidis. $\odot$. In sterilibus Galloprovincix, circà Nicæam.

$$
\text { 556. C E N T R A N T H U S. }
$$

Corolla basi calcarata; stamen 1. Catera ut in Valeriana.

3327. Ruber. Foliis ovato-lanceolatis. F. In lapidosis et maritimis Galliæ australis.

3328. Angustifolius. Foliis linearibus. \%. In saxosis montium Burgundiæ, Jurassi et Alpium.

$$
\text { 557. F E D I A. }
$$

Calicis limbus erectus, lobis 2 emarginatis; corolla ecalcarata, 5 -loba, inæqualis; stamina 2 ; ovarium 3-loculare; capsula carnosa, 3-locularis, loculis 2 abortivis.

3329. Cornu-copice. Foliis ovato-obtusis sessilibus subintegris. $\odot$. Circà Nicæam.

\section{V A L E R I A N E L L A.}

Calicis limbus minimus, 5-dentatus; corolla ecalcarata, 5-loba, irregularis; stamina 3; capsula 3-locularis, loculis 2 sæpè abortivis.

333n. Olitoria. Canle dichotomo, foliis lanceolatis integerrimis, fructu nudo. $\odot$. In cultis ad vineas et agros.

333т. Dentata. Caule dichotomo, foliis lanceolatis integerrimis, fructu 3-dentato, dentibus binis brevissimis. $\odot$. Inter segetes.

3332. Vesicaria. Caule dichotomo, foliis lanceolatis dentatis, fructa inflato globoso. $\odot$. Circà Nions in Delphinatu?

3333. Cornnala. Canle dichotomn, foliis lanceolatis dentatis, fructu 6-dentato. $\odot$. In arvis Galliæ australis, propè Aureliam.

3334. Echinata. Foliis dentatis, fructu lineari 3-dentato, dente extimo majore recurvato, floribus regularibus. $\odot$. In arvis Gallix australis, in Limania Arverniæ.

3335. Punila. Canle diclıotomo, foliis imis dentatis, summis lincaribus multifidis, fructu nudo. $\odot$. Monspelii. 


\section{OR D O L Y. RU B I A C E AE.}

Calix ovario adherens, 4-5-lobns; corolla regularis, ovario in-

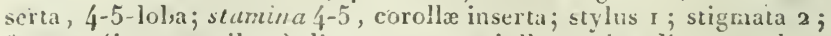
fructus (in nostratibus) dispermus, seminibus subnudis; corculun rectum in perispermo corneo; radicula infera; cotyledunes foliaceæ. - Rubiaceæ nostrates lerhx, radicibus rubescentibus, foliis integris verticillatis.

$$
\text { 559. S H E R A R D I A. }
$$

Corolla infundibuliformis, 4-fidus; fructus calicinis dentibus persistentibus et accretis coronatus.

3336. Arvensis. Foliis senis, floribus sessilibas terminalibus umbellatis. $\odot$. In arvis.

\section{0: A S P E R U t A.}

Corolla infundibuliformis, 3-vel-sæpiùs-4-fida; baccǽ 2 siccæ, calicis limbo non coronatæ.

333 - Arvensis. Foliis senis vel octonis obtusis, floribus terminalibus sessilibus aggregatis, bracteis ciliatis. $\odot$. In arvis.

3338. Hirta. Foliis senis hirtis acutis internodio longioribus, floribus terminalibus aggregatis sessilibus bracteas superantibus. $2 \mathcal{L}$. In saxosis editiorum Pyrenæorum.

3339. Hexaphylla. Foliis senis rigidiusculis glabris lavibus linearibus, floribus umbellatis terminalibus subsessilibus bracteas superantibus. $2 \mathcal{H}$. In saxosis suprà Tendam.

33 fo. Orlorata. Foliis octonis lanceolatis, florum fasciculis pedunculatis, fructibus hirsutis. 2 . In sylvis et umbrosis.

33ł1. Taurina. Foliis quaternis ovato-lanceolatis trinerviis, floribus polygamis fasciculatis vel verticillatis terminalibus. 2 . In montosis et umbrosis Pedemontii, Delphinatûs, Monspelii.

33ł2. Tinctoria. Foliis linearibus, inferiorihus senis, intermediis gnaternis, canle flaccido, floribus mmbellatis petiolatis, floribus plerisque 3 -fidis. $\mathcal{F}$. In collibus aridis et lapidosis.

3. \}. Cynanchica. Foliis quatemis linearibus, superioribus opposicis, canle erecto firmo, floribus 4 -firlis. $2 \mathrm{C}$. In collibus lapidosis ct pratis aridis. - An prioris varietas?

33 个. Lavigata. Foliis quaternis ellipticis uninerviis lavibus, fructibus scabris. 2 . In montibus Lugdunensibus, circà Narbonem, Airgentoraium.

$$
\text { 56I. c R U c I A } \mathbf{N} \text { E } \mathbf{L} \text { L } \mathbf{A} \text {. }
$$

Corolla infundibuliformis, tubo gracili, limbo brevi 4 -5-fido; calicis lacinia 2 oppositæ profunda; fructus calice non coronatas.

33:. Ansusifolin. Erecta, foliis senis linearibus, floribus spicatis. $\odot$. In siccis arenosis et lapidosis Gallix australis.

$33^{\prime}$ i. Latifoliu. Procumbens, foliis quaternis lanccolatis, foribis 
spicatis. $\odot$. In siccis et sterilibus Nicæx, Galloprovinciæ, Occitanix.

3347. Monspeliaca. Procumbens, foliis acutis, caulinis 'fnaternis ovatis, rameis quinis linearibns, floribus spicatis. $\odot . \ln$ silbulosib circit Nicxanı, Monspelium, Monteut-Albanum, Viennam.

33 9 . Maritima. Procumbens suffruticosa, foliis quaternis mucronatis, floribus oppositis 5-fidis. b. In sabulosis maritimis Gialloprovincia et Occitanix.

$$
\text { 56i2. G A L I U M. }
$$

Corolla rotata aut campanulata, 4 -fida; fructus calice non coronatus.

\section{§. I. Fructu glabro non tuberculoso:}

\section{* Florilus luteis.}

33ł9. Verum. Foliis suboctonis linearibus sulcatis, ramis floriferi\& brevibus. 24. In pratis ad sepes et vias.

335o. Megalospermum. Foliis senis lanceolatis acuminatis margine hispirlis, peduneulis geminatis terminalibus, caule ramosissino prostrato. - $-a$, In monte Cenisio ; $\beta$ ( $G$. arenarium. Lois. Fl. gall. S5.), in arenosis maritinis à Bayona aul Nanuetes.

335 . Cruciata. Foliis quaternis trinerviis hirsutis, floribus polygamis quadrifidis, pedunculis diphyllis. 2 . Ad sepes et vias.

3352. Pedementanum. Foliis quaternis hirsutis, floribus polygamis 4 -fidis, pedunculis 3 - 4 -floris aphyllis. $\odot$. In sterilibus $\mathrm{Pc}-$ demontii.

3353. Vernum. Foliis ovalibus quaternis snbrigitlis trinerviis ciliatis, floribus polygamis 4 -fidis, pedunculis dichotomis aphyllis. భ. In montosis et umbrosis Pyrenæorum et Pedemontii.

\section{** Floribus rubris.}

3354. Rubrum. Foliis quinis senisve linearibus patulis margine scabris, floribus subterminalibus, pedunculis brevissimis, caule ramosissimo. - In collibus aridioribus Galloprovinciæ.

3355. Purpureum. Foliis quinis senisve lineari-setaceis, pedunculis ramosis capillaribus folio longioribus. $\mathcal{Y}$. In Pedemontio ad oras sylvarum et in collibus.

$$
\text { *** Floribus allis. }
$$

3356. Sylvaticum. Foliis octonis ellipticis lævibus subtus scal)ris, floralibus binis, pedunculis capillaribus, caule lævi tảmosissimo tereti geniculis tumido. 2 . In Alsatia, Delphinatu et Parisiis.

3357. Linifolium. Foliis suboctonis lanceolato-linearibus glaberrimis, predunculis paniculatis capillaribus, caule tereti. $F^{\text {. In un- }}$ brosis Delphinatûs, Galloprovincix et circà Genevaln.

3358. Glaucum. Foliis senis ant octonis subtùs glincis lincaribus snhmucronatis margine revolutis, pedunculis dichotomis, canle Jevi subtereti adscendente. 2L. In lapidosis umbrosis Gulloprovinkixe, Pedemontii, Delphinatû̀, Genevæ. 
335. Rubioides. Foliis quaternis lanceolato-ovatis rigidis trinerviis, margine nervisque hispidis, caule erecto. $\mathcal{F}$. In pratis Vallesiæ inferioris, in Palatinatu circì Latiteren.

336o. Palustre. Foliis quaternis senisve obovatis obtusis inæqualibus, caule diffuso $\{$-gono. 2 . In pratis humidis et ad marginem fossarum et rivorum.

336r. Mollugo. Foliis octonis ovato-linearibus subserratis patentissimis mucronatis, caule flaccido anguloso ramoso, ramis patentibus. 24. Ad sepes et vias humidas frequens.

3362. Erectum. Foliis senis octonisve lanceolatis margine aculeatoserrulatis mucronatis, panicnlis trichotomis, canle lævinsculo flaccido. $\Varangle$. In pratis hmmidis montosis Pyrenæorum, Dclphinatûs, Galloprovinciæ, Pedemontii.

3363. Aris!atum. Foliis octonis lanceolatis læribus mucronatis, panicula capillari, corollæ lobis aristatis, canle tetragono subdebili. 24. In sylvis montosis Galloprovinciæ.

3364. Cineri' $m$. Foliis senis longè ellipticis rigidis serrato-aculeatis subtis glaucis, floribus paniculatis terminalibus, canle sublignoso. 2 . Ad vineas in Pedemontio, in saxis apricis Vallesiæ inferioris.

3365. Tenuifolium. Foliis senis linearibns rigidis snlcatis retrorsùm scabris, floribus terminalibus, pedicellis trichotomis, caule ramoso rigido 4-gono lævi. 4 . In saxosis secus Rhodanum in Delphinatu, in collibus circà Nicæam, Narbonem.

3366. Lave. Foliis subseptenis planis linearibus lavibus mucronatis, floribus subumbellatis, canlibus glabris diffusis adscendentibus. 2. In pascuis montosis et sylvis siccis.

3367. Bocconi. Foliis senis subasperis mucronatis, pednnculis subtrichotomis, caulibus $\{$-gonis prostratis basi pubescentibus. 2 . In saxosis et sylvis montosis circà Parisios, Stampas, Genevam, in Arverniæ montibus.

3368. Mucronatum. Foliis suboctonis scabris linearibus mucronatis, pedunculis ramosis, corolla lobis aristatis, caule adscendente inferne hirto supernè glahro. $\mathcal{F}$. In pascuis submontanis, locis sterilibns, in Pyrenæis, Delphinatu.

3369. Angrlicum. Foliis subsenis lineari-lanceolatis mucronatis margine cauleque scabris, floribus paniculatis terminalibus, pedunculis bifidis ant trifidis. $\odot$. In siccis, lapidosis vel arenosis.

337o. Divaricatum. Foliis subseptenis linearibus hispidis, caule stpernè ramis capillaribus dichotomis et divaricatis paniculato. $\odot$. In arenosis et lapidosis Occitaniæ propè Narbonem.

337 r. Uliginosum. Foliis senis lanceolatis retrorsùm serrato-actrleatis mucronatis rigidis, caulis angulis aculeato-scabris. $\mathcal{4}$. In turfosis paladosis circà Genevam, Hunningam, Parisios.

3372. Supinum. Foliis subsenis lineari-lanceolatis mucronatis subasperis, caulibus prostratis ramosissimis. $2 \mathcal{H}$. In aridis et lapidosis.

33-3. Pyrenaicum. Foliis scnis linearibus acutissimis erectis niti- 
dnlis basi tumidis, floribus axillaribus solitariis suhsessililus, cau libus suleatis flaccidis. 24. In P'yrenzeis et in Jelphinatu.

337f. Pumilum. Ioliis subseptenis lincari-setaceis subtis hisuleatis levibus, floribus pedunculatis subumbellatis. 24. In saxosis Pyrenæorum et $\mathbf{A}$ lpinm Pedemontii.

3375. Saxatile. Foliis senis obovatis obusis, canle ramosissino) procumbente. 2f. In saxosis editiormu Pyrenæuı um et Alpium Pedemontii.

\section{§. II. Fructu glabro tuberculoso.}

33-6. Harcynicum. Foliis subsenis obovatis acutis, caule procumbeute, ramis confertis clongatis, pedunculis multifloris. $2 \zeta$. In montosis siccis circà Hunniugam, Lausanuze, in Pyrenæis el Vogesis.

3377. Spurium. Foliis senis lanceolatis carinatis scabris retrorsum aculcatis, pedunenlis fructiferis recurvis folio longioribus. $\odot$. In locis cultis frequens.

3378. Tricorne. Foliis suboctonis lanceolatis margine retrorsùm aculeatis, pedunculis axillaribus trifloris, fructibus nutantibus. $\odot$. In arvis et locis cultis frequens.

3379. Saccharatum . Foliis subseptenis linearibus patulis margine autrersùm aculeato-scabris, floribus polygamis, pedunculis apice trifloris. $\odot$. In locis cultis.

\section{III. Fructu pilis hirto.}

338o. Aparine. Foliis octonis lanceolatis carinis scabris retrorsum aculeatis, geniculis villosis, fructuum pilis uncinatis, caule ramoso. $\odot$. In arvis, ad sepes et vineas.

338r. Vaillantii. Foliis octonis lanceolatis carinis scabris retrorsùm aculeatis, geniculis subvillosis, fructuum pilis uncinatis, caule simplici. $\odot$. Circa Parisios in locis cultis.

33S2. Litigiosun . Foliis quaternis senisve linearibus, pedunculis divaricatis capillaribus subtrichotomis, fructu hispido, caule debili ramoso. $\odot$. In locis siccis, ad muros et vias, circà lacum Lemanum.

3383. Murale. Foliis inferioribus senis, mediis quaternis, summis binis linearibus, ramis simplicibus, floribus verticillatis subsessilibus, fructu ovoideo hispido. $\odot$. Ad muros et in sterilibus Gallia australioris.

3384. Maritimum. Foliis verticillatis lanceolato-ovatis hispidis senis quaternis et binis, pednnenlis unifloris, caule basi repente hirto. \&. In Pyrenæis, Nonspelii, Nicææ.

3385. Boreale. Foliis quaternis lanceolatis trinerviis glabris, caule erecto, frnctibus hispidis subsquamosis. $\mathcal{F}_{i}$ In montosis et lapidosis ad sepes.

3386. Rotundifolium. Foliis quaternis subrotundo-ovatis trinerviis hispido-ciliatis, caule decumbente, fructibus hispidis. 4 . In sylvis umbrosis montium. 


\section{V A I J L A A N T I A.}

Corolla campanulata, 3-f-fida; frnctus 3-cornis.

3387. Muralis. Glabra, foliis quaternis, floribus polygamis, maș culis trifidis. $\odot$. Ad rupes et nuros Gallix Nediterranex.

$$
\text { 564. R U B I A. }
$$

Corolla campanulato-patens, 4 5-loba; stamina 4-5; baccæ 2 , glabı . snbrotundx.

33SS. Tinctorum. Foliis annuis subsenis, coroll subcal!osis, caule scalıro. $2 F$. In arenosis Monspelii, etc.; colitur. in Alsatia, Eelgio, etc.

3359. Peregrina. Eoliis perennantibus subsenis, corollæ lobis mucronato-aristatis, caule seabṛo. 4 . In Delphinatu, circà Lugdunum.

339o. Lucida. Foliis perennantibus quatcynis lacidis, corollæ lobis submucronatis, caule lævi. $\xi^{\circ}$. In sterilibus et saxosis circà $\mathrm{Pa}_{\mathbf{a}}$ risios.

\section{O R D O L X I. C A P R I F O L I A E AE.}

Calix opario adhorens, sæpè basi bibracteatus, limbo integro aut diviso; corolla regularis, nunc mononopetala 4-5-fida, nunc 4-5-petala, petalis basi latioribus; stamina corolla lohis numero. iequalia; stylus I aut o; stigma 1-3; bacca aut capsula liubo calicino sæepiùs coronata, mi-aut-multilocularis; corculum in apice perispermi carnosi ; radicula supera. - Frutices foliis oppositis, floribus.sæpiùs corymbosis.

\section{† Calix bracteis cinctus; stylus simplex; corolla monopetala.}

\section{L I N N $\approx$ A.}

Calix 5-filuns, basi cinctus caliculo persistente 4-partito; corolla campanulata, 5-loba; stamina 4, 2 breviora; bacca sicca ovata 3-locularis, loculis 2-spermis.

3391. Borealis. b. In saxosis et umbrosis montinm, in Alpibus.

Vallesiacis, Sabaudis, in Alsatia, circà Monspelium.

$$
\text { 566. L O N I C E } \mathrm{R} \text { A. }
$$

Calix 5-rlentatus; corolla tubulosa, campanulata vel infundibuli= formis, 5-fida, subinæqualis; stamina 5; bacca 1-2-3-locularis, loculis polyspermis.

\section{§. I. Baccis solilariis (CAPRIFOLIUM).}

3392. Caprifolium. Floribus ringentibus verticillatis terminalibus sessilibus, foliis summis connato-perfoliatis. b. Ad sepes et vineas, .. in Gallia australi.

3393. Periclymenum. Floribus ringentibus capitatis terminalibus, foliis omnibus distinctis. b. Ad sepes et in nemoribus. 


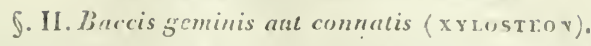

330 f. Nigra. Peduneulis hifloris, barcis distinetis, foliis ellipticis glabris integerrimis. b. In montibus Galloprovincia, Delphinatus, Arvernia, Jurassi, Cenisii.

3395. Aylosteum. Pecunculis biforis, baccis distinctis, foliis ovatis acuminatis integerrimis pubescentibus. b. In tubrosis et sejibus.

3306. Pnrennica. Pedunculis bifloris, baccis distinctis, foliis oblongis glabris, floribns subregularibus. b. In montibus Pedemontii, Gall provincix, in Pyrenæis.

3397. Alpigena. Perlunculis bifloris, baccis coadunatis didymis, foliis ovatoslancenlatis subhirsutis. b. In nontosis et tumbrosis Alsatix, Galloprovinciæ, Delphinatûs, Arverniæ, Sabaudiæ, Segusii.

33g5. Corrulca. Pedunculis biftoris, baccis coarlunatis globosis, stylis indivisis, foliis ovatis. $b$. In sylvis editioribus et montosis Galloprovincix, Delphinatûs, Arvernice, Sabaudiæe et Vogesorum.

\section{$\dagger \dagger$ Calix bracteis cinctus; siylus unicus; corolla} subpolypetala.

\section{7. v I s c U m.}

Monoicum rel dioicum. Calix marginc integro vix prominulo; petala 4 , brevia, basi coalita. Mlasc. Antheræ 4, sessiles, mediis petalis insertæ. Fenı. Ovarium calicis margine coronatum; stigıa 1 ; bacca globosa, I-sperma.

3399. Album. Foliis lanceolatis obtnsis, canle dichotomo, spicis axillaribus. b. In truncis et ramis malorum, quercuum, ulmorum, etc.

340o. Oxycedri. Aphyllum ramosum erectum carnosum hinc indi vaginulis obtectum. - In ramis juniperi oxyecdri.

$\dagger+\dagger$ Calix bracteis cinctus; stylus nullus ; stigmata 5; corolla monopetala.

568. Y I B U $\mathrm{R}$ N U $\mathbf{m}$.

Calix parvus, 5-fidus; corolla campanulata, 5-loba ; stamina 5, laciniis corollæ alterna; bacca monosperma.

\section{S. I. Bacca coronata (Tixus).}

3दor. Tinus. Foliis integerrimis ovatis, ramiticationibus venarum subtùs villoso-glandulosis. 3. In lanidosis et umbrosis Galliæ australis.

\section{f. II. Bacca nuda ( $\mathrm{IBUKN \textrm {M }}$ ).}

3402. Lantana. Foliis cordatis scrratis venosis subtùs tomentosis. b. In lumetis ad sepes.

34o3. Opulus. Foliis glabris trilobis acuminato-dentatis, petiolis glandulosis. Ђ. In nemoribus, ad sepes. 


\section{9 . S А м в U c U s.}

Calix parvus, 5-fidus; corolla rotata, 5-luba; stamina 5, laciniis corolia aiterna; baced 1 -locularis, 3-sperma.

34o\%. Ehulus. Cymis 3-partitis, stipnlis foliaceis, caule herbaceo. 2. Ad margine's viarum et fossarun humidarum.

3fo5. Nigra. Cymis 5-partitis, caule arboreo. 1). Ad sepes, in solo subhumido.

3406. Racenosa. Racemis compositis ovatis, canle arboreo. b. In montosis Alsatiæ, Galloprovinciæ, Jurassi, Segusii.

†††† Calix ehracteatus; stylus I; corolla polypetala.

$$
\text { 570. C o R N U s. }
$$

Calix 4 -dentatus; petala 4 ; stamina 4 , petalis alterna; drupa non coronata, foeta nuce 2 -loculari 2-sperima.

340\%. Mas. Arborea, umbellis involncrum æquantibus, antè folia nascentibus. ๖. In nemoribus et ad sepes

34o8. Sanguinea. Arborea, ramis erectis, foliis ovatis, cymis depressis. b. Ad sepes et in sylvis.

$$
\text { 57 I. H E D E R A. }
$$

Calix 5-dentatus; petala 5; stamina 5, iisdem alterna; antheræ basi bifurcatæ; bacca 5 -locularis, loculis 1 -spermis, sepimentis in maturitate obliteratis.

3409. Helix. Foliis quinquangularibus 5-lobisque, floralibus oratis, umbella erecta. ๖. In sylvis ad sepes et antiquos muros.

\section{OR D O L XII. U M B E L L I E R AE.}

Calix ovario adharens, limbo 5-dentato, aut integro subullo; petala 5 ovario aut glandulx ovarium tegenti inserta; stamina 5 , petalis alterna et cum iisdem inserta ; styli 2 , sæpiùs persistentes, divarieati; fructus scissione bipartibulis constans ex duabus akenis nempi seminibus calice adhærentibus, superiùs propendentibus ex axe filiformi, primùn coalitis, demùm à basi ad apicem segregatis; corculum minimum ad apicem perispermi lignosi; radicula supera. - Herbæ foliis alternis, sæpiùs decompositis; floribus umbellatis aut rarissimè capitatis, involucro et involucello sæpiùs cinctis.

\section{† Unbelliferce verce floribus albidis aut purpuras- centibus.}

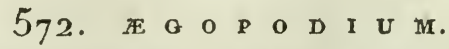

Calix integer; petala inflexo-cordata, inequalia ; fructus ovalioblongus utrinque $3-5$-costatts ; involucrun involucellaque nulla.

3.10. Podagraria. Foliis caulinis summis termatis ovatis. $\mathcal{F}$. Ad sepes et in pomariis. 


\section{U M B E L L I F E R R: \\ 573. Р 1 M $\mathbf{P}$ Y N F. L I, $\Lambda$ :}

Calix integer; petala integra, inflexo-cordata, subxqualia; fructus ovali-oblongus, striatus; involucrum involucellay ae nulld.

3411. Saxifraga. Foliis radicalibus piunatis, foliolis subrotundio argutè dentatis, eanlinis bipinnatis lineariluss. $2 f$. In pascnis siceis.

3ł1 . Magna. Foliis subuniformibus pinnatis, foliolis omuibus Iol)atis, impari tribbo. 4 . In locis incultis et all oras sylvarum.

3ł13. Dissecta. Voliis omnibus pinnatis, pinnis multipartitis, segmentis sublinearibus acutis. 2 . In sabulosis aridis.

$3413^{*}$. Tragium. Foliis piunatis erectis, foliolis cuncatis incisis, summis simplicibus, fructibus hirsutis. Vilk. Delph. 2. p. 6o5. 24. In Delphinatn ail Judem montis ( $\boldsymbol{S} t .-J u s t)$.

34r4. Disica. Pumila, umbellis numerosissimis simplicibus compositisque, radice fusiformi, foliis multifidis linearibus. $\sigma^{\top}$. Inter saxa montana.

$$
\text { 574. S E S E I I. }
$$

Calix integer; petala æqualia, inflexo-cordata ; fructus parvns, ovatus, striatus; semina intùs concava; involucrum nullum.

3415. Hippomarathrum. Involucellis connato-monophyllis. 2 . Inter saxa, in Pedemontii provincia Canapicensi.

3416. Annuum. Foliorum vaginis emarginatis, involucellis umbellulis longioribus. $\odot$, Linn. $\sigma^{\top}, \mathrm{Cr} .24, \mathrm{~V}$ ill. Ad rupes et in pratis siccis.

34r . Montanum. Foliorum vaginis integris, foliis glaucis, radicalibus bipinnatis, caulinis angustissimis. $\mathcal{C}$. In montanis aridis.

3418.' Elatum. Canle elongato, geniculis callosis, foliis bipinnatis, foliolis angustis lincaribus, fructibus scabris. $\sigma$. In mpntanis et ad oras sylvarum.

$3418^{*}$. Saxifragum. Caule filiformi divaricato, foliis duplicatoternatis linearibus, umbellis subsexfidis. 2 . Lin. spec. 374 . C. Bauh. prod. 8f. - Ad lacum Lemanum, circà Novidunum.

34i9. Tortunsum. Caule rigido divaricato ramosissimo. $\mathcal{F}$. Inter saxa Galliæ meridionalis.

3420. Carvi. Foliis bipinnatis, foliolis decussatis, involncro monophyllo, petalis bifidis. $\sigma$. In pratis montanis.

$$
\text { 575. I M P E R A T } \mathbf{T} \text { O } \mathrm{R} \text { I A. }
$$

Calix integer ; petala inflexo-emarginata, subæqualia ; fructns compressus, ellipticns, margine cinctus, utrinquẻ 3 -costatus; involucrum nullum.

3421. Ostruthium. Foliis ternatis, foliolis trilobis. 2 . In pascuis montanis.

3422. Sylvestris. Foliis bipinnatis, foliolis ovatis serratis, vagina ventricosa. 24. In locis humidis et oris rivulorum frequens.

3423. Verticillaris. Foliis tripinnatis, foliolis ovato-deltoideis, ramis verticillatis. 2 . In Pedemontio, circà Terdonam et Aquas Staticllas. 
3 手. Nodifora. Foliis ter aut quater ternatis, ramis verticillatoparriculatis. 2C. In umbrosis Delphiuatûs, Pedemontii.

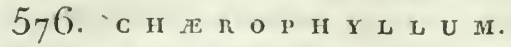

Calix integer; petala emarginata, inæqualia; fruetus oblongus aut cylindricus, slaber, striatus aut lævis; involucrum nullum.

\section{§. I. Fructibus lavibus.}

3f25. Sylvestre. Canle ramoso, geniculis tumidiusculis, foliolis laciniisque approximatis. $\mathcal{H}$. In pratis et ad sepes frequens.

2426. Alpinum. Caule subsimplici, geniculis tumidiusculis, foliolis laciniisque distantibus. $2 \mathcal{F}$. In lapidosis montanis Delphinatûs et Galloprovincix.

3427. Sativum. Umbellis lateralibus subsessilibus. $\odot$. In hortis cultum.

\section{j. II. Fruclu strialo.}

3 . 2 S. Aureum. Caule equali, foliolis incisis, scminibus sulcatis coloratis, stylis divaricatis. 2 . In umbrosis montanis.

3 fag. Hirsulum. Caule æquali, foliolis incisis, seminibus striatis, stylis snbparallelis. $\mathcal{F}$. In humidis montanis.

3.j3). Odoratum. Seminibus profundè sulcatis costis membranaceis. 24. In pratis montanis.

-3łз r. Tenulum. Caule maculato scabro, geniculis tumidiusculis. 24. In locis incultis et sepibns.

$$
\text { 577. S C A I D I x. }
$$

Calix integer ; petala inæqualia, emarginata; fructus tenuiter striatus, subhispidus, rostro longissimo subulato terminatus; involucrum nullum.

3'́32. Pecten Veneris. Foliolis multifidis, seminibus inter costus glabris, rostro compresso dorso glabro. $\odot$. Inter segetes frequens.

3433. Australis. Foliolis multifidis, seminibus inter costas hispidis, rostro attenuato dorso hispido. $\odot$. Locis aridis in provinciis mediterraneis.

$$
\text { 578. c o }
$$

Calix 5-dentatus; petala inflexo-cordata, extcrioribus majoribus ; fructus sphæricus aut didymus, seminibus subsphæricis; involucrum nullum aut $\mathrm{r}$-phyllum.

343 \% Salivume. Fructibus globosis. $\odot$. In agris.

3435. Testiculatum. Fructibus didymis. $\odot$. Inter segetes in provinciis mediterraneis.

$$
\text { 579. 死 } \mathbf{T} \text { H U S A. }
$$

Calix integer ; petala inæqualia, inflexo-cordata; fructus ovatus aut oblongus, striatus aut sulcatus; involucella dinidiata, deflexa ; involucrum nullum aut $\mathbf{1 - 2 - p h y l l u m . ~}$

3\}36. Cynapium. Foliis conformibus. $\odot$. In locis cultis frequens. 
3437 . Bunius. Foliis rarlicalibus pinnatis, canlinis multipartico-sezaccis. 5 ? $\odot$ ? In lapidosis provinciarum australiorum.

$$
\text { 580. C I C }
$$

Calix integer; petala ovata integra, apice inflexa subroqualia ; frucens ovatus, sulcatus; senina convexa, 5-costata; involucrum nullume ant x-phyllum.

3438. Aquatica. Unbellis oppositifoliis, vaginis obtusis. F. Ad stagna et lossas aquosas.

$$
58 \text { I. E. N A N T IT E. }
$$

Calix tenuiter 5 - dentatus; petala disci inflexo-cordata subxerualia, radii maxima difformia; fructus oblongus aut ovatus, sulcatus, calice coronatus.

3439. Plecllandrium. Foliis 3-pinnatis, pinnulis laciniisque divaricatis. 24 . In stagnis et fossis aquosis.

34fo. Fistulosa. Radice repente, petiolis fistulosis, umbella pauciradiata. 2 . In paludibus frequeus.

3ұłr. Globulosa. Radice fusiformi raunsa, foliolis omnibus linearibus, fructibus in capitulum glohosum aggregatis. 2\%. In stagnis provinciarum australiorum.

3łł 2 Pencedanifolia. Tuberibus radicalibus ellipticis, foliolis omnibus linearibus, involucro subnullo, fructibus cylindricis. $\mathcal{F}$. In fossis et paludibus.

34ł3. Pimpinelloirles. Foliolis radicalibus cuncatis fissis, canlinis linearibus integerrimis clongatis, involucro polyphyllo lineari. 4 . In pratis paludosis.

3444. Crocata. Foliolis omnibus cuneatis multifidis subrqualibas, iuvolucro polyphyllo. 2 . In aquosis et ad ripas fluviorum.

\section{2 . B U B}

Calix subinteger; petala lanceolata, incurva, snbxqualia ; fractus ovatus, striatus, villosus.

3445. Mncedonicun. Caule herbaceo ramosissimo pubescente, foliolis rhombeo-ovatis, umbellis numerosissimis. $\sigma$. In pratis siccioribus circà Nicæam.

\section{S I U $\mathbf{M}$.}

Calix subinteger; petala lancealata aut cordata, inflexa; fractus ovatus aut oblongus, glaber, striatus.

\section{I. Petalis obcordatis.}

3446. Latifolium. Caule erceto, foliis pinnatis, foliolis oblongo-lanceolatis æqualiter serratis. 2 . Ad sepes et in paludosis.

3447. Angustifolium. Caule erecto, foliolis inæqualiter lobatis serratisque, umbellis pedunculatis oppositifoliis. 4 . In rivulis fussisque.

$$
\mathbf{V}_{2}
$$


344 . Nodiflorum. Canle procumbente, foliis pinnatis, foliolis oratolanceolatis, umbellis oppositifoliis sessilibus. $2 F$. In rivulis et margine fluviorum.

3419. Repens. Caule repente, foliolis subrotundis dentato-incisis, unbellis pedunculatis oppositifoliis. $\mathcal{F}$. In paludibus et inundatis turfosis.

3450. Sisarum. Caule erccto, foliis pinnatis, floralibus ternatis. 2 . In hortis.

345r. Falcaria. Foliis pinnatis, foliolis linearibns decurrentibus. భ. In arvis ct ad sepes. - Drepanophyllum falcaria. Moench. supl. 2.

3452. Verticillatum. Foliolis multifido-capillaribus subverticillatis. 2. In pratis humidis.

\section{S. II. Petalis lanceolatis.}

3153. Internedium. Caule procumbente gracili, foliolis profunde tripartitis subverticillatis. $\odot$ ? In stagnis circà Aquas Tarbellicas.

3454. Inundatum. Caule repente, foliis inferioribus multipartitocapillaceis, superioribus pinnatifidis, umbellis 2-3-radiatis. $\mathcal{Y}$, Lam. $\sigma^{\prime}$, All. $\odot$, Linn. In fossis et paludibus.

3455. Segetun . Caule erecto, foliis pinnatis, foliolis subrotundis dentatis, umbellulis cernuis. $\delta$. In agris snbhumidis.

3456. Amomum. Canle erecto, foliis pinnatis, foliolis ovatis denticulatis, umbellis erectis. $\sigma^{\top}$. Ad sepes et in glareosis.

$$
\text { 58\%. A N G E L I c A. }
$$

Calix sub-5-dentatus; petala lanceolata, incurva; fructus ovatus rotundusve, angulosus, gliber; semina 5-costata, costis lateralibus majoribus.

$3 \nmid 57$. Archangelica. Foliis hipinnatis, foliolis ovato-lanceolatis, impari lobato. $2 \%$. In montanis circà Taurinum, in Galloprovincia, Alsatia.

3458. Rasoulsii. Foliis 3-pinnatis, folinlis lanceolatis serratis decurrentibus. 27 . In Pyrenzis, Delphinatu, Perlemontio.

3459. Aquilegifolia. Foliis trilobis incisis. $\mathcal{Y}$. In pascnis montanis Galloprovincix.

3460. Levisticum. Foliis 2-3-pinnatis, foliolis cuneatis incisis. 24 . In pascuis montanis australioribus.

$$
\text { 585. L I G U S } \text { T I C U } \mathbf{M} \text {. }
$$

Calix subinteger; petala incurva; fructus oblongus, glaber, costis quinque in utroque semine, prominulis, crassis.

346r. Peloponense. Foliis multiplici-pinnatis, foliolis pinnatis incisis, involucris lanceolatis. 2 . In Alpibus Pedem. Delphin. Prov.

3462. Austriacum. Foliis biternatis, foliolis pinnatifidis incisis, involucris linearibus. 24. Ad aquas in montanis Prov. Delphin. Pedem. Sabaud. 
3463. Apioides. Foliis tripinnatis, foliolis pinnatifulis lincaribus mucronatis, involucris nullis. 2 . In dumetis an pricis 1) elphinatuss.

3464. Fernlacenm. Foliis bipinnatis, folinlis pinnatificlis, laciniis linearihus subcarnosis, involucen polyphyllo pinnatifido. $\mathcal{F}$. In Alpibus Pedemontii, Delplinatus, Galloprovincia.

3465. Pyrenaum. Foliis tripinnatis, foliolis pinuatifulis, Jaciniis linearibus mucronatis, involucris subnullis, senimum costis tribus membranaceis. 2 . In Pyrenxis, $\mathrm{Al}$ pibusque Pedemontii et Delplinatûs.

3466. Tenuifolium. Foliis radicalibus ternatis, foliolis tri-aut-multifidis linearibns, involucro monoplyyllo scarioso, involucellis polyployllis linearibns flores superantibns, umbella pauci-radiata, seminibus 3-costatis. 2 E. E fissuris rupium Pyrensorum editiorum.

3.67. Mutellina. Caule simplici subnudo, involucellis dimidiatis. 24. In pascuis Afpium et montis Aurei.

3.68. Me'um. Foliis 2-3-pinnatis, foliolis capillaribus multifidis, seminibus elongatis. $\mathcal{F}$. In pascuis montanis.

$$
\text { 586. D A N A A. }
$$

Calix subinteger; petala integra, incurva; fructus ovatus, didymus, ex seminibus duobus subrotundis lavibus.

3469. Aquilegifolia. Foliis tritematis, foliolis cuneatis trilobis incisis. $\mathcal{F}$. In collibus lapidosis et subalpinis Pedemontii.

$$
\text { 587. I A s E r } \text { P } \mathbf{I} \text { T } \mathbf{I} \text { U } \mathbf{M} \text {. }
$$

Calix subinteger; petala apice inflexa, patentia, subæqualia; fructus ovatus aut oblongus; semina convexa, costis quatuor membranaceis.

347o. Latifolium. Foliolis obliquè cordatis dentatis, dentibus mucronatis, seminum alis crispis. 4 . In montanis.

347ı. Gallicum. Foliolis cuneiformibus trifidis, laciniis oblongis obtnsinsculis apice calloso-mucronatis. $\%$. In montibus aridis australioribus.

3472. Prutenicum. Foliolis lanceolatis integerrimis, extimis coalitis, caule infernè hispido. $2 \%$; Linn. $\sigma^{\circ}$, All. In dumetis et sylvis Delphin. Pedem. Sabaud. Moguntiæ.

3 -3. Siler. Foliolis lanceolatis integerrimis simplicibus ternatisque, seminum costis obtusis. $\mathcal{F}$. In montibus australioribus.

347'́. Hirsutum. Foliis suprà-decompositis hirsutis, involucri foliolis lanceolatis margine membranaceis apice ciliatis. 2 . In pascuis Alpinis.

3475. Simplex. Caule nudo simplici, foliis pinnatis multifidis acntis linearibus, involucri foliolis plerumquè laciniatis. $\mathcal{F}$. In pascuis Alpinis.

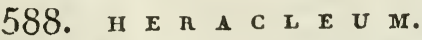

Calix subinteger; petala emarginata, apice inflexa, exterioribus 
radii majoribus bifidis; fructus ellipticus, compressus, striatus, apice ensarginatus; semina margine menbranacea.

3 7 -6. Sphondylium. Foliis pinnatis, foliolis pinnatifidis incisis serratis. 4 . In pratis frequens.

3477. Pyrenaicum. Foliis simplicibus cordato-palmatis subtùs tomentosis albis. $\mathcal{H}$. In pascuis Pyrenæormm.

3. - S. Alpinum. Foliis simplicibus cordatis palmatis subtù glabris. 24. In pascuis et ad oras sylvarmm Aipimn.

3f-9. Minimum. Caule prostrato, foliis bipinnatis, foliolis lanceolatis glabris. 2 . In lapidosis Alpinis Delphinatûs.

$$
\text { 589. С }
$$

Calix integer; petala subæqualia, integra, apice inflexa; fructus ovatus, striatus, cortice fungoso.

3480. Mritimum. Foliis lanceolatis carnosis. $\mathcal{Y}$. Inter saxa maritima, nec non in Pedemontio et Pyrenæis.

\section{5go. A $\mathbf{T}$ H}

Calix integer; petala emarginata, apice inflexa, snbinæqualia; fructus ovalis aut oblongus, striatus, villosus aut pubescens.

348r. Libanotis. Foliis bipinnatis glabris, foliolis pinnatifidis, laciniis oratis acutis. $2 \mathcal{C}$. Ad sylvas in montanis.

$34^{8}$. Cretensis. Foliis tripinnatis, foliolis incisis, laciniis linearibus hirsutis. 2 . In montibus editioribus.

3483. Matthioli. Foliis tripinnatis, foliolis incisis, laciniis linearicapillaceis'glabris. $\mathcal{F}$. Inter saxa montinm Delphinatûs.

$$
59 \mathrm{I} . \quad \text { S E L I N U } \mathrm{M} \text {. }
$$

Petala æqualia, cordata; fructus glaher, ovalis, oblongus rotundusve, compressus; semina 5-costata, costis lateralibus prominulis; involucrum nullum aut polyphyllum.

\section{I. Involucro polyphyllo.}

3484 . Cervaria. Foliolis lanceolatis integris inæqualiter serratis, umbella 8-10-radiata. 2. In lapidosis montanis Alpium;, Jurassi, Alsatix.

3 年5. Orenselinum. Foliolis divaricatis cuneiformibus incisis trifidis pinnatifidisve. 2 . In sylvis et montanis.

3486. Sylvestre. Foliolis pinnatifidis incisis, stylis subparallelis, caule lævi. 2 . In sylvis montanis Arverniæ, Pedemontii, Alsatiæ et circà Moguntiam.

3彳8;. Palustre. Foliolis pinnatifidis, laciniis lineari-lanceolatis, umbella radiis pubescentibus, stylis divaricatis. $\mathcal{\Psi}$. In paludibus et pratis montanis.

3983. Austriacunı. Foliolis ovatis trilohis, Inbis cuneiformibus incisis mucrone albido apice instructis. 2 . In monte Aureo et montibus Delphinatûs. 
3.j.g. Monnieri. Foliolis pinnatifidis incisis, laciniis lincarilns, seminum costis omnilus membranaceis. $\odot$. In provinciis anstralioribus.

\section{II. Involucro nullo.}

3.q9o. Carvifolia. Canle sulcato acutangulo, foliis 3-pinnatis " foliolis numerosis pinnatifidis incisis. $\mathcal{F}^{\circ}$. In sylvis humidis et stagnis umbrosis.

3fọr. Chabreci. Canle tereti striato, foliis pinnatis, foliolis pinnaiifidis, laciniis lincaribus decussatis, umbella 10-radiata, involuccllis 3-phyllis setaccis. $\mathcal{H}$. In pratis, sylvis et dumetis humidis.

3íg?. Dimiliatum. Caule tereti striato, vagina foliornm angusta, foliis pinnatis, foliolis pinnatifidis, nmbella 20 -radiata, invo-

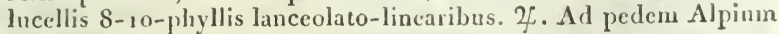
circà Octodurum.

3493. Pyrenaum. Canle tereti striato subnudo subsimplici, umbella $\{$ - 7 -radiata, involucellis polyphyllis setaceis. 24 . In pascuis montanis l'yrenæorum, Arverrix et Vogesorum.

$$
\text { 50. 2. C I C U T A. }
$$

Calix integer; petala inrequalia, inflexo-cordata; fructus subglohosus; semina gibbosa, costis quinque tuberculatis.

3q94. Major. Caule ramoso maculato. $\sigma^{3}$. Ad sepes humidas.

$$
\text { 5g3. в U N I U M. }
$$

Calix integer; petala æqualia, inflexo-cordata; fructus ovali-oblongus, striatus, striarum interstitiis tuberculatis; involucrum nullum aut polyphyllum.

3495. Bulbocastanum. Involucris involucellisque polyphyllis. $2 \digamma$. In arvis et pascuis subhumidis.

3496. Denudatum. Involuccllis nudis. 2 . In pratis montanis Arvernix, Ccbennarum et Delphinatûs.

$$
\text { 59/. A M M } 1 .
$$

Involncra pinnatifida; calix integer; pctala inflexo-cordata, in disco æqualia, in radio inæqualia; fructus parvus, subrotundus, glaber, stritutus.

3497. Majus. Foliis inferioribus pinnatis, foliolis lanceolatis, superioribus multifidis, laciniis lanccolato-lincaribus. $\odot$. In arvis.

3 íg. Glaucifolium. Foliolis omnibus multifidis linearibus, unbella patula. $\odot$. In arvis.

3499. Fisnaga. Foliolis omnibus multifidis lincaribns, umbella maturatione contracta, radiis in receptaculum subcarnosum coalitis. $\odot$. In pascuis maritimis.

$$
\text { 595. D A U c u s. }
$$

Involncra pinnatifida; calix integer; petala inflexo-cordata, exterinribus radii majoribus; fructus ovatus, hispidus; semina interne striata, externe convexi, costis parvis membranaccis. 
35oo. Carotta. Caule hispido, foliis 2-3-pinnatis villosis, foliolis incisis, laciniis linearibus acutis. $\delta$. In pascuis arvisque.

35or. Mispidus. Caule hispido, foliolis laciniisque folioram inferiorum ovatis obtusis, superiorum lanceolato-linearibus. 2 . In saxis maritimis propè Dicppam.

3502. Gummifer. Caule subhispido, foliolis omnibus obtusis incisis crassis glabris. 2 . In littoribus maris Mediterranci.

35o3. Maritimus. Caule glabro lævi aut scabro, foliolis subsimplicibus liucaribus. $2 \%$ ? In littoribus maris Mediterranei.

$$
\text { 596. c A u c A L I s. }
$$

Calix 5-dentatus; petala inflexo-cordata, exterioribus radii majoribus bifidis; fructus ovali-oblongus hispidus, aculeis nunc sparsis nune in costis ordinatis.

\section{I. Fructuum aculeis compressis in costis longitudinaliter ordinatis (CAUCALIS).}

3504. Grandiflora. Foliis bipinnatis, involucellis lanceolatis margine scariosis, petalis exterioribus maximis. $\odot$. In arvis.

35o5. Latifolia. Foliis pinnatis, foliolis lanceolatis decurrentibus. $\odot$. In arvis inter segetes.

35o6. Platycarpos. Foliolis pinnatifidis incisis, involucro 3-1/phyllo, fructibas ovatis subcompressis, caule sparsim piloso. $\odot$. In provinciis australioribus.

3507. Maritima. Foliolis pinnatifidis incisis, involucro 2-3-phyllo, fructibus ovatis subcompressis, caule humili pubescente. $\odot$. In arenosis maritimis Occitanix et Galloprovinciæ.

3508. Daucoides. Foliolis pinnatifidis, involucro nullo, fructu subcylindrico, caule subglabro. 0 . In incultis et limitibus arvorum.

S. II. Fructum aculeis numerosis sparsis subaduncis (TORILIS), * Pilis adpressis, caulinis deorsùm, floralibus sursùm versis.

3509. Parviflora. Foliolis pinnatifidis nuiformibus, involucro nullo. $\odot$. In arvis, locis aridis.

35̃ı. Arvensis. Foliolis ovato-lanceolatis, terminali majore, involucro subnullo, caule humili. $\odot$. In arvis et ad vias.

35ı. Anthriscus, Foliolis ovato-lanceolatis, terminali majore, involuero 4-5-phyllo, caule elato. $\odot$. In locis incultis et ad sepes.

35 г 2. Nodiflora. Umbellis lateralibus subsessilibus, seminum aculeis subunilateralibus. $\odot$. In locis aridis, ad margines arvorunı.

\section{** Pilis nullis aut patulis.}

3513. Scandicina. Caule lævi, fructibus ovatis. $\odot$. Ad sepes et io inarginịbus arvorum.

35r f. Nodosa. Creniculis tumidiusculis, fructibus cylindricis. 0. In sepilus ét mubrosis circà Parisios, Nicæam, Genuam. 


\section{U M B E L L I F E R I. \\ 597. T}

Calix 5-dentatus; petala inflexo-cordata, exterioribus radii majoribus bifidis; fructus compressus, orbicularis, unargine calloso sulcato; semina plana.

35,5. Officinale. Foliorum inferiormm foliolis ovatis incisis crenatis, superiorum linearibus dissectis. $\odot$. In provinciis australioribus ad arva.

3516. Maximum. Foliolis lanceolatis serratis, terminali majore. $\odot$. In* incultis et narginibus arvorum.

\section{$+\dagger$ Umbellifere vere floribus luteis. 593 . P E U c E $\mathbf{n}$ A $\mathrm{N}$ U $\mathbf{M}$.}

Calix minimus, 5-rlentatus; petala xqualia, oblonga, apice inflexa ; fructus ovalis, subcompressus, striatus, margine attenuatus, subalatus.

3517. Parisiense. Foliis tripinnatis, foliolis linearibus angustissinis, involucro S-10-phyllo. F. In sylvis circà Parisios, Rothomagum? - Flores albi.

35r8. Officinale. Foliis ter aut quater ternatis, foliolis filiformi-linearibus. F. In umbrosis subliumidis.

3519. Silaus. Foliis tripinnatis, foliolis lanceolato-linearibus, involucris subdiphyllis. $\mathcal{Y}$. In pratis.

3520. Alsaticum. Foliis tripinnatis, foliolis pinnatifidis, involucris polyphyllis. 2 . In sylvis subhumidis Alsatix, Galloprovincia.

$$
\text { 599. A Р I U M. }
$$

Calix integer; petala æqualia, subrotunda, apice inflexa; fructus ovatus aut globosus; semina externe convexa, costis quinque parvis prominulis; involucrum nullum aut $1-3$-phyllum.

35̃21. Petroselinum. Foliolis caulinis linearibus, umbellis pedunculatis. $\delta$. In umbrosis Galloprovincix; in hortis cultum.

3522. Graveolens. Foliolis caulinis cuneiformibus, umbcllis plerumque sessilibus. $\delta$. In paludibus et ad rivulos; in hortis cultum.

$$
\text { 600. A N I T H U M. }
$$

Calix integer; petala integra, subrqualia, incurva; fructus lentiformis, compressus; semina hinc plana, indè convexa, 5-costata; involucrum involucellaque nulla.

3523. Foniculunı. Foliis decompositis, laciniis capillaribus, seminum costis subrqualibus. $\sigma$. In lapidosis aridis.

\section{OI. S M Y R N I U M.}

Calix integer; petala acuta, carinata, apice incurva, subxqualia ; fructus ovato-globosus, ventricosus; semina semilunata, costis tribus prominulis; involucrum involucellaque nulla.

3524. Olusastrum. Foliis caulinis ternatis petiolatis serratis. $\sigma^{7}$. In paṣcuis humidis Galloprovinciæ, Pedemontị et Belgii. 


\section{G02. $\mathbf{p}$ A $S$ 'T $I$ I $A$ A $A$.}

Calix integer; petala integra, incurva, subæqualia ; fructus cllipticus, compressus; semina apice emarginata, subalata, costis tribus vix exsertis; involucrum et sæpiùs involucella nnlla.

3525. Sativa. Foliis simpliciter pinnatis. $\delta$. In locis incultis, ad sepes et vias.

3526. Opopanax. Foliis pinnatis, foliolis hasi antica excisis. 4 .

Ad margines arvorum in provinciis mediterraneis.

$$
\text { 603. т н A P S I A. }
$$

Calix integer; petala lanceolata, apice inflexa; fructus oblongus, compressus, utrinqui emarginatus, latere membrana cinctus; involnerum involucellaque nulla.

3527. Villosa. Foliolis dentatis villosis basi coadunatis. 2F. Locis sterilibus umbrosis in provinciis mediterraneis.

$$
\text { 604. F E R U L A. }
$$

Calix integer; petala oblonga, integra, apice inflexa, subæqualia; fructus ovalis, compressus; semina elliptica, dorso obscurè trinervia, margine angusto cincta.

3528. Communis. Foliolis linearibus longissinis simplicibus, umbellis ternatis. $2 \mathrm{f}$. In montanis secus mare Mediterranenn.

3529. Nodiflora. Foliolis linearibus angustissimis, umhellis pedunculatis ad nodos verticillatis. $2 C$. In vineis in provinciarum mediterranearum.

$$
\text { 605. c A }
$$

Calix integer; petala xqualia, lanceolata, apice inflexa; fructus magnus, ovali-cylindricus, angulosus, cortice crasso fungoso.

353c. Laerigata. Foliis supra-decompositis glabris, laciniis seta* ceis brevibus, seminibus lævibus glabris. $4^{\circ}$. In provincis mediterraneis.

$$
\text { 6o6. }
$$

Calix integer; petala integra, xqualia, incurvata; fructus ovatus rotundusve, dorso utrinqué gibbosus, striatus, latere subcompressus; folia integra.

3ธิ3 . Fruticosum. Frutescens, foliis lanceolato-obovatis integerrimis. Ђ. In provinciis mediterraneis.

3532. Rotundifolium. Involucris nullis, foliis perfoliatis. $\odot$. Inter segetes.

3533. Longifolium. Involucris sub-5-phyllis, involucellis pentapliyllis ovatis, foliis ovatis amplexicanlibus. 2 . In lapidosis montanis Alpium, Jurassi, Arvernix, V'ogesorum.

353\%. Stellatum. Involncellis coadunatis, involucris 3-phyllis. $\mathcal{Y}$. In pascuis et rupibus umbrosis $A$ lpium.

3535. Pyrenceum. Involucellis 5-phyllis subrotundis, involucris 3phyllis umbelle radios æquantilus, foliis lanceolatis, superiorit bus cordatis amplexicaulibus. 2 . In rupibus Pyrenæorum. 
3536. Falcatum. Involucellis 5-phyllis acutis, involucris 1-3phyllis inaqualibus, foliis lanceolatis, canle flexuoso. ₹f. In lapidosis aridis, al sepes et inter dumeta.

3537. Graminifolum. Involucellis sub-7-phyllis, involucro 3-5pliyllo, foliis radicalibus linearihus, caulibus monopliyllis. 2 \% Iı lapidosis et saxosis montanis Delplinatûs.

3538. Ramunculoides. Involucellis 5-phyllis cospidatis, involucris 3-4-pliyl!is umbella radiis brevioribus, foliis radicalilous angustis. 25 . In montibus.

3539. Caricifolium. Involucellis 5-plyyllis cuspidatis, involucris 12-phyllis umbella raclie brevioribus, folis radicalibus linearibus. 2 . In Alpibus inter lapides saxą̣ıe.

35 qn. Rigidum. In volneris involncellisque minimis, canle dichotomo subnudo. $\mathcal{F}$. In lapidosis aridis povinciarum nediteranearmm.

35 ז. Odontites. Involucellis radios umbellularmu superantibus et involucris 5-phyllis lanceolatis acuminatis, ramis divaricatis. $\odot$. In pascuis sterilibus et collibus australioribus.

35 2. Semicompositum. Involıcris involucellisque 5-playllis linearilanceolatis, foliis lanceolatis ofunsis mucronatis, fructibus stabris. $\odot$. In locis sterilibus ad mare Mediterraneum.

3543. Tenuissimum. Involucris involuecllisque sub-5-phyllis brevibus, florbus subsessilibus, foliis linearibus acutis, fruclibus scabris. $\odot$. In sterilibus herbosis et maritimis.

3544. Gerardi. Involucellis nmbellula radios superantibus et involucris 5 - pluyllis lincari-subulatis inaqualibns, foliis omnibus linearibus. $\odot$. Locis sterilibus in provinciis mediterrancis.

35ł5. Junceum. Involucellis umbellnlam vix superantibus 5-phyllis, involucris 2-3-phyllis lineari-lanceolatis, foliis lincaribus. $\odot$. In margine arvorun et sepibus.

\section{$+\dagger+$ Umbellifere anomala. \\ 607 . E с н I N O P II o r A.}

Involucrum 3-4-phyllun ; involucella turbinata, r-phylla, sexfila, inæqualia; umbellnle flosenli marginales pedicellati, masenli, cilice 5-dentato, petalis patulis inaciualibus; flosculus centralis feminens sessilis, petalis enarginatis; semen unicum (altero abortivo), involucello indurato et pedicellis persistentibus spinosis tectum.

35 6. Spinosa. Foliolis subulato-spinosis. 2 . In littoribus maris

Mediterranci et circà Namnetes.

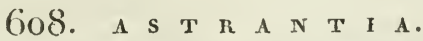

Calix 5-dentatus, persistens; petala incurva, biloba; fruetus ovatus; semina 5-costata, costis transversè rugosis; involucclla flores superantia.

3547. Epipactis. Foliis quinquelobis obtusis serratis, involncris obtusis serratis. 2 . In Pedemontii monte Pennino, prope vallem Augustanam.

3548. Major. Foliis radicalibns quinquelobis, lobis trifidis acutis dentatis, involucris integerrimis. 2C. In y yascuis montauis. 
3549 . Minor. Foliis radicalibus digitatis, foliolis septenis noveniše lanceolatis profundè dentatis. $\mathcal{F}$. In pascuis Alpium et Pyrenæorum.

6og. S I N I C U L A.

Calix subinteger ; petala integra, apice inflexa; fructus ovatus, subglobulosus, non bipartihilis, aculcis uncinatis hispidus; umbellula hemisphæricæ.

3550. Europar. Foliis radicalibus simplicibus, flosculis omnibus sessilibus. $2 \underset{j}{2}$. In sylvis.

$$
\text { GIO. E R Y N G I U M. }
$$

Flores sessiles, capitati, paleis intermixti; calix 5-partitus, persistens; petala oblonga, apice inflexo basi adnato; fructus ovalioblongus, squamis paleiformibus sæpè hispidus.

355 . Maritinum. Foliis radicalibus subrotundis plicatis spinosis, palcis tricuspidatis. 2 . In arenosis maritimis.

3552. Campestre, Foliis radicalibus bipinnatis, foliolis decurrentibus ovatis variè contortis, caule ramosissimo. $2 \%$. In locis incultis.

3553. Bourgati. Foliis radicalibus orbiculatis ternatis, foliolis incisis laciniisque diraricatis, capitulis conicis, caule stricto. $2 \mathrm{j}$. In herbosis Pyrenæorum.

3554. Spina-alba. Foliis radicalibus digitatis, capitulis maximis, involncris pinnatifidis. 2 . In lapidosis aridis Galloprovinciæ et Bolphinatûs.

3555. Alpinum. Foliis radicalibns cordacis integris, involucris pinnatifidis. 2 . In pascuis Alpium et Jurassi.

3556. Planum. Foliis radicalibus elliptico-cordatis, capitulis rotundis, paleis simplicibus. 2 . In Alpibus Galloprovinciæ Italiz vicinis.

$$
\text { 6II. I Y } \mathbf{Y} \text { D } \quad \text { R O C O }
$$

Calix subinteger; petala integra, xqualia; fructus orbicularis, compressus, bilobus, nervosus.

3557 . Vulgaris. Foliis peltatis orhiculatis crenatis, umbella 5-8flora. $\mathcal{Y}$. In paludibus.

\section{O R D O L X I I I. S A X I F R A G E AE.}

Calix adhxrens aut rariùs liber, limbo 5-lobo; petala $4-5$ apice calicis inserta, ejusdem laciniis alterna, interdum nulla; stamina cum petalis inserta, eorum numero dupla aut æqualia; styli 2 persistentes ; capsula birostris, bivalvis, uni-aut-bilocularis, poro 16 rminali dehiscens, valvis in biloenlaribus introrsum flexis; semina dissepimento aut inæ capsnlæ inserta; perispermun carnosum; corculum rectum; radicula infera. - Herbæ habitu vario.

$$
\begin{aligned}
& \text { †Corolla polypetala. } \\
& 6 \text { I2. S A X I F R A G A. }
\end{aligned}
$$

Calix adhærens aut liber, 5-partitus; corolla 5-petala; stamina to; capsula 2-locularis. - Flores sxpiùs albi. 
5. I. Ovario calici adharente ( $\mathrm{SA} \times \mathrm{FRACA})$.

* Foliis coriaceis indivisis allernis.

3558. Inngifolia. Foliis malicalibus lineari-lanceolatis longissimis integris basi ciliatis margine leproso squanosis, caule paniculato, calicibus piloso glandulosis. 2 . In saxis Pyrenzorum et $A / p i u n$ maritimarmm.

3559. Pyramidalis. Foliis radicalibns lingnlatis patulis cartilagineoserratis, catule panicnlato, calicibus filoso-glandulosis. $2 \mathcal{F}$. Ad rupes in Pyrenais et $A l_{\text {pibus. }}$

3560. Aizonn. Foliis radicalibus oblongis cartilagineo-serratis, caulo paniculato, calicibus glabris. $\mathcal{Y}$. Ad rupes montium frequens.

$356 n^{*}$. Mutala. Foliis radicalibus lingulatis margine cartilagineis subintegris basi ciliatis, caulinis basi villosis, canle paniculato, calicibus glandulnso-pilosis. $\mathcal{C}$. In Alpibus Sabaudis arl montem Brezon observavit Berger. - S. mutata. Jacq. ic. rar.3. t.456. Flores crocei.

356r. Media. Foliis radicalibus lingulatis acutis integerrimis glabris, cunlinis calicibusque piloso-glandulosis, petalis staminibusque calice minoribus. 2 . In saxis Pyrenæorum orientalium. Petala rosea.

3562. Luteo-purpurea. Foliis radicalibus integris glabris, caulinis calieibusque piloso-glandulosis, floribus paniculatis, petalis conniventibus calice longioribus. 2 . In saxosis umbrosis Pyrenæorum. - Petala lutea; calix purpureus.

3563. Aretioides. Foliis radicalibus integris oblongis obtusis glabris, caulinis calicibusquc piloso-glandulosis, floribus capitatis , petalis calice duplù longioribus. 2 . E fissuris rupium in Pyrenæis. - Flores lutei.

3564. Casia. Foliis linearibus confertis recurvatis perforato-punctatis basi ciliatis glaucis, caule subnudo. 2 . In locis vento perflatis Alpium Pedem. Delphin. et Pyrenaoram.

3565. Aspera. Foliis lancenlato-lincaribus mucronatis lævibus margine sxpiù ciliis asperis instructis, petalis oblongis calice obtuso duplo longioribus. 2 . In saxosis et apricis Alpium, Pyrenæorum, montium Arverniæ. - Flores ochroleuci croceo punctati. Planta polymorpha.

\section{* Faliis coriaceis integris opposilis.}

3566. Oppositifolia. Foliis oppositis confertis ovatis ciliatis, floribus solitariis subsessilibus, petalis ovatis genitalia duplù superantibus. 2 . Ad rupes in editioribus Alpibus et Pyrenxis. - Flores purpurei.

3567. Biflora. Foliis oppositis subdistantibus oboratis basi subciliatis, floribus geminatis subsessilibus, petalis linearibus genitalia æquantibus. 4 . Ad lapides schistosas in excelsis Alpibus ce rariùs in Pyrenxis. - Flores rosei.

3568. Retusa. Foliis oppositis imbricatis trigonis acutis basi ciliatis, 
floribus solitariis pedunculatis, genitalibus exsertis. 2 . Ad rupes in editionbus Pyrenæis et Alpibus Pedem. Delphin. - Hores purpurei.

\section{*** Foliis sublterbaceis integris aut dentatis.}

3569. Aizoides. Foliis sparsis linearibus subciliatis integerrimis, caulibus subsimplicihns adscendentibus. $2 F$. In umbrosis et humidis sccus rivulos montium. - Flores lutei sæpé croceo maculati.

357o. Planifolia. Foliis imhricatis oblongis obtusis integris planis, petalis ovatis calicem pr:bescentem duplò superantibus. 24 . In rupes lomidas editissimas Alpium et Pyrenæorum. - Flores ochroleuci.

357x. Androsacea. Foliis radicalibus lanceolatis utrinquè angustatis pilosis, caule nudo $\mathbf{1 - 2}$-floro. 2 . Ad rupes subhunidas in Alpibns et Pyrenæis.

3572. Nivalis. Foliis radicalibus obovatis crenatis subsessilibus, caule nudo, floribus congesiis. 2 . In summis Arvernir montibus.

357.3. Rotundifolia. Foliis jetiolatis rotundato-renifornibus dentatis, caule paniculaio. $\mathcal{4}$. In umbrosis montium.

3574. Granulata. Foliis petiolatis rotundato-reniformibus sublobatis, caule subracenoso, ralice granulata. 24 . Ad oras sylvarum.

35-5. Bulbifera. Foliis radicalibus petiolatis reniformibus, canlinis sessilibus ovatis incisis. canle ad basim pedunculorum bulbifero. 2 . In saxosis sterilibus Pedemontii.

$$
\text { **** Foliis lobatis. }
$$

35-6. Tridactylices. Foliis canlinis cuneiformibus trifidis alternis, caule erecto ramoso. $\odot$. In canapis et muris frequens.

357\%. Petraa. Foliis caneiformibus confertis integris tri-aut-quinquedentatis, caule erecto ramoso. $\odot$. In rupibus Alpium Pedem. Delphin. et Pyreuzorum.

3578. Adscendens. Friiis palmato-tri-iut-quinquepartitis, lobis trifidis, caule adscendente apice pubescente ramoso-paniculato. 25. Secus rivulos Pyrenæorum et nontium Corsicæ.

3579. Ajus afn'ia. Foliis radicalibus palmato-tri-ant-qninquepartitis, caulinis linearibus indivisis, caulibus arlscendentibus mulifloris. 24. In saxosis hnmidis secus nives in Pyrenæis.

3j5o. Pedemontana. Foliis rosulatis snbtriangularibus apice trilobis, Jobis apice lentatis, caule nudo erecto, floribus subcoryubosis. 2 . E fissuris rupium in Alpibus Pedemontanis.

358r. Geranoides. Fnliis radicalihus renifornibus quinquelobis multifidis longè petiolatis, floribus subcapitatis tubulosis, calicibus urceolatis pubescentibus. 2 . Ad rupes umbrosas Pyrenxorum.

3583. Ladanifera. Foliis gummiferis petiolatis quinquelobis, lobis integris, floribus subpaniculatis. 2 . Ad rupes muscosas in Pyrenxis oricutalibus. 
3583. Pentadactylis. Foliis rigilis ghaberrimis quindpuelobis, Jobis linearibus integris obtuss, floribus subpaniculatis. 2 . Acl rupes in Pyreneis oricutalibus.

3584. Intricatu. Foliis cuneiformibus, superne nervis subparallelis, apice $4-5$ lobis linearibus instructis, canle nudo, pediccllis divatricatis, petalis ovatis. $2 \mathrm{~F}$. In rupibus subhumidis Pyrenteorum.

35S.̃. Fixarala. Foliis cunciformilus, supernè nervis sulpparallelis, appice Jobis $4-5$ lincaribus insuructis, catule nuclo, pedicellis stric-

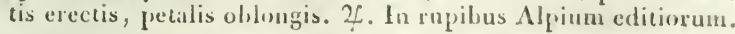

3586. Pubescens. Ioliis pubescentibus subviscidis in petiolum angustatis apice 3-5-lohis, caule subudodo pubescente, floribus subpanieulatis, staminum filanentis persistentibus demùm purpureis. Z. Ad rupes in Alpibus et Pyrenceis.

3587. Groenlandica. Foliis pubescentibus subviscidis densè imbricat is apice 3-5 lobis, scapo nudo pubescente, floribus subcapitatis, staninum filamentis persistentibus demum purpureis. 24. Ad summas rupes Pyrenxoruni.

3585. Muscoides. Foliis glabris subviscidis lincaribus integris aut trilobis, scapo apice pubescente, floribus subcapititis, petalis oblongis angustis. 2 . In rupibus Alpium et Pyrenæorum. - Flores ochroleuci ant rubescentes.

$35 S_{9} . H_{y}$ pnoides. Foliis confertis linearibus trifidis acutis, surculorum iu gemmas axillares convolutis, caulibus floriferis erectis, surculis prostratis. $\mathcal{F}$. Inter saxa in montibus Arvernix et Gallix anstralis.

๑. II. Ovario libero, calice demium reflexo (нхратіса, Neck.).

$35 y^{\circ}$. Hirculus. Foliis canlinis lanceolatis alternis nndis inermibus integris, caule simplici erecto. $2 \digamma$. In paludosis turfosis Jurassi et circà Albergiam. - Flores lutei.

35gı. Cuneifolia. Foliis radicalibus cunciformibus obtusissimis repandis glabris, petiolo brevi subnudo, scapo ${ }_{4}$ paniculato. $2 i$. In umbrosis Alpium et Pyrenarorum.

3592. Umbrosa. Foliis radicalibus obovatis subretusis cartilagineocrenatis, petiolo limbum æquante pilis rufis vestito, scapo paniculato. 2 . In umbrosis Pyrenæorum.

3593 . Hirsuta. Foliis radicalibus cordato-ovalibus retusis cartilagineo-crenatis subglabris, petiolis hirsutis limbo duplò longioribus, scapo paniculato. $2 \mathcal{\zeta}$. In umbrosis Pyrenæorum.

359\%. Geum. Foliis radicalibus reniformibus dentatis ntrinquè pilosis, petiolis hirsutis limbo duplò longioribus, scapo paniculato. 4 . In umbrosis Pyrenæorum.

3595. Stellaris. Foliis radicalibus oblongo-cuneiformibus subcarno- sis integris ant dentatis, scapo ramoso, petalis æqualibus oblongis. 4 . In hunidis Alpium, Pyrenæorum, nontium Arverniæ.

3596 . Clusii. Foliis radicalibus oblongis petiolatis dentatis, scapo ramoso, petalis inæqualibns, lobis calicinis nerrosis. 2L. In luumidis umbrosis Pyrenicorum. 
t† Corolla nulla.

\section{I3. c H R Y S O S P L E N I U Mr.}

Calix ovario adhxrens, 4 -5-fidus, subcoloratus; petala nulla; stamiua 8-1o; styli 2 ; capsula r-locularis.

3597. Oppositifolium. Foliis oppositis. 24 . In humidis umbrosis imprimis montium.

359 S. Alternifolium. Foliis alternis. 2 . In humidis umbrosis imprimis montanis.

$$
\text { 6I4. A D } 0 \text { x A. }
$$

Calix ovario adhærens, $4-7$-fillus, extùs $2-\{$-squamosus; petala nulla; stamina $8-10$; styli $\{-5$; bacca globosa, 4 -5-locularis; radicula supera.

3599. Moschatellina. 4 . Ad sepes et in nemoribus.

\section{O R D O L X I V. CR A S U L A C E AE.}

Calix liber, partitus; corolla basi calicis inserta, mono-aut-sæpiùspolypetala, lobis aut petalis numero partes calicis æquautibus; stamina partium corollæ numero æqualia aut dupla; ovaria distincta, tot quot lobi corollce; squanıa nectarifera ad basime externam cujusque ovarii; folliculi tot quot ovaria, uniloculares, inties rima lonGitudinali dehiscentes, polyspermi; perispermum tenue, carnosum; corculum rectum; radicula infcra. - Herbæ foliis ssepiùs alternis carnosis glabris, floribus cymosis.

\section{† Corolla monopetala.$$
\text { 6I5. U M B I L I C U S 。 }
$$

Calix 5 -fidns; corolla monopetala tubulosa 5 - fida, lobis rectis acutis; stamiua 10 ; ovaria 5 ; squamæ ovatæ.

36oo. Pendulinus. Radice tuberosa, foliis peltatis crenatis, caule subsimplici, floribus racemosis pendulis, bracteis integris. 2 . Ad muros vetustos et rupes prov. australiorum et occidentalium.

36ог. Erectus. Radice repente, foliis peltatis crenatis, caulc subsimplici, floribus racemosis erectis, bracteis dentatis. 2 . In Pedemontio? Nicæx? Lugduni? Monspelii?

\section{† Corolla polypetala.$$
\text { 6I6. B U L L I A R D A. }
$$

Calix 4-fidns; petala 4; stamina 4 ; ovaria 4 ; squamæ lineares, calicis longitudine; folliculi polyspermi.

3602. Vaillantii. Caule erecto dichotomo, foliis oblongis acutis pedunculo brevioribus. $\odot$. In umbrosis humidis ad oras aquilegiorum Fontisblcaudi.

$$
\text { 6I7. T I L L I } \mathrm{A} \text {. }
$$

Calix 3-partitns; petala 3 ; stamina 3 ; ovaria 3 ; folliculi dispermi medio transversè coarctati. 
36o3. Muscosa. Floribus sessilibus. $\odot$. In humidis ad oras aquilegoran Fontisbleaudi et in prov. australibus.

$$
\text { 6.8. c } \mathrm{r} \text { a } \mathrm{S} \text { s } \mathrm{U} \text { L } \mathrm{A} \text {. }
$$
bvatx.

Calix 5-7-fidns; petala 5-7; stanina 5-7; ovaria 5-7; squame

36of. Rubens. Foliis altcrnis fusiformibus subdepressis glat)ris, ramis villosis, floribus unilateralibus sessilibus. $O$. In cultis et rincis.

$$
\text { 6rg. S } \mathrm{x} \text { D } \mathrm{U} \text {. }
$$

Calix 4-7-fidus, sæpiùs 5-fidus; petala et ovaria totidem; stamina numero petalorum dupla; squami ovatæ, obtusie, integræ.

\section{I. Planifolia, floribus luteis.}

36o5. Rhodinla. Radice tuberosa, floribus abortu dioicis corymboso-capitatis. $\mathcal{F}$. In umbrosis et rupestribus montium australiorum.

\section{§. II. Planifolia, floribus albis aut purpurascentibus.}

36o6. Telephium. Foliis sparsis aut oppositis ovatis serratis, canle crecto, corymbo folioso. $2 \mathcal{F}$. Ad un uros, vineas et inter lapirics.

3607. Anacampseros. Foliis sparsis cuneiformibus intererrimis, caulibus rlecumbentibus, floribus corymbosis. 4 . Inter rupes apricas, in Alpibus Saband. Pedem. Galloprov.

36o8. Stellotum. Foliis sparsis ovatis angulatis, floribus lateralibus sessilibus solitariis, folliculis stellatim patentibus. $\mathcal{\Psi}, \odot$. In lapidosis umbrósis Pedeinontii, Arvernia, prov, australiorum.

3609. Atsinefolium. Foliis sparsis ant oppositis integris ovatis, inferioribus subperiolatis, caule debili pubescente paniculato, petalis aristatis. $\sigma$. In petrosis umbrosis Pedemontii.

36ro. Cepcea. Foliis sparsis oblongo-lanceolatis, caule ramoso paniculato pubescente, petalis aristatis. $\odot$. In lapidosis secus colles et muros.

361 r. Gallinides. Foliis verticillatis obovatis, caule ariscendente glxbro paniculato, petalis acutis. $\delta^{7}$. In Corsica, Pedemontio, Biessia, Lngduni.

f. III. Teretifolia, floribus albis purpurascentibus ant corruleis.

361 2. Cruciatum. Foliis verticillatis semi-teretibus oblongis obtusis, superioribus sparsis, caulibus patulis basi ramosissimis, floribus corymbosis. 4 . In Alpibus Pedemontii Xonregalensibns.

3613. Album. Foliis sparsis teretiuscnlis oblongis obtusis patentibns, cyma ramosa: $\odot$. In muris et lapídibus frequens.

3614. Turgidum. Foliis sparsis terctínsculis oroideis obtusis, surculorum imbricatis, cyma ramosa. - In muris circà Aquas Bigerronum (Bagnères).

3615. Atratum. Foliis sparsis teretibus obtusissimis, canle ramisque 
crectis, floribus corymbosis fastigiatis. $\odot$. In rupibus apricis Al pium, Pyrenæorum.

3616. Dastphyllum. Foliis oppositis ovatis obtnsis pinguibus, caulibus infirmis appe pubescentilus, flotibus lasè racemosis sæpius hexapetalis. $2 \mathcal{F}$. In aridis $A$ p pum et mutium unstraliormm.

36r7. Anglicum. Foliis subalternis ovatis gibbis pingnibus, cunlibns infirmis gracilibus pedicellisque glabris, cyma bifila. $\odot$. In sylvis inter muscos in Pyrenxis.

3618. Hirsutum. Foliis villosis semi-teretibus, inferioribns confertis, superioribus sparsis, caule basi stolonilero, fluribus cyunsis, petalis aristatis. $0^{7}, 24$. In rupibus Alpinm Pedemontit, montium Arvernia et Occitanix, I'yı

3619. Villosum. Foliis sparsis ol,longis suprà planinsculis pedunculisque axillaribus unifloris pubesentibus, petalis obtusiusenlis. $\odot$. In pratis paludosis montiun, secus aquilegia Fontisbleaudi.

3620. Heptapetalunt. Foliis sparsis ovato-oblongis planiusculis, floribus paniculatis, petalis 6 - 7 lanceolatis aristatis. - Ad rupes in Corsica. - Flores azurei.

\section{IV. Foliis teretibus basi solutis; fonribus luteis.}

362 1 . Acre. Foliis subovatis adnato-sessilibus gibbis ercctiusculis alternis, cyma trifila. 2 . In apricis et muris frequens.

3622. Glaciale. Foliis subovatis adnato-sessilibus gibbis ercctiuscnlis alternis, floribus subternis congestis terminalibus, caule rimisque radicanibus. $2 \mathrm{C}$. In Alpibus Galloprovinciæ propè nives.

3623 Sexangulare. Foliis teretibus adnato-sessilibus subpatulis ternatim verticillatis, in surculis sexfuriam imbricatis, cyma trificla. 24. In pratis siccis.

362\%. Saxatile. Foliis sparsis semi-teretibus obtusis basi solutis, caule ramoso decumbente, cyma trifida. $\odot$. In saxosis apricis Alpium, Pyrenxorum, Vogesorum.

3625. Reflexum. Foliis sparsis subnlatis basi solutis erectis, floribus cymosis subcorymbosis, cymæ ramis virgineis reflexo-nutantibus. $2 L$. Ad rupes et muros.

3626. Hispanicum. Foliis sparsis teretibus acutis basi solutis erectis glaucis, floribus cymosn-corymbosis, petalis 6-7 lanceolatis erecto-conniventibus. 2 . In saxosis Delphinatûs, Galloprovinciæ, Narbonis. - Flores ochrolenci.

3627. Altissimum. Foliis sparsis teretibns acutis basi solntis, superiorihns suprà planis, floribus densè cymosis, petalis 6-8 patentibus. 2 , b. Inter saxorum fragmenta in Pyrenæis circà Valletrian, in Sabaudia propè Maurianam.

\section{S E M P E I V I V U M.}

Calix 6-12-fidus; petala et ovaria totiden ; stamina petalorum numcro dupla; squamx ovatæ, latæ, emarginatx aut laceræ.

\section{§. I. Floribus purpurascentibus.}

3628. Teclorum. Foliis ciliatis, propaginibus patentibus, floribus 
doilecagynis, squanis cuneiformibus carunculatis. 2f. Ad rupes Alpimm et Pyrenæornm, in muris et tectis.

3629. Montanum. Foliis pubescentibus, propiginibus patentibus imberbibus, floribus snbdolecasynis, squamis minimis. F. Ad
rupes apricas in $\Lambda$ lpibus et Pyrencis.

363o. Arachnoiltum. Propaginihus globosis villis intertextis, floribus enneagynis, squamis oblongis truncaio-dentatis. 2 . Ad rupes apricas Alpium et Pyrenæorum.

\section{§. II. Floribus ochroleucis.}

3631. Globiferume. Foliis ciliatis, propaginibus globosis, florilus patentibus dodecagynis. 2 C. In Alpibus Pcdemnntii, Vallesix, montibus Alsatix.

3632. Ilitum. Foliis ciliatis, propaginibus globosis, floribus tubulosis hexapetatis. 2f. Ad rupes in Pedemontio, etc.

\section{O R D O LX V. PORTU L A C E AE.}

Calix apice divisus; corolla calici inserta, pentapetala, monopetala aut nulla; stanina corollx inserta; ovarium liberum aut basi adlıxiens; stylus o ant $1-3$; capsula uni-aut-multilocularis, loculis mono-aut-polyspermis; perispermum farinaceum centrale; corculum incurvum aut annulare. - Herbæ aut frutices habitu vario.

\section{I. T A M A R I $\mathbf{x}$.}

Calix persistens, 5-partitus; petala 5 , calicinis laciniis alterna; stamina 5-10, libera vel monadelpha; ovarium liberum, 3-gonun; stylus integer ant in 2-3 stigmata fissus; capsula oblonga, 3-gona, 1-locularis, 3-valvis, polysperma, seminibus papposis; perispermum nullum; corculum erectum; radicula infera.

3633. Callica. Floribus 5-andris, spicis lateralibus, foliis lanceolatis amplcxicaulibus imbricatis. Ђ. Sccus fluvios et in pratis maritimis, etiam propè Ausionem.

3634. Germeanica. Floribus ı-andris, spicis terminalibus, foliis sessilibus lineari-lanccolatis. b. Secus mate rivos et torrentes in arenosis.

\section{T E L E P H I U M.}

Calix 5-partitus, persistens; petala 5, callici rqualia; stamina 5 , corolla breviora; styli 3 ; capsula 3-quetra, 3-valvis, polysperma, receptaculo seminifero centrali.

3635. Imperati. Foliis alternis. $2 \%$. In siccis et calidioribus Galliat australis.

$$
\text { 623. C O R R I G I O L A. }
$$

Calix 5-partitus; persistens, calicinis laciniis membranaceis, margine albidis; petali 5 , calici xqualia; stamina 5 , corolla breviora; styli 3; semen unicum, 3-quetrum, calice connivente tectum.

3636. Litcoralis. Floribus pedunculatis. $\odot$. In arenosis secus rivos, circà Lutetiam, Argentoratum, et in Gallia australi. 


$$
\text { 624. P O R } T \text { U L A C A. }
$$

Calix persistens, compressus, 2-valvis; petala 5 ; stamina 6-r2; ovarium calici basi subadnatuan; siylus i; stigmuta $4-5$; capsula circumscissa, polysperura, receptaculis seminiferis centralibus 5 .

363 - Oleracea. Iolits cuncifornibns confertis levibus scsilibus,

floribus sessilibus. $\odot$. In locis cultis.

$$
\text { 625. } \mathbf{M} \text { ○ } \mathbf{N} \text { T I A. }
$$

Calix persistens, 2-3-valvis; corolla I-petala, 5-partita, laciniis 3 alternis minoribus; stamina $3-5$; styli 3 ; capsula caiice tceta, 3-valvis, 3-sperma.

3638. Foniana. $\odot$. In humidis, secus aquas.

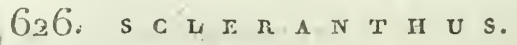

Calix ovario adilırens, tuhulosus, collo coarctatus, suprà 5-firlus; corolla o; stamina 5-10, calici inseria; styli 2 ; capsula 1-sperma. 3639 . Perennis. Calicihus fructûs clausis. 2 i. In arvis arenosis. 36 fo. Annuzs. Calicibus fructûs patulis. $\odot$. In arvis.

\section{O R D O L X V*. F I C O I D E AE.}

Calix monophyllus, definitc̀ partitus, liber aut ovario adhærens; corolla summo calici inserta, polypetala, aut petalis basi cnalitis mouopetala, aut cum calice coalita; stamina numero indefinita, summo calici inserta; styli plures; capsula aut drupa multilocularis, loculis numero slylorum polyspermis; semina angulo loculorum interiori affixa; corculum incurvum; perispermum farinaceum centrale. - Folia succulenta.

\section{$66^{*}$. M E S E II B R Y $A$ N T II E M U M.}

Calix ovario adhærens, persistens, 5-fidus; petala plurima, linearia, basi coalita; styli $4-10$, sæpiùs 5 ; capsuliı umbilicata, curnosa. $360^{*}$. Nodiflortem. Foliis alternis teretinsculis obtusis basi ciliatis, petalis calice breviorihus. Lin Spec. 687. Pl. Grass. t. 88. $\odot$. In arenosis maritimis Corsica, circà Urcinium (Lois.).

\section{O R D O L X VI. C A C T I.}

Calix polyphyllns, ovario adhorens; petala numero indefinita, cum calice inserta; stamina numero indefinita; stylus $\mathrm{I}, \mathrm{tubulosus;}$ stigma multifidum; bacca umbilicata, unilncularis, polysperma, seminibus in pulpa nidulantibus; perispermum nullum; corculun incurvum aut spirale. - Frutices caulibus carnosis, sæé folia æmulantibus, pilorum fasciculis aut aculcis quincunci ordine dispositis.

$$
\text { 627. c A c } \mathrm{T} \text { U } \mathrm{s} \text {. }
$$

Vide caracterem ordinis.

36fx. Opuntia. Articulato-prolifer laxus, articulis ovatis compressis, spinis setaceis, floribns.luteis. b. Ex America orta, sponté nunc crescit in Galloprovincia, Pedemontio. 


\section{O R D O LX VII. G ROS S U LARIAE.}

Calix ovario adharens, 5-fidus; petala 5 et stamina 5, calici insertu; stylus bifilus; stigunata 2 ; bacea glolosá, 1-locularis, polysperma, receptaculis 2 oppositis seminiferis; corculum reetum, minimum, al basim perispermi cornei. - Frutices foliis alteruis, pulinato-5-lobis.

$$
\text { 628. R I в E s. }
$$

Vide raracterem ordinis.

\section{f. I. Inermia ( $\mathrm{IBEs}$ ).}

36 2. Rubrum. Inerme crectum, racemis glabris nutantibus, floribus planis, foliis obuısè 5-lobis. b. In vallibus Jurassi et humiliorum Alpium.

3643. Petranm. Inerme crectum, racemis pilosiusculis erectis, floribus planiusculis, foliis acuminato-lobatis inciso-dentatis, caule erecto. ๖. In montibus locis umbrosis, inter lapides juxtà rivos.

36狧. Alpinum. Inerme erectum, racemis crectis, floribus planis, bracteis flore longioribus. b. Ad sepes in montosis.

36, Nigrum. Inerme erectum, racemis laxis, foliis subtùs punctato-glandulosis, floribus campanulatis, bracteis pedicellis brevioribus. 2 . In montibus Arverniæ, Delphinatûs, Pedemontii, Monspelii.

\section{II. Aculeata (grossularia).}

3646. Uva crispa. Ramis aculeatis, foliis rotundè Iobatis, pedicellis bractea monophylla instructis $1-2$-floris. $b$. Ad sepes; $\beta$, in hortis culta.

\section{O R D O L X V III. S A L I G A I AE.}

Calix liber, tubulosus, persistens; petala summo calici inserta, numero definita, interdum nulla; stamina medio calicis inserta, cjusdem laciniis numero dupla aut æqualia; ovarium simplex; styJus 1; capsula calice tecta, uni-aut-multilocularis; semina numerosa, receptaculo centrali adfixa; perispermum nullum; corculum rectum; radicula infera. - Herbæ sæpius oppositifoliæ.

$$
\text { 629. L } 9 \text { т }
$$

Calix cylindricus, striatus, 6-12-dentatus; petala 6 (rard 4 ant 5) ; stamina 6-r2; capsula oblonga, 2-!ncularis, 2 -valvis, y alvis interdium apice 2-fidis.

\section{I. Foliis oppositis; staminibus 12 aut ultrà.}

36iz. Salicaria. Foliis oppositis cordato-lanceolatis subhirsutis, floribus spicatis. 4 . Frequens secus rivos, stagna et fossas aquaticas.

๑. II. Foliis alternis; staminibus 6 vel minus.

36 8. Hyssopifolia. Foliis alternis linearibus, floribus hexapetalis.

Q. In humidis arenosis circa Parisios, et in Gallia australi. 
3619. Thymifolia. Foliis alternis linearibus, imis oppositis, flori=

bus tetrapetalis. $\odot$. In humidis Galliæ anstralis.

630. \& I a U x.

Calix coloratus, campanulatus, 5-lobus, lobis extùs revolutis; corolla 0 ; stamina 5 ; capsula globosa, calice cincta, $x$-locularis, 5valvis, 5-sperma, receptaculo globoso.

365̃o. Naritima. 24. In Oceani et rariùs Mediterranei maritimis; in salsis Palatinatûs.

$$
\text { 63I. S U F F R E N I A. }
$$

Calix campanulatus, 4 dentatns, dentibus erectis; corolla o; stamina 2 oppositu; stylus 1; capsula ovato-oblonga, 1-locularis, 2valvis.

365ז. Filiformis. $\odot$. In oryzariis, circà Vercelias in Pedemontio. - E flora delendum est synunynıon Lobelii, quod, observante cel, Bellardio, pertinet ad Paronychiam verticillatam.

$$
\text { 632. p E p L I s. }
$$

Calix campanulatus. I2.dentatus, dentibus 6 alternis brevioribus; petala 6 , interdùm abortiva; stamina 6 ; capsula 2 -locularis, non pehiscens.

3652. Portula. Floribus 6-andris axillaribus solitariis, foliis petiolatis subrotundo-ovatis. $\odot$. In paludosis.

$$
\text { 633. с E R A T о P H Y L L U M. }
$$

Nonoicum. Calix multipartitns. Masc. Stamina $14-20$. Fem. Germen compressum; stigma obliqunu; nux monosperma, ovatoacuninata; perispermum nullum? corculum erectum; cotyledones divisæ; radicula infera.

3653. Demersum. Foliis dichotomo-bigeminis, fructibus 3-spino-

sis. 2f. In stagnis, fluviis et fossis.

$365 \%$. Submersum. Foliis dichotomo-trigeminis, fructibus muticis.

2 . In stagnis, fluviis et fossis.

\section{OR D O L X I X. O N A G R A R I AE.}

Calix monophyllus, ovario adharens, tubulosus, apice divisus; petala scepüu 4, summo calici inserla, rariùs o; stamina cum pezalis inserta, eorumdem numero æqualia aut dupla; stylus 1 ; fructus multilocularis, polyspermus, seminibus apice loculorum adfixis; perispermum nullum; corculun rectum; radicula supera, cotyle-donibus longior. - Herbæ særiùs oppositifoliæe.

$$
\begin{aligned}
& \text { † Genera Onagrariis affinia. } \\
& 634 \text {. С A I I I T I I C H E. }
\end{aligned}
$$

Monoica vel hiermaphrodita; calix o; petala 2. Masc. Stamen r, exsertum. Fem. Stgli 2; capsula 4-locularis, loculis 1-spermis nota dehiscentibus.

3655. Sessilis. Fructibus sessilibus. $\odot$. In fossis stagnantibus. 
3656. Pedunculata. Fructibus pertunculatis. $\odot$. In aquilegiis Iontisbleauli.

$$
\text { 655. н I P P U R I s. }
$$

Calix integer, miniuus; corolla o; stamen 1 ; stylus antherse sulco receptus; ovarium adhaerens, 1-spermun, calice suprà marginaımm; corculum 2-lobum, perispermo carnoso cinctum; radicula cotyledonibus longior.

365 . Fulgaris. Foliis verticillatis $10-12$ linearibus acutis. $2 \%$. In fossis aquaticis ad marginem stagnorum.

\section{$+\dagger$ Onagraria vere; ovaria plurima. 636. м Y R I о $\mathbf{p}$ H Y L $\mathbf{L}$ U}

Monoicnm. Calix 4-phyllus. MIasc. Petala 4 (interdùm nnlla); stamina S. Fene. Ovaria 4 , libera; nuces 4 , I-sperme, snbglobosx.

3658. Spiratum. Floribus masculis interrupte spicutis. 2 . In aquis stagnantibus.

3659. Verticiliatume. Floribns omnibus verticillatis. 2 . In aquis stagnantibus.

\section{$+\dagger+$ Onagrarice vera; ovarium unicum.}

$$
\text { 637. c I r c } \text { × A. }
$$

Calix brevis, caducus, 2-partitus; pctala 2 ; stamina 2 ; capsula pyritormis, pilis squamosis hirta, 2-locularis, 2-sperma, non dehiscens.

366o. Lutetinna. Canle erecto hirsuto, foliis ovatis subserratis pubescentibus. $\mathcal{F}$. In nemorosis.

366ı. Alpina. Caule depresso glabro, foliis cordatis dentatis nitidis glabris, calice membranaceo. 4 . In liumidis et umbrosis editiorum monıium.

$$
\text { 638. 'т } \mathbf{r} \text { A } \mathbf{P} \text { A. }
$$

Calix persistens, f-partitus; petala 4 ; stamina $\{$; germen 2-loculare, loculo uuo abortivo; capsula nuciformis, dura, coriacea, $2-f$ coruubus spinosis; semen magnum, carnosum; cotyledones inæquales. 3662. Natans. 2 F. In stagnis et fossis Versaliaruın et ferè totius Gallix.

$$
\text { 639. I s N A } \mathrm{R} \text { n I A. }
$$

Calix tubulosus, 4 -fidus; corolla o; stamina 4 ; stylus simplex; stigma 1 ; capsula 4-locularis, polysperma.

3663. Palustris. 25. In aquis stagnantibus vel rivis lentis, circà

Cenonıanum, Abbavillam, Nannetes, secus Ligerem, propè Aureliam, Genevam, in Alsatia, Burgundia, Pederıontio, Delphinatu, Aquitania.

$$
\text { 640. E N O T H E R A. }
$$

Calix elongatus, limbo 4-partito, caduco; petala 4 ; stamina 8 ; 
pollen riscosum; capsula elongata, obtusè 4-gona, 4-locnlaris, 4valvis, poiysperma, seminibus non papposis.

3664. Biennis. Foliis ovato-lanceolatis planis, caulęmuricato villuso, staminibus corolla brevioribus. $\sigma^{7}$. In dumosis humidis, ex Virginia orta.

$$
\text { 64I. E P I L O } \mathbf{B} \text { I U } \mathbf{M} \text {. }
$$

Calix elongatus, limbo 4-partito caduco; petala 4; stamina 8 ; pollen non viscosum; capsula elongata, obtusè 4-gona, 4-locularis, 4-valvis, polysperma, seminibus papposis.

\section{I. Floribus irregularibus, genitalibus declinatis.}

3665. Spicatum. Foliis. sparsis lincari-lanceolatis integerrimis venosis, floribus inæqualibus subspicatis, pedicellis in axilla hractearum. 4 . In sylvị montosis.

3666. Rosmarinifolium. Foliis sparsis linearibus obsoletè denticulatis aveniis, petalis subæqualibus, pedicellis bracteam gerentibus. $2 \digamma .$, In sylvaticis circà Lutetiam; $\beta$, ad torrentes Alpium in arenosis.

\section{§. II. Floribus regularibus; staminibus erectis; petalis emarginatis}

366 . Hirsutum. Foliis oppositis alternisque subamplexicaulibus ovato-lanceolatis serratis glabriuscnlis venis hirsutis, caule ramosissimo hirsuto, stigmate 4-partito. F. Propè aquas.

366s. Molle. Foliis oppositis alternisque subsessilibus lanceolatis denticulatis molliter utrinquè pubescentibus, caule simplici villoso, stigmate 4-partito. $\mathcal{4}$. In humidis et umbrosis.

3669. Palustre. Foliis oppositis alternisve glabris lanceolatis integerrimis, fructu pubescente, canle tereti erecto subluirsuto, stigmate indiviso. 2 . Ad marginem fossarum et stagnorum.

36-0. Tetragonum. Foliis lanceolatis glabris denticulatis, imis oppositis, canle 4 -gouo subglabro, stigmate indiviso. 2 . In inundatis et ad marginem stagnorum et fossarum.

$36-\mathrm{r}$. Roseum. Foliis ternis oppositis aut alternis glabris ovato-acuminatis denticulato-serratis amplexicaulibus, nervis subhirsutis, canie erecto simplici, stigmate indiviso. 2 . In Alpibus, in Pyrenæis propè Valletriam.

3672. Montanume. Foliis oppositis ovato-lanceolatis glabris dentaiis subsessilibus, stigmate 4-partito. $2 \%$. In sylvis montosis, in Alpibus et Pyrenæis.

36-3. Origanifolium. Foliis ovato-acuminatis subserratis oppositis stibglabris, caule glabro adscendente suprà nutante, stignate indiviso. 4 . Ad rivos et fontes $\mathrm{Al}$ pium et Pyrenæorum.

3674 . Alpinum. Foliis glabris obtusis ovato-oblongis integerrimis oppositis subnitidis, caule basi repente, stigmatc indiviso. $2 \mathcal{f}$. In saxasis inundatis Alnium el Pyrenæorum. 


\section{O R D O LXX. MI R T I.}

Calix monophyllus, ovario adharens, persistens, divisus; petala sapiüs 5, summo culiri inscrea; staminn 20 el ultrit, ralici sub petalis inserta; stylus 1 ; fructus polyspermus uni-aut-multilocular is ; perispermum nullum; cotyledones planx ; corculum rectum ant curvum. - Arbores aut frutices, foliis sæpiins oppositis, pellucialo-punctatis.

$$
\text { 642. P II I L A D E L P H U S. }
$$

Calix turbinatus, 4-5-partitus; petala 4-5; stigma 4-5-fidum; capsula calici semi-adnata, 4-locularis, 4-valvis, polysperma ; sepinecuta seminifera, valvis opposita; scuina arillo apice fiubritito donata.

36-5. Cornnarius. Foliis subrlentatis. ๖. Ad sepes in Vallesia inferiori, Pedemontio, Delphinatu.

$$
\text { 6/43. M } ~ \text { × R } \mathrm{T} \text { U s. }
$$

Calix 5-fidus; petala 5 ; stigma obtusum ; bacca orata, sphærica, limbo calicis coronata, 2-3-locularis, loculis 1-5-spermis; semina subossea.

36-6. Communis. Floribus solitariis, involucro dipliyllo. b. In collibus e't sylvis aridis agri Nicæensis et Galloprovinciæ austrilioris.

$$
\text { 64/. P U IN I c A. }
$$

Calix coriaceus, coloratus, 5-6-fidus; petala 5-6; stigma capitatum ; bacca sphærica, cortice coriaceo donata, calice coronata, transversè bipartita, suprà 7-9-locularis, infrà 3-4-locularis; semina numerosa, pnlpa cincta; cotyledones spirales.

3677. Granatum. Foliis lanceolatis, caule arboreo. b. In Gallia australiori.

\section{O R D O LXXI. R O S A C AE.}

Calix plerumquè persistens, divisus, nunc adhærens, nunc liber aut ovaria obtegens; petala summo calici inserta, sapiùs 5 ; stamina calici sub petalis inserta, numero indefinita; ovarium simplex aut multiplex; fructus varins; seminum leylus sub apice lateralis cui funiculus inseritur ex imo pericarpio cnatus; perispermum nullum; corculum rectum. - Arbores ant herbæ, foliis alternis.

\section{T R I B U S I. P O II A C E I.}

Calix 5-fidus; pelala 5; ovarium simplex, calici adnatum ; styliplures; pomum umbilicatum, calicinis lobis coronalum, muliloculare; radicula infera; caulis lignosus; flores completi hermaplırodili; stamina circiter 20; folia simplicia seu pinnata.

$$
\text { 645. m A L U s. }
$$

Siyli 5, hirsuti, basi coaliti; pomum sphæroideum, glabrum, 
apice et hasi umbilicatum, 5-loculare, seminibus cartilagineis, in quoque luculo binis.

36-8. Communis. Foliis oratis acutiusculis subdentatis, floribus umbellatu-sessilibus. b. In sylvis et sepibus.

$$
\text { 6/.6. P y R U s. }
$$

Styli 5, basi liberi; ponumum turbinatum, apice tantùm umbilicatum. Cætera ut in Maln.

3679. Communis. Foliis ovato-lanceolatis subdentatis suprà lævibus, pedunculis corymbosis. b. In sylvis et sepibus.

369n. Cydonia. Foliis ovatis mollibus integerrimis subtis tomentoso-incanis, floribus solitariis axillaribus breviter peduncnlatis. b. In provinciis meridionalibus spontanea, in liortis culta.

$$
\text { 647. C R A T Æ G U s. }
$$

Pomum sphæricum; semina 2-5, cartilaginca; styli 2-5.

368r. Torminalis. Foliis cordato ovatis laciniato-lobatis serratis, lobis infumis divaricatis acutis, floribus corymbosis. b. In sylvis.

3652. I atifolia. Foliis ovato-subrotundis sinualo-dentatis basi angulosis subtùs tomentosis, floribus coryubosis. b. In sylva tiontisbleaudi.

3693. Aria. Foliis ovatis dentatis subtus tomentosis, floribus corymbosis. b. In sylvis.

368千. Chamerenespilus. Foliis ovatis serratis utrinquè glabris, floribus corymbosis digynis. ๖. In dumetosis Alpium, Pyrenæorum,

3685. Amelanclier. Foliis ovatis dentatis sulgglabris, flotibns racemosis, petalis lanceolatis. Ђ. In lapidosis ad rarlires Alpium, Jurassi, Vogesorum, Pyrenæorum, circà Fontembleaudi, in Corsica.

$$
\text { 648. M E s p I L U s. }
$$

Styli $1-5$; pomum sphæricum; semina $2-5$, ossea.

3656. Oxyacantha. Spinosa, foliis glabris laciniatis, lobis acutiusculis divaricatis, floribus subcorymbosis monogynis, segmentis calicinis acutis. Ђ. Ad sepes et oras sylvarum frequens.

3687. Oxyacanthoides. Spinosa, foliis subtrifidis ohtusis dentatis glabris, floribus subcorymbosis digynis, segmentis calicinis acutis. b. Circà Parisios.

36S8. Azarolus. Subspinosa, foliis obtusis subtrifidis subdentatis pubescentibus, segmentis calicinis ovatis. b. In campis vineisque circa Monspelium; in prov. australibus culta.

368. Pyracantha. Spinosi, foliis ovato-lanceolatis subcrenatis, floribus corymbosis, segmentis calicinis obtusis. b. Ad sepes in Galloprovincia, Delphinatu, Sahaudia, ct 'Tarbx.

36̂ๆo. Germanica. Spinosa aut inermis, foliis orato-lanceolatis subdentatis subtùs subtomentosis, floribus solitariis sessilibus terminalibus, calicinis laciniis elongatis acutis. b. In sylvis et ad sepes, 
369r. Cotoneaster. Ineruis, foliis ovatis integerrimis acutinsculis subtus tomentosis, ovariis glabris. b. In saxosis cabidioribus.

$369 \mathrm{r}^{*}$. Eriocarpa. Inermis, foliis ovatis integerrimis olıtusis subtus tomentosis, ovariis lanatis.b. In lapidosis Jurassi ct ad pedem montis Salevæ. - Mespilus t'mentusa. Wild. spec, 2. p. 1012. Schl, eent. exs. n. 52, non Lam.

$$
649 \text {. s o r в U s. }
$$

Styli 3; pomum globosum vel turbinatum, molle; semina 3 , carsilaginea.

36.92. Aucuparia. Foliis pinnatis utrinque glabris. b. In sylvaticis frequens.

3693. Domestica. Foliis pinnatis subtùs villosis. b. In sylvis Alsa= tix, Galloprovincix, Pedemontii.

\section{T R I B U S I I. ROS A.}

Ovaria plurima monosperma monosty lı, intrì calicem urceolatum. collo coarchutum recondita; radicula supera; caulis lignosus; flores completi hermaphrodili; stamina circiler 20; folia pinnala; stipula petiolo adharentes.

$$
\text { 650. R o s A. }
$$

Calix nrceolatus, collo coarctatus, 5-fidus, laciniis 2-3 foliaccoappendiculatis; petala 5 ; fructus è calice demùn puiposo constans ; semina plurima, ossea.

\section{I. Fructibus globosis.}

369 个. Eglanteria. Calicum tubis globosis peduncnlisque glabris, aculeis rectis, serraturis foliorum villoso-glandulosis. b. In collibus Pedemontii, Galloprovinciæ, in sepibus Suessonum. - Flores lutei aut punicei.

3695. Sulphurea. Calicum tubis subaculeatis globosis, pedunculis glabris, aculeis rectis, foliclis ovalibus eglandulosis glaucis pubescentibus, stipulis laceratis. b. Ex Oriente orta, in hortis culta multiplex, in Galloprovincia fortè spontanea. - Flores sulphurei.

3696. Arvensis. Stylis in colımnam cylindricam glabram coalitis, stigmatibus distinctis, canle repente. b. In arvis et dumetis.

3697. Pimpinellifolia. Calicum tubis globosis glabris, laciniis foliolisque glabris eglandulosis, caule erecto, aculeis rectis. 万. In lapidosis et collibus.

369 . Myriacantha. Calicum tubis globosis glabris, laciniis foliolisque piloso-glandulosis, caule erecto, aculeis confertis rectis. b. In Delphinatu aut circà Lugdunum.

3699. Cinnamomea. Calicum tubis globosis pedunculisque glabris, acnleis canlinis geminis axillaribus, petiolis subinermibas. b. In collibus Arverniæ, Vogesorum, Lausannæ et Pedenontii.

3goo, Villosa. Cạlicum tubis glohosis pedunculisque hispidis, acu- 
leis caulinis sparsis, petiolis aculeatis, foliis utringuè tomentosis. ๖. In collibus et dumetis. - Var. ¿ Pyrenæis fructu lævi.

\section{II. Fructibus oblongis.}

37or. Tomentosa. Calicum mbis oratis peduncnlisque hispidis, aculcis caulinis sparsis subiduncis, petiolis aculeatis, foliolis ovatis utrinque tomentosis. 5 . In dumetis Arvernix, Jurassi.

3702. Collina. Calicum tubis oratis pednuculisque glabris, aculeis caulinis subaduncis, petiolis subaculeatis, foliolis ovatis tomentosis. b. Iu dnmetis circà Parisios, Cenomanum, Narbonem, Taurinum.

37o3. Turlinata. Calicum tubis turbinatis basi hispidis, pedunculis hispirlis, aculeis caulinis aduncis, petiolis villosis. b. In hortis culta wultiplex.

37o4. Centifolia. Calicum tubis ovatis pedicellisque hispidis, acnleis sparsis rectiusenlis, petiolis inermibus, foliolis duplo serratis margine filoso-glandulosis. b. In hortis culta multiplex.

3,05. Misscosa. Calicum tubis ovatis, laciniis pedunculis petiolis ranulisque hispidis glanduloso-viscosis, aculeis ramorum sparsis rectis. $b$. In hortis culta multiplex.

37o6. Semperflorens. Calicum tubis oblongis pedunculisque hispidis, aculeis rectis, petiolis subaculeatis, foliolis simpliciter serratis margine pubescentibus. $\boldsymbol{b}$. In hortis frequenter culta multiplex.

3 zn7. Pomponia. Calicum tubis ovato-turbinatis pedunculisque hispidis, acnleis rectis, foliolis subtìs pubescentibus. b. In liortis culta multiplex. - Flos roseus in margine dilutior.

3;o8. Remensis. Calicum tubis ovatis subglabris, peduncnlis subglandulosis, petiolis cauleque tenuissimè aculeatis, foliolis ovatis serratis, serraturis glandulosis. b. In Burgundiæ et forsan Campaniæ collibus, in hortis culta multiplex. - Rosa parvifolia. Wild. spec. 2. p. I078.

37og. Gallica. Calicum tubis ovatis subglabris, pedunculis hispidis, caule petiolisque hispido-aculeatis, foliis subtùs glancis, serraturis glandulosis. b. In collibus Genevæ, Taurini, Segusii, Aureliæ, Arverniæ, in hortis culta.

37ro. Rubiginosa. Calicum tubis ovatis glabris, peduncnlis hispidis, petiolis cauleque aculeatis, aculeis recurvis, foliolis ovatis subtìs glanduloso-pilosis. $\bar{b}$. In collibus siccis, secus vias, in dumetis.

37г. Rubrifolia. Calicum tubis ovatis pedunculisque glabris glancescentibus, petiolis aculeatis, canle aculeis sparsis uncinatis, foliolis oblongis argutè serratis glabris, floribus subcorymbosis. In pratis frigidis montium Arverniæ, Alpium, Pyrenæornm, Vogesorum.

3712. Alpina. Calicum tubis ovatis glabris, fructibus pendulis, pedunculis hispidulis, caule inermi. b. In lapidosis montium.

3.73. Pyrenaica. Calicum tubis ovatis pedunculisque hispidis, fruç 
tibus pendulis, canle subinermi, petiolis hispido-aculcatis. b. In Pyrenxis et Alpibus Genevensibus.

37r4. Sempervirens. Cialienm tubis ovatis pedunculisque hispidis, caule petiolisque aculeatis, floribus subumbellatis, fractcis lanccolatis, folivis ovato-tanceolatis glaberrimis.b. In sepibus et dumetis Galloprovinciæ, Oecitaniæ.

3715. Mosehata. Calicum tubis ovatis pedunculisque villosis, caule petiolisque aculeatis, tuliolis oblengis acuminatis glabris, floribus subcorymbosis. Ђ. In agro Ruscinonensi.

3716. Canina. Calicum tubis ovatis pedunculisque glabris, caule petiolisque aculeatis, aculeis uncinatis, calicinis laciniis pinnatifidis, foliolis glabris (ant in var. $k$, subtis pubescentibus). b. In sepibus et dumetis.

$3716^{k}$. Sepium. Calicum tubis oblongis pedunculisque glabris, caule petiolisque aculeatis, acnleis uncinatis, foliolis ovato-acutis, subtùs glanduloso-pilosis. b. In sepibus circá Luteiam. $-R$. sepium. Thuil. 1. p. 252 . R. canina $\beta$, Fl. fr. n. $3 \approx 16$ 。

3717. Alba. Calicum tubis ovaris glabris, pedunculis hispidis, caule petiolisque pubescentibus aculeatis, foliolis glabris, laciniis calicinis pinnatifidis. Ђ. In sepibns et dumetis, in hortis culta multiplex.

\section{T R I B U S I I I. A G R I M O N I A C E}

Ovaria I-sperma, I-styla, solilaria vel definitn, calice ore urccolato obtecta; radicula supera; cuulis herbaceus aut suffruticosus; flures sepiüs apelali interdim unisexuales; folia pinnata vel digitata.

$$
\text { 65I. P O T E R I U M. }
$$

Flores dioici, apetali; calix coloratus , 4 -lohus, extus 3-squamosus. ATasc. Stamina 3o. Fem. Oraria 2 ; stigmata ienicillata; semina 2 calice capsulæformi inclusa.

3 ; 1 S. Sanguisorba. Inerme, caulibus subangulosis, staminibus calicem longè superantibus. 2 . In pratis siccis et montosis.

379. Hybridum. Inerme, canlibus teretibus hirsutis, staminibus calicem vix superantibus. $\mathcal{H}$. In Gallia australi?

3720. Spinosum. Sufruticosum, spinis ramosis divaricatis, floribus spicatis, bracteis ciliatis. $\supset$. In Pedemontio australiori.

$$
\text { 652. S A } \text { i G U I S O } \mathrm{R} \text { B } A \text {. }
$$

Flores hermaphroditi, apetali; calix coloratus, 4-lobus, basi bisquamosus; stamina 4 ; ovaria 2 ; stigmata simplicia; semina 2 in calice capsulæformi inclusa.

372x. Officinalis. Glabra, spicis ovatis, staminibus corolla subæqualibıs. 2 . In pratis siccis.
653.

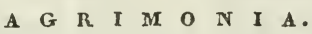

Calix 5-Iobus, involucello bilobo cinctus; petala 5; stamina 12-2o; pvaria 2 ; semina 2 in calice capsulxeformi inclusa. 
3732. Eupatoria. Calicibns fructigeris hispidis, foliis pinnatis, fo= liolis ovato-oblongis, spicis pedunculatis. 2 . Ad sepes et vias.

3723 . Odorata. Calicibus fructigeris hispidis, foliis pinnatis, foliolis oblongis, inferioribus diminutis, spicis pedunculatis. 4 . In sylvaticis vallis Montis-Maurentiaci.

\section{A t $\mathrm{C}$ H $\mathbf{E}$ M I L L $\mathbf{A}$.}

Calix 8-fidus, laciniis 4 alternis minoribus et cxterioribus; corolla $o$; stamina \& brevissima; ovarium 1 ; semen calice obtectum.

372i. Tulgaris. Folits renitormibus 9 -lobis, margine nervisque subhirsutis. 2 . In pratis et syivis montanis.

3725. Alpinn. Foliis digitatis serratis subtus sericeo-argenteis. 2T. In pratis et lapidosis montium.

372.5. Penta!hrl'a. Foliis quinatis multifidis glabris. $2 F$. In her bosis et frigilliorihns editiorum Alpium.

3-27. Arvensis. Foliis trifidis pubescentibus, lobis 2-vel-3-fidis, floribus sessilibus axillaribus. $\odot$. In arvis.

$$
\text { 655. S I B B A L D } \text { I A. }
$$

Calix patens, ro-fidus, laciniis 5 alternis minoribns; petala, stamina, ovaria, styli, stigmata 5 , semiua calice demùm clausu obtecta. 3-23. Procumbens. Foliis ternatis, foliolis superne glabris snbtis pilosis, floribus corymbosis, petalis lanceolatis acutis longitudine calicis. 2 . In pratis firigidioribus Alpim et Pyrenæorum.

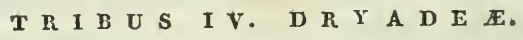

Ovaria I-sperma, $1-s t y l a, ~ l i b e r a$, plurima, receptaculo communi insita; radicula supera; caules herbacei rarò fruticosi; stamina circiter 20.

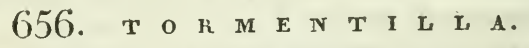

Calix 8-fidus, laciniis 4 alternis minoribus; petala 4 .

3729. Erecta. Canle erectiusculo, foliis sessilibus. $\mathcal{~}$. Ad vias, oras sylvarum, in graminosis.

3730. Reptans. Caule prostrato, foliis petiolatis. 2 . In sylva dicta Cressy propè Abbatisvillam.

$$
\text { 657. P O T E N T I L L A. }
$$

Calix rn-fldus, laciniis 5 alternis minoribus; petala 5 ; receptaculum seminiferum, parvum, persistens, non carnosum, sæpè pilosum.

9. 1. Floribus luteis; foliis pinnatis (PExtaphylloides).

3-3r. Fruticnsa. Foliis pinnatis, caule fruticoso. Ђ. In montibus Tendx in Pcdemontio, ad sepes Alsatix superioris.

3-32. Anserina. Foliis interruptè pinmatis subtìs sericeis, foliolis arguti: serratis, caule repente, pedunculis unifloris. F. Frequens ad rias et in sublumidis. 
3733. Supuna. Foliis piunatis subhirsutis, foliolis oblangis profunle dentatis, caule decumbente dichotomo, pedunculis axillarilus solitaiis. $\odot$ In Lapulosis vel arenosis intundatis Parioiis, in Burgundia, Lotharingia, Argentorati.

373 4. Mulifula. Foliis bipin:atifidis quarrijugis superne glabris subtirs tomentosis. seguentis distantibus, fluibus sutecorymbosis, caule adscendente. $2 i$. In montihus P'edemontii.

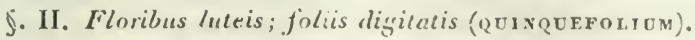

3-35. Recta. Foliis inferioribus petiolatis septenatis, foliolis serrato-dentatis, supeaioribus sulsessilibus quinatis, stipulis externè inciso pinnatifudis, caule crecto. 2 C. In apricis Galloprovincia, Pedemontii, Delphinatûs, Occitanix, Burguudia, Bressix.

3-36. Hirla. Foliis quinatis septenatisque, foliolis cuneiformilus incisis pilosis, stipulis integris, caule erecto hirto. 24. In lapidusis Gallize australis, Alsatix superioris et circà Parisios.

3737 . Intermedia. Foliis serratis, radicalibus septenatis, mediis quinatis, superioribus ternatis, caule adseendente ramoso, pedunculis longis nnifloris. $2 \%$. In montibus Detphinensibus inter saxa.

3-38. Sabauda. Foliis radicalibus quinatis, canlinis tematis, foliolis subtùs subluirsutis cuneiformibus profondie deutatis, caule erectiusculo pubescente, petalis emarginatis calice majoribus. $\mathcal{\Psi}$. In pascuis altioribus Alpiun Delphinatûs, Sabaudiæ, Pedeunontii.

3739. Pyrenaica. Foliis radicalibns quinatis, caulinis ternatis, foliolis hirtis oblongo-cuneiformibus, calicinis iaciniis sulrequalibus corolla brevioribus, caule erectiusculo. 2 f. In Pyrenæorum pratis.

37. o. Aurea. Foliis radicalibus quinatis, caulinis ternatis subsessilibus, foliolis margine albo-viliosis, caule adscendente, petalis obcordatis calice majotibus. 2;. In pascuis et herbosis montium.

374r. Verna. Foliis quinatis obovatis dentatis pubescentibus, canlibus declinatis ramosis, petalis obcordatis calice majoribus. $\mathcal{F}$. Ad vias et in collibus siccis.

$37^{2}$. Opaca. Foliis hirtis radicalihus septenatis quinatisve, foliolis cuneiformibus deutatis, petalis retusis calicis longitudine, caulibus filiformibus decumbentibus hirtis. $\mathcal{F}$. In aridis et sabulosis circà Taurinum, in Galloprovincia, Arvernia?

37\}3. Cinerea. Foliis quinatis sericeo-tomentosis, foliolis ovatis dentatis, petalis calice obtuso paulò majoribus, caulibus prostratis. 2 . In saxosis Delphinatûs circì Vapincum.

3744. Reptans. Foliis quinatis subhirsutis, foliolis ovatis obtusis dentatis, caule repente, pedunculis axillaribus unifloris. 2C. A.1 marginem agrorum in subhumidis.

3745 . Argentea. Foliis quinatis, folinlis cuneiformibus semi-pinnatifirlis subtù albo-tomentosis, caule erecto tomentoso. 24 . In incultis.

3746. Inclinata. Foliis quinatis ternatisve, foliolis lanceolatis obtusè serratis subtìs villosis, caule adscendente hirsuto, petalis 
retusis calici villosissimo xqualibus. 2 . In Delphinatu propd Siguyer.

37f-. Nivea. Foliis ternatis incisis subtus tomentosis, canle adso cendente. 2 . In Alpibus Vallesiacis Galliæ conterminis, in sabulusis circà Nannetes.

37 f9. Irigulu. Foliis ternatis hirsutis, foliolis ovatis dentatis, floribus solitariis terminalibus, petalis obcordatis, caulibus erectinbculis nanis. $\mathcal{F}$. In Alpibns editissimis propè nives.

$3-\{9$. Subruculis. Incana, pilis densè fasciculatis brevibus, foliis ternatis, foliolis ovato-ob!ongis obtusis dentatis. 24. In lapidosis montibus Gratoprovinciæ, Delphinatûs, Pedemontii, Palatinatûs.

3-5̃o. Grandifora. Foliis ternatis subhirsutis, foliolis ovatis profundè scratis, petalis emarginatis calice duplo longioribus, caule erectiusculo. 2 . In pratis Aipinis Sabaudiæ, Pedemontii, Galloprovinciæ, Fóntisbleaudi.

\section{III. Floribus allis; foliis pinnatis.}

3-5r. Rupestris. Foliis inferioribus pinuatis, foliolis ovato-rotmndatis dentatis glabris, caule erectu. $2 f$. Ad saxa in Alpibus, Pyrenæis, Bressia montibus.

\section{S. IV. Floribus albis; foliis digritatis.}

3-52. Caulescens. Foliis quinatis, folinlis apice conniventi-serralis subtìs et margine pubescentibus, caulibus érectitisculis, florihus corymbosis, petalis subcureiformibus calice paulo longioribus. 2f. Ad muros et saxa in montosis.

3-53. Valderia. Foliis quinatis, foliolis ovatis subcunciformibus serratis subtins albido-tomentosis, canle erecto pubescente, floribus subcoryubosis, petalis calice paulò brevioribus: $\underset{j}{\mathcal{C}}$. Inter saxa in Alpibus Petemontanis.

3ิ75\%. Nìalis. Foliis utrinquè sericeo-villosis, radicalibus septenatis, caulinis teruatis, foliolis obovatis apice dentatis, caule erecto, petalis calice paulo brevioribus. 24 . In saxis frigidioribus Alpium editiorm et Pyrenæorum.

3755. Alchemilloilles. Foliis quinatis lanceolatis snbtùs albo-scriceis apice comniventi-dentatis, eaule erecto pubescente, floribus corymbosis confertis, petalis ovatis emarginatis calici xqualibus. 24. In saxosis editiorum Pyrenæorum.

3-56. Alba. Foliis quinatis lancenlatis apice conniventi-denticulatis subtis albo-sericris, caulibus filiformibus procumbentibus, flo-a ribus paucis pedunculatis, petalis oheordatis calici æqualibus. 24. In graminosis montium Galloprovincix.

3757 . Splentens. Foliis ternatis rarò quinatis subtìs scriceo-lanatis, foliolis ovato-oblongis apice serratis, peciolis hirstitissinis, caulibus decumbentibus, floribus paucis longe pedicellatis, petalis obcordatis. $2 \mathcal{C}$. In sabulesis et graminosis ad oras sylvarum, Fontisbleandi et in Pyrenæis; Lemovicii, Aquitanice.

3-58. Nitida. Foliis tcrnatis quinatisve utrinquè pilnso-sericeis cumirirenti-tridentatis, 
conniventi-tridentatis, camlibus erectiusculis pilosis $\mathbf{r}-\mathbf{3}$ floris, petalis calice uajoribus. $2 F$. In umbrosis frigidionibus montium Delphinatûs, Sabaudix.

3759. Frogara. Foliis ternatis ovalibus obtusis crenatis subtus vilInsis, caulibus subfilitornibus decumbentibus hirsutis, petalis obcordatis catici xquahbus. 2F. In sylvis et sterihibus vere.

3-60. Micrantha. Foliis ternatis subtus villosis ovalihus ohtusis crenatis, caulibus prostratis hirsutis nanis, petalis caliee brevioribus subintegris. 2 . In suxosis Pyrenæorum editiorum.

$$
\text { 658. F } \mathbf{n} \text { A }
$$

Calix patens, 10 -lidus, laciniis 5 alternis minoribus; petala 5 ; receptaculum puposum, hemisphæricam, plermuqué caducum.

3-61. Vesca. Calice fructûs reflexo, foliis subtis subsericeis longe petiolatis, pubesecntia petiolorum patentissina. $2 \%$. In collibus montosis inter muscos.

$$
\text { 659. C O M A R U it. }
$$

Calix ro-fidus, laciniis 5 alternis minoribus; petala 5 ; receptaculum grande, ovatum, spongiosum, persistens.

3-62. Palustre. 4 . In uliginosis.

$$
\text { 66o. G } \mathbf{E} \cup \mathrm{m} \text {. }
$$

Calix ro-fidus, laciniis 5 alternis minoribus; petala 5 ; receptaculum oblongum, hirsutum; semina longè barbata, sepiùs geniculata, plumosa vel apice uncinata.

\section{J. I. Seminum aristis medio contortis.}

3-63. Urbanum. Floribus erectis, aristis nulis, foliis caulinis ternatis, radicalibus tyrato-pinnatis. $2 F$. In nemorosis et umbrosis ad sepes.

3764 . Rivale. Floribus nutantibus, petalis longitudine calicis, aristis plumosis. 4 . In aquosis montinm secus rivos. - Flores purpurascentes.

3765. Pyrenæum. Floribus subnutantibus, petalis calice longioribus, aristis pilosis apice glablis. 24. In Pyrenæis cditioribus.

5. II. Seminum aristis rectis.

3766. Montanum. Caule unifloro subnudo, aristis plımosis, foliis pinnatis hirsutis, foliolo extimo maximo subrotumdo, inferioribus sensim minoribus. $2 \mathcal{\zeta}$. In pascuis montium editissinis propè nives.

3767. Reptans. Caulibus unifloris, aristis villosis, foliis pinnatis incisis pilosis, flagellis reptantibus. $2 f$. In pctro, Alpium editiorum júxtà nives æuternas.

$$
\text { 66i. D } \mathrm{r} \times \mathrm{x} \text {. }
$$

Calix S-fidus, laciniis æqualibus; petala 8 ; receptaculum conicum, pubescens; semina barbata; aristæ plumosæ, medio non contorize. 
3-68. Octopetala. Foliis simplicitus. 2 . In pratis siccis et nudis Alpium, Jurassi, Pyrenæorum.

$$
\text { 662. } \mathrm{R} \text { U B U s. }
$$

Calix patens, 5-fidus; petala 5 ; receptaculnm breve, conicum, glabrum; seniua pulposa, in baccam compositam aggregata.

3;63. Saxatilis. Foliis ternats glabric, flagellis reptantibus herbaceis, acinis paucissinis. $b, 2$. Iu lapidosis montanis ad oras sylvarunı.

3770. Cusius. Foliis teruatis subtùs subhirsutis, lateralibus bilobis, caule frnticoso aculeato decumbente tereti. ๖. Ad sepes, vias, secus muros.

377r. Glandulosus. Foliis ternatis utrinquè villosis, caulibus sarmentosis prostratis aculeatis, ramis floriferis erectis petiolisque villoso-glandulosis aculeatis, petalis angustis. b. In sylvis montium Jurassi, Pedemontii, Delphinatûs, Pyrenæorum.

3772. Corylifolius. Foliis quinatis ternatisque subtù subpilosis, foliolis lateralibus sessilibus, caulibus subangulosis, aculeis rectiusculis. b. Ad sepes.

3-73. Fruticosus. Foliis quinatis ternatisque súbtìs incano-tomentosis, foliolis lateralibus petiolatis, canlibus angulosis, aculeis aduncis. b. Ad sepes orasque sylvarum fiequens.

3774́. Tomenısus. Foliis ternatis obovatis acutis inæqualiter dentatis utrinquè molliter tomentosis lateralibıs subincisis, caulibus vix angulosis aculeatis. Ђ. In dumetis petrosis Fontisbleaudi, Monspclii, Taurini.

3775. Idaus. Foliis quinato-pinnatis ternatisque subtùs incanis, caule aculeato subrecto, petiolis canaliculatis. $\mathrm{b}$. In petrosis montium Galloprovinciæ, Delphinatûs, Pedemontii, Alsatiæ, Jurassi.

\section{T R I B U S V. U L M A R I E.}

Ovaria libera, definita, monostyla; capsula tot quot ovaria, mono-vel-polyspermac; radicula supera; flores plerumqué completi hermaphroditi; stamina indefinita.

\section{S P I $\mathrm{R}$ 死 A.}

Calix patens, 5 -fidus; petala 5 ; ovaria $3-13$; capsulæ totidem uniloculares, intùs bivalves; semina $\mathrm{I}-3$, suturæ valvarum internæ adfixa.

\section{f. I. Fruticosa.}

3756. Salicifolia. Foliis oblongis serratis glabris, racemis decompositis. $b$. In montibus Arvernix.

3777. Crenata. Foliis obovatis acutis glabris, apice integris aut crenatis, coiymbis confertis pedunculatis. b. a, Ex Sibiria et Hungaria; $k$, in Gebennis.

\section{II. Herbacea.}

3778. Filipendula. Foliis pinnatis, foliolis uniformibus serratis ovato-oblongis, floribus paniculato-coryubosis. 4 . In sylvis pratisque umbrosis. 
3759. C'maria. Foliis pinnatis subtus tomentosis, impari najore trilobo, lateralibus indivisis, corymbis proliferis. 24 . In pratis humidis.

3-80. Aruncus. Foliis suprł-decompositis, spicis paniculatis, floribus dioicis. 24. In sylvis montosis Pyrenæurum, Jurassi, Beugesiæ, Arverniæ, Vogesorum.

\section{T R I B U S Y I. D R U P A C E E.}

Ovarium simplex, liberum, monosılum; diupanucleo I-2-spermo; membrana seminis interna lumidiuscula, subcarnosa; radicula supera; caulis lignosus; flores completi, hermaphrodili; stamina indefinila; folia simplicia, glandulis basivel in petiolis donata; calix 5-lobus; petala 5.

\section{4. c E r A s u s.}

Drupa carnosa, rotunda, glabra, uno latere subsulcata, polline glanco non couspersa; nucleus læevis, rotundatus, angulo subprominulo laterali.

$378 r$. Padus. Floribus racemosis, racemis pendnlis, foliis ovatolanceolatis deciduis glabris duplicato-serratis, petiolis biglandulosis b. Ad sepes et in sylvis, in Pedemontio, Delphinatu, Lotharingia, Alsatia, Pyrenæis, Arvernia, Lutetiæ.

$3 \delta_{1}{ }^{*}$. Laum-cerasus. Floribus racemosis, foliis sempervirentibus dorso biglandulnsis. Lin. Sp. 678. 3. Ex Oriente orta, nunc in provinciis australibus quasi spontanca.

3-82. Mahaleb. Floribus corymbosis terminalibus, foliis ovatis dentatis glabris. $b$. In ineultis et sylvaticis.

3-83. Semperflorens. Floribus racemosis, calicibus serratis, foliis ovato-lanceolatis serratis basi glandulosis. ๖. u, In bortis culta; $\beta$, in sylvis.

3754. Capmniana. Umbellis lateralibus paucifloris, foliis subpa. tulis ovato-lanceolatis glabris, ramis patulis, fructu sphærico acido. b. In sylvis? in hortis culta.

3-85. Juliana. Umbellis lateralibus paucifloris, foliis ovato-lauceoJatis sæpiùs pendılis serratis, ramis erectis, fructu subcordato molli non acido, $b$. In hor is culta.

3786. Avium. Floribus umbellatis subsessilibus, foliis ovato-lan, ceolatis subtìs subpubescentibus, ramis patulis, fructu orato molli non acido. $b$. In sylvis montosis.

3787. Duracina. Floribus nmbellatis subsessilibus, foliis dentatis pendulis, ramis erectis, fructu subcordato duro subfragili. $\zeta$. In hortis culta.

$$
\text { 665. P } \mathrm{R} \cup \mathrm{N} \text { u } \mathrm{s} \text {. }
$$

Drupa carnosa, glabra, uno latere sulcata, pulvere glanco obtecta ; 
nucleus ovato-oblongus, compressus, subscaber, margine sulcatoangulosus, apice acutus.

3-SS. Spinnsa. Pedunculis solitariis, foliis elliptico-lanceolatis subtus pubescentibus, fructibus erectis, ramis spinosis. b. Ad sepes in aridis.

วิ-\$9. Brigantiaca. Floribus lateralibus confertis, foliis ovatis mucronatis duplicato-serratis, staminibus exsertis petalis duplù longioribus. b. In Alpibus Delphinensibus.

3790. Domestica. Pedunculis subsolitariis, foliis ovato-lanceolatis subtus suhhirsutis, ramis patulis, fructibus ovato-subsphæricis. 5 . In sylris; in pomariis culta.

379r. Pyramidalis. Pedunculis subsolitariis, ramis erectis, foliis ovato-oblongis; fructibus oblongis. b. In hortis culta.

666. A R M E N I A C A.

Drupa rotundata, uno latere sulcata, tomento brevi obtecta; nucleus rotundatus, compressus, margine altero obtuso, altero acuto, utrinquè sulcato.

3792. Vulgaris. Floribus sessilibus, foliis ovato-subcordatis dentatis glabris. b. Ex Armenia orta, in sylvaticis Montisferrati spontanea? (All.); in hortis culta.

$$
\text { 667. A M } \text { y G D A L U s. }
$$

Drupa oblonga, subcarnosa, tomento brevi induta; nucleus oblongus, lævis, apice acutus, hinc indè porosus.

3793. Fulgaris. Floribus subsessilibus subgeminis, folinrum serraturis infimis glandulosis. $b$. In Gallia australi frequerıs.

668. F E R S I c A.

Druparotundata, carnosa, nunc glabra, nunc tomentosa; nuclens ovatus, irregulariter sulcato-rimosus, rimis anastomosantibus.

3794. Vulgaris. Fructu tomentoso. b. In hortis culta, ex Persia orta.

3795. Lavis. Fructu glabro lævi. b. Orta ex Persia? in hortis culta.

\section{O R D O LX X I I. L E C U M I I O S AE.}

Calix monophyllus, sæpiùs 5-fidus ; corolla calici inserta, pentapelala, nune (in exoticis) regularis rosacea, nunc irregularis papilionacea, petalo snperiore vexillum, duobus lateralibus alas, duobus inferis sæpè coalitis carinam constituentibus; stamina sapiús ro, nunc libera, nunc monadelpha, nunc diadelpha, nempè 9 coalita et I liberum; ovarium liberum; stylus 1 ; leguinen forma varium; sæpiùs bivalve, uni-aut-rariùs-biloculare; semina uni suturx laterali affixa; perispermum nollum ; radicula (in papilionaceis ) in lobos inclinans; colyledones crasse, interdium germinantes in folia non mutatæ. - Frntices ant herbæ, foliis alternis, sæpiùs compositis, stipulis axillaribus, foliolis noctu variè dormientibus. 
t Siamina omnia libera.

66g. с E $\mathrm{A}$ A $\mathrm{T}$ o $\mathrm{N}$ I $\mathrm{A}$.

Flores apetali, polygami; calix 5-fidus, inxcrualis; stamina 5-7 longa, calici inserta; ovarinm disco carmoso 5-lobo, in licumapludoditis staminifero cinctum; silicua clongata, conıpressa, intis puiposa, cxtus subcoriacea, spontè nou dehiscens; semina dura, nitidit.

37gf. Siliqun. b. In saxosis maritimis apricis Galloprovincix, circa

Nicæann, Monachimm (Monaco).

$$
\text { 67o. c E r c I s. }
$$

Calix urccolatus, basi ventricosus, 5-dentatus; corolla papilionacea unguiculata; carina dipetala, vexillo acqualis, alis brevior; stanina in declinata; legumen compressum, supuà membranaceo-alatun, polyspermum.

3797. Siliquastrum. Foliis cordato-orbiculatis glabris. b. In sylvis

et inter saxa Gailiæ mediterraneæ.

$$
\text { 67I. A N A G Y R I s. }
$$

Calix urceolatus, persistens, 5 -dentatus; corolla papilionacea; vexillum breve, inversè cordatum; cariua dipetala; stamina 10 ; legumen elongatum, compressum, subincurrum, polyspermum.

3rọs. Fotida. Foliis ternatis. b. In saxosis et collibus submontanis

Galliæ mediterrancæ, propè Nicæam, Arelatem, Monspelium.

\section{$\dagger+$ Stamina monadelpha.}

$$
\text { 672. U L E x. }
$$

Calix profundè bipartitus, lobis carinatis, basi squamosus; carina dipetala; stamina monadelpha; legumen turgidum, vix calice longius; semina pauca.

3-99. Eurnpeus. Dentibus calicinis obsoletis conniventibus, bracteis ovatis laxis, ramulis erectis. b. In sterilibus ad vias frequens.

38oo. Nanus. Dentibus calicinis lincenlatis distantibus, bracteis minutis adpressis, ramulis decumbentibus. ந. In collibus aridis et sabulosis, Fontisbleandi, in Pyrenxis, Occitania, Aquitania.

$$
\text { 673. G E N I S T A. }
$$

Calix bilabiatus, labio superiore bidentato, inferiore tridentato; carina decumbens, genitalia non ritè includens; stamina monadelpha; legumen oblongum. - Flores særiùs lutei.

\section{f. I. Ramis incrmilus.}

38or. Monosperma. Foliis lanceolatis sericeis sessilibus, ramis teretibus striatis subnudis, racemis lateralibus paucifloris, floribus subaggregatis, leguminibus monospermis. b. Monspelii. - Flores albi.

3802. Purgans. Foliis lanceolatis sericeis subsessilibus, ramin. 
teretibus striatis, floribus axillaribus solitariis. b. In sterilibus nontosis prov. mediterrancarnn, Lugduni, Arveruiæ, Aureliæ.

3803. Cinerea. Foliis lanceolatis sessilibus sericeis, ramis teretibus decem-sulcatis, floribus axillaribus solitariis subsessilibus puhescentibus. b. In collibus Delphinatûs, Galloprovinciæ, circà $\mathrm{Ni-}$ cram, Aginnum.

38of. Juncea. Foliis lanceolatis glabris, ramis junceis oppositis teretibus apice floriferis. b. In Occitania, Pedemontio, Galloprovincia, Delphinatu australiori, circa Tarban.

3805. Tinctoria. Foliis lanceolatis glabris, ramis teretibus striatis erectis, floribus racemosis, leguminibus glabris. b. In collibus et ad oras sylvarum.

$3805^{*}$. Ovata. Foliis oblongo-ovatis leguminibusque hirsutis, ramis teretibus striatis hirsutis, floribus racemosis. $b$. In collibus 'Iuninensibus observavit clar. Balbis. - G. ovata. Wild spec. 3. p. 9 ;́.

38of. Pi'osa. Foliis lanceolatis complicatis, floribus axillaribus subsessilibus, leguminibus corollis calicibusque sericeo-pilosis, canle striato procumbente. b. In petrosis et sabulosis.

3807. Prostrata. Foliis lanceolatis acutis, pedunculis axillaribus teruis foliis sublongioribus, corollis glabris, caulibus prostratis, ramis striatis, leguminibus pilosis. b. Inter lapides in Burgundia, Jurasso.

3808. Humifusa. Foliis lanceolatis utrinquè birsutis, floribus solitariis subsessilibus, corollis sericeis, ramis prostratis striatis leguminibusque hirsutis. Ђ. Propè Vapincum.

3809 . Sagittalis. Ramis ancipitibus membranaceis articulatis, foliis ovato-lanceolatis sessilibus distantibus. 2 . In lapidosis et sabulosis.

39ı. Triquetra. Fo!iis ternatis, summis simplicibas, ramis triquetris procumbentibus. Ђ. In Corsica.

381 . Scoparia. Foliis ternatis solitariisque oblongis, floribus axillaribus breviter pedicellatis, leguminibus margine pilosis, ramis angulatis. 5 . In incultis ubiquè, exceptis provinciis Alpinis.

\section{§. II. Ramis spinosis.}

3812. Scorpius. Foliis oblongis acutis sericeis, ramis teretibus striatis patentibus spinosis, floribus axillaribus confertis breviter pedicellatis. Ђ. In sterilibus montosis Galloprovinciæ, Delphinatûs australioris, Occitaniæ, Aquitaniæ.

3313. Angrlica. Foliis oblongis glabris, spinis simplicibus compositisve, ramis floriferis inermibus, florihns axillaribus solitariis subracemosis, corollis legumiuibusque glabris. b. In collibus aridis sabulosis, Fontisbleaudi, etc.

3814. Germanica. Foliis lanceolatis hirsutis, spinis foliosis simplicibus compositisque, ramis floriferis inermibus, racemis terminalibus nudis, carina pubescente, leguminibus pilosis. 2 . In collia bus lapidosis aut sabulosis. 
38r5. Hispanicn. Foliis lauccolatis villosis, spinis compositis pungentibus, racemo terminali subcapitato, earinis legunimibusque demum glabris. b. In collibus lapidosis et apricis Gallia mediterranex.

3Sıf. Lobelii. Foliis simplicibus ternatisque subtomentosis, ramis alternis tuberculosis spinesissimis, floribus axillaribus subsolitariis subsessilibus, corollis sericeis.b. In montibus Galloprovinciæ, Corsicæ.

3817. Horridu. Foliis oppositis ternatis linearibus, floribus subgeminis terminalibus, ramis angulatis spinosis oppositis, calice pubescente. Ђ. Circh Baionam, Burdigalam, in Pyrenæis editioribus et circà Lugdunum.

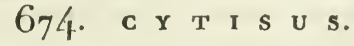

Calix bilabiatus, labio superiore 2-dentato, inferiore 3-ilentato; carina erecta, genitalia includens; stamina monadelpha; legumen compressum, basi subattenuatun. - Folia ternata; flores lutei.

\section{†. I. Calice brevi, campanulato.}

38ı. Laburnum. Racemis simplicibus pendulis, foliolis ovato-oblongis. . In lapidosis demissorum Alpium, Jurassi, collium Bressixe, Bengesiæ, Burgundix.

38ı. Nigricans. Racemis terminalibns erectis, calicibus leguminibusque pubescentibus, foliolis ellipticis subtùs pubescentibus. $b$. In sylvis cæsis sterilibusque agri Pedemontini.

3820. Sessilifolius. Racemis erectis, calicibus doractea triplici, leguminibus glabris, foliis floralibus sessilibus. $b$. In collibus aridis et apricis secus sepes et nemora, in Occitania, Delplinatu inferiori, circà Nicæam, Taurinum.

382 r. Complicalus. Racemis erectis laxis terminalibns, ramis divaricatis, foliolis complicatis, calicibus leguminibnsque glandulosomuricatis. b. In Pictonico agro et prov. occillentalibus, Monspelii et in Gislloprovincia.

3822. Spinosus. Floribns axillaribus confertis, foliolis obovatis, calicibus leguminibusque glabris, ramis angulatis spinosis. b. In montosis et aridis Galliæ Meditcraneæ et Corsicæ.

3823 Lanigerus. Floribus axillaribus, ramis spinosis, foliolis pubescentibus, bracteis calicibusque sericco-hirsutis, leguminibus tumidiusculis villoso-lanuginosis. b. In Corsica.

382 . Candicans. Pedunculis confertis subtcrminalibus, foliis obovatis pubescentibus, pilis adpressis, ramis angulatis, Jegnminibus coupressis hirtis. $b$. Iu provinciis mediterraneis, in Corsica et in agro Pictonico (Bon).

38:5. Tinifolius. Racemis terminalibns ercctis, foliis ternatis sessilibus linearibus subtus sericeis, ramis teretibus sulcatis. b. In Stæchadum insulis.

3826. Triflorus. Floribus pedunculatis axillaribus subternis, foliolis. ovatis obtusis hirsutis, leguminibus compressis snbarcuatis villosissimis, 3. Circà Antipolim, Olbiam, in Occitania, Narbonis. 
5. II. Calice tubuloso.

3927. Capitatus. Floribus capitatis terminalibus, ramis erectis teretibus villosis, folinlis ovato-ellipticis villosis. b. In provinciis meridionalibus ad oras sylvarunı et in collibus.

3825. Argenleus. Floribus subsessilibus axillaribus, foliolis lanceolatis sericeis, leguminibus linearibus scriceis, canlibus decumbentibus. b. In lapidosis sterilibus et apricis Galliæanstralis.

$$
\text { 675. L u } \mathbf{p} \text { I } \mathbf{s} \text { u s. }
$$

Calix hilabiatus; carina dipetala; stamina monadelpha; legumen coriaceum, oblongum, polyspermum. - Folia quinata.

3S20. Albus. Floribus alternis chracteatis, calicis labio superiore integro, inferiore tridentato. $\odot$. In provinciis meridionalibus, cultus.

383 ). Varius. Floribus semi-verticillatis bracteatis, calicis labia superiore bifido, inferiore subtridentato. $\odot$. In provinciis meridionalibus inter segetes.

383 r. Angustifo/ius. Floribus alternis bracteatis, labio calicis superiore bifido, inferiore integro, fololis lineari-lanceolatis planis. ๑. Circà Tarbellicus-Aquas, Burdigalam, Cenomanum, Aurelian.

3832. Luteus. Floribas verticillatis bracteatis, labio calicis supcriore bipartito, inferiore tridentato. $\odot$. In arvis, Monspelii.

3833. Hirsutus. Floribus alternis bracteatis, caule foliisque pilosis, labio superiore calicis bipartito, inferiore tridentato. $\odot$. Monspelii.

$$
676 . \quad 0 \text { N o N I s. }
$$

Callix rampanụlatus, 5-fidus, laciniis linearibus; vexillum striatunı; staminu monadelpha; legumen inflatum, sessile; scmina pauca.

\section{¡. 1. Floribus subsessilibus.}

3ิs3. Antiquorum. Floribus solitariis foliolo majoribus, folin inferioribus ternatis lanceolatis apice dentatis, ramisque spinosis. glabris. 25. Ad vias et fossas, in Arvernia, Nicææ, Taurini, Segusii. - Flores purpurascentes, ut in 2 sequentibus.

3335. Arvensis. Floribus subgeminatis axillaribus, foliis inferioribus ternatis ovatis subviscosis serratis, ramisque spinosis villosis. 24. In arvis, $\beta$ in sabulosis maritimis et secus torrentes.

3536. Allissinta. Floribus geminatis, foliis inferioribus ternatis ellipticis serratis pubcscentibus, caule inermi villoso-viscoso. 2 . In sabulosis Pedemontii, Vallesiæ, Sabaudiæa, Moguntiæ.

3937. Parviflora. Floribus sessilibns lateralibus, foliis ternatis oblongis pubescentibus serratis, stipulis lancenlatis denticulatis, calicibus scariosis corolla longioribns. 2 . In saxosis collibusque sabulosis. - Flores lutei, ut in 3 sequentibus.

3833. Minutissima. Floribus scssilibus lateralibus, foliis ternatis cuncatis glabris, stipulis setaceis integerrimis, calicibus scarioșs corolla longioribus. $\odot, \mathcal{O}^{7}$. In saxosis apricis Galliạ australis. 
3839. Striata. Florilus solitariis subsessilibus, foliis ternatis obcordatis pubescentibus dentatis, corollat ealice viscoso longiore. 2 . In pascuis Gebennensium, Pyrenæorum.

384́o. Variegata. Florihus solitariís subperlunculatis, foliis simplicibns ovato-cunciformibus dentatis, canle proeumbente tomentoso viscoso. $\odot$. In maritimis Galloprovinciæ, propè Stæcharlum insulas?

\section{II. Floribus peclunculatis.}

38 fr. Reclinata. Pedunculis muticis axillarihus uniforis, folii longituline, foliis ovato-rotumblatis subcarnosis dentatis, leguminibus cernuis, caule diffuso subviscoso. $\odot$. In maritinis Occitanix.

3Sła. Cenisia. Pedunculis muticis axillaribus unifloris folio duplò longioribus, folinlis cuncatis stipulisque serratis, caulibus prostratis. $2 F$. In pascuis siccis sylvisque subumbrosis $\Lambda$ lpium Delph. Pedem. Galloprov. - Flores purpurascentes, ut anteced. et ser.

3843. Cherleri. Pedunculis unifloris subaristatis, foliis ternatis apice dentatis, subtis villoso-viscosis, calicibus coroila longioribus. $\odot$. In sabulosis demissorum montiun Gralliæ australis et Corsice.

384f. Ramosissima. Pedunculis unifloris aristatis eernuis folio duplo longioribus, foliis ternis lineari-obovatis, stipulis olblongis. 27. In sabulosis maritinis Nicææ. - Flores lutei, ut in 2 seq.

3845. Viscosa. Pedunculis unifloris aristatis longitudine foliorum, foliis simplicibus oblongis serratis viscosis, infimis ternatis. $\odot$. In Gallia australiori, circa 'Tendam, in Galloprovincia, Monspelii.

38 ff. Natrix. Pedunculis unifloris aristatis folio longioribus, foliis ternatis viscosis oblongis apice dentatis, canle sufiruticoso. . Ad oras sylvarum et viarum.

3847. Fruticosa. Pedunculis subtrifloris, stipulis scariosis vaginalibus, foliis subsessilibus ternatis lanceolatis serratis, caule fruticoso. b. In collibus montibusque apricis Galloprovinciæ. - Fl. purp.

3848. Rotundifolia. Pedunculis subtrifloris, calicibus triphyllo-bracteatis, foliis ternatis ovatis dentatis, caule fruticoso. 2 , b. In Alpibus et Pyrenæis, secus torrentes. - Flor. purpur.

$$
\text { 677. A N T H } \mathbf{x} \text { L } \mathbf{L} \text { I } \mathrm{s} \text {. }
$$

Calix orato-oblongus, medio inflatus, ore connivens, persistens, 5dentatus; stamina monadelplia; legumen parvum, 1-2-spermum, calice tectum.

\section{I. Caule herbaceo.}

3849. Tetraphylla. Herbacca, foliis quaterno-pinnatis inæqnalibus, floribus lateralibus. $\odot$. Secus vias et agros provinciarum mediterranearum et Corsicæ.

355o. Vulneraria. Herbacea, foliis pinnatis inxqualibus, capitulo terminali duplicato. 2 . In pascnis montosis frequens.

385r. MIontana. Herbacea, foliis pinnatis æqualibus scriccis, capitulo terminali globoso. 2 . In apricis montium Galliæ australis, ) elphinatûs, Sabaudix, Jurassi. 
3852. Gerardi. Herbacea, foliis pinnatis inæqualibns, pedunculis lateralibus folio longioribus, caritulis aphyllis. $\odot$. Inter pinetos in sylvis maritimis Galloprovinciæ, Corsicæ.

\section{j. II. Caule lignoso.}

3353. Barba Jovis. Fruticosa, foliis pinnatis æqualibus sericeotomentosis, bracteis capitula globosa in ultiflora æquantibus. ๖. In saxosis maritimis Galloprovinciæ circà Nicæam, in Corsica.

3854. Cytisoides. Fruticosa, foliis ternatis inæqualibus, calicibus lanatis lateralibus. b. In collibus excclsis Ruscinonensis agri.

38.55. Hermannix. Fruticosa, foliis ternatis lincari-cuneatis sessilibus, calicibus campanulatis, ramis spinescentibus. b. In Cossica.

\section{$\dagger \dagger \dagger$ Stamina diadelpha; legumen uniloculare; cotyle.} dones semper è terra exserta, in folia seminalia plerumque abeuntes; folia ternata seu impari pinnata.

$$
678 \text {. P S O R A L E A. }
$$

Calix 5.fidns, persistens, punetis callosis arlspersus; petala 5 libera; stamina diadel pha aut monadelpha; legnmen inonospermum.

$3 \AA 56$. Bituminnsa. Foliis ternatis, foliolis ovato-lanceolatis . petio- lis pubescentilus lævibus, spicis capitatis pedunculatis axillaribus. b. In sterilibus apricis Galliæ australis.

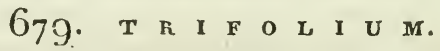

Calix tubulosus, persistens, 5 -dentatus; carina simplex, alis vexilloque brevior; legumen minimum, I-2-spermum, calice tectum; tlores capitati; folia ternata.

\section{I. Calice glabro post inflorescentiam non inflato; vexillo caduco; floribus albis vel rubentibus.}

3857. Alpinum. Capitulis umbellaribus, scapo nudo, legnminibus dispermis pendulis, foliis lineari-lanceolatis. 2 . In pascuis editiorum montium.

3858. Strictum. Capitulis ovatis, legnminibus dispermis erectis, foliolis oblongis serrulatis, stipulis rhombeis glanduloso-denticulatis. $\odot$. In pratis collibısque nudis, Fontisbleaudi, in Galloprovincia, Pedemontio, secus Aturmm.

28.̃. Repens. Capitulis umbellaribus, leguminibus 4-spermis, calicinis dentibus inæqualibus, foliolis ovato-oblongis emarginatis scrrulatis, caule repente. 2 . In pratis et graminosis frequens.

3860. Hybridum. Capitulis umbellaribus, leguminibus 4 -spermis, calicinis dentibus subæqualibus, foliolis ovato-oblongis emarginatis serrulatis, caule adscendente. $\mathcal{\psi}$. In pratıs subliumidis circà Parisios, etc.

$356_{1}$. Ciespirnsum. Capitulis nmbellaribns, leguminibus 4-spermis, calicinis dentilus æqualibus, foliolis obovatis obtusis serratis, caule erectiusculo. $\mathcal{F}$. In pascuis Alpinis et ad vias montium.

2862. Clomeratum. Capitulis sphæricis axillaribus terminalibusçue 
sessilibus, calicinis dentibus aequalibus subulatis patulis rigilis, foliulis obovatis scsrulatis. $\odot$. Circà Nicæam, Mouspelium, 'Tarbellieas-Aquas, in pratis siccis.

3863. Suffocatum. Capitulis sessilibus lateralibus terminalibusve, dentibus calicinis lanceolatis acutis recurvis corolla longioribus. $\odot$. In sabulosis maritinis circà Nicaam.

8. II. Calicilus villosis vel hirlis post inflorescentiam non inflatis; vexi!lis caducis; floribus albis vel rubentibus.

396' Subterraneum. Capitulis villosis 5-floris, coma centrali reflexa rigidi fructum obvolvente. $\odot$. In graminosis, collibus et ad oras sylrarum.

3S65. Saxatile. Capitulis villosis subglobosis, calicinis dentibus subulatis corollam æuaantibus, caulibus erectis, foliolis lanceoJito-cuneatis emarginatis. $\odot$ All. $\delta$ Vill. Secus torrentes in Alpibus editioribus.

3866. Cherleri. Capitulis villosis globosis terminalibus solitariis, calicinis dentibus setaccis corolla longioribus, caulibus procunnbentibus, foliolis obcordatis integerrimis. $\odot$. In sylvaticis maritimis Galliæ Mediterrancæ.

3867. Hispidum. Capitulis villosis globosis terminalibus involucratis, calicinis dentibus setaceis corollit brevioribus, ciulibus erectis. $\odot$. In Monteferrato, Corsica, Monspelii.

3868. Ciliosum. Capitulis subrotundo-ovatis diphyllis, canlibus ercctiusculis ferè glabris subangulosis, foliolis ovato-oblongis utrinque attenuatis. $\odot$ Thuil. $\sigma^{\prime}$ Desf. Ad oras sylvarum Fontisbleaudi.

3869. Lappaceum. Capitulis subglobosis hispidis, dentibus calicinis subulatis corollam aquantibus, caule diffuso, foliolis obovatis retusis. $\odot$. Ad marginem agrorum in provinciis meridionalibus.

3Szn. Rubens. Spicis cylindraceo-oblongis, calicinis dentibus villosis, infimo longitudine corolla monopetalæ inæqualis, stipulis ensifornibus, foliolis lanceolatis obtusis serrulatis, caule erecto. $2 \mathcal{F}$. In pratis et ad margines sylvarum in montibus.

3S7 1 . Pratense. Spicis densis ovatis, calicis dente infimo tubo corollæ monopetalæ inæqualis brevince, stipulis aristatis, foliolis ovalibus subintegerrimis, caule adscendente. 2 . In pratis frequens, cultum.

3872. Medium . Spicis laxis subglobosis solitariis, calicis dente infimo tubum corollæ monopetalæ subæqualis æquante, stipulis subulatis, foliolis ellipticis tenuissimè scrrulatis, caulibus ramosis flexuosis. 2 4 . In sylvis pratisque lapidosis.

§\$ -3. Alpestre. Spicis densis subglobosis subgeminatis, calicis dente infimo tubum corollæ monopctalæ subæqualis æquante, stipulis setaceis, foliolis lanccolatis tennissimè serrulatis, canlibus simplicissimis strictis. 24. In pascuis montium editiorum Pedem. Delph. Pyrenæorum.

3874. Pannonicum. Spicis densis oblongo-ellipticis solitariis, calicis 
dente infimo tubum corollx monopetalæ inxqualis breviore, stipulis subulatis, foliolis ob」ongo lnceolatis integerrimis emarginatis villosis, caulihus simplicissimis strictis. $2 \mathrm{~F}$. In humidis Alpium Pedem. Delph., cincà Nontem-Albanum?

38-5. Incarnatum. Spicis oblongis villosis obtusis aphyllis, foliolis subrotundo-obendatis ovatis crenatis villosis. $\odot$. In pratis subhumidis Parisiis, Monspelii, Gineva.

38-6. Ochroleucum. Spicis villosis ovato-rotundatis, canle ercctiusculo ramoso-pubescente, foliolis oblongis infimis obcordatis, calicis dente inferiore longissino. 2 . Circà Parisios, Gratianopolin, Abbatis-Villam, etc.

38\%. MIontanum. Capitulis ovatis terminalibus, vexillis subulatis apicc cmarginatis, calicibus glabris aut pubescentibus, caule crecto. 25 . In pascuis montosis.

38-S. Angustifolium. Spicis villosis conico-oblongis, dentibus caJicinis setaceis subæqualibus, foliolis linearibus. $\odot$. In arvis Gallix australis.

3879. Aruense. Spicis villosissinis subcylindraceis, dentibus calicinis setaceis, corolla sublongioribus, foliolis obovato-linearibus. $\odot$. In arvis frequens.

388o. Stellatum. Spicis pilosis oratis, calicibus patentibus, caule diffuso, foliolis obcordutis. $\odot$. Secus vias et agros in Gallia australi.

$38 \mathrm{~S}$ r. Squarrosum. Spicis oblongis subpilosis, calicum infimo dente longissimo reflexo, caule herbaceo erecto. $\odot$. Ad sylvas et stagna circà Parisios, 'Tarbellicas-Aquas, in Gall provincia.

3S82. Irregulare. Spicis ovatombtusis densis terminalibns, calicin is laciniis subxqualibus 3-nervii snbhirsntis, caule erectinsculo, foliolis oblongis subintegris. $\mathcal{\Psi}, \odot$. In pratis maritimis circà Antipolim, Narbonem.

3583. Clypeatum. Spicis ovatis, calicibus patulis dente infimo maximo lanceolato, stipulis ovatis, foliolis obovatis. 4 . In Pedemontio prope Casal-Borgone.

3884. Scalrum. Capitulis ovatis axillaribus sessilibus, calicinis dentibus inæqualibus lanceolatis mucronatis rigidis recurvis, foliolis obovatis serrulatis. $\odot$. In sabulosis Parisiis, ctc.

3855. Striatum. Capitulis terminalibus axillaribusque ovatis sessiJibus basi involucratis, calicibus striatis pilosis inæqualibus, foliolis obovatis subintegerrimis pubesecntibas. $\odot$. Ad vias, secus Aturum, Parisiis, etc.

1. III. Calicibus post inflorescentiam inflatis; vexillis caducis; foribus albis vel rubentibus.

3856. Spumosum. Capitulis ovatis, calicibus fructiferis ovatis ventricosis glabris, dentibus setaceis recurvis, involucris universalibus membranaceis 5-phyllis, caule crecto. $\odot$, Linn. $\underset{\%}{2}$, Ger. Ad vias et in graminosis Galliæ australis.

3897. Kesupinatum. Capitulis subrotundis, corollis resupinatis, 


\section{L, E G U M I N O S A R.}

calicibus fructiferis inflatis membranaceis prabescentibus, deutibus setaccis, eautibus prostratis, foliolis obovatis aculis. $\odot$. Iu pratis montium hund infiequens.

3888. Tomentosum. Capitulis globosis, calicibus fruetiferis inflatis membranaceis tomentusis, dentibus obliteratis, canlibus prostratis. 24, Linn. ○, Ger. Desti en herbosis matrimis Galliax anstralis.

3SSy. Frastijerum. Capitulis subrotundis, calicibus fructiferis inflatis membranaccis pubescentibus, dentibus setaceis binis reflexis, canlibus repentibus, foliolis obovatis obtusis. 2 . Ad vias et in graminosis circà Parisios, Nicæam, cıc.

\section{j. IV. Vexillis persistentibus, deorsium post inflorescentiane deflexis; floribus luteis.}

3S9o. Spadiceum. Spicis ovalibus imbricatis, calicinis dentibus subpilosis subulatis, binis superioribus ovatis brevissimis, caule erecto, foliolis obovatis, intermedio sessili. $\odot$. In pratis montanis.

3891. Agrariume. Spicis ovalibus imbricatis, calicinis dentibus subulatis inæqualibus glabris, canle crecto, foliolis lanceolato-cuneatis, intermedio sessili. $\odot$. In pratis subhumidis.

$389^{2}$. Procumbens. Spicis ovalibus imbricatis, caulibns subprocumbentibus, foliolis obovatis intermedio petiolato, vexillis striatis. $\odot$. In pratis sicecis ad marginem sylvarum.

38y3. Filifornee. Spicis capitatis hemisphæricis, canlibus subprocumbentibus, foliolis obcordatis intermedio petiolato, vexillis lavibus. $\odot$. In sabulosis ad vias et in pratis.

$$
\text { 680. M E L I L O T U S. }
$$

Calix tubulosus, 5 -dentatus; carina simplex, alis vexilloque brevior; legumen calice longius; flores laxè racemosi.

3394 . Oficinalis. Leguminibus racemosis pendulis subrugosis acutis 1-2-spermis, caule erecto, foliolis ovato-oblongis lentatis. 24 . - In pratis et ad sepes frequens.

3895. Italica. Leguminibus racemosis obtusis subspliæricis rugosis, canle erecto, foliolis integris. ๑. Monspelii, Nicææ, in Pyrenæis。

3896. Parviflora. Leguminibus pendulis subrugosis ovatis, caule crecto, foliolis obtusis basi attenuatis serratis. $\odot$. In pratis siccis collibusque apricis Pedemontii.

3897 . Sulcata. Leguminibus I-spermis oboratis obtusis arcuatim rugosis, foliolis sublinearibus serratis, caule diffuso, racemis folio longioribus. $\odot$. In Occitania.

3898. Messanensis. Leguminibus $\mathrm{I}-\mathrm{spermis}$ ovatis acutis arcuatim rugosis, foliolis cunciformibus truncatis subdentatis, caule erecto, racemis folio brevioribus. $\odot$. In Pedemontii circà Novariam.

$$
\text { 68I. M E D I G A G O. }
$$

Calix subcylindricus, 5-fidus; carina à vexillo subremota; legu- 
men polyspermum, forma varium, sumper falcatum rel in spiram contortum. - Flores sæpiùs lıtei.

\section{I. Leguminibus arcuatis vel circulariter curvatis.}

3899. Sativa. Pedunculis racemosis, leguminibus lævibus cochleato-contortis, stipulis integerrimis, foliolis oblongis dentatis, caule erccto glabro. 2 . In pratis et ad muros, colitur in pecudum usum.

3gon. Falcata. Pedunculis racemnsis, leguminibus contorto-falcatis levibus, foliolis nblongis apice dentatis, caulibus basi prostratis. 2 . In puatis siccis et montosis.

3901 . Cinmerata. Pedunculis racemosis, leguminibus contortocochliatis subpubescentibus, foliolis integerrimis apice emarginatis, canibus erectiusculis. - Iı montibus Tendæ propè Barra.

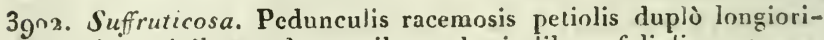
bus, leguminibus pubescentibus subspiralibus, foliolis ovato-rotundatis subintegris, caulibus prostratis suffruticosis. $\mathcal{4}$. In Pyrenxis propè Valletriam.

39o3. Lupulina. Spicis ovalibus, leguminibns reniformilus i-spermis pubescentibus striatis, foliolis ovatis apice subdentatis, caulibus procumbentibus. $\sigma$. In arvis, graminosis et ad muros.

3904. Rañiata. Pedunculis $2-3$-floris, leguminibus planis glabris semi-orbicularibus margine dentato-ciliatis, foliis ovalibus denticulatis. $\odot$. Circà Nicæam.

3905. Circinnata. Pedunculis 2-4-floris subcorymbosis, leguminihus reniformibus margine dentatis, foliis impari-pinnatis, foliolis oratis integris. $\odot$. In maritimis Mediterranei.

\section{II. Ieguminibus cochleatis, spiris pluribus. \\ * Leguminibus glabris, inermibus.}

39o6. Orbicularis. Pedunculis 1-2-floris, leguminibus inermibus orbiculatis planiusculis, foliolis obtusis inverse-cordatis apice dentatis, caulibus diffusis. $\odot$. In pratis, cultis et arvis Gulliæ australis.

3907 . Scutellata. Pedunculis 1-2-floris pubescentibns, leguminibus suprà convexo-hemisplıricis subtùs planis, foliolis ovato-oblongis ambitu dentatis. $\odot$. In agris et inter segetes $G$ alliæ australis.

39o8. Ternata. Pedunculis multifloris, leguminihus cylindricis utrinquè planis, stipulis ciliato-dentatis, foliolis obovatis dentatoserratis. $\odot$. In arvis et incultis Galloprovinciæ.

3979 . Turbinata. Pedunculis 1-2-floris, leguminibus cylindricis medin ventricosis apicibus convexis, stipulis dentatis, foliolis rhombeo-ovatis dentatis. $\odot$. In arvis, inter segetes Galliæ australis.

39ı. Tuberculata. Pedunculis I-2-floris, leguminibus cylindricis dorso tuberculis incrassatis duplici serie ordinatis, stipulis basi dentatis, foliolis rhombeo-ovatis dentatis. $\odot$. In provinciis meri- dionalibus. 
** Leguminibus pubescentibus subspinosis.

39r. Rigidula. Pednnculis 2-3-floris, Jeguminibus cylindraceis utrinquè applanatis dorso noricato spiunois, stipulis basi dentatis. ๑. In Gallia australi, ad fossas circà Aurelian?

3912. I'illosa. Pedunculis ^-floris, leguminibus villosis utrinque planis dorso aculeatis, stiputis seticeo-dentatis. $\odot$. In sterilibus et arvis Galloprovinciæ, circà Parisios.

3̂9r3. Minima.Pedunculis $\mathbf{- f l o r i s , ~ l e g u m i n i b u s ~ a c u l e i s ~ u n c i n a t i s , ~ s t i - ~}$ pulis integris, caule foliisque villosis. $\odot$. In pratis et campestribus.

3914. Marinn. Pelunculis multifloris, leguninibus tomentosis submuricatis, stipulis integris, foliolis cunciformibus tomentosis integerrimis. 24 . In maritimis Galliæ australis, in Corsica, NigriMonasterii insula.

39r5. Intertexta: Peduncnlis $\mathbf{t}-\mathbf{2}$-floris, leguminibus ovalibus, aculeis piloso-lanatis setaceis intricatis, stipulis ciliato-dentatis, foliolis obovatis dentatis. $\odot$. In arvis et cultis Gallix australis.

\section{*** Leguminibus gialris spinosis.}

39ı6. Echinus. Pedunculis 5-6-floris petiolis Iongioribus, leguminibus ovalibus lavibus, aculeis setaceis imbricatis. $\odot$. In Gallia australi, circà Nicæam.

3917. Laciniata. Pedunculis $\mathrm{y}-2$-floris, leguminibus cylindraceis, aculeis subulatis rectis uncinatis, stipulis ciliato-dentatis, foliolis linearibus inciso-dentatis truncatis. $\odot$. In arvis Gallix australis.

39 18. Muricata. Pedunculis multifloris, leguminibus glabris utrinquè planis, anfractibus quinis, acnleis subulatis brevissinis, stipulis ciliato-dentatis, foliolis rbombeo-ovatis dentatis. $\odot$. In pratis.

3gr9. Maculata. Pedunculis 2- 4 -floris, leguminibus cochlcatis utrinquè compressis, aculeis subulatis arcuatis, stipulis dentatis, foliolis obcordatis dentatis maculatis. $\odot$. In sabulosis subhunidis et herbosis.

3920. Apiculata. Pedunculis 3-7-floris, leguminibus cochleatis utrinquè planis, anfractibus tribus reticulatis margine muricatis, stipulis ciliato - dentatis, foliolis obovatis apice vix denticulatis. $\odot$. Inter segetes circà Niexam, Abbavillam.

392r. Denticulata. Pedunculis 5-7-floris, leguminibus cochleatis utrinquè planis, anfractibus binis reticulatis margine aculeatis, aculeis divergentibus, stipulis ciliato-dentatis, foliolis obovatis denticulatis. $\odot$. In Gallia australi.

3922. Coronata. Pedunculis 3-5-floris petiolo longioribus, leguminibus subpnbescentibus, anfractibus binis, aeuleis subrectis marginalibus coronæformibus, stipnlis dentatis, foliolis obovatis apice dentatis. $\odot$. In arvis Galliæ australis.

3923. Terebellum. Pedunculis 3-4-floris, Icguminibus cochleatis cylindricis, anfractibus quinis, aculeis brevissimis distichis subulatis reflexis, stipulis ciliato-dentatis, foliolis oboratis retusis dentatis. ๑. In Galloprovincia, Occitania. 


\section{T R I G O N E L L A.}

Calix campanulatus, 5 -fides; carina minima; alæ vexillumqus sulppatentes, corollam 3 -petalam mentientes; legunen oblongum, compressum vel cylindricum, acuninatum, erectiusculun, polyspermum.

\section{§. I. Leguminibus pedunculatis compressis.}

392 . Hvbrida. Leguminibus 3-4 pedunculatis compressis glabris, stylo i:amatis 3-spernis, foliolis cuneiforntibus subintegris glabris. 2 . In Corbariensibus montibus.

3925. Corniculata. Leguminibus 8-10 pedunculatis compressis declinatis subfalcatis 6-8-spermis, foliolis ovatis apice dentatis. $\odot$. In Gritlia anstrali.

3926. Ornithnpndioides. Leguminibus 2-3 pedunculatis subcompressis subfalcatis $8-10-$ spermis, caulibus declinatis, foliolis ovatis denticulatis. $\odot$. In collibus circà Cadomun?

\section{§. II. Leguminibus subsessilibus cylindricis.}

3927. Fonum grcecum. Legnminibus sessilibus strictis erectiusculis : ubfalcutis acuminato-conicis, caule erecto. $\odot$. Ad margines agrotum in Gulia australi.

3928. Polycerata. Leguminibus subsessilibus subquaternis congestis crectis subrectis longis linearibus, caulibus diffusis, foliolis cuneiformibus apice dentatis. $\odot$. In arvis et incultis Galliæ australis.

3929. Alonspeliaca. Leguminibus sessilibus subsenis congestis arcuatis divaricatis inclinatis brevibus, caulibus prostratis, foliolis ovatis subtis subpubescentibus denticulatis. $\odot$. Ad margines agrorum in Gallia atustrali.

\section{L o}

Calix tubulosus, persistens, 5-fidus; alæ vexillo breviores sursùm conniventes; legunien oblongum, erectum, cylindricum, interdùne alis foliaccis quadrangulum.

\section{I. Leguminibus alis foliaceis quadrangularibus}

(TETRAGotorobus).

3930. Siliquosus. Leguminibus solitariis membranaceo-quadrangulis, caulibus decumbentibus, bracteis lanceolatis. $2 F$. a subvillnsa, in pratis humidis; $\beta$ glabra, in maritimis. - Flores pallidè lutei.

393 I. Tetragonolobus. Legnminibus suhsolitariis membranaceoquadrangulis, bracteis ovatis, caulibus subdecumbentibus hirsutis, foliolo intermedio subdentato. $\odot$. Circà Nicæam. - Florcs purpurei.

3932. Conjugratus. Leguminibus conjugatis membranaceo-quadran-, gulis, bracteis oblongo-ovatis, foliolis subrhomboideis. $\odot$. Monspelii, in paludosis Arverniæ.

3933. Edulis. Leguminibus binis ternisve gibbis incurvis subquadrangulis, caule adscendente, foliis glabris, stipulis oyatis. $\odot$. In incultis ad margines agrorum, Nicæx, Oneliæ. 


\section{f. II. Legruminibus compressis (LOTEA).}

393f. Ornithoporlinides. Leguminibus subternatis an cuat is compressis, caulsbus dirrusis. $\odot$. In cricetis maritimis Cilloprovincix, Nicxe, Monspelii, Aquitanix, Arvernixe.

$3934^{*}$. Coimelmensis. Peduncuiis subunifloris, caulc ramoso procumbente, foliolis obovatis, leguninibus lincaribus compressis. ○. Circà Forunt-Juiii (f'réjus) olsservavit cel. Balbis. L. coimbrensis. Wild. sp. 3. P: 139 o. Plantie cultæ folia glabra, spoutaneie inferiora glabra, superiora apice piloso-ciliata.

\section{III. Leguminibus teretibus ( Lotes).}

3935. Citisoides. Capitulis 2-f-floris longè pedunculatis, canlibus basi prostratis subramosis, pedicellis calicibusque incanis, foliulis obtusissimis. $\odot$. In sterilibus maritimis Nicææ, Massilise et in Corsica.

3936. Corniculatus. Capitulis depressis 8-ro-floris, canlibus subdecumbentibus, leguminibus cylindricis patentibus rigidis. 2 . In pratis frequens, pù solo variabilis.

$39^{3} 7$. Hispirlus. Capitulis $4-5$-floris subnudis, pedicellis calicibus stipulis foliolisque lispillis, caulibus prostratis ramosis. $\odot$. In Corsica.

3938. Hirsutus. Capitulis 7-8-floris subpatulis, caule erecto hirto suffruticoso, leguminibus ovatis. Ђ. In humidis maritimis Galliæ mediterraneæ, Viennæ $\mathrm{ct}$ in Limania.

$39^{3} \mathrm{~g}$. Rectus. Capitulis globosis 2o-floris, caule erecto villoso, leguminibus gracilibus brevissimis rectis, stipulis subcordatis b. Secus rivos in Gallia australi.

$$
\text { 68\%. D O R Y C N I U } \mathbf{~ M . ~}
$$

Calix 5-dentatns, 2-labiatus; stigma capitatum; legumen turgidum, I-2-spermum.

39яo. Suffruticnsume. Foliolis lineari-lanceolatis acutis, calicinis dentibus ovatis, caule fruticoso. b. In sterilibus ct sabulosis Galliæ australis.

394 r. Herbaceum. Foliolis obovatis obtusis, calicinis dentibus ovatis, caule herbaceo. 4 . Secus flumina, circà Gratianopolim, Camberiacum, Taurinum.

$$
\text { 685. P H A S E O L U S. }
$$

Calix 2-labiatus, labium superins emarginatum, inferius 3-dentatum; carina et genitalia in spiram contorta; legumen oblongum, polyspermum.

3942. Vu'garis. Caule volubili, racemo solitario foliis breviore, pedunculis geminatis, bracteis calice minoribus patentibus, leguminibus pendulis. $\odot$. Ex India ortus, colitur in hortis olitoriis.

39f3. Multiflorus. Caule volubili, racemo solitario longitudine foliorum, pedunculis geminatis, bracteis calice minoribus adpressis, leguminibus pendulis. $\odot$. Ex America meridionali? colitur. 
39 你. Tianus. Caule erecto lavi, bracteis calice majoribus, leguminihus compressis pendulis rugosis. $\odot$. Ex India? colitur in hortis olitoriis.

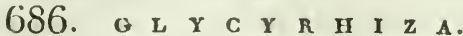

Cálix tubulosus, 2-labiatus; labium superius laciniis 4 inæquali bns, inferius simplex, lineare; carina dipetala; legumen ovatum, subcompressum, 3-6-spermuin.

39 5 . Glabra. Leguminibus glabris, floribus racemosis, stipúlis nnllis, foliolis ovatis subretusis subtus subglutinosis. 2 . In provinciis neridionalibus.

$$
\text { 687. G A I E G A. }
$$

Calix campanulatus, dentibus 5 subulatis suræqualibus; legumen oblongum, crectum, compressum, sxpiùs torulosum.

39 ff. Officinalis. Foliis pinnatis, foliolis lanceolatis mucronatis glabris, stipulis sagrttatis, leguminibus erectis strictis. 4 . In pratis Pedemontii secus rivos, passim in tota Galiia.

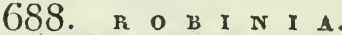

Calix parvus, camplanulatus, sub-\{-dentatns; stylus anticè hirsutus; Jegumen oblongum, compressum, polyspermum; semina conpressa.

3947. Pseuciacacia. Raccmis pedicellis nnifloris, foliis impari-pinnatis, stipulis spinosis, legunsinibus lrvibus. b. Ex Virgiuia orta, hinc indè culta.

$$
\text { 689. c o } \mathbf{L} \text { U } \mathbf{T} \text { E } \mathbf{A} \text {. }
$$

Calix 5-filus ; carina obtusa ; stylus per totam longitudinem deorsùm barbatus; legumen $\mathrm{r}$-loculare, inflatum, sutura superiore intùs tumida seminifera debiscente.

3948. Arborescens. Canle arborescente, foliolis obcordatis emarginatis, pedunculis subsexfloris, leguminibus apice clausis. 1). Ad sepes in Gallia australi usque ad Genevam, Burgundiam, Arverniam.

$$
\text { 6go. P. н а с А. }
$$

Calix 5-fidıs; carina obtusa ; stylus minimè barbatus; stigma capitatum; legumen 1-loculare, turgidum, in calice subpedicellatum, sutura superiore iutùs incrassata seminifera.

วิ949. Alpina. Carinis vexillo subæqualibus, stipulis lineari-lanceolatis, leguminibus inflatis utrinquè acntis subglabris. 4 . In petrosis editiorum Alpium et Pyrenæorum.

395̃o. Frigida. Carinis vexillo subæqualibus, stipulis magnis foliaceis erectis, leguminibus inflatis hirsutis. 4 . In declivibus petrosis subgraminosis Alpium editiorum.

3951. Glabra. Caule ramoso prostrato, foliolis ovato-lanceolatis, florum alis integerrimis, leguminibus glabris ovoideis resupinais? 2f. In humilioribas $\Lambda_{\text {p }}$ ibrs Galloprovincia: 
3952. Australis. Gaule ramoso prostrato, stipulis rotundis obtusis, alis bifidis carina longioribus, leguminibus junioribus hirsutis. ff. In lapidosis abruptis montium.

3953. Astrngalina. Caule raınoso prostrato, stipulis lanceolatis acutis, alis carina brevioribus, leguminibus junioribus lirsutis. 24. In pascuis Alpiun editiorum.

$\dagger+\dagger+$ Staminibus diadelphis ; leguminibus bilocularibus sepimento longitudinali completo vel incompleto.

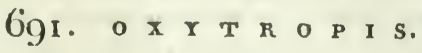

Calix 5-fidus; carina in mucronem rectum supernè desinens; legamen biloculare aut subbiloculare, sutura superiore introflexa.

\section{§. I. Stipulis petiolo adharentibus.}

3954. Montana. Subacaulis villosa, legumiuibus erectis tereti-oblongis villosis stylo acuminatis semi-bilocalaribus, carinis breviter mucronatis. 2 . In pratis montanis editioribus et siccis laud infrequens. - Fores purpurei ut in sequentibus.

3955. Uralensis. Acatilis villoso-sericea, leguminibuserectis ovatocylindraceis inflatis pubescentibus styliferis bilocularibus. 4 . In herhosis fertilibus AIpiuu Pedemontii et in Pyrenæis.

3956. Campestris. Acaulis subsericea, scapis folio subxqualibus, leguminibus erectis ovato-inflatis pubescentibus semi-bilocularibus. 4 . In pratis excelsis et nudis collium et montium. - Flores ochroleuci ut in sequentibus.

3957. Foetida. Acaulis glabra viscosa, scapis supernè lanatis, legtrs minibus erectis tereti-inflatis subincurvis. Ff. In lapidosis Alpium.

פ. II. Stipulis petiolo non adharentibus.

3958. Pilosa. Caulescens erecta villosa, legnminibus erectis tereti subulatis villosis. 4 . In saxosis montium Galliæ australis.

$$
\text { 692. A S T R A G A L U S. }
$$

Calix 5-dentatus; carina obtusa; legumen biloculare aut subbiloculare, sutura inferiore introflexa.

9. I. Stipulis petiolo non adharentibus; floribus purpureis.

395g. Austriacus. Diffusus herbaceus, foliolis linearibns emarginatis, leguminibns pendulis ovato-oblongis eompressis. 2 . In saxosis Pedemontii, editiorum montinm Arverniæ, et in aggeribus arenosis Aquitaniz.

396o. Stella. Diffnsus, capitulis pedunculatis, leguminibùs radiátis rectis subulatis nitcronatis. $\odot$. Monspelii.

${ }^{3} 96$ r. Sesameus. Diffusus, capitulis subsessilibus, leguminibus erèctis subulatis acumine reflexis. ๑. In siccis et nudis Gallix australis.

3962. Vesicarius. Procumbens, calicibus inflatis, beguminibue 
erectis ovatis hirsutis calice longioribus. $2 f$. In montanis Gallix australis.

3963. Peritaglottis. Procumbens, foliolis truncatis; leguminibus capilatis compressis echinato-cristatis. $\odot$. In Galloprovincia, Corsica.

3964. Purpureus. Prostratus, foliolis apice bidentatis, leguminibns erectis capitatis hirsutis, loculis 3 -spermis. 24 . In pascuis montosis Gialloprovincia.

3965. IYypoglotis. Prostratus, foliolis emarginatis, leguminibus erectis capitat is hirsutis, loculis monospermis. 4 . In pascuis montosis Galloprovinciæ, Argentorati, inter Moguntiam et Nierstein.

3966. Leontinus. Prostratus, leguminibns ovatis villosis, pedunculis trigonis, foliolis ovatis, vexillo alis paulò longiore. $\mathcal{Y}$. In $\mathrm{Al}$ pibus Vallesiacis, monte Cenisio, et valle Segusiana.

$3966^{*}$. Crlaux. Diffusus, lcguminibus erectis ovatis callosis inflatis, vexillo lineari longissimo. $2 F$. In castello dicto Bombaz, inter Avenionem et Cabellionem, secus Druentiam.

396 . Onobrychis. Diffusus, leguminibus erectis triqnetris dorso carinatis, vexillo alis duplò longiore. $\mathcal{C}$. In pratis siccis Alpium Sabaud. Delpli. Pedem. Galloprovinciæ.

§. II. Stipulis petiolo non adharentibus; floribus ochroleucis.

3968. Depressus. Diffusus ant subacaulis, foliolis emarginatis, leguminibus cernuis rectis tereti-depressis glabris. 4 . In Pyrenæis Alpibusque Genevensibus.

3969 . Hamesus. Canlescens procumbens, legumivibas subulatis recurvatis glabris. $\odot$. In siccis et lapidosis.

397o. Glycypleyllos. Prostratus, leguminibus snbtriquetris arcuatis sessilibus glabris. $2 \digamma$. In pratis ad sepes haud infrequens.

397x. Epiglottis. Procumbens, leguninibus cernuis cordatis mucronatis replicatis pubescentibus. $\odot$. In nemoribus et montibus Galloprovinciæ.

3972. Cicer. Diffusus, leguminibus subglobosis inflatis mucronatis pilosis. 24. Ad muros et vias in Alsatia, ad radices Jurassi, etc.

3973. Alopecuroides. Spicis subpedunculatis ovato-globosis condensatis, leguminibus 4-spermis, calicibus lanatis corollam adæquantibus. $\mathcal{H}$. In Delphinatu.

3974 . Narbonensis. Spicis sessilibus globosis abbreviatis condensatis, leguminibus sub-4-spermis, calicibus lanatis corolla brevioribus. 2 . Narbonis.

\section{III. Stipulis petiolo adharentibus; petiolo indurato apice spinoso ( TRAGACANTHA).}

3975. Massiliensis. Floribus subspicatis, calicibus 5-dentatis, foliolis tomentoso-ineanis. b. In maritimis Massiliæ.

39-6. Aristatus. Florihus subspicatis, calicibns semi-quinquefidis anistitis. 1). In Pyreuæis, montc Cenisio, Delphinatu. 
5. IV. Stipulis petiolo allucrentibus; petiolis munquime spinosis. 3977. Exscapus. Acaulis, rallice herbaceo-sueruleuti, flurilus sul,sessilibus aggregatis, leguminibus hirsutis complessis sessililus. 2. In Alpibus V'allesiacis.

39) 8. Incanus. A caulis incanus, foliolis ovatis, leguminilus subuJatis subarcuatis subtomentosis apice reflexis. 2 . In sterilibus Galliæ australis.

3979. Monspessulanus. Acaulis, Inguminibus subulatis teretibus subarcuatis glabris, vexillo longissino. 2 . In Gallia anstrali.

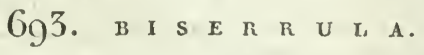

Calix 5-dentatus; carina obtusa; legunen 2 -loculare, conipressum; valvæ dorso sinuato-dentatx.

393o. Pelecinus. $\odot$. In maritimis Galloprovincix, Monspelii.

$+\dagger+\dagger+$ Stamina diadelpha; legumina ı-locularia; cotyledones nec foliacece, nec ex terra prodeuntes; folia abruptè pinnata, petiolo in filamentum vel cirrhum producıo.

$$
60 / 4 . \quad \text { L A } \quad \text { T } \text { н } \mathbf{~} \text { R U s. }
$$

Calix 5-fidus, laciniis superioribus 2 brevioribus; stylus planus, apice latiusculus, antici hirsutus vel pubescens; legumen oblongum, polyspermun.

\section{\$. I. Annui, pedunculis 1-3-floris.}

398r. Aphaca. Perlunculis $\mathrm{r}$-floris, cirrhis aphyllis, stipulis sagittato-cordatis. $\odot$. In arvis inter segetes.

3932. Nissolia. Pedunculis 1-floris, foliis simplicibus, stipulis subulatis. $\odot$. In arvis lapidosis, in dumetis el ad margines pratorum.

39§3. Ochrus. Pedunculis I-floris, petiolis decurrentibus menubranaceis diplıyllis, stipulis unllis. $\odot$. Iuter segetes circà Nieæam, Monspelium, Tarbellicas-Aquas.

399 4. Articulatus. Pedunculis sub-I-floris, petiolis alatis polyphyllis, foliolis alternis lanceolatis. $\odot$. Nicæx, in Occitania, juxla Tarbellicas-Aquas.

39 95 . Sativus. Pedunculis $r$-floris sub flore articulatis, cirrith diphyllis tetraphyllisque, leguminibus oratis conıpressis dorso bimarginatis. $\odot$. In arvis et cultis, colitur in agris.

3gS6. Cicera. Pedunculis $\mathrm{I}$-floris sub medio articulatis, cirrhis diphyllis, leguminibus ovatis compressis dorso canaliculatis. $\odot$. In arvis Galliæ australis usque ad Gencram.

3987. Angulatus. Pedunculis I-floris aristatis, cirrhis diphyllis simplicissimis, foliolis linearibus, seminibus angulatis. $\odot$. Inter segetes et in stcrilibus incultis.

3988. Spharicus. Pedunculis I-floris aristatis stipulis brevioributs. 
cirrhis diphyllis simplicissimis, foliolis ensiformibus, seminibus sphæricis. $\odot$. In siccis et lapidosis circà Taurinum, in Gallopiov., Delphin., Monspelii, Valletriæ.

3989. Setifolius. Peduuculis r-floris, cirrbis diphyllis, foliolis setaceo-linearibus, caulibus decumbentibus, leguminibus ovatis. $\odot$. In aridis et sterilibus Galliæ australis.

399?. Annuus. Pedunculis 2-floris, cirrhis diphyllis, foliolis ensiformibus subnervosis, stipulis linearibus, leguminibus compressis glabris. $\odot$. In arvis Galliæ australis.

3991. Odoratus. Pedunculis 2 -floris, cirrhis diphyllis, foliolig ovato-oblongis, leguminibus hirsutis oblongis. $\odot$. $\alpha$, ex Sicilia? $\beta$, ex. Ceylona; in liortis cultus.

3992. Hirsutus. Pedunculis 2 3 -floris, cirrhis diphyllis, foliolis lanceolatis mucronatis, leguminibus compressis hirsutis, seminibus scabris. $\odot$. In arvis et incultis.

\section{II. Perennes, pedunculis multifloris,}

3993. Tuberosus. Pedunculis 5-6-floris, cirrhis diphyllis, foliolis obtusis subenerviis mucronatis, radice tuberosa. 2 . Ad margines agrorum.

399'. Pratensis. Pedunculis 2-8-floris, cirrhis diphyllis, foliolis lanceolatis trinerviis, stipulis sagittatis foliola æquantibus. $2 \mathcal{C}$. In pratis humidis. - Flores lutei.

3yg?. Sylvestris. Pedunculis 4-5-floris, cirrhis diphyllis, foliolis ensiformibus, internodiis membranaceis. $\psi$. In sylvis pratisque montosis.

3996. Latifolius. Pedunculis multifloris, cirrhis diphyllis, foliolis. ovalibus mucronatis, internodiis menıbranaceis. $2 \mathcal{F}$. In vineis pratisque umbrosis Galliæ australis.

$3_{99}$. Heterophvllus. Pedunculis 6-8-floris, cirrhis dipbyllis tetraphyllisque, foliolis oblongis trinerviis mucronatis, internodiis menbranaceis. 2 . In pratis lapidosis Galliæ australis.

39008. Palustris. Pedunculis 3-6-floris, cirrhis polyphyllis, foliolis lineari-lanceolatis acutis, stipulis semi-sagittatis lanceolatis, internodiis membranaceis. $2 C$. In pratis humidis et paludosis.

\section{5 . P I s. U $\mathbf{x}$.}

Calix 5-fidus, lacinīi 2 superioribus brevioribus; stylus 3-gonus, infrà carinatus; stigma hịrsutum; legumen oblongum, polyspermum; semina globosa; hylus rotundatus.

3999. Sotivum. Petiolis te ctibus, stipulis infernè rotundatis crenatis, pedunculis multifloris. $\odot$. An cx cultura pisi arvensis varietas? in hortis cultum.

40oo. Arvense. Petiolis teretihns, stipulis crenatis, pedanculis I-flo: ris. $\odot$. In arvis Fontisbleaudi, Argentorati, Arverniz.

4оот. Muricimum. Petiolis suprà planiusculis, caule angulato, stipulis sagittatis, pedunculis multifforis, 24 . In petrosis maritimin

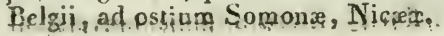




\section{6g 6.0 r.}

Calix 5-fulus, laciniis a superioribus brevioribus; stylus gracilis, lineris, apice hirsutus; legumen oblongum, teretiusculum, fwly sperпиıи; liylus interdum linearis.

4002. Syluaticus. Foliis pinnatis hirsutis $7-10$-jugis, foliolis ovato. oblongis, stipulis semi-sagittatis, caule ramoso decumbente basi hirsnto. 24. In montibus Arvernix, Beugesiæ, Sorricinii, Pyrenæorum.

4003. Niger. Foliis pinnatis 4-6-jngis, foliolis ovatis, caule ramoso anguloso $\Psi$. In vineis et nemoribus.

4on'. Luteus. Foliis pinnatis 3-5-jugis, foliolis lanccolatis subtù glancis, stipulis semi-sagittatis basi dentatis, caule simplici anguloso. 24. In pratis sylvisque montosis Jurassi, Pyrenacorum, Delphinatûs, Galloprovinciæ, Pelemontii et Arverniæ.

40o5. Vernuis. Foliis pinnatis 2-3-jugis, foliolis ovatis acuminatis, stipulis semi-sagittatis integerrimis, caule simplici anguloso. $2 \mathrm{i}:$ In nemorosis Gallix australis.

\{0o6. Tuberosus. Foliis pinnatis 3-1-jugis, foliolis lanceolatis subtús glauco-pallidis, stipulis semi-sagittatis integerrimis, caule alato. 2 . In sylvis ei umbrosis.

400 - Fi'iformis. Foliis a-jugis, foliolis linearibus, stipulis semisagittatis petiolo longioribus, caule filiformi subramoso. 24 . In sterilibus herbosis Galliæ anstralis.

4oos. Albus. Foliis 2-jugis, foliolis linearibus, stipulis simplicibns petiolo multò brevioribus, caule simplici. 24 . In pratis et ad vias, propè Vapincumin, in Gebennis.

40o9. Saxatilis. Foliis 2-jngis, foliolis linearibns, imis apice 3 -dentatis, stipulis semi-sagitatis, canle simpliei gracili, pedunculis unifloris. $\odot$. In collibus aridis et lapidosis Galloprovinciæ.

$$
\text { 697: v I' c I A. }
$$

Calix tnbulosus, 5 -fidus, laciniis a superioribus lirevioribus ; styJns filiformis, angulo recto cum ovario, supernè et subtìs ápice hirsutus; legumen oblongusi, polyspermum; hylus lateralis, ovatus ved linearis.

\section{I. Floribus loñgè pedunculatis.}

foro. Pisiformis: Pedunculis multifloris, foliis 4 -jugis, foliolis oratis subcordatis, inferioribus cauli approximatis. $2 \mathcal{f}$. In sylvaticis Pedemontii, Galloprovinciæ, Burgundiz, Alsatix, Palatinatûs.

fort. Dumetorum. Pedunculis nultifloris, foliis 4-jugis, foliolis reflexis ovatn-lanceolatis mucronatis, stipulis subdentatis. $\mathcal{F}$. In dumetis sylvisque niontosis.

fo12. Sylvatica. Pedunculis multifloris folio longioribus, foliolis elliptico-oblongis submucronatis, stipulis lunatis sctaceo-dentatis. Y. In sylvis montosis:

\{ог3. Gerardi. Pedunculis multiforis folio brevioribns, foliolis. 2. 4 
oblongis subpubescentibus, stipulis semi-sagittatis integerrimis lanceolatis. $2 \mathrm{f}$. In pascuis mon:osis Occitanix, Galloprovincia.

4or年. Cracca. Pedunculis multifloris folio longioribus, floribus imbracais, foliolis linearibus subincanis, stipulis semi-sagittatis lineari-subulatis integerrimis. $\mathcal{F}$. In ineultis et arvis.

4015. Onolyryioides. Pedunculis multifloris folin longiorihus, floribus distantibus, foliolis linearihus, stipulis semi-sagittatis linearilanceolatis basi dentatis. $\odot$. In pratis et arvis montion.

4016. Atro-purpurea. Pedunculis multifloris folio subbrevioribus, floribus unilateralihus, foliolis oblongo-lanccolatis mucronatis, stipulis setaceo-dentatis, caule tetragono hirsuto. $\odot$ Desf., Ger. 25 Tourn. In Stachadum insulis.

4017. Monantha. Pedunculis $\mathbf{1 - 2 - f l o r i s ~ f o l i o ~ b r e v i o r i b u s , ~ f o l i o l i s ~}$ linearibus truncatis mucronatis. $\odot$. Circù Nicæam.

4018. Ervilia. Pedunculis subbifloris aristatis folio brevioribus, foliolis linearibus obtusis, stipulis hastatis, leguminibus articulatis. $\odot$. In arvis.

\section{§. II. Floribus axillaribus subsessilibus.}

40r9. Sativa. Ieguminibus sessilibus subbinatis, foliolis oblongoovatis truncatis mucronatis, stipulis dentatis semi-sagittatis notais. $\odot$. In arvis, colitur in pecillum usum.

4n2n. Lathyroides. Leguminibus sessilibus solitariis erectis glabris, fuliis inferioribus 2-jngis, superioribus 4-6-jugis. $\odot$. In tectis et arenosis.

4021. Amphicarpa. Leguminibus sessilibus, inferioribus subterraneis, foliolis lincaribns truncatis, stipulis semi-sagittatis. $\odot$. In Galloprovincia, Monspclii.

4022. Pyrenaica. Leguminibus sessilibus solitariis, foliis 3-6-jugis, folinlis cuncato-ovatis truncatis longè mucronatis, stipulis maculatis semi-sagittatis. $\odot$. In Pyrenæorum pratis.

4023. Lutea. Leguninibus sessilibus solitariis reflexis pilosis, caulibus dif́nsis, stipulis coloratis, vexillo glabro. $\odot$. Ad vias et inter segetes.

40ź. Hybrida. Leguminibus sessilibus reflexis pilosis, caule erecto, vexillo villoso. $\odot$. In macilentis.

$4034^{*}$. Hirta. Leguminibus sessilihus solitariis reflexis hirtis, foliolis linearihus mucronatis pilosis, rexillo glabro. Balb. misc. alt. - In agro Nicæensi detexit ecl. Baluis.

4025. Seprum. Legnninibus subpedicellatis subquaternis erectis, folinlis ovatis integerrimis nervis hirsutis, exterioribus decrescentibus. $2 \mathcal{C}$. Ad sepes, in umbrosis.

\{026. Narbrnensis. Legnminibus subsessilibus subternatis compressis, foliis inferiopibus 2 -jugis, mediis 4 -jugis, superiorilus 6-jugis, stipulis infernè subintegris, snpernè setaceo-laciniatis. $\odot$. In Gebennis, propi Narbonem, in Arvernia, Aquitamia, Pedeinontio, Nicxæ. 
4027. Bithynica. Leguminilus sessilibns atut pedunculatis solitariis erectis, foliolis $2-6$ ovali-lanceolatis, stipulis profundi dentatis. $\odot$. Inter segetes propè 'T'arbam, Montem-Albaumm, Bayonnam, Aquas-T́arbellicas, Nicáa.

$$
\text { 6g8. ғ А в } \mathbf{~} \text {. }
$$

Legumen grande, coriacenm, subtumidum, seminilus oblongis, bylo terminali; cirrhi subnulli; cætera $m$ in Vicia.

4028. Vulgaris. $\odot$. E finitimis Caspii maris orta, in hortis et agris culta.

$$
\text { 699. } E \mathrm{R} \text { v } \mathrm{U} \text { M. }
$$

Calix 5-filıs, laciniis linearibus, acutis, corollam subxquantibus; stigma glabrum; legumen oblongum, 2-4-spernum.

4029 Telraspermum. Pedunculis subbifloris, leguminibus glabris \&spermis, foliolis oblongis truncatis. $\odot$. Inter segetes, ad vias et in collibns.

4o3o. Hirsutume. Peduncnlis 2-4-floris, leguminibus birsutis 2-spermis, foliolis sub!inearibus obtusis. $\odot$. In arvis, interdum in ncmorosis.

4031. Lens. Peduncnlis 2-3-floris, leguminibus brevibus 2-3-spermis, foliolis oblongis, subobtusis. $\odot$. In arvis inter segetes.

$$
\text { 700. C I C E R. }
$$

Calix 5-partitus, longitudine corollæ, laciniis 4 supcrioribus vexillo incumbentibus; legumen rhomboideum, turgidou, s-spermum.

4032. Arietinum. Pedunculis unifloris, seminibus globesis gibbis, foliolis serratis. $\odot$. Cultum, pracipuc in Gallia australi.

†††††† Stamina diadelpha; legumina transversé multilocularia, loculis I-spermis, spontè non dehisceritibus.

$$
\text { 70I. S C O R P I U R U S. }
$$

Calix 5.fidus; carina infernè a-fida; legumen oblongnm, coriaceum, revolutum, sulcatum, articulatum, articnlis contractis.

4033. Vermiculata. Pedunculis I-floris, leguminibns squamis obtusis undiquè tectis. $\odot$. In arvis Galliæ anstralis, Nicææ, Monspelii.

4034. Mruricala. Pedunculis $\mathrm{r}-3$-floris, leguminibus extrorsiun obtusè aculcatis. $\odot$. Ad vias et margines agrorum in Gallia , anstrali.

40.35. Sulcata. Pedunculis 3-4-floris, leguminihus extrorsùm spinis acntis distinctis. $\odot$. In arvis et ad vias in Gallia anstrali.

4036. Subvillosa. Pedunculis 2-4-floris, leguminibus extrorsùm spinis confertis longis acutis. $\odot$. In arvis Galliæ anstralis.

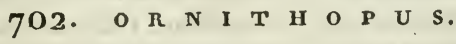

Calix 5-dentatus, tubulosus; carina minima; legnmen arcuatum, gracile, teres, acutum, articulatum, articulis cylindricis. 
4037. Perpusillus. Foliis pinnatis 8-9-jugis, floribus capitatis bractea suffultis, leguminibus teretiusculis incurvatis. $\odot$. In sabulosis subumbrosis.

4038. Compressus. Foliis pinnatis 14 -jugis, floribus capitatis bractea suftultis, leguminibus compressis recurvatis rugosis. $\odot$. Nicææ, Monspelii, Cenonami.

4039. Durus. Foliis pinnatis glabris, floribus capitatis nudis, leguminibus teretibus recurvatis. $\mathcal{f}$ ? In sabuletis, juxtả Aquas-Tarbellicas et Tarban.

4040. Scorpioides. Foliis ternatis subsessilibus, impari maximo. $\odot$. Ad agrorum margines in Gallia australi.

$$
\text { 703. H I P } \mathbf{P} \text { O C R E P I s. }
$$

Calix inǽqualiter 5-dentatus; vexilli ungue calice longiore; legumen oblongum, compressum, nembranáceum, articulatum, curvum, iltera sutura emarginato-dentatum.

4́̊ł. Unisiliquosa. Leguminibus sessilibus solitariis erectis. $\odot$. In ${ }^{2}$ sterilibus Galloprovinciæ, Monspelii, Nicææ, Arverniæ, Jurassi?

4o 2 . Multisiliqunsa. Leguminibus $3-4$ confertis pedunculatis circularibus margine altero lobatis. $\odot$. In arvis sterilibus Gallia allstralis.

40ł3. Comosa. Leguminibns 5-8 confertis perlunculatis arcuatis scabris utroque margine sinuatis. 4 . In prátis sabulosis sterilibus.

$$
\text { 704. C O R O N I L L A. }
$$

Calix campanulatus, 5-dentatus, dentibus superioribus 2 approximatis, inferioribus 2 minoribus; petala longè unguiculata; legumén teres, rectum, articulatum aut inter semina contractum; semina. oblouga aut cylindrica.

4044. Emerus. Frnticosa, pedunculis subtrifloris, petalornm unguibus calice tripld longioribus, canle angulato.b. Ad sepes et in dumetis, in Jurassi Alpiunque vallibus, et in piov. australibus.

4045. Juncen. Fruticosa, foliolis quinatis ternatisque subcarnosis glaucis obtusis, stipulis minimis marcescentibus. b In dnnetis collibusque apricis Galliæ mediterraneæ, Nicææ, Massiliæ.

4046. Stipularis. Fraticosa, foliolis subnovenis, stipulis foliaceis oppositis suborbiculatis mucronatis caducis. b. In apricis montusis Gallix australioris.

497. Glauca. Fruticosa, foliolis septenis cunciformibus obtusissimis aut emarginatis, stipulis lanceolatis. b. In maritimis Gallix mediterraneæ.

4048. Coronata. Suffruticosa, foliolis septenis ellipticis submacronatis, infernis cauliapproximatis, stipulis minimis oppositifoliis bifidis, umbellis sub-ro-floris. . In lapidosis et collibus Galliæ austratis.

4049. Minima. Sinffuticosa procumbens, foliis novenis ovatis mucronatis, infernis à caule distantibus, stipulis membranáceis rippositifoliis bifidis, umbellis sub-10-floris. b, 2 . In saxosis Galize qustralis, circà Gencram, etc. 
4049*. Montana. Subherbacea erecta, foliolis undenis et ultrà ovatis mucronatis, infernis canli approximatis, stipulis oppositifoliis bifidis, nubellis 20-floris. - C. montana. Scop. carn. 2. n. 912. 1. 44. 4 . In Jurasso circà Neocomum.

405n. Varia. Herbacea diffusa, foliolis plurimis lanceolatis glabris, leguminibus teretibus erectis. $\odot$. Ad vias et margineu agrurum. - Flores rosei.

$$
\text { 705. S E C U R I G E R A. }
$$

Flores coronillæ; legumen compressunu, articulatım, longè subulato-cornutum; semina parallelipipeda.

4051. Coronilla. ๑. Circầ Nicæaın frequens, in Arverniæ campis.

$$
\text { 706. H E D Y S A R U M. }
$$

Calix persistens, 5 -fidus; carina magna, transversim obtusa ; legumen articulis orbicularibus compressis, levibus ant tubereulosis.

4o52. Obscurum. Canlesceus flexuosum, foliis pinnatis ovatis gła bris, racemis axillaribus erectis, bracteis pedunculo longioribus, articulis leguminis penduli glabris. 4 . In Alpibus editiorihus.

4053. Coronarium. Caulescens diffusum, foliolis $7-9$ ovatis marginc subhirsutis, extremo majori, leguminis articulis subrotundi aculeatis nudis. 2 . In Pedemontii pratis circà Rivoli.

4054. Humile. Canlescens procumbens, foliis pinnatis lineari-oblongis subtùs pubescentibus, alis brevissinis, legumiuis articnlis subroundis hirsutis aculeatis. 4 . In lapidosis montium Galliz australis.

$$
\text { 707. O N O B R Y C H I s. }
$$

Calix 5-fidus; carina transversè obtusa; alre brevissimæ; legumen compressum, breve, r-loculare, r-spermum, sæpiùs aculeis hirtum, sutura superiore complanatum et truncatum.

4055. Sativa. Caule erecto, foliis pinnatis cmeatis glabris, carins vexillo breviore, leguminibus glabris aculeato-dentatis. 2 . In collibus et pascuis siccis cretaceisque.

4056. Montana. Caule decumbente, foliis pinnatis, foliolis ovatooblongis suhtùs pilosis, carina vexillo longiore, alis dentibus calicinis brevioribus. $2 f$. In pascuis Alpium editiortum haud infrequens.

4057. Supina. Caule diffuso subhirsuto, foliolis oblongis vix mucronatis, carina ct vexillo alis dentibusque calicinis brevioribus, leguminibus pubescentibus. 2 . Ad vias et in pascuis herbosis Delphinatûs, Vapinci.

fo58. Saxatilis. Cuule adscendente, foliis pinnatis r2-r5-jugis linearibus snbincanis, alis dentibus calicinis sublongioribus, leguminibus glabris aculeatis. $2 \mathcal{L}$. In saxosis collibnsque apricis $G$ allix australioris.

6o59. Caput-galli. Caule erecto, foliis pinnatis oblongis glabris, àentibus caliciṇis corollam subacquantibus; legnuiuibus rotundatis 
pubescentibus aculeatis, crisı dentibus subulatis spinosis. $2 \mathrm{C}$. Ia pascuis et secus torrentes Galliæ autralis, Nicææ, Galloprovinciæ, Arverniæ.

406o. C'rista-galli. Caule erecto, foliis pinnatis oblongis glabris, petalis subæuralibus, leguminibus aculeatis, cristæ dentibus lanceolatis denticulatis. $\odot$. In sterilibus Galloprovinciæ australis, et agri Nicæensis.

\section{O R D O L X I I. T E R E B N T H A E AE.}

Calix monophyllus, sæpiùs liber, partitus ; petala interdìm nulla, sepiùs definita, basi calicis inserta, ejusden laciniis alterna ; staunina cum petalis inserta, eorumdem numero æqualia aut dupla; ovarium simplex aut multiplex; fructus varius; perispernum nullum; corculi radicula in lobos reflexa. - Arbores aut frutices, foliis alternis simplicibus ternatis aut inpari-pinnatis. - Ordo nondum satis definitus.

$$
\begin{gathered}
\text { † Ovarium simplex, liberum; fructus r-locularis, } \\
\text { } 7 \text {-spermus. } \\
\text { 708. R II U s. }
\end{gathered}
$$

Calix 5-partitus; petala 5; stamina 5; styli 3 breves; drnpa fota nuce I-sperma.

4061. Cotinus. Foliis simplicibus obovatis, pedicellis florum steri-

lium denı̀m pilosis. b. In collibus Galliæ australioris, circà Nicxam, Gratianopolim, in Pedemontio.

4062. Coriaria. Foliis pinnatis, foliolis ovato-oblongis dentatis sub-

ths villosis, spicis congestis densis. ๖. In siccis et lapidosis Galloprovinciæ, Monspelii, Nicææ, T'aurini.

†† Ovarium simplex, liberum; fructus multilocularis.

$$
\text { 709. C N E O F U M. }
$$

Calix persistens, ninimus, 3 -dentatus; petala 3 ; stamina 3 ; stylus 1 ; stigmata 3 ; bacca sicca, 3-locularis, locnlis 1-spermis.

4063. Tricoccon. b. In lapidosis Gallix australioris et apricis Sabaudix.

$$
\text { 7 IO. P I S T A C I A. }
$$

Dioica, apetala. Masc. Amenti squamis I-floris; calix minimus, 5-lobns; stamina 5. Fen. Laxè racemosi; calix minimus, 3-lobus; styli 3 ; drupa sicca, ovata sel subglobosa, fota nuclco osseo Ispermo.

406\%. Vera. Foliis impari-pinnatis, foliolis subovatis ternis quinisve. 5. E Syria in Italiam et in Galliam mediterraneam migravit.

4o65. Terebinthus. Foliis impari-pinnatis, foliolis ovato-lanceolatis septenis. b. In suxosis et collibus Gallix mediterraneæ. 
4066. Lentiscus. Foliis abrupti pinnatis, foliolis lanceolatis. $b$. In Gallia mediterranea.

\section{†† Orarium adnalum (NUCULACEx).}

7 I I. J U G L A N S.

Monoica, apetala. Masc. Amentacei, singulis squama duplex, exterior triangularis dorso interioris adfixa, interior transversè oblonga ex utroque latere 3-loba; stamina r2-2.́, diseo glanduloso inserta. Fem. Solitarii in genmulis squamis \& cadncis; ovanium adlıærens; styli 2 ; stigmata clivata, apicelacera; drupa ovata, ficta r nucleo osseo 2 -valvi in 4 semi-loculos diviso, $r$-sperma, semine sinuoso infernè 4-lobo; corculum erectum.

fo67. Regia. Foliolis subnovenis ovalibus glabris subserratis subiequalibus, fructibus globosis. b. Ex Persia? nunc in tota Gatlia frequens.

\section{O R D O L X X I V. F R A N G L A C E AE.}

Calix monophyllus, definitè divisus; corolla nulla, monopetala aut sæpiùs polypetala, calici aut disco calicino inserta, lobis aut petalis calicis laciniis numero equalibus; stamina petalis numero æqualia, inter aut autè petala inserta; ovarium simplex, liberum, disco calicino cinctum; fructus nunc bacca multilocularis ant multinux, nunc capsula multilocularis, valvulis internè septiferis; perispermum carnosum; corculum rectum; radicula infera.-Arbores aut frutices, foliis stipulaceis, alternis aut oppositis.

\section{† Stamina petalis alterna.}

\section{I 2. S T A P}

Calix 5-lobus, disco urceolato intùs instructus; petala 5 ; stamina 5; germen 2-3-lobum; styli 2-3; fructus 2-3-rapsularis, capsulis inflatis infernè coalitis; semina ossea, globosa, basi truncata, in medio sepimeuti inserta.

4o68. Pinnata. Foliis pinnatis. ๖. Ad sepes et in collibus Pedemontii, Alsatiæ.

$$
\text { 713. E V O N }
$$

Calix 4-5-fidus, planus, disco peltato intùs instrnctus ; petala 4-5, patentia; stamina $4-5$, imposita glandulis suprà discunı prominulis; stylus 1 ; capsula 5-locularis, 5-valvis; semina arillo vel integumento colorato externo obtccta, angulo loculorum interno inserta.

4069. Europaeus. Floribus plerisque 4 -andris, pedunenlis compressis multifloris, stigmatibus subulatis, foliis glabris. ๖. Ad sepes et in dinmetis.

407o. Latifolius. Floribus plerisque 5-andris, pedunculis filiformibus teretibus multifloris, foliis lato-ovatis, ramis levibus. b. In montosis sylvis Monspelii, Prov. Pedem. Delphin. Moguntix. 


\section{4 . I L $5 \mathrm{x}$.}

Calix minimus, 4 -dentatus; petala 4 , basi coalita ; stamina 4 ; stigmata 4; bacca rotundati, foeta nucleis 4 monospermis.

$407 \mathrm{r}$. Aquifolium. Foliis ovatis acutis spinosis nitidis undulatis,

Horibus axillaribus subumbellatis. $\mathrm{b}$. Ad sepes et in sylvis.

$$
\begin{gathered}
+\dagger \text { Stamina petalis opposita. } \\
715 . \text { N U s. }
\end{gathered}
$$

Calix urceolatus, 4-5-fidus; petala 4-5, interdum abortiva; stamina $4-5$; stylus 1 ; stigmata $2-4$; bacca $2-4$-locularis, $2-4$-sperma semina basi hylo curtilaginoso promiunlo instructa.

\section{§. I. Ramis spinosis.}

4072: Catharticus. Floribus 4-fidis dioicis, foliis ovatis argute dentatis. b. In sylvis, ad sepes.

4073. Infectorius. Floribus 4 -fidis dioicis, caalibus procumbentibns. b. In sterilibus et aridis Galliæ australioris.

40-4. Saxatilis. Floribus 4 -fidis hermaphroditis, foliis ellipticis. b. In saxosis Delphinatûs.

4075. Oleoides. Floribus 4 -fidis hertnaphroditis, foliis oblongis integerrimis margine revolutis. b. Inter Cannam et Carcassonem.

\section{II. Ramis inermibus.}

40-6. Alaternus. Floribus dioicis, stignate triplici, foliis ovatooblongis serratis. Ђ. In Gallia australi , circà Nannetes.

407\%. Frangula. Floribus monogynis hermaphroditis, foliis integerrinis. $b$. In dumetis subhumidis.

40-8. Alpinus. Floribus dioicis, foliis ovali-lanceolatis glanduloso-crenulatis. $\mathrm{b}$. In sylvis montosis.

4079. Pumilus. Repens basi ramosissimus, floribus hermaphrodiis, foliis ovatis crenatis nervis sabtùs subtomentosis. b. In rimis saxorum montium.

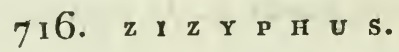

Calix patens, 5-fidus; petala 5; stamina 5 ; styli 2; drupa ovata, feta nucleo 2-loculari 2-spermo.

4080. Vulgaris. Aculeis geminis, altero recurvo, foliis ovato-oblongis retusis glabris dentatis. b. Ex Syria ad regiones mediterraneas migırit.

$$
\text { 717. P A L I U R U S. }
$$

Calix patens, 5-ficlus; petala 5 ; stamina 5 ; styli 3 ; drupa sicca, margine lato membranaceo cincta, foeta nucleo 2-3-loculari. 408r. Aculeatus. Aculcis geminis, inferiore reflexo, foliis ovatis subdentatis trinerviis, floribus axillaribus laxè racemosis. valle Augustana, circà Nicsam, in Galloprotincia, Occitania et Delphinatu austraki. 


\section{O R.D O L X I V. B E R B ER I D E AE.}

Calix infinite polyphyllus aut partions; petala hyprgyna, calicinis laciniis numero xqualia, iisdem sapiüs opposila; stamina toe quot pelalı, iistem oppostta; antherefilamentis adnatce, it basi ud apirem valvula deliscentes; ovarium simplex, liberum; stylus I aut o; frnctus unilocularis, sæpiùs polyspermus; semina imo loculo adfixa; perispermum carnosum; corculum rectum; radicula infera.

$$
\text { 7 I8. B E R B E R I s. }
$$

Calix 6-phyllus, extìs 3 bracteatus; petala 6 , basi interna glaridulis 2 instructa; stigma latum, sessile, persistens; bacca ovata, cylindrica, 1-locularis, 2-3-sperma.

4083. Vu/garis. Racemis simplicibus pendulis, foliis obovatis ciliato dentatis. b. Ad sepes et margines sylvarum."

$$
\text { 7 I9. E P I M E D I U M. }
$$

Calix 4-phyllus, foliolis patentibus, calucis, 2 basi 1-bracteatis; petala 4, singula squamula petaloidea caliciformi discolore basi interna instructa; stamina 4; stylus è summo germine lateralis; stigma simplex; silicula oblonga, 1-locularis, 2-valvis, polysperma.

4083. Alpinum. 24. In umbrosis montinm, in Burgundia prope Divioncm, in Alsatia Alpibusque Pedemontanis.

\section{OR D O L X X VI. P A P A E R A C E AE.}

Calix liber, plerumque diphyllus, cadncus; petala hypogyna saipüus 4; stamiua plurima; ovarium ı; stylus sæpè o; stigma divisum, persistens; fructus capsularis aut siliquosus, unilocularis, polyspermus; semina receptaculis lateralibus adfixa , involucris menbranaceis semitecta; perispermum carnosum; corculum rectum ; radicula infera. - Herbæ habitu vario, succo sæè lactescente colorato.

\section{† Stamina numero indefinita.}

$$
\text { 720. N Y M P H EA. }
$$

Calix 4-5-phyllus; petala plurima, multiplici seric disposita, in terioribus staninum filamenta mentientibus; stamina numerosissima, nultiplici serie ordinata; stylus o; stigmata 8-10, linearia, radiantia; bacca sicca, globoso-conica, loculis tot quot stigmatie polyspernis; senuina ovata, Invia i perispermum farinaceum; corculizm turbinatum, tunica propria (vitello) obtectum.

4084. Lutea. Foliis cordatis integerrimis, lobis approximatis, calice 5-phyllo petalis longiore, $\Psi$. Ln stagnis et tossis. - Flores super aquam exserti.

4085. Alţa. Foliis cordatis integerrimis, lobis imbriçatis rotundis, calice 4-phyllo petalis minore. 24 . In stagnis et aquis quictis. Flores super aquam natantes. 


\section{I. P A P A V E R.}

Calix cadıcus, 2-phyllus; petála 4; stigma 6-r2-radiatum; capsula oblongo-globosa, plurimis foraminibus sub stigmatis corona dehiscens, iucompletè 6-12-locularis; semina numerosissima, adnata placentis capsulæ parietibus insertis.

\section{§. I. Capsulis hirtis.}

4086. Hylridum. Capsulis subglobosis torosis hispidis, caule folioso multifloro. $\odot$. In arvis et cultis circà Parisios.

4087. Aryemone. Capsulis clavatis hispidis, caule folioso multifloro. $\odot$. In arvis et cultis.

4088. Alpinum. Capsula subrotunda hispida, scapo unifloro nudo hispido, foliis bipinnatis, pinnis integris et divisis. 2 . In lapidosis editiorum montium.

\section{§.II. Capsulis glabris.}

4089. Rharas. Capsulis globosis glabris, caule piloso multifloro, foliis pinnatifidis incisis, stigmate ro-radiato. $\odot$. In arvis frequens inter segetes.

409\%. Dubium. Capsulis oblongis glabris, caule multifloro, setis supernè adpressis infernè patulis, foliis pinnatifidis incisis, stigmate 7 -radiato. $\odot$. In arvis et cultis, Lutetix, etc.

4091. Sonıniferum. Capsulis globosis calicibusque glabris, foliis amplexicaulibus incisis glabris. $\odot$. Ex Europa australiori, in hortis culta, ferè spontanea.

4092. Cambricum. Capsulis glabris oblongis, caule multifloro lævi, foliis pinnatifidis incisis subtus glancis. 4 . In Pyrenæis Arvernize et Lugduni montibus. - Flores sulphurei.

$$
\text { 722. C H E L I D O. N I U M. }
$$

Calix caducus, 2-phyllus; petala 4 ; stigma capitatum, bilobum; capsula elongata, subcylindrica, siliquxformis, 2-3-valvis; placentæe 2-3 intrà valvarum suturas sitæ, persistentes.

\section{I. Capsulis lavibus (СНEIIDONIUM).}

4o93. Majus. Pedunculis umbellatis, foliis profunde pinnatifidis, lobis obtusis. 2 . Ad sepes et muros, in umbrosis.

\section{f. II. Capsulis asperis ( $\mathrm{LAUCIUM}$ ).}

4094. Glaucium. Pedunculis unifloris, foliis amplexicaulibus sinuatis, caule glabro. $\odot$. In arenosis secus mare, lacus et flumina.

4095. Corniculatum. Pedunculis unifloris, foliis sessilibus pinnatifidis, caule hispido. $\odot$. Inter segetes Nicææ, Monspelii, AquisSextiis.

4og6. $H_{9}$ bridum. Pedunculis unifloris, foliis pinnatifidis, lobis linearibns, caulc lævi, siliquis trivalvibus. $\odot$. In arvis propè A usionem, in Galloprovincia, Occitania. 
$\dagger \dagger$ Stamina numero definita.

\section{C o R Y D A L I S.}

Calix minimus; petala 4 , irregularia, unum calcaratum; staminum filamenta diadelphat singulus fasciculus $1-3$ antheras getons; capsula siliqueformis, r-locularis, 2-valvis, polyspernat; semina placentis 2 filiformibus intrà valviun suturas positis allixa.

4097. Tuberosa. Caule simplici, racemo terminali, bracteis oblongis pedunculo longioribus, foliis biternatis oblongis acutiusculis, radice uberosa cava. $2 \zeta$. $\Lambda \mathrm{d}$ scpes et in uubrosis.

4098. Bulbosa. Caule simplici, racemo terminali, bracteis cuneatis digitatis pedunculo longioribns, foliis biternatis, radice bulbosa solida. 2 F. In umbrosis sublumidis montanis.

4099. Lutea. Caule diffuso ramoso obtusangulo, bracteis minimis lineari-subulatis, foliis bipinnatis, radice fibrosa, capsulis 6-8spermis corolla brevioribus. 24. In montosis Gallix australioris, circà Narbonem, Nicæam.

410o. Claviculata. Caule ramoso scandente, foliis inferioribus biternatis, rameis simpliciter termatis cirrhosis, rarlice fibrosa, siliquis 2-3-spermis. $\odot$. In lapidosis, dunetis ad sepes, MLonspelii, Cenomani, Nannetum, Armoracix.

$$
\text { 724. F U M A } \Omega \text { I A. }
$$

Calix minimus; petala 4 , irregularia, unicum calcaratum; staminum filanenta diadelpha, fasciculus singulus antheras 3 gerens; nux sphærica, I-locularis, I-sperma; semen funiculo umbilicali parieti interno capsulæ alligatum.

4101. Capreolata. Caule ramoso scandente, foliis triternatis, foliolis pbovato-cuneatis incisis, petiolis partialibus cirrhoso-convolntis. $\odot$. In arvis et ad sepes humidas Occitanix, Galloprovinciæ, Pedemontii.

4102. Officinalis. Canle ramoso diffuso, foliis suprà-decompositis, foliolis cuneiformibus lanceolatis incisis, nucibus globoso-retusis. $\odot$. In hortis, arvis et cultis.

4103. Parviflora. Caule ramoso diffuso, foliis supra-decompositis, foliolis 3-partitis linearibus canaliculatis, spicis laxis, nucibus globoso-acntis. ○. In arvis arenosis, Parisiis, Monspelii, Agenni, in Galloprovincia, Arvernia.

4104. Spicata. Caule ramoso erecto, foliis suprà-decompositis, foliolis 3-partitis filiformitus, spicis ovatis densis, nucibus oblongis compressis. $\odot$. In agris et cultis Galliæ australioris.

$$
\text { 725. H Y P } \quad \mathbf{E} \text { C }
$$

Calix minimus, 2-phyllus; petala 4 triloba, interioribus 2 minimis approximatis; stanina 4; styli 2 , breves; capsula elougata, siliquxeformis, transversin at ticulata, articulis $\mathrm{I}$-spermis.

4105. Procumbens. Siliquis arcuatis compressis articulatis. $\odot$. In arvis præsertim maritimis Galloprovinciæ, Ausionis, Monspelii, Corsicæ. 
4106. Pendulum. Siliquis cernuis teretibus non articulatis. $\odot$. In arvis circh Aquas Sextias, Monspelium.

\section{O R D O LXXVII. CR U CIFERAE.}

Calix /-phyllus, plerumquè deciduus; pcta! $a$ 午, in crucem disposita, disco hypgyno inserta, laciniis calicinis alterna, sæpiùs unguiculata; stamina 6, tetiarlynama, nempè q majora; ovarium $\mathbf{r}$, disco stuminifero inıpositunı; stylus 1 aut o; stigma 1-2; fructus siliqun aut silicula, sæpiùs bilocularis, polyspermus, bivalvis, valvis lıberis in longum debiscentibus, oppositis dissepimento membranaceo marginato, non nunquàm rostri instar ultrà prominulo; perispcrumum nullum; corculi incurvi radicula in lobos proni; folia seminalia, apicc emarginata. - Herbe alternifoliae.

\section{T R I B U S I. SILIQU O S I.

$$
\text { 726. R A P H A } \text { N U s. }
$$

Calix connivens; discns ovarii glandulosus; siliqua nunc mnltilocularis, cylindrica loculis biserialibus, nunc articulata articulis ventricosis mnilocularibus, nunc unilocularis.

$4 \mathrm{ng}$. Sativus. Foliis lyratis, siliquis teretibus torosis bilocularibus.

$\odot$. Colitur in hortis.

4ros. Raphanistrum. Foliis lyratis, siliquis teretibus articulatis lævibus unilocularibus. $\odot$. Inter segetes.

$$
\text { 72.7. S I N A P I s. }
$$

Calix patentissinus; discus ovarii 4-glandulosus; siliqua apice rostrata.

4ing. Nigra. Siliquis glabris racemo adpressis, foliis glabris. $\odot$. In agris et ruderitis.

4110. Erurnides. Foliis lyratis oblongis glabris, calice villnso, siliquis lævibus, caule subscabro. $\odot$. In Gallia Narbonensi ad vias et vineas.

4111. Arvensis. Siliquis multangulis toroso-turgidis glabris rostro ancipite Inngioribus. $\odot$. In agris.

4112. Orientalis. Siliquis cylindricis retrorsùm hispidis, apice rostro compresso glabro. $\odot$. Circà Neocomum, Moguntiam, et in Pedemontio.

41 3. Alba. Siliquis hispidis, rostro longissimo ensiformi basi pubescente. $\odot$. In agris.

4ri4. Incana. Siliquis racemo adpressis levibus, foliis inferioribus lyratis scabris, sumnis lanceolatis, caule scabro. $\odot$. In aridis saxosis.

$$
\text { 728. B R A s s I c A. }
$$

Calix connivens, basi gibbosus; discus ovarii 4-glandulosus; siliqua teres, compressa, cylindrica aut tetragona; semina sphærica. 
G. I. Siliquis muticis vel rostro brevissimn nbeuso.

6115. Perfoliata. Foliis corlatis amplexicaulihus glabris, siliquis tetragonis. ๑. In Gallia orientali inter segetes. - lores albidi.

410. Aruensis. Foliis glabris amplexicaulibus spathulatis repandis, superioribus corlatis integerrimis, siliquis obtusc tetragonis. 24. In Pedemontii et Galloprovincix agris. - Flores violacci.

4117. Alpina. Foliis caulinis cordato-sagittatis amplexicaulibus, radicalibus ovatis petiolatis. 2 . In Palatinatûs, Alsatix, Delphinatûs, Pedemontii et Gralloprovincix montibus ncmorosis.

4118. Oleracea. Radice caulescente carnosa tereti, foliis omnibus glabı is glancis repandis lubatisve. $\delta$. In rupilsus maritimis Normandix, in hortis culta.

4rig. Asperifolia. Radice carnosa crassa, foliis inferioribus lyratis asperis, supcrioribus amplexicaulibus cordato-ol,longis glaberrinis. $\sigma$. In arenosis Belgii (Lin.), ubiquè culta.

4roo. Richerii. Foliis petiolatis oblongis glabris subdentatis, rarlice caulescente, siliquis acuminatis. 24 . In Alpibus Delphin. Pedem. Gulloprov.

\section{f. II. Siliquis stylo ensiformi rostratis (ERUCA).}

4121. Eruca. Foliis lyratis, canle hirsuto, siliqnis glabris. $\odot$. In Gallia australi. - Flores flavidi venosi.

4122. Eracastrum. Foliis runciuatis, caule hispido, siliquis lævibus. ๑. In ruderatis, ad murns, ctc. - Flores latei.

4123. Cheiranthus. Foliis petiolatis pinnatifidis dentatis subhispidis, siliquis glabris, rostro basi monospermo. $\sigma^{7}$. In stcrilibus arenosis Delphinatûs, Pedcmontii, Alsatiæ.

4124. Montana. Foliis petiolatis runcinatis subglahris subradicalibus, siliquis glabris, rostro basi monospermo. $\%$. In Alpibus Delphinatûs et Pyrenæis.

$$
\text { 729. H E S P E R I S. }
$$

Calix connivens et clausus, foliolis 2 basi gibbis; petala sxpè obliqua; discus ovarii 2-glandulosus; stigma bilamellatum; siliqua cylyndrica aut compressa; semina margine destituta.

4125. Alliaria. Foliis cordatis dentatis. $ఠ$. In umbrosis sepibus.

4126. Matronalis. Canle simplici erecto, foliis ovato-lanceolatis denticulatis, petalis obtusè emarginatis submucronatis. $\sigma^{\top}$. In umbrosis sylvarum in Grallia australi, Jurasso et circł Parisios.

4127. Laciniata. Canle ramoso hispido, foliis obovatis dentatis, radicalibus basi subincisis. $\widehat{c}$. In rupibus apricis Pedemontii, Galloprovinciæ. - Ilores sulphurei.

4128. Africana. Caule ramosissimo diffuso aspero, foliis lanceolatis petiolatis acutè dentatis scabris, calicibus siliquisque pilosis. $\odot$. In Gallia Meditcrranea.

4129. Verna. Caulc erecto ramoso, foliis caulinis cordatis amplexicaulibus scrratis villosis. $\odot$. In Gallia Mediterranea. 
41.3n. Alaritima. Caule difuso scabro, foliis cllipticis snbintegris obtusis seabriusculis, petulis enurginatis. $\odot$. In Lalliæ meridionalis arenosis maritinis; in lıortis culta.

413!. Parvifura. Foliis ol,longis obtusis subsinuatis tomentosis, siliquis pubescentibus, rostro brevi glibro. $\odot$. In Galloprovinciæ et Corsicæ arenosis maritimis.

$$
\text { 7 う̈O. C H }
$$

Calix connivens, clausus, fuliolis 2 basi gibhis; discus ovarii 2glandulosus; stigma bificlun ; siliqua longa, compressa, quandoque subtetragona, interdum apice 1-3-rostra; semina marginata.

4132. Tricuspidatus. Foliis lyıatis, siliquis apice tricuspidatis. $\odot$. In atenosis maritimis Galliæ Meditersancæ, in Cursica et circà Nannetes.

4133. Tristis. Foliis linearibus subsinuatis, floribus sessilibus, petalis undatis, canle lıuticoso. b. In Sabaudiæ, Pedemontii, Galliæ Mediterraneæ arenosis sterilioribus, ad muros.

413\%. Litloreus. Foliis lanceulatis subrlentatis subtomentosis subcarnosis, petalis eınarginatis, siliquis tomentosis, rostro glabro acuto. $2 \mathrm{C}, \delta$. In maritimis à Nicæa ad Nannetes.

4r35. Annuus. Foliis lanceolatis subdentatis obtusis incanis, siliquis tomentosis cylindricis apice acutis, caule herbaceo. $\odot$. In Galliæ Narbonensis maritimis; colitnx etiann in hortis.

4136. Incanus. Foliis lanceolatis integerrimis obtusis incanis, siliquis tonentosis apice truncatis compressis, canle sulfruticoso. b. In Gallix meridionalis maritimis ; colitur in hortis.

4137. Sinuatus. Foliis tomentosis, inferioribus sinuatis, rameis indivisis, siliquis tomentosis compressis muricatis.3. In Galliæ neridionalis maritinis.

4138. Cheiri. Foliis lanceolatis acutis glabris, ramis angulatis, canle suffruticoso. $\sigma, 2 \digamma$; b. Ad muros, in tectis. - Flores ferrugineolutei.

$$
73 \mathbf{I} \text {. E R } \mathbf{Y} \text { S I M U } \mathbf{M} \text {. }
$$

Calix connivens, clausus; discus ovarii 2-glandulosus; stigma capitatum; siliqua tetragona. - Flores Lutei.

4:39. Murale. Foliis lanceolatis subdentatis subnudis, caule recto simplicissimo, siliquis subglabris, petalis emarginatis. $\delta$. In montosis lapidosis.

4t4o. Helveticum. Foliis lancenlatis angnstis dentatis nudis, caule erecto, petalis integris, siliquis adpressè pubescentibus stylo acuminatis. $\delta^{\nearrow}$. In montosis stcrilibus Alpiun et Pyrenæorum.

41fr. Ochroleucus. Foliis lanceolatis subglabris subdentatis, caule debili decumbente, siliquis adpressè pubescentibus stylo acuminatis. 27. In lapidosis Jurassi et Alpiun.

4142. Cheirunthoides. Foliis lanceolatis integerrimis, siliquis glabris patulis. $\odot$. In arvis. 
1r/33. Hierarifolium. Foliis Lanceolatis anote dentatis, ranle simplici, siliquarmm erertarmu slignate bilobo, pilis radiato-flocenlosis. $\odot$. In arenosis sterilioribus.

41 f́. Virgatum. Foliis lanceolatis subdentatis, siliquarum crectarum strictarmm pilis ratiato-flocculosis, caule ramosissimo virgato stricto. 0 . Circà Gienevam.

41;5. Repandum. Foliis lanceolatis repando-rlentatis, raccmis oppositifoliis, siliquis subsessilibus horizontalibus. $\odot$. In P'cdemontii Alpinis maritimis.

4146. Barbarea. Voliis inferioribus lyratis, lobo terninali rotundatn, superioribus obovatis dentatis. $\odot$. In tivulis.

4147. Precox. Foliis inferinribus lyratis, superiorihns pinnatifidis, laciniis lineari-oblongis integerrimis. $\sigma^{7}$. In humidis herbirlis Pyrenæorum et Galloprovincia.

$$
\text { 732. S I S Y M }
$$

Calix patens aut clausus; peta!a patentia, ungue brevi; stigma 1, ohtusum ; siliqua longa, teres, valvis rectis non clasticis. - Flores sæpiùs lucei.

§. I. Siliquis oblongis brevibus sapiüs declinatis (вRACIтодовоs).

4148. ZVasturtitim. Foliis pinnatis, foliolis subcordatis pedicello subbrevioritus. 2 . Ad fontes. - Flores albi.

4149. Sylves/re. Foliis pinnatis, foliolis lanceolatis serratis, radice repente. 2 . In ripis, tivnlis et ruderatis.

4150. Palustre. Foliis pinnatifitis serratis, petalis calice brevioribus, siliquis.oblongo-ovatis. $\odot$. In todis et ad fluviormm ripas.

4151. Amphibium. Foliis oblongo-lanceolatis pimatifidisve serratis, petalis calice longioribus, siliquis oblongo - ovatis. 2 . In aquosis stagnantibus.

4152. Prenaicum. Foliis inferioribus lyratis, superioribus bipinnutifidis anplexicanlibus, siliquis subovatis. 2 F In Pyraneis, Gebennis, Arvernia, Peslemontio, Vogesis et circi Lugdunnm.

4153. Tanacetifolium. Foliis pinnatis, foliolis lanemolatis incisoserratis, extimis conflueutibus, siliquis gracilibus. 2 . In summis Alpium.

\section{II. Siliquis linearibus ( SISYMBRIOM).}

* Caule subnudo.

415\%. Murale. Foliis lanceolatis sinuato-serratis lavinsculis, caule subscabro adscendente. $\odot$. Ad muros inque arenosis cultis.

4155. Suxatile. Acanle, foliis pinnatifilis linearibus subpilosis Inhis obusis remotis, siliquis subtetragonis, scapis Jævibus. 2 . In Galloprovincia ad rupen S.-Victoriz.

4156. Repandum. Acaule, foliis oblongis repando-sinuatis, scapisque glabris, siliquis compresso-tetragonis. 2 . In Delphiuatu et Pedemontio. 
4157 . Vimineum. Acaule, foliis lyratis lævibus, scapis adscendentibus, petalis calici subæqualibus. $\odot$. Parisiis, Aureliæ, in Delphin. et Pedemontio.

4158. Arenosum. Caule subfolioso hirto, foliis lyratis rectangulodentatis hispidis, pilis ramosis. $\odot$. In arenosis Alpinis, Parisiis, A bbavilla, Vogesorum, Burgundiæ, Lugduni et prov. anstraliorum. - Flores lilacei.

$$
\text { ** Caule folioso. }
$$

4159 . Tenuifolium. Foliis glabris subintegerrimis pinnatifidis bipinnatifidisque, supremis integris, siliquis erectis. $2 \%$. In ruderatis, ad muros.

416n. Polyceratiunt. Foliis repando-dentatis, siliquis axillaribus sessilibus subulatis aggregatis. $\odot$. Passim in Gallia meridionali.

4161. Pinnatifidum. Foliis pinnatifidis glabris, lobo terminali majore obtuso, inis integris, racerno brevi. 4 . In rupibus Alpium, Pyrenæoruiu, Arverniæ montium. - Flores albi.

4162. Burs efolium. Foliis pinnatifidis glabris, lobo terminali majore, superioribus subintegris, canle folioso erecto, ràcemo flexuoso. $\odot$. In Pyrenæis. - Flores albi.

4163. Supinum. Foliis dentato-sinuatis, siliquis axillaribns subsessilibus solitariis. $\odot$. Parisiis ad ripas, Lugduni, Vapinci.

$4{ }^{16}$. Asperum. Siliquis scabris, foliis pinnatifidis, pinnis linearilanceolatis subdentatis. $\mathcal{L}$, Ger. $\odot$, Linn. In palustribus Galliæ wediterrancæ, Delphinatûs, Arverniæ, etc.

4165. Sophia. Foliis decomposito-pinnatis, petalis calice minoribus. $\odot$. In muris, tectis, maceriis.

4166. Irio. Foliis runcinatis dentatis nudis, caule lævi, siliquis crec- tis. $\odot$. In cultis, muris, tectis.

4167. Loeselii. Foliis runcinatis acntis hirtis, canle hispido. $\odot$. In cultis et siccis, circà Parisios et in Pedemontio.

4ifis. Taraxacifolium. Foliis runcinatis, inferiorum laciniis ciliatis, superiorum laciniis linearibus nudis, caule simplici, siliquis declinatis. - In montibus Sedenensibus Galloprovinciæ.

4169. Acutangulum. Foliis runcinatis subnodis laciniis acutis, siliquis scakris, calice patente. $\mathcal{F}$. In Pyrenæis et Alpibus.

417o. Ernsimifolium. Foliis runcinato-sinnatis glabris, siliquis subtetragonis lavibus, calice patente. 2 , All. $\odot$, Pour. In rupibus Perdenontii et Pyrenæorum orientalium.

417. Obtusangulum. Foliis pinnatifidis obtusis dentatis amplexicaulibus, caule retrnrsùm bispido, siliqnis subtetragonis. $\odot$. In numıusis arilis Alpium, Pyrenæorum, Galliæ Narbonensis, circà Lutetiam, Moguntiam.

4172. Officinale. Foliis runcinatis, lobis rectangulis acutis terminali maximo, spicis virgatis, siliquis spic adpressis. $\odot$. In ruderatis.

4173. Strictissimum. Foliis oblongo-lanceolatis dentatis pubescentibus petiolatis, siliquis patentibus. 2 . In Delphinatûs et Pedernontii montibus asperis upricis. 
Calix connivens, foliolis 2 majuribus, basi gibbis; discus ovarii nudus vel -glandulosus; siliqua louga, crecta, linearis. - I lores albi.

\section{I. Foliis cau!'inis amp'exicaulibus.}

4) 亿. Perfolinta. Foliis radicalibus dentalis hispidis, caulinis integerrimis amplexicantibns glabris, siliquis erectis strictis. $\widetilde{\sigma}$. In pascuis siccis, apricis, sylvaticis.

4155. Auricuiata. Foliis amplexıcaulibus obtusis seaberıimis, siliquis erectis strictis teretiusculis perlicello sexirs tongionibus. $\odot$. In Pedemontii, Delphinatûs et G.lloprovinciæ montcsis, ad musus.

41-6. Saxatilis. Foliis amplexicanlibus olumsis seabris, siliquiserectis strictis planis subtetragruis striatis pedicello uipló longiorilus. ठૅ. In Galloprovinciæ, Delphinatûs, Pedenontii stcrilibus saxosis. 417\%. Alpina. Foliis incanis oblongo-lanceolatis anplexicaulibus acutè dentatis, pilis apice radiantibus, siliquis compressis. 2 F. In Alpibus et Pyrenxis.

41-8. Turrila. Foliis amplexicanlibus lanceolatis subdentatis, siliquis decurvis planis linearibus margine incrassatis. $\odot$. In sabulosis Lutetiæ, ete.

Gr:9. Hirsuta. Foliis omnibus hispidis, caulinis amplexicaulibus inedio ilentatis, ramis erectis strictis, siliquis subtetragonis. $\sigma^{7}$. In pascuis sylvaticis.

4rSo. Allinnii. Foliis glabris lucidis radicatis ovatis subdentatis, caulinis lanceolatis argntè dentatis semi-amplexicaulibus, siliquis compressis strictis. - In pratis humilis Pedemoniii.

4ISI. Bellidifolia. Foliis subdentatis, radicalibus obovatis, caulinis lanceolatis, caule folioso, siliquis rectis compressıs. $\mathcal{H}$. In $\mathrm{Al}_{\text {p }}$ ium Pedemontii humidis saxosis.

4182. Scabra. Foliis subdentatis hispidis, radicalibus obovatis, canlinis lanceolatis, caule folioso, siliquis secundis. $\mathcal{F}$. In Alpibus.

4183. Stricı. Foliis rigidis dentatis obtusis hispidis, radicalibus sublyratis, pilis sæè bifucis, canlibus hispidis, petalis erectis. 24 . In rupibus Alpium Sabaud. Delphin., Pyrenæorum, Corbaricusium.

\section{§. II. Foliis caulinis nullis aut sessilibus.}

4194. Thaliana. Foliis ciliatis, raticalibns oblongis petiolatis, canlinis lanceolatis sessilibus, carle erecto basi hirto, siliquis glaberrimis. $\odot$. In sabulosis sylvaticis.

4185. Serpyllifolia. Foliis ellipticis integerrimis sessilibus, mule 1lexuoso decumbente subpiloso. $\odot$. In rupibus et muris Delnhinatûs, Galloprovincix, Pyrenæormu.

4136. Ceerulea. Glabra, foliis obovatis apice subdentatis, caule wub,liphyllo, racemo cernuo. 7 . In summis $\mathrm{Al}_{\mathrm{p}}$ ibus glacialibus Pedemontii. - Flores corulei. 
$418 \%$. Petrea. Foliis subradicalibus lyrato-pinnatifidis petiolatis glabris, lobis obtusis, siliquis rectis compressis. $\Varangle$. In Arverniæ siccis montosis.

4185. Halleri. Foliis subglabris, caulinis sublyratis, rameis lanceolatis incisis sessilibus, caule hirto debili ramoso, siliquis patulis. $\sigma$. In Pedemontii humidis montosis, et circà Moguñtiam.

$$
\text { 734. C A R D A M I N E. }
$$

Calix parrus, hiulcus ; petala patentia , unguibus longis erectis; siliqua linearis, clasticè desiliens, valvis à basi ad apicem rcrolutis, dissepimento æqualibus. - Flores albi aut subpurpurascentes.

4189. Alpina. Foliis simplicibus oblongo-ovatis integerrimis, caule florifero foliis altiore. 2 . In summis Alpium et in Monte-Aureo.

4 go. Resedifolia. Foliis inferioribus indivisis, superioribus trilobis pinnatisque. $2 f$. In umbrosis sylvaticis Alpium, Arrerniæ, Occitaniæ, P'yrenæorum.

4ı1. Thalictroirles. Foliis simplicibus ternatis pinnatisque, foliolis obtusis quinis trilobis. 6 . In rupestribus Alpium, Pyrenæorum.

4192. Asarifolia. Foliis simplicibus subrotundis cordatis. 2 In glareosis humidis $\Lambda$ lpium Pedemontii, Galloprovincix.

4rg3. Trifolia. Foliis ternatis obtusis, caule subnudo. 2F. Passin in Gallia, in umbrosis.

4194. Granulosa. Foliis radicalibus simplicibus subrotundis longissimè petiolatis, caulinis pinnatis, foliolis lanceolatis, radice granulata. $2 \xi$. In pratis collium Taurinensium.

4ị5. Craca. Foliis pinnatis, foliolis palmatis æqualibus petiolatis. $\odot$. In Corsica.

4196. Latifolia. Foliis inferioribus quinato-pinnatis, superioribus ternis, foliolis dentato-subangulatis subglabris. $\odot$. In Pyrenæis ad rivulos.

4inj. Amara. Foliis pinnatis, inferiorum foliolis subrotnndis, superiorum oblongis, caule basi stolonifero. $\odot$. In nemorosis humidis Lutetiæ, Arverniæ, Alpium, etc.

4198. Pratensis. Foliis pinnatis, foliolis radicalibus subrotundis, caulinis linearibus, caule apice glauco. $\mathcal{F}$. In pascuis aquosis.

4r99. Hirsuta. Foliis sublirsutis pinuatis, inferiorum foliolis subrotundis petiolatis, superiorum oblongo-linearibus. $\odot$. In hortis cultis umbresis.

430ก. Parvifnra. Foliis glabris pinnatis, inferiorum foliolis subrotundis sessilibus, superiorum linearibus integerrimis obtusis. $\odot$. In pratis Gullia mediterranca, Vasconiæ.

4201. Impatiens. Foliis pinnatis incisis basi auriculatis, auriculis acutis amplexicaulibus. 3 . In nemoribus glareosis.

$$
\text { 735. D E N T A R I A. }
$$

Calix oblongus, connivens; stigma emarginatum; siliqua elasticec 
desiliens, valvis à basi ad apicem revolutis, dissepimento valvulis longiore.

4202. Enncaplylla. Foliis ternis termatis dentatis, axillis foliorum nudis, staminibus longitudine corolla. $\odot$. In Pedeuontii, Arverniæ montosis unubrosis.

4203. Digitata. Foliis digitatis, foliolis dentatis. 24. In Alpibus, Pedemontio, Delphinati, Jurasso, in umbrosis nontanis.

4204. Pinnata. Foliis pinnatis, foliolis oblongis xqualiter dentatis. 2 . In montosis.

4205. Bulbifera. Foliis inferioribus pinnatis, summis simplicibus, axillis foliorum bulbiferis. 24. Ail radices montiun nmbrosas, Lutetix, Tamrini, Argentorati, in Arvernia, Picardia.

T R I B U S I I. S I L I G U L O S

$$
\text { 756. L U N A R I A. }
$$

Calix connivens, foliolis 2 basi gibbis; silicula magna, integra, elliptica, compresso-plana, pedicellata, valvis planis disscpimento sequalibus et parallelis; semina pauca, compressa. - Flores albi aut violacei.

4206. Annua. Foliis oppositis obtusè dentatis, siliculis ellipticis utrinquè obtusis. $\sigma^{\top}$. In Alsatiæ et Galloprovinciæ unbrosis humidlis.

4207 . Rediviva. Foliis alternis mucronato-dentatis, siliculis oblongis utrinquè attenuatis. $\mathcal{C}$. In nemorosis Vogesorum, $\mathrm{Al}_{\text {pium }}$ Pyrenxorum.

$$
\text { 757. B I s c U T E L L A. }
$$

Calix connivens, coloratus, foliolis 2 basi gibbis; petala oblonga, apice patentia; silicula compresso-plana, bisorbiculata, orbiculis monospernis latere imo stylo adnatis. - Flores lntei.

4208. Auriculata. Calicibus ntrinquè gibbis, siliculis scabris in stylum cocuntibus. $\odot$. In Delphinatûs, Galloprovinciæ et Pedemontii montosis, siccis, incultis.

4209. Laevigata. Siliculis lavibus, foliis lanceolatis integris serratisque. 2 . In Alpium Pedemontii, Delphinatûs, Pyrenæorum sterilibus inque Alsatia.

42го. Saxatilis. Silicnlis subscabris, caule subfolioso, foliis dentatis incisisque. 4 . In aridis Alpium et Pyrenæorum.

$421 \%$. Coronopifolia. Siliculis levibus margine ciliatis, foliis dentatis hirtis. $\odot$. In montosis sterilioribus Pedemontii? Delphinatûs? Pyrenæorım?

$$
\text { 738. c L Y P } \mathbf{E} \text { o L } \mathbf{A} \text {. }
$$

Calix erectus; petala oblonga, integra ; silicula orbiculata, compresso-plana, I-locularis, I-sperma, valvulis planis membranaceis.

4212. Jonthlaspi. $\odot$. In Delphinatûs, Burgundiæ, Galliæ meditcrraneæ sabulosis, ad muros. 


$$
\text { 739. P E L T A R I A. }
$$

Silicula suborbiculata, compresso-plana, unilocularis, 1-3-sperma, 2-valvis, valvis planis non dehiscentibus.

4213. Alliacea. Foliis amplexicaulibus oblongis indivisis. 2 . In

montibus Pedemontanis circà Fenestrelle.

$$
\text { 740. } \Delta \text { L } \mathbf{x} \text { s s U } \mathbf{m} \text {. }
$$

Calix connivens ; petala apice patentia, filamenta interdùm denticulo introrsum notata; silicula orbiculata, compressa, valvulic subplanis; scmina pauca.

\section{§. I. Floribus albis.}

4214. Marilimum. Caulibus suffruticosis procumbentibus, foliis lineari-lanceolatis subincanis, siliculis subrotundis integris 2-locularibus dispermis. $\mathcal{F}$. In Galliæ mediterraneæ sterilibus præcipuè maritimis.

4215. Spinosum. Ramis floriferis spinosis persistentibus, foliis lineari-lanceolatis obtusis sericeis. ๖. In rupibus Occitaniæ, et circà Lutetia:u ad Rambulituı?

4216. Ha! inifolium. Caulibus suffruticosis procunubentibus, foliis spatluala-ohlongis subtus cánis, ramis foriteris unermibus, seminibus marginatis nembranaceis. 3 . In ropibus apricis Pedemontii et Pyreuæorum orientalium.

\{217. Incanum. Caule herbaceo erecto, foliis lanceolatis incanis integerrimis, floribus corymbosis, petalis hifidis. $2 \mathcal{L}$. In arenosis apricis Gallia mediterrancx, Perlenıntii, Arveınia, Palatinatûs.

\section{II. Florilus luteis flavisque.}

4218. Argenteum. Caulibus erectis sufruticosis, foliis spathulatooblongis subtù incanis, racemis paniculatis, siliculis oratis incanis. b. In montibus Pedemontanis.

4219. Alpestre. Caulibus adscendentibus suffruticosis, foliis snbrotundo-spathulatis incanis, racemis corymbosis. b. In montosis sterilibus Pedemontii, Delphinatûs, Gälloprovinciæ, circà Augustomagum?

4220. Mnntanum. Caulibus herhaceis subdifusis, foliis incauis, inferioribus ellipticis incanis, superioribus sublanceolatis, raceıno simplici. F. In apricis montosis Alpinm, Pedenontii, Galliæ australis, circà Fontembleandi, Moguntiam.

4221. Calycinum. Caulibus herbaceis, foliis oblongis obtusis incanis, staminibus omnibus dentatis, calicibus persistentibus, siliculis subemarginatis. $\odot$. In arenosis, apricis.

4222. Campestre. Caule herbaceo, foliis oblongis obtusis incanis, siliculis orbiculatis integris pilosis, calicibus deciduis. $\odot$. In sterilioribus tampestribus, præcipuè in Gallia australi.

4223. Clypeatum. Caule erecto herbaceo, foliis oblongis tomentosis subdentatis, siliculis oblongis compresso-planis, petalis linearibus acuminatis. $\odot$, Linn. $\delta$, All. In Gallix mediterraneæ maricimis. 


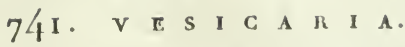

Silicula globulosit, inflata, 2-valvis, valvulis uembranaceis, concavis; semina plana, marginata vel nuda et subrotunda. Caetera ut in Alysso.

422\%. Utriculata. Caule lerbaceo erecto, foliis levibus Jancenlatis integerrinis. 2 . In montosis Pedemontii, Dulphinatûs, Burgundix.

$$
\text { 742. D R A B A. }
$$

Calix erectus; petala oblonga, subpatentia, ungue brevi, nunc integra, nunc emarginata aut bifida; stylus brevissimus; silicula ovata, oblonga, integra, compressa vel contorta, valvulis planis; semiua non marginata.

4225. Aizoides. Scapo nudo, foliis lanceolatis rigidis margine ciliatis, petalis emarginatis (flavis). 2 . In sumnis Alpinis, Jurasso, Pyrenæis, Arverniæ montibus.

4226. Ciliaris. Foliis linearibus rigidis margine ciliatis, petalis integris (albis), caule subnudo. $\mathcal{F}$. In Alpibus Sabaudis eı Barcinonensibus.

4227. Pyrenaica. Scapo nudo, foliis cuneiformibus palmatis trilobis. ' 2 . In summis Pyrenæis, Alpibus Pedemontii, Delphinatûs, Galloprovincix.

4228. Verna. Scapo nudo, foliis oblongis acutiusculis subserratis sublirsutis, petalis bifidis. $\odot$. In sylvaticis et ad muros.

4229. Stellata. Foliis oblongis obtusiusculis cauis pubescentibus integerrimis dentatisve, pilis stellatis, scapo subunifolio erecto. 24, b. In summis Alpibus Pedemontii, Delphinatûs, Galloprovincix, et in Pyrenxis.

423o. Nivalis. Foliis lanceolatis integerrimis subpubescentibus ciliatis, pilis stellatis, scapo nnifolio decumbente, calice glabriusculo, petalis retusis. 2 . In Pyrenæis, Galloprovinciæ et Sabaudix Alpibus.

423r. Muralis. Canle ramoso, foliis ovatis amplexicaulibus dentatis, siliculis glabris patentibıs. $\odot$. In nemoribus et ad muros humidos.

4232. Incana. Foliis caulinis numerosis incanis, siliculis oblongis obliquis subsessilibus. $\sigma$. In Galliæ meridionalis montanis.

$$
\text { 745. C O C H L E A R I A. }
$$

Calix hinleus, foliolis concavis; petala patentia; stylus brevis; siliculi integra, globulosa aut ovata, 2-locularis, bivalvis, valvis gibhis obtusis, loculis 1-2-spermis.

4233. Officinalis. Foliis radicalibus cordato - suhrotundis, caulinis oblong̣is subsinuatis, siliculis globosis. $\sigma$. In littoribus Oceani, inque Pyrenais et Pedemontanis montibus ad rivulos.

423\%. Danica. Foliis hastato-angulatis, omnibus petiolatis deltoideis, siliculis ellipticis. $\odot$. In maritimis Belgii, Picardix, Armoracix, Nannctum. 
4235. Armoracia. Foliis radicalibus lanceolatis crenalis, caulinis incisis. 2 . In fossis et ad rivulos.

4236. Glastifolia. Foliis caulinis obcordato-sagittatis amplexicauli-

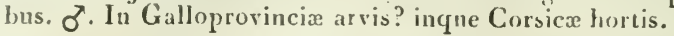

4237. Dralia, Foliis oblongo-lanceolatis amplexicaulibus dentatis subglabris, corymbo paniculato. 2 . In Arvernir, Delphinatîs, Galliæ mediterraneæ, Pederuontii cultis arvis, frequens circà Lutetiam.

$$
\text { 744. S E N E B I E R A. }
$$

Calix hialcos; silicula emarğinata, didyma, bivalvis, valvis rugosis uon dehiscentibus disscpintento longioribus; senina solitaria, nuila.

4238. Pinnatifirla. Foliis pinnatifidis. $\odot$. In Aquitaniæ umbrosis, humidis. - Nasturtiolum pinnatum. Nanch. suppl. 7 .

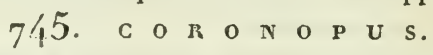

Silicula suborbiculata, integra, compressa, rugosa, bilocnlaris, 2-ralris, valvis non deliiscentibus dissepimento æqualibus.

4239. Vulgaris. Foliis pinnatifidis, caule depresso. $\odot$. In apricis nudis humidis.

$$
\text { 746. L } \mathbf{E} \text { P I } \mathbf{D} \text { I } \mathbf{U} \mathbf{M} \text {. }
$$

Calix patulus; petala æqualia; silicula integra, ovata, compressa, valvulis carinatis; semina numerosa, non marginata.

42 io. Latifolium. Foliis ovato-lanceolatis serratis. $\mathcal{F}$. In umbrosis. 42 I. Iberis. Foliis inferioribus lanreolatis serratis, superioribus linearibus integerrimis, ramis virgatis difnsis. 2 . In ruderatis, ad vias.

4242. Alpinum. Foliis pinnatis integerrimis glabris, canle flnrifero nudo arlscendente, petalis calice majoribus, silionlis lancerslatis utrinque acutis. 24 . In Alpium, Pyrenæorum, Arverniæ montiun humidis rupestribus.

42\{3. Petraum. Foliis pinnatis integcrimis, caule ramnso folioso, petalis emarginatis calice minoribus. ๑. In lipidosis Pyrenæorum, Alpium, Cebennarum, circà Moguntiann, Fontembleaudi, Nannetes.

424i. Procumbens. Canle hasi ramoso, ramis adscendentihus, foliis inferioribns pinnatifidis, superinribus lanceolatis indivisis, petaiis calicis longitudine. $\odot$. In subhumidis Monspelii, Galloprovinciæ, Lugduni, Burgundiæ, Fontishleaudi, Nannetum.

4245. Rotundifolium. Foliis subearnosis ohtusis, inferioribus petiolatis subrotundo-ovatis, canlinis oblongis amplexicaulibns, caule subsimplici. 24 . In rupestribus frigidissimis Alpium. - Noccæa rotundifolia. Moench. suppl. 89 .

$$
\text { 747. T } \text { H L A s } \mathbf{p} \text { I. }
$$

Calix patulns; petala æqualia; silicula ohcordata, compressa, apice emarginata, 2-valvis, valvis carinatis dorso sxpiùs "ppendiculatis. 
9. I. Toncu'is monospermis (xastertem).

42 16. Rurlerale. Foliis radicalibus dentatu-pimatis, canlinis linearibus integerrimis, siliculis subenarginatis. $\odot$. Ad vias in ruderatis.

42iz. Sativun . Foliis mulifulis oblongis. $\odot$. In hortis cultuın.

42 18. Wudicaule. Suapo nudo simplicissimo, foliis pinnatifidis. $\odot$. In sylvaticis arenosis Gallix Nabonensis, Vogesorum, Belgii, circả Lùtetian, êtc.

§. II. Silicula triangulait, loculis polyspermis (Ca pSELta).

4249. Bursa-pasıoris. Foliis radicalibus pinnatifidis. $\odot$. In cultis ruleratis vulgatissima.

ఏ. III. Silicu'a suborbiculata, loculis polyspermis (TII L SPI).

425n. Arvense. Foliis oblongis dentatis glabris, siliculis orbiculatis. $\odot$. In cultis et vineis.

425r. Allitceum. Foliis oblongis obtusis dentatis glabris, siliculis ovatis ventricosis, margine brevi. ๑. In Pedenontii, Burgundix, Lotharingix, Lugduni vincis et cultis.

4252. Saxatile. Foliis lanceolato-linearibus obtusis carnosis integerrimis, siliculis snbrotundis. $\odot$. In Delplinatûs et Gallize ınediterrancze saxosis montosis.

42 73. Perfoliatum. Foliis glabris subdentatis, caulinis cordatosagittatis sessilibus, radicalibus oblongis petiolatis, siliculis obcordatis, caule ramoso. $\odot$. In agris apricis.

425\%. Montanum. Foliis glabris, radicalibus subcarnosis obovatis integerimis, caulinis oblongis amplexieanlibus subsagittatis, corollis calice majoribus. 24 . In pratis siccis, in Alpibus, Arvernia, Burgundia, Palatinatu.

4255. Alpestre. Foliis subdentatis, caulinis amplexicaulibus, petalis Iongitudine calicis, caule simplici, siliculis obcordatis. 2 . In pratis Jurassi, Pysenæorum, montis Cerisii.

42.56. Heternph $/$ lum. Caulibus adscendentibus, foliis glabris, radicalibus petiolatis obtusis integris lyratisque, caulinis erectis cordato-sagittatis, basi dentatis, siliculis ovatis. 24 . In Pyrenæis.

4257. Cantpestre. Foliis sagittatis dentatis incanis, siliculis subro. lundis glabris. $\odot$ All. $ठ \mathrm{Linn}$. In arvis, viis argillosis, apricis.

4258. Hirtum. Foliis caulinis sagittatis villosis, silicurlis subrotundis pilosis. $\delta$ Linn. 24 All. In argillosis Gilliæ meridionalis.

$$
\text { 748. I } \mathrm{B} \text { E } \mathrm{R} \text { I } \mathrm{s} \text {. }
$$

Calix patens; petala patentia, 2 exteriora majora; silicula orbicularis, subcompressa, margine acuto suprà cmarginato cincta, valvis navicularibus compressis.

\section{I. Fruclibus racemosis.}

4259. Semperforens. Frutescens, foliis spathulatis glabris integerrimis obtusis. Ђ. Ex Oriente orta, culta in hortis. 
426o. Sempervirens. Frutescens, foliis glabris linearibus integerrimis acutiuseulis, corymbis racemosis. ๖. In rupestribus Galliz Mediterraneæ, Pyrenæorum.

4361. Saxatilis. Frutescens, foliis pubescentibus acutis integerrim is, inferioribus linearibus, superioribus lanceulatis. b. In Galliæ Mediterratieæ montanis rupestribus.

4262. Amara. Herbacea, foliis lanceolatis acutis subdentatis, siliculis bicuspidatis, cuspidibus rectis brevibus. $\odot$. In agris montosis, vine is.

4263. Pinnata. Herbacea, foliis pinnatifidis. $\odot$. In Grallix Mediterraneæ maritinis, inque Delphinatus, Pedemontii, Lugduni apricis glareusis.

4264. Intermedia. Herbacea, ramis divaricatis, foliis lanceolatis, radicalibus apice subserratis, caulinis integerrimis, silicnlis apice truncatis, cuspidibus brevibus recta divergentibus. $\sigma$. Circà Rothomagum ad ripas calcareas Sequanæ.

\section{II. Fructibus unbellatis.}

4265. Umbellata. Herbacea, foliis lanceolatis acuminatis, inferioribus serratis, snperioribus integerrimis, siliculis bicuspidatis. $\odot$. In agro Nicæensi, in hortis culta.

4266. Linifolia. Herbacea, foliis linearibus, radicalibus serratis, caulinis integerrimis, caule paniculato, corymbis hemisphæricis. $\sigma^{7}$. In Gallia Mediterranea.

426-. Spathulata. Herbacea, foliis subcarnosis glabris subrotundis integerrimis petiolatis, petiolis ciliatis. $\odot$. In Pyrenæis. - Iberis carnosa. Wild. sp. 3. p. 455 ?

4268. Nana. Herbacea, foliis subrotundo-spathulatis apice subdentatis glabris, canlinis linearibus integerrimis, siliculis bicuspidatis. ๑. In Delphinatûs, Galloprovinciæ et Pedemontii Alpibus.

$$
\text { 749. M Y A G } R \text { U } \mathbf{M} \text {. }
$$

Calix subpatulıs; petala æqualia, unguiculata; silicula ovata vel globulosa, stylo conico terminata, loculis polyspermis, valvis concavis subhemisphæricis.

4269. Sativum. Siliculis obovatis polyspermis, foliis amplexicaulibus pilosis. $\odot$. Inter segetes.

42;o. Saxatile. Siliculis globosis, foliis petiolatis oblongis serratis scabris, canle paniculato. $\mathcal{H}$. In rupestribus Alpinis.

$$
\text { 750. C A K I L E. }
$$

Calix subelausus; discus ovarii 4 -glandulosus; stylus simplex vel nullus; stigma obtusum; silicula tiarticulata, articulis monospermis non dehiscentiluns.

4271. Maritima. Siliculis tetragonis dimidio utrinque calcaratis foliis pinnatifidis carnosis. $\odot$. In maritimis à Galloprovincia ad Belgium.

42\%2. Perennis. Siliculis nodosis, articulis ovatis, foliis pinnatifidis, 
laciniis sinubusque dentatis. 2 K inn. $\delta$ All. In Peslemnntii arenosis, in D.lphinatûs? Galloprovincie ağtis, viis, circà Lugchumum, Mogumtian, Montem-Albannm.

4a73. Rugnas. Siliculis clavatis sulcatis pilosis, foliis nblongis obtusis dentatis $\odot$. Inter segetes Pedemontii, Dedphinatus? Alsatie.

427ł. Perfotiula. Siliculis obcordatis monospermis trilocularibus, toliis sagitlatis anplexicanlibus. $\odot$. Inter segetes $C_{\text {allie }}$ meridionalis, burgundiæ, Arvernice et circà Lutetiam.

$$
75 \mathrm{I} \text {. B U N I A s. }
$$

Calix patens; petala longiora, unguibus erectis; silicula snbrotunda, 3- focularis, loculis monospermis, valvis osseis non deluiscentilus.

4275. Erucago Siliculis tetragonis tetrapteris quadrilocularibus, foliis rarlicalibus runcinatis, caulinis lanceolatis. $\odot$. In Gallize australis agris humidiusculis.

4276. Paniculata. Siliculis ovatis subangulatis bilncularibus reticulato-rugosis, foliis lanceolatis subdentatis sagittatis amplexicanlibus. $\odot$. In agris.

427\%. Cuchlearioiles. Siliculis monospermis ovatis obtusinsculis subrngosis, foliis radicalibus petiolatis Jyratis, caulinis sagittatis amplexicaubbns dentatis. $\odot, \sigma$. Ad versuras et in vineis Pedemontii, Gallia Mediterraneæ, Arvernia, circà Lutetian.

$$
\text { 752. C R A M B } \mathbf{E} \text {. }
$$

Staminum 4 majorum filamenta apice bifurcata hinc antherifera; silicula pedicellata, globulosa, 1-sperma, r-locularis, non dehiscens.

42-S. Maritima. Foliis pinnatifidis inciso-dentatis cauleque glabris.

2. In maritimis à Nicæa ad Picardiam.

$$
\text { 755. I s A ' } \mathrm{r} \text { I s. }
$$

Calix modices patens; petala ungnicnlata, patentia; stylus nnllus; stigma capitatum; silicula linguxformis, ovato-oblonga, compressa, non debiscens, monospcrma, bivalvis, valvis compresso-carinatis.

4279. Tinctoria. Foliis radicalibus crenatis, caulinis sagittatis, siliculis lanceolatis basi attenuatis. $0^{\star}$. Ad vias inter segetes Delphinatûs, Lutetiæ, et colitur in Gallia australi.

4280. Alpina. Foliis integerrimis cordatis, siliculis oblongis utrinquè obtusis. 2F. In monte Vesulo.

\section{O R D O L X X VIII. C A P P A R I D E AE.}

Calix polyphyllus aut monophyllus, partitus ; petala $4-5$ luypogy$n a$; stamina sæpiù indefinita; ovarium stipitatum; stylus nullus ant hrevis; stigma simplex; siliqua aut bacca polysperma; perispermux nullum; corculum incurvum, radicula in lobos prona. 


\section{† Capparidea legitima. 754. c A P P A R I s.}

Calix 4 -phyllns, carlucus; petala 4 patentia; stamina plurima, lon . ga; stignat sessile; siliqua carnosa, pedicellata, ovata vel cylindrica; senina in pulpa niduiantia.

428r. Spinosa. Pedunculis I-floris solitariis, stipalis spinosis, foliis annuis, siliquis ovalibus. $\zeta$. In rimis nnurorum sasorumque Galloprovincix.

\section{+ + Plante Capparideis affines. 755. R E S E D A.}

Calix $\{-6$-fidus; petala $\{-6$ irregularia, sæpiìs laciniata; stamina 10-2n; ovarium snlsessile; styli 3-5 brevissimi; capsula angulosa, Ilocularis, apice dehiscens, polysperma.

4282. Luteola. Foliis lanceolatis undulatis integris, calicibus 4 -fidis, caule erecto. $\sigma$. Ad vias.

4283. Glanca. Foliis linearibus basi acutè dentatis, floribus 4-gyuis, caule diffuso. 8 . In Pyrenæis.

428 . Sesamoides. Foliis lanceolato-linearibus integris, fructibus stellatis. $\odot$. In arvis sabulosis circà Mlonspeñinm, Cenomanum, Tarbellicas-Aquas, in Pyrenæis.

4285. Alba. Foliis pinnatifidis subundulatis, floribus 4-gynis, calicibus 5-partitis. $\odot$. In sabulosis maritimis Galliæ Mediterrane:.

4286. Undata. Foliis pinnatifidis undulatis, floribus 3-4-gynis densè spicatis, frnctibus 3-( raro 4)-aculeatis. 2 . In Uccitania.

4287. Lutea. Foliis pinnatifidis undulatis, superioribus 3 -fidis, calicibns 6-partitis, fructibus oblongis triangularibus apice truncatis. $\odot$ Linn. 24 Desf. Ad vias et muros, in sabulosis.

4288. Plygteuma. Foliis radicalibus inicgerrimis spatulatis obtusis, caulinis semi-trilobis, calicibus maximis 5-partitis. $\odot$. In arvis sabulosis.

4289. Odorata. Foliis undulatis integris trilobisque, calicibns corollam æquantibus. 8 . Ex Egypto et Barbaria, culta propter odorem.

$$
\text { 756. P A R N A S S I A. }
$$

Calix 5-partitus, persistens; petala 5-6; squamæ 5-1o, ciliatoglandulosæ, hasi petalorum insertx; stamina 5 ; ovarium sessile, liberum ; stignata a-4 persistentia; capsula 4 gona, 4 -valris, valvis apice dehiscentibus, septa inempleta gerentibus; corculum rectum. 429o. Palustris. Foliis radicalibus cordutis, nectariis multisetis. 2 . In pratis hamidis paludosisque montanis.

$$
\text { 757. D R O S E R A. }
$$

Calix 5 -firlus; petala 5 marcescentia; stamina 5 ; styli 5 ; cap. sula rotundata, calice corollaque cincta, $\mathrm{r}$-locularis, 3-5 valvis semina numerosa; corculum rectum ad basim perispermi carnosi. 
\{29r. Rotundifolia. Folis a adicalibus orbiculatis. $\odot$. In paludusis et turfusis.

4292. Longifolia. Foliis radicalibus ovali-oblongis. $\odot$. In pratis humidis et paludosis.

4293. Anglica. Noliis radicalibus lincaribus, floribus 8-gynis, capsulis q-valvibus. 2f. In guludosis circà Moguntiam.

$$
\text { 758. A L D R O V A N }
$$

Calix persistens, campanulatus, 5-partitus, laciniis ovalibus concavis; pelala 5 ; stamina 5 ; styli 5 ; calpsula 1 -loctalaris, 5 -gonda, 5-valvis; semina 10, capsule parietibus adfixa.

429\%. Vesiculosa. 2f. In lacubus Pedemontii natans.

\section{O R D O I X X I X. R U T $\triangle \mathrm{CE} A \mathrm{E}$.}

Calix monophyllus, 5-lobus; petala 5, lypogrna, calicinis lobis alterna; stamina to aut 15 ; vvarinm simplex, liberum ; stylus 1; fructus mullicapsularis aut multilocularis; perispermum carnosum, rariùs nullum; corculum rectum; cotyledones planse - Herbe aut suffrutices, foliis sæpiùs glanduloso-punctatis.

$$
\begin{gathered}
+ \text { Foliis oppositis, slipulaceis. } \\
759 . \text { T r I B U L U s. }
\end{gathered}
$$

Stigma 5-lobum; nuces 5 approximatæ, aculeatæ, 2-í-loculares, 2-4-spermi.

1295. Terrestris. Foliis subsexjugis subæqualibus, seminibus 4 -co:nibus. $\odot$. In arvis et ad vias Galliæ australis, et in insula FigriMonasterii.

$$
\begin{gathered}
+\dagger \text { Foliis alternis, exstipulatis. } \\
760 . \text { n U T } .
\end{gathered}
$$

Calix persistens, 4-5-partitus; petala $4-5$, cochleariformia, unguiculata; stamina $8-10$; ovarinm basi $8-10$ poris nectariferis donatum; capsula globosa , 4-5-locularis , 4-5-loba.

4296. Graveolens. Foliis decompositis, foliolis subcarnosis oblongis obtusis, petalis integerrinis. 2f. In sterilibus Galliæ australis.

4297. Montana. Foliis decompositis, foliolis linearilus, petalis integerrimis. $\%$. In petrosis montanis Gallix anstrails et circit Parisios.

4298. Chalepensis. Foliis decompositis, petalis margine dentatociliatis. 24. In Occitania.

$$
\text { 76I. P } \mathbf{I} \text { G A } \mathbf{N} \text { U } \mathbf{m} \text {. }
$$

Calix 5-fidus, persistens, laciniis 5 longis, foliaceis ; stamina 15 ; stigma 3-gonum; capsula globosa, subtrigona, 3-locularis, 3-valvis.

4299. Ilarmala. Foliis multifidis carnosis, caule herbaceo ranoso diffnso. 24. Circà Nicæan. 
attenoato, petalis crenatis. 2 C. In saxosis maritimis circà $\mathrm{Nar}$ bonem.

4319. Hirtus. Floribus subsolitariis, squamis calicinis senis ovatis mucronatis calice nultù brevioribus, petalis ereuatis, foliis margine scabris. 24 . In collibus Delplinatûs, Galloprovincix.

$4319^{*}$. Alpestris. Floribus solitariis ant subaggregatis, squamis calicinis quaternis ovatis mucronatis calice mults breviorihus, petalis emarginatis subcrenatis. - D. alpestris. Bab. acard. Tur. - P. 1 I. t. r. - In pascuis Alpium maritimarmm.

4320. Furcatus. Canle dichotomo 2-f-floro, floribus solitariis, pedunculis distantibus, squamis calicinis oppositis subbinis tubo multù brevioribus. $\{$. Ad margines agrorum propi Tendam in Pedemontio.

4321 . Virgineus. Floribus solitariis, squamis calicinis brevissimis obtusissimis, binis distantibus, petalis crenatis, caulibus patucifloris, foliis cespitosis linearibus rigilis. 2 . In saxosis provinc. merid.

4322. Deltoides. Floribus solitariis, squamis calicinis ovato-lanceolatis acutis subbinis, foliis obtusiusculis subpubescentibus, petalis crenatis, caulibus sterilibus decumbentibus. $\mathcal{Y}$. In incultis et umbrosis.

4323. Superbus. Floribus paniculatis subfastigiatis, squamis calicinis brevibus ovatis mucronatis, petalis ultrà medium pinnatomaltifidis fance pilosis, caule erecto. $\delta$. In nemoribus et pratis umbrosis montanis.

432f. Monspeliacus. Floribus solitariis, squamis calicinis subnlatis rectis tubo pauld brevioribus, petalis digitato-multifidis, caule erecto. 4 . In Alpibus Pyrenæis et Monte-Aureo.

4325. Plumarius. Floribus solitariis, squamis calicinis binis ovalibus brevissimis submucronatis, corollis digitato-multifitlis fance pubescentibus. $\mathcal{~}$. In hortis cultus, forsan in prov. anstralibus spontaneus.

4325*. Arenarius. Canlibus adscendentibns unifloris, foliis linearibus subciliatis, squamis calicinis brevibus ovatis submucronatis, petalis dentato-multifidis. 2 . In arenosis maritimis à Bayona ad Nanuetes. - D. arenarius. Lin. $S_{p}$. 589? Thor. land. 1 7 r. non Hop. Scop. D. gallicus. Pers. Ench. $49^{5}$.

4326. Casius. Caulibus suhunifloris, squamis calicinis subrotmndis brevibus, petalis crenatis pubescentibus, foliis margine scabris. భ. In saxosis montanis Jurassi, Montis-Aurei, Alpium Delphin.

$4326^{*}$. Tener. Caule unifloro, petalis fumbriatis glabris, squamis calicinis quaternis lanceolato-linearibus tubo paulò brevioribus. D. tener. Balb. acad. 'Tur. 7.p. I3. t. 3. - Ad margines agrorum in montibus Tendx.

4327. Alpinus. Caule I-floro, petalis crenatis, squamis calicinis acutis calice sublongioribus, exterioribus foliaceis. $2 \underset{L}{ }$. In pascuis montanis Galloprovinciæ, Pedemontii. 


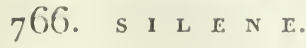

Calix tubulnsns, sæpé ventricosus, 5-dentatus; petala 5, longè unguiculata, fance rartus unda, sxpius squamis corvanta, limbo seppius 2-lido; stamina 10 ; styli 3 ; capsula 3 locularis, in 6 valvas dehiscens.

\section{S. I. Culice glabro.}

432S. Inflata. Calicibus inflatis reticulatn-venosis, fance subnuda, foliis ovatis, caule erecto dichotomo. 24 . In arris pratis et ad vias frequens.

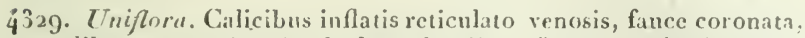
canlibus prostratis vel subadscendentilus, floribus solitariis geminisve. $\mathcal{F}$. In maritimis sabulosis inter lapides et secus Alpium et Jurassi correntes.

433o. Campamila. Canle erecto gracili 2-3-floro, floribus subcernuis, fauce nuda, calice infundibuliformi, foliis lincarilus. $\mathcal{Z}$. In saxosis umbrosis Alpim Pedenontii.

4.33 . Rupestris. Canle dichotomo multifloro, floribus erectis, petalis emarginatis, calicibus ovoikleis, foliis lanceolatis. $\sigma^{7}$. In saxis umbrosis Pyren. Alp. Voges. Cebennarum.

4332. Puadridentata. Petalis quadrilobis, caule dichotomo, foliis lincaribus recurvis. $\odot$, Lim. 2$\}$, All. In Alpibus inter saxa propi nives.

4333. Saxifraga. Canlibus subunifloris, peduncnlis longitudine canlis, foliis glabris linearibus, calicibus clavatis, petalis bifidis. 2C. In saxosis apricis Pedemontii, Galloprovincix, Pyrenæorum.

4334. Acaulis. Cespitosa iepressa, foliis patulis linearibus, flori bus solitariis, petalis emarginatis. $2 f$. In montanis editissimis. Var. $\gamma$ : pedunculo longissimo insignita potiùs species distincta.

4335. Inciperta. Caule dichotomo paniculato, calicibus subinflatis, petalis brevissimis emarginatis, foliis glabris lanceolatis. $\odot$. In provinciis meridionalibus inter linornm segetes.

4336. Polyphylla. Foliis fasciculatis setaceis, ramorum florentium oppositis, floribus pedicellatis terminalibus et in dichotomia solitariis. 2 . In arvis et submontanis in Delphinatu.

4337. Bicolor. Glabra subriscosa, canlibus basi ramosis patulis, ramis erectinsculis, floribus terminalibus, calice tereti reticulato, petalis hifidis (sup. albis, subtis purpur.). $\odot$. In arenosis à Bayona ad Nannetes.

4338. Armeria. Floribus fasciculatis fastigiatis, foliis superioribus corlatis glabris, petalis integris. $\odot$, Linn. $\sigma$, Vill. In sylvis lapidosis submontanis Delphin. Pedem. Galloprovinciæ, Monspelii, Moguntix.

4339. Belten. Caule dichotomo, foliis ovato-oblongis, calicibus ovatis venoso-reticulatis, fance coronata. $\odot$. Monspelii.

43ło. MIuscipula. Caulibus viscosis repetito-dichotomis, floribus 
axillaribus scssilibus, foliis glabris. $\odot$. In sterilibus Galloprovinciæ, Monspelii.

\section{S. II. Calice hirsuto.}

43ir. Otices. Petalis linearibus indivisis undulatis glabris, floribus verticillato-spicatis dioicis, pedunculis glabris, caule subuudo. 2 . In sterilibus arenosis.

43'2. Ilalica. Pubescens, petalis semi-bifidis, fauce nuta, calice tubuloso, panicula diclotoma laxa, ramis longis patcntibus, floribus erectis, foliis ovato-lanceolatis. 2 . In lapidosis ad scpes, in Pedem. Delphin. Oceitania.

43ł3. Nutans. Floribus lateralibus secundis cernuis, panicula nutante, petalis 2-firlis, foliis cespitosis lanccolatis. 2 . In vincis et nemoribus, ad muros.

43\}. Paraloxa. Floribus sxpius ternatis, calicibus to-sulcatis caulibusque viscidis, foliis inferioribus subspatulatis, superioribus linearibus, fauce subcoronata, petalis bifidis. 4 . In Delphi11:atu arl saxal et in vineis.

行j. Viridiflora. Petalis bifidis, foliis ovalis scabriusculis acutis, panicula clongata subaphylla. $\sigma$. In lapidusis ad rineas in. Pedenicntio.

43f6. Viccensis. Villnso-viscosa, foliis lincaribus obtusis subcarnosis, panicula subdichotoma, petalis bifidis, fructibus oratis. $\odot$. Circì Nicæau secus Varum et mare.

43' iz. Noctiflora. Calicibus ro-angularibns renosis, dentibus tnbum equantibus, caule diclıotono, petalis bifislis. $\odot$. In arvis cultis secus vias in Vogesis, Alsatia, Delplin. Galloprov. Nicæa,

43:5. Cordifolia. Caule simplici, foliis ovato corrlalis acutis, floribus subsessilihns terminalihus, petalis bifidis. $2 \mathrm{f}$. In saxosis montiun Pedemontii, agri Nicxensis.

43 f). Vullesia. Caulibus r-3-floris decunbentibus, foliis lanceoJatis tomentosis longitudinc calicis, petalis obcordatis. 24. In sterilibus editissimis Alpíum Valles. Pedemont.

435n. Corsica. Caulibus ramosis prostratis, floribus solitariis terminalibus, foliis ovato-obtusis calicibusque lirsuto-viscosis, potalorum ungue calice multò longiori. $\mathcal{Y}$. In arenosis maritimis Corsicæ.

435ั. Ciliata. Pubescens, flnribus pancis lateralibus secundis, petalis bifidis, calicibus tubulosis in-striatis, foliis lincarihus hasi ciliatis. 2L. In sterilibus et editioribus montium Arvernia, Pyrenæorum Narbonensiunı.

4352. Gallica. Hirsuta, flopibus subspicatis alternis secnndis, petalis integris, fructibus erectis. $\odot$. In atvis et petrosis circu Parisios, Nannetes, Monspelium.

4353. Anglica. Hirsuta, petalis suhemarginatis, floriius subspicatis ercetis, fructibus reflexis pedunculatis alternis. ๑. In arvis sabulosis propè Abbavillam, Parisios, Nicæam. 
435\%. Cerastoiles. Hirsuta, floribus solitariis lateralilus, petialis emarginatis, fructificationibus erectis, calicibus subsessilibus sub-

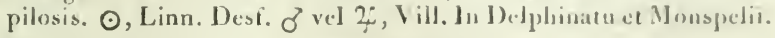

4355. Ouinquevulnera. Hirsuta, floribus solitariis lateralibus, petalis integerrimis suhrotundis, fructibus erectis alteruis. $\odot$. In arvis sabulosis Alsatix, Nicæx, Galloprovincix, Monspelii, Aquitanix.

4356. Tridentata. Hirsuta, floribus latcralibus et terminalihns subsessilibus erectis, petalis tridentatis, foliis inferioribus spathulato. ovatis, superis linearibns. $\odot$ ? In lapidosis 'l'arbr.

4357. Spicata. Hirsuta, foliis radicalibus ovatis subsrabris, caulinis lanceolato-linearibus, floribus spicatis secmulis, calicilus striatis, fructibns erectis sessilihus. $\odot$. In arvis, ad vias, in olivetis $\mathrm{Di}$ cææ, Galloprovincix, Uccitanix.

4358. Sericea. Floribus terminalibns subsolitariis pedunculatis, caule basi ramoso, foliisque lineari-Ianceolatis scriccis. $\odot$. In sabulosis maritimis propè Unclian, in Corsica.

1359. Conica. Calicibus fructûs conicis striis 30 notatis, foliis nollibus lanccolatis, petalis bifidis. $\odot$. In sabulosis apricis et inter segetes circà Parisios, etc.

436o. Conoidea. Calicibıs fructûs globosis acuminatis striis 30 notatis, foliis glabris, petalis integriusculis. $\odot$. Ad narginem agrorum et in sabulosis apricis Nicax, Segusii, Monspelii, Mognntix, etc.

$$
\text { 767. с U c U B A I U s. }
$$

Fructus carnosus, 1-locularis, non dehiscens. Crtera ut in Silenc. 4361. Baccifer. Calicibus campanulatis, petalis distantibus, ramis divaricatis, foliis ovatis. 2 C. In umbrosis et vincis Galliæ australis.

$$
\text { 768. L }
$$

Calix tubulosus, 5 -dentatus; petala 5, unguiculata, emarginata vel laciniata, fauce sæpius coronata; stauina so; styli 5 ; capsula I-aut-5-locularis.

5. I. Capsula 5-loculari; limbo petalorum subintegro (viscaria).

4362. Viscaria. Caule geniculis viscoso. 4 . In pratis siccis et sabulosis Fontisbleaudi, Argentorati.

\section{II. Capsula 1-loculari; limbs petalorum disserto lipartito}

\section{(LYCHVIS).}

4363. Chulcedonica. Floribus fasciculatis fastigiatis, petaljs bifidis. 2 . In Russia australi, colitur in hortis.

4364. Flos-cuculi. Floribus laxè paniculatis, petalis laciniatis, capsula subrotunda. 2F. In pratis sublumidis.

4365. Alpina. Glabra, floribus densè umbellato-capitatis, petalis bifidis. 2 . In pratis editiorum Alpium.

4366. Dioica. Dioica subvillosa, caule geniculato erecto, petalis obcordatis. 2 . Ad vias et sepes. - Flores albi. 
4367. Sylvestris. Dinica ant hermaphrodita hirsuta, canle geniculato debili, foliis ovatis. 2 . In umbrosis humidis. - Flores rubri.

\section{III. Capsula 1-Loculari; limbo pelalorum subintegro} (AGROSTEMA).

43CS. Coronaria. Tomentosa, foliis ovato-lanceolatis, perlunculis clongatis unifloris, petalis emarginatis serratis. 2 . In lapidosis et arl marginem sylvarum in Alpibus.

4369. Flos Jovis. 'Womentosa, floribus umbcllato-caritatis, petalis emarginatis. $2 \mathrm{C}$. In sixosis apricis, pratisque Alpiun el Palatinatûs.

437o. Coeli-rosa. Glabra, foliis lineari-lanceolatis, petalis emarginatis. $\odot$. Circà Nicæam, in Corsica.

6. IV. Fauce nuda; dentibus calicinis foliaceis corollam superantibus ( CITHAGO).

437ı. Githago. Hirsuta, petalis integris. $\odot$. Abunde inter segetes.

$$
769 . \quad \text { V E L } \quad \text { E } \quad \text { z I A. }
$$

Calix tubulosus, 5-6-dentatus ; petala 5-6, brevia, mguibus filiformibus, limbo emarginato; stamina $5-6$; styli 2 ; capsula 1 -locularis.

4372 . Rigida. $\odot$. In aridis et ad marginem agrorum Gallix australis.

$$
770 . \quad F \quad R \quad A \quad N \quad K \quad E \text { N I A. }
$$

Calix subcylindricus, 5-dentatus; petala 5 , unguibus canalieulatis, sqnamula coronatis; stamina $5-6$; stylus 1 ; stigntata $2-3$; eapsnla 1 -locularis, 2 -3-valvis.

4.3-3. Lavis. Floribns solitariis, petalis snbrepandis obtusis, foliis linearibus basi ciliatis. 2 . In maritimis austalibus Mediterranei et Occani.

437亿. Irirsuta. Floribus fasciculatis, petalis subrepandis obtusis, foliis linearibus oblongis, caule hirsuto. 24 . In maritimis Monspelii, circà Narbonen, in Nigri-Monasterii insula et propè Nannetes.

4375. Pulverulenta. Floribns solitariis, petalis subrepandis, foliis ovatis subtùs pulverulentis. $\odot$. In maritimis Galliæ Mediterrancer.

\section{T R I B U S I I. A L S I N E}

Calix 4-5-phyllus vel ad basim usque 4-5-partitus.

$$
77 \text { I. O R T E G.I A. }
$$

Calix 5-partitus; corolla o; stamina 3 ; stylus 1 ; stigma capitatum; capsula 1 -Iocularis, 3 -valvis; semina imæ capsulæadfixa.

13̈6. Dichotoma. Canle dichotomo, pedunculis 1-floris. 2F. In Pedemontio propè Giareno. 


\section{A R I O P H Y L L E T. \\ 772. $\mathrm{P}$ o}

Calix 5-partitus; petala 5, brevia, emarginata; stamina 3 ; styli 3 ; capsula 1 -locularis, 3 -valvis.

437\%. Tetraphyllum. Caule ramoso prostrato, foliis quaternis. $\odot$.

lit cultis et ad sepes umbrosas (xallia australis.

$$
\text { 775. B U F F O N I A. }
$$

Calix 1-partitıs; petala 4́; styli 2 ; capsula compressa, r-locularis, 2-valvis, 2-sperma.

43-5. Anmua. Caule laxè panienlato, calice striato. $\odot$. Ad sepes et vias in Gallia australi.

437n. Perennis. Canle apicc ramoso, ramis erectis, calicc margine scarioso. 2 . In lapidosis collibus Occitania, Arrerniæ, Vallesiæ.

$$
774 \text {. S A G I N A. }
$$

Calix 4-partitus; petala 4 ; stamina 4; styli 4 ; capsula 4 -locularis (Lin.) vel 1-locularis (Gort11.), 4-valvis.

438n. Procumbens. Caulibus glabris procumbentibus. $\odot$. Ad muros $\mathrm{ct}$ in areis sabulosis.

438r. Apetala. Canle ercctiusculo, pedunculis pubescentibus, floribus subapetalis. $\odot$. Ad muros circì Taurinum, in Delphinatu. 4392. Erecta. Caule erccto glabro, floribus solitariis longè pedunculatis. $\odot$. In pratis siccis stcrilibus.

$$
\text { 775. A L s I N } \mathbf{E} \text {. }
$$

Calix 5-partitus; petala 5-bifida; stamina 3 -S; styli 3 ; capsula Ilocularis, 3-6-valvis.

4383. Media. Canle latere alterno villoso, petalis 2-partitis, foliis ovato-cordatis. $\odot$. In hortis et ad sepes frequens.

438 亿. Umbellata. Floribus umbellatis, petalis dentatis. $\odot$. In collibus et ad retustos muros.

$$
\text { 776. Ir ⿷ } \text { н I I N G I } \mathbf{A} \text {. }
$$

Calix 4-partitus; petala 'f; stamina $S$; styli 2 ; capsula r-locularis, 4-valvis.

4385. Muscosa. 24. In montosis humidis, ad oras sylvarnm.

$$
\text { 777. E L A T I N E. }
$$

Calix 4-partitrs; petala $\{$, unguibus destituta; stamina 8 ; ovarium orbiculare, depressum; styli 4 ; capsula 4-locularis, 4 -valvis.

4386. Hydropiper. Foliis oppositis, floribus alternis. 2 . In aquilegiis fossisque inmuatis lontisbleaudi, Tarbæ, Nannetum. - Var. hicxandra circà Cenomanum.

4357. Alsinastrum. Foliis verticillatis, floribns axillaribus verticillatisque. 2 . In aquilegiis Lutetix, Fontisbleaudi, Argentorati, Mulhusæ. 
Calix 5-partitus; petala 5 , integra; stamina 5 vel 10 ; styli 5 ; capsula 1 -locularis, 5-valvis.

\section{I. Foliis basi stipulatis, verticillatis.}

435s. Arvensis. Foliis verticillatis, floribus decandris, seminibus non membranaceis. $\odot$. In sabulosis arvis.

4389. Pentandra. Foliis verticillatis, floribns subpentandris, seminibus nıcnbrana marginatis. $\odot$. In sabulosis ciscà Parisios, etc.

\section{II. Stipulis nullis; foliis oppositis.}

4igo. Nodosa. Foliis subulatis lavibus subobtusis, infinis latè vaginantibus, junioribus in axilla fasciculatis , caulibus subsimplicibus paucifloris, petalis calice dıplò majoribus. 2 . In sabılosis Lumidis circà Parisios, Abrincas, Argentoratum, Sanctum-Valaricum, in turfosis Jurassi.

439r. Pilifera. Foliis lincaribus aristatis subrigidis glabris fasciculatis, caulibus repentibus ramosis cespitosis, petalis calice duplo majoribus. - In montibus editioribus Corsicæ.

4392 . Clabra. Decumbens, foliis filiformibus glabris subacutis, petalis calice majoribus. $2 \mathrm{~F}$. In pratis umbrosis et montosis Vallesiæ, Pedeınontii.

4393. Saginoides. Glabra, foliis lincaribns læribus, pedunculis solitariis longissimis, petalis calice brevioribus. 2 4 . In humidis circá Valletriam, Abrincas.

43ý. Subulata. Subpilosa, foliis subsecundis lineari-subulatis subaristatis, pedunculis solitariis longissimis, petalis calicis longitudinc. $\mathcal{F}^{\mathrm{S}} \mathrm{S}$. $\odot$ Wild. In súbulosis humidis circà Parisios ct Abrincas.

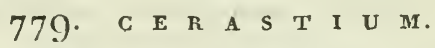

Calix 5-partitus; petala 5, bifida; stamina ro; styli 5 ; capsula 1 locularis, globosa vel cyliudrica, dentibus to a pice dehiscens.

\section{J. J. Petalis calicem non superantibus.}

4395. Vulgatum. Hirsuto - viscosum subdifusum, foliis ovatis, floribus subfasciculatis pedicello æqualibus, petalis emarginatis calicem æquantibns, capsnlis oblongis. $\odot$ Sm. $2 f$ Desf. In ruderatis.

4ig6. Viscosum. Hirsnto-viscosum erectiusculnm divaricatum, foriis lanceolato-oblongis, floribus paniculatis pedicello brevioribns, petalis bifidis calicem subæcruantibus, capsulis oblongis. $\odot$. In ruderatis.

4397. Prachvpetalum. Canle erecto tomentoso dichotomo, foliis ovatis, floribus paniculatis, calice villoso petalis longiore, capsulis oblongis. $\odot$. Circà Cenomanum, Argentorntum, in agris.

4'99. Semi-decandrum. Parvulum cespitosum, caule sub-viscoso, foliis erectis ovato-oblongis, floribus subglomeratis pentandris, petalis emarginatis calice brevioribus, capsulis cylindricis. $\odot$. In sabulosis, ad muros et marginen agrorum frequens. 
§. II. Pelalis calice lonğioribus.

430.9. Tomentosum. Albo-tomentosum, foliis lineani-oblongis, pedunculis ramosis, capsulis oblongis. 2f. In Occitania, Galloprovincia, Monspelii, in Jurasso.

fion. Latifolium. Foliis ellipticis scahıis, pedunculis terminalibus simplicibus subsolitariis, petalis bifidis, capsula ovata turgida. 2 .

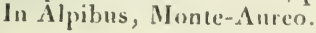

4for. Lanatum. Foliis ovatn-subrotundis rensé lanatis, capsnlis oblongis, cauliculis hrevissmis subbifloris, petalis enarginatis. $2 \mathcal{F}$. In Pyrenæis et $\Lambda$ piluus.

4 $\mathrm{f}^{\mathrm{n}}$. Arrense. Foliis lineari-lanceolatis pubescentibus, corollis calice rluplò majoribus, capsulis ohlongis, caulibus basi subprostrais. $\mathcal{F}$. In versuris agrorum, ad vias.

4fo3. Alpinum. Foliis ovato-lanceolatis, panicula dichotoma panci . flora, capsulis oblongis incusvis. $\mathcal{F}$. In herbosis $\mathrm{h}_{\text {un }}$ idis AJpiun, Pyicnaorum.

fíf. Strictum. Foliis lineruribus acuminatis subglahris, peduncnlis bifloris calicibusque tomentosis, capsulis oblongis. 2C. In petrosis Alpinis et Monte-Aureo.

4 10.5. Suffruticnsum. Foliis lineari-subulatis subhirsutis, caule ramoso erectiusenlo, pedunculis elongatis, calice pubescente marsine scarioso. 2 . In montihus Gallo-provincix, Pedemontii, Delphinatûs. - Cicrastium laricifolium.Vill. Dauph.4.p. Głf́. ex Balb.

fín. Aquaticum. Foliis cordatis sessilibus, floribus solitariis, fuctibus pendulis sulgglobosis. 2F. In fossis aquosis propé lacus.

$$
\text { 780. C H E R L E F I } \mathbf{A} \text {. }
$$

Calix 5-partitus; petala 5, minima, emarginata; stamina ro; styli 3 ; capsula 3-valvis, 3-Jocularis, loculis 2-spermis.

4fo-. Sedoides. 2 . In pratis lapidosis, prope nives æternas, in Alpibus et Pyrenæis.

$$
78 I . A \text { R E N A R I A. }
$$

Calix 5-partitus; petala 5, integra; stamina ı ; styli 3 ; capsula Ilocularis, in valvas 5 deliscens.

\section{§. I. Foliis exstipnlatis, non subulatis.}

4 108 . Tetraquetra. Foliis ovatis carinatis recurvis quadrifariam imbricatis, floribus subcapitatis. $\mathcal{H}$. In sterilibus montosis Galliæ Mediterraneæ.

4 fog. Peploides. Foliis ovatis acutis carnosis. 2 . In sabulosis maritimis Oceani.

4fro. Biflora. Foliis obovatis obtusis, caulibns procumbentibus, pedunculis bifloris lateralibus. $\mathcal{F}$. In $\mathrm{Al}$ pibus editissimis propé nives.

4'1r. Balearica. Cespitosa repens, foliis oratis lucidis subcarnosis, pedunculis clongatis 1 -floris. $\mathcal{F}$. In Corsica. 
4́\{12. Cerastiifolia. Cespitosa sublignnsa ramosa, foliis ovato-lanceolatis 3 - nerviis pubescentibus, pedunculis terminalibus uniflor is piloso-glantlulosis. - In rimis saxorum in l'yrenæis.

4ir3. Trinervia. Canle gracili ramoso, foliis ovatis acutis petiolatis ciliatis nervosis. $\odot$. In nemorosis.

亿́1 4. Ciliatr. Foliis oblongo-obovatis subpetiolatis basi ciliatis, petalis calice majoribus, calicinis foliolis lanceolatis subnervosis. $2 F$. In petrosis nontium Gall prov. Delph. Sabaud. Pedem.

4'fr. Serpillifnlin Foliis suboratis acutis sessilibus levibus, corollis calice brevioribus. $\odot$. Ad muros, in subulosis arvis.

fif6. MIontana. Foliis lineari-lanceolatis, caulibus sterilihus Jongissimis procumbentibus, pedunculis terminaibus longis nnifloris, fructiferis nutantibus. 2 . In sterilibus montanis circà Cenomanum, Turones, Valletriam.

4fi7. Purpurascens. Cespitcsa decumbens, ramis erectis 2-3-floris, foliis ovato-lanceolatis acuminatis glabris, pedicellis folia vix superantibus, ealicibus lanceolacis lævibus margine scariosis. 2 . In Pyrenæis editissimis. - Aren. cerastoides. Pers. Ench. 502.

4'18. Eanceoluta. Cespitosa, ramis adscendentibus, foliis linearilanceolatis acutis rigidis Inngitudinaliter nervosis, pedicellis foliis dupld longioribus, petalis calicem paulù superantibus. $\%$. In pratis lapidosis $\mathrm{Al}$ pium Pedemontii.

4́rg. Polysonoides. Foliis linearibus obtusis, caulibus procumbentibus, pedunculis geminis unifloris snbterminalibus basi ljiJracteatis, calicibus obtnsis enerviis. $2 \%$. In pratis saxosis Alpium editiormun Vallesia, Saband. Pedem.

4420. Uliginosa. Erecta basi ramosa glabra, ramis supernè nudis, pedunculis unifloris longissimis erectis, foliis linearibus mollibus, petalis emarginatis calice lævi majoribus. $\mathcal{Y}$. In paludosis turfosis Jurassi.

\section{§. II. Foliis exstipulatis subulatis.}

\$421. Austriaca. Foliis lineari-subulatis, ramis erectis, pedunculis terminalibus longissimis binis subpilosis, petalis obtusis emarginatis, calicibus 3-nervis acutissimis. $\mathcal{L}$. In lapidosis nmbrosis Alpium Pedemontii, Delphinatûs.

4́łz. Grandifora. Foliis subulatis planis striatis, radicalibus confertis, caulibus subnnifloris pedunculis longissimis pubescentibus. 2:. In petrosis Alpium editiorum et montium Occitaniæ.

$4 \mathbf{1}^{*}$. Linifora. Caulibus suberectis infernè rampsis elongatis, foliis lineari-subulatis, pedunculis 1-3 terminalibus unifloris longis subscabris. 24. In Alpibus Delplin. Pedem. - A. liniflora. Jacq. coll. 2. t. 3. f. 3. A. capillacea. All. ped. t. 89 . f. 2. A. striata. Vill. Dauph. t. 4\%?

4\{́23. Triflora. Foliis lineari-subulatis basi ciliatis, floralibus calicibusque ovato-acuminatis subpungentibus, caule diffuso, ramis erectis nudiuseulis subtrifloris, 光. In montosis sabulosis Fontisbleandi, in Pyrenxis. 


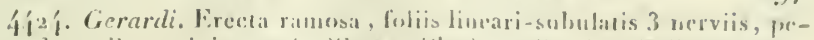

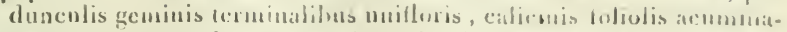
tis margine membande is trincsvis. F. In pratss steribibus Alpiunt, Gallojouv. et :elph.

1925. Ferna. Cespitosa multicanlis, foliis subulatis obtusiusculis ncrvosıs, candibus subpaniculatis elongatis, calicilus acumintas

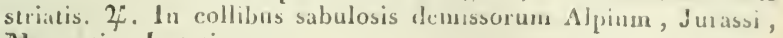
Moguntix, Lutctia.

4亿26. Mispida. Cespitosa crecta multicaulis piloso-hispirla, panirnla dichotoma, foliis subulatis calicibusrue subtus hispidis. 2广. Monsjelii.

4\{27. Tenuifolia. Foliis subulatis setaccis, cauleque ranosissimo dichotomo, calicibns subulatis striatis corullis longioribus. $\odot$. Ad muros et in sabulosis. - Var. glabra et piloso-viscosa.

4i2s. Recurra. Glalua, fuliis radicalibus congestis recurvis subulatis, caulibus eespitosis simplicibus subuifloris, calicilns ovatolanceoiatis striatis. 24. In pratis saxosis $\Lambda$ pium editiorum Pedemontii et Vallesix.

4́29. Setacer. Glabra, caule ramosissimo, floribus paniculatcfastigiatis, foliis setaceis fasciculatis sccundis, calicibuswrato-acutis margine allo-membranaccis. 24. Super saxa in collibus circà Parisios, Fontisbleauli.

4ł3n. Fasciculata. Glabra, foliis subulatis fascienlatis setaceis, canlibus erectis strictis subsimplicibus, floribus fasciculatis, pedicellis folin brevioribus, calicibus acuminatis petalo triplo longioribus.

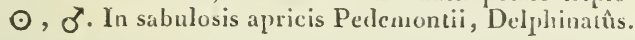

443r. Mucrnnata. Glabra cespitosa ramosa, foliis setaceis, panieula subdichotoma, pedunculis folio longioribus, calicibus aristatis petala supcrantibus. $\odot$ ? In saxosis Occitanix.

S. III. Slipulis scariosis ad basim foliorum (SPERGULARIA).

4432. Segetalis. Foliis subulatis subsecundis, petalis calice brevioribus, pedunculis defloratis subpendulis. $\odot$. Inter segetes circd Parisios, Rothomagum, Taurinum, in Delphinatu.

4\{33. Rubra. Canlibus prostratis, foliis filiformibus internodin brevioribus, seminibus compresso-angulatis. $\odot$. In arris sabulosis ant maritimis salsis Lotharingiæ.

4434. Marginata. Caulibus prostratis, foliis semi-cylindricis carnosis internodia æquantibus, seminibus ala membrantcea cinctis. $\odot$. In pratis et sabulosis maritimis Picardix, Normandiæ, Occitaniæ ct in Delphinatu (Vill.).

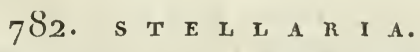

Calix 5-partitus; petala 5, bifida; stamina 10; styli 3 ; capsula locularis, 6-valvis.

4435. Nemorum. Foliis cordatis petiolatis, panicula dichotoma. $¥$. In nemoribus et umbrosis.

4436. Mantica. Caule elongato stricto, foliis lanceolatis, pedun- 
culis longissimis, calicibus lævibus margine scariosis. $\odot$. In pratis subhumidis demissorum montium Pedem. Helvet.

$44^{3} 7$. Hnlostea. Caule erecto stricto, foliis lanceolatis margine scabro-serrulatis, petalis calice triplo longioribus. 2 . Ad sepes et in dumetis.

4\{3̂s. Claura. Caule erectiusculo debili, foliis lineari-lanccolatis margine lævibus, floralibus scariosis, petalis calice duplo longioribus. 2 . Ad fossas in pratis humidis Parisiis, Argentorati, Ambiani.

4439. Graminea. Foliis linearibus margine lævihus, caulibus diffusis, floribus panieulatis divaricatis, petalis calicis longitrdine. 2. Ad marginem sylvarum et in pratis.

4ffo. Aquatica. Caule decumbente, foliis ovato-oblongis, petalis calice brevioribus. $\odot$. In paludosis et ad fossas.

444r. Cerastoides. Caulibus cespitoso-decumbentibus, foliis oblongis, pedunculis unifloris geminatis, petalis calice majoribus. $2 \mathcal{F}$. In herbosis humidis propè nives in Alpibus et Pyrenáis.

тв ви III. Genus Alsineis affine.

783. $\mathbf{L}$ I $\mathbf{N}$ U $\mathrm{Mr}$.

Calix persistens, 5-partitus ; petala 5, unguiculata ; stamina 5, bas! subcoalita; squamulæ 5 , staminibus alternæ; styli 5 ; capsula globosa, mucronata, multivalvis; senina ovata, coupressa.

\section{§. I. Floribus luteis.}

4442. Gallicum. Calicibus subulatis acutis, foliis lineari-lanceolatis, inferioribus confertis, paniculæ pedunculis nunc bifloris, petalis calici subæqualibus. $\odot$. In arvis et sterilibus Galliæ australis et occidentalis.

4fł3. Haritinum. Calicibus oratis acutis muticis, foliis linearilanceolatis, inferioribus ellipticis oppositis, petalis calice duplò longioribus. $\mathcal{F}$. In herbosis maritimis Gallix australis.

44亿任. Campanulatum. Calicibus lanceolato-linearibus, foribus ternatis, foliorum basi utrinquè punctata glandulosa. 2 . In collibus lapidosis Galliæ anstralis.

4445. Strictum. Calicibus subulatis, foliis lanceolatis strictis mucronatis, margine scabris. $\odot$. Ad vias in Galloprovincia et Occitania.

๑. II. Floribus coeruleis v'el rubescentibus, foliis alternis.

4446. Usitatissimum. Calicibus ovatis acutis trinerviis capsulisque mucronatis, petalis crenatis, foliis lanceolatis, caule subsolitario. $\odot$. In arvis culum.

4447. Narbonense. Calicibus acuminatis margine membranaceis, foliis lanceolatis strictis scabris acuminatis, caule tereti supen è ramoso. 2 . In sterilibus Occitaniæ et Pedemontii.

4148. Alpinum. Calicinis foliolis exterioribus subacutis, interiori- 
hus obtusissinis, foliis lincaribus acutiusculis, calulibus erectis. 2f. In pascuis Jurissi et demissorum Alpium.

4fí. Angrustifolium. Calicihus ovatis acutis trinerviis margine subuembranaceis, folies lincaribus acutis rinerviis, canlihus decumhentibus. 2f. Ad vias circh Cenomanum, in Pyrenass, Occitania, Galloprovincia, circà Naunctes.

4\{5o. T'enuifolium. Calicibus acuminat is ciliato-glandulosis, foliis lineari-setaccis retrorsinm scabris. 2 . In collibus aridis circà $\mathrm{Ya}$ risios et in tota feri Gallia.

4451. Hirsutum. Calicibus glandulosu-pilosis, canle foliisque oratolancenlatis 5-nerviis hitsutis, floribus 4-gynis. 2 C. Ad sepes et in dumctis, in agro Nicæensi et Pedemontano.

$$
\text { 5. III. Filoribus albis, foliis oppositis. }
$$

4\{52. Catharticum. Caule dichotomo, calicibus 5-phyllis integris, floribus 5 -andris 5 -gynis. $\odot$. In pratis siccis.

4453. Radio!n. Caule dichotomo, calicibus 4-phyllis lobatis, floribus 4 -andris 4 -gynis. $\odot$. In umbrosis humidis.

\section{O R D O L X X X I. VI OLA C E AE.}

Calix 5-partitus; petala 5, hypogyna, incqualia, unnm sxpè calcaratum ; stamina 5, hypogyna; ovarium 1, liberum; stylus I; antheræ sæè coalitæ; capsula 1-Locularis, 3-valvis, polysperma, valvis medio seminiferis; perispermum tenue, carnosum; corculum rectum. - Herba foliis sæpins alternis, stipulatis.

$$
784 \text {. v I o } \mathbf{L} \text {. }
$$

Calix 5-partitus, laciniis infr: basim productis; petala 5 , inæqualia, supremum majus basi calcaratum; antheræ coalitæ, apice membranaceæ.

\section{\$. I. Sligmate acuio recurvo (VIOLA).}

4454. Pinnata. Acanlis, foliis multifidis, laciniis lobatis. 2 . In Alpibus Pedemontanis propè nives.

4455. Hirta. Acanlis, foliis cordatis, petiolis capsulisque pilosohispidis, calicibus obtusis. 24. In siccis montosis Lutetix, Argentorati, in Delphinatu, Pedemontio, Aquitania.

4456. Odorata. Acaulis, stolonibus reptantibus, foliis cordatis glabris, calicibus obtusis. 4 . Ad sepes et in umbrosis.

4457. Pyrenaica. Acaulis, foliis subcordatis glabris, petiolis apice dilatatis, calicibus obtusis calcare brevissimo. $2 C$. In Pyrenais inter saxa.

4458. Palustris. Acaulis, foliis reniformibus utrinquè glabris $s u b-$ tùs nervosis, calicibus obtusis calcare brevissimo. 4 . In muscosis humidis montanis.

4459. Nummularifolia. Glaberrima, caulibus indivisis brevissimis, foliis subrotumdis integris, stipulis lanceolatis dentatis. 2 . Iu suxosis $\mathrm{Al}_{\text {pium Peden. Delphin. }}$ 
446o. Cenisia. Glabra, caulibus filiformibus indivisis procumbentibus, foliis ovatis petiolatis, calicibus acutis, stipulis linearibus integris. 2 . In saxosis Alpium Pedem. Galloprov.

4461. Valderia. Pubescens, caulibus filifornibus indivisis procumbentibus, foliis inferioribus ovalibus, superioribus oblongo-linearibus utrinquè attenuatis, calicibus acutis, stipulis integris. $2 \mathrm{C}$. In saxosis Alpium.

4462. Mirabilis. Caule triquetro, foliis reniformi-cordatis, floribus canlinis apetalis, radicalibus corollatis. $\mathcal{F}$. In collibus umhrosis circà 'Taurinum, Scgusium, Gratianopulim, Genevam.

4.63. Arenaria. Caulibus simplicibus subpubescentibus diffusis, foliis cordato-subrotundis subglabris crevulatis, stipulis lanceolatis dentatis, ealicibus acutis. $2 f$. In sabulosis Vallesix inferiuris et montis Cenisii?

446\%. C'anina. Caule adultiore adscendente subtriquetro, foliis cordatis acutis, stipulis elongatis dentato-ciliatis, calicibus acutis. 4. Ad sepes et in ericetis.

4465. Lancifolia. Caule adultiore adscendente, foliis ovato-lanceolatis subglabris, stipulis elongatis dentato-ciliatis, calicibus acutis. 2 . In ericetis et sabulosis Aquitaniæ et Hollandiæ.

4466. Montana. Caulibus erectis, foliis ovato-lanceolatis subcordatis longè petiolatis. 2 . In pratis montosis Alpium, Jurassi, circà Moguntiam.

4467. Biflira. Caule I-2-floro bifolio, foliis petiolatis reniformibus serratis. 2 . In pratis humidis Alpium, Jurassi, Pyrenæorum.

\section{§. II. Stigmate erecto, infundibuliformi (JACEA).}

4468. Tricolor. Glabra, canle angulato ramoso diffuso, floribus calice duplò majoribus, stipulis pinnatifidis. $\odot$. In pratis montosis demissornm Alpium et Jurassi.

4469. Arvensis. Glabra, caule angulato ramoso diffuso, petalis calice vix longioribus, stipulis basi pinnatitidis. $\odot$. In arvis et cultis fiequens.

4ł7o. Rothomagensis. Hispida, caulibus ramoso-diffusis, foliis oralibus, stipulis pinnatifidis. 2 . In rupibus secus Sequanam à Rochomago ad Meduntam, in aggeribus arenosis Dunikerkx.

447r. Lutea. Caule triquetro simplici erecto, foliis oblongis subpetiolatis dentatis, stipulis pinnatifidis subciliatis. 2 . In pratís Alpium, Jurassi, Vogesorum.

4772. Calcarata. Caule abbreviato, foliis subradicalibus oblongis basi attenuatis subcrenatis, stipulis lanceolatis subdentatis, calcare calice multò longiori. $\mathcal{~} \zeta$. In pascuis montium editiorum fréquens.

4473. Cornuta. Caule folioso, foliis cordato-subrotundis crenidis subciliatis, stipulis dentatis subciliatis. 2 . In Pyrenæis editioribus. 


\section{O R D O L X X XII. C I S I I.}

Calix 5-partitus, persistens; petala 5, hyposyna, aqualia, caduca, expansa; stantina immumera, hypogvia ; vvarium I, liberum; stylus r; capsula polysperma, 1-10-lncularis, tri-aut-multivalvis; semina mediis valvis ant imis loculis adnata; perispermun carnosum; corculun curvum aus spirale. - Frutices ant herba suffruticosa, foliis sapiüs oppositis stipulaceis.

$$
785 \text {. c I s } \mathrm{T} \text { u s. }
$$

Calix æqualis; capsula 5-1o-locularis, 5-ro-valvis, valvis medio septiferis; semina loculorum angulo interno ad basiun infixa; corculum spiraliter tortum.

\section{I. Floribus roseis ant purpureis.}

4474. Crispus. Foliis lanceolatis trinerviis rugosis pubcscentibus margine crispis, floribus subsessilibus. b. In insulis Stæchadum, Nicææ, Monspelii, Narbonis.

4475. Incanus. Foliis sessilibus lanceolatis basi angustatis aut spathulatis tomentosis rugosis, pedicellis villosis. b. In collibus incultis Narbonis, Nicææ.

4476. Albidus. Foliis sessilibus oblongo-ellipticis subtrinerviis, pedicellisque tomentosis albidis. b. In collibus aridis provinciarum nuediterranearnm et Corsica.

\section{II. Floribus albidis aut lutescentibus.}

4477. Salviafolius. Foliis petiolatis ovatis rugosis utrinque hirsutis, pilis stellatis. b. In collibus et saxosis provinciarum australiorum.

$4477^{*}$. Hirsutus. Foliis sessilibus oblongis, supernè pilosis, subtìs pilis stellatis pubescentibus, pedunculis multifloris, capsulis calice maximo lisirsuto et pyramidali tectis. Lam. Dict. 2. P. 17. ら. In Armoracia circà Landernacum (Landerneau).

4478. Longifolius. Foliis lanceolatis acutis in petiolum ciliatum angustatis, pedunculis axillaribus multifloris. b. In montibus $\mathrm{Coc}$ bariensibus.

4479. Laurifolins. Foliis ovato-lanceolatis petiolatis trinerviis supr \& glabris, subtùs tomentosis, pedunculis multifloris subylabris. In collibus australiorihus.

448o. Ledon. Foliis subsessilibus lanceolatis nervosis suprà glabris, floribus corymbosis erectis, pedunculis calicibusque villoso-sericeis. Ђ. In provinciis mediterraneis.

478r. Monspeliensis. Foliis lineari-lanceolatis sessilibus atrinque villosis trinerviis, pedunculis ramosis villosis. b. In collibus sic cis à Nicæa ad agrum Ruscinonensem, in Corsica, Delplinatu australiori.

$$
\text { 786. H }
$$

Calix inæqualis, laciniis 2 extimis minoribus; capsula I-locularis, 
3-valvis; semina valvarum medio adnata; corcuiums curvum. - Flores sipiùs lutei.

\section{I. Foliis basi exstipulatis.}

$4481^{*}$. Ifalimifolinm . Fruticosmm erectum, folis oppositis lanceolato-obovatis subtriuerviis incanis, pilis stellatis mininis, pedunculis calicibusquc leprosis glabris, foliolis 2 calicinis linearibus. Linn. spec. -38.5 . In arenosis maritimis Corsicæ, circà Urcinium (Lois.). - Flores flavi purpuro-maculati.

4;92. Umbellatum. Frucicosum tortnoso-erectum, foliis oppositis linearibus, floribus umbellatis. I). In sylvis at dnnetis arenosis, circì l'ontembleaudi, Cenomanum et Aureliam. - Flores albi.

4'183. Levipes. Suffruticosmm adscendens, foliis alternis fusciculatis filiformibus glabris, pedunculis racemosis. b. Inter saxa aprica in provinciis mediterraneis.

$48_{4}$. Fumana. Sulfruticosum procumhens, foliis alternis liaearibus margine scabris, ramis unifloris. Ђ. In collibus apricis.

4\{85. Lunulatum. Sufruticosum erectum parvulum, foliis oppositis ellipticis subglabris ciliatis, pedicellis $2-4$ aggregatis terminalibus. b. In montanis Pelemontii. - Flores lutei lunula crocea notati.

4186. Elandicum. Suffrnticosum procumbens, foliis oppositis oblongis ciliatis hinc indè pilosis utrinquè viridibus, calicibus villosis, petalis enarginatis. b. In pascuis collibus montanisque apricis.

$4\{8$. Marifolium. Snffruticosum procumbens, foliis oppositis oratis aut oblongis subtus cano-tomentosis, floribus racemosis. b. In rupibus apricis submontanis.

4ł98. A'yssoides. Snffruticosum erectiusculum, foliis oppositis ovato-oblongis, pilis stellatis scabrosis, calicis triphylli pilis simplicibus. b. In ericetis Cenomanite, Aquitanix, agri Ruscinonensis et Agiuneusis.

4fSo. Tuberaria. Subherbaceum erectum, foliis radicalibus oratis trinerviis tomentosis, caulinis glabris lanceolatis, summis alternis. f. In rupibus Nicæx, Galloprovincix, insularnm Stæchadum et Monspelii.

419o. Guliatum. Herbaceum erectum, foliis oppositis oblongis trinerviis hirtis radicalibus ohoratis, racemis ebracteatis, petalis integris. $\odot$. In arenosis. - Petala lutea ferè semper fusco-maculata.

\section{j. II. Foliis basi stipulatis. \\ * Floribus luteis.}

4491. Ledifolium. Herbaccum erectum subglabrum, floribus lateralibus alternis, pednuculis erectis calice brevioribus. $\odot$. In siccis et sterilibus Nicææ, Provinciæ, Occitaniæ.

$449^{2}$. Salicifolium. Herbaceum patulum villosum, floribus racemosis, pedunculis horizontalibus calice longioribus. $\odot$. In sterilibus apricis Nicax, Galloprovincix; $\beta$, Vâllcsix.

4 '93. Lavandulcefolium. Sulfruticosum erectum cano-tomentosum, 
foliis lanceolato-linearibus, floribus racenusis confertis secumelis pendulis. b. In coliibus at idis Massilie.

4ígi. Glutinosum. Sullruticosmm tortursum srectusenlum, foliis

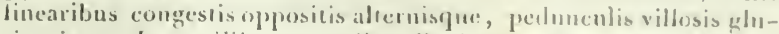

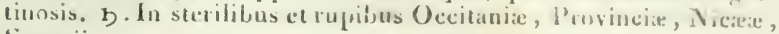
Signsii.

4í95. Fu/gare. Sufruticosum procumbens, foliis ovato ollongis subpilosis sulutis incanis revolutis, stipulis lanceolatis, calicibus subglabris. b. In pascuis siceis frequens.

49́96. Cirandiforum. Suffruticosum erectiusculum, foliis ovalnoblongis sulppilosis sulpplanis, stipulis lancenlatis, calicibus subglabris. b. Ad oras sylvarmu in montanis Provincia, Pedemontii.

4497. Hirtum. Sulfuticosum erectinsenlum, foliis ovatis revolutis, calicibus hispidis. b. In aridis Gallia anstralis.

\section{* * Iloribus allis ant roseis.}

4 49. Roseum. Suffuticosum procumbens, foliis oblongis subpilosis revolntis, superue pilis fasciculato-radiatis, stipulis danceolatis, calicilıs subvillosis. b. Nicæx, Onclix $t \iota$ in Pyenæis.

4499. Polifnlium. Suffuticosum procumbens, fuliis oblongo-ovatis subtirs incanis, calicibus glabris. b. In sylvis Gallix.

4500. Pilosum. Suffruticosum crectiusculnu, foliis linearibus revolutis subtios incanis, calicibus glabris. b. In collibus apricis Gallia australis.

45or. Pulverulentum. Suffuticosum prostratum, foliis oblongis revolutis utrinquè cano-pubescentibus, calicibus sulutomentosis. b. In collihns petrosis et sterilibus Lntetix, Anrclix, Genuze, Uccitania, Pyrenæorum.

4502. Apenninume. Suffuticosum patulum, foliis ollongo-lanceolatis revolutis subtìs incanis supernè demim glalı is, calicibus pubescentibus. b. In collibus apricis Fontisbleandi, Rothomagi.

\section{O R D O L X X X I I I. T I L I A E AE.}

Calix polyphyllus aut multipartitus; petala hypogyna, definita, calicinis laciniis alterna; stamuna lupogyna, innumera, sxpins distincta; ovarium simelex, liberum; fructus uni-ant-unltilocularis, baccatus ant capsularis, mono-ant-polyspernus; perispermum cainosum; corculum subincurvum, planum. - Arbores, foliis alternis simplicibus stipulaceis.

$$
787 . \text { T I L I }
$$

Calix caducus, 5-partitus; petala 5; stamina plirima; ovarium globosnnı, hirsntum; stylus filiformis; stigma capitatum, 5-dentatum ; nux non dehiscens, 5-locularis, loculis dispermis, demum I-locularis, I-sperma.

4503. Microphylla: Foliis cordato-subrotundis acuminatis arguti

$$
\text { C. } \mathrm{c}_{2}
$$


serratis, nuce subglobosa vix costulata tenuissima fragili. Ђ. In sylvis.

द5̃. Platyphyllos. Foliis cordato-subrotundis acuminatis inæuqualiter serratis, nuce turbinata, costis prominentibus insignita, lignosa crassa. b. In sylvis passim; colitur in hortis et areis.

\section{O R D O L XXXIV. M A L V A C E AE.}

Calix sapiüs duplex, interior mnnoplyyllus, exterior nunc polyphyllus nunc monophyllus; petala hvpogyna, regu!aria, imo staminum tubo sæpè adnata, basi subcoalita; stamuna lypongna, innumerc, monadelpha; ovarium liberum, simplex, sæfie lobatum; stylus sæpiùs 1 ; stigmata plurima; fructus in nostratibus capsularis inunc multilocularis, sæpiùs multicapsularis; perispermum nullumi corculi lobi in radiculam incurvi ac corrugati. - Herba aut frutices foliis alcernis simplicibus stipulaceis.

\section{† Fructus multicapsularis. 788. Ir A $\mathbf{L}$ o $\mathbf{P}$.}

Calix duplex, internus 5-partitus, externns 3-phyllus; capsulse plures, capitato-aggregdtæ, 1-spermæ, non dehiscentes.

4505. Malachoides. Foliis oblongis obtusis integris crenatis suprà glabris, pedunculis solitariis axillaribus. 4 . In Galloprovincia.

$$
\text { 78g. II A L v A. }
$$

Calix duplex, internus 5-fidus, externus 3-phyllus ; capsulæ plarimæ, in circulum dispositæ, sæpiùs I-spermæ, non dehiscentes.

\section{§. I. Pedunculis axillaribus conferlis.}

4506. Parviftnra. Caule patulo, foliis angulatis, floribns axillaribus sessilibus glomeratis, calicibus glabris patentibus. $\odot$. Circà Nicæam.

4507. Niccensis. Canle prostrato, foliis angnlatis acntis, pedunculis erectis, calicibus pilosis. $\odot$. Circà Nicæam.

4508. Rotundifolia. Caule prostrato, foliis cordato-orbiculatis obsoletè 5 -lobis, pedunculis fructiferis declinatis. $\odot$. Ad vias et in incultis frequens.

4509. Syluestris. Caule erecto herbaceo, foliis 7 -lobatis acutis, pedunculis petiolisque pilosis. 2 . In incultis et ad sepes frequens.

4510. Crispa. Caule erecto, foliis glabris angulatis crispis, floribns axillaribus glomeratis. $\odot$. Ex Syria orta, subspontanea in cultis et hortis.

\section{II. Pedunculis axillaribus solitariis.}

$45 \mathrm{rr}$. Alcea. Canle erecto, pilis radiantibus, foliis inferioribus angulatis, superioribus 5-partitis scabriusculis, calicis exterioris foliolis oblongis obtusis. 2 . Ad sylvarum oras in incultis et umbrosis.

45r2. Moschata. Caule erecto, pilis simplicibus basi tnberculosis, 
foliis radicalibus reniformibus incisis, entinis 5-partitis pinmatrmultifidis, calicis cxterioribus foliolis lincaribus. $2 \mathcal{f}$. In siccis ct sterilibus.

45ı3. Tournefortiana. Subglabra, foliis radicalibus 5-partitis 3-Iobis linearibus, pedunculis folio caulino longioribus, eaule decunbente. $\odot$. In maritimis Occitanix.

$$
\text { 790. A L } \quad \text { T } \text { II }
$$

Calix duplex, interior 5-fidus, exterior profundè 6-9-fidus; capsulæ plures, :-spermx.

\section{j. I. Capsulis margine membranaceo sulcato cinctis.}

4514. Roser. Foliis 5-seu-7-lubato-angulatis. 8 . Circà Nicæam et in montibus Galloprovincix.

\section{§. II. Capsulis non marginatis.}

45r5. Officinalis. Foliis tomentosis oblongo-ovatis obsoletè 3-lobis dentatis. $\mathcal{H}$. In subhumidis secus rivos.

4516. Narbonensis. Foliis tomentosis, inferioribus 5-7-lobis, saperioribus 3-lobis. 24. Circà Narbonem.

4517. Cannabina. Foliis tomentoso-scabris, inferioribus palmatodigitatis, summis ternatis, foliolo intermedio longissimo. 2 . Ad sylvarum oras, ad sepes et in vineis Occitan. Galloprov.

4518. Hirsuta Foliis cordatis obtusis 5-lobis suprà glabris, caule hirsuto. $\odot$. Ad sepes et in incultis.

$$
\text { 79I. L A } \mathbf{V} \text { A } \mathbf{T} \text { E } \mathbf{R} \text { A. }
$$

Calix duplex, interior 5-fidus, exterior monophyllus 3-fidus; capsulæ plurinæ, I-spermæ. - Pili radiati ant fasciculati.

45r9. Olbia. Caule fruticoso, foliis quinquelobo-hastatis, floribus solitariis. 万. Circà Nicæam, Telonem, etc.

4520. Triloba. Caule fruticoso, foliis subcordatis subtrilobis rotundatis crenatis, stipulis cordatis, pedunculis aggregatis. $b$. Circà Monspelium.

१ว̃21. Maritima. Caule fruticoso, foliis subrotundis obtusè angulatis crenatis tomentosis, pedunculis solitariis axillaribus. $\mathbf{b}$. In saxosis Mediterranei.

4522. Arborea. Caule herbaceo arboreo, foliis 7-angularibns tomentrsis plicatis, pedunculis confertis axillaribus. $\sigma$. In saxosis maritimis circa Nicæam, in Corsica.

4523. Thuringiaca. Canle herbaceo tomentoso, foliis subtomentosis, inferioribus angulatis, superioribus trilobis, lobo intermedio longiore obtuso, pedunculis axillaribus solitariis. 2 . Circà $\mathrm{Ni}$ cæam, Monspelium?

4jof. Punctata. Caule herbaceo punctato-scabro, foliis subtomentosis, inferioribus orbiculato-cordatis, summis 3-lobis, pedunculis solitariis folio longioribus. $\odot$. Circà Nicxam et Forum-Julii.

$$
\text { C c } 3
$$




\section{S T E G I A.}

Calix cluplex, internus 5-fidus, externus 5-6-lobatus; receptaculum apice latescens in plicentam orbicularem, capsalas ad basim in circulam ordinatus tecti instar tegentem. - Piii simplices.

4525. Lavatera. Canle herhaceo superne hispido scalro, foliis inferioribus subrotundo-cordatis, superioribus angulatis, summis trilubis, lobo intermedio lanceolato, pedunculis solitariis folio brevioribus. $\odot$. In olivetis Villæfrancæ, Monspelii ?

$$
\text { 793. S I D A. }
$$

Calix simplex, 5-fidus; capsulæ plurimæ, in circulum dispositæ, approximatæ, 1-loculares, 1-2-3-spermæ, 2-valves.

4526. Abutilon. Foliis subrotundo-centatis acuminatis dentatis tomentosis, pedunculis solitariis petiolo brevioribus, capsulis biaristatis truncatis. $\odot$. In Pedemontio propè pagos et in vineis.

$$
\begin{gathered}
+t \text { Capsula simplex, mulilocularis. } \\
794 \text {. } \text { I I B I s c U s. }
\end{gathered}
$$

Calix duplex, internus 5 -lobus, externus polyphyllus vel multipartilus; styius I ; stigmata 5 ; capsula 5-locularis, 5-ralvis.

4527. Syriacus. Foliis cunciformi-ovatis trilobis dentatis, calice exteriore suboctophyllo interioris longitudine, caule arboreo. b. Ex Syria et Carniola ortus, in hortis cultus.

4528. Paltustris. Foliis ovatis subcordatis acuminatis subtrilobis serratis subtùs canescentibus, calicibus tomentosis subæqualibus, extcriore $10-12$-lobato, caule herbaceo simplicissimo. - Secus oras Aturi et in stagnis maritimis Aquitaniæ.

4529. Trionum. Foliis dentatis, superioribus 3-partitis, lobis lanceolatis, intermedio longissimo, calice interiore inflato membranaceo nervoso. $\odot$. In campis Pedemontii, Novaram inter et Tecinum.

\section{O R D O L X X X. G E R A I E AE.}

Calix persistens, 5-partitus aut 5-pliyllus; petala 5, hypngyna, unguiculata, sæp̀ inæqualia aut irregularia; stamina hypogy'nn, numero definita (5-In); filamenta inæqualia. interr'ium basi coalita ant sterilia; ovarium simplex, liberum, pentegnnum, interdim glandulis 5 cinctum; stylus 1 ; stigmata 5 ; fuctus nunc simplex 5-locularis, munc ex arilitis 5 in aristam productis; semina solitaria; perispromatm nullum; corculmu incurvun. - Herbæ foliis stipulaceis alternis sæpiùs lobatis aut mnltifidis.

\section{+ Ceraniece verce.$$
\text { - 795. E R O D I U } \mathbf{~} \mathbf{1} \text {. }
$$

Calix 5-phyllus; petala 5 , interdim subirregularia; stamina 5 fertilia, cum filamertis 5 sterilibus alternantia et monadelpha; glandulæ mellifera 5, basi staminunı; arilli monosperni aristati ad basin receptaculi rostrati, aristis spiralibus introrsum barbatis. 
5. I. Foliis compositis, pinnatis ternatisque.

453n. Petramm. Acanle, peonnculis ralicalibns multifloris, protalis

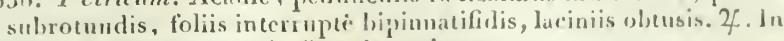
Uecitania et Pyrenais in fissuris rupium.

453 г. Clandulosum. Acaule, podunculis radicalilus multifloris, petalis subrrualihus ovato-acutis, foliis intermpte bipinnatifidis, laciniis lancenlatis acutis. 2 . In Pyrenxis.

4532. Cirntarium. Caulescens, peiluneulis multifloris, petalis inrequalihus calice longioribus, foliis pinnatis, pinnis oblongis piunatifidis incisis. $\%$. In cultis, sterilibus, etc.

4533. MToschatum. Canle procumbente, pedunculis multifloris, petalis aqualihus calice unijoribus, foliis pinnatis, foliolis subpetinlatis basi inaqualihus objongis inciso-dentatis. $\bigcirc$. In Ga!lia Mediterranea, circà Basilaeam et Abbatisvillam.

4.34. Ciconiume. Caule strigoso, pedunculis subbiforis, foliis interruptè bipinnatifillis laciniatis. $\odot$. In Gallia meridionali.

4535. Crninum. Caule villoso, pedunculis submultifloris, foliis ternatis crenato-rlentatis, foliolo intermedio pinnatifido petiolato.

$\odot$. Monspelii in sepibus.

\section{§. II. Foliis lobatis.}

4536. Malactøoirles. Caule hirto, pednnculis mnltifloris, foliis puhescentibus cordato-ovatis sublobatis crenatis, calicis foliolis ovatis olitusis, arista brevissina. $\odot$. In Gallia mediterranea.

4537. Corsicum. Canle hirto, pedunculis nnifloris biflor isve, foliis ovatn-cnrdatis sublobatis crenatis tomentosis, calicis foliolis acuminatis. 24? In Corsica. - Planta interdium acaulis.

4538. Maritimum. Caulibus depressis; pedunculis bifloris, foliis cordatis incisis crenatis, aristis glabris. 2 . In Galliæ Narbonensis, Picardiæ et Armoraciæ maritimis.।

4539. Litınreume. Caulescens, pedunculis multifloris elongatis, foliis trilobis, lobis divaricatis crenatis, aristis barbatis. 2\%? In Narbonensibus maritimis.

45 fo. Chnmadrynides. Acanle, pednnculis radicalibns nuifloris articulatis, foliis cordato-orbiculatis crenatis. $\mathcal{F}$. In Corsica, in monte S.-Michælis.

$$
\text { 796. G E R A N I U M. }
$$

Calix 5-phyllıs; petala 5 , regularia; stamina 10 , monadelpha, . alterna, longiora, basi glandulæ melliferæ 5 adnata; arilli 5 monospermi ad basim receptaculi rostrati, aristis subconvolutis intùs non barbatis.

45\% Sanguineum. Pedunculis unifloris, foliis quinquepartitis trifidis orbiculatis. 2 . In pratis siccis, sylvaticis.

1543. Macrorhizum. Pedunculis bifloris, calicibus globnso-inflatis, petalis integris, pistilln Inngissimn, foliis quinquelobis dentatis, caule dichotomo. 25 . In Pedemontii Alpilons.

$$
\text { C. } 4
$$


45亿3. Phoum. Pedunculis bifloris, foliolis calicinis aristatis, arillis apice transversè plicatis. $\mathcal{2}$. In pratis Alpium, in Belgio.

4544. Reflexum. Pedunculis bifloris, foliolis calicinis muticis, petalis retroflexis apice laceratis, arillis apice transversè plicatis. $\mathcal{F}$. In Alpibus, Arvernia.

4545. Nodosum. Pedunculis bifloris, petalis emarginatis, foliis caulinis trilobis serratis, inferioribus 5-lobis, lobis oblongis acuminatis, arillis pilosis pilis adpressis. $2 \zeta$. In Delphinatûs, Galliæ mediterranex alpinis.

4546. Sylvaticum. Pedunculis bifloris, foliis subpeltatis quinquelobis inciso-serratis, caule erecto corymboso, arillis pilosis. 4 . In Alpibus, Pyrenæis, inque montanis sylvosis.

4547. Palustre. Pedunculis hifloris longissimis declinatis, foliis quinquelobis dentatis, caule decumbente adscendente, petalis integris. 2 . In pratis humidis.

45\%S. Aconilifolium. Pilosnm, pilis brevibus adpressis, pedunculis bifloris, foliis subpeltatis septempartitis, Iobis laciniatis, caule dichotomo corymboso, petalis calice majoribus, aristis pubescentibus. $\mathcal{F}$. In Alpibus.

4549. Pratense. Pilosum, pilis laxis, pedunculis bifloris, foliis subpeltatis multipartitis rugosis acutis, petalis integris, aristis pilosis. 2. In pratis humidis.

4550. Argenteum. Acaule, pedunculis hifloris, foliis subpeltatis septempartitis ntrinquè sericeo-tomentosis, laciniis linearibus trifidis, petalis emarginatis. $\mathcal{F}$. In summis Alpibus.

45.5x. Cinereum. Subacaule, pedunculis bifloris subradicalibus, foliis 5-7-partitis ntrinquè cinereis pubescentibus, laciniis obtusis trifidis, petalis emarginatis. 4 . In Pyrenzis.

4552. Pyrenaicum. Cále erecto, pedunculis bifloris, foliis reniformibus 5-7-lobatis, lobis oblongis obtusis triftdis crenatis, petalis emarginatis, arillis pubescentibus, seminibus lævioribus. $\mathcal{F}$. In Pyrenæis, Alpibus.

4553. Lucidum. Pedunculis bifloris, foliis lucidis 5-lobis rotundatis, calicibus transversè corrugatis, arillis multicarinatis. $\odot$. In montosis saxosis.

4554. Molle. Pedunculis bifloris, foliis reniformibus lobatis, lohis trifidis, petalis emarginatis longitudine calicis mutici, arillis glabris transversim rugosis, seminibus lævioribus. $\odot$. In pratis siccis, in aridis campis, etc.

4555. Columbinum. Pedunculis bifloris folio longioribus, foliis partitis, lobis multifulis linearibus, petalis emarginatis longitndine calicis aristati, arillis glahris lævibus, seminibus rugosis. $\odot$. In pratis siccis, sepibus.

4556. Dissectum. Pedunculis bifloris folio brevioribus, foliis partitis, Inbis laciniatis, petalis emarginatis longiturline calicis aristati, arillis pilosis, seninibus rugosis. $\odot$. In pratis humidis.

4557. Rotundifolium. Pedunculis bifloris, petalis integris longita- 
dine calicis aristati, foliis reniformibus lohatis, arillis subnembranaceis hirsutis, seminibus rugosis. $\odot$. In cultis et ad muros.

4558. Pusillum. Pedunculis bifloris, petalis emarginatis longitudiue calicis nutici, foliis lobatis, lobis trifulis, arillis pubesentibus, seminibus levioribus. $\odot$. In ruleratis cultis.

4559. Robertianum. Pedunculis hifloris, foliis ternatis quinatisque trifulo-pimmatifidis, petalis integris calice aristato duplo fongioribns, arillis reticulatis. $\sigma$. In nemoribus, rupibus, sterilionibus sylvaticis, etc.

\section{†† Plante Geranicis affines.}

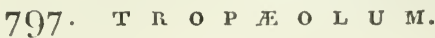

Calix 5-partitus, coloratus, calcaratus; petala 5, irregularia, 2 superiora sessilia remota, 3 inferiora unguiculata basi ciliata; stamina 8 , filamentis distinctis; baccæ subcrosæ 3 , monosperaæ, non dehiscentes, imo stylo affixæ.

456o. Majus. Foliis peltatis repandis, petalis obtusis. $\odot$; multiplex, 4. Colitur in hortis. - Ex Perua, in Europam anno $168 \%$.

$$
\text { 798. I M P A } \mathbf{T} \text { I } \mathbf{E} \text { i } \mathrm{s} \text {. }
$$

Calix 2-phyllus, minimus; petala 4 , hypogyna, irregularia, inxqualia, superius fornicatum, inferius breve calcaratum; stamina 5 , antheris coalitis; capsula oblonga, 5-locularis, 5-valvis, polysperma, clasticè dessiliens, valvis in spiram contortis.

456r. Balsamina. Pedunculis unifloris aggregatis, foliis lanceolatis, superioribus alternis, nectariis flore brevioribus. $\odot$. Colitur in hortis; in India spontanea.

4ั̃62. Noli-tangere. Pedunculis multifloris solitariis, foliis oratis. 2. In nemoribus.

\section{0 x $\quad$ i $\mathbf{L}$ I $\mathbf{s .}$}

Calix persistens, 5-prartitus; petala 5, hypogyna, æqualia, regularia; stamina 10 , hypogyna, filamentis basi subcoalitis, alternis brevioribus; antheræ liberæ; capsula brevis aut oblonga, 5-gona, 5-locularis, locnlis mono-aut-polyspermis.

4563. Acetosella. Acaulis, pedunculis radicalibus unifloris folio longioribus, foliis ternatis obcordatis, stylis longitudine staminum interiorum, radice articulata. $\mathcal{~}$. In sylvis nemoribusque umbrosis.

4564. Stricta. Canle erecto ramoso, pedunculo umbellifero petiolis breviore, foliis ternatis obcorlatis, petalis ohtusis, stylis longitudine staminum interiorum. 24. In Pedemontii, Gencræ, Palatinatûs sepibus, sylvosis.

4565. Cormiculaln. Canle ramoso decnmbente radicante, perlunculo subumbellato petiolis breviore, foliis ternatis obcordatis, stylis longitudine staminum interiorum. 2 . In scpibus et vineis. 


\section{ORDO I XXXVI. SARMENTACEAE.}

Calix monophyllus, lirevis, subinteger; peiala 4-6 sæpiùs 5 , lypogyna, basi latiora; stamina tot qune peiala, iisden opposita, rlisco hypogyno inseria; ovariun r. Jiberum; siyhus r ant o; bacca uni-aut-multilncularis, mono-ant-pniysperma; semina nsea, perispermo destituta; corenlum rectun; cotyledones plane, radicula infera. - Frutices sarmentosi, foliis alternis, cirrlits ant peclunculis oppositifoliis.

\section{V I T I S.}

Calix 5-dentatus; petala 5, sæpiùs basi dehiscentia; stigma capitatum; orarium 5-loculare; bacca !-locularis, 5-sperma.

4566. Sativa. Floribus hermaphroditis, foliis paimato lohatis, b.

In sepihus et umbrosis Aquitaniæ, Occitaniæ, Prorinciæ, Alsatiæ, etc., spontanea; uliquè culta.

\section{OR D O L X X II. MELIA C E AE.}

Calix monophyllus, petula 4-5, hypogy'na, sæpè basi coalita ; stamina monadelpha; anthera numero petalorum recuales aut dupix, al apicem aut parielem internum tubi staminum; ovarium simplex, liberum; stylus I; fructus varius. - Frutices alternifolii.

\section{SOI. II E I, I A.}

Calix parvus, 5-lobns; petala 5; antheræ in, ad parietem internum tubi in-dentati; drupa globosa, nucleo 5-loculari, 5-spermo; perispermum tenue, carnosum.

4567. Azedarach. Foliis bipinnatis, foliolis lævibus nvatis denta-

tis. ๖. Nicææ; in Galloprovincia et Occitania quasi spontanea.

\section{O R D O LX X X VIII. HES P E R I E AE.}

Calix monophyllus; petala hypogy'na, sæpiùs 5 basi latiora et interdùm coalita; stamina sapè filamentis coalita; ovarium simplex, liberum, monosiylum ; bacca nultilncularis ; semina axi ccnirali adfixa; perispermu:m nullum; corculum rectum; cotyledones carnose; radicula supera. - Arbores foliis alternis persistentibus pellucido-glandulosis.

\section{2. $\quad$ C I $\quad \mathrm{T}$ R U $\mathrm{S}$.}

Calix parvus, 5-lohus; petala 5; staminum filamenta polyarlelpha; antheræ circiter 20 ; bacca cortice cxterno glanduloso colorato, iuteriore albo membranaceo, 9-1S-locularis, loculis polyspermis.

4ว̆fS. Medica. Petiolis linearibus, foliis ovatis acuminatis. ந. Ex Asia minori in Europam australem nigravit.

4569 . Aurantium. Petiolis alatis, foliis acnminatis, caule arborco.

b. Ex India in Europam australem migravit. 


\section{ORDO L X X I X. II Y P F I C E AE.}

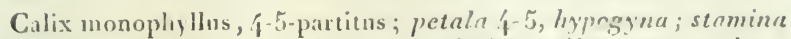
hypogyna, nemerosa, in fasciculos plurimes filmentes conlata; ovatium 1 , liberum; styli 3-5; fructus polyspormus, ratius carnosus, 1-locularis, sappius capsularis, 3-5-locularis, 3-5-valvis, valvarum marguilus introrsim flexis; perispernmm nullum; corculum rectum; rudicula infera. - Herbx aut suffutices, foliis oppositis sicpie glandulosis, floribus lutcis.

$$
\text { SOJ. A N D R O S } \pi: \text { MI U } \mathrm{NT} \text {. }
$$

Stamina in fasciculos 5 coalita; styli 3 ; hacca 1 -locularis, placentis temis baccx parictibus adfixis ope laminx primim integra demim bipartitie.

45-o. Officinale. Floribus termiualibus, ealicinis foliolis inær fualibus subrotundo-ovatis wbtusis, foliis ovatis sessilibus, caule fruticoso ancipiti. b. Sccus fossas et rivos in neinorosis Gallixaustralis et occidentalis.

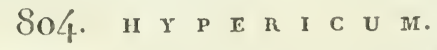

Stamina in fasciculos 3 vel 5 coalita; styli 3 , in cxoticis 5; capsula 3-locularis.

\section{§. I. Laciniis calicinis integris.}

G5̆-r. Quadrangulunn. Caule herbacen quadrangulosubramoso, foliis ovatis pellucido-punctatis, laciniis calicinis lanceolatis. $2 f$. In paludosis fossisque humilis.

4572. Dutium. Canle olsoletè quatrangulo, foliis obtusis impuncta-

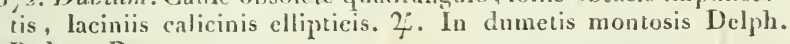
Pedem. Pyrenæorum.

4j̃-3. Perforatum. Caule ancipiti, foliis obtnsis pellucilo-punctatis, laciniis calicinis lanceolatis. $2 \%$. In sylvis et incultis ad sepes frequens.

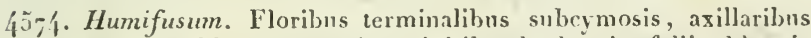
solitariis, caulibus prostratis ancipitibus herbaceis, foliis oblongis obtusis. 2 . In sabulosis et siccis; $R$, caule erecto Jumili, floribus 4 partitis, $\widetilde{0}$, in agris post messes propè Grationopolim.

45-5. Crispum. Canle tereti, foliis sessilibus lanceolatis basi undulato-dentatis. $\mathcal{F}$. In monte Cenisio.

\section{II. I, aciniis calicinis dentatis vel ciliato-glanduiosis.}

45-6. Fimbriatum. Floribus 3-\{-5-gynis corymbosis terminalibns, calicibus ciliato-dentatis, caule simplici adscendente, foliis ovatis sessilibus margine nigro-punctatis. $2 C$. In pratis subhumidis umbrosis Jurassi, Delplinatûs, Pedemontii.

4577. Montanum. Floribus corymboso-paniculatis terminalibns, calicibus serrato-glandulosis, foliis oblongis amplexicaulibus inpunctatis margine nigro-maculatis, caule tereti crccto. $\mathcal{C}$. In sylvis uontanis. 
4578. Pulchrum. Calicibus serrato-glandulosis, caule tereti, foliis amplexicaulibus cordatis glabris. $2 \mathcal{F}$. In sylvis siccis et petrosis.

4579. Hirsutum. Calicibus serrato-glandulosis, caule tereti erecto pubescente, foliis oblongis basi attenuatis pellucido-punctatis, subtus pubescentibus. $\mathcal{4}$. In sylvis montosis.

458ก. Tomentosum. Calicibus serrato-glandulnsis villosis, foliis oblongis obtusis semi-amplexicaulibus flexuosis tomentosis, canlibus adscendentibus. 2 . In pratis subhumidis et sccus rivos Gallia australis.

458r. Elodes. Calicibus serrato-glandulosis glabris, foliis subrotundo-ovatis sessilibus pubescentibus, caule tereti repente. $\mathcal{Y}$. In pratis humidioribus paludibnsque tnrfosis.

4582. Numnularium. Calicibus obtusis serrato-glandılosis, foliis orbiculatis subcordatis petiolatis glabris, caulibus teretibus adscendentibus. 2 . In saxosis montosis Delph. Pyıen. Voges.

45S2*. Linearifolium. Calicibus serrato-glandulosis, caule tereti erecto, foliis linearibus obtusis glabris. Vahl. Symb. 1. p. 65. $\mathcal{F}$. In ericetis circà Bajonam (Vahl.); in rupibus maritimis propè Abrincas observavit Artur-Villarmoi.

4583. Coris. Calicibus linearibus obtusis scrrato-glandnlosis, foliis linearibus nargine revolutis quaternis, caulibus fruticosis. 2f. In collibus aridis Galloprov. Pedem. circà Nicæam.

\section{O R D O X C. A C E R A.}

Calix monophyllus, persistens , 5-fidus ; petala aut nulla aut 5, naguiculata, disco hypogyno inserta, calicinis lobis alterna; stamina distincra, disco inserta, numcro definita; ovarium liberum, sinplex aut trilobum; stignata $1-2$; capsula 2-3-locularis, loculis 1 spermis; perispermum nullum; radicula in lobos prona. - Arbores foliis oppositis.

\section{A C E R.}

Calix 5-partitus; petala 5 ; stamina sæpiùs $S$; ovarium bilobnon; stylus I; stigmata 2, acuminati ; samaræ 2 , basi unitæ, alato-membranaceæ, I-loculares, I-2-spermæ.

4584. Pseudo-platanus. Foliis 5-lobis inæqualiter serratis obtusis, racemis pendulis subtomentosis. $\mathbf{b}$. In sylvis montanis.

4585. Platanoides. Foliis 5-lobis acuminatis acutè dentatis glabris, floribus corymbosis erectiusculis glabris. $\mathbf{b}$. In sylvis montosis Arvernix, Alpium, Cebennarum.

4j86. Opulifalium. Foliis 5-lobis subrotundis obtusè dentatis, racemis pendulis, fructibus cymosis alis approximatis. b. In Alpibus Delphinensibus ct Segusianis.

4587. Campestre. Foliis 5-lobis olutusis glabris, racenis erectis, cortice suberoso rimoso. Ђ. In sylvis et ad sepes.

\{58S. MInnspessulanum. Foliis trilobis integerrimis glabris annuis. 
b. In saxosis apricis Occitania, Detplinatûs, Galloprovincie, Pedentontii.

$$
\text { 806. } \text { E s c u L U s. }
$$

Culix campanulatus, 5-dentatus; petala 5, inxrualia; stamiua 7, distincta, inæqualia, declinata ; stylus s subulatus; capsula coriacea, 3-locularis, 3-valvis, loculis dispermis, sxpè 1-2 abortivis.

4589. Hippocastanum. Foliis digitatis septenis, corollis 5-petalis patulis. ๖. Ex India ortum, numc in Gilia subspontuneum.

\section{O R D O X C I. R A N N C U A C E AE.}

Calix polyphylus, interdium nullus; petala plurima, hypogina, nunc regularia numcro definita, numc irregularia numero indefinita aut definita squanifornia cucullata aut calcarata; stamina hyposyna, numero sapius indefinita; ovaria raro solitaria, sapiùs plurime, receptaculo inserta, unonostyla ; capsulæ tot quot ovaria, nunc I-spermæ non dehiscentes, nunc polysperma sutura longitudinali dehiscentes; corculum minimum ad apicem aut busim perispermi cornei. -Herbæ aut frutices foliis sæpius alternis lobatis, cxstipulatis, basi vaginantibus.

† Ovaria plurima; capsula r-sperma non dehiscentes.

$$
\text { 807. C L E M A T I S. }
$$

Calix nullus vel minimus, bilobus; petala $\{-5$; stamina exteriora interdùm spontè abortiva et petaloidea; capsulx plares, sæpiùs caıdato-plumosæ. - Frutices sarmentosi, oppositilolii.

ஒ. I. Floribus paniculatis; pedunculis ramosis (CLEMATIS).

459o. Vitalba. Caulibus sarmentosis, foliis pinnatis, foliolis scandentibus cordatis inciso-lobatis. 24 . Ad sepes frequens.

459r. Flammula. Caulibus sarmentosis, foliis inferioribus pinnatis laciniatis, summis simplicibus integerrimis lanccolatis. b. Ad sepes et in dumetis Galliæ australis.

4592. Erecta. Caulibus ercctis, foliis pinnatis, foliolis ovato-lanceolatis integerrimis subtis pubescentibus, corollis 4-5-petalis. 2 . In sterilibus et incultis Galliæ australis.

4593. Maritima. Caulibus prostratis simplicibus hexagonis, foliis pinnatis linearibus. 2 . In incultis mastimis Galloprovincix et Nonspelii.

9. II. Floribus axillaribus; pedunculis simplicibus (ATRAGENE).

459 4. Alpina. Caulibus sarmentosis subherbaceis, foliis biternatis serratis acuminatis, petalis numerosis exterioribus magnis, interioribus parvis spathulatis. $\mathcal{F}$. In saxosis et dumetosis Alpium.

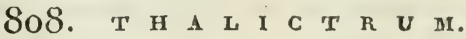

Calix nullus; petala $4-5$, caduca; capsulæ plures, sulcat $x$, muncrone subrecurvo terminatæ. 
4595. Alpinum. Caule simplicissimo subnu io, racemo simplici terminali. 2f. In Pyrenæis editioribus, $A_{I^{i}}{ }^{i}$ cosque Vallesiacis.

45y6. Tuberosum. Floribus maxımis terminalibus pentapetalis, radice fasciculata, fibris tuberosis. 24. In Pyrenxis.

4597. Fotidum. Foliis pubescentibus, caule paniculato filiformi ramosissimo folioso. $2 \mathcal{F}$. In apricis saxosis Delpls. Gallopr. Occit. Saband.

4599. Minus. Foliolis subrotundis trifidis incisis, floribus cernuis. 2. In pratis montosis circà Parisios, etc.

4テ̃99. Nrutans. Foliolis suhtus glaucis trilobato-acuminatis, paniculæ ramis longis patentibus, floribus pendulis, fructibus erectis. $2 \dot{F}$. In Alpibus Cicnevensibus.

460o. Majus. Foliolis subrotundis subcordatis trifidis mucronatis subtùs glaucis, pauicula fuliosa, floribus cernuis. 4 . In Alpibus Vallesia.

460 I. Angustifolium. Foliolis lanceolato-linearibus integerrimis, paniculat erecta, canle subramoso. 4 . In pratis Alsatiæ, Galloprovincix, ad sepes propi Genevan.

4602. Simplex. Caule folioso simplicissimo angulato, floribus paniculatis cernuis. 2 . In pratis paludosis Galloprov. Occit. Delph.

4Go3. Flavum. Canle folioso sulcato, foliolis oratis trilobis, panicula multiplici erecta. 2, . In pratis humidis ad sepes et fossas ; $\beta$, paniculata subsimplici. - Argentorati.

4604. Speciosum. Caulc tereti lævi subglauco, foliolis subtùs glaucis, floribus densc̀ subcorymbosis. 2 . In Gallia Monspeliensi.

4605. Aquilegifolimn. Foliis foliolisque basi stipulaceis, caule tereti, floribus terminalibus densc paniculatis. $\mathcal{F}$. In sylvis pratisque umbrosis montium.

$$
\text { 80g. A IN E M O N E. }
$$

Involucrum calicinum à flore remotum, 3-phyllum, foliis simplicibus laciniatisve; petala 5-9; capsulæ plures, caudato-plumosx aut mucronatæ.

\section{I. Seminibus arista longa plumosa terminatis (pulsatilia).}

4606. Vernalis. Foliis pinnatis, foliolis tripartitis obtusis glabriusculis, flore erecto. 2 . In pascuis siccis et sterilibus montium.

4607. Halleri. Foliis pinnatis, foliolis tripartitis acuminatis villosis, flore crectiusculo. $\mathcal{F}$. In pratis lapidosis Alpium.

4608. Pulsatilla. Foliis bipinnatis, petalis rectis. 4 . Ad margines sylvarum et in pratis montosis.

4609. Prutensis. Foliis bipinnatis, petalis apice reflexis. 4 . In herbosis siccis et montosis Arvernix, Galloprovincix, circa Tarbellicas-Aquas, etc.

46ro. Alpina. Foliis caulinis ternis connatis suprà-decompositis glabriusculis, foliolis pinnatifidis obtusis, flore patulo. $\mathcal{\psi}$. In 


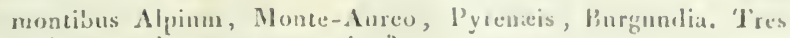
varictales, forsan verad specics?

\section{II. Seminibas arista nulla vel brevissima dunatis (A.N EMONF.'.}

GGux. Hortensis. Foliis radicalibns digitatis, laciniis trifilis, caulinis ternis lancerlatis connatis snbdivisis, seminibus lanatis. 2f. In ste ilibus Galloprov. Vullesie, Nictex.

46เ2. Coronaria. Foliis ratlicalibus teruato-decomprositis, dentibus mucronatis, involucro folioso, scminibus lamatis. 2f. Circà Nicæan, Monspelii.

4613. Baldensis, Foliis biternatis, foliolis tripartitis, laciniis trifidis, involncro folioso, seminibus lanatis, stylo persistenti brevissimo. 2. In saxosis Alpinu editioran Pedemontii.

4614 . Sylvestris. Canle bifloro folioso, foliis tripartitis, laciniis trifidis ientatis, seminibus subroimulis lanatis, stiguate persistenti. 2. Ad sepes et in sylvis Alsatio, in vineis Lotharingia.

4615. Trifolia. Caule unitloro, foliis caulinis ternis ternatis, foliolis ovatis dentatis. 2L. In sylvis circi Parisios, in pratis montosis Pedemontii, Monspelii, propé Rannetes.

4616. Nemorosa. Canle unifloro, foliis caulinis ternis ternatis, foliolis lanceolatis trifido-dentatis, corolla G-petalu. $\mathcal{F}$. In nemorosis, ad seyes.

46: j. Ranunculoides. Caule subbifloro, foliis canlinis ternis ternatis, foliolis subtrifidis apice dentatis, petalis oblongis obtusis patentibus. 24. In nemoribus pratioque umbiosis.

461S. Narcissiflora. Floribus unbellatis involueratis, foliis radicatlibus palmatis inciso-dentatis. 2 . In pratis siceis et montosis Galloprov. Pédem. Delph. Subaud.

$$
\text { 810. H E P A T I C A. }
$$

Calix 3-phyllus, persistens; petala 6; causulæ plures, oblongæ , subacuminate, nudx.

4Gig. Triloba. Foliis trilobis integerrinis. 2 . In umbrosis montinm.

$$
\text { SI I. F I G A R I A. }
$$

Calix 3-phyllus, cadncus; petali 8-9, intis basi squamula instructia ; caysulæ plures, compresse, obtusi.

4620. Ranunculoiles. Foliis cordatis angulatis petiolatis, caule 1floro. 2 . In uubrosis ct humidis, ad sepes, primo verc.

$$
\text { 8I2. A D O N I S. }
$$

Calix 5-phyllus; petala 5, interdium plura; capsulsa numerosa, ovatæ, submucronatæ.

46:1. Annua. Caule glabro supernè sulcato, foliis multifilo-linearibus, petalis 5-8 ovato-oblongis nugue nitido basi notutis, seminibus glubi is. $\odot$. In arvis circâ Parisios, Taurini, Monspelii. 
4622. Vernalis. Caule subsimplici ad florem usque folioso, ramis sterilibus, foliis vaginantibus suprà-decompositis linearibus, petalis 6-15 oblongis, capsulis villosis. 2 . In Alpibus editioribus propè nives æternas.

4623. Apennina. Caule erecto, foliis radicalibus pedunculatis decompositis sublinearibu , floribus pedunculatis nudis, capsulis glabris angulosis. $2 \%$. In Pyrenæeis.

$$
\text { 8I 3. R A N U N C U L U S. }
$$

Calix 5-phyllus; petala 5 , intùs basi squamula donata; capsulæ plures, mucronatx, compressæ, læves vel spinis tuberculisve instructæ.

\section{I. Floribus albis; foliis integris.}

462 '. Pyrenreus. Foliis linearibus indivisis, canle erecto snbsimplici unifloro apice subtomentoso. $\mathcal{H}$. In pascuis editis Alpium ct Pyrenæor um.

46.5. Amplexicaulis. Foliis ovatis nervosis acuminatis amplexicaulibus, caule multifloro apice glabro. 4 . In pascuis fertilibus Pyrenæorum et Monspelii.

4626. Parnassifolius. Foliis nervosis, radicalibus subrotundo-ovatis subcordatis, caulinis sessilibus orato-lanceolatis, caule apice subtomentoso. 2 . In Pyrenæis et Alpibus.

\section{§. II. Floribus allis; foliis laciniatis.}

4627. Aconitifolius. Foliis 5-lobis dentatis, intermediis 3-fidis, floralibus summis digrtatis sessilibus lanceolatis. 2f. Secus rivos et ad oras sylvarum in Alpibus, Pyrenæis, Arverniæ et Occitaniæ montibus.

4628. Lacerus. Foliis radicalibus petiolatis cuneiformibus multilobatis, lobis lateralibus grossè serratis, caulinis linearibus subsimplicibus, caule multifloro. $\mathcal{F}$. In pascuis fertilibas Alpium editiorum.

4629. Asiaticus. Foliis ternatis biternatisqne, foliolis 3-firis incisis, caule infernè ramoso aut simplici. $\zeta$. Ex $\Lambda$ sia ortus, in hortis cultus.

463o. Glacialis. Foliis ternatis, foliolis tripartito-multifidis, canlinis sessilibns, caule subtrifloro, calicibus lirsutis. 2 . In saxorum rimis propè nives æternas in Alpibus et Pyrenæis.

463r. Alpestris. Foliis radicalibus subcordatis obtusis tripartitis, lobis 3-lobatis, caulinis lanceolatis integerrimis, canle 1-floro. 4. In Alpibus, Jurasso et Pyrenæis haùd infrequens.

4632. Seguieri. Foliis 3 partitis, lobis multifido-laciniatis acutis, omnibus petiolatis, caule multifloro, calicibus glabris. $\underset{j}{\mathrm{~F}}$. Inter rupium fragmenta, secus torrentes Alpium editiorum.

4633. Rutcefolius. Foliis pinnatis ternatisque, foliolis tripartito-multifidis incisis, caule subsimplici, corolla 8-10-petala. 4 . Inter saxa propè nives æternas in Alpibus Delph. Pedem. et Vogesis. 
463\%. Mederacens. Foliis subromndis 3-Johis crendtis ant integerrimis, caule repente, petalis minimis acutis, scminilms transverse striatis. 2C. In humidis et paludusis Belgii, propec Abbatisvillam, in aquile giis sylva $\Lambda$ urelianx. $-V$ arietaten loliis inferioribus submersis multifido-capillaceis in Armoracia olservavit Artur-Villarmoi.

4635. Aqnatilis. Foliis submersis capillaceis, emersis 3-vel-5-hulis cuneiformibus, petalis obovatis magnis, seminibus transversé striatis. 24. In aquilegiis et fossis frequens et multiformis, folits nunc ounibus capillaccis, nunc ommihus peltatis, etc.

\section{III. Hloribus luteis, foliis laciniatis.}

4636. Montanus. Foliis 5-lobis dentatis, inferioribus glaberrimis, caulinis sessilibus digitatis, laciniis lineari-lanceolatis integerrimis, caule $\mathrm{t}$-fluro. 24 . In pascuis montanis Jurassi ct Alpium Delph. et P'edem.

4637. Villarsii. Foliis omnibus subhirsutis, radicalibus 3 -lohis inæqualiter incisis apice dentatis, caulino sessili 3-vcl-5-lobn lincari; canle subunifloro. 24. In pascuis Alpium Sabaud. et Delpl.

4638. Gouani. Foliis 5-lobis dentatis, caulinis sessilibus palmatis, laciniis lanceolatis dentatis, caule $\mathrm{I}$-floro. $\mathcal{F}$. In saxosis Pyrencorum et Pedemontii.-Flos magnus.

4639. Sceleratus. Foliis glabris inferioribus palmatis, summis digitatis, caule multilloro, fructibus oblongis. $\odot$. In paludosis et acjuosis.

46 fo. Auricomus. Foliis radicalibus reniformibus crenatis incisis, caulinis digitatis lincaribus, canle multifloro. 4 . In umbrosis primo vere.

4641. Spicatus. Foliis 5-lobis dentalis, caule hirsuto subnudo subsimplici, scninibus longè spicatis. 24. In aridis Pedemontii, in Atigustana valle.

46女2. Repens. Calicibus patulis, peduncnlis sulcatis, sarmentis repentibus, foliis decompositis. 2 . In pratis et cultis subumbrosís.

46ł3. Acris. Calicihus patulis, pedunculis teretibus, foliis tripartito-multifidis, summis linearibus. $\mathcal{F}$. In pratis et pascuis frequens.

467千. Lanuginosus. Calicihus patulis, pedúneulis teretibus, canle petiolisque hirsutis, foliis 3 -fidis lobatis crenatis holosericeis. $2 \mathcal{f}$. In sylvis pratisque montanis.

4645. Míonspeliacus. Sericeo-incautis, foliis tripartitis, laciniis 3lobis, caule subsimplici subnado subunifloro, calicibus reflexis. 24. In herbosis ad margines a'grornm Monspelii, in Gallopror. australi et in Delphinatı.

46 6. Clecenpizylios. Calicibus patulis, pedunculis sulcatis, canle erecto subbifloro, foliis compositis lineari-nultifidis, fructibus oblongis. 4 . In siccis montosis et umbrosis Lutetix, Monspelii, Cenowani.

D d 
469 F. Falcalus. Foliis cuneiformilus 3-partitis. 1.ciniis multifidis filiformibus, seminibus spicatis lalcatis, scapo nudo 1-floro. $\odot$. In arvis Galliæatustralis.-Stanuina 5-S. An potius genus proprium? 4648. Bulbnsus. Calicibns retroflexis, perluncuiis su cutis, caule erecto multifloro, foliis decompositis, radice bulbosa. $2 \%$. In pratis et ad sepes frequens.

4649. Philonotis. Calicibus dennim reflexis setosis, perinneulis sulcatis, foliis 3-particis inciso-lobatis hirsutis, fructu subgloboso, seminibus mag ginc leviter tuberenlosis. $\odot$. Ad oras aquilegion un et fossarum.

465̃o. Parviflorus. Seminibus muricatis, foliis simplicibus laciniutis acutis lirsutis, caule diffuso. $\odot$. In arvis.

665r. Muricatus. Seminibus aculeatis, foliis simplicibus lobatis obtusis glabris, caule diffuso $\odot$. In humidis Gulliæ australis, circà Nicæanı, in Arveıniæe paludosis.

4652. Arvensis. Senninibus aeuleatis, foliis superioribus decompositis linearibus. $\odot$. In arvis inter segetes.

\section{IV. Floribus luteis, foliis integris vel dentatis.}

4653. Bullatus. Foliis ovatis serratis subtùs in nervis hirsutis, scapo nudo 1 -floro. 2 . Ín Corsitit cireà Urcininm.

4654. Thora. Foliis reniformibus subtrilobis crenatis, caulino sessili, floralibus lanceolatis, caule subbifloro. 2 . In Aipibus Sab. Ped. Delph. in Jurasso et Vogesis.

4655. Nodiflorus. Foliis ovatis petiolatis, floribus sessilibus. $\odot$. Ad oras aquilegiorum sylvæ Fontisbleauli.

4656. Graminens. Glaberrinıns, foliis lanceolato-linearibus integerrimis, caule erecto paucifloro. 2 . In pratis sabulosis Fontisbleandi, Monspelii.

465̃. Lingna. Foliis lanceolatis subserratis, caule crecto pubescente. 24 . In stagnorum oris et fossis aquaticis.

4658. Flanmula. Foliis ovato-lanceolatis petiolatis, caule declinato. $\odot$. In pratis humidis. - Variat caule erecto et humifuso, foliis integris ant dentatis, oblongis ant ovatis.

4659. Reptans. Foliis linearibus, caule repente. 24. In regionibus montosis secus lacus Generæ, Neocomi el Alpinm.

$$
\text { 8I 4. M Y } 0 \text { s } u \text { R } U \text { s. }
$$

Calix 5-phyllus, coloratus, eaducus, foliolis infrà insertionen caudatis; petala 5 , brevia, nnguibus tubulosis filiformibus; stamina 5-12; capsulx plures, acutæ, receptaculo longissimo impositæ, spicatæ.

466ก. Minimus. $\odot$. In sabulosis nuper exsiccatis, ad aquilegiorum oras. 
†† Ovaria plurima; capsula inliss longrududinativima dehiscences; pelalı irregularia.

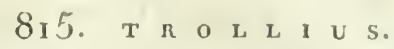

Calix s/1-phyllus, coloratus; petala 9, tubulesat, unilabiata, calice breviora; capsulx plures, subcyliadricer, capitatie:

466r. Eumparus. Calicibus conniventibus, petalis longitudine sta ninum. F. In pratis muntauis et $A I_{\text {pinis. }}$

$$
\text { SiG. H E } I \text {, } L \text { E }
$$

Calix 5-phy!lus, nunc persistens coriaceus, nunc caducus fragilis sæpiìs coloratus; petala 5 , calice multò breviora, cucullata, bilubiatu vel triloba; capsulx 3-6, compressæ, mucronatæ.

\section{I. Foliolis calicinis persistentibus subcoriaceis.}

4662. Foetidus. Caule multifloro folioso, foliis perlatis. 24. In sterilibus lapidosis ad vias.

4663. Lividus. Caule multifloro folioso, foliis ternatis. Z. In Corsica.

466\%. Niger. Scapo subbifloro subnudo, foliis pedatis. $\mathcal{4}$. In petrosis umbrosis montiun, in valle Augıstana, circà Nicæam, in Alsatia.

4665. Viridis. Caule hifido, ramis foliosis bifloris, foliis digitatis. $\mathcal{2}$. In sylvis et petrosis ad radices montium.

\section{פ. II. Foliolis calicinis caducis petaloideis.}

4666. Hyemalis. Flore folio insidente, foliis radicalibus peltatis multifidis, laciniis integerrimis. 2 4 . In liumidis umbrosis ad ra-dices Alpium et Jurassi, primo vere.

4667. Thalictroices. Canle folioso subramoso, foliis uni-vel-biternatis subtrilobis glancis, floribus pedunculatis solitariis minimis. 4. In umbrosis montium in Pyrenæis, Arvernia, circa Gratianopoliun.

$$
\text { 8I7. N I G E L L A. }
$$

Calix magnus, coloratus, 5-phyllus, basi angustatus; petala 5.8, calice breviora, bilabiata ; capsulæ 5-10, oblongæ, acuminatæ, mucronatæ, munc distinctæ, nunc in capsulam multilocularem coalitæ.

4668. Damascena. Florihus involucro folioso multifdo cinctis. $\odot$. In arvis et vineis Galliæ australis.

4669. Arvensis. Floribus nudis, pistillis corollam xquantibus, capsula oblonga infernè coarctata. $\odot$. In arvis inter segetes.

$$
\text { SIS. G A } \mathrm{R} \text { I }
$$

Calix 5-phyllus, minimus; petala 5, calice majora; stamina 10 ; capsulæ 3, polyspermæ, subcoalitæ. 
46-0. Nigellastrum. $\odot$. In vineis et olivetis Galloprovincia, eirck Nicæan, Nanceium?

$$
\text { 8I9. A Q U I L E G I } \mathbf{A} \text {. }
$$

Calix 5-phyllus; petala 5, cucullata, limbo obliquè truncato, tubo conico ohtuso apice recurro; ovaria 5, squamis 10 cincta; capsulæ basi coalitæ, erectæ, mucronatæ.

4671. Julgaris. Cucullis incurvis, foliis 3-lobatis, lobis petiolatis 3-partitis subrotundis obtusè dentatis. 2\%. Ad sepes in unbrosis. 46-2. Viscosa. Cucullis incurvis, caule subnudo subunifloro viscoso-piloso, foliis subtrilobis. 2 . In umbrosis Alpium.

46-3. Alpina. Cucullis rectis, foliis 3-lobatis, lobis 3-partitis linearibus. $\%$. In umbrosis hamidis Alpium Sabuudiæ, in Pyrenæis.

$$
\text { 820. D E I P H I N I U M. }
$$

Calix coloratus, 5-6-partitus, lacinia superiore infrà calcarata; petala 2- $\{$, calcare calicino tecta; capsulæ erectæ, solitariæ aut ternatæ; semina sæpiùs subhirta.

\section{I. Capsulis solilariis; calcare intius I-phyllo.}

46j- $\{$. Consolida. Cucullis monophyllis, caule brachiato diffuso, floribus sparsis. $\odot$. In agris inter segetes.

4675. Ajacis. Cucullis monophyllis, canle recto spicato. $\odot$. Ex Helvetia ortum? colitur in omnibus floralibus hortis.

\section{§. II. Capsulis ternatis; calcare intics 2-phy'llo.}

46076. Peregrinum. Cucullis diphyllis, corollis enneapetalis, foliis mnltipartitis obtusís. $\odot$. In Uccitania, propè Montem-Albanum, circà Nicæam.

4672. Elatum. Cucullis diphyllis, labellis ovatís emarginatis, Iaciniis brevissimis inæqualibus, foliis snbpeltatis 3 -partitis, laciniis multifidis. 24. In petrosis umbrosis Alpium Valles. Pedenı. Delph.

4678. Staphysagria. Cucallis diphỵllis calice brevioribus, foliis palmatis, Inbis obtusis. $\odot$. In ruderatis maritimis subumbrosis Gallix mediterrataex.

$$
\text { 82 I. A C O I I T U M. }
$$

Calix 5-phyllus, coloratus, foliolo superiore cuncavo galeato; petala plura, minima, squamulosa; 2 supcriora (nectaria, Línn.) elungati, sub galea recondita, longé unguiculata, limbo reflexo labiato, ungue incrassato obtuso; cupsulæ sæpiits ternæ, oblongæ, erectæ, acuminatæ.

\section{§. I. Floribus luteis.}

4679. Lycoctonum. Cuculli calcare spirali, labio orato emargi- 
nato, calicis galea conica elungata, foliis paluatis puluescentibus, laciniis trifidis dentatis. F. In sylvis mulurosis montium.

465o. Pyrenaicum. Cuculli calcate spirali, foliis maximis 7-11folatis, lobis 3-5 laciniato-palnatis incisis, floribus dense racemosis. 4 . In Pyrenais.

468r. Anthora. Cueulli ealcare refracto uncinato, labio adscemlento obeordato, galea conica roturulata, foliis multifulis, laciniis linearibus. 2 . In apricis montosis in Jurasso, Alpibus Sab. Delph. Pedeiu.

\section{II. Floribus caruleis vel violaceis.}

4682. Napellus. Cuculli calcare recto obtuso, labio lanceolato adscendente bifislo, galea convexa, foliis nitidis 5-partitis, laciuiis 3-partitis incisis linearibus. 24. In humidis nıontium.

4683. Paniculatum. Cuculli calcare adunco obtuso, labio lanceolato revoluto bificlo, galea convexa, foliis nitilis digitato-5-partitis, laciniis lanceolatis 3 -fido-iucisis, pedunculis pubescentibus divaricatis. 2 . In montibus Galloprov., Monte-Aureo, in Delph.? Pedem.

$+\dagger \dagger$ Ovaria plurima; capsula polysperma, intis longiludinali rima dehiscentes; pelala regularia.

$$
\text { 822. C A L T H A. }
$$

Calix nullus; petala saltem 5 ; capsulæ 5-12, compressæ, acuminatæ, patentes.

4684. Palustris. Caule erecto. 2C. In paludosis et ad fossarum ct stagnorum oras.

$$
\text { 823. P 太 }
$$

Calix persistens, 5 -phyllus vel 5 -partitus; petala saltem 5 , majora, rotundata; ovaria $2-5$ stigmatibus crassis donata; capsulæ ovatooblongæ, ventricosæ, sæpiùs tomentosx, mucronatie; semina subglobosa, lævia, nitida.

4685. Officinalis. Foliis decompositis uulis, foliolis lobatis, lobis lato-lanceolatis, capsulis rectinsculis tomentosis. $\mathcal{F}$. In nemoribus et umbrosis montium Galliæ australis.

$\uparrow+\dagger+$ Ovarium unicum; bacca $\mathbf{1}$-locularis polysperma, seminibus placente adfixis.

$$
\text { 821. A }
$$

Cillix 4-phyllus, caducus; petala 4; ovarium unicum; stylus 0 ; stigma capitatum; bacca 1 -locularis, polysperma, seminibus placente laterali adfixis.

4686. Spicata. Racemo orato, fructibus baccatis. 2 f. In sylvis montosis.

$$
\mathrm{D} \text { :? } 3
$$




\title{
GENERA INCERTA SEDIS.
}

\author{
825. C O R I A R I A.
}

Flores nane monoici vel ex abortu dioici, nunc hermaphroditi; perigonium simplex, 5 -partitum; stamina 10 , liypogyna ; anthera subsessiles, oblongæ, crectæ, loculis basi distinctis; in centro floris ovaria 5 basi coalita, glandulis 5 prominulis interpositis; capsulx 5 , y-spermx, spontí non dehiscentes.

4687 : Myrtifolia. Foliis ovato-oblongis. ๖. In provinc. mediterraneis ad sepes.

$$
\text { 826. II o } \mathbf{N} \text { o } \mathbf{T} \mathbf{R} \text { o } \mathbf{P} \boldsymbol{\Lambda} \text {. }
$$

Calix 4-phyllus, coloratus; petala 4, hypogyna, foliolis calicinis alterna; stamina $S$; ovarium liberum ; stylus cylindricus ; stigma peliatum ; capsula ovato-oblonga, 4-sulea, 4-locularis, 4-valvis, seminibus numerosis receptaculo centrali 4 -angulo adfixis.

468s. Hypopitys. Fmribus lateralibus octandris, terminali decandro. 2 . In pinetis, faginetis et quercetis.

N. B. Cum additamentis hinc indè interjectis, species gallicæ hic memorata, sunt 4866 . 


\section{N D E X.}

A.

Anagallis.

$\begin{array}{ll} & \text { Anagyris. } \\ \text { Pag. 153. Anarihinum. } & \\ 1-6 & \text { Anchusa. }\end{array}$

A rama.

Pag. 2n4.

3 i.

233.

210.

21 Andruse.

AC'ANTHACEAE.

Acantlus.

Acer.

- ACERA.

Achillea.

Aconitum.

Acorus.

AC () TYLEDONES.

Acro-tichum.

Acıx...

A.liınthum.

Adonis.

Aduxa.

Alicidinm.

AFgerila.

AEgopedium.

AEgilops.

AEsculus.

AEthusil.

Agaricus.

Agave.

Agrimonia.

Agrostis.

Aira.

Ajuga.

Alchemilla.

Aldrovanda.

ALC:AE.

Alisma.

ALISUACEAE.

Allium.

Alnus.

Alopecurns.

Alsine.

Alıbæa.

1birl. Andiomeda.

412. Andioperon.

I'birl. And nsice.

292. Androsemum.

420. Audryala.

15\%. Anemone.

I. Anetlinm.

15. A igelica.

421. Anthemis.

$9^{5 .}$

249.

137 .

2) 6 .

411.

$26 \mathrm{r}$.

414.

3.3.

308.

291.

112. Anthoceros.

415. Anthoxanthum.

$9^{\circ}$.

320. Anthyllis.

49. Antirnhinnm.

i\%. Apliyllanthes.

3o4. Apium.

135. APi)CINEAE.

120.

3/,5.

233.

152 .

313.

246.

413. Ayruilegia.

306. Ariabis.

27. Aibulus.

166. Aictinn.

333. Arenaria.

123. Aristolochia.

420.

$3-5$.

249 .

268 .

3,95 .

127. ARISTULOCHIAE. Ibid.

21. ARUIDEAE. I'́9.

33\%. Armeniaca. 3 \%o.

385. Aruica. 285.

1. Artemisia. $2 S S$.

156. Arrm. 149.

155. Arundo. 128.

363. Asarnm. ISy.

180. Aselepias. 247.

120. ASPARAGEAE. 153.

393. Asparagus. Ilid.

405. Asperngo. 240.

3-8. Asperula. 298.

AMARANTHACEAE. 198. Asphodelus. 160.

Amaranilius. Chid. Aspiclium.

Ansaryllis.

Ambrosia.

A MIFITACEAE.

Anmi.

Amygdains.

Anacyclus.

165. Aspleuium.

18\%. Aster.

377. Astragalus.

3i1. Astrantia.

340 . Athamantha.

29o. Athyrium.

11 个.

113.

280 .

355.

315 .

3 เо.

Dd \& 11 . 
424

Atractylis.

Atriplex.

Atropa.

Avena.

Azalea.

Ballota.

Balsamita.

Barkhausia.

Bartsia.

Barthramia.

Batrachospermum.

Bellis.

Bellium.

BERBERIDEAE.

Berberis.

Beta.

Betonica.

Betula.

Bidens.

Biscutella.

Biserrula.

Blasia.

Blechnum.

Blitum.

Bioomyces.

Boletns.

BORRAGINEAE.

Borrago.

Botrychium.

Botrytis.

Brassica.

Briza.

Bromus.

Brunella.

Bryonia.

Bryum.

Bubon.

Buffonia.

Bulbocodium.

Bullaria.

Bulliarda.

Bunias.

Buninm.

Buphtlualmum.

Buplevrum.

Butomus.

Pinxbaumia.

Buxus.

Byssus.

Cacalia.
I N D E X.

Pas. 2;6. Cachrys.

195. CAC'ÍI.

237. Cactus.

126. Cakile.

248. Calamagrostis.

Calendula.

225. Calla.

287. Callitriche.

262. Calluna.

212. Caltha.

105. Calicium.

II. Campanula.

Pag. 3í,

324 .

Ibid,

382 .

$12 f$.

256.

149.

326.

249.

俩。

72.

$25 \mathrm{r}$.

287. CAMPANULACEAE. Ibid.

285. Camphorosma. Ị8.

367. Cannabis.

Ibid. CAPPARIDEAE. 383.

195. Capparis. 38'.

224. CAPRIFOLIACEAE. - 302 .

ro. Capsicum. 237 .

293. Cardamine. 376 .

377. Carduncellus. 268.

357. Carduus. 269 .

90. Carex. 138 .

I3. CARIOPHYLLEAE. 386.

195. Carlina. 276.

72. Carpesium. 287.

23. Carpinus. 181 .

238. Carthamus. 267 .

24. Castanea. $18 \mathrm{I}$.

I16. Cittanance. 266.

14. Cancalis. 3 I2.

37o. Caulinia. I50.

132. Celsia. 234.

Ibid. Celtis. 183.

228. Centaurea. 270.

250. Centranthus: 297.

ro\%. Centunculus. 204 .

307. Ceramium. 8.

393 . Ceratophyllum: $\quad 326$.

I58. Cerastium. 304 .

46. Cerasus. 339.

320. Ceratonia. 34r.

383. Cercis. Ibid.

3rт. Cerinthe. 238.

293. Ceterach. 115.

314. Chærophyllum. 306.

157. Chamærops. 153.

106. Chamagrostis. 134 .

88. Chantransia. 10.

13. Chara. 118.

Chciranthus. $37 x$.

376. Chelidionium. 368. 
I N D E X.

425

CHENOPODEAE, Pag, i9\% Cortusa.

Chenopodium.

Cherleria.

Chirnnia.

Chlora.

Chondrilla.

Clitysanthemum.

Clirysocoma.

Chrysosplenium.

Cicer.

Cichorium.

Cicuta.

Cicutaria.

Cinara.

Cineraria,

Circæa.

Cirsiuns.

CISTI.

Cistus.

Citrus.

Cladonia,

Clathrus.

Clavaria.

Clematis.

Cleonia.

Clinopodium.

ij). Ciorydialys.

Pas. 207.

305. Corylus.

3 .

2. $\{5$. Crambe. 383.

243. Crassula. 32 r.

256. CKASSULACEAE. 321).

286. Cratagus. 330.

270. Cirepis. 261.

320. Cressa. 2'/2.

361. Crithmum. 310.

267. Crochs. 167 .

3ir. Croton. 388 .

30-. Crucianella. 298.

273. CRU CIFERAE. 370.

28亿. Cirypsis. 120.

327. Cucubalus. 391.

273. Cucumis. 251.

401. Cucurbita. Ibid.

Ibid. CUCURBITACEAE. 25̃o.

410. Cunila. 217.

2r. Cuscuta. 2/20.

43. Cyathus. 56.

i9. Cyclamen. 208.

413. Cymbidium. Iz2.

229. Cynanchum. 2$\} 6$.

226. Cynoglossum. 2 r.

377. Cynosurus. 134.

Clypeola.

Cineorum.

Cochlearia.

COLCHICACEAE.

Colchicum.

Collema.

Colutea.

Comarnm.

COMPOSITAE.

Conferva.

CONIFERAE.

36\%. CYPERACEAE.

379. Cyperus.

15\%. Cypripedium.

3.5S. Cytinus.

S r. Cytisus.

35 个.

337. Dactylis.

255. Danaa.

Danthonia.

Coniocarpon.

1,5. Daphne.

190.

68. Datnra. 236 .

Conoplea.

14. Daucus.

3 iा.

Convallaria.

154. Delphinium.

420.

CONVOLVULACEAE. 24r. Dentaria. 3-6.

Convolvulus.

Coniza.

Coriandrum.

Coriaria.

Coris.

Corispermnm.

Coronilla.

Coronopus.

Cornicularia.

llid. Dianthus.

387.

279. Diatoma.

3o6. DICOTYLEDONES. 175 .

422. Dicranum.

205. Dictamnus, 3ล6.

198. Diderma. 54 .

362. Dilymodon. 97.

380. Digitalis. 29,

Gin. Diospiros. 24́7.

$30 \%$ Diotis. $29 \%$.

Cornus.

Corrigin!a.

ॐ3. DIPSACEAE,

294. 
426

Dipsacus.

Dodecatheon.

Doronicum.

Dorycnium.

Draba.

Dracocephalum.

Drepania.

Drosera.

Dryas.

E

Echinaria.

Echinopliora.

Echinops.

Echium.

Elatine.

ELAEAGNEAE.

Elæagnus.

Elychrysum.

Elymus.

Empetrum,

Encilypta.

Endocarpon.

Ephedra.

Fpilobium.

Epimedium.

Epipactis.

EQUISETACEAE.

Equisetum.

Erica.

ERICACEAE.

Erigeron.

Erineum.

Erinus.

Eriophorum.

Erodium.

Erviun.

Eryngium.

Erysinum.

Erysiphe.

Erythronium.

Eupatorium.

Euphorbia.

FUPHORBIACLAE.

Euphrasia.

Evonymus.

Exacum.

Faba.

Fagus.

Focdia.

Ferula.

F.
I N D E X.

Pag. 204. Festuca.

208. I icaria.

28\%. FICUIDEAE.

353. Ficns.

3-9. FILICES.

228. Fontinalis.

263. Fragaria.

Pag. 128.

415 .

32 千.

183.

112.

III.

33 -

381. FRANGULACEAE. 365.

33 . Frankenia. 392.

Fraxinus.

24- Fritillaria.

134. Fucus.

3,5. Fumaria.

26-. Funaria.

238. FUNGI.

$3(3)$

I 8 . Galactites.

I9o. Galanthus.

27,7. Galega.

137. Guleobilolon.

250. Guleopsis.

96. Galinm.

8̧. Garidella.

17\%. Geastıum.

328. Genista.

367 . Gentiana.

I72 GFN'TIANEAE.

II. GFRANIEAE.

Ibirl. Geranium.

24S. Geropogon.

Ibid. Geum.

27y. Cladiolus.

15. Glaux.

23o. Glechoma.

I45. Globularia.

406. GLOBLLARIAE.

361. Glveyrhiza.

3,6 Grnaphalium.

372. GRA IINEAE.

56. Gratiola.

158. Grimmia.

27\%. GRUSSULARIAE.

185. Gymnosporangium.

lbid. Gymnnsiomum.

2: 1. Gypsophila.

365. 246.

Hedera.

II.

216.

$\times 59$.

$369^{4}$.

103.

13.

$2-3$.

166.

354 .

226.

224.

$2 !) 9 \cdot$

$4: 9$.

55.

$34 \mathrm{x}$.

244 .

243.

406 .

407.

266.

337 .

$16 \%$

326 .

223.

20 4.

Ibid.

35 '.

278.

$12 n$.

234.

96 .

325.

44.

94.

386.

363

36r. Helianthemum. 401.

I8r. Helianthus. 29 '

297. Heliotropium. 238.

3if. Helleborus. 
Helminthia.

Helopodium.

Helotiunn.

Helvella.

Hemerocallis.

Hepatica.

HEPATICAE.

Heraclenm.

Herniaria.

HESPERIDEAE.

Hesperis.

Hibiscus.

Hieracium.

Hippoerepis.

Hippophae.

Hippuris.

Holcus.

IIordeum.

Hottouia.

Humulus.

Hyacinthus.

Hydnum.

HYDROCHARIDEAE.

Hydrocharis.

Hydrocotyle.

Hydrodyction.

Hymenophyllum.

Hyosciamus.

Hyoseris.

Hypecoum.

HYPERICEAE.

Hypericum.

Hypnum.

Hypochæris.

Hypoderma.

HYPOXYLA.

Hyssopus.

Hysterium.

Iheris.

Ilex.

Imbricaria.

Impatiens.

Imperatoria.

Inula.

IRIDEAE.

Iris.

Isatis.

Isidium.

Isnardia.

Isoctes.

Ixia.
I N D E X.

Pag. 265.

72. Jasinne.

15. JASMINEAE.

J. Pag. 255.

19. Jasminum.

16o. Jugians.

415. JUNCENE.

S9. Juncus.

3og. Jungermannia.

199. Juniperus.

4io. K.

371. Kobresia.

406.

258. LABIATAE.

363. Lactuca.

I 9 . Lagurus.

327 . Lamarckia.

I38. Lamium.

з3 . Lampsana.

205. Lappa.

184. Larix.

160. Laserpitium.

22. Lathræa.

173. Lathyrus.

Ibid. LAURINEAE.

3ı6. Laurus.

12. Lavandula.

112. Lavatera.

236. Ledum.

263. Leersia.

369. LEGUMINOSAE.

4ir. Lemna.

llid. Leontodon.

roz. Leonurus.

263. Lepidium.

I.

42.7

215.

216.

365.

150 .

351.

9 I.

I $\div 6$.

145.

217.

$25 \%$.

125.

Ibid.

223.

255.

268.

1,6 .

309.

215.

$35 \%$.

19 r.

Ilid.

221.

405.

2 /8.

122.

3 fo.

I 1 .

$26 \%$.

236.

38 o.

64. Lepra. 68.

58. Lcskea. 106.

221. Leucoium. 366.

64. Leuzea. 27.3.

Licea. $5 \mathbf{5}$.

38 . LICHENFS. 68.

366. Ligusticum. 308.

82. Ligustrum. 216.

409. Lilac. 215.

305. LILIACEAE. 159.

2So. Lilium. Ilsid.

166. Limodorum. $\quad 173$.

Ibicl. Limosella. 23o.

383. Linaria. 231 .

69. Lindernia. 230.

32\%. Linnxa. 302.

1\%. Linum. 399 .

167. Lithospcrmum. 239 . 
Littorella.

Lobaria.

Lobelia.

Lolium.

Lonicera.

Lotus.

Lnnaria.

Lupinus.

Luzula.

Lychnis.

Lycinm.

Lycogala.

Licoperdon.

LY COPODIACEAE.

Lycopodium.

Lycopsis.

Lycopus.

Lysimachia.

Lythrum.

Malaxis.

Malope.

MIalus.

Malva.

II ALVACEAE.

Mraniliagora.

Marchantia.

Marrubium.

Marsilea.

Matricaria.

Mayanthemum.

Mays.

Medicago.

Meesia.

Melampyrum.

Melia.

MELIACEAE.

Melica.

Melilotus.

Melissa.

Melittis.

Mentha.

Menvanthes.

Menziesia.

Mercurialis.

Merendera.

Nerulius.

Nescmbryanthemum.

Mespilus.

Micropus.

Molıringia.

Molucella.

M.
Pag. 202. Momordica.

86. Monilia.

Pag. 25r.

1 '́

254. MONOCOTYLEDONES.

137.

3o2. Monotropa.

352. Montia.

3-7. Morchella.

344. Morus.

I50. Mucor.

39 r. Muscari.

237. MUSCI.

54. Myagrum.

55. Myosutis.

I16. Myosurus.

Ibid. Myrica.

240. Myriophyllum.

217. MYRTI:

205. Myrtus.

422.

324 .

43.

IS3.

53.

$16 \mathrm{t}$.

93.

382.

2 亿o.

418.

180.

327 .

329 .

Ibid.

325 .

N.

Næmaspora. 63.

172. Narcissus. 63.

4\%4. Nardns. 335.

329. NAYADES. 18.

Ibid. Nayas. 119.

136. Neckera. 11 i.

236. Neottia. 17 1.

91. Nepeta. 221.

225. Nerium. 246.

117. Nicotiana. 236.

287. Nigella. 4 i 9.

$15 \%$. Nonea. 239.

34. Nostoch.

10. NYCTAGINEAE. 203.

1lid.

410. Nymphæa. 367.

Ibill. $\quad 0$.

125. Ocymnm. 229 .

3 49. Cinauthe. $30 \%$.

228. Enothera. 327.

Ibid. Olea. 316.

222. Oligntrichum. J02.

243. ONAGRARIAE. 326 .

248. Onobrychis. 363.

385. Ononis. 34 4.

158. Onopordum. 268 .

26. Onosma. 239.

32\%. Opegrapha. $6 \%$.

33o. Ophioglossum. . 16 .

200. Oplirys. 150.

393. ORCHIDEAE. I68.

226. Orchis. IGid. 
Origanura.

Ornithogalum.

Ornithopus.

Orobanche.

Orobus.

Oitegia.

Oithotrichum.

Orvala.

Oryza.

Osmunda.

Osyris.

Oxalis.

Oxytropis.

Pronia.

Paliurus.

PAL JNE.

Pancratium.

Panicum.

Papaver.

PAPAVERACEAE.

Parietaria.

Paris.

Parnassia.

Paronychia.

Paspalum.

Passerina.

Pastinaca.

Patellaria.

Pedicularis.

Peganum.

Peltaria.

Peltigera.

Peplis.

Persica.

PERSONATAE.

Pertusaria.

Peucedanum.

Peziza.

Pliaca.

Phalangium.

Phalaris.

Phallus.

Phaseum.

Phaseolus.

Philarlelphus.

Phillyrea.

Phlenm.

Phlomis.

Physalis.

Physcia.

Phytcuma.
Pag. 22G. I'liyulacea.

162. Picris.

361. Picridium.

з年. Pilobolus.

359. Pilularia.

3y?. Pimpinella.

ros. Pinguicula.

223. Pinus.

122. Pislacia.

115. Pisum.

189. Placodium.

409. PLAN'IAGINEAE.

355. Plantago.

Platanus.

42I. PLUMIBAINEAE.

366. Plumbago.

153. Poa.

165. Podospermum.

122. Pohlia.

36S. POLEMONIACEAE.

367 . Polemonium.

18\%. Polyantlies.

154. Polycarpon.

384. Polyenenum.

199. Polygala.

I33. POLIGONEAE.

I9\%. Polygonum.

3 I4 Polypodium.

73. Polypogon.

212. Polystichum.

355. Polytrichum.

378. Populus.

37. Portulaca.

326. POR'IULACEAE.

3 fo. Potamogeton.

229. Potentilla.

6\%. Poterium.

313. Prenauthes.

16. Primula.

35. PRIMULACEAE.

16r. Prismatocarpus.

12I. Prunus.

43. Psora.

93. Psoralea.

353. Pterigynandrum.

329. Pteris.

216. Precinia.

121. Pulinonaria.

226. Punica.

237. PIRENACEAE.

85. Pyrethrum.

254. Pyrola.

305.

230.

$1=5$.

$36\}$.

358.

$8 \mathrm{I}$.

200.

lbid.

182.

203.

203.

130.

265.

103.

2 年.

243.

166.

$39^{3}$.

$19^{8 .}$

208.

$19 \mathrm{r}$.

rbid.

I1 5 .

120 .

114.

101.

179.

324.

323 .

155.

33 个.

333.

256 .

207.

204.

25 .

339.

$-8$.

$3 \% 6$.

97.

113.

你。

239 .

329.

217.

286.

${ }^{2} 49$. 


\section{0}

Pyrus.

Quercus.

R.

Ramondia.

RANUNCULACEAE.

Ranunculus.

Raphauus.

Reseda.

Reticularia.

Rhagadiolus.

Rhamnus.

Rheum.

RHINANTHACEAE.

libinanthus.

Rhizocarpon.

Rhizomorpha.

RHIZOSPERMLAE.

Rhododendron.

RHODORACEAE.

Rhus.

Ribcs.

Riccia.

Ricinus.

Rivularia.

Robinia.

Foccella.

Rosa.

ROSACEAE.

Rosmarinus.

Rottbolla.

Rubia.

RUBIACEAE.

Rubus.

Runiex.

Piuppia.

Putia.

RUTACEAE.

Riuscus.

S.

Saccharum.

Sagina.

Sagittaria.

SALICARIAE.

Salicornia.

Salix.

Salsola.

Salvia.

Salvinia.

Sambucus.

Samolus.
I N D E X.

Pag. 33o. Sanguisorba.

Sanicula.

Santolina.

Saponaria.

236. SARMENTACEAE.

413. Satureia.

416. Saxifraga.

3-0. SAXIFRAGEAE.

3ś.. Scahiosa.

5\%. Scandix.

256. Scheuclizeria.

366 . Schœenus.

19亿. Scilla.

208. Scirpus.

212. Scleranthus.

-8. Sclerotium.

58. Scolopendrium.

117. Scolymus.

248. Scorpiurns.

247. Scorzonera.

36\%. Scrophularia.

325. Scutellaria.

9o. Scypliophorus.

IS8. Secale.

2. Securigera.

35\%. Sedun.

7. Selinum.

33r. Sempervivum.

329 . Senebiera.

218 . Senecio.

135. Serapias.

3os. Seriola.

298. Serratula.

338. Seseli.

193. Sesleria.

155. Sherardia.

385. Sibbaldia.

Ibid. Sibthorpia.

155. Sida.

Sideritis.

Silene.

125. Sinapis.

393 . Sisymbrium.

15. Sinm.

325. Smilax.

197. Smyrninm.

1;. SOLANEAE.

197. Solannm.

218. Soldanella.

I17. Solidago.

304. Sonchus.

208. Sorbus.
Pag. 333.

316 .

$29^{\circ}$.

356.

410.

220.

316.

Ibid.

29 .

306.

$15 \%$

I4́.

$16 i$.

145 .

32 .

58.

113.

267 .

$36 \mathrm{r}$.

265.

$23 \mathrm{r}$.

229.

71.

136.

363.

$32 \mathrm{I}$.

3 ro.

322.

38 o.

$2 \mathrm{~S}_{2}$.

I 1 .

263.

270.

305.

13 ; .

298.

$33 i$.

211.

406.

$22 \mathrm{I}$.

389 .

$3-0$.

373.

307.

154.

3 I 3 .

234.

237.

$20 \%$.

282.

257.

331. 
I N D E $X$.

13

Sparganium.

Spathularia.

Pagr. 148. 'Till MELE.W:

1!). Tliymus.

$39 \%$ ' lilia.

50. II!I ICENE.

9. Tillai.

Gg. Fummia.

9 \%. 'Totiollia.

195. 'Turlylium.

338. Tormentilla.

95. 'Tumbla

5.4. 'Tuzzia

80. Trachynotia.

225. 'T'ragnologon.

273. Trazus.

365. Trapa.

302. Tremella.

406. Tribulus.

397 . 'Trichia.

191. 'T'richostomum.

53. Trientalis.

69. 'Trifolimm.

S-. 'Triglochin.

56. Trigenclla.

15. Triticum.

r2f. Trollius.

17-' Tropæolum.

15\%. Tuber.

2 i. Tubercularia.

326. Tubulina.

23ิg. Tulipa.

2í. Tulostoma.

Tussilago.

285. 'Typha.

323. TYPHACEAE.

s55. U.

28s. Ulex.

262. Ulnus.

97. Llra.

l'ag. igo.

$32 \%$

403.

libil.

320.

103.

r.i.

313.

334.

100.

$21 \%$.

$13 \%$.

266.

122.

327 .

18.

355.

52 .

98.

206.

$3 ; 6$.

157 .

352 .

335 .

419.

409 .

58.

5 \%.

52.

359.

56.

282 .

'Tagetes.

Tamarix.

Tamus.

Tanacetım.

Taraxacum.

'Targionia.

Taxus.

Telephinm.

77. UMBELLIFERAE.

323. Unbilicaria.

36f. Umbilicns.

$9^{5}$. Urceolaria.

Tetraplis.

Teucrium.

'Thalictrum.

'Thapsia.

'I'helebolus.

Thelephora.

Theligonum.

Thesium.

Thlaspi.

Thrincia.

'Thymbra.

219 . Uredo.

413. Urospermum.

314. Urtica.

56. URTICEAE.

21. Usnea.

198. Utricularia.

IS9.

38o. Vaccinium.

V.

Ití.

3 í.

I $\$ 3$.

2.

30 .

SS.

3 20.

79

47.

$2 f .6$.

18 f.

I 83.

70.

264. Vaillantia.

22r. Valeriana.

250 .

302.

296. 
VAEERIANEAE. Pag. 29G. VIOLACEAE.

Valerianelia.

Vallisneria.

Variolaria.

Vaucheria.

Velezia.

Veratrum.

Verbascum.

Verhena.

Veronica.

Verruearia.

Vesicaria.

Viburnum.

Vicia.

Villarsia.

Vinca.

Viola.

297. Viscum.

174. Vitex.

68. Vitis.

13. Volvaria.

$392 . \quad$ W.

158. Weissia,

235.

$21 \%$ Xanthinn!.

$\mathrm{X}$.

66. Xeranthemum.

359. Xyloma.

303.

359. Zacintha.

$\mathrm{Z}$ 。

243 . Zanichellia.

2;6. Zizyphus.

399. Zostera.
Pag. 399

303.

217

410.

79.

96.

I 85 .

277.

263.

155.

366 .

149.

\section{Finis Indicis.}





$5+x+1$

(w) $8+2$

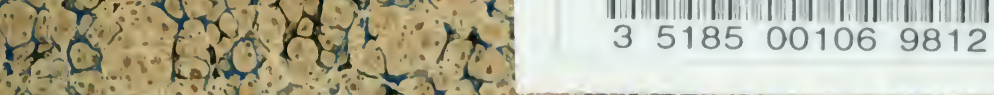

47.50

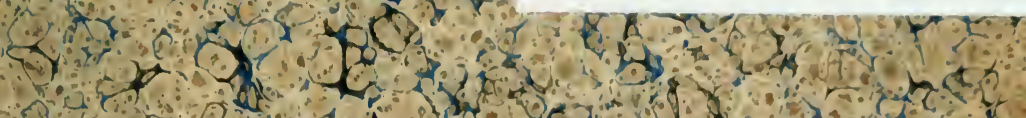

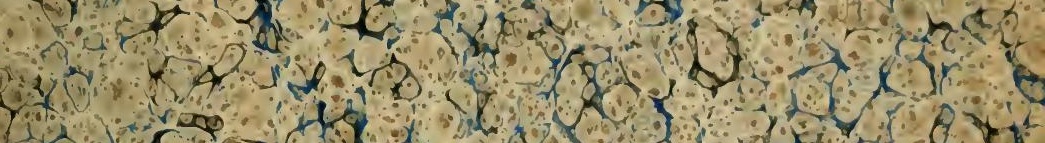

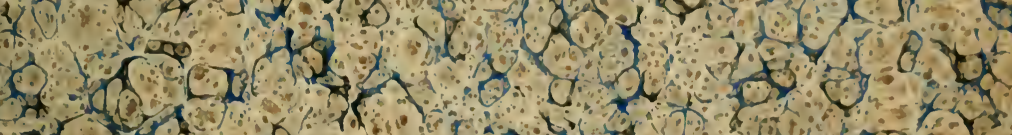

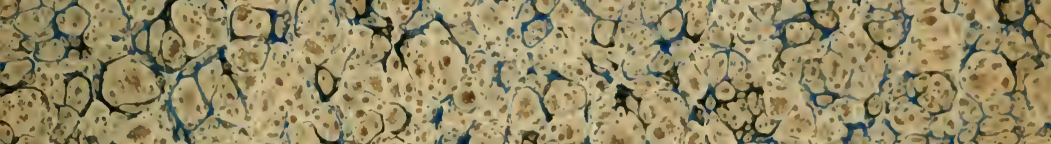

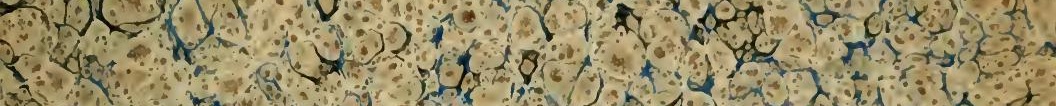

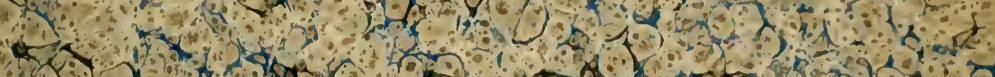

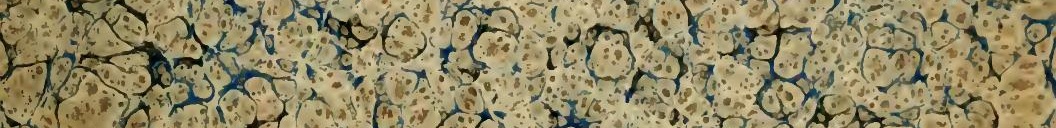

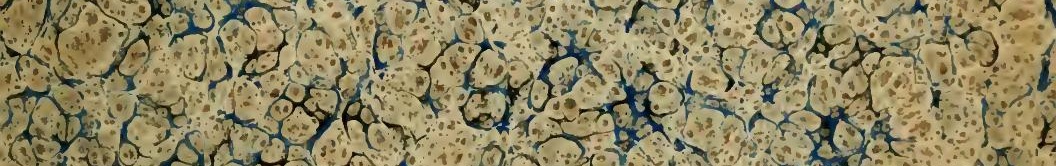

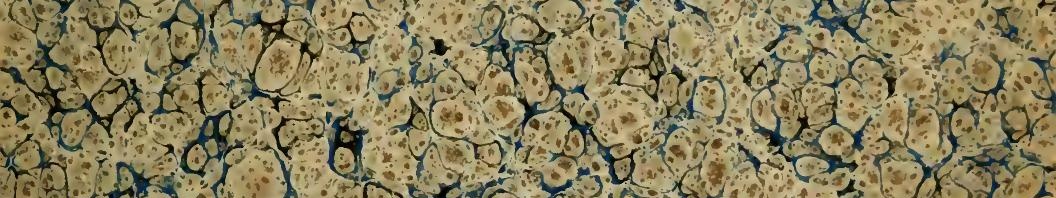

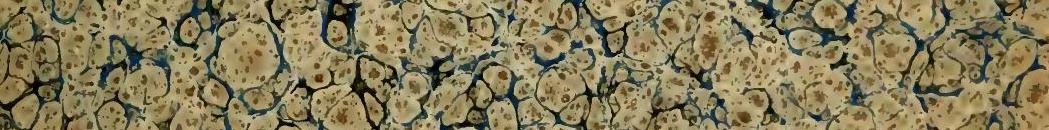

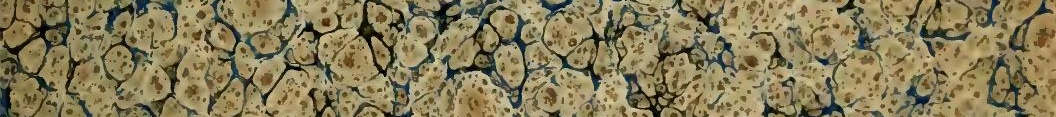
21,12 .

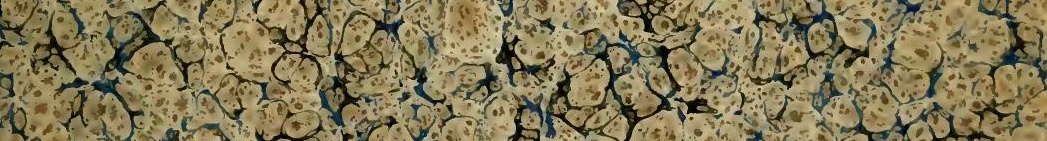

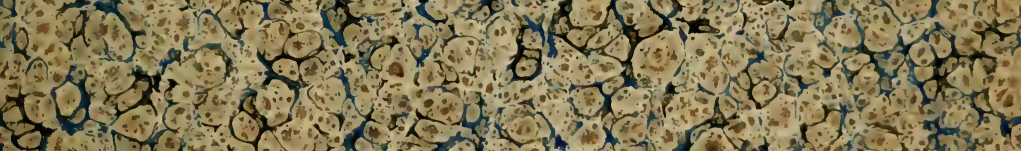
(4. $150.16 \%)=$

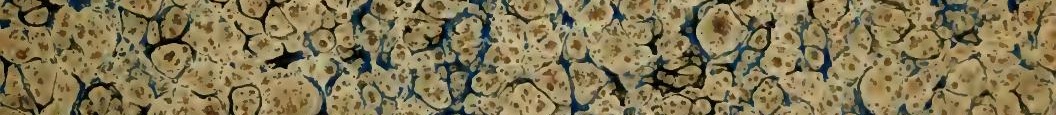

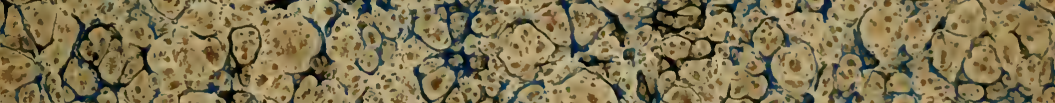
1 0.0 .

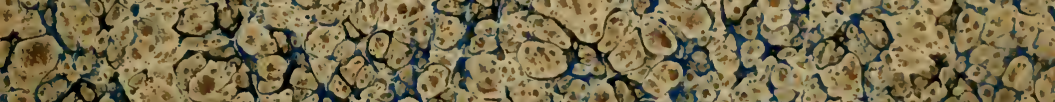

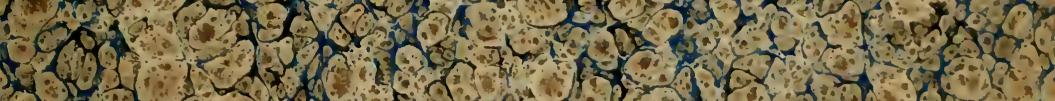
2. (1) $-1,1)$ (1)

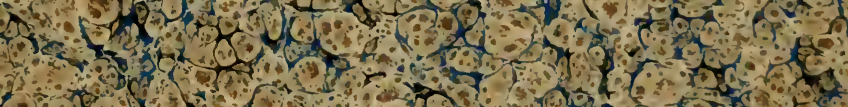

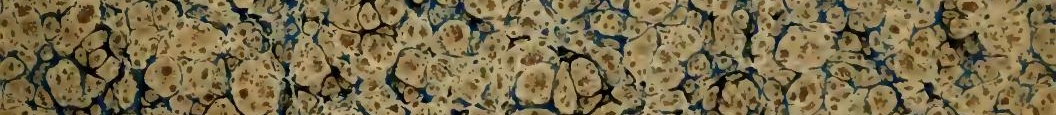

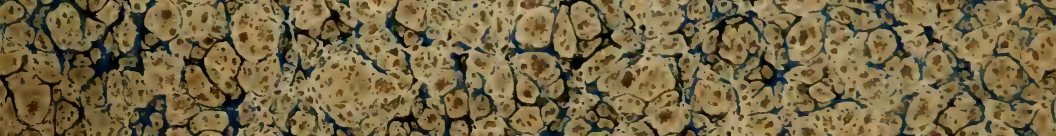


